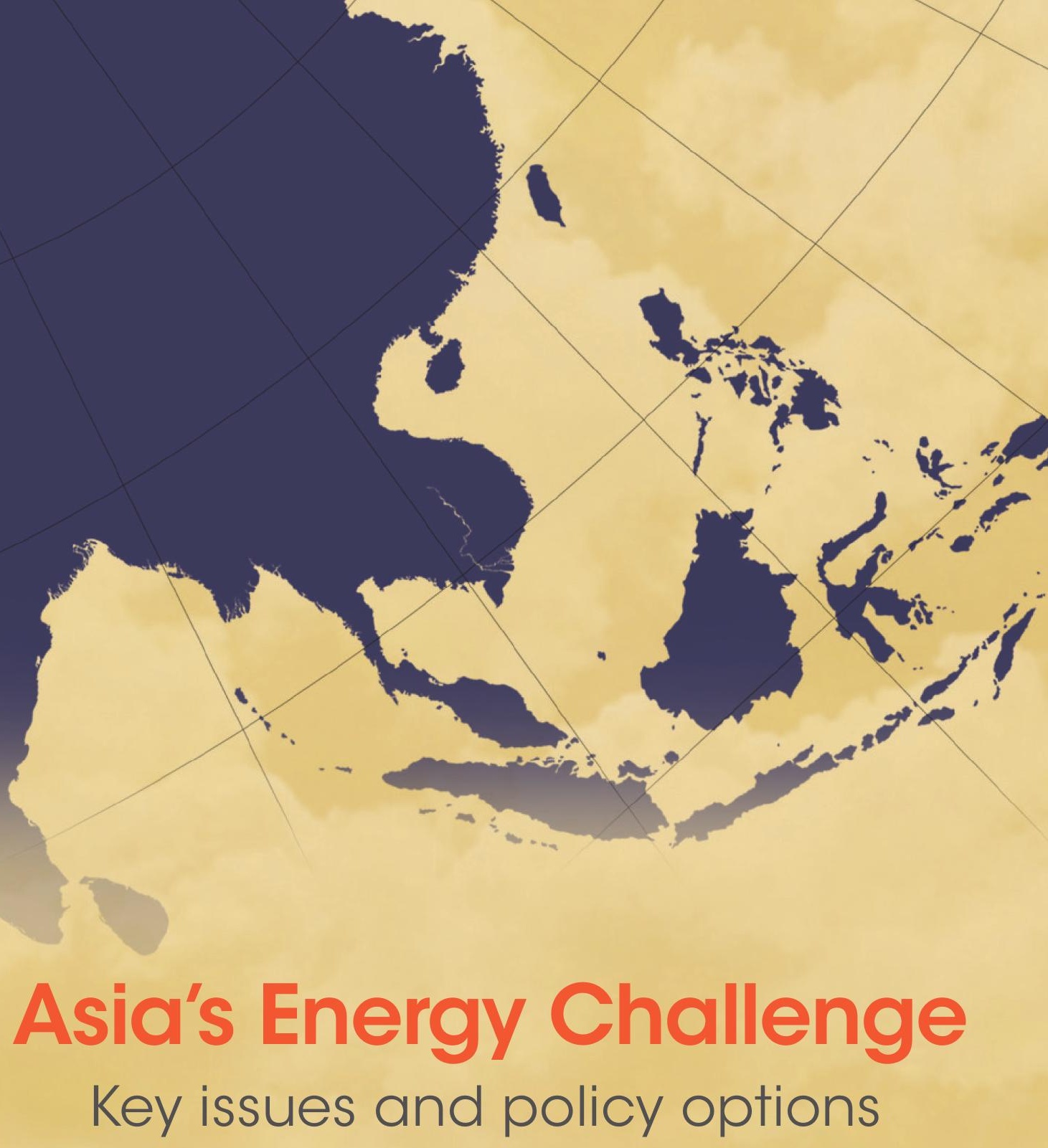

Edited by Minsoo Lee, Donghyun Park, and Harry D. Saunders

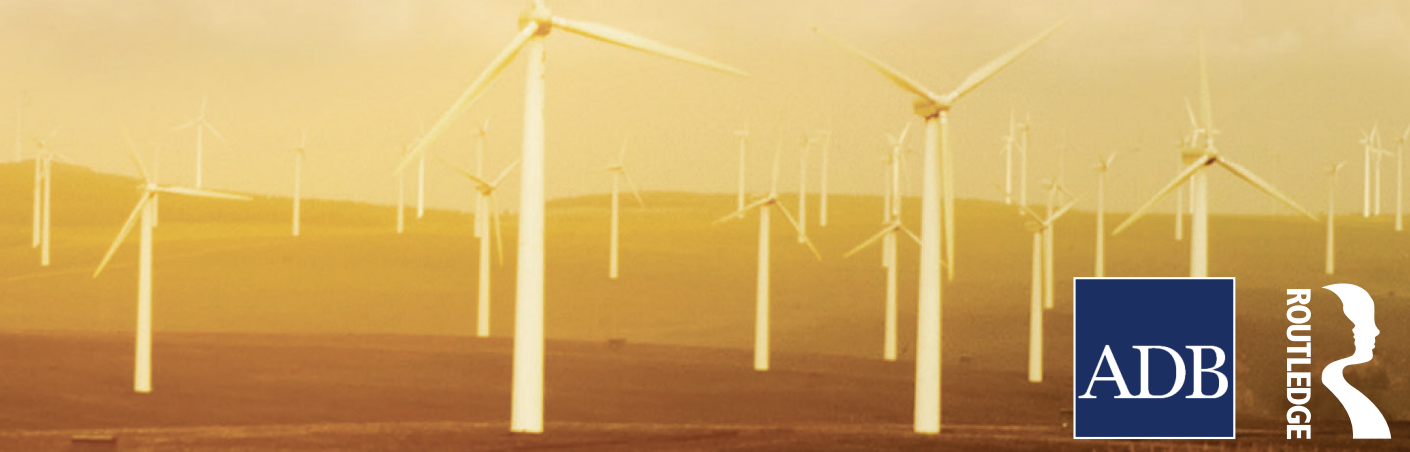




\section{Asia's Energy Challenge}

This book examines key issues and policy options in the development of Asia's energy security. Rapid growth has transformed Asia's presence in the world economy: Past growth has dramatically improved Asia's living standards, lifting millions out of poverty. Future growth will do the same. But, crucially, can Asia secure the energy it needs to fuel this dramatic economic expansion? This book stresses that the threefold challenge of energy supply security, environmental sustainability, and affordable access requires a multipronged approach. The book also explains that the region must actively contain its rising demand, aggressively explore new energy supply sources and technology, and progressively promote the regional integration of energy markets and infrastructure.

The book also highlights that, unless there is a paradigm shift in the current energy use, Asia will struggle to deliver the inclusive growth needed to lift millions of its citizens out of poverty. The book also considers the range of policy reforms and technological developments that can ensure a future of ample, affordable, clean energy for Asia.

Minsoo Lee is a Senior Economist in the Macroeconomics and Finance Research Division of the Economics and Research Department at the Asian Development Bank (ADB). Prior to joining ADB, he was an Associate Dean and a tenured Full Professor at Peking University, HSBC Business School. His main research fields are international finance, international trade, applied econometrics, and energy economics.

Donghyun Park is currently Principal Economist at the Economics and Research Department (ERD) of the Asian Development Bank (ADB), which he joined in April 2007. Prior to joining ADB, he was a tenured Associate Professor of Economics at Nanyang Technological University in Singapore. Dr. Park has a $\mathrm{PhD}$ in economics from UCLA and his main research fields are international finance and trade.

Harry D. Saunders conducts research in energy economics, evolutionary biology, and the law of evidence theory as his "hobby." He earns his living by consulting to executive teams who face major, risky decisions. Research is driven by curiosity and is entirely self-funded. Harry enjoys the fact that he has numerous academic colleagues worldwide in each of these three disciplines. He has a $\mathrm{PhD}$ in engineering-economic systems from Stanford. 



\section{Asia's Energy Challenge Key issues and policy options}

\section{Edited by \\ Minsoo Lee, Donghyun Park, and Harry D. Saunders}

Co-publication of the Asian Development Bank and Routledge

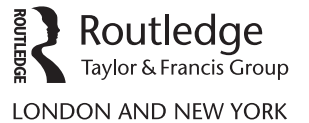


First published 2015 by Routledge

2 Park Square, Milton Park, Abingdon, Oxon, OX14 4RN

and by Routledge

711 Third Avenue, New York, NY 100117

Routledge is an imprint of the Taylor \& Francis Group

(C) 2015 Asian Development Bank

Typeset in Times New Roman

by Sunrise Setting Ltd, Paignton, UK

Printed and bound in Great Britain by

All rights reserved. No part of this book may be reprinted or reproduced or utilised in any form or by any electronic, mechanical, or other means, now known or hereafter invented, including photocopying and recording, or in any information storage or retrieval system, without permission in writing from the publishers.

\section{Library of Congress Cataloging-in-Publication Data}

Asia's Energy Challenge: key issues and policy options / edited by

Minsoo Lee, Donghyun Park and Harry D. Saunders. pages $\mathrm{cm}$

Includes bibliographical references and index.

1. Energy security-Asia. 2. Energy consumption-Asia. 3. Energy resources development-Asia. 4. Energy policy-Asia. I. Lee, Minsoo. II. Park, Donghyun. III. Saunders, Harry D.

HD9502.A782A767 2015

$333.79095-\mathrm{dc} 23$

2013050060

The views expressed in this publication are those of the authors and do not necessarily reflect the views and policies of the Asian Development Bank (ADB) or its Board of Governors or the governments they represent.

ADB does not guarantee the accuracy of the data included in this publication and accepts no responsibility for any consequence of their use.

By making any designation of or reference to a particular territory or geographic area, or by using the term "country" in this document, ADB does not intend to make any judgments as to the legal or other status of any territory or area.

ADB encourages printing or copying information exclusively for personal and noncommercial use with proper acknowledgment of ADB. Users are restricted from reselling, redistributing, or creating derivative works for commercial purposes without the express, written consent of ADB.

Note:

In this publication, " $\$$ " refers to US dollars.

6 ADB Avenue, Mandaluyong City

1550 Metro Manila, Philippines

Tel +6326324444

Fax +6326362444

www.adb.org

For orders, please contact:

Department of External Relations

Fax +6326362648

adbpub@adb.org

ISBN 13: 978-0-415-74930-5 (hbk)

ISBN 13: 978-1-315-76853-3 (ebk) 


\section{Contents}

List of figures ix

List of tables xvii

Notes on contributors xix

Preface xxii

\section{PART I}

Asia's energy challenge 1

1 An overview 3

MINSOO LEE, DONGHYUN PARK, AND HARRY D. SAUNDERS

The challenge 3

Containing burgeoning energy demand 6

Tapping cleaner energy supply 16

Fostering regional market collaboration 25

Asia's energy challenge, reprised 27

\section{PART II}

Energy security, sustainability, and affordability

2 Oil security in Asia and the Pacific

DAVID ISAAK

Introduction 33

Oil in context 33

Oil prices 37

Oil demand 42

Oil supply 53

Critical issues in oil security 61

Energy and financial markets in Asia 72

Summary of policy recommendations 76 
vi Contents

3 Energy security, sustainability, and affordability

in Asia and the Pacific

NORBERTO FUEYO, ANTONIO GÓMEZ, AND CÉSAR DOPAZO

Introduction 81

Indicators 82

Indexes from 2010 to 203586

The benefits of integration 109

International benchmarking 117

Alternative scenarios 122

Conclusions and policy recommendations 127

4 Energy access and energy security in Asia and the Pacific

BENJAMIN K. SOVACOOL

Introduction 132

Defining energy poverty and access 132

Energy access as an energy security concern 138

Financing sustainable energy for all 145

Policy recommendations 150

\section{PART III}

Energy and the environment

5 The environment and energy security in Asia and the Pacific

BENJAMIN K. SOVACOOL

Introduction 161

Climate change 161

Air pollution 166

Water quality and availability 167

Land-use change 169

Environmental impact of energy technology options 171

Conclusions 179

6 Macroeconomic impacts of energy efficiency improvements in Asia

DEEPAK SHARMA, SUWIN SANDHU, AND SUCHI MISRA

Introduction 186

Methodological framework 187 
Macroeconomic impacts 193

Policy trade-offs and implications 212

\section{PART IV}

Options for energy supply and integration

7 Diversification of energy supply: prospects for emerging energy sources

MICHAEL M. D. ROSS

Introduction 229

Unconventional gas 229

Photovoltaics 257

Wind energy 271

Appendix: Formation and exploitation of natural gas 284

8 Policy issues in Asia's power sector: balancing economic growth and sustainability

JONG HO HONG, CHANGHUN KIM, AND HEEYOUNG SHIN

Introduction 293

Current status and future prospects for electricity supply and demand 294

Key policy issues by country 304

Comparisons and policy recommendations 315

Conclusion 319

9 Nuclear power development in Asia

HOLGER ROGNER AND KEE-YUNG NAM

Introduction 324

The global situation 324

Nuclear power and green growth 332

Critical issues in nuclear power development 340

Technological changes 351

Outlook for nuclear power 354

Conclusions 358

10 Asia's energy challenge: regional cooperation and integration for energy security

MINSOO LEE, DONGHYUN PARK, AND HARRY D. SAUNDERS

Introduction 362

Integrating power and gas delivery systems 363 
viii Contents

Resource synergies 367

Strategic oil stockpiling 370

Key obstacles to regional cooperation and integration 371

11 Energy in the People's Republic of China and India in 2010 and 2035

CÉSAR DOPAZO, ANTONIO GÓMEZ, AND NORBERTO FUEYO

Introduction 375

People's Republic of China 378

India 403

\section{PART V}

Key findings and policy recommendations

12 Findings and recommendations

MINSOO LEE, DONGHYUN PARK, AND HARRY D. SAUNDERS

Current state of energy security in developing Asia 437

Curbing burgeoning energy demand 439

Tapping a cleaner energy supply 440

Fostering regional market synergies 442

Policy options for a brighter Asian energy future: every watt counts 444

Index 


\section{Figures}

1.1 Projected energy-related carbon dioxide emissions from developing Asia 4

1.2 Asian proportion of energy poor 5

1.3 Developing Asia's share of gross domestic product and primary energy consumption, 2010-2035 7

1.4 Sensitivity of energy consumption to projected energy intensity, 2010-2035

1.5 The benefits of replacing electricity with gas 14

1.6 Fuel composition for Asia's energy requirements 17

2.1 Developing Asian primary energy demand by source 34

2.2 Primary energy demand by region 35

2.3 Recent crude oil price forecasts 37

2.4 World Bank pump prices for selected countries, $2010 \quad 42$

2.5 Oil demand by sector in developing Asia, 1970-2010 43

2.6 Asian oil demand by sector and grouping, $2010 \quad 45$

2.7 Liquefied petroleum gas demand by sector in developing Asia, $2010 \quad 46$

2.8 Kerosene demand by sector in developing Asia, $2010 \quad 48$

2.9 Kerosene demand in developing Asia, 1970-2010 49

2.10 Diesel/gasoil demand by sector in developing Asia, $2010 \quad 50$

2.11 Asian fuel oil and direct-burned crude demand, 1970-2010 51

2.12 Comparison of Asian Development Bank and FACTS global energy oil demand forecasts, 1990-2035 52

2.13 Oil production outlook through 2035 in developing Asia 54

2.14 Net oil imports through 2035 in developing Asia 55

2.15 Regional shares of total oil imports, $2010 \quad 56$

2.16 Destination of Middle Eastern oil exports, $2010 \quad 58$

2.17 Cracking-to-distillation ratios for various regions, 2012

3.1 Primary energy intensity in $2010 \quad 87$

3.2 Primary energy intensity in $2035 \quad 88$

3.3 Change in primary energy intensity, 2010-2035 89

3.4 Carbon dioxide intensity of the primary energy mix in $2010 \quad 90$

3.5 Carbon dioxide intensity of the primary energy mix in 2035 
3.6 Change in carbon dioxide intensity of the primary energy mix, 2010-2035

3.7 Primary energy intensity versus carbon dioxide intensity of the primary energy mix, 2010-2035

3.8 Energy self-sufficiency vs primary energy diversification, 2010-2035

3.9 Energy self-sufficiency in $2010 \quad 95$

3.10 Energy self-sufficiency in 203596

3.11 Primary energy diversification in $2010 \quad 97$

3.12 Primary energy diversification in 203598

3.13 Expected electricity outlays based on tariffs in $2012 \quad 100$

3.14 Expected electricity outlays based on tariffs in 2012101

3.15 Expected electricity outlays based on levelized electricity cost in 2012 and $2035 \quad 102$

3.16 Expected electricity outlays based on levelized electricity costs in 2012

3.17 Expected electricity outlays based on levelized electricity cost in 2035

104

3.18 Change in expected electricity outlays based on levelized electricity cost, 2012-2035

3.19 Expected electricity outlays based on levelized electricity cost in Central Asia, the Developed Group, and East Asia, 2012-2035

3.20 Expected electricity outlays based on levelized electricity cost in the Pacific, Southeast Asia, and South Asia, 2012-2035

3.21 Regional primary energy intensity vs carbon dioxide intensity of the primary energy mix, 2010-2035

3.22 Regional energy self-sufficiency vs primary energy diversification, 2010-2035

3.23 Energy self-sufficiency vs primary energy diversification by region, 2010-2035

3.24 Regional expected electricity outlays based on levelized cost of electricity, 2012-2035

3.25 Regional change in expected electricity outlays based on levelized cost of electricity, 2012-2035

3.26 Change in the power (electricity) sector diversification indicator, 2010-2035

3.27 Ratio of regional levelized electricity cost to national levelized electricity cost in 2035

3.28 Carbon dioxide emission intensity in Asia and the Rest of the World in 2010 and 2035

3.29 Primary energy intensity in Asia and the Rest of the World in 2010 and 2035

3.30 Primary energy intensity and carbon dioxide intensity of the primary energy mix in Asia and the Rest of the World in 2010 and 2035 
3.31 Energy self-sufficiency and primary energy diversification in Asia and the Rest of the World in 2010 and 2035

3.32 Expected electricity outlay in Asia and the Rest of the World in 2010 and 2035

3.33 Primary energy intensity in business-as-usual scenario vs Asian Century/business-as-usual scenario

3.34 Primary energy intensity in Asian Century/alternative scenario vs Asian Century/business-as-usual scenario

3.35 Carbon dioxide intensity of the primary energy mix in business-as-usual scenario vs Asian Century/business-as-usual scenario

3.36 Carbon dioxide intensity of the primary energy mix in Asian Century/alternative scenario vs Asian Century/ business-as-usual scenario

3.37 Carbon dioxide emission intensity in business-as-usual scenario vs Asian Century/business-as-usual scenario

3.38 Carbon dioxide emission intensity in Asian Century/alternative scenario vs Asian Century/business-as-usual scenario

3.39 Energy self-sufficiency in business-as-usual scenario vs Asian Century/business-as-usual scenario

3.40 Energy self-sufficiency in Asian Century/alternative scenario vs Asian Century/business-as-usual scenario

3.41 Primary energy diversification in business-as-usual scenario vs Asian Century/business-as-usual scenario

3.42 Primary energy diversification in Asian Century/alternative scenario vs Asian Century/business-as-usual scenario

3.43 Expected electricity outlay in business-as-usual scenario vs Asian Century/business-as-usual scenario

3.44 Expected electricity outlay in Asian Century/alternative scenario vs Asian Century/business-as-usual scenario

4.1 Energy access according to poorest and richest quintiles in selected countries

4.2 The pro-poor public-private partnership model 147

5.1 Per capita energy-related carbon dioxide emissions, 1990 and $2010 \quad 163$

5.2 Share of greenhouse gas emissions in top ten countries, $2010 \quad 163$

5.3 Forest area as a percent of land area in selected countries, 1990 and 2010

6.1 Energy efficiency scenarios

6.2 Attributes for assessing the impacts of energy efficiency improvements

6.3 Changes in gross domestic product in historic trends scenarios 195

6.4 Changes in total output for Asian Century scenarios 197

6.5 Changes in total employment 201

6.6 Energy intensity trends, 2010-2050 205

$\begin{array}{lll}6.7 & \text { Energy rebound effect } & 206\end{array}$ 
6.8 Herfindahl Index 208

6.9 Greenhouse gas intensity trends, 2010-2050 213

6.10 Summary of impacts and policy implications for the People's Republic of China 214

6.11 Summary of impacts and policy implications for India 216

6.12 Summary of impacts and policy implications for Indonesia 218

6.13 Summary of impacts and policy implications for Japan 220

6.14 Summary of impacts and policy implications for the Republic of Korea 221

6.15 Summary of impacts and policy implications for Malaysia 223

6.16 Summary of impacts and policy implications for Thailand 224

7.1 Dry natural gas production by source in the United States (trillion cubic feet per year) 230

7.2 Natural gas price at the wellhead and shale gas production in the United States

7.3 Average production profiles for shale gas wells in major shale plays in the US by years of operation

7.4 Annual average Henry Hub spot natural gas prices

7.5 Ratio of Brent crude oil price to Henry Hub natural gas price on an energy equivalent basis

7.6 Major shale basins of the People's Republic of China 236

7.7 Shale gas basins of India and Pakistan 237

7.8 Indonesian coal bed methane basins 241

7.9 Coal bed methane production and coal mine methane capture and utilization in the People's Republic of China 243

7.10 Asian solar resource 258

7.11 Crystalline silicon photovoltaic module prices 259

7.12 Photovoltaic module price as a function of installed capacity 259

7.13 Cumulative installed photovoltaic and wind capacity, 1996-2012

7.14 Utility-scale photovoltaic system price projections to $2020 \quad 261$

7.15 Levelized cost of energy for utility-scale photovoltaic systems constructed from 2010 to 2020

7.16 Estimates of levelized cost of energy for photovoltaic systems constructed from 2010 to 2030

7.17 Levelized cost of energy for utility-scale photovoltaics versus gas, coal, and nuclear generation in the Republic of Korea

7.18 Levelized cost of energy for utility-scale photovoltaic versus hydro, gas, coal, and nuclear generation in the People's Republic of China

7.19 Mean wind speed at 80 meters

7.20 Capacity factor for three 1.8 megawatt turbines with different rotor diameters and hub heights

7.21 Global cumulative installed wind capacity, 1996-2012 273

7.22 Wind capacity installed by continent, 2004-2012 
7.23 Total wind capacity as of 2012 in Asia 274

7.24 Installed capacity and technical potential for wind in Asia 275

7.25 Wind project capital costs in Denmark and the United States, 1980-2005

7.26 Wind project capital costs in Europe and the United States, 2003-2010

7.27 Turbine prices in 2008 and 2010 in selected countries 277

7.28 Capacity factors achieved by old and new turbine technology 277

7.29 Estimated levelized cost of energy for onshore wind in North America and Europe, 1980-2010

7.30 Levelized cost for wind-generated electricity versus gas, coal, and nuclear generation in the Republic of Korea in 2011, 2020 , and 2030

7.31 Levelized cost for wind-generated electricity versus large hydro, gas, coal, and nuclear generation in the People's Republic of China in 2011, 2020, and 2030

7.32 Average levelized cost of onshore and offshore wind generation, 2009-2011

7A Geology of conventional and unconventional gas 284

8.1 Primary world and Asian energy demand 295

8.2 World and Asian electricity generation 295

8.3 Estimations of greenhouse gas emissions from thermal power generation

8.4 Electricity consumption per capita 296

8.5 Electricity consumption by gross domestic product 297

8.6 Final energy demand by energy source 298

8.7 Projections of fuel mix in electricity generation 299

8.8 Final energy demand by energy source 299

8.9 Projections of fuel mix in electricity generation 300

8.10 Final energy demand by energy source 301

8.11 Projections of fuel mix in electricity generation 301

8.12 Japan's power generation mix after the Fukushima nuclear
accident

8.13 Final energy demand by energy source 303

8.14 Projections of fuel mix in electricity generation 303

8.15 Supply shortage at peak times in India 307

8.16 Coal thermal efficiency 307

8.17 Electricity distribution losses 308

9.1 Regional distribution of nuclear power as of 31 December $2012 \quad 325$

9.2 Overnight cost for 1,000 megawatts of electricity from various generating technologies (top) and for typical unit sizes (bottom) 335

9.3 Levelized electricity cost of various generation options at discount rates of $5 \%$ and $10 \%$

9.4 Shares of cost components in total generating costs at a $10 \%$ discount rate 
9.5 Life-cycle greenhouse gas emissions of various electricity generating options

$\begin{array}{lll}\text { 9.6 Air pollutants from selected energy chains } & 340\end{array}$

$\begin{array}{lll}\text { 9.7 Public exposure to radiation from global sources } & 345\end{array}$

9.8 Non-radioactive solid wastes from various generation technologies 347

9.9 Classification of nuclear reactor generations 352

9.10 Annual projections of total nuclear generating capacity, 2005-2012 355

9.11 High projections for Asian Development Bank members 357

9.12 Low projections for Asian Development Bank members 358

11.1 Causes of the high primary energy intensity in the People's Republic of China in 2010

11.2 Causes of the primary energy intensity in the People's Republic of China in 2035

11.3 Intensity of carbon dioxide emissions in 2010 for selected economies

11.4 Intensity of carbon dioxide emissions of the primary energy mix in 2010 in selected economies

11.5 Primary energy consumption by fuel in 2010 in the People's Republic of China

11.6 Measures to reduce carbon dioxide emission intensity in the People's Republic of China in 2010

11.7 Primary energy consumption by fuel in the People's Republic of China in 2035

11.8 Means to reduce the intensity of carbon dioxide emissions in the People's Republic of China in 2035

11.9 Oil consumption in the transport sector in the People's Republic of China under three scenarios, 2010-2035

11.10 Crude oil consumption in the People's Republic of China under three scenarios, 2010-2035

11.11 Energy consumption by mode of transport in the People's Republic of China under the business-as-usual scenario, 2010-2035

11.12 Total power required in the People's Republic of China under three scenarios, 2010-2035

11.13 Total carbon dioxide emissions in the People's Republic of China under three scenarios, 2010-2035

11.14 Carbon dioxide intensity of the power sector in 2010 in selected economies

11.15 Carbon dioxide emissions in the power sector in the People's Republic of China under four alternative scenarios, 2010-2035

11.16 Energy mix in 2035 in the People's Republic of China under four alternative scenarios

11.17 Additional cost per unit of carbon dioxide saved under three scenarios 
11.18 Total energy intensity of the industry sector in 2010 in selected economies

11.19 Carbon dioxide intensity of the industry sector in 2010 in selected economies

11.20 Total energy consumption by industry in the People's Republic of China in 2010 and 2035

11.21 Total energy consumption in the industry sector in 2010 and with best available technologies in 2010 in the People's Republic of China

11.22 Total energy consumption of households in the People's Republic of China in 2010 and 2035 by fuel

11.23 Number of appliances per 100 households in urban and rural areas in the People's Republic of China, 1990-2010

11.24 Total energy consumption by households in the People's Republic of China in 2010 and 2035 by activity

11.25 Total household energy consumption in the People's Republic of China when natural gas replaces biomass and coal for heating and cooking, 2010

11.26 Primary energy intensity and gross domestic product per capita in selected economies

11.27 Causes of the high primary energy intensity in India in $2010 \quad 406$

11.28 Household energy consumption by fuel in India in 2010406

11.29 Biomass energy use in households in India in $2010 \quad 407$

11.30 Electricity distribution losses and gross domestic product per capita

11.31 Causes of high primary energy intensity in India in $2035 \quad 409$

11.32 Causes of high primary energy intensity in India in 2035410

11.33 Primary energy consumption by fuel in India in 2010 and 2035411

11.34 Measures to reduce carbon dioxide emission intensity in India in 2010

11.35 Measures to reduce carbon dioxide emission intensity in India in 2035

11.36 Measures to reduce carbon dioxide emission intensity in India in 2035

11.37 Oil consumption in the transport sector in India under three business-as-usual scenarios, 2010-2035

11.38 Oil consumption in the transport sector in India under three Asian Century scenarios, 2010-2035

11.39 Total energy consumption by mode of transport in India, 2010-2035 417

11.40 Total power generation required in the business-as-usual and the business-as-usual medium and accelerated scenarios in India, 2010-2035

11.41 Total power generation required in the Asian Century Business-as-Usual and the Asian Century-business-as-usual medium and accelerated scenarios in India, 2010-2035 
11.42 Total carbon dioxide emissions in the business-as-usual and the business-as-usual medium and accelerated scenarios in India, 2010-2035

11.43 Total carbon dioxide emissions in the Asian

Century-business-as-usual and the Asian

Century-business-as-usual medium and accelerated

scenarios in India, 2010-2035

11.44 Carbon dioxide emissions in the power sector for four business-as-usual scenarios in India

11.45 Fuel mix for generating electricity in 2035 for four business-as-usual scenarios in India

11.46 Additional Investment Cost per Unit of Carbon Dioxide Emissions for Three Business-as-Usual Scenarios in India

11.47 Carbon dioxide emissions in the power sector in India for four Asian Century business-as-usual scenarios, 2010-2035

11.48 Mix of fuels for generating electricity in India in 2035 in four Asian Century business-as-usual scenarios

11.49 Additional cost per unit of carbon dioxide emissions saved in India for four Asian Century business-as-usual scenarios

11.50 Energy consumption of the industry sector in India in 2010 and 2035 by industry

11.51 Energy consumption in India's industry sector in 2010 and with best available technologies in 2010

11.52 Energy consumption of households in India in 2010 and 2035 by fuel

11.53 Energy consumption of households in India in 2010 and 2035 by activity

11.54 Energy consumption in Indian households in 2010 and substituting biomass for cooking with natural gas 


\section{Tables}

1.1 Fossil fuel consumption subsidies 9

2.1 Energy information administration assessment of conventional $\begin{array}{ll}\text { oil and gas production costs } & 39\end{array}$

2.2 International Energy Agency estimates of oil production costs 39

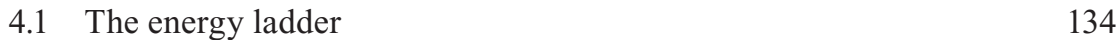

$\begin{array}{ll}\text { 4.2 Energy services and access levels } & 135\end{array}$

4.3 Number and share of population without access to modern energy services, $2009 \quad 136$

4.4 Global national, rural, and urban electrification numbers 137

4.5 Gross domestic product per capita and energy consumption and $\begin{array}{lr}\text { poverty in selected countries, } 2002 & 140\end{array}$

4.6 Health impacts of indoor air pollution 141

4.7 Benefits of modern energy services for women 143

4.8 Generation requirements for universal electricity access, 2030 146

4.9 Annual investments required to achieve sustainable energy for all objectives

5.1 Environmental dimensions of energy security in Asia and the Pacific

5.2 Estimated economic and social impact of disasters in selected Pacific island economies, 1950-2008

5.3 Water use (consumption and withdrawals) for selected power plants

5.4 Global leaders in carbon dioxide equivalent emissions from deforestation

5.5 Impacts of energy systems on climate change, air pollution, water availability and quality, and land-use change $\quad 172$

$\begin{array}{lll}6.1 & \text { Model coverage } & 188\end{array}$

6.2 Scenario assumptions, 2010-2050 191

6.3 Percentage of value-added by sector 198

$\begin{array}{lll}6.4 & \text { Total final energy demand } & 203\end{array}$

6.5 Net energy-import dependency 209

$\begin{array}{ll}\text { 6.6 Total greenhouse gas emissions } & 211\end{array}$

7.1 Regional estimates of unconventional gas in Asia 234 
7.2 Shale gas resources in promising Asian countries 235

7.3 Estimates of technically recoverable shale gas resources in the People's Republic of China 235

7.4 Estimates of technically recoverable shale gas resources in India 237

7.5 Annual methane emissions from operating coal mines and $\begin{array}{ll}\text { coal bed methane resources } & 238\end{array}$

7.6 Annual methane emissions from operating coal mines, $2010 \quad 239$

7.7 Photovoltaic levelized cost of energy scenario assumptions 262

7.8 Sensitivity of photovoltaic levelized cost of energy to variations in input parameters 263

7.9 Levelized cost of wind-generated electricity in the People's Republic of China and India, 2011279

8.1 Cost of generating electricity by fuel source in Japan, 2004-2030 312

$\begin{array}{ll}8.2 \text { Power sector comparisons } & 316\end{array}$

9.1 Policy responses to the Fukushima Daiichi accident 327

9.2 Nuclear capacity and generation in Asian Development Bank member countries

9.3 Pros and cons of nuclear power as a technology in support of green growth

10.1 Proven reserves of natural gas and oil in Asia 368

10.2 Proven reserves of coal in Asia 369

$\begin{array}{ll}11.1 & \text { Macroeconomic variables } \\ 11.2 & 377\end{array}$

$\begin{array}{lll}11.2 & \text { Primary energy mix } & 378\end{array}$

$\begin{array}{ll}\text { 11.3 Mix of fuel for generating electricity } & 378\end{array}$ 


\section{Contributors}

Dopazo, César is a Professor in Fluid Mechanics at the University of Zaragoza. His research is in the fields of combustion, turbulent mixing, turbulent reacting flows, heat and mass transfer, two-phase flows, spray formation, pollutant dispersion, hydrodynamic and ultrasonic cavitations, and, in general, on industrial aerodynamics and hydrodynamics.

Fueyo, Norberto is a Professor in Fluid Mechanics at the University of Zaragoza. $\mathrm{He}$ is a specialist in the modeling of energy systems. His current research interests include: bottom-up models of energy systems; large-scale quantification of the potential and costs of renewable energies; modeling of conventional (coal, gas) power generation; oxycombustion and other low-carbon combustion technologies; fuel cells; water-energy interactions; energy efficiency and structural change.

Gómez, Antonio is a Research Fellow in the Numerical Fluid Dynamics Group and in Oficina de Transferencia de Resultados de Investigación at the University of Zaragoza. His $\mathrm{PhD}$ thesis Renewable Energy and Energy Scenarios for Spain was granted the University of Zaragoza's Premio Extraordinario de Doctorado.

Hong, Jong Ho is a Professor in the Graduate School of Environmental Studies, and acting director of the Asian Institute for Energy, Environment and Sustainability (AIESS), Seoul National University. His teaching and research are focused on environmental and resource economics and policy. He has also held research and academic positions at Hanyang University, Kyoto University, and the Korea Development Institute.

Isaak, David is a specialist in the analysis and modeling of hydrocarbon industries, with an emphasis on Asia and the Middle East. He was coordinator of the Energy Program at the East-West Center in Honolulu, Vice President of FACTS, and Research Director at the SRTC. Presently, he consults for Downstream Hydrocarbon Analysis and he is also a Distinguished Associate at FACTS Global Energy.

Kim, Changhun is an Associate Research Fellow in the Energy Demand Management Research Division of the Climate Change Policy Research Group 
at the Korea Energy Economics Institute (KEEI). He received his $\mathrm{PhD}$ in economics from Seoul National University. His main research field is energy and environmental economic modeling, specializing in the structural analysis of computable general equilibrium models.

Misra, Suchi is currently pursuing a PhD in the Energy Planning and Policy Program at UTS. She is also working at the Renewables and Carbon Farming Division of the Clean Energy Regulator Australia. Prior to this, she worked as a Research Assistant at the Centre for Energy Policy (UTS). She has expertise in the modeling and analysis of energy industry issues.

Nam, Kee-Yung is Principal Economist at the ADB. Previously, he was an Energy Economist/Energy Planner in the International Atomic Energy Agency (IAEA) in Vienna, Austria. He also consulted for IAEA and Integriertes Research Management Consulting and Services in Vienna, where he undertook quantitative and qualitative studies of energy-economic-environmental issues.

Rogner, Holger is the International Atomic Energy Agency's (IAEA) manager of Programme C, which includes the Planning and Economic Studies Section (PESS), the International Nuclear Information Section/Nuclear Knowledge Management Section (INIS/NKM), and the Library. Before joining the IAEA in 1997, Dr. Rogner was the Director of the System Analysis Group of the Institute for Integrated Energy Systems (IESVic) at the University of Victoria, Canada, where he also held the position of Adjunct Professor within the Department of Mechanical Engineering.

Ross, Michael has worked with emerging energy technologies for over 15 years. He has held research positions with the CANMET Energy Diversification Research Laboratory of Natural Resources Canada and the Advanced Energy Systems Group of the Department of Technical Physics and Mathematics at Alvar Aalto University in Helsinki, Finland. Since 2003, he has been the head of RER Energy.

Sandhu, Suwin is a Lecturer in the Energy Planning and Policy Program and a Core Researcher in the Centre for Energy Policy at University of Technology, Sydney (UTS). Prior to that, he worked at the Australian Bureau of Agriculture and Resource Economics (ABARE), focusing on the analysis of energy markets. He has expertise in energy market modeling and analysis of climate change responses.

Sharma, Deepak is a Professor and the Director of the Energy Planning and Policy Program and the Centre for Energy Policy at the University of Technology, Sydney (UTS). He has more than 35 years of professional experience in academia, as well as in the public and private sectors. He is actively engaged in teaching, research, and consulting in the fields of energy and environmental policy.

Shin, Heeyoung is currently a Research Associate at the Korea Development Institute (KDI). A recent graduate with an MA from the Graduate School of 
Environmental Studies at Seoul National University, her research fields are energy economics and the environment. With experience in engineering, a multinational corporation, and the media, she engages in research with an interdisciplinary perspective.

Sovacool, Benjamin is Director of the Danish Center for Energy Technologies at AU-Herning and a Professor of Business and Social Sciences at Aarhus University in Denmark. He is also Associate Professor of Law at Vermont Law School and Director of the Energy Security and Justice Program at their Institute for Energy and the Environment, as well as the Editor-in-Chief of the peer-reviewed international journal Energy Research and Social Science. He works as a researcher, consultant, and teacher on issues pertaining to renewable energy and energy efficiency, the politics of large-scale energy infrastructure, designing public policy to improve energy security and access to electricity, and building adaptive capacity to the consequences of climate change. 


\section{Preface}

It is beyond dispute that rapidly growing Asia confronts a daunting energy challenge in the decades ahead. Securing an adequate physical energy supply, building environmental sustainability, and ensuring affordable energy access for all Asians - these three goals combine to produce a tangled policy conundrum, the appendages of which weave together to create stubborn contradictions and apparently insoluble tradeoffs.

This volume is the product of assembling 14 of the best minds available worldwide from a broad swath of energy-related areas of expertise and tasking them to wrestle this problem into tractability. In the spring of 2012, the Asian Development Bank (ADB) charged the Economics and Research Department with identifying a group of respected energy experts who would draft background papers addressing elements of the problem identified by staff and who would meet in December 2012 to discuss and debate their findings. These intense sessions, augmented by the participation of key ADB experts and additional outside expert reviewers, were designed to achieve disagreement and agreement in a clear, systematic way. Following this encounter, participants were charged with revising their background papers in light of learning from the discussions and ADB staff assembled from these a document that would become the theme chapter of ADB's annual Asian Development Outlook, published in April 2013. This theme chapter, while not retreating from the magnitude of the challenge, primarily highlighted the areas of agreement that are remarkably meaningful and, accordingly, provide powerful and useful prescriptions for policymakers.

Nevertheless, policymakers, it was felt, needed to have the benefit of seeing the explicit and unadulterated views of participants stated in their own words and to have at their immediate disposal the deep analyses supporting these views. This is the purpose of the present volume.

This volume is arranged in four parts: Part I summarizes the challenge in a broad overview and points to the central messages on which contributing experts share broad agreement. Part II addresses the three foundational pillars of a robust Asian energy policy, that is, energy security, sustainability, and affordability. This part begins with world oil expert David Isaak, who reveals the disturbing and seemingly relentless prospect of rapidly expanding Asian oil imports, but 
who also identifies concrete policy options that can help deal with this most crucial of energy security issues.

Norberto Fueyo, Antonio Gómez, and César Dopazo then provide a quantitative assessment of the foreseen future for Asia along each of the three dimensions, showing that, while Asia's primary energy intensity is projected to decrease, the carbon dioxide intensity is set to increase because of shifts in the energy supply mix. They further show that Asia's energy self-sufficiency will decrease, but that affordability will increase dramatically; they identify great potential for the regional integration of energy systems that can enhance the introduction of renewables and so reduce energy import dependence. Part II ends with an indepth and ethically troubling look by Benjamin Sovacool at the current state of energy poverty in Asia and the prospects and prescriptions for advancing energy affordability and access.

Part III takes a close look at the energy-environment nexus. Benjamin Sovacool examines the four-pronged environmental risks associated with Asia's growing energy use - climate change, air pollution, water availability and quality, and land-use change - and makes the case that in the absence of radical policy changes, Asia has particular vulnerability to these threats and faces substantial impacts to human health, reductions in fresh water availability, deforestation, and rising sea levels. He argues that policymakers must internalize the hidden external costs of all energy sources in energy prices. Deepak Sharma, Suwin Sandhu, and Suchi Misra investigate the potential for energy efficiency improvements to reduce emissions and find the potential for energy efficiency to be substantial and to simultaneously enhance various macroeconomic welfare measures but warn policymakers to be attentive to improvements that in some cases could perversely increase energy consumption.

Part IV attacks the difficult issue of creating in Asia an energy supply structure that can properly and effectively address the threefold question of energy security, sustainability, and affordability. Michael Ross analyzes the prospects for unconventional gas and renewable sources, such as wind and photovoltaics to accomplish this and finds the potential limited, with the costs of renewables remaining stubbornly high and renewables difficult to integrate into the grid. $\mathrm{He}$ also shows that unconventional gas faces Asia-specific technical and environmental challenges. Jong Ho Hong, Changhun Kim, and Heeyoung Shin explore power sector issues in the major economies of Asia and find substantial room for improving the efficiency of the systems and call for a major policy push toward renewables and a careful re-examination of nuclear power. Holger Rogner and Kee-Yung Nam then undertake an in-depth analysis of nuclear power in Asia, finding that it possesses favorable economics; modest safety, proliferation, and waste disposal risks; and highly favorable greenhouse gas emission mitigation potential. Its benefits are restricted mostly by public acceptance, thereby posing a thorny problem for policymakers. Minsoo Lee, Donghyun Park, and Harry D. Saunders then highlight the significant benefits to be derived from the regional integration of energy markets and infrastructures. Finally, César Dopazo, 
xxiv Preface

Antonio Gómez, and Norberto Fueyo provide a detailed look at the energy-economy structure of the People's Republic of China and India over the next 25 years, delving into the underlying forces that have kept energy intensities high and environmental performance poor and evaluating specific policy initiatives that can help correct these problems.

Part V concludes the volume with a summary of the key findings and recommendations for policymakers that point the way toward a resolution of Asia's formidable energy challenge. It is argued that bold, aggressive, comprehensive policy action is urgently called for.

It is hoped that readers of this volume will find themselves, as a result of the hard work of our respected contributing authors, more thoroughly prepared to engage in the policy debates that must soon occur in Asia if it is to realize its goal of making the 21st century the Asian Century.

Minsoo Lee, Donghyun Park, and Harry D. Saunders 
Part I

Asia's energy challenge 



\title{
1 An overview
}

\author{
Minsoo Lee, Donghyun Park, and \\ Harry D. Saunders
}

\section{The challenge}

\section{The three pillars of Asian energy security}

Developing Asia's spectacular economic emergence augurs a major realignment of the world economy. Developing Asia's gross domestic product (GDP) will more than quadruple from 2010 to 2035, and by 2050 the region will generate over half of global GDP. This promising vision of the 21st century is often called the Asian Century. Past growth has dramatically improved Asian living standards lifting millions out of poverty. Future growth will do the same, but crucially, can developing Asia secure the energy it needs to fuel this dramatic economic expansion?

The question is not simply one of identifying where such energy will come from; rather, true energy security for Asia rests on three foundational pillars: the adequacy and reliability of the physical energy supply; environmental sustainability; and affordable access. This tripartite nature of the energy challenge calls for a nearly Herculean balancing act to avoid unsatisfactory trade-offs that weaken one or more of the pillars and so defeat the Asian quest for energy security.

Asia needs an ample supply of clean, affordable energy to continue its rapid growth in the coming decades. Conventional energy supplies in the region are insufficient to support the current pace of growth as feeding this growth in the traditional way would lead to even greater dependence on imported fuel. Yet forgoing expansion of the energy supply would require developing Asia to scale back its growth ambitions. That is the challenge to shoring up the first pillar of energy security. As for the second pillar, if the region continues its heavy reliance on fossil fuels, emissions will substantially damage global and local environments. The third pillar is equally unnerving: as home to the majority of the world's "energy poor"-people who must rely on traditional energy sources - developing Asia must also expand access and maintain affordability if growth is to benefit society as a whole.

Addressing this multiplex of issues requires a multipronged approach. The region must actively contain its rising demand, aggressively explore new energy sources and technologies, and progressively promote the regional integration of energy markets and infrastructure. Without a paradigm shift in current energy supply and use, Asia will struggle to deliver the inclusive growth needed to lift millions of its citizens out of poverty. 


\section{The magnitude of the challenge}

Adequacy and reliability of the physical energy supply

Securing adequate energy is daunting because Asia cannot rely solely on its endowment. The region may well possess a quarter of the world's coal reserves, but it has only $16 \%$ of conventional gas reserves and $15 \%$ of technically recoverable oil and natural gas liquids. To bridge this gap, it will have to triple oil imports by 2035 , rendering it even more vulnerable to external energy price shocks (see Chapter 2, Figure 2.14).

\section{Environmental sustainability}

Meeting developing Asia's growing energy needs without radical shifts in the energy supply will result in both local and global environmental deterioration; local air and water quality will suffer the consequences. On its current energy path, which foresees substantial penetration of new and renewable energy supplies, Asian emissions will soon swamp global targets. Without radical changes to the region's energy mix, the consumption of fossil fuels will climb, doubling oil consumption and tripling natural gas consumption. Even highly polluting coal consumption will rise by an astounding $81 \%$. This would double carbon dioxide $\left(\mathrm{CO}_{2}\right)$ emissions to nearly 24 billion tons per year by 2035 . Developing Asia alone would then emit more than the 22 billion tons that climate change experts see as that year's maximum sustainable $\mathrm{CO}_{2}$ emissions for the whole world (Figure 1.1).

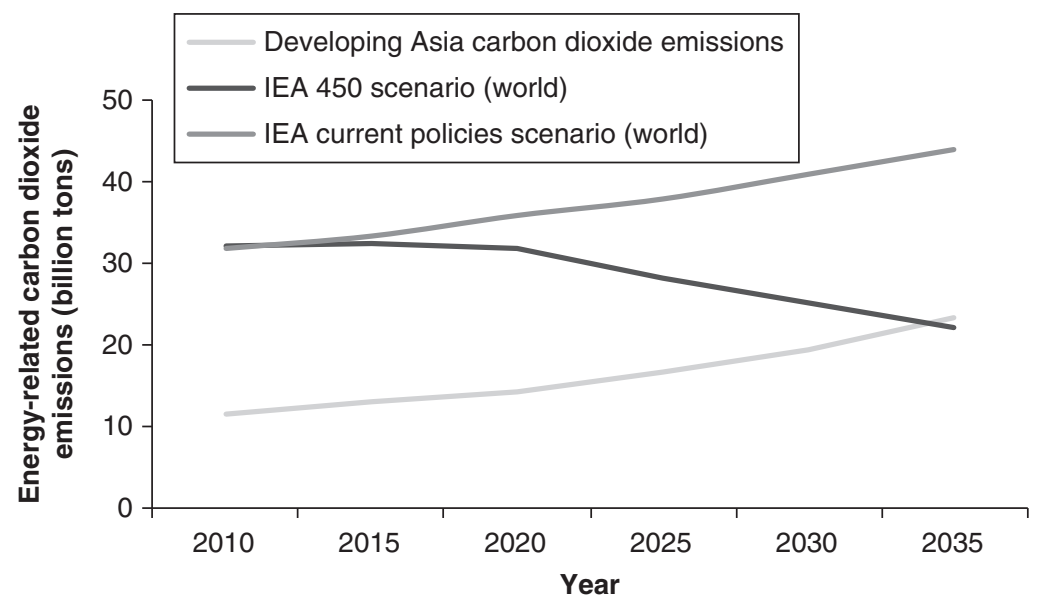

Figure 1.1 Projected energy-related carbon dioxide emissions from developing Asia Source: IEA 2011c; ADB 2013.

Note: IEA = International Energy Agency. 


\section{Affordability and access}

Securing an adequate physical energy supply and promoting environmental sustainability are difficult enough, but achieving these goals at costs that enable practical access to energy for the Asian energy poor at prices they can afford significantly compounds the challenge. For Asia, this is no small matter.

Asia has the unfortunate distinction of having most of the world's energy poor. Energy poverty perpetuates hunger by forcing women and children to spend hours gathering fuel that they could spend earning incomes or studying. Nearly half of the world's people without electricity live in Asia as do the majority of people who rely on traditional fuels such as wood, charcoal, and dung. In 2010, 2.8 billion Asians - 79\% of the world's energy poor — relied on such traditional fuels which provide low-quality energy while often destroying natural ecosystems (Figure 1.2).

Affordable access to modern energy is shockingly deficient in Asia. In 2010, some $18 \%$ of Asians - 628 million individuals - had no electricity. In that year, the percentage of the population continent-wide without electricity that relied on biomass for cooking was higher in Africa than in Asia, but some Asian countries such as Bangladesh approached the African average (IEA 2012a).

Energy is a basic human need. It is required to heat, cool, prepare, and preserve food; to provide light; to communicate; and to operate modern conveniences as well as to enable the delivery of social services like education, health, and recreation. Expanding access to energy for Asia's legions of energy poor is

\section{Without access to electricity}

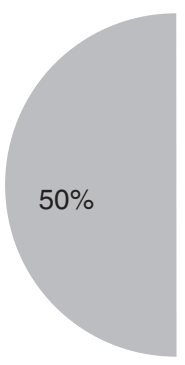

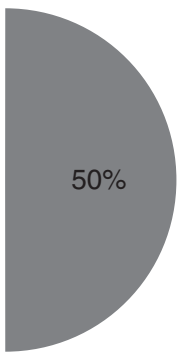

Asia $\square$ Rest of the World

\section{Dependent on traditional fuels ${ }^{a}$}

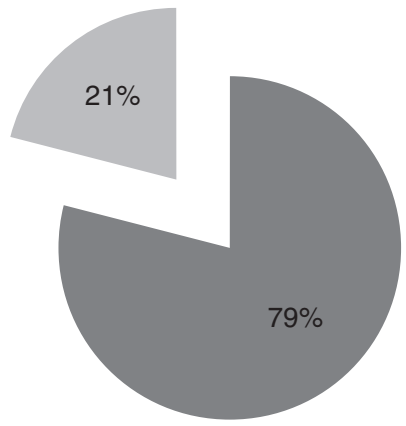

Figure 1.2 Asian proportion of energy poor

Source: IEA 2012a, Chapter 4.

Note: ${ }^{a}$ The traditional fuels category includes all types of solid fuels and kerosene, not just biomass. Electrification numbers for Asia taken from 2012 Rapid Assessment and Gap Analyses and United Nations Development Programme Energy Country Briefs supplemented with World Bank population data for 2011. Global electrification and solid fuels numbers for non-Asian countries taken from IEA (2011a). 
an urgent priority because the failure to do so will perpetuate substantial public health hazards. Yet traditional fuels like kerosene, fuelwood, dung, charcoal, and coal still supply much of the energy used in Asia (see Chapter 4 this volume).

\section{Summary}

Asia's energy challenge is formidable, but it is very far from hopeless. Instead, bold and decisive action on three fronts - actively containing rising demand, aggressively exploring new sources and technologies, and progressively promoting the regional integration of energy markets and infrastructure-holds the promise of an Asian Century solidly afoot the three pillars of Asian energy security. We explore each of these in the following sections.

\section{Containing burgeoning energy demand}

Economic growth of the magnitude foreseen for developing Asia requires abundant new energy supplies, but while the link is strong and robust, energy use and economic growth are not immutably locked together.

\section{Energy and economic growth}

In 2010, Asia contributed 28\% of global GDP and accounted for $34 \%$ of world energy consumption. If Asia follows the expected growth trajectory, by 2050 its per capita GDP will reach Europe's current level, and its share of global GDP will nearly double to $52 \%$, making about 3 billion additional Asians affluent (ADB 2011). Asia will already account for $44 \%$ of global GDP by 2035 . This economic expansion will require huge amounts of energy (Figure 1.3).

The link between economic value created (GDP) and the energy used by firms and households depends on a complex host of factors. Forecasts of energy use must comprehend all these factors, but a common if less than ideal approach is to project likely changes in energy intensity — changes in the physical energy used to generate each unit of GDP - as a summary measure intended to capture the combined trends of all the determining drivers. Assumptions on the evolution of energy intensity do, however, have significant effects on forecast demand. For example, if Asia's energy intensity trend follows its expected path, the region's share of global energy use is projected to increase to $51 \%$ by 2035 (Figure 1.3 baseline).

This is a conservative estimate reflecting an optimistic projection of energy intensity trends. The baseline model used in this study endogenously projects energy intensity declining by $3.2 \%$ per year on average over the forecast horizon. This would bring energy intensity in 2035 down to $45 \%$ of its 2010 value - an improvement by more than half. This compares with the historical trend from 1990 to 2000 of $2.47 \%$ improvement per year that is used in the less optimistic scenario. If energy intensity follows its historical trend, Asia's share of world energy consumption would be as high as $56 \%$ by 2035 (Figure 1.3 less optimistic). 

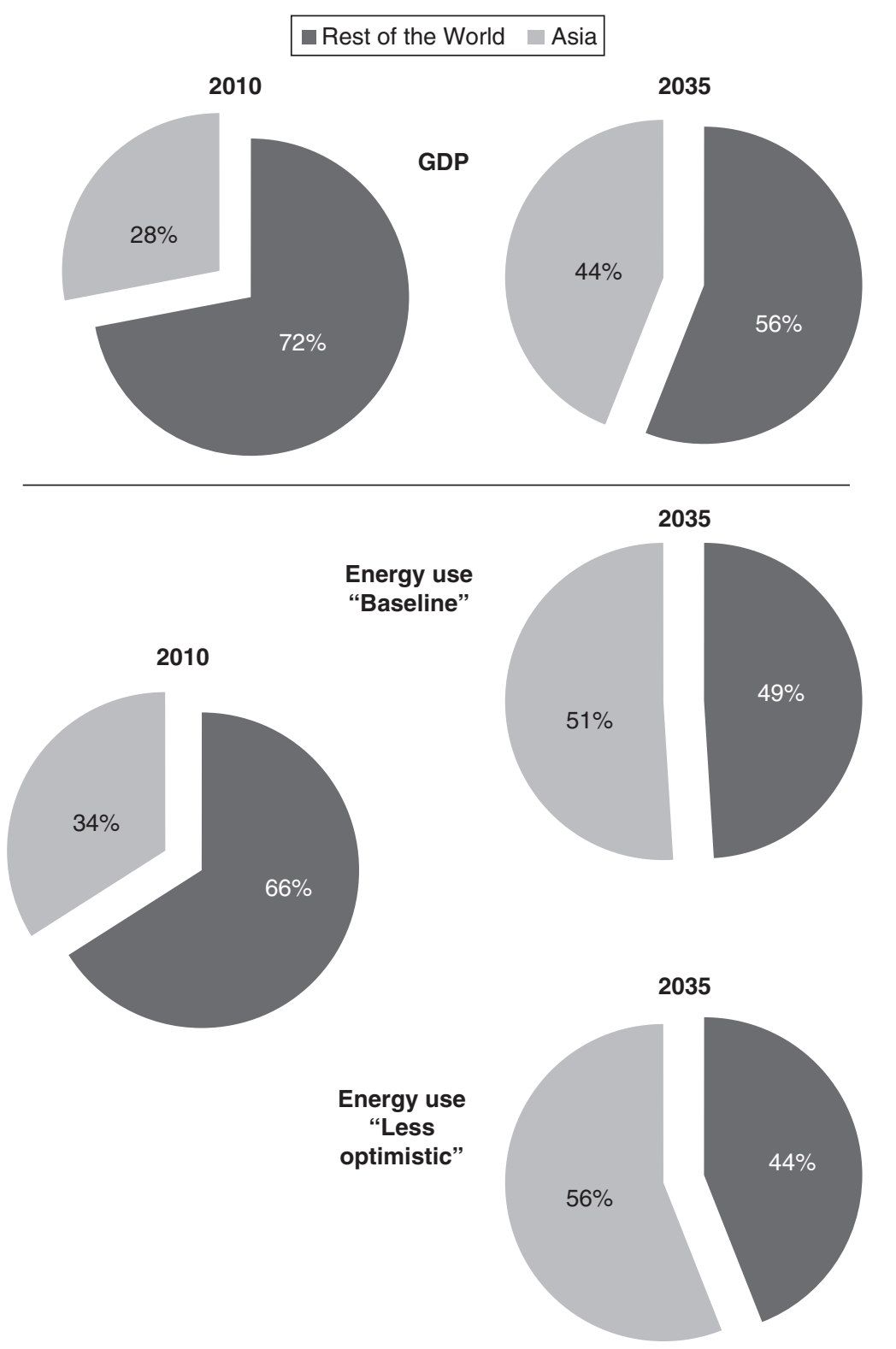

Figure 1.3 Developing Asia's share of gross domestic product and primary energy consumption, 2010-2035

Source: IEA 2012a; Authors' calculations. 


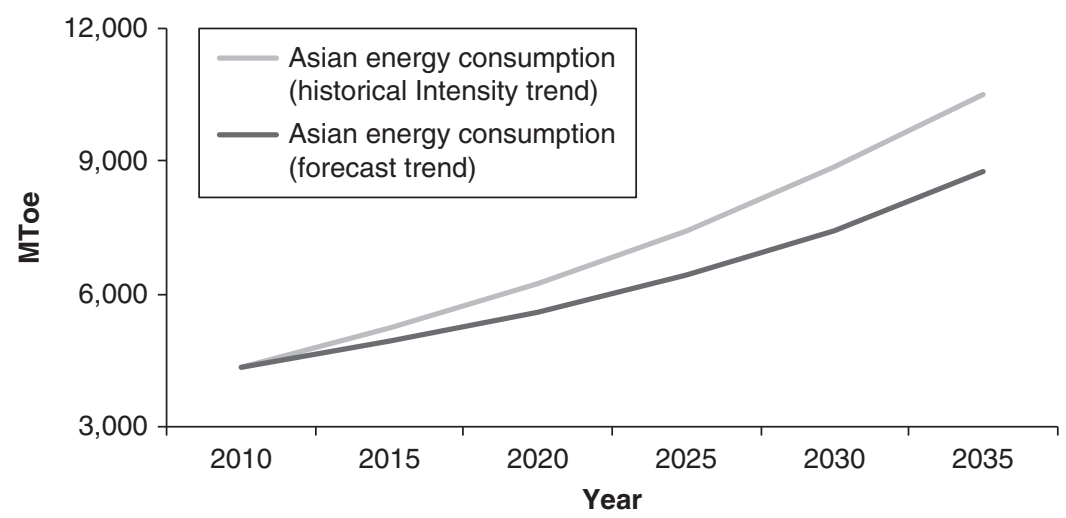

Figure 1.4 Sensitivity of energy consumption to projected energy intensity, 2010-2035 Source: Authors' calculations.

Note: MToe $=$ million tons of oil equivalent.

The resulting uncertainty is large. Figure 1.4 shows the growth of energy consumption under the two scenarios.

Critically, Asia's energy consumption is projected to double from 2010 to 2035 even under the optimistic baseline scenario despite the projected improvement in energy intensity trends. Energy consumption will increase despite substantial improvements in energy efficiency because of sharply increased per capita GDP. While Asia's population is forecast to grow only modestly by $0.7 \%$ annually, Asians will drive more and use air conditioning more as they become increasingly affluent.

Asia enjoys an array of promising options to check its energy appetite. Three broad strategies offer pathways to more efficiently manage demand even in the short term. First, eliminating consumer subsidies and taxing greenhouse gas (GHG) emissions will move the price of energy toward its true cost. If GHG taxation is undertaken intelligently, it can avoid suppressing economic activity and compromising affordability. Second, green innovations such as smart cities, clean transportation, and substituting gas for electricity will improve energy efficiency and environmental sustainability. Third, changing behavior can curtail wasteful energy consumption.

Demand management is promising, but it presents various challenges. Tackling outmoded subsidies requires political will, green innovation requires investment in technology and prudent infrastructure design, and changing behavior entails instilling fundamentally new attitudes.

\section{Energy prices that reflect true costs}

Eliminating consumer subsidies

Consumer subsidies designed to guarantee affordability and protect households from the potentially large shocks of fuel price increases artificially reduce the 
Table 1.1 Fossil fuel consumption subsidies (\$ billion)

\begin{tabular}{lrrrrr}
\hline & 2007 & 2008 & 2009 & 2010 & 2011 \\
\hline Developing Asia & 90.6 & 177.0 & 94.6 & 113.7 & 161.7 \\
Latin America & 51.7 & 71.0 & 25.5 & 40.2 & 59.5 \\
Middle East & 124.0 & 193.9 & 124.7 & 170.4 & 204.2 \\
Africa & 36.5 & 51.5 & 26.7 & 41.2 & 48.1 \\
Eastern Europe & 39.4 & 61.3 & 39.7 & 46.9 & 49.5 \\
\hline
\end{tabular}

Source: OECD/IEA.

price of energy and thus encourage overconsumption. Most Asian governments provide some form of subsidies though they vary widely. Subsidies in developing Asia are larger than elsewhere except in the Middle East, and they are increasing as Table 1.1 shows.

Such subsidies are well intentioned or at least popular, but they increase energy consumption, distort energy development planning, and when applied unevenly, provide incentives for adulteration and illegal cross-border sales. Worse, the main beneficiaries of energy subsidies are not the poor. If the intent is to make energy more affordable, only the poorest quintile should benefit from the subsidy. In fact, the poor in Asia benefit little from subsidized fuel prices because many lack electricity and gas connections, few own vehicles, and most use public transport sparingly. The International Energy Agency (IEA) surveyed nine Asian countries with the highest fossil fuel subsidies along with two countries in Africa and found that only $15 \%$ of the benefit of kerosene subsidies - and a paltry $5 \%$ of subsides for liquefied petroleum gas - went to the poorest quintile (IEA 2011a).

As the stated intent of energy subsidies is to provide affordable energy to the disadvantaged, a better solution would be to give the target populations direct cash benefits or energy coupons. Poor households are identified for benefits like food distribution, educational support, and medical treatment. The energy subsidy could be similarly targeted. For example, a cash payment scaled to the energy used by a typical energy-poor household - not tied to the household's energy consumption-would extend access without encouraging wasteful use. In fact, a beneficiary household would have incentives to use less energy and keep the surplus from the payout for other needs. This achieves the objective of restraining energy use without creating the perverse incentives that so frequently drive energy systems off track. Replacing general energy subsidies with subsidies targeting the energy poor can immediately restrain energy demand without denying those in need. Such a policy can go a long way toward laying the foundation for Asian energy security.

\section{Taxing greenhouse gas emissions}

Market energy prices rarely reflect the true price of energy when such negative externalities as pollution are factored in. A widely touted option is the so-called 
carbon tax on emissions of GHGs. The argument in favor of a carbon tax is that the price of energy should cover such externalities to create incentives to reduce energy consumption and to develop new clean technologies that would strengthen two of the three pillars of Asian energy security: adequate energy supply and environmental sustainability. The third pillar, affordability and access, is more problematic.

In fact, aside from the well-known political impediments to their adoption, GHG taxes face two primary difficulties. First, a carbon tax raises energy prices and thus undercuts affordability compromising that pillar of Asian energy security. Second, increased energy prices suppress economic activity and compromise Asia's economic growth goals. The first of these can be addressed by using tax proceeds to fund targeted subsidies to make affordable energy available to the poor as described previously. Keeping a carbon tax from inhibiting economic activity is trickier but possible. One solution is for governments to use tax proceeds to reduce the cost of another production input to offset higher energy costs. The European Commission has evaluated this kind of revenue recycling (Kouvaritakis et al. 2005). Of course, tax proceeds used to fund subsidies for the poor reduce the funds available to offset reductions in economic output, but the tax itself will arguably advance the day of a cleaner, more affordably energy supply.

The United Kingdom introduced a "climate change levy" that compensated corporate payers of a carbon tax by reducing their contributions to employees' social insurance essentially giving firms a break on their payroll taxes to offset increased energy costs. However, the government reneged on the promised reduction a few years later by returning social insurance contributions to the previous rate. A general lesson from this experience is that governments can be tempted to use proceeds from a carbon tax and similar schemes for unintended purposes when a fiscal shortfall arises, but it also shows that such a program can be implemented if the political will exists. In 2003, the Council of Ministers of the European Union issued a directive that allowed member states to "offer companies tax incentives in return for specific undertakings to reduce emissions" (European Commission 2004). Such initiatives are voluntary at the moment, but the decision points to a growing perception that GHG taxation with revenue recycling may offer a powerful tool for policymakers.

\section{Gains from green innovation}

There is a lot of scope for technological innovation that can promote energy efficiency as well as environmental sustainability. Good city planning and design can lower individual and aggregate energy requirements, for example by expanding the role of public transport. Gaseous transportation fuels such as compressed natural gas $(\mathrm{CNG})$ can mitigate the environmental impact of urban transportation. Substituting gas for electricity in end-use applications saves gas and displaces coal and other dirtier types of energy. Although green innovation requires large investments in new technology and infrastructure, the benefits are potentially huge. 


\section{Smart cities that save energy}

A rapidly growing body of research supports the idea that clever planning and design can enable new urban centers to deliver significant environmental and energy savings. As Asia grows, new cities will emerge; this relatively clean slate provides the opportunity to substantially redefine urban design. Industrialized countries in which rural-to-urban migration has largely run its course lack this opportunity.

Urbanization itself offers benefits in energy efficiency and environmental protection. In the industrialized world, residents of compact urban centers individually consume less energy and water than their suburban and rural counterparts. They live in smaller spaces, consume less, discard less trash, and rely far less on cars for transportation since walking, cycling, or public transportation are practical options that use energy far more efficiently than private cars (Owen 2009).

The benefits can be multiplied. Careful urban design can apply knowledge of mobility patterns to create compact, walkable neighborhoods. Shared-use mobility and thoughtfully agglomerated office buildings can reduce transportation energy demands. Well-designed communication and control systems can provide real-time information on the use of energy, water, and other resources that can help consumers alter consumption and movement patterns to maximize their efficient use. Asian urban centers are taking the form of megacity hubs with suburban satellite cities. Rapid transportation systems like bus mass transit systems in the People's Republic of China (PRC) and subways in India help lower energy use and improve the environment and quality of life (ADB 2012). Careful urban planning can take advantage of cogeneration opportunities in which waste heat from power generation can serve the heating and cooling needs of commercial buildings and households if the geographic configuration is compact enough.

Smart cities may rely on telecommuting and telepresence to minimize travel costs, to design work flows that allow teams to work asynchronously while enabling flexible work hours, to provide real-time information to enable more efficient consumption and travel patterns, to establish on-demand and real-time control of materials and energy flows to residences and businesses, and to remotely control industrial and commercial processes.

In Asia, moving toward this new growth paradigm is a matter of considerable urgency if its promise is to be realized. Whereas Europe needed 150 years from the beginning of serious urbanization to shift a majority of its population into urban centers, North America took only 105 years and Asia will need only 95 years (ADB 2012). From 1980 to 2010, Asia added more than a billion people to its cities pushing urban densities higher than in the rest of the world. In 2010, Asia was home to 12 of the world's 23 megacities. This rapid urbanization is expected to continue bringing Asia's urban population from the current $43 \%$ to $50 \%$ in 2025. Considering the large Asian population, the strong trend in urbanization will continue thereafter opening the door to a new growth paradigm if the process is properly managed. Implementing green, smart cities in Asia will require a major shift in urban planning; additional public finance will be needed for higher upfront capital and maintenance costs. 


\section{Clean, green transportation}

Compressed natural gas and other gaseous fuels have been introduced into urban transport mainly to address the pollution caused by gasoline and diesel internal combustion engines. Recognizing the contribution natural gas can make to better air quality and other benefits, the Republic of Korea and India among others have stepped up efforts to promote transport using $\mathrm{CNG}$. The magnitude of savings will vary across countries, but petroleum will undoubtedly be saved, and local pollution will be reduced. Both reductions would make using CNG and other gaseous fuels beneficial in Asia especially for adequate energy supply and local environmental sustainability.

Plug-in hybrid electric vehicles and battery electric vehicles both reduce local air pollution. The former run on a combination of conventional fossil fuels and a battery that is recharged by regenerative braking. Battery electric vehicles also use regenerative braking but rely mostly on the grid power supply to recharge their batteries, so their lifecycle energy and GHG savings depend on the mix of the sources powering the grid. The result is primarily a shift of pollution away from where the vehicles are operated to where the electricity is generated. If the grid electricity is generated using coal, both lifecycle energy use and GHG emissions are higher from battery electric vehicles than from plug-in hybrids. If the electricity is primarily from hydropower, however, emissions are very low.

Both options shift pollution out of urban centers. The PRC is aggressively deploying electric vehicles in line with a strategy of co-evolution between electric vehicles and developing grid generation using renewable energy (IEA $2011 b, c)$. The country has begun with a three-stage pilot project dubbed the Ten Cities Ten Thousand Vehicles Program, though it actually covers 25 cities, with 12 cities in the first stage (Beijing, Changchun, Changsha, Chongqing, Hangzhou, Heifei, Jinan, Kunming, Nanchang, Shanghai, Shenyang, and Shenzhen). The plan calls for electric vehicle ownership to reach 5 million by 2020 accounting for 5\% of total vehicle ownership (IEA 2011b).

This strategy is rightly called "co-evolution" as the development of electric vehicle fleets and power generation using renewable energy reinforce each other. The introduction to the power grid of intermittently available renewables creates challenges for reliability and stability that can be mitigated by connecting a fleet of electric vehicles through a "smart grid" (a technological advance discussed in the section "Fostering regional market collaboration"). Batteries in electric vehicles can store renewable power that is produced in excess of system load, and two-way charging infrastructure can allow electric vehicle batteries to feed back into the grid during peak demand. Such "spinning reserves" for power systems provide backup power that is immediately available and potentially reduce the cost of investment in generating capacity, strengthen the stability of the system, and provide backup against system failures. Meanwhile, electric vehicle owners can earn rebates by providing these services to the grid thus reducing their operating costs.

Clean transport requires a major shift in services. Mass road transit systems can operate fleets with gaseous fuels, and private ownership can move toward 
electric vehicles. Initially, public finance can promote research and development and help build the critical mass of vehicles that brings the cost of gas and electricity distribution per vehicle down to manageable levels. Clean transport becomes more competitive as it grows.

\section{Switching electricity for gas}

Energy efficiency can be improved dramatically by replacing electricity with gas in end use. For countries engaging in major expansions of power and gas systems, it also carries with it the potential for large capital investment savings. There is no need for new technology to make this option feasible: it is practical and implementable today. While this concept is at root fundamentally simple, understanding the source of its merits requires a little reflection.

Consider using a cubic meter of gas two ways for cooking. One option is to burn the gas in a gas-fired power plant that converts about $40 \%$ of the energy in the gas into electric energy that a family can use to power an electric cooktop (Government of the United States, EIA 2013a). If that same cubic meter of gas were instead delivered directly to power a gas cooktop, the same cooking energy would require only $40 \%$ of the original cubic meter of gas. The family would still have $60 \%$ of the cubic meter with which to prepare the next meal and half of the meal after that.

It is apparent that the energy supply system is better used if households purchase gas cooktops instead of electric ones. It makes little sense to burn gas in a power plant to boil water to generate electricity with which to boil water on an electric cooktop when instead, you can burn gas to boil water right in your kitchen. Replacing electricity with gas in many households and businesses would extend the useful life of natural gas reserves thus enhancing the adequacy of energy supply by conserving gas resources. Further, using gas instead of electricity for cooking substantially reduces emissions.

Gas can replace electricity for a number of end uses among them certain industrial processes; space heating and cooling; water heating; and powering appliances such as cooktops, ovens, clothes dryers, and refrigerators. As fuel cell technology develops and becomes more cost effective in the future, it is possible to envision entire communities fueled by gas alone with gas-fired fuel cells delivering the electricity to service electric lighting, televisions, computers, modems, routers, servers, and all manner of communication devices.

The story is even more compelling if the power plant in our example uses coal instead of gas. Coal is a much dirtier fuel for generating power than natural gas as it produces more emissions that are more problematic. To the extent that electric power is generated with coal, replacing electricity with gas for end uses offers even greater emission benefits (Figure 1.5).

Figure 1.5 illustrates how replacing electricity with gas in end uses obviates the need for much larger quantities of coal used as primary energy and obviates the need for investing in expensive coal-fired generation capacity. Manufacturers of appliances, home heating and cooling equipment, and industrial capital equipment 


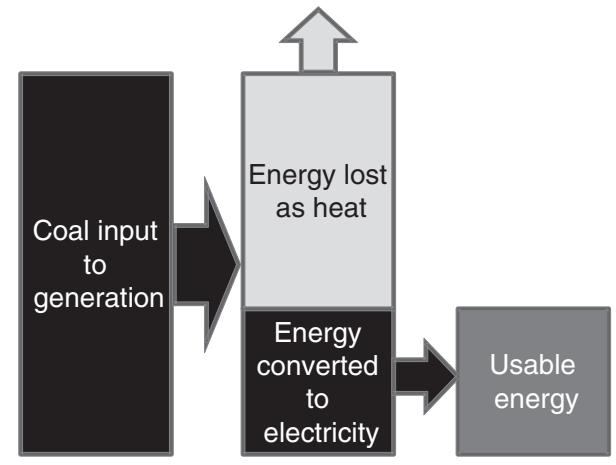

vs.

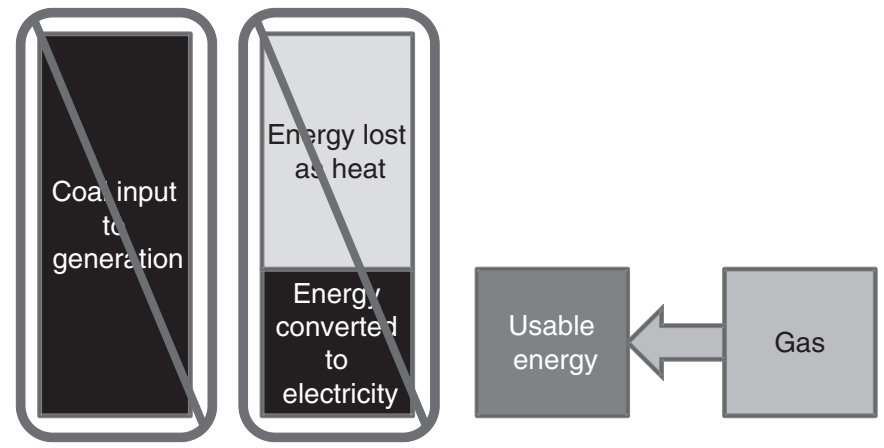

Figure 1.5 The benefits of replacing electricity with gas

Source: Authors.

can be encouraged to promote gas over electric designs. Doing so will gradually reshape the fuel demand profile. If end users demand gas, energy providers will respond. Furthermore, the potential for investment savings is large. The infrastructure to generate, transmit, and distribute electricity is much more expensive to build than the infrastructure to deliver gas.

Why is this not a strategy aggressively pursued by the industrialized world? In some cases, it has actually been a small part of energy planning, but much of the industrialized world is locked into existing electric and natural gas transmission and distribution systems. These systems are highly developed but shaped more by historical happenstance than by comprehensive planning to minimize investment cost and maximize energy efficiency. Moreover, these systems arose at a time when gas and utility regulators operated largely independently of one another and had little incentive to find efficiency measures that could benefit from careful coordination between gas and electricity delivery. 
In contrast, as Asian societies expand their gas and electricity systems into new areas - as they will with rapid urbanization and efforts to serve the energy poor-they can make a fresh start. While it may not be possible to replace electricity with gas for all new end uses in the near future, it is possible to reshape electricity and gas delivery systems in new ways that minimize redundancies and save capital costs, conserve energy resources, and reduce emissions. This strategy will therefore advance all three pillars of Asian energy security.

If gas supplies become more abundant in Asia through, for example, the aggressive development of unconventional sources, the natural and immediate inclination is to use gas as much as possible to replace dirty coal in generating electricity. This strategy seems obvious, but a broader view points in a different direction. Natural gas has more value for environmental protection and energy conservation if it is used instead to replace electricity in end uses- 2.5 times the value as the cooking illustration showed. In any case, the future development of gas and electricity transmission and distribution systems should be coordinated. Gas and electric utilities generally operate within regulatory frameworks, but sometimes the frameworks are only loosely coordinated. The economic advantages of minimizing infrastructure duplication will combine with energy savings and emission reductions to provide strong motivation to better coordinate gas and electricity systems in new infrastructure.

\section{Beware of rebound effects}

A large and growing body of research has shown that energy efficiency gains do not bring one-for-one reductions in energy consumption because of the so-called "rebound effect." In extreme cases, improved efficiency can backfire spurring outright increases in energy consumption. It appears that improvements in energy efficiency act much as energy price reductions or energy subsidies by encouraging higher energy use. ${ }^{1}$

What is particularly troublesome for Asia is that rebound effects appear to be larger in developing economies than in industrialized economies. (A fuller discussion of this phenomenon is found in Chapter 6, Figure 6.7 which finds a substantial risk of backfire in Asia using state-of-the-art general equilibrium modeling.) Yet even with rebound effects, energy efficiency gains advance the cause of affordable access by reducing the effective cost of energy and spurring

\footnotetext{
${ }^{1}$ A large and growing body of literature going back to Jevons (1865) and pioneered in the modern era by Brookes (1979) and Khazzoom (1980) assesses the magnitude of the rebound effect. Recent studies include Saunders $(1992,2008,2013)$, Sorrell $(2007,2009$, 2014), Turner $(2013,2014)$, Tsao et al. (2010), and Shellenberger, Nordhaus, and Jenkins (2011). Roy (2000, 2014) first suggested that rebound effects in developing countries may be larger than in industrialized countries. Li and Han (2012) showed energy efficiency rebound in the PRC to have been very large from 1997 to 2008, backfiring in three of those years. Lin and Liu (2013) analyzed passenger transportation in the PRC from 1994 to 2010 and found rebound at 107\% - another backfire. Chakravarty, Dasgupta, and Roy (2013) provide a good survey of the literature.
} 
economic growth by making energy cheaper for producers. If the rebound falls short of backfire, efficiency gains improve environmental sustainability and the adequacy of energy supply by reducing energy use. Careful attention to managing rebound effects can ensure that investments in energy efficiency strengthen all pillars of Asian energy security.

\section{Awareness and conservation programs}

The potential exists to reduce purely wasteful energy use by altering individual behavior. Lights that burn when no one is present, trains that run on schedule but without passengers, individual car trips when carpooling is possible, and machinery idling instead of shutting down during a production stoppage are all examples of energy used for no constructive purpose. Programs designed to raise public awareness of the social value of eliminating energy waste can have a positive impact despite their reliance on altruism and social pressure rather than proven market signals.

As with managing demand in general, Japan provides a good example of the potential of conservation programs in the Setsuden ("saving electricity") movement that emerged following the Fukushima Daiichi nuclear accident. It helped lower peak usage by $15 \%$ during the summer of 2012 and prevented power outages after the tsunami. This attests to the potential of media awareness campaigns to change the behavior of firms and households, but in light of the extreme circumstances under which the program was initiated, the experience may not be easily replicated elsewhere. Furthermore, while Japan was successful in drastically reducing peak electricity usage (megawatts), it is unclear whether much energy was saved (megawatt hours) or simply shifted to off-peak hours or whether what was saved could be removed on a permanent basis without harming economic activity. Nevertheless, the success of the campaign and what was learned have led Japan to further explore ways to improve energy efficiency.

Although the exact magnitude of energy savings obtainable by eliminating purely wasteful energy use is uncertain, doing so would come at virtually no cost. In summary, it is absolutely necessary to better manage demand to bring Asia significantly closer to the goal of energy security by reducing the risk of inadequate supply and promoting environmental sustainability, but the supply side of the equation must also be solved by augmenting the supply of clean, affordable energy. Fortunately, like the demand side, the supply side is full of promising options.

\section{Tapping cleaner energy supply}

Current baseline projections for the supply required to meet the baseline demand projections in Figure 1.4 show a mix heavily weighted toward fossil fuels (Figure 1.6).

Evident in Figure 1.6 is the expected future decline in energy use growth rates arising from the accelerated reduction in energy intensity illustrated in Figure 1.4. This is the inflection point visible in the year 2010. Also abundantly evident is 


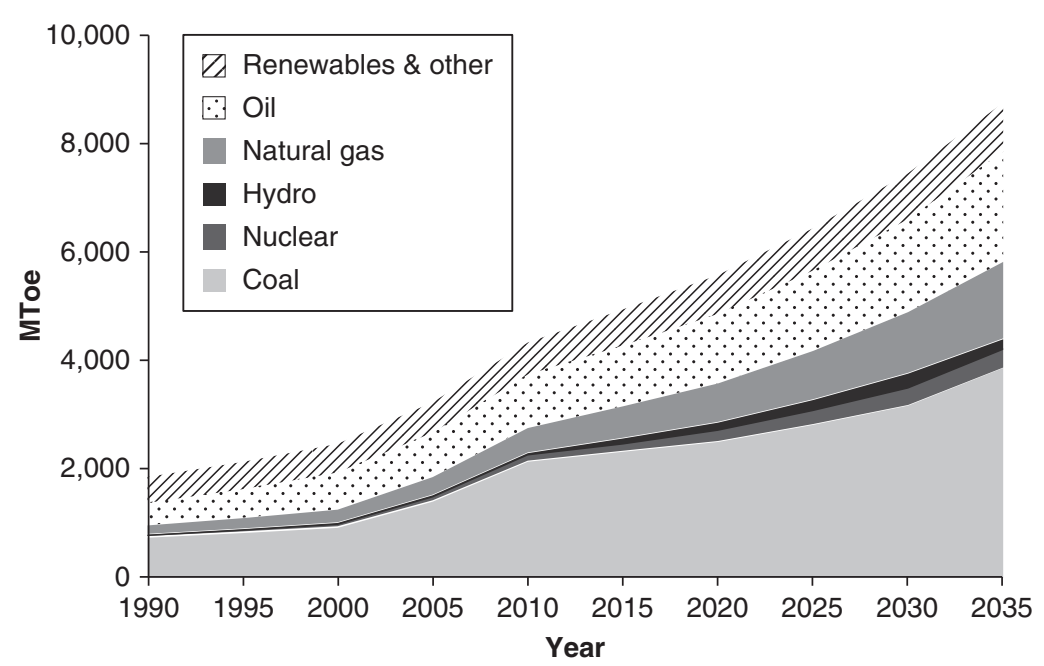

Figure 1.6 Fuel composition for Asia's energy requirements

Source: Authors' calculations.

Note: MToe $=$ million tons of oil equivalent.

the dramatic increase in the consumption of fossil fuels with oil consumption doubling and natural gas consumption tripling. Most prominently, coal consumption would rise by a full $81 \%$ in this projection. While new and existing renewable supplies including hydro will increase substantially in absolute terms, they will not be enough to offset the dramatic increase in fossil fuel use. This is what leads to the grim picture of developing Asia's future $\mathrm{CO}_{2}$ emissions illustrated so dramatically in Figure 1.1.

Is this portrayal of developing Asia's energy supply inevitable? The answer is surely not. First, the measures to manage demand described in the preceding section can help, and second, energy supply technology is shaped by human ingenuity and innovation. Expanding its energy supply in a way that is environmentally sustainable will require Asia to more aggressively pursue a combination of renewable and cleaner nonrenewable sources and technologies to make carbonbased fuels cleaner to use. These possibilities are described in great detail in chapters that follow. Here we highlight key elements.

\section{Expanding renewables}

Current projections show the use of renewables increasing by half over the forecast period. Hydropower more than quadruples, but all renewables together still account for only $13 \%$ of the power generation mix in 2035. Is there an opportunity to substantially strengthen the role of renewables beyond these forecast levels? 
Wind, solar, and other renewable energy technologies directly harness naturally available sources. These technologies can substitute for fossil fuels in generating electricity, reducing harmful emissions, and improving environmental sustainability. Biofuels can potentially replace oil-based transportation fuels and thus reduce the need for oil imports and enhance energy supply, but several difficulties prevent expanding renewables enough to make a major difference in the near future. Perhaps most fundamental is the need for renewable sources to be cost competitive with the fuels they seek to replace. While various renewables have enjoyed significant cost reductions and are already economical in certain locales and remote areas, renewable energy generally remains too costly to be competitive. This is likely to change; how quickly is unclear.

Uncompetitive cost is not the only difficulty. Biofuels pose the risk of usurping agricultural land used to grow food if their production is to expand by the magnitude required to make a significant contribution. Using solar and wind to replace coal or oil in power generation is technically tricky primarily because they are intermittent. This complicates integrating large-scale solar and wind generation into power systems in a way that maintains system reliability, stability, and the ability to quickly adjust output to minute-by-minute changes in system demand. Many argue that being cost competitive should be understood as factoring in environmental and other social costs that are external to the standard equations of microeconomics. However, capturing these externalities with subsidies or taxes and mandates creates the risk of increasing energy prices and cramping economic activity unless combined with revenue recycling. Also, the more expensive electricity derived from renewables undermines affordability, the third pillar of energy security. Policymakers have to consider such tradeoffs.

Nonetheless, one can argue that the long-term economic benefits garnered from the large-scale use of renewable energy outweigh short-term costs. Instruments such as feed-in tariffs during the introductory years of high-cost renewable technologies assure suppliers a reasonable price per kilowatt hour to mitigate their commercial risk and thereby stimulate investment in larger capacity.

Increasing the capacity to generate electricity using renewables by whatever means accelerates learning and starts to reduce costs so that the longer-term economic benefits of a cleaner energy supply can be realized sooner. The costs of climate change could be very large, and public health costs associated with burning fossil fuels are bound to grow with their expanded use. There is economic benefit in avoiding these costs sooner rather than later.

\section{Wind power}

Wind power has been rapidly expanding throughout the world including in the PRC and India, and the potential in Asia is enormous. According to one study (Shah 2012), Mongolia and the PRC could each install over 1 terawatt (1 million megawatts or 1,000 gigawatts) of wind capacity that together would generate more than 3,000 terawatt hours annually. This is over $60 \%$ of the PRC's total electricity consumption of 4,937 terawatt hours in 2012. Afghanistan, Kazakhstan, 
and Viet Nam could each install over 100 gigawatts. The only country currently exploiting more than $5 \%$ of its potential is India which is exploiting $30 \%$ largely due to an accelerated depreciation allowance. The wind resource is, however, distributed unevenly across Asia endowing a handful of countries with huge potential but leaving many with little.

As described further in Chapter 7, while wind is commercially more competitive than photovoltaic generation, it is not yet competitive enough to compete commercially with conventional forms of generation because it is intermittent which hobbles it with low capacity factors. Forecasts show the levelized cost of wind power falling by $20 \%-30 \%$ from current levels by 2030 making it nearly competitive with other forms of generation (see Chapter 7 Figure 7.31). The levelized cost is determined considering all operational costs using a discount rate to spread the capital and financing cost over the life of the project and including a reasonable return on investment.

If coal and gas prices were to escalate over this time frame, the relative economics of wind would improve accordingly. Challenges remain, however, in integrating this intermittent resource into the power grid as it is often most bountiful in locations distant from demand centers which requires lengthy connections with power grids.

In summary, wind power has numerous advantages over conventional power as it is virtually free of GHG emissions and emits no other air pollutants, but the prospects for wind power to become cost effective within the forecast horizon are uncertain. If technological developments accelerate, it can become competitive sooner. Small wind turbines are available that can provide electricity to small communities in remote locations cost effectively because the locale makes other options expensive. They can thus help expand access to energy, but making it affordable to poor households requires public financing.

\section{Solar power}

Solar power has been developed in two main directions, one using photovoltaic technology and the other concentrating the sun's rays to provide heat for a turbine. Photovoltaic cells convert solar energy into electricity using semiconductors. Concentrated solar power uses an array of mirrors to converge the sun's rays on a central tower to heat fluid and raise steam to run a turbine much as in a conventional thermal power plant. This technology has the option, with added cost, to store solar energy in a salt solution and to use it to generate electricity at night.

Photovoltaic technology has been applied in various ways since the 1960s. Despite the fact that it is safe, clean, and extremely reliable and requires no fuel and little maintenance, it has always been too expensive to achieve grid paritythe ability to compete commercially on the grid without subsidies. This may be changing, however, as the decades-long decline in photovoltaic module prices has accelerated in the last five years leading some to speculate that grid parity is likely by the mid-2010s. 
Should grid parity be achieved, it will have immense implications for all Asian economies as they all need more power sources and have solar resources ranging from good to excellent. However, availability during daylight hours only, combined with the challenges of finding tracts of land big enough to accommodate large photovoltaic capacity, may limit penetration unless cheaper storage is developed, but it is already the cheapest way to electrify small communities far from the grid, like remote islands in the Pacific, the Philippines, and Indonesia; the mountains of Bhutan and the PRC; and the sparsely populated plains of Mongolia. It thus has a potential role in providing electricity to hundreds of millions of Asians currently without power.

How will photovoltaic prices evolve over time? Figure 7.18 in Chapter 7 compares the levelized cost of solar power from utility-scale plants (generally with a capacity above 10 megawatts) with some conventional technologies in the PRC from 2010 to 2030. It suggests that even by 2030, photovoltaic generated electricity will struggle to compete with large hydropower, cheap coal, nuclear, and cheap gas at today's prices unless more investment is forthcoming to further develop the technology. If, however, coal and gas prices were to escalate significantly, solar could become more competitive.

\section{Hydropower}

Hydropower has a number of attractive attributes. It is a clean resource with few GHG emissions and emits virtually no other pollutants during operation. It is renewable, and once the initial capital costs have been borne, it provides energy extremely cheaply. In addition, large hydropower projects are commercially viable and do not require financial support from governments. Hydropower plants that reliably store energy behind a dam complement intermittent solar and wind energy and can respond quickly to variations in power demand to help maintain a reliable electricity supply.

Asia has substantial hydro resources, only $20 \%$ of which have been developed (IEA 2013). Asia's developed hydropower capacity in 2010 was 337 gigawatts (Government of the United States, EIA 2011), but the total hydro potential approaches 1,700 gigawatts. The aggressive expansion of hydro would, however, entail some problems. Local opposition to hydropower development can be strong as is clear in India. Conflicts often arise over the loss of agriculturally productive land and the need to resettle communities. Furthermore, the communities that lose their land and homes to a new reservoir often do not benefit when water is diverted into canals for irrigation downstream. Tensions run higher when rivers cross international frontiers or even provincial boundaries. Environmental concerns extend to the loss of scenic valleys, habitat destruction, and fishery disruption.

A wild card is climate change. It may alter precipitation and thus river flows in a developed catchment rendering reservoir storage capacity far from optional. Interestingly, the more violent storms and extended droughts that global warming is expected to cause will require greater water storage capacity for irrigation 
and flood prevention. This could make building dams for hydropower simultaneously part of a larger strategy to address climate change.

\section{Biofuels}

Biofuels emit GHGs as do such conventional fuels like gasoline and diesel; however, they are produced from biomass which sequesters $\mathrm{CO}_{2}$ from the atmosphere for photosynthesis while growing. Therefore in principle, burning such fuels does not cause a net increase in atmospheric concentrations of $\mathrm{CO}_{2}$. Accordingly, their development and use can theoretically advance environmental sustainability. In addition, biofuels are liquids and therefore a convenient substitute for oilbased transportation fuels that can reduce the need for oil imports and enhance the adequacy of energy supply.

The current generation of biofuels has three significant problems. First, biomass cultivation, transportation, and processing require energy that must be subtracted from biofuel energy content to arrive at net energy output. In some cases, the net gain is small. Second, the first-generation biofuels compete with food production by directly using food crops or land used to grow them. With its large poor population, Asia already faces challenges producing enough affordable food. Food security could be jeopardized if too many farmers choose to switch to biofuel crops. Third, biofuels are not yet cost competitive with traditional transportation fuels so typically require significant subsidies.

Research is underway worldwide to address the first two issues by producing biofuels from materials that do not compete with food production using the so-called "cellulosics" in crop residues, plants with high-energy content that grow well on degraded land, and algae. At this point, these technologies are not yet cost competitive, but if they reach fruition they could make a substantial contribution.

As with solar and wind, biofuels other than ethanol are not yet cost competitive. The IEA shows the cost of producing conventional biodiesel in 2011 at nearly double that of gasoline and projects that it will remain more expensive than gasoline for the foreseeable future. On the other hand, the IEA projects that ethanol costs will fall below gasoline costs before 2020 because of scale expansion and efficiency improvements. Second-generation biofuels from cellulosics, both ethanol and biodiesel, are not projected to become cost competitive with gasoline until sometime around 2030 (IEA 2011c).

In summary, as with solar and wind, the prospects for biofuels to improve the adequacy of energy supply and environmental sustainability depend heavily on aggressive investment in new technologies that will reduce their cost and overcome land-use conflicts.

\section{Summary}

In the end, all renewables escape the fate of oil, gas, coal, and fission-based nuclear fuel: the potential to be consumed to exhaustion. Without the successful 
development of truly breakthrough technologies, only renewables can sustain future generations indefinitely. Therefore, the question is not whether Asia should invest in renewable energy but how quickly and how much it should invest. The primary obstacle to renewables - that they are for the most part not yet cost competitive with alternative sources - will inevitably diminish with time and technological progress.

\section{Expanding nonrenewables}

While renewables offer considerable promise, fossil fuels will continue to play a key role in the time frame considered here. The current forecast shows natural gas and coal use increasing over the forecast period and a modest increase in nuclear power. Is there an opportunity to expand the use of these fuels in a clean, safe way? Gas is cleaner than coal, and existing and emerging technologies may enable the use of coal in a more environmentally sustainable way. These questions are examined next and in greater detail in Chapters 7 and 9.

\section{Unconventional gas}

The current forecast shows natural gas production more than tripling over the time frame increasing its share of supply from about $10 \%$ to $16 \%$. Could this be improved by more aggressively developing unconventional gas supplies? Recent experience in the industrialized world shows that unconventional gas has the potential to come online quickly and to significantly change the energy supply picture.

The appeal of this idea is great. Unconventional gas resources such as shale gas and coal bed methane offer the promise of replacing coal in power generationeither directly or indirectly by substituting gas for electricity in end uses-and oil in producing certain petrochemicals. Shale gas and coal bed methane are chemically equivalent to conventional natural gas.

The conventional way to produce natural gas is to drill and extract it out of "traps" or folds and pockets in underground sedimentary layers. Natural gas also exists in deeper layers, typically shales from which the gas found today in the shallower traps migrated in geologic time. This "source rock" is much easier to find than traps and contains much larger quantities of gas (see the appendix to Chapter 7). Traps are sparsely distributed compared with the source rock that extends over large areas in a basin.

The advent of horizontal drilling combined with hydraulic fracturing"fracking" - has rendered large volumes of gas accessible. In the United States (US), the shale gas share of all gas production exploded from 8\% in 2007 to $30 \%$ in 2011 (Government of the United States, EIA 2013b). Could this shale gas revolution be extended to Asia?

Asia almost certainly has significant reserves of unconventional gas, but where it is and how much of it is technically recoverable is uncertain (IEA 2012a,b; Rogner 1997; McGlade, Sorrell, and Speirs 2012). Indications are that 
the PRC has the largest shale gas resources in the world at nearly $20 \%$ of the global total while India, Pakistan, and possibly Indonesia likely hold substantial resources as well (see Chapter 7, Table 7.2). Both India and the PRC have substantial coal bed methane (Table 7.5).

Obstacles to developing these resources include the fact that unlike in North America, the geology in Asia is not well understood and appears to be more challenging, the data are sparse, prospective gas fields are in densely populated areas, and the water required for fracking may conflict with local needs.

On the whole, the aggressive development of unconventional gas has the potential to enhance the adequacy of supply, affordability, economic growth, and environmental sustainability if local environmental impacts can be carefully managed. In Asia, however, the magnitude of the resource that can be developed is uncertain as is the rate at which it can be produced. Serious issues of environmental and population disruption need to be tackled. While not a truly clean resource, unconventional gas could provide a cleaner bridge to a future less dependent on fossil fuels.

\section{Nuclear power}

The proposition that nuclear power should be expanded in Asia is fraught with contention, but a responsible accounting of Asia's energy challenge is incomplete without a discussion of the pros and cons of initiating or extending a nuclear energy program and of the challenges facing policymakers who must grapple with this thorny issue. Governments will reach their own conclusions based on their individual situations.

Despite re-evaluating nuclear programs in the aftermath of the Fukushima accident, most current construction of nuclear plants is in Asia. Nuclear power compares favorably with other options by measures of GHG emissions and air pollution as it ranks with hydro and wind power as a low emitter. During operation, nuclear power plants, like renewables, emit virtually no air pollutants like nitrogen oxides, sulfur dioxide, or particulates.

Nuclear is cost competitive with fossil fuels and cheaper than present-day renewables. The major financial impediment is the typically very large upfront capital costs that are often exacerbated by extended schedules for clearing regulatory and permit hurdles. Yet, when evaluated on a lifecycle basis that incorporates the costs of construction, interest during construction, fuel, operation, maintenance, waste management, and decommissioning, nuclear compares favorably with conventional power plants. The advent of small modular reactors should improve these economics.

A hypothetical phasing out of nuclear power over the forecast period would cause a significant increase in fossil fuel use for power generation. If no new nuclear plants were built and existing plants were retired, the capacity lost by 2035 would be offset mostly by coal and gas. Renewables would make at best a modest contribution. Phasing out nuclear power would increase Asian power sector emissions by $8.6 \%-10.8 \%$ in 2025 and by $7.8 \%-13.3 \%$ in 2035 (ADB 2013). 
The region's ability to achieve sustainable growth with low GHG emissions would be uncertain without nuclear power.

This evaluation sidesteps widespread public concerns about nuclear safety, especially in the wake of the Fukushima meltdown. Additional public concerns exist over the handling and disposal of radioactive waste and associated risks. Finally, the expansion of nuclear power creates worries about the proliferation of nuclear weapons. New generations of nuclear power promise to reduce these risks.

In summary, nuclear power holds the promise of minimizing GHG emissions and air pollution. It is cost effective and becomes even more cost effective if construction lead times can be shortened. Small modular reactors present a promising new development for speeding up construction. Safety risks arise from the possibility of nuclear accidents, and nuclear materials must be carefully handled and disposed of. Public opinion and geopolitical considerations will undoubtedly be key in determining the future of nuclear power in Asia.

\section{Cleaner coal}

Truly significant reductions in GHG emissions could be obtained by using technologies that remove carbon and other GHG components from the emissions of coal- and gas-fired power plants. Asia's energy future would have far different GHG consequences if the coal used for generating power were more benign. GHG-benign coal requires carbon capture and storage technology for power plants that is at an early stage of development and thus very expensive.

Supercritical and ultra-supercritical power plants reduce emissions by increasing the efficiency of converting coal and gas to electricity and have been in operation for some time in the PRC and Japan. Countries in Asia that plan a larger share of coal in their primary energy mix or that have the capability to use related technologies include India, Indonesia, the Republic of Korea, Malaysia, Pakistan, and Viet Nam. These countries can lower their GHG emissions by using supercritical and ultra-supercritical technology for all new coal-fired power plants. Capital costs would increase marginally by about $2 \%$, but coal use and thus $\mathrm{CO}_{2}$ emissions would decline by $10 \%-15 \%$; lower fuel costs improve the economic viability of such projects.

Considering the large and growing role of coal in Asia's energy mix, the need to progress toward cleaner coal technologies is clear. Unlike in developed economies, where electricity demand has flattened out, Asia will have to expand production. Given Asia's needs and technical capabilities, the development of clean coal technology potentially offers immense environmental benefits and commensurately large commercial opportunities.

\section{Summary}

The foregoing analysis lays out the opportunities and challenges associated with a wide range of sources of energy supply - most of which depend on new technologies - that can help Asia achieve energy security. Each new energy source has its merits and shortcomings. Individually, their contribution to improving 
Asia's energy security will be limited, but collectively the various sources can make a big difference especially when combined with better management of demand. Asia must therefore strive on all fronts to secure ample, affordable, clean energy supplies. Developing these future technologies will often require government support in the early stages while firms pursue commercial viability. While each source has its limits, every drop-every watt-counts.

\section{Fostering regional market collaboration}

Aggressive action to both manage demand and to promote new, clean supply technologies can advance the cause of Asian energy security, but these advantages will not be fully realized without measures to bring demand and supply together more efficiently. Achieving energy security will thus require cooperative programs that integrate energy delivery systems on a regional scale.

Cross-border energy markets and infrastructure connectivity have so far been largely ignored in regional cooperation and integration. This is unfortunate in light of the rapidly rising energy demand in Asia that makes energy security a regional challenge that would benefit greatly from a collective regional response. The lack of regional cooperation and integration is all the more glaring as jointly promoting energy savings and security would not require new technology or pose the high cost and financial risk developing it might entail. What is required is the political will to cooperate and the mutual confidence that makes cooperation possible.

Cross-border collaboration is technologically and commercially viable. What is missing in Asia is the political commitment to cooperate in energy markets and to build the necessary infrastructure.

\section{Integrating electricity and gas delivery systems}

The potential benefits of coordinating electricity and natural gas networks across borders are immense. Power system failures and gas supply disruptions have major consequences that can be mitigated by properly designing collective delivery systems from the outset to optimize delivery without undue concern about borders to enable cost minimization and energy efficiency gains. As described previously, unfettered by the rigid infrastructure already in place in the industrialized world, developing Asia has the opportunity to coordinate the development of gas and electricity grids to realize gains in energy efficiency, environmental improvements, and investment savings from substituting gas for electricity in end uses. Even within each of these systems there are large gains within easy reach of prudent policymakers and regulators via geographic integration.

\section{Interconnected electricity systems}

The incentives to interconnect electric power systems are strong in terms of improved reliability, more effective fuel conservation, and broader economic benefits. Larger systems typically deliver power at lower costs per kilowatt hour than do smaller ones, owing to economies of scale and diversified generation 
mix. Interconnected systems reduce capital costs by sharing backup generation capacity, and larger systems generally use less primary energy per kilowatt hour of electricity delivered.

Interconnection advances the cause of energy efficiency. Larger systems can generally accommodate larger baseload-generation units that typically enjoy greater fuel-conversion efficiency than do smaller units. The larger and more interconnected the power systems, the greater the energy efficiency gains. Large interconnected systems make it practical to implement large hydropower projects as is evident in Central Asia where building large dams for power generation in the Kyrgyz Republic or Tajikistan could not be justified for such small national systems.

Cross-border connections enable high-voltage transmission lines and direct connections that improve energy efficiency. Less electricity is lost in transit when it is transmitted at higher voltages; however, high-voltage lines are expensive to build and therefore economical only for transmitting large loads over long distances that are often larger and longer than an isolated market can accommodate. High-voltage, direct-current connections improve grid stability and by minimizing transmission losses, energy efficiency.

Regional cooperation and integration is already under way but has scope for expansion. Asia is a long way from the unified regional power grid Europe has, but there is no reason why it cannot entertain this ambition. In the short run, most cooperation and integration is taking place in subregions and among close neighbors.

\section{Interconnected gas systems}

Similar economies and efficiencies are realizable by connecting natural gas systems. Where gas endowments exceed domestic energy demand, interconnected markets would allow idle natural resources to be used like any other exportable commodity to create a revenue stream to help meet development needs. Crossborder gas pipelines also offer the opportunity to create gas distribution networks that economically serve the needs of communities along the route-communities that might otherwise not be served. As discussed earlier, cooktops and furnaces can run on gas to avoid losing energy in electricity generation. Large pipeline networks operating at high pressure also provide storage capacity to help maintain a reliable supply during small technical interruptions.

\section{"Smart grids" to integrate renewables}

As an energy system comes to depend more on renewables, it needs to become more intelligent. Solar and wind are intermittent resources that cannot be relied on to deliver power on demand. Solar is available only by day, and then unpredictably depending on cloud cover. Wind is highly variable and likewise unpredictable. Wind barely correlates with times of high system demand and solar correlates only somewhat better, so integrating these unpredictable renewables into the power grid poses significant technical challenges. Large, intelligent 
systems can take advantage of time-of-day demand differences across time zones and swing power across large areas as solar and wind system outputs rise and fall.

Attendant to this problem is the need to incorporate distributed generating systems that generate electricity not in centralized power plants but from small local sources such as solar panels on buildings, small on-site generators and cogenerators, and local biomass- and waste-based power systems. Sometimes local sources are joined together in microgrids that operate locally for the most part but with a connection to the main grid. Integration challenges the central grid operator to maintain appropriate voltage and phase synchronization and ultimately, system stability.

Intelligent systems that can adjust to accommodate decentralized generation and renewable generation can optimize the system toward maximizing generation from renewables, minimizing costs, and improving the reliability of service. This requires that smart grids in different countries are able to communicate with one another so they can operate together seamlessly. System optimization in the service of Asian energy consumers depends on strong regional cooperation.

The widespread use of electric-powered transport will introduce challenges along with opportunities. Smart, interconnected power grids that tie together electric vehicle fleets in geographically dispersed markets can charge the vehicles when surplus renewable energy is available, store electricity in the vehicles' batteries, and during high grid demand draw power back from any idle vehicles that are plugged into the grid in an intelligent "co-evolution" of power systems and transportation.

\section{Asia's energy challenge, reprised}

It would be irresponsible to make light of the enormity of the task facing Asia given the stark realities presented in the first section of this chapter. Asia's economic emergence, tied as it is to a corresponding thirst for energy, carries with it threats to the availability of supply, environmental sustainability, and universal access to affordable energy. Failure in any of these three pillars of energy security would require Asia to scale back its economic ambitions and to forgo the vision of a clean Asian Century.

Formidable though it may be, Asia's energy challenge is likewise an opportunity. Against this stark picture, it is possible to see in Asia the equivalent of a global greenfield site wherein a youthful energy infrastructure poised for massive growth and a population rich with intellectual prowess enables the deployment of new energy paradigms drawing on new knowledge for managing demand, on new supply technologies, and on intelligent integration of energy systems. In Part V, there are concrete policy prescriptions for Asia to lead the world by example into an era in which energy security is no longer a cause for deep concern and in which energy scarcity, environmental degradation, and energy poverty are one day relegated to the distant past. 


\section{References}

Asian Development Bank (ADB). 2011. Asia 2050: Realizing the Asian Century. Manila: ADB.

—. 2012. Green Urbanization in Asia. In Key Indicators for Asia and the Pacific 2012. Manila: ADB.

2013. Asian Development Outlook: Asia's Energy Challenge. Manila: ADB.

Brookes, L. 1979. A Low Energy Strategy for the UK by G. Leach et al.: A Review and Reply. Atom. 269. pp. 3-8.

Chakravarty D., S. Dasgupta, and J. Roy. 2013. Rebound Effect: How Much to Worry? Current Opinion in Environmental Sustainability. 5 (2). pp. 216-228.

European Commission. 2004. The Energy Taxation Directive. http://ec.europa.eu/taxation customs/taxation/excise_duties/energy_products/legislation/index_en.htm (accessed February 2014).

Government of the United States, Energy Information Administration (EIA). 2011. World Shale Gas Resources: An Initial Assessment of 14 Regions Outside the United States. April. http://www.eia.gov/analysis/studies/worldshalegas/ (accessed February 2014).

—. 2013a. Natural Gas Summary. http://www.eia.gov/dnav/ng/ng_sum_lsum_dcu_ nus_a.htm (accessed February 2014).

—. 2013b. Table A6. Approximate Heat Rates for Electricity, and Heat Content of Electricity. Monthly Energy Review. March. http://www.eia.gov/totalenergy/data/ monthly/pdf/sec13_6.pdf (accessed February 2014).

International Energy Agency (IEA). 2011a. Energy for All: Financing Access for the Poor. Paris: Organisation for Economic Co-operation and Development (OECD)/IEA. http://www.worldenergyoutlook.org/media/weowebsite/2011/weo2011_energy_for_all. pdf (accessed February 2014).

—. 2011b. Technology Roadmap: Biofuels for Transport. Paris. http://www.iea. org/publications/freepublications/publication/name,3976,en.html (accessed February 2014).

—. 2011c. World Energy Outlook 2011. Paris. http://www.worldenergyoutlook.org/ publications/weo-2011/ (accessed February 2014).

- 2012a. Golden Rules for a Golden Age of Gas: World Energy Outlook Special Report on Unconventional Gas. Paris. http://www.worldenergyoutlook.org/goldenrules/ (accessed February 2014).

_. 2012b. Technology Roadmap: Hydropower. Paris: International Energy Agency. http:// www.iea.org/publications/freepublications/publication/2012_Hydropower_Roadmap.pdf? bcsi_scan_97e98328e2b67804=0\&bcsi_scan_filename=2012_Hydropower_Roadmap. pdf (accessed February 2014).

- 2013. Hydropower: A Key to Prosperity in the Growing World. http://www. ieahydro.org/uploads/files/hydropower_a_key_to_prosperity.pdf (accessed February 2014).

Jevons, W. S. 1865. The Coal Question: Can Britain Survive? First published in 1865. Republished 1906. London: Macmillan.

Khazzoom, D. 1980. Economic Implications of Mandated Efficiency Standards for Household Appliances, Energy Journal. 1 (4). pp. 21-40.

Kouvaritakis, N., N. Stroblos, L. Paroussos, T. Revesz, E. Zalai, and D. Van Regemorter 2005. Impacts of Energy Taxation in the Enlarged European Union, Evaluation with GEM-E3 Europe. Final report. Study for the European Commission. http://master. e3mlab.ntua.gr/reports/energy_tax_study.pdf 
Li, L. and Y. Han. 2012. The Energy Efficiency Rebound Effect in [the People's Republic of] China from Three Industries Perspective. Energy Procedia. 14. pp. 1105-1110.

Lin, B. and X. Liu. 2013. Refined Oil Pricing Mechanism Reform and Energy Rebound for Passenger Transportation in [the People's Republic of] China. Energy Policy (in press).

McGlade, C., S. Sorrell, and J. Speirs. 2012. A Review of regional and Global Estimates of Unconventional Gas Resources. In I. Pearson et al. eds. Unconventional Gas: Potential Energy Market Impacts in the European Union. Luxembourg: Publications Office of the European Union.

Organisation for Economic Co-operation and Development/International Energy Agency (OECD/IEA). Fossil Fuel Subsidies and Other Support. http://www.oecd.org/site/ tadffss/IEA\%20fossil\%20fuel\%20subsidy\%20data.xlsx (accessed 12 March 2013).

Owen, D. 2009. Green Metropolis: Why Living Smaller, Living Closer, and Driving Less are the Keys to Sustainability. New York: Riverhead Books.

Rogner, H. H. 1997. An Assessment of World Hydrocarbon Resources. Annual Review of Energy and the Environment. 22. pp. 217-262.

Roy, J. 2000. The Rebound Effect: Some Empirical Evidence from India. Energy Policy. 28 (6-7). pp. 433-438.

Saunders, H. D. 1992. The Khazzoom-Brookes Postulate and Neoclassical Growth. The Energy Journal. 13 (4). pp. 131-148.

- 2008. Fuel Conserving (and Using) Production Functions. Energy Economics. 30. pp. 2184-2235.

- 2013. Historical Evidence for Energy Consumption Rebound in 30 US Sectors and A Toolkit for Rebound Analysts. Technological Forecasting and Social Change. 80 (7). pp. 1317-1330.

Shah, J. 2012. Mongolian Renewable Energy. Presented at the ADB workshop Quantum Leap in Wind. Ulaanbaatar. 17-18 May.

Shellenberger, M., T. Nordhaus, and J. Jenkins. 2011. Energy Emergence: Rebound and Backfire as Emergent Phenomena. Oakland: The Breakthrough Institute. http:// thebreakthrough.org/archive/new_report_how_efficiency_can (accessed February 2014).

Sorrell, S. 2007. The Rebound Effect: An Assessment of the Evidence for Economy-wide Energy Savings from Improved Energy Efficiency. London: UK Energy Research Centre. http://www.ukerc.ac.uk/Downloads/PDF/07/0710ReboundEffect/0710Rebound EffectReport.pdf (accessed February 2014).

— 2009. Jevons' Paradox Revisited: The Evidence for Backfire from Improved Energy Efficiency. Energy Policy. 37 (4). pp. 1456-1569.

_. 2014. Energy Substitution, Technical Change and Rebound Effects. Energies 7. pp. 2850-2873. doi:10.3390/en7052850.

Turner, K. 2013. Rebound Effects from Increased Energy Efficiency: A Time to Pause and Reflect. The Energy Journal. 34 (4). pp. 25-42.

- 2014. The Added Value from a General Equilibrium Analysis of increased efficiency in household energy use. Ecological Economics 100. pp. 51-62.

Tsao, J. Y. et al. 2010. Solid-state Lighting: An Energy-Economics Perspective. Journal of Physics D: Applied Physics. 43 (35). pp. 1-17. 



\section{Part II}

\section{Energy security, sustainability, and affordability}





\title{
2 Oil security in Asia and the Pacific
}

\author{
David Isaak
}

\section{Introduction}

The term "energy security" has meant many things over the decades since the first oil crisis in 1973 and 1974. For most, although not all, energy analysts, it has come to denote far more than simply tying up a diverse portfolio of crude oil supply contracts. Not all crudes are useable in all refineries, and price impacts can be crippling even if there is no cutoff of supply. Price controls - particularly subsidies - can result in huge economic costs and can cause massive distortions. Furthermore, almost no one consumes crude oil; instead, oil products with various degrees of substitutability with other fuels are consumed. While a political scientist might have been perceived as a good guide to energy security in the 1970s, today energy security demands an understanding of technology, economics, and environmental science in addition to an understanding of politics.

This chapter examines oil in the context of other energy sources then moves on to the outlook for oil prices and the implications of current forecasts, the demand for oil and for oil products by sector, fuel substitution and oil supply, the outlook for production in developing Asia, the importance of product trade, reliance on particular regions, and the critical role of refinery capabilities. Finally, oil security is discussed with a focus on specific problems and possible remedies.

\section{Oil in context}

Almost every graph of energy demand in Asia and the Pacific shows the same general picture: a curve or set of stairs that moves steeply upward. Figure 2.1 is a standard example and shows the tremendous growth in primary energy demand in developing Asia from 1990 through 2010.

The most prominent feature of the chart is growth. Primary energy demand more than doubled between 1990 and 2010. In 1990, developing Asian demand was about the same as North American demand, but by 2010, demand in developing Asia substantially exceeded that of North America and Europe combined. Furthermore, there was growth in every primary energy source from coal to oil to "other" which in this figure includes geothermal, wind, solar, peat, and miscellaneous energy sources, but in developing Asia more than $90 \%$ of this is 


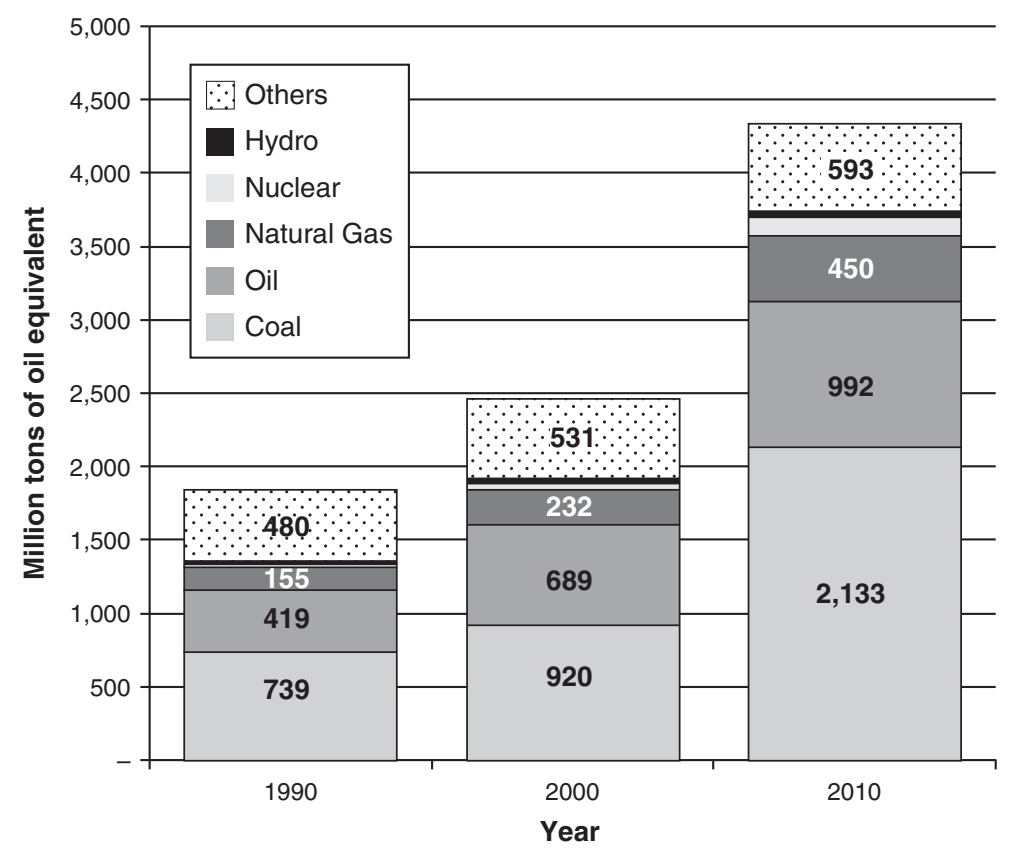

Figure 2.1 Developing Asian primary energy demand by source Source: ADB 2013.

biomass, biofuels, and other agricultural waste. More than half of that bioenergy is from the People's Republic of China (PRC) alone.

Charts like these are invariably so dominated by the impression of growth that the changes in consumption patterns are often hidden. Rapid growth is happening across all energy sources, but the rates of increase are very different among fuels. Between 1990 and 2010, the use of coal and natural gas nearly tripled, nuclear increased to five times its 1990 level, but oil demand, on the other hand, increased to "only" about $240 \%$ of its 1990 level. In other words, although oil showed extraordinary demand growth by standards elsewhere in the world, it showed comparatively restrained growth compared to other fossil fuels or to nuclear energy.

The result has been a dramatic shift in the composition of primary energy demand. Figure 2.2 puts this shift in the context of Europe and North America and of Latin America, another rapidly developing region.

One important trend is the increase in the role of gas in all regions. This is not surprising in North America or Latin America which are both major gas-producing regions. Similarly, the trend is to be expected in Europe where there is substantial production and also well-developed systems for imports via both pipelines and liquefied natural gas (LNG) tankers. The rapidity of the expansion in gas demand 


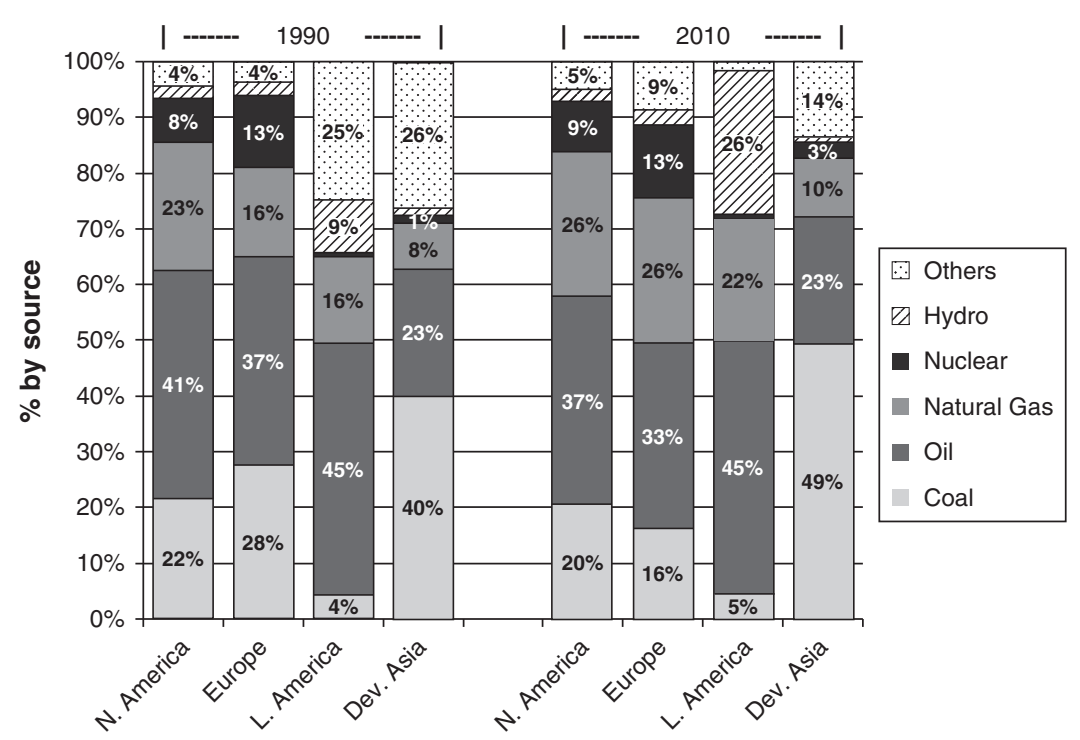

Figure 2.2 Primary energy demand by region

Source: ADB 2013; BP 2012; IEA 2012a,b.

in developing Asia is, however, remarkable as it has not only required a massive increase in production, it has also required a substantial, ongoing expansion in import infrastructure.

It is important not to confuse oil demand with the share of oil in energy demand shown above. In Europe demand rose after 1990 but then began declining around 2005; by 2010 it was roughly at its 1990 level again (IEA 2012a). In United States (US) and Canada, 2010 demand levels were above 1990 levels (IEA 2012a; Government of Canada, NEB 2011). Despite the fact that North America and Europe saw no overall decline in oil demand across this period, the contribution of oil to total energy consumption fell in both regions.

In coming years, however, absolute demand is projected to decline substantially in both Europe (IEA 2012c) and the US (Government of the United States, EIA 2012). Oil demand in Canada is projected to increase (Government of Canada, NEB 2011), but for North America as a whole the additional volumes are more than offset by forecast declines in the US. In coming years, therefore, North America and Europe are likely to see major declines in oil demand and even sharper declines in oil's role in total energy supply.

In a similar vein, in developing Asia and in Latin America the shares of oil in total energy demand in Figure 2.2 were static between 1990 and 2010. This disguises the fact that oil demand grew rapidly in this period, but the demand for other fuels grew even faster leaving oil's share of energy demand unchanged across the decade. 


\section{David Isaak}

To take a closer look, demand for oil in developing Asia grew from 419 million tons of oil equivalent (MToe) in 1990 to 992 MToe in 2010. The biggest reason for the static share of oil was the enormous expansion of other fossil fuels, notably coal. Coal has long been the mainstay of the Asian energy system in certain countries (notably the PRC and India), and it has undoubtedly restrained the growth of oil demand in the face of rapidly expanding economic growth, but as most people will admit, coal presents a host of environmental challenges.

From a very low base, natural gas demand has been expanding at an astonishing rate which is all the more astonishing given that few Asian countries are major gas producers. The region takes almost $67 \%$ of the world's trade in LNG. If some of the major energy consumers were to accelerate domestic gas output (possibly from unconventional sources), there is little doubt that gas would gain an even greater energy share.

It is a truism in most energy circles that oil is ultimately a transport fuel, and it is true that liquid fuels for transport are the hardest energy sources to replace although natural gas as compressed natural gas (CNG) and LNG now seems poised to make substantial inroads into gasoline and diesel demand in the US (Deal 2012; Burns 2012). Boeing is even looking into LNG-powered aircraft by 2030, though sophisticated, high-efficiency versions are not expected until after 2040 (Warwick 2012).

In Asia, however, there are still major non-transport uses of oil that have substantial resilience for many reasons. One is availability, i.e., coal and gas are not produced or imported everywhere. Another is that Asian exports today need more petrochemicals than the US or Europe needed in the 1950s because manufacturers now use less steel and aluminum and more plastics. Also, the sheer speed and scale of Asian economic expansion has driven some manufacturers to set up their own oil-fired power plants to meet demand without waiting for the utility grid to deliver power.

The famous energy economist Paul Frankel observed that the important thing to understand is that oil is a liquid (Frankel 1946). This seems obvious, but it is profound. Oil is easy to store and is the easiest fossil fuel to transport. Unlike coal, it can be pumped from place to place, and unlike gas it does not have to travel under continuous pressure. Add to this the fact that one oil product or another can do anything that other fuels can do and it is no wonder that oil demand continues to grow in Asia. That said, given its expense and its political nature, it is also not at all surprising that other sources of energy in Asia are growing faster.

The danger with oil continues to be that its production costs are typically a small percentage of its market price. With prices today over $\$ 100 /$ barrel, there are still fields with production ("lifting") costs under \$10/barrel (Government of the United States, EIA 2009). While it is true than in some cases the cost of finding low-cost oil adds substantially to the true cost, those upfront costs are "sunk costs" and do not determine when the field will be withdrawn from production. Even if finding and developing costs are included, production costs can still be a small fraction of the market price. In contrast, for most renewables, some coal, and much new LNG, production costs are a large percentage of the market price. 
In the past, this has meant that oil prices could slump substantially without curtailing production which can ruin the economics of many competing energy sources. Most policymakers worry about how high oil prices might go, but one of the big questions is how low oil prices can go over a prolonged period.

\section{Oil prices}

\section{Crude oil price outlook}

In the last few years, most forecasts showed a slow and steady upward climb toward \$120-\$150/barrel in 2030, although some had higher-case alternatives. More recently, sentiments have changed. Although many of the forecasts still point to prices of $\$ 130 /$ barrel or more in 2030 , many are now looking at a nearterm easing or even decline across the rest of the present decade.

Figure 2.3 shows the US Energy Information Administration (EIA 2012) current forecast along with the FACTS Global Energy (FGE) most recent forecasts (FGE 2012a,b) and the International Energy Agency (IEA) forecasts from the World Energy Outlook 2012 (IEA 2012c). It should be noted that these forecasts

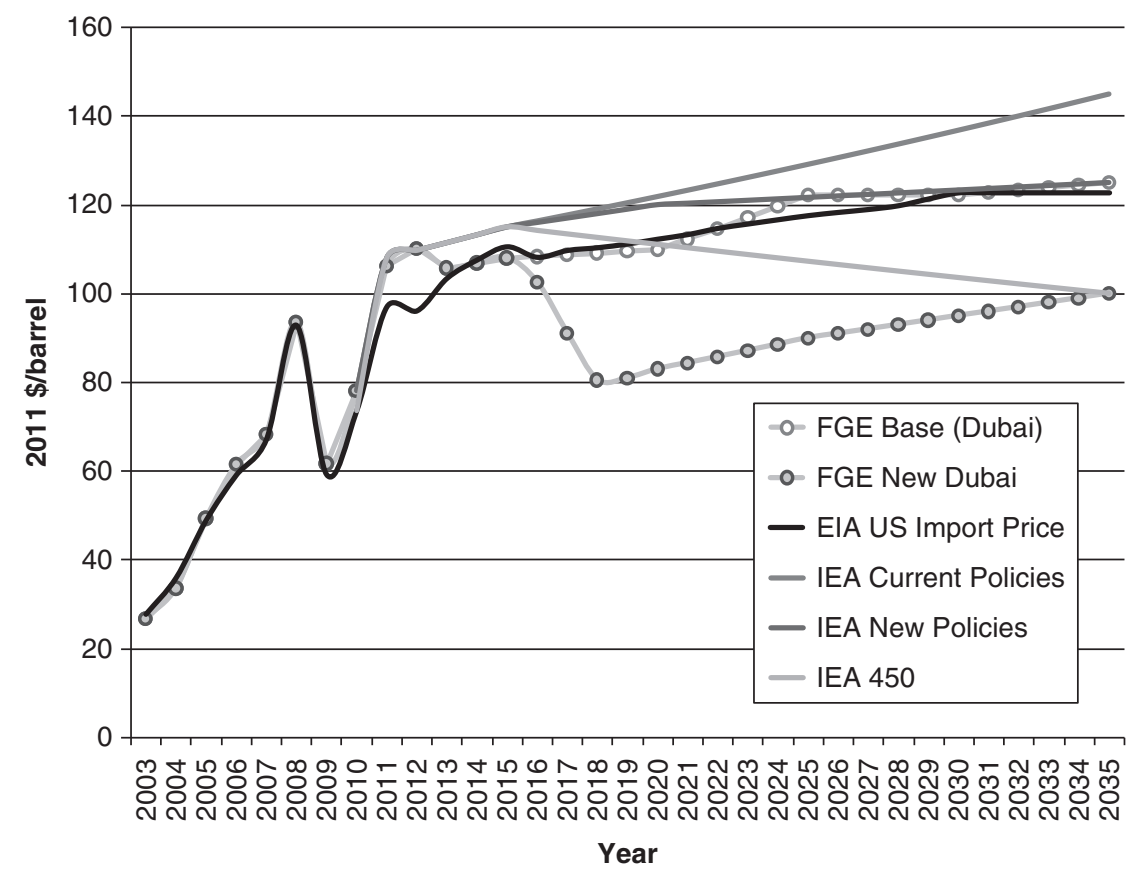

Figure 2.3 Recent crude oil price forecasts

Sources: Government of the United States, EIA 2012; IEA 2012c; FGE 2012a.

Note: EIA = Energy Information Administration; FGE = FACTS Global Energy; IEA = International Energy Agency. 
all operate on a slightly different basis. For EIA, it is the weighted average import price into the US; for IEA it is the weighted average import price into IEA members; for FGE, it is the market price of Dubai crude. These forecasts therefore differ significantly even in historical years such as 2010 and 2011.

Earlier forecasts from the Organization of the Petroleum Exporting Countries (OPEC) also foresaw prices in the \$85-\$95/barrel range through the end of the decade (International Energy Forum 2012) though the most recent OPEC forecasts have become somewhat more bullish. The World Bank sees a slow decline in prices through 2015 (World Bank 2013b). The near-term softness in the market foreseen in many projections is due to a number of factors. One is high prices suppressing demand; another is the boom in shale-based light crudes in the US foreseen by both IEA and EIA (IEA 2012c; Government of the United States, EIA 2012). A final factor is changing demand in the developed world. New energy-efficiency fleet standards (Bastiani, Heywood, and Hope 2012), hybrid cars, and alternative fuels are all cutting into demand in Europe and North America. The legendary invincibility of growth in US demand for gasoline has proved to be an illusion. Demand has been on a slow downward trend since 2007; many expect that trend to accelerate. The emergence of the US as a major gasoline exporter has been a consequent surprise (Government of the United States, EIA 2013).

Is there a floor price for oil? There must be, but it is easy to quarrel about how it is set; many assessments have been wrong in the past. Until recently, the EIA attempted to assess the upstream costs of producing conventional oil and gas in major regions around the world (Table 2.1). One problem with interpreting the numbers is that the costs of both gas and oil are mixed together, but since they are often co-produced this is arguably a better indicator than a methodology that attempts to attribute production costs between the two. One of the benefits of the EIA approach is that it separates lifting costs (the actual cost of operations) from the original exploration and development (finding costs). Both of these are important, but over a span of a few years, it is the lifting costs that determine the minimum price of oil.

As the table shows, the total upstream costs vary from $\$ 17.70$ to $\$ 54.10 /$ barrel, but the actual operating costs (lifting costs) for conventional oil are still all below $\$ 15 /$ barrel which is not much of a floor in the shorter term. What complicates the picture is that unconventional oil-oil sands, bitumens, and shale liquids - now contribute a significant and growing percentage of world oil supply.

IEA has compiled estimates of production costs for oil including unconventional oil and oil from new production regimes (Table 2.2). Although they do not break out lifting costs, they do suggest that even very common practices such as enhanced oil recovery have significantly higher prices than the classic oilfields of the Middle East.

Bernstein Research (Mackenzie 2012) has studied the costs of the top 50 listed oil and gas companies and has concluded that the marginal cost of oil production has now reached more than $\$ 90 /$ barrel. If demand is strong, this marginal cost strongly influences the price and also may be a good indicator of longer-term 
Table 2.1 Energy information administration assessment of conventional oil and gas production costs

\begin{tabular}{lccl}
\hline & \multicolumn{3}{l}{ 2011 dollars per barrel of oil equivalent } \\
\cline { 2 - 4 } & $\begin{array}{l}\text { Lifting } \\
\text { costs }(\$)\end{array}$ & $\begin{array}{l}\text { Finding } \\
\text { costs }(\$)\end{array}$ & $\begin{array}{l}\text { Total upstream } \\
\text { costs }(\$)\end{array}$ \\
\hline United States - average & 12.77 & 22.63 & 35.40 \\
Onshore & 13.35 & 19.55 & 32.90 \\
Offshore & 10.58 & 43.52 & 54.10 \\
All other countries - average & 10.43 & 15.86 & 26.30 \\
Canada & 13.31 & 12.66 & 25.96 \\
Africa & 10.81 & 36.71 & 47.52 \\
Middle East & 10.37 & 7.33 & 17.70 \\
Central and South America & 6.51 & 21.42 & 27.93 \\
\hline
\end{tabular}

Source: Government of the United States, EIA 2009 converted to 2011 dollars by the author.

Table 2.2 International Energy Agency estimates of oil production costs $(2011 \$ /$ barrel $)$

\begin{tabular}{lcr}
\hline Oil source & \multicolumn{2}{c}{$\begin{array}{l}\text { Production cost } \\
\text { (\$/b range) }\end{array}$} \\
\hline Middle East/North Africa oilfields & 6 & 29 \\
Other conventional oilfields & 6 & 41 \\
$\mathrm{CO}_{2}$ enhanced oil recovery & 6 & 84 \\
Deep/ultra-deep-water oilfields & 33 & 68 \\
Enhanced oil recovery & 33 & 86 \\
Arctic oilfields & 33 & 104 \\
Heavy oil/bitumen & 33 & 71 \\
Oil shales & 54 & 118 \\
\hline
\end{tabular}

Source: IEA 2008 converted to 2011 dollars by the author.

Note: $\mathrm{b}=$ barrel, $\mathrm{CO}_{2}=$ carbon dioxide.

pressures, but this says little about how far prices can drop over a shorter-term horizon. Marginal costs are also very reflective of miscalculations - projects that cost more than expected - and of strategic investments or experimental production schemes.

Hydrofracturing (fracking) shale introduces a new factor into the market. Unlike conventional oil development when exploration costs can be very high, much of the cost of fracking is operational. The overall costs are estimated at $\$ 50-\$ 70 /$ barrel in the US (Bullis 2012), but the exploration costs are a small proportion of this. This argues that if costs were to fall toward shale liquid production costs that the supply response would be fairly swift and would tend to drive prices back up. If liquids from shale grow as many now predict, they may offer a new and more responsive floor. This would seem to argue that oil prices are likely to stay 
above $\$ 70 /$ barrel in the longer term; the total production costs shown in Table 2.2 suggest that there are longer-term pressures that will tend to draw prices upward.

Under this outlook, it seems unlikely that oil will severely challenge alternatives on a prolonged basis although some renewable energy projects may come under pressure. At the same time, the likelihood that oil prices will soar above $\$ 150 /$ barrel for long periods also seems improbable. The most likely outlook at present is that the world is in for an extended period of high — but not necessarily climbing-oil prices.

\section{Oil pricing policies in Asia and the Pacific}

A comprehensive analysis of oil pricing policies in the region would comprise a major study. Over the years, many Asian economies created two problems with their pricing policies. First, many have had subsidized/controlled oil prices that encourage excess consumption and place large financial demands on the central government. Second, governments have often adopted differential fuel pricing policies that have had unintended consequences.

The problems with subsidized energy prices are most obvious in energy importers: when world prices rise, governments find that the costs can become crippling. Direct subsidies from government coffers are not the only problem. Some countries that have encouraged international oil companies to develop refineries locally discovered that no one is willing to build a refinery and import crude oil at market prices when faced with a controlled market in domestic products.

Subsidies face a political conundrum. When oil prices are low, it seems like the ideal time to remove subsidies as the relative impact would be low, but it is also easy for the government to pay for subsidies. When prices rise steeply, eliminating subsidies has a greater impact on consumers. Very few countries are willing to emulate the PRC in 2008 and launch price reforms in the middle of an oil price spike.

Subsidies are often explained as a means of ensuring energy for the poor. While this is a laudable goal, subsidizing prices for everyone to benefit a single group is inefficient and encourages overconsumption. Most economists would argue that giving the poor cash to spend as they wish is the only efficient means of helping them, although such a scheme is easier to propose than to implement. In any case, most governments are now aware that subsidies are problematic and most that still subsidize energy prices are trying to move toward market pricing.

Differential pricing is a constant temptation for policymakers; in many ways it is more insidious economically than subsidies. There have been many examples in Asia over the years. For instance, Indonesia's low kerosene prices began as an effort to encourage low-income households to burn kerosene instead of cutting down the forest for firewood, but producers had to add massively expensive hydrocrackers to refineries to keep pace with demand, and at one point, the electric 
utility was burning kerosene to generate power. A similar situation emerged when Thailand kept kerosene prices low for similar reasons. Enterprising Thais soon figured out they could buy cheap kerosene, convert it into diesel fuel, and then sell the diesel at much higher prices.

Most of the more egregious differential pricing policies have been corrected although subsidies on household liquefied petroleum gas (LPG) may become a problem in coming years. Subtle and not-so-subtle problems like duties, however, remain. It is not uncommon for finished products to face high duties while "refinery feedstock" faces much lower ones. This means that some refiners have imported "reduced crude" as a feedstock and promptly resold it as fuel oil. Some refiners have even bought diesel on the external market, converted it into fuel oil, imported the mixture as a heavy feedstock for distillation, and then distilled the diesel back out at a much lower cost than importing the diesel directly.

Many governments have decided that diesel is a "productive" use of energy while gasoline is a "consumptive" use of energy and have priced them accordingly. As might be expected, the result is usually an influx of diesel-powered passenger cars. The point is that differential pricing can easily distort both demand and business decisions. Keeping oil prices below external market prices is a recipe for serious fiscal problems and for driving up demand. A government is certainly justified in keeping oil prices above external market prices to dampen demand or to internalize perceived externalities, but deviating significantly from external market prices can also have insidious consequences.

Figure 2.4 shows gasoline and diesel pump prices in selected Asian Development Bank (ADB) members and a few Western countries. The US has no policy on differential pricing and also has comparatively low crude prices and highway taxes. It therefore offers a kind of reference case: no subsidies and no policybased pricing. In principle, one would expect that diesel would cost more per gallon or barrel than gasoline since diesel has more energy per unit of volume, but pricing seldom reflects this. Except in Pakistan, the United Kingdom (UK), and the US, gasoline is always priced at a higher rate-often much higher. There is no obvious connection between these policies and levels of development: Bangladesh; Hong Kong, China; and New Zealand all share this policy. One thing that is notable, however, is that there is a definite correlation between being a crude exporter and maintaining low pump prices. While the pump prices are not outrageously low (as in Saudi Arabia or Venezuela), it is notable that six of the seven countries with the lowest prices are Brunei Darussalam, Indonesia, Kazakhstan, Azerbaijan, Malaysia, and Viet Nam.

Domestic pricing policies are not often thought of as energy security issues, but they have a significant effect on them. Artificially low prices eat away at domestic energy supplies or in the case of importing countries push their imports to higher levels. In addition to the general level of pricing, a pattern of pricing that is not related to the prevailing relationships on the external market can produce all manner of distortions that make it difficult for governments to manage their energy infrastructures or to respond to external market changes. 


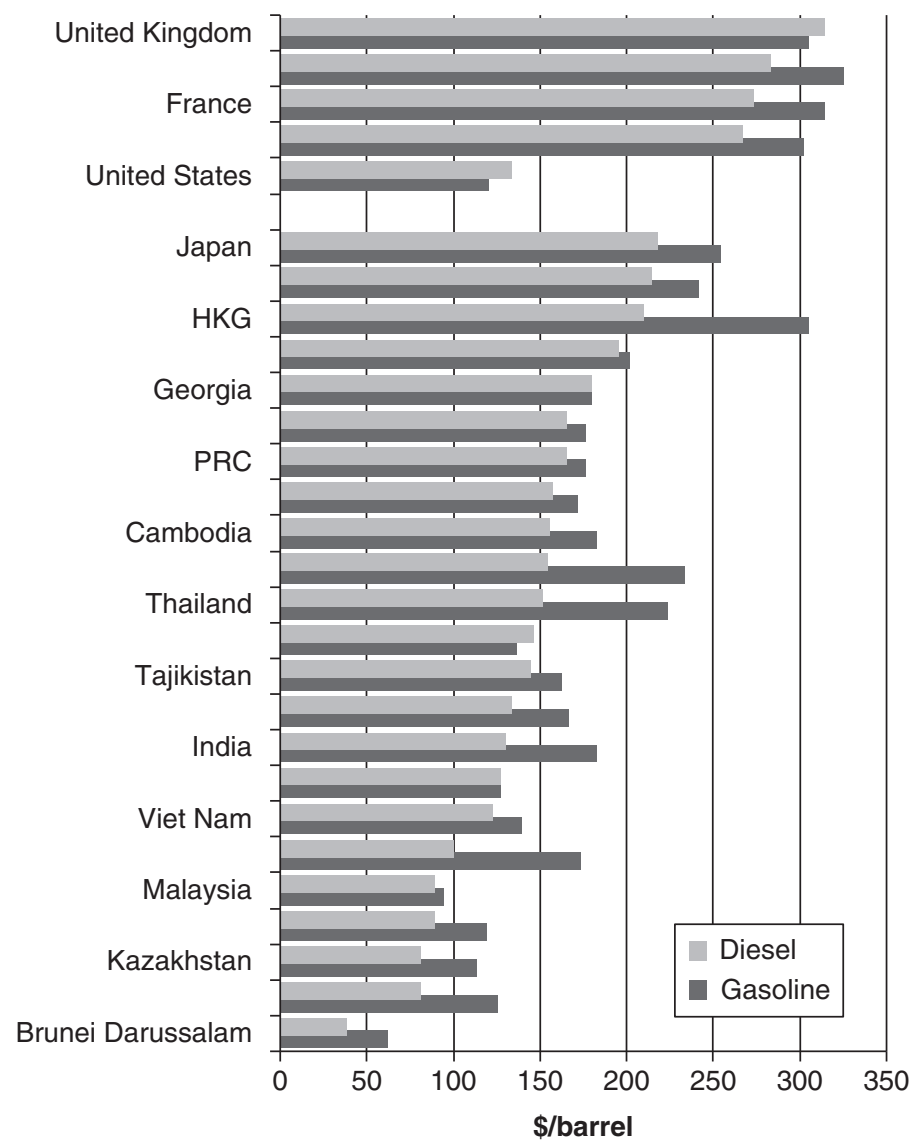

Figure 2.4 World Bank pump prices for selected countries, 2010

Source: World Bank 2013a.

Note: $\mathrm{PRC}=$ People's Republic of China; HKG = Hong Kong, China.

\section{Oil demand}

\section{Composition by product and end use}

Statistics on the demand for oil today are quite good in terms of consumption by product, but numbers by sector are much less precise as they are gathered from domestic sources and governments use different classification systems. Transport and power are the two sectors that are generally well defined although certain aspects of power generation get mixed with the industry sector at times. Despite the imprecise nature of the data, use patterns by sector are vital for projecting future total demand. The FGE data system draws on both standard sources such 
as the IEA B2020 system as well as domestic statistics and on contributions from local specialists, but the numbers are far from perfect and are constantly revised. That said, it is hard to understand where growth will occur and where there are opportunities for substitution without relying on these estimates.

Asia is the most diverse region in the world, so there are exceptions to most generalizations. There are, however, some features that separate Asia as a whole from other regions. The role of coal is the most obvious example, but there are also differences in end uses of oil that set Asia apart from the Euro-American paradigm that tends to dominate energy analysis. A qualitative description of the Euro-American paradigm would probably include the following beliefs.

- The least substitutable use for oil is in transport; therefore, the transport share of the energy use of a barrel tends to be $67 \%$ or more.

- $\quad$ Power is the most substitutable use for oil, so oil tends to get driven out of power.

- Industrial uses of oil are also readily driven out.

- The direct use of oil in the residential and commercial sector is minor and declining.

Figure 2.5 illustrates many of the characteristics of Asian oil demand that deviate from the paradigm as well as some that agree with it. The share of oil in the

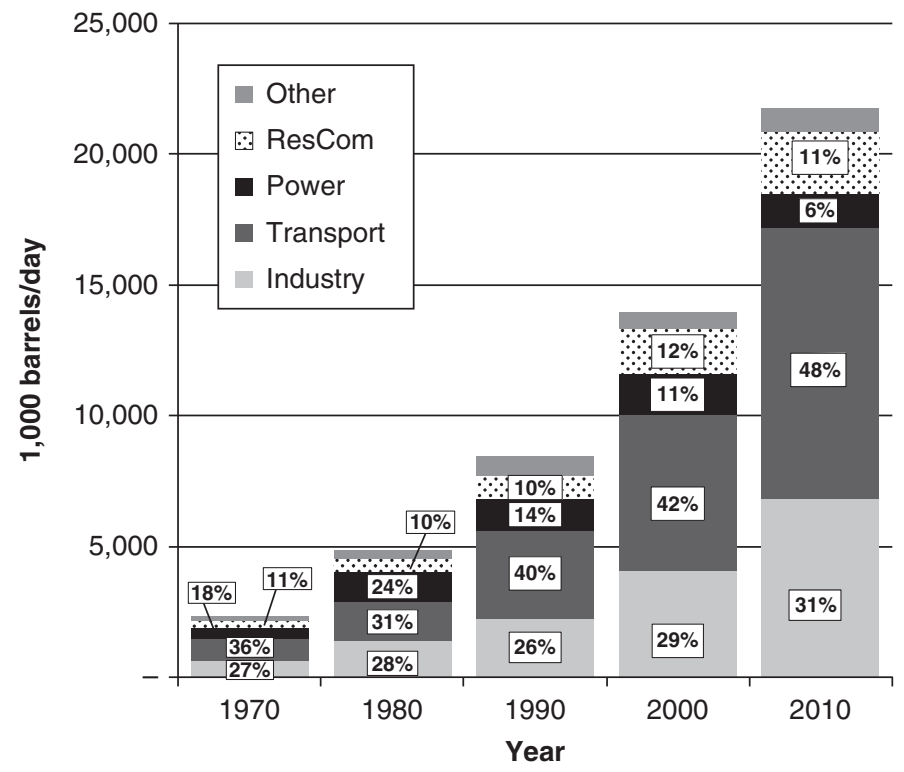

Figure 2.5 Oil demand by sector in developing Asia, 1970-2010

Source: IEA 2012d,e; FGE 2012c.

Note: ResCom $=$ residential and commercial. 
power sector has been severely squeezed since 1980 although its absolute volume grew through 2000. After 2000, its share and its volume both fell. Despite this, it is difficult to drive oil out of power altogether in rapidly developing economies; non-oil utility power supplies are often countered by local or private generation to support new industries or communities. This can be seen most readily in the PRC where the use of oil as fuel in utilities is virtually zero, but in remote areas or in new industrial developments, oil is still burned; this pattern may persist for many years. These users may switch from oil as alternatives become available or as utility supplies expand, but new users without access to alternatives or utility supplies will probably emerge. The power sector share of oil demand will probably continue to decline, but the fall in the absolute volume of oil demanded will be relatively slow.

Oil in transport (including international bunkers) has indeed grown steadily in both volume and share, but it is only recently that transport has approached half of Asian demand. The industrial use of oil has seen steady growth and since 1990 has even increased its share of demand. (Industrial use here includes heavy construction and therefore picks up "other" products such as bitumen.) Most of this is not, however, conventional industrial heat or engine power. Currently about $50 \%$ is petrochemical feedstock and another $25 \%$ is products such as lubes, waxes, and bitumen. Process heat and similar traditional industrial uses of oil are generally flat in volume terms and account for only about $25 \%$ of industrial use. Although this segment of industrial demand will tend to be pushed out by alternatives, vigorous growth in feedstock and "other" uses is expected (FGE 2012c).

A surprising feature of the Asian market to many is the steady growth in residential and commercial uses of oil ("ResCom"). This sector maintained a relatively steady share of demand and even increased its share from 1990 to 2000 . There has recently been a decline, but the absolute volume continues to grow as demand increased by $3.3 \%$ annually from 2000 to 2010 . This aggregation hides many different kinds of uses, but the dominant ones are middle distillates for space heating in East Asia (especially in the Republic of Korea) and cooking and lighting fuels (mostly LPG and kerosene) in many developing countries (IEA 2012d,e).

It is reasonable to ask if most of these contrasts with the Euro-American paradigm aren't simply the result of stages of development, i.e., as developing Asian economies become richer, won't they also begin to fit the Euro-American mold? The answer is yes and no. Australia and New Zealand not only fit the EuroAmerican paradigm but are even ahead of the curve. Shares of transport in total oil demand are currently around $76 \%$ in Australia and $88 \%$ in New Zealand. Oil for power generation and for residential and commercial use is nearly nonexistent, and industrial use is small and declining (IEA 2012a).

The situation in Japan is quite different. The share of oil for power generation to total oil was low prior to the Fukushima nuclear accident, but oil in industry has always been important. In 2010, industry still accounted for more than $33 \%$ of demand - a higher share than in developing Asian countries. Most is for petrochemical feedstock - a demand not easily substituted by other energy sources. The residential and commercial use of oil has also been high in Japan at times 
accounting for nearly $20 \%$ of demand. This has been restrained by greater use of other fuels-primarily gas from LNG imports and substituting electricity for fossil fuels (IEA 2012a).

Transport's share of oil demand in Japan is still well below 50\% in part because they drive less than Americans and Australians, but it is also because they use so much more oil in other sectors notably in industry. Petrochemical production, particularly chemicals from naphtha, is a relatively non-substitutable use of oil as are many of the other minor inputs into industrial uses such as lubes and waxes.

In Japan and in the neighboring Republic of Korea, oil is indeed being driven out of the power sector, and as gas reticulation expands, it will slowly be pushed out of the residential and commercial sector as well. The general pattern of demand in these two countries is nevertheless distinctly Asian rather than Western. Indeed, as Figure 2.6 shows, there is a good argument for an "Asian" and even an "East Asian" pattern of oil demand by sector. Australia and New Zealand fit the Euro-American paradigm perfectly, but they are extreme outliers in the overall picture. Overall, the pattern in the PRC looks a good deal like that in Japan. In some ways, this should not be too surprising. The PRC adopted the same essential strategies of export-led, manufacturing-based growth that were pioneered by Japan and developed further by the Republic of Korea. Since this strategy was adopted in a very different oil price environment, however, the PRC has moved directly to a pattern that is quite similar to its Northeast Asian neighbors.

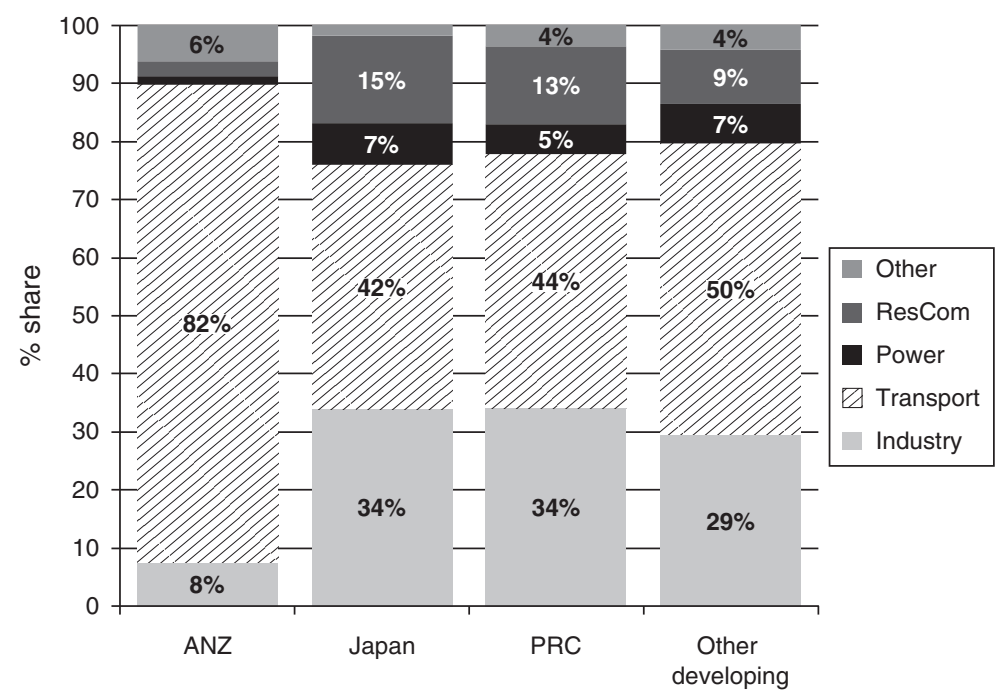

Figure 2.6 Asian oil demand by sector and grouping, 2010

Source: IEA 2012d,e; FGE 2012c.

Note: ANZ = Australia and New Zealand; PRC $=$ People's Republic of China; ResCom $=$ residential and commercial. 


\section{Liquefied petroleum gas}

Liquefied petroleum gas (LPG) is one of two "refined products" that are often derived from the primary production of oil or even gas rather than from refining. LPG production from primary sources has been expanding rapidly in the Middle East and is now the main source of LPG exports from that region. LPG now accounts for about $9 \%$ of all oil-product demand in developing Asia. Over the last decade, LPG demand expanded more rapidly than overall oil demand at $6.1 \%$ per annum (IEA 2012d,e; FGE 2012c).

LPG is used in many different sectors. Small amounts have been burned in the power sector sometimes as the most readily available fuel and sometimes to meet emission standards (the latter primarily in Japan). By far the largest use of LPG in developing Asia is in the residential and commercial sector; it consumes 67\% and its share is steadily growing (Figure 2.7). In many economies, this is the result of deliberate policies to encourage substituting cheaper LPG for scarce domestic kerosene or to switch away from biomass to prevent deforestation.

The industrial use of LPG is complex and is steadily falling; there is scope for more to be pushed out if alternatives such as gas are available. As the price of naphtha has risen, LPG as a petrochemical feedstock has grown rapidly (14\% per annum over the last decade). This growth is likely to continue but at a much lower rate; most of this expansion in use has been as a co-feed with naphtha, and most existing units are now taking as much LPG as they can manage. There will be additional growth as a feedstock, but new increments of demand for LPG as chemical feed already require substantial capital investments (Chung 2013). LPG is now supplementing rather than displacing naphtha.

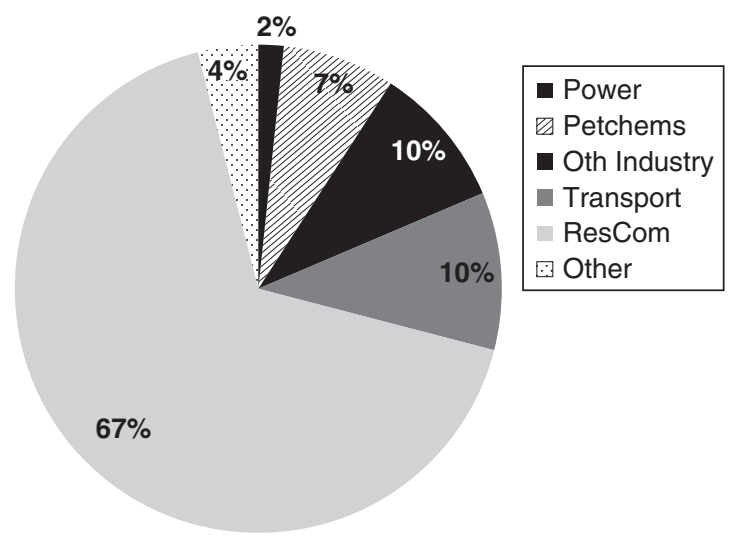

Figure 2.7 Liquefied petroleum gas demand by sector in developing Asia, 2010 Source: IEA 2012d,e; FGE 2012c.

Note: Oth $=$ Other; Petchems $=$ petrochemicals; ResCom $=$ residential and commercial. 
At one time, LPG was a major emerging transport fuel especially for fleet vehicles such as taxis. Growth continues in this area, but the dominant and growing use by far is in the residential and commercial sector. The PRC, India, and Indonesia among others have turned to LPG as cooking fuel to dampen what seemed like an uncontrollable surge in kerosene demand.

\section{Naphtha}

Naphtha is used almost solely in industry although India has at times burned naphtha in gas turbines for power generation. Apart from a small volume blended to solvents, the main use is feed to ethylene crackers. Naphtha in 2010 accounted for about $15 \%$ of all oil product demand in Asia - the third largest, exceeded only by diesel and gasoline (IEA 2012d,e; FGE 2012c). Naphtha demand has grown at $7.8 \%$ per annum over the last decade. The engine of this growth has been the PRC, where naphtha demand increased from 344,000 barrels/day in 2000 to more than 1.1 million barrels/day in 2010, but other newer producers such as Singapore and Thailand have also seen rapid growth, and the petrochemical sector in the Republic of Korea continues to expand.

Naphtha feedstock is only somewhat substitutable. Ethane from natural gas can be cracked into ethylene, but this does not produce the valuable propylene or butylene byproducts needed for more advanced plastics and rubbers. LPG can produce propylene and butylene, but only heavier feedstock produces substantial volumes of the byproduct known as "pyrolysis gasoline" which is the main source of aromatic building blocks in petrochemicals.

\section{Gasoline}

Most accept the generalization that gasoline is solely a transport fuel, and this is approximately true, but it is also an important fuel for some farm machinery and agricultural equipment. There is no clean line between the two sectors. As mentioned previously, gasoline has faced considerable price discrimination in many Asia economies as a consumptive fuel. Faced with a "middle distillate bulge" in the barrel, many governments began moderating this price discrimination in the 1990s, and gasoline demand began to grow more rapidly. In 2010, gasoline demand accounted for $17 \%$ of oil-product demand and had grown by $5.6 \%$ per annum over the previous decade. While this rate of growth is expected to moderate as development in Asia proceeds, gasoline's share of the barrel is expected to increase, though not nearly to the levels seen in North America or Australia (FGE 2012b).

\section{Jet fuel}

Jet fuel by definition should be purely for transport, otherwise it should be classed as kerosene. In 2010, jet fuel made up only about 5\% of Asian demand 
(less than LPG) but had a high growth rate from 2000 of $6 \%$ per annum. The demand for jet fuel is expected to grow significantly and to increase its share of the barrel (FGE 2012b).

\section{Kerosene}

Kerosene has never been one of the dominant products in the Asian demand barrel, but it was long the most politically charged product as the cooking fuel of the poor as well as the main heating fuel in Japan and the Republic of Korea. In 1980, kerosene accounted for about $8 \%$ of all oil product demand in Asia and was still above 7\% in 1990, but demand peaked in 1999 and has fallen rapidly in the last decade at $4.9 \%$ annually so that in 2010 kerosene accounted for only $2 \%$ of oil demand in developing Asia (FGE 2012b). As Figure 2.8 shows, that demand is still overwhelmingly concentrated in the residential and commercial sector.

The industrial use of kerosene might seem surprising, but it is also known as number 1 fuel oil, i.e., a very light diesel. What Figure 2.8 cannot show is how effectively governments have driven kerosene demand downward. Much of the impetus for change came from the Asian financial crisis in 1997 when many governments found themselves with plummeting currencies and high oil subsidies. As Figure 2.9 shows, over the following years a combination of price reforms and fuel substitution efforts not only curtailed growth in kerosene demand but ultimately reversed it.

Price reform was an important factor in many economies, but in all of them the availability of alternative fuels was also important. This included not only LPG substitution campaigns but also the spread of natural gas reticulation in some.

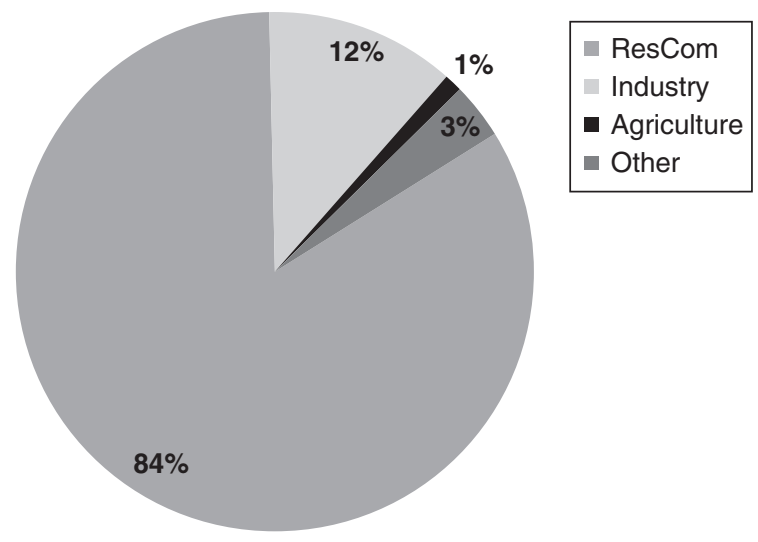

Figure 2.8 Kerosene demand by sector in developing Asia, 2010

Source: IEA 2012d,e; FGE 2012c.

Note: ResCom $=$ residential and commercial. 


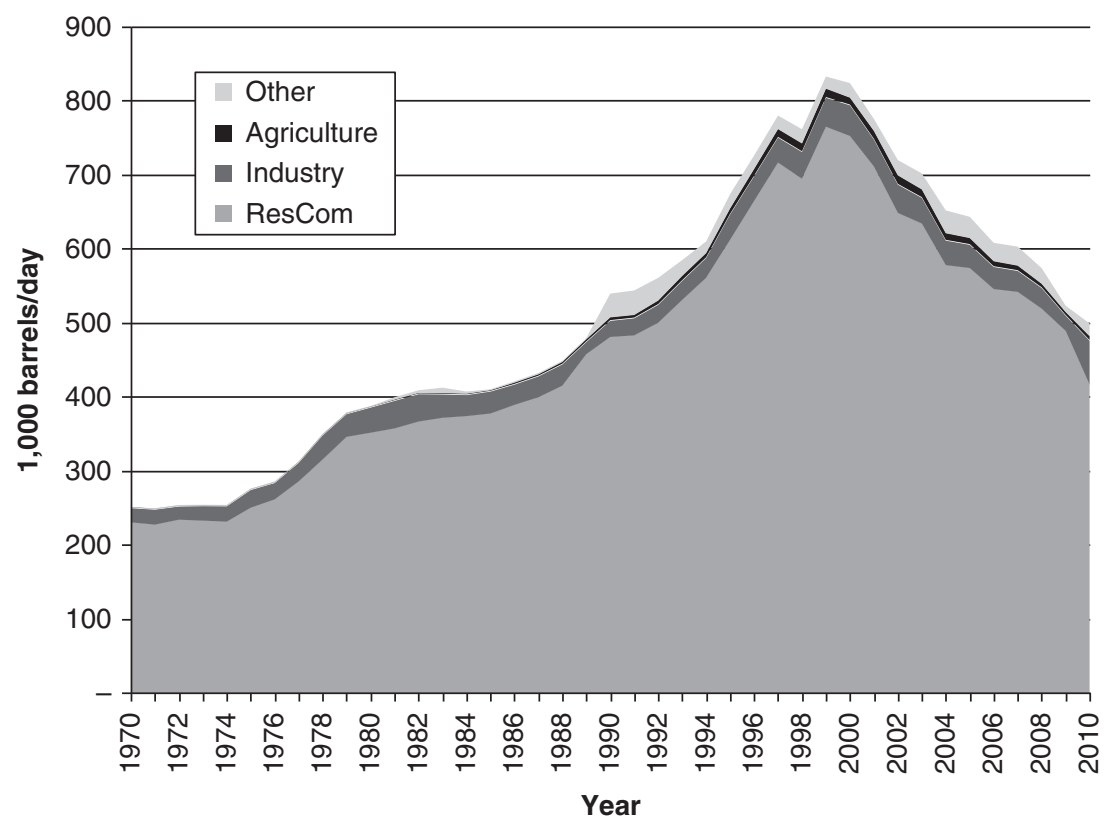

Figure 2.9 Kerosene demand in developing Asia, 1970-2010

Source: IEA 2012d,e; FGE 2012c.

Note: ResCom $=$ residential and commercial.

\section{Diesel (gasoil)}

Diesel is the dominant fuel, accounting for $31 \%$ of oil product demand in developing Asia in 2010. Diesel probably has the widest range of use by sector of any oil product, playing several roles in transport (road, rail, domestic waterborne, and international shipping bunkers) and in industry, power, home and commercial heating, and agriculture. Demand for diesel generally grows at rates somewhat greater than those for general oil, and absolute demand has grown in every sector. Growth in power has been the weakest at less than $2 \%$ per annum over the last decade. The use of diesel in agriculture has also been in the range of $2 \%-3 \%$ annually while growth in all forms of transport and in the residential and commercial sector has been over 5\% annually. As Figure 2.10 shows, transport use accounted for about $62 \%$ of diesel demand in 2010 ( $57 \%$ in 2000). In this regard, Asia might be seen as moving toward the Euro-American paradigm.

One challenge for Asia will be to slow the growth in diesel demand in the residential and commercial sector. Unlike kerosene that is used mainly in households, diesel tends to often be used for central heating in commercial or public establishments some of which (government buildings for instance) are arguably less price sensitive than households, so small-scale measures such as making LPG locally available in cylinders will have little impact. 


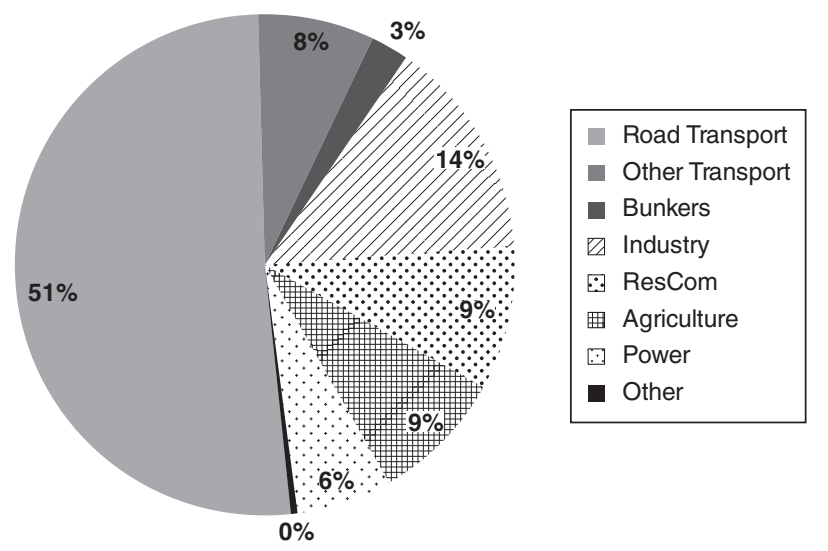

Figure 2.10 Diesel/gasoil demand by sector in developing Asia, 2010

Source: IEA 2012d,e; FGE 2012c.

Note: ResCom $=$ residential and commercial.

\section{Fuel oil}

In the continuum of oil substitutability, jet fuel sits at one end (presently no substitutes) and fuel oil at the other (many substitutes). Fuel oil is generally used for direct heating and therefore finds itself in competition with coal and gas in many applications; it further competes with virtually any energy source in power generation. The major exception is use in transportation. Although fuel oil is not commonly thought of as a transport fuel, it is still used in some rail transport and is the dominant fuel in international marine bunkers. It should be noted that all of the figures discussed here include marine bunkers as part of demand. This is contrary to the practice of IEA and other groups that treat bunkers as a kind of export with no importer. In a way, the IEA view makes sense as the demand is arguably shared between the loading port and the destination port. In practice, however, ignoring bunker demand gives a very distorted picture of energy needs as export-led economies in Asia rely on bunkers to move their exports. As Figure 2.11 shows, bunkers should not be ignored as they amount to $42 \%$ of fuel oil demand and are growing while other major uses are declining.

The changes in Asian fuel oil demand over the last four decades tell a dramatic story. Figure 2.11 includes direct-burned crude typically used in the power sector as a fuel-oil substitute. Japan - not included in Figure 2.11- has long been the largest burner of crude in Asia largely because local sulfur emission constraints make burning of even low-sulfur fuel oil impossible in some areas, but other countries such as the PRC also burn substantial volumes of crude largely because of transport constraints. (For the record, Asia is not the sole crude-burning region. Huge volumes are burned in Iraq and Saudi Arabia and some in Kuwait.) 


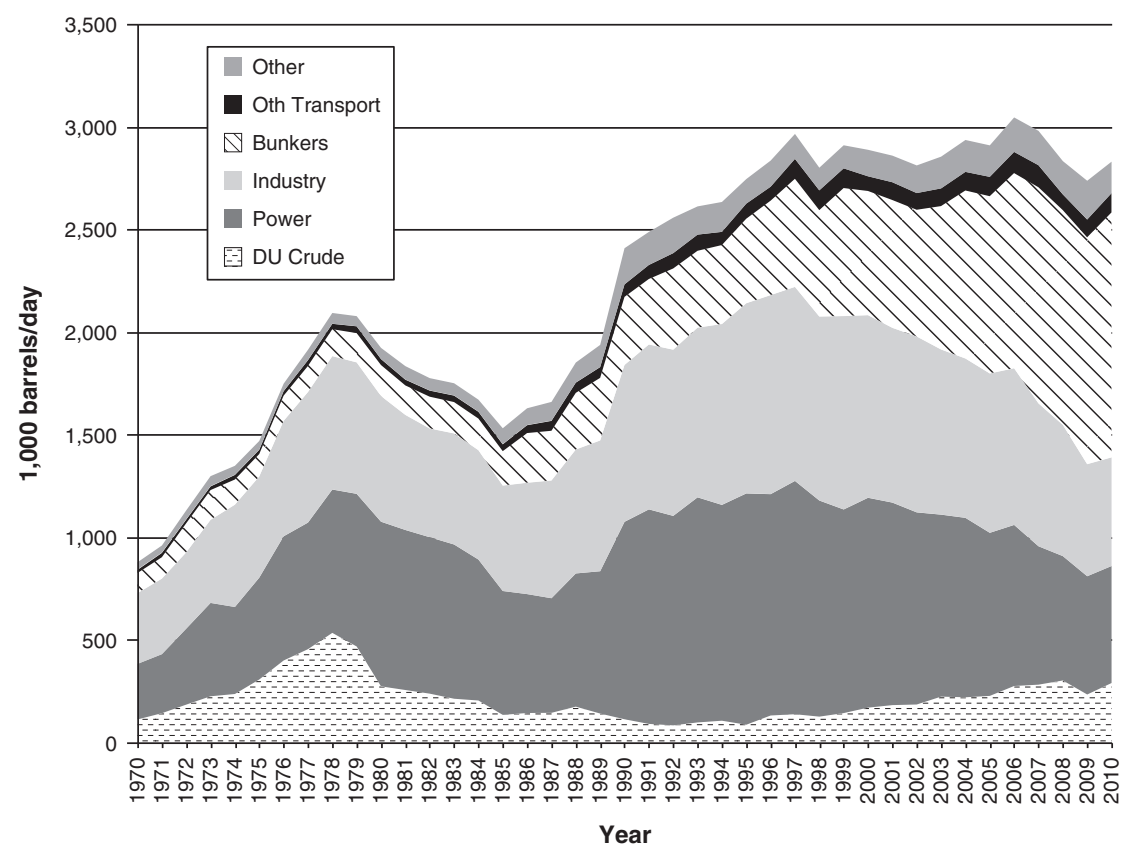

Figure 2.11 Asian fuel oil and direct-burned crude demand, 1970-2010

Source: IEA 2012d,e; FGE 2012c.

Note: $\mathrm{DU}=$ direct use (primarily direct burning but includes small petrochemical feed use); Oth $=$ other.

The price increases of the 1980s sharply curtailed the use of both crude and fuel oil in power generation, but the rapid growth of Asian economies in the 1990s soon drove demand for power generation upward again. In the last decade, this use of oil was again squeezed down reaching an historic low in 2009.

The industry sector has followed essentially the same pattern as the power sector-a price-induced squeeze in the 1980s, an economy-driven expansion in the 1990s, and a gradual phase-down in the last decade. In fact, the picture would be a remarkable downward trend since the mid-1990s were it not for bunkers. In 1995, bunkers were about $15 \%$ of fuel oil/direct-use crude demand in Asia as opposed to $42 \%$ in 2010; they are likely to constitute half of fuel oil demand (including direct-use crude) in the near future.

As long as Asia remains the main exporter of manufactured goods to the world, bunker demand seems set to continue growing. That does not necessarily mean than fuel-oil bunkers will continue to grow, however, as forthcoming International Maritime Organization regulations on sulfur emissions will challenge the entire system of relying on high-sulfur fuel oil for marine transportation. 


\section{David Isaak}

\section{Other oil products}

Taken together, "other" oil products_-bitumen, petroleum coke, lubes, waxes, and miscellaneous minor products - amount to about $8 \%$ of Asian oil demand. This is small but is higher than the shares of jet fuel or kerosene. These are primarily nonenergy products and are mostly attributed to the industry sector if heavy construction is included. As development proceeds, the use of these other fuels tends to grow rapidly as infrastructure expands and manufacturing becomes more sophisticated. In developing Asia, that means that demand for these fuels is likely to grow rapidly in the next few decades before settling down to maintenance levels.

\section{Outlook}

Broad energy balances such as the ADB Asian Century scenario (ACS) are generally conducted in aggregated form with tons of oil equivalent of primary fuels as the main denominator. More commercially oriented analyses like those done by FGE tend to focus on individual fuels as the primary unit. FGE published forecasts run only to 2030, so it was necessary to extend them to 2035 by trending individual product growth rates. In addition, FGE works in volume (thousand barrels per day) rather than mass (million tons per year), and conversions between these units are based on assumed densities rather than recorded data. It was therefore pleasing to discover that up and down across the forecast period, the FGE base forecast for oil demand in Asia is within a few percentage points of the ADB scenarios (Figure 2.12). Indeed, in percentage terms the disagreements

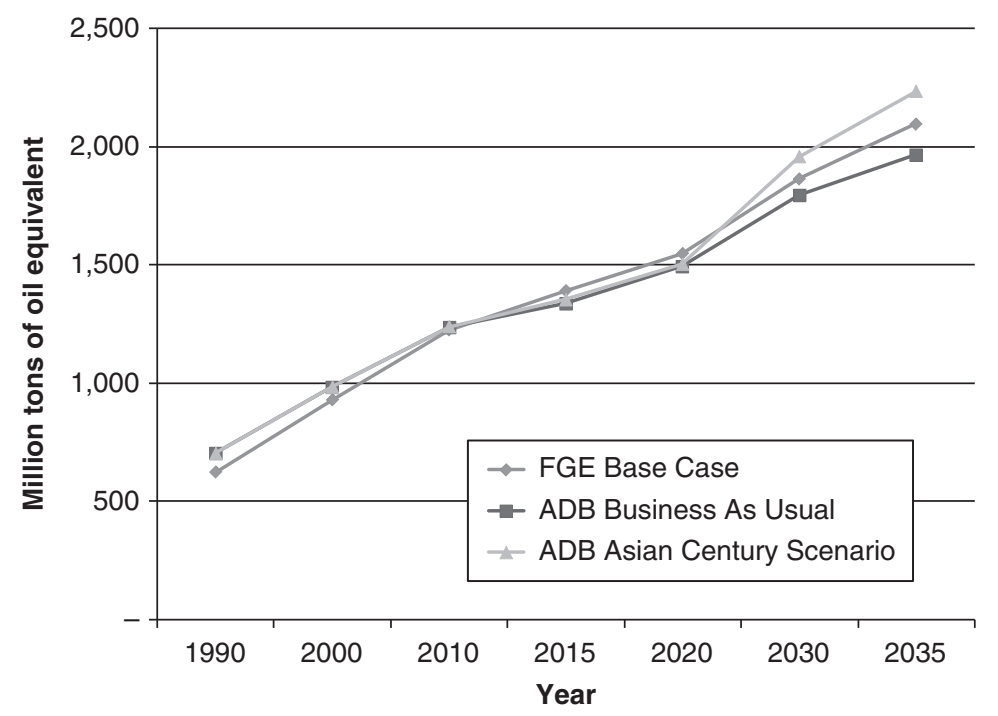

Figure 2.12 Comparison of Asian Development Bank and FACTS global energy oil demand forecasts, 1990-2035

Source: ADB 2013; FGE 2012c.

Note: $\mathrm{ADB}=$ Asian Development Bank, FGE = FACTS Global Energy. 
in the forecasts are of the same size as the disagreements in the estimates of 1990 and 2000 historical consumption $(5 \%-6 \%)$.

The Middle East, North America, and the Russian Federation are usually considered to be the centers of world gas production and indeed they are, but Asia has made tremendous progress in developing its resources. Between 1990 and 2011, gas output in the region more than doubled; excluding the new Central and West Asian countries (that do not include Afghanistan and Pakistan) it more than tripled (BP 2012).

LNG imports in the region more than doubled over the last decade; almost $50 \%$ originated outside the region. The traditional LNG importers-Japan; the Republic of Korea; and Taipei,China - have been joined by the PRC, India, Thailand, and most recently, Singapore. A new import terminal is also under design for the Philippines (Platts 2013).

Countries with large coal resources such as Australia, the PRC, and India have been quick to use coal to push out oil wherever possible. There are greenhouse gas consequences to this strategy, but it is clear that it has played a vital role in keeping oil imports from growing even more rapidly than they have. Most of the easy substitutions of coal for oil have probably already occurred although there may be room for additional substitution in some areas where coal is not presently available, but a major factor in damping growth in oil demand has been and will continue to be the availability of gas. Gas has already had a major impact in residential and commercial demand, and it readily substitutes for oil in power generation and in non-feedstock uses in industry. In the US, low-priced gas from shale is now penetrating the transport sector and is expected to have a growing impact on oil demand (Kelley-Detweiler 2012).

It is impossible to say what Asia would look like today without growth in gas consumption. As an upper limit, if we assume that all of the growth in gas demand between 1990 and 2011 displaced potential oil demand on an MToe basis, then current oil demand in Asia could be higher by $33 \%$ - nearly 9 million barrels/day of additional oil.

Oil and gas are not freely fungible, but they are more fungible than oil and coal. The most dramatic supply-side option for keeping oil demand growth somewhat restrained is to introduce more gas. Thus, the potential in Asia for shale gas, coal bed methane, and other unconventional gas is perhaps the most important question about the future of oil (see Chapter 7).

\section{Oil supply}

\section{Production outlook for developing Asia}

Asian economies are active exporters of high-quality, sweet crudes, but frequently they maintain their exports only by importing lower-grade crudes and refined products. Asia is not a crude-rich region. Only three countriesAzerbaijan, the PRC, and Kazakhstan — produce more than a million barrels/day. Indonesian production has been just under 1 million barrels/day for several years, and unless trends change, it seems to be in a state of slow decline. Although growth prospects are good for the frontier areas in new Central and 


\section{David Isaak}

West Asia, there is presently little expectation of major increases in output in other parts.

The fact that analysts are not expecting an oil production boom in Asia does not rule one out. Oil production is full of surprises, and forecasts running 10 years ahead are often shown in retrospect to have been quite naive. That said, prospecting has been undertaken with great urgency in most of Asia for the last three decades, so the chances of massive, undetected, conventional reserves seems small.

There are two possibilities that might change the picture at least to some degree. In some economies, exploration by multinationals is either not allowed or is restricted to only the most challenging - rather than the most promising areas. Some of the multinationals suggest that crude reserves could be increased considerably if they were "invited in" to more promising geological areas presently controlled by national oil companies. It is impossible to rule this assertion out, but it should be taken lightly.

The second possibility is that oil production could increase based on unconventional sources. There do not appear to be large deposits of oil sands or bitumen in Asia, so the only open question is what might be offered by liquids from shale. This has been significant in the US where many of the shale deposits have been "wet" (containing LPG and heavier liquids on up to what are effectively full-range crude oils) or "dry" (containing mostly methane and ethane). So far most of the Asian shales explored tend to be dry, but it is far too early to draw any conclusions.

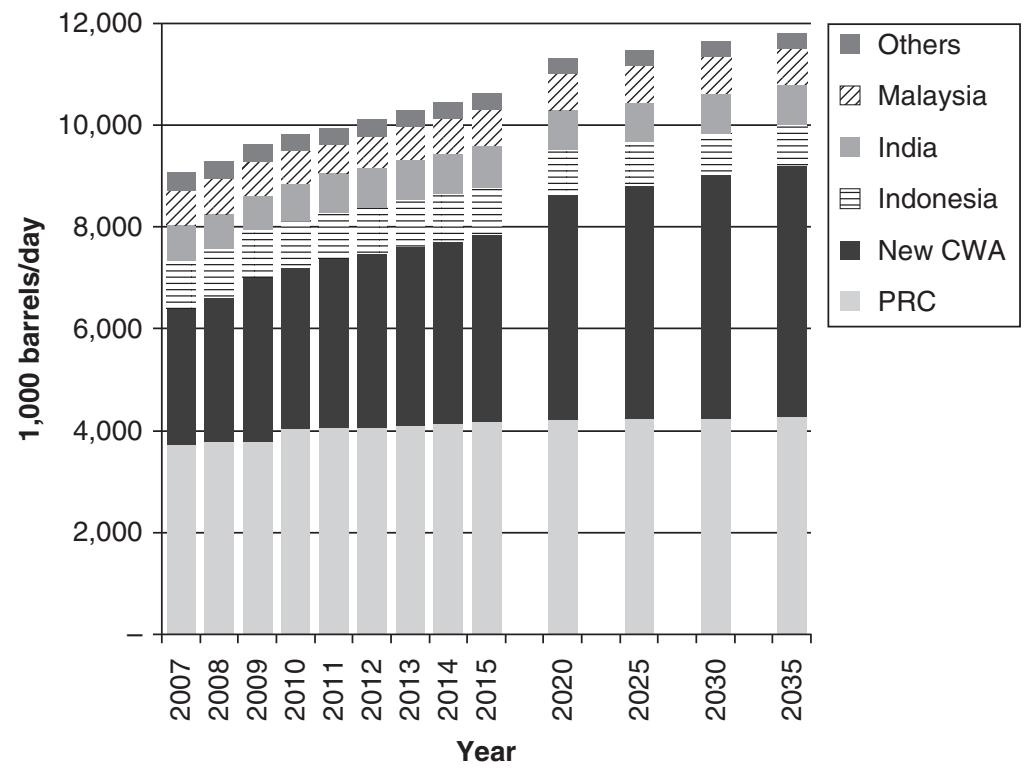

Figure 2.13 Oil production outlook through 2035 in developing Asia

Source: FGE 2012c and author's calculations.

Note: $\mathrm{CWA}=$ Central and West Asia; $\mathrm{PRC}=$ People's Republic of China. 
Under the circumstances, there is little choice but to adopt the outlook in Figure 2.13 based on what is understood about the near future which gives the FGE oil production outlook through 2020 extended through 2035 by applying the 2015-2020 growth rates for each country/grouping.

It is worth noting that in Figure 2.13, the major growth has come from frontier areas - specifically the new Central and West Asian countries. Others (notably the PRC) have managed to achieve increases in output that are expected to continue while still others have taken steps that allowed them to stave off looming declines.

Could production be a few million barrels per day higher? By 2035, it certainly could be. Could it be a few million barrels per day lower? Yes, although that seems less probable. In either case, oil imports today already greatly exceed oil production in the region, and given growing demand, even substantial increases in production are unlikely to alter the overall picture.

\section{Import requirements}

Only in the very near term can we say much about the likely composition and destination of Asian imports. With demand growing rapidly and major expansions in refining capacity underway not only in Asia but also in exporting regions (notably the Middle East), we can do little more than attempt to quantify net oil imports in Figure 2.14 which shows oil demand in the ACS less the production

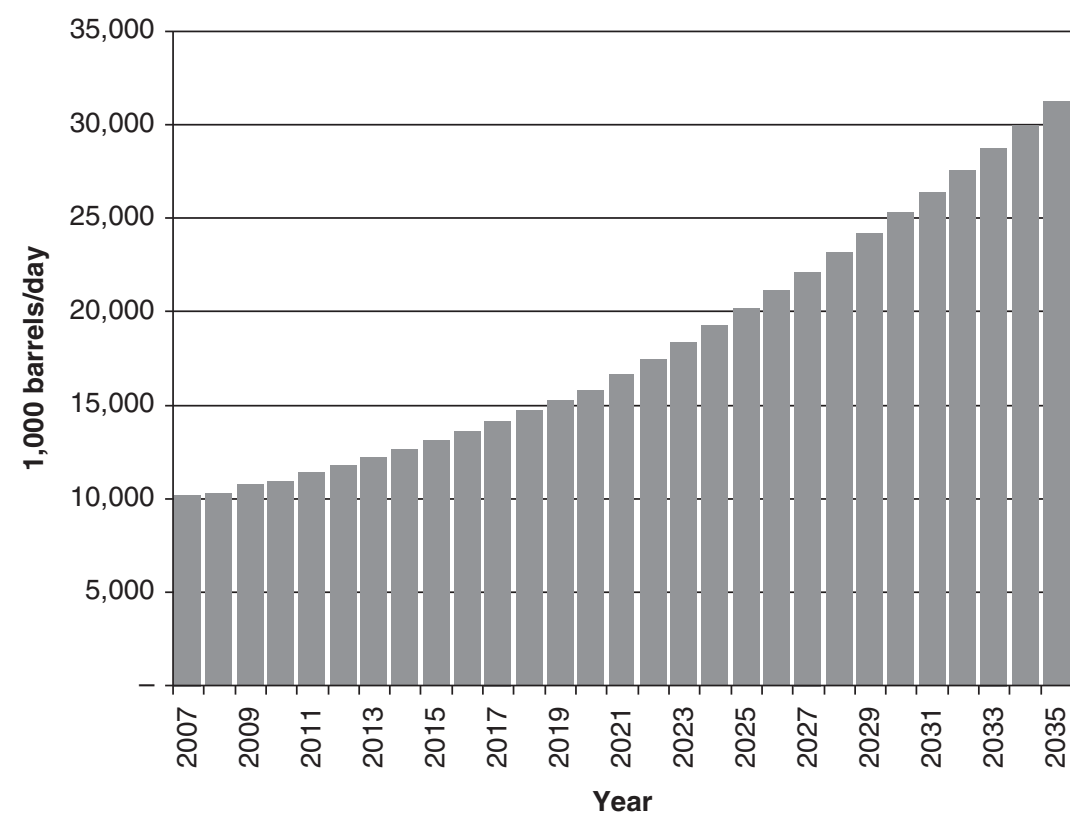

Figure 2.14 Net oil imports through 2035 in developing Asia

Source: ADB 2013 and author's calculations. 


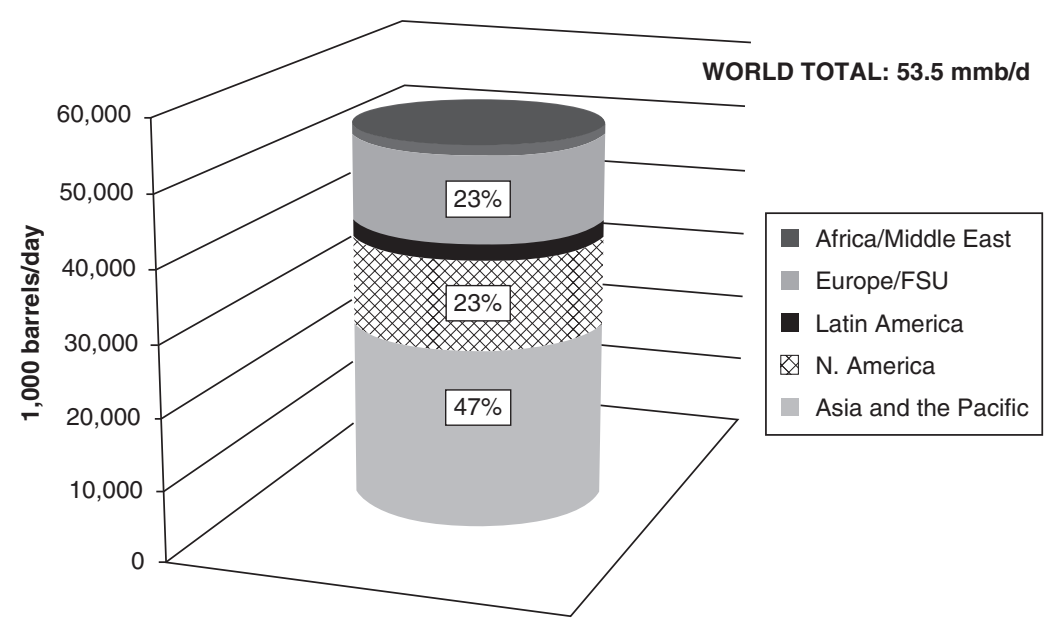

Figure 2.15 Regional shares of total oil imports, 2010

Source: BP 2012.

Note: FSU = former Soviet Union; $\mathrm{mmb} / \mathrm{d}=$ million barrels/day.

outlook shown previously. This demonstrates the power of compound growth. Although in the ACS the growth rate is less than $2.5 \%$, this adds up to a tremendous increase in oil imports from under 11 million barrels/day in 2010 to 31.3 million barrels/day in 2035 which means in 2035 developing Asia will import nearly 3 barrels of oil for every 1 imported today.

To put those numbers in perspective, in 2011 Middle East exports of oilincluding both crude and products_-amounted to 18.9 million barrels/day (BP 2012). Total world exports of oil amounted to 53.5 million barrels/day (Figure 2.15). In other words, if world oil exports remained constant, by 2035 under the ACS, Asia would be taking nearly $60 \%$. How plausible is such a scenario? It is not wholly implausible. Such an increase in imports will put pressure on the market, but Asia is already the largest importing region in the world. In 2010 total oil imports (including Australia, Japan, and New Zealand) were slightly greater than North America and Europe combined (Figure 2.15).

If US and European oil demand continues to contract and oil production and exports continue to gradually increase (as is happening currently notably in Iraq and the US), and countries continue to set policies that limit growth in oil demand, then it is possible that Asian imports could increase to the levels predicted. If not, it will be a battle that will drive crude prices up.

\section{The growing importance of product trade}

At one time, trade patterns of the Asia and Pacific region were simple. Most countries with refineries imported crude and made up any deficits with product 
imports, mostly from Singapore. The growth of Middle East export refining as well as Middle East gas processing (which produces steadily increasing volumes of naphtha and LPG exports) offered a new source of products. As Asian refining increased on the heels of soaring Asian oil demand, more countries entered the product market as exporters as well as importers. Today the PRC, India, Japan, Malaysia, the Republic of Korea, and Thailand all typically export more than 200,000 barrels/day each of refined products; India and the Republic of Korea each export well over 1 million barrels/day. India and the Middle East are beginning to create a reliable arbitrage between the Atlantic Basin and Asia, and Asian cargoes of various products, notably diesel, sometimes move to Europe (IEA 2013).

In 2000, product imports accounted for about $25 \%$ of Asian oil supply; in 2011 they had expanded to about 31\% (FGE 2012b). This may sound like a modest change, but it occurred at a time when Asian demand was expanding rapidly, so the result was an increase in product imports of more than $70 \%$. The Asian trade in products is now huge with 8.3 million barrels/day of imports and nearly 6 million barrels/day of exports.

At one time the product market was "thin" enough that a growing deficit in a single importer could have a major impact on the overall availability of a given product. In general, this is not as true today simply because the market has expanded so much. Because of the bewildering — and constantly shifting - array of product specifications in different countries, however, a given grade of a product can still be too thin, and import levels can cause serious market distortions. All in all, the development of a large and active product market has given individual countries and refiners more flexibility in meeting demand, but steps could be taken to make the market more useful and effective.

\section{Reliance on Middle East oil exports}

The Middle East is of course the world's largest exporting region and the source most importers look to for the marginal barrel of crude. The Middle East is a strategic oil center of great importance, and most Americans and some Europeans will stipulate that a major military presence in the Middle East is needed to guarantee the security of oil imports. Oil is a relatively unified market, so a disruption anywhere affects everyone, but few voters or politicians understand that logic, so the situation in Figure 2.16 is potentially explosive. In 2010, just over 10\% of all Middle Eastern exports went to Europe; less than $10 \%$ went to North America; $76 \%$ went to Asia. It would be easy for Asia to accommodate all Middle Eastern exports.

In practice, this will not happen - although US imports from the Middle East apart from Iraq and Saudi Arabia have dropped to nearly zero. Corporate connections will keep some volumes of oil flowing westward. For example, Saudi Aramco now owns substantial refining capacity in the US and will use at least some of it for their own crude. There are also investments by multinationals that will tend to move some volumes west because of tactical considerations. In terms 


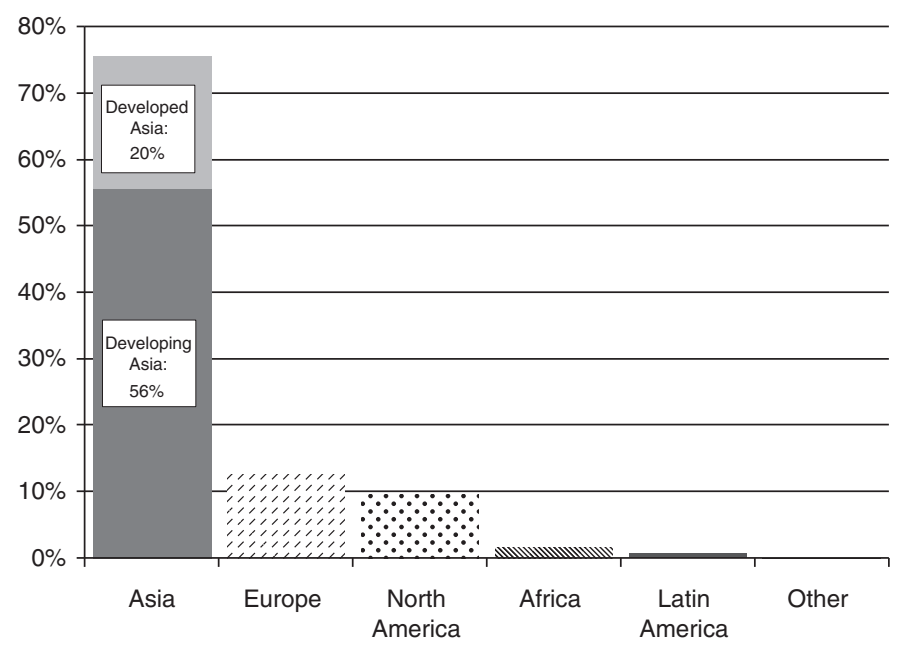

Figure 2.16 Destination of Middle Eastern oil exports, 2010

Source: BP.

of physical capabilities, however, North America and Europe no longer really need Middle Eastern oil.

This creates a politically fraught situation. The obvious problem is the large US military presence in the Persian Gulf. In a time of budget austerity, will spending US dollars to defend Asian oil supplies sound like a popular campaign slogan? On the other hand, will stepping aside to allow a major Asian military presence in the gulf be popular? There is another angle to this situation, however. The Asia and the Pacific region dominates the market for Middle Eastern oil to a remarkable extent which ought to give the buyers increased leverage - a topic addressed in the section entitled "Destructive Competition?"

\section{Crude quality and refining capabilities}

As mentioned previously, the Asia and Pacific region is not crude rich, but the crudes it produces are primarily low sulfur (sweet). The most famous tend to be medium-to-light crudes such as Minas (Indonesia) and Tapis (Malaysia), but there are also ultra-heavy sweet crudes such as Duri (Indonesia), Pyrenees (Australia), and QHD (offshore PRC). Many of the larger refiners in the region have negligible crude production (Japan, the Republic of Korea, and Taipei,China) or production far short of demand (India). Their refining systems developed on a mix of sweet Asian crudes coupled with an ever growing share of sour Middle Eastern crudes.

Other countries, notably the PRC and Indonesia, have long supplied the bulk of their own needs, so most of their refining was constructed to handle only low-sulfur crudes. In the PRC, many refineries were constructed of mild steel 
that literally cannot withstand high-sulfur crudes. As imports have mounted, Indonesia has relied on importing sweet crudes from other Asian sources as well as from West Africa. The PRC initially followed this pattern (and still imports African crudes), but it soon became apparent that it would have to become a major importer of sour crudes from the Middle East.

Coupled with a gradual tightening of environmental standards around the region, most Asian refiners have faced ongoing trade-offs between scarce, expensive sweet crudes and the large capital costs of installing capacity to handle sulfur. Although it might seem that the logical thing to do is build extensive desulfurization, the decision is not so simple because crude oil is not desulfurized; rather, the intermediate products created after the crude has been distilled into its various cuts are. The heavier the cut, the more difficult and costly it is to desulfurize and the higher the percentage of sulfur it contains. For example, in a crude like Arab light containing $1.8 \%$ sulfur, the gasoline cut will contain about $0.025 \%$ sulfur while the fuel oil cut will contain more than $3 \%$. What is more, the fuel oil will generally contain almost all of the other difficult contaminants such as metals as well as the bulk of the noncombustibles (ash).

In practice, it is even slightly more complex. The straight-run fuel oil-the portion of the oil that still has not boiled at $650^{\circ} \mathrm{F}\left(343^{\circ} \mathrm{C}\right)$ - is typically sent on to a vacuum distillation tower that splits it into vacuum gas oil $\left(650-1050^{\circ} \mathrm{F}\right)$ and vacuum bottoms $\left(>1050^{\circ} \mathrm{F}\right)$. This results in a further concentration. The vacuum gas oil from Arab light contains about $2.4 \%$ sulfur; the vacuum bottoms contain $4.2 \%$ sulfur and virtually all of the metals.

A hydrotreater to desulfurize gasoline or diesel at a typical refinery costs tens of millions of dollars; a hydrotreater for vacuum gas oil can cost hundreds of millions, but one to desulfurize and demetalize straight-run fuel oil (or worse, vacuum bottoms) typically costs around a billion dollars. For this reason, desulfurizing is seldom undertaken simply to produce low-sulfur fuel oil for sale. Once the fuel oil — or portions of it - is desulfurized, it is usually more valuable as cracker feed than on the low-sulfur fuel oil market.

"Crackers" are units in refineries that take large, heavy molecules and break them into lighter molecules in the gasoline, kerosene, and diesel range. The most common of these are fluid catalytic crackers and hydrocrackers. These generally take vacuum gas oil as their feedstock, though some of them can run on desulfurized and demetallized full-range fuel oil. Such units are comparatively uncommon and are called "resid" crackers (typically abbreviated as RFCCs and RHDCs.)

Cracking in a given unit is never $100 \%$, so some form of cracked fuel oil is usually returned. In most refineries, this cracked material is usually blended with the vacuum bottoms and the mixture is called "cracked fuel oil" which is typically used as ship bunkers or in power generation. Any fuel oil sold without any cracked material blended into it is called virgin fuel oil and generally sells at a premium as virgin fuel oil can be sent for cracking while cracked fuel oil generally cannot be cracked again.

Except in the rare cases where whole fuel oil is desulfurized and demetallized and run to a resid fluid catalytic cracker or hydrocracker, a typical cracking 
refiner has a ready outlet for vacuum gas oil but ends up with a substantial amount of vacuum bottoms that are often very high in sulfur and even when made from low-sulfur crudes, usually high in metals and very difficult to process except in a unit called a coker. Cokers take vacuum bottoms or even whole fuel oil and thermally crack them into lighter products leaving behind a large quantity of petroleum coke that contains most of the metals and much of the sulfur. The heavy liquids - coker vacuum gas oil — can with some pretreating be sent on as cracker feed to fluid catalytic crackers or hydrocrackers, and the lighter liquids can be used as blendstock in finished products though they are relatively low in quality and may require considerable treatment before blending. The coker is a vital element in most full conversion refineries, i.e., those that produce little or no fuel oil. In the US, fuel oil is now less than $4 \%$ of the product barrel starting from crudes that in many cases yield more than $50 \%$ fuel oil on distillation.

There are many ways to gauge refinery capabilities. The Nelson Complexity Index, for example, is a good measure of sophistication but gives an undue weight to complex units such as lubes or alkylation. In terms of what a refinery can do to convert fuel oil to lighter products, the easiest to understand is the cracking-todistillation ratio. This is simply the capacity of each kind of major cracking unit divided by the crude capacity of the refinery. (Visbreakers and thermal crackers are excluded from these totals because most of them do comparatively little in the way of conversion.) Figure 2.17 offers an overview of the cracking-to-distillation ratio by type and region as of the end of 2012 .

The US has the highest cracking-to-distillation ratio with cracking capacity amounting to about $55 \%$ of crude capacity. The US also has the highest ratio of coking to distillation; in fact, $40 \%$ of all coking in the world is in the US. This reflects a long history of imports of very heavy, generally high-sulfur crude oils from Canada, Mexico, and Venezuela as well as a very low demand for fuel oil. What is perhaps more surprising is the fact that the PRC ranks just behind the US with a cracking-to-distillation ratio of about $45 \%$ and holds nearly $25 \%$ of the world's coking capacity. (Note that these figures are all based on statistics gathered directly from sources in the PRC; most data in industry journals under report PRC refining capacity by a substantial amount.)

The PRC has long minimized fuel oil use and has tried to squeeze every drop of light products out of a barrel of oil. The country has had the technology to build both cokers and fluid catalytic crackers since the 1970s and has developed some advanced cracker designs that have been licensed in other countries. The PRC has cut fuel oil consumption to about $6 \%$ of its demand barrel; $33 \%$ is for ship bunkers (FGE 2012c).

The rest of Asia lags far behind the PRC, but fuel oil is still about $13 \%$ of the demand barrel. Asia excluding the PRC is quite similar to Europe in cracking ratios. Some of this reflects European access to lighter crudes, but it should be noted that European refining is on the decline (with present utilization under $80 \%$ ), so even though European consumption of fuel oil is only around $9 \%$ of the demand barrel, there is less fuel oil to be cracked than the crude capacity might suggest. In the rest of the world, fuel oil demand remains rather high at about $16 \%$ of the demand barrel (BP 2012). 


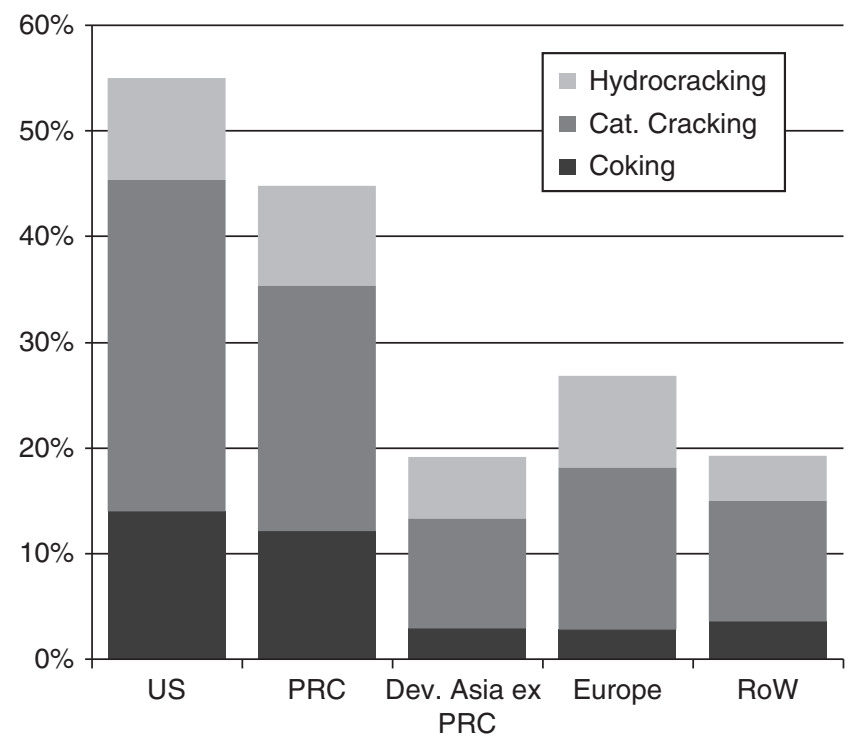

Figure 2.17 Cracking-to-distillation ratios for various regions, 2012

Source: Kootungal 2012, FGE 2012d, and author's calculations.

Note: PRC = People's Republic of China; Dev. Asia ex PRC = developing Asia excluding PRC; $\mathrm{RoW}=$ rest of the world; US $=$ United States.

At present, Asia is expanding and rationalizing refining simultaneously. Capacity is being closed in Australia and Japan, and new capacity is being built most notably in the PRC, India, Malaysia, Pakistan, and Singapore. By 2020, the overall result should be an expansion of $15 \%$ in crude capacity accompanied by an expansion of $16 \%$ in coking, $11 \%$ in catalytic cracking, and $20 \%$ in hydrocracking. The net result is a slight increase in the overall cracking-to-distillation ratio (FGE 2012d; author's calculations).

There are two main reasons to focus on cracking that are discussed further in the sections "The challenge of International Maritime Organization bunker regulations" and "Refinery configuration as a security issue", respectively. The first is that the planned International Maritime Organization regulations may severely cut current fuel oil demand in bunkers, and the second is that limited cracking and upgrading limits the kinds of crudes that can be processed.

\section{Critical issues in oil security}

\section{Traditional and contemporary views on oil security}

Arguably the concept of oil security dates back to Winston Churchill's time as First Lord of the Admiralty of the UK when a comprehensive program was 
undertaken to ensure the reliable availability of oil at all of Britain's "coaling stations" around the globe. More recent concerns, however, grew out of the oil crises of the 1970s and early 1980s and were highly colored by the Arab Oil Embargo that attempted to deny oil supplies to certain economies or groups of economies. Price increases and perceived shortages following the Iranian revolution increased concern about what could be done to maintain ongoing supplies of oil in the event of a disruption.

In fact, it is not clear that there were physical shortages that were not caused by excess stockpiling and keeping vehicle tanks full. The rapidity of price increases also may have led to speculative hoarding when oil companies were afraid to sell stocks of crude or product on a given day because the price might be much higher on the next. The economic dimension was always a concern of governments, even if it was overshadowed in public debate by the threats to the security of the physical supply. In the name of protecting their economies and eliminating profiteering, many (including for a time the US) introduced price controls to keep prices low. As might be expected, price ceilings and controls had their own consequences in terms of demand distortions and impacts on national treasuries. The US freed up prices in 1980, but price caps and subsidies of various sorts remained widespread in Asia throughout the 1980s, and even today not all domestic prices are market related.

As the market has matured with neither OPEC nor the multinationals able to control prices or destinations, the concept of "the oil weapon" has quietly evaporated. Oil certainly remains a tool of political influence, but it is a flimsy weapon. Oil kept flowing through the two Gulf wars, and supplies are still readily obtainable despite the current sanctions against Iran. While loss of supply from a given source may be inconvenient as in the 1991 Gulf War when supplies of oil from Kuwait dropped to zero, there was no supply crisis for any individual economy. The market responded with a price spike then rapidly cooled down. Indeed, it is difficult to find instances of physical cutoffs of oil based on anything other than natural disasters. About the only case anyone can cite is from the PRC to the Democratic People's Republic of Korea, but the cutoff of subsidized oil to a tiny country receiving the bulk of its oil through a single pipeline is not a lesson for the oil market at large.

Similarly, although not all price subsidies have yet vanished, many governments would like to eliminate them if it were politically feasible. If assuring physical supply is not the challenge, and insulating domestic economies from the market is deemed neither wise nor practical, then what is oil security? The goal of oil security is to increase the resiliency of domestic economies and the international market to the effects of changes in the terms of oil supply. The "terms of oil supply" encompass changes in availability domestically and internationally as well as changes in prices. Resiliency involves adapting to change with minimal economic dislocations. Change is inevitable though unfortunately not predictable. The role of governments should be to help take advantage of changes when beneficial and to reduce their harm when they are challenging. 
This concept of resiliency is a useful touchstone in evaluating policy options. The following measures tend to increase oil security.

- Increase oil production. This seems so obvious, but there is a corollary: It doesn't matter too much who is producing the oil. If Country A increases oil output, then it is clearly the main beneficiary, but Country B also benefits because A now imports less oil or even becomes an exporter.

- Decrease oil demand. Once again, the main beneficiary is the country that cuts its oil demand, but the region and the market all benefit.

- Increase production of alternatives to oil. This may not only decrease oil demand as such but also offers substitution options if oil prices suddenly increase.

- Increase stocks of energy/oil. In the short term, stocks act as if supply on the market had increased. Once again, the effect is beneficial no matter who holds the stocks.

- Increase fungibility. Anything that allows energy to move more freely to where it is needed makes the system more resilient to disturbances. This can mean more transport infrastructure, or more flexible refineries, or increased harmonization of product specifications. It can also mean concentrating on oil alternatives that are readily substitutable in critical end uses rather than on the total of British thermal units produced.

- Increase market responsiveness. This covers a broad set of issues including domestic pricing policies, market transparency, using hedging and futures markets, and a greater number of participants in the market.

\section{Pricing policies}

As discussed previously, pricing is one area where governments often introduce serious distortions into the economy. The problems with keeping all oil prices too low are obvious: demand is encouraged to expand at an unrealistic rate, and the difference between market prices and the domestic price is paid for somewhere in the system. The problem is most obvious when the treasury pays directly for subsidies, but indirect subsidies such as setting the prices a national oil company may charge incur at least the same level of economic loss. In fact, the losses could be larger in indirect subsidies because company investment decisions are likely to be distorted; at a minimum, the incremental value of finding more oil is undervalued.

More subtle problems occur when governments choose to subsidize or to control only a few fuel prices. The resulting distortions can take on many forms. In extreme cases, fuel smuggling can become rampant as can adulterating products. If a national oil company is responsible for supply, huge capital investments may be made in refining to keep up with demand for the subsidized product. In few cases do such price subsidies benefit only the group to which they are directed; fuel subsidies for the poor are often enjoyed by the rich as well, and in many cases businesses are able to find ways to take advantage of the subsidized fuel for 
their own purposes. Once a subsidy becomes entrenched, it develops a constituency and becomes hard to remove.

Systems involving subsidies do not tend to be resilient as they are attempting to form a dike between the force of the market and a portion of the domestic economy. History shows that such systems tend to succumb to economic pressure, and the adjustment that follows can be unpleasant and can result in dislocations. There are two arguments for fuel subsidies. One is that they support the poor, but the best way to accomplish this is to give the intended beneficiaries money, not to restructure the entire pricing system. Second is that they support energy-intensive businesses. That is bound to be the case, but it also tends to increase rather than decrease oil demand and exposure to changes in the oil market.

Policies that hold prices at above-market levels are not uncommon and have long been in place in Europe. They usually involve taxes, often a combination of value added and flat taxes. Taxes that keep prices above levels in the external market obviously depress demand and reduce reliance on oil, but if they are too high, they may also depress overall economic growth. Obviously, higher prices discourage businesses that depend on cheap energy supplies, so some economic activity may be shifted to other locations, but in terms of oil security this may not be a bad thing.

Higher prices for oil also make alternatives more competitive and provide a cushion for them if oil prices take a sudden fall. Above-market oil prices also offer a policy option denied to subsidies: if prices rise too high, the extra taxes or charges can be reduced. In particular, there is the option of temporarily pegging value-added taxes at a flat rate rather than letting them rise in proportion to the external market.

In summary, oil subsidies decrease oil security. Market-based prices create fewer distortions and economic losses. Prices well above levels on the world market may also have economic consequences that increase oil security by reducing growth in demand, supporting alternatives, and if needed, adding a tax that can in principle act as a cushion if prices soar too high.

\section{Oil stocks and oil-sharing agreements}

Oil stockpiling is a simple and appealing concept as it increases the amount of oil available to an economy. One of the IEA's most basic rules is that every member must hold a minimum of 90 days of the previous year's net oil imports (Bamberger 2004). The idea of minimum stockholding is to some extent an extension and formalization of what many might consider good business practice. For many governments, it also has the appeal that the main burden could be on the private sector; refiners could simply be required by law to hold a certain number of days of oil the same way that a minimum amount of working capital must be held in a bank. The analogy is, however, faulty. Money held long-term in the bank earns interest. Oil held in tanks, on the other hand, does not accrue interest. It takes money to build and maintain the tanks, money to buy the oil to fill them, and money in terms of opportunity costs to have capital tied up and not employed.

Holding large stocks is costly, and companies - even national oil companiestend to resist stringent stockpiling rules. When such a rule was instituted in 
Thailand, the refiners pointed out (correctly) that the concept as originally proposed gave substantial price advantages to product importers who had to hold only a certain number of days of product stocks but did not have to hold crude. This sort of problem can be solved by adjusting holdings to make them equal.

The IEA stocking policy doesn't mean that the logical level is similar for everyone. A major oil producer can argue that from its perspective the resource in the ground is a stock although it is in fact less accessible and responsive than oil in a tank at a terminal. In fact, IEA members that are net oil exporters are exempted from the strategic stockpile requirements. A country like Singapore where most oil imports are just passing through either as crude to be re-exported as products or as products to be re-sold does not face a threat to domestic supplies even if stocks are kept at very low levels relative to total sales.

IEA members Japan and the Republic of Korea hold strategic stocks in excess of IEA requirements. Among non-IEA members, Thailand; the PRC; and Taipei,China have major strategic reserves; the PRC has major expansion plans; India is developing an ambitious strategic reserve system; and plans for strategic reserves have also been made in the Philippines (Hook 2011).

One of the most interesting proposals for stockholding was the one discussed several years ago by the Republic of Korea and Saudi Aramco. The idea was that Saudi Aramco wanted large holdings of crude in East Asia for marketing reasons, and the Republic of Korea wanted ready access to crude in case of a market disruption. The plan was that the Saudis would store their oil there and draw on it as desired unless a supply emergency occurred in which case Korean refiners would have right of first access. Although "first access" suggests a major advantage - one that probably doesn't really exist short of a war in the immediate vicinity - the idea of exporters holding stocks in the importing region is intriguing. Today, with concerns over the Straits of Hormuz, it may be time to revisit this concept.

The Republic of Korea has been innovative in other ways regarding storage. PEDCO, the nation's petroleum development corporation, has a large strategic storage system against emergencies. In times of price spikes but no real threat of a cutoff, Korean refiners have been allowed to draw "loans" of physical barrels from PEDCO tanks and then repay them with barrels purchased later when market prices decline. In this way, the "strategic" reserve has had a practical, tactical effect on costs and prices. Whether curbing price spikes in a PEDCO-style approach justifies the amount of public money invested is questionable. If, however, a government has already decided to hold a major strategic stockpile, the PEDCO experience suggests that there may be more creative approaches to managing the stock than the sit-and-wait-for-an-emergency method used by the US for its strategic petroleum reserve.

Oil stockpiling naturally leads to oil-sharing agreements. One original IEA goal was to ensure effective oil sharing in the event of a major disruption, but this key element of the 1970s mission has gradually assumed a much lower profile. As a history of the IEA notes, "By the time of the 1994 Commission Decision, however, the IEA's emergency response policy had evolved toward greater emphasis on co-ordinated oil stock drawdowns accompanied by related measures 
such as demand restraint, fuel switching and surge production, as distinct from oil sharing" (Bamberger 2004).

To some extent, this change in emphasis reflects the change in the world oil market since the days of the oil crises in the 1970s and 1980s. At the time of the Arab oil embargo, control of world distribution and pricing was firmly in the hands of the major oil companies. OPEC did an effective job of wresting control away from the majors but was unable to maintain control over transport and trading. (OPEC devoted a good deal of research into how to maintain a worldwide system of destination controls and failed to find a solution.) What emerged in the 1980s and 1990s was a real international market in oil with prices driven by spot trading and eventually by active futures markets.

That said, there has been continued interest in oil-sharing agreements. The Association of Southeast Asian Nations Petroleum Security Agreement of 1986 provided for oil sharing in the event of a shortfall of $10 \%$ of supply in any member, and this was updated by a new agreement and protocol in 2009 (Nicholas 2009). The agreement, however, specifies only that oil will be provided on a bestendeavor basis; there is no central mechanism for administration.

Such an agreement could indeed be useful if a single member faced a physical cutoff of oil supply while the others did not. In today's market, such an event would more likely be the result of a natural disaster than of politics. In the $21 \mathrm{st}$ century oil market it is hard to imagine a political or international event that would be so targeted as to cut off supply to one economy and not neighboring ones. Such an event is easy to imagine in the LNG market, however, as controlled source-to-destination channels are still the dominant means of sales, but oil is no longer delivered through such specific channels.

In 2007, Japan and the Republic of Korea signed an agreement to share supplies from their strategic reserves in the event of an emergency (Kang and Lee 2007). Japan also announced that it would be open to oil-sharing agreements with other countries with the Japanese strategic reserves as the main holding reserve. An agreement has also been concluded with New Zealand, and the Philippines also expressed interest (Marasigan and Isla 2011).

When most oil was controlled from source to destination by either large integrated oil companies or by exporters, it was reasonable to worry about targeted cutoffs; oil-sharing plans were an important response to this problem. Today the market faces many challenges, but the scenario of targeted cutoffs is one of the least likely. One place where oil-sharing agreements could play an important role, however, is in regional stockpiles. Centralized storage serving many economies could make good sense, but the conditions for drawing on and sharing the oil would need careful thought.

\section{Gas and unconventional gas sources}

As discussed previously, perhaps the most important unknown in future Asian oil demand is future Asian gas supply. Gas is relatively fungible with oil in a number of important end-use sectors and offers an efficient, easily handled 
substitute (after some changes in equipment) in others. Beyond the issue of gas as such, one of the unpredicted results of shale-gas development in the US was the increase in shale liquid output, both LPG and actual crude oil. Now that the structures and plays are better understood, increasing attention is being devoted to developing those structures where the liquids predominate. What had been the "shale gas revolution" has changed into the "shale liquid revolution" with gas as a useful byproduct.

Shale is not equitably distributed in Asia nor is coal that can be the source for coal bed methane. Once again, such developments help ease pressure on the international oil market either directly (shale liquids) or indirectly (gas reducing oil demand). There are thus benefits to the region as a whole even if it appears that only the resource owner is profiting.

\section{The challenge of International Maritime Organization bunker regulations}

At present, the International Maritime Organization has ruled that international bunker fuels can contain a maximum of 3.5\% sulfur by weight (down from the $4 \%-4.5 \%$ that was once common). There are, however, regions called emission control areas where the standards are much tighter. The first was the Baltic/ North Sea where bunker sulfur was limited to a maximum of 1\%. The EU also allows no more than $0.1 \%$ sulfur fuel to be burned while in EU ports. In August 2012, phasing in the emission control area for North America began, also lowering bunker sulfur to 1\%. Puerto Rico and the Virgin Islands will follow in 2014, and the Mediterranean, Australia, and other areas are likely to in coming years (Meech 2010). The big change will come in 2015 when the limit in emission control areas is dropped from $1 \%$ to $0.1 \%$ sulfur. There are almost no crudes that produce $0.1 \%$ sulfur fuel oil, and although refiners have known about the coming standards for years, it appears no investments in desulfurization have been made to meet them. In general, refiners are assuming that some other measures will have to be adopted.

The problem becomes more pressing toward the end of the decade. At present, the International Maritime Organization plans to limit all non-emission control area fuels to $0.5 \%$ sulfur after 2020 , a rather large drop from $3.5 \%$. Since the majority of the world's bunkers are still 3.5\% sulfur, there is a good deal of concern that this new standard cannot be physically met. The organization will meet in 2018 to rule whether the new standard will be imposed in 2020 or whether it will be delayed to 2025; most observers are betting on the latter. It seems clear that there will not be enough low-sulfur fuel oil-either $0.1 \%$ or even $0.5 \%$ sulfur - to meet the demand. There will be plenty of cracked, high-sulfur fuel oil, however, that will have lost its natural market.

At present, there are three major contenders for meeting the future specifications. The first is low-sulfur diesel which can easily meet the $0.1 \%$ limit. Most vessels traveling in and out of emission control areas would probably need dual tanks to switch to diesel when they are transiting. Diesel of $0.5 \%$ sulfur is now 
widely regarded as high-sulfur diesel and would be in ample supply if there were a market for it. Still, this involves a major dislocation in the market greatly expanding diesel demand and shrinking demand for fuel oil.

The second contender is onboard sulfur scrubbers. This would allow ships to burn higher-sulfur fuels and remove the sulfur as well as most of the nitrogen oxides and particulates. Most of the scrubbers remove sulfur 92\%-95\% efficiently, so scrubbing probably still wouldn't allow a ship to burn 3.5\% sulfur fuel oil in an emission control area though scrubbed $1 \%$ fuel oil would work. The investment, of course, is huge, and the technology is still in the developmental stages.

The third possibility is LNG. Many ship owners are betting on this for ships trading within emission control areas mostly in coastal traffic. At present, it is hard to envision a worldwide LNG bunkering system to support all international trade.

Unless onboard scrubbers win the day, high-sulfur fuel oil will be in long supply. This suggests that countries may wish to consider leaving room for onshore consumption such as in power plants with scrubbers or that an expansion of coking capacity may be needed to convert it into lighter products. In short, the new International Maritime Organization rules pose a looming problem whose implications are still far from clear.

\section{Refinery configuration as a security issue}

Refinery configurations are primarily a commercial issue, but they do have security implications. Ultimately this goes back to the goal of increasing fungibility. Very simple refineries have no cracking and little or no desulfurization. To meet specifications in most markets, a refinery like this will have to choose a very specific, narrow set of crude oils-most likely light, low-sulfur, expensive crudes. The refiners in this position will be in direct competition with each other for the limited supply of such crudes and will tend to bid up the price.

Specialty crudes may flow in one direction when almost all other crude flows are moving in another. In extreme cases, the market price of the crude may be higher than the value of what the average refiner can make from it, and the crude will move to only a handful of locations rather than interacting with the market. True, fungibility will return if the crude is converted into products, but this situation cuts into the flexibility of the market.

A more important and relevant example is the plight of Canadian bitumen. Produced from oil sands, the material is so heavy that it sinks in water and requires diluents (called dilbits) to flow through a pipeline. It is this sort of crude that is planned to be exported to the US through the proposed Keystone XL pipeline that was rejected by President Obama in January 2012 (Eilperin and Mufson 2012) but is due to be reconsidered in the near future. The Canadians took steps not to remain reliant on a single nation as a sole outlet by making plans to build an export pipeline to the Pacific and move the super-heavy crude to oil-hungry Asian buyers, but enthusiasm for the plan has quietly vanished. The problem is 
that there are no obvious customers in Asia. Bitumen crudes are useful only to refiners with heavy cracking capacities, especially coking. Although the PRC has considerable coking capacity, much of it is in the interior and is devoted to local crudes. In terms of handling bitumen as a feedstock, there are only a handful of refiners with the capability in Asia.

Apart from the potential for shale liquids that tend to be light and low in sulfur, most of the world's untapped, unconventional oil resources are in the Canadian oil sands or in a belt that wraps around the western and southern edge of the Caribbean from Mexico to Venezuela to Trinidad and Tobago. These are all super-heavy crudes or tar sands or bitumen deposits, and the main outlet for the heavier grades is the US. Developing these deposits is slowing down because they have no markets beckoning; in effect they are cut off from the world oil market.

In a more logical world, the US would absorb more of these super-heavy crudes which match US refining configurations and export some of the surplus of light, sweet crudes (from shale) to where they are needed, but US law prohibits exporting crude without a specific (and difficult-to-obtain) exemption. So the oil locked up in the Americas does not have a major effect on the market and is not being developed. Blame US policy but also blame refinery configurations in Asia. Demand for oil is soaring, and the region is already consuming most of its own output, most of the output from the Middle East, and a big slice of production from Africa. The large undeveloped resources are in the Americas, but Asia, the world's largest consuming and importing region, can't make use of most of them.

\section{Product specifications as a security issue}

Most oil-product specifications apart from international fuels like bunker and jet fuel are a matter of national environmental policy, and except for the fact that wind and water know no boundaries, this doesn't seem like a regional issue. Unfortunately, the lack of coordination in specifications from country to country acts as a barrier to the free flow of petroleum products and therefore has the effect of decreasing regional energy security. In a crisis, even if products were in surplus in one country, they might not be useable in another facing a shortfall.

It might seem like this is simply a matter of passing legislation that would allow product specifications to be loosened in times of emergency, and in some cases such measures would indeed solve the problem. In other cases, however, it is not nearly that simple. For example, catalytic converters on automobiles can be poisoned by levels of lead or sulfur that are acceptable in the gasoline blends of many countries, and equipment can be disrupted or function at lower efficiency if not run on the fuel for which it has been designed and tuned. The truth is that many product specifications around the world are essentially protectionist measures disguised as environmentalism.

If there was ever an oil issue that could be solved by regional consultation and harmonization this is it, though it is far too much to expect that all of Asia will converge on a single set of specifications. To some extent, environmental quality is a luxury of development, and not every economy can afford to accelerate to the 
levels of product quality in Japan, for example, though some details of the specifications in Japan could be questioned. What may be possible is to settle on agreed levels of specifications. For example, if market leaders in diesel/gasoil are $0.5 \%$ sulfur, $0.25 \%$ sulfur, $0.05 \%$ sulfur, and 50 parts per million sulfur, then a country shouldn't move to a standard of $0.35 \%$ sulfur or $0.1 \%$ sulfur. Similarly, one country insisting on a 60 minimum cetane number and another on a 56 minimum cetane index only complicates international trade. This may in fact be the goal of some companies and even some national oil companies, but it constrains oil security. There is no need to adopt a uniform set of specifications, but it should be possible to agree on where limits are needed.

The greater the degree of harmonization among product specifications, the more economies can assist each other in times of market disruption or in the event of refinery disasters or unexpected downtimes. In addition, the greater the degree of harmonization, the more efficient the markets will tend to become for each product. Products with specifications that apply to only a small segment of consumption are notorious for falling out of step with other segments of the market. Both of these factors - the ability to offer assistance with product supplies and the increased size and liquidity of markets — can greatly enhance regional energy security.

\section{Overseas investment and international trading}

Investment in overseas exploration and production is a useful way to increase oil security, but it is often misunderstood as there continues to be an emphasis on the physical supply chain from the oil source back to the country. It may be logical to carry physical volumes of a new crude to a home country especially if it requires special processing and the company can make coordinated investments in refining to handle it. In some cases, however, it may make more sense to sell the crude on the market and buy another if the transportation hurdles are too high or if the crude is poorly suited for the home market. There have been a number of cases in which a national oil company has invested in a distant project and has been forced to bring the oil back for use in domestic refining. It makes for good newspaper headlines and photo opportunities, but it may not make good economic sense.

In any case, overseas investment by Asian oil companies should be encouraged. Oil exploration and production require massive (and increasing) capital expenditures, and it only makes sense that Asian importers should make capital available to the industry and share in the profits. In some cases, national oil companies may be invited to invest where private companies would not be welcome.

Overseas investment also increases the number of participants in the market. This leads directly to international trading. Traders are still looked upon with a degree of suspicion by some as they seem to simply buy and sell without necessarily producing anything. This may be true, but typically traders are acting on behalf of producers or consumers, and in oil, traders are often closely involved in arranging transport and in packaging larger or mixed product cargoes. Because barriers to entry are low, trading houses quickly see excess profits whittled away by competitors. 
This not only makes for a more flexible market, it also increases transparency. The more participants there are in the market, the harder it is to keep secrets, and the greater the number of transactions, the greater the chance of discovering accurate prices. While the futures market deals in paper barrels (see section entitled "The futures market"), the physical trading market deals in real, "wet" barrels that need to be exchanged by a particular date. For individual oil products and specific crudes, the spot market is the key pricing mechanism, and a reliable spot price requires a large number of transactions by a large number of unrelated participants. Some spot markets like the low-sulfur waxy residue market in Singapore have become increasingly unreliable simply because there are not enough individual sales.

In terms of physical delivery, at the margin it is the traders in wet barrels who fill in unexpected supply gaps and structure actual delivery. A large, diverse trading market increases fungibility and transparency and is to the benefit of everyone.

\section{Destructive competition?}

As presently constructed, sellers of crude and products in the Middle East are an oligopoly; OPEC members (Iran, Iraq, Kuwait, Qatar, Saudi Arabia, and the United Arab Emirates) are open about their intentions to try to control prices for their own benefit while Bahrain, Oman, and Yemen are essentially tagging along. On the other side of the transaction are all the Asian oil importers, some negotiating for supply through individual companies, others through national oil companies, and some via joint-venture refineries with Middle Eastern national oil companies.

The largest structure in today's oil trading is a virtual pipeline that runs from the Middle East to Asia carrying $76 \%$ of its oil exports; as mentioned previously, without much realignment in current trading patterns, Asia could take all of it. Without Middle Eastern exports, Asia would be in deep trouble, but without Asia as an export destination, the Middle East would be in trouble just as deep because the rest of the world doesn't need or want an extra 15 million barrels/day of oil.

Why are the economies in the world's largest oil-importing region generally paying a premium for crudes and nervous about supply arrangements? The suppliers are an oligopoly and the buyers are a diverse, unorganized market comprising some private companies, some state-owned companies, some governments, some multinationals, and some companies partly owned by the sellers. It is a classic example of divide and conquer: the buyers are in competition with each other rather than with the sellers. Can this dynamic be changed? In principle yes, but in practice most Asian buyers tend to regard other Asian buyers as "the competition." This is the weakest possible position for collective bargaining. A buyer's alliance is definitely worth exploring as without Asia, Middle East oil would be homeless.

Although it must seem as if the oil-surplus nations are in an enviable position, it is worth keeping in mind that their economies have fluctuated more extremely than any in Asia. When the price of oil is too high, it is an occasion for nervousness; when the price of oil is too low, it is an occasion for despair. Oil is a major 


\section{David Isaak}

concern in Asia as well, but it is one concern among many. In the Middle East, it is the primary concern. In the 1980s, there was an ineffectual producer-consumer dialogue that mainly involved discussions between European importers and Middle Eastern exporters. Today a similar dialogue between Asian importers and Middle Eastern exporters might find substantive issues to discuss.

Finally, an unpleasant reality is that the US is spending billions to protect oil supplies that mainly flow to Asia. This makes sense in terms of the market, but it is hard to explain to voters. Ultimately, Asian countries have a greater vested interest in the Straits of Hormuz than do Washington or Brussels. This is also an issue that ought to be considered in any discussions.

\section{Energy and financial markets in Asia}

\section{The futures market}

There is probably no more controversial issue in oil than the effects of the futures markets on prices. There are good arguments that the futures market has acted to increase transparency and has established a worldwide benchmark that sellers cannot ignore; there are equally compelling arguments that futures markets increase price volatility.

Volatility is not always a bad thing. From 1973 to the early 1980s, market prices were to a great extent governed by the expectations of a handful of oil companies and a handful of oil exporters all nervously watching the movement of spot prices (which they also influenced). The system responded only slowly to changes in external circumstances, e.g., from 1979 to 1984, oil prices increased at the same time that demand fell steeply.

The emergence of futures markets let a wider array of participants assess signals from the market and also allowed companies to take out insurance against unanticipated price movements, i.e., to hedge. The futures market often overreacts, often exaggerates trends, and frequently actually moves in illogical directions given the information at hand, but it also corrects itself rapidly. A short spike or trough in the futures market is better than a multiyear disequilibrium in the price of actual crude deliveries.

It is worth noting that the OPEC nations refused for many years to recognize the relevance of the futures markets, but this changed dramatically when Saudi Aramco based its crude prices to North America on the New York Mercantile Exchange (NYMEX) West Texas Intermediate (WTI) contracts and its prices to Europe on InterContinental Exchange (ICE) Brent contracts. (This has changed recently as the crude situation in the US has shifted. WTI is now severely underpriced relative to the world market, and the Saudis have adopted pricing to North America on the basis of the Argus Sour Crude Index.) Although the Dubai Mercantile Exchange (DME) was established in 2007 trading contracts on the average of Dubai plus Oman prices, Saudi Aramco continues to price its exports to Asia as a premium over Dubai (which amounts to only 60,000 barrels/day of crude) rather than on the DME futures price. 
In understanding the role of futures markets, it is important to distinguish between commercial and noncommercial participants. Commercial participants are in the oil business and take positions in the futures market to hedge against physical trades and decisions they are making in the real world. (In some cases, they are also acquiring oil for delivery through the futures exchange, but this is a tiny fraction of the total number of contracts.) There is no question that the futures market provides a vital function for them. Noncommercial participants are investors who are not using the futures market to procure or hedge oil supply. In some cases they are seeking to use oil as a hedge against exposure in other areas; in some cases they are simply speculating hoping to profit by predicting which way the market will move. Speculators have a bad image, but they provide a critical element in the futures market: financial liquidity. For every futures contract sold, there must be a counterparty to buy it; noncommercial participants increase the number of potential counterparties. Since speculators are also more inclined to turn their contracts over rapidly seeking better positions, they add to the overall liquidity of the market.

In the US, there were limits on the involvement of noncommercial participants until 2000 when changes in the laws allowed a much greater degree of noncommercial involvement. Prior to 2000, noncommercial contracts on NYMEX stayed below $30 \%$ of the total; at the time of the large oil-price spike in 2008, noncommercial contracts on NYMEX soared to about $55 \%$ of the total. The correlation has led to claims that speculation caused or at least sharply accentuated the 2008 price spike. Medlock and Jaffe (2009) suggest that measures should be enacted to return noncommercial participants to lower levels. Others point out that although prices promptly fell in the 2009 recession, they rapidly climbed again in 2010 and 2012 suggesting that the high prices of 2008 were driven by market fundamentals that were temporarily undermined by the financial conditions of 2009 (Jickling, Millar, and Nerurkar 2011). This issue is still a topic of ongoing debate and research.

\section{The EIA Energy and Financial Markets Initiative}

By 2009, claims and counterclaims about the role of the futures market in avoiding or creating market distortions had become heated. At this time, Richard Newell, the new EIA Administrator, announced the Energy and Financial Markets Initiative with goals under four headings.

- Expanded collection and publication of data. The traditional EIA data gathering efforts have been supplemented with other data to increase market transparency. The goal is to fill in the gaps between physical market conditions and the movements of energy prices in financial markets and to make information on market fundamentals more widely available.

- New analytical reports. In the EIA's own words, the goal of this effort is to “... develop analytical reports that identify the many factors potentially 
influencing oil and other energy prices - including consumption, production, inventories, spare production capacity, geopolitical risks, speculation, hedging, investment, and exchange rates - and describe the relationship of these factors to prices, the timeframes over which these relationships tend to hold, and the mechanisms underlying them" (Commodities Now 2009). This rather sweeping agenda also will feed into existing price forecasts by attempting to quantify uncertainty bands around forecast numbers.

- Outreach efforts. The twin goals of this effort are to assemble panels of experts on the relationship between energy and finance and also to make the results of studies on the topic available to the public including to investors.

- Interdepartmental coordination. The EIA has established working relationships with the Commodity Futures Trading Commission, the Department of the Treasury, the Federal Energy Regulatory Commission, the Federal Reserve, the Federal Trade Commission, and the Securities and Exchange Commission.

This initiative should be understood as both a research effort and as a tool for increasing market transparency as transparency is critical to the efficient functioning of a futures market.

To date, the main results have been a number of new publications and data services as well as some collaborative research efforts. A good deal of academic research on the 2008 price spike has also been sponsored, but no definitive conclusions have been reached. There is some evidence that it was driven by market fundamentals, but there are also suggestions that the trends in the market fundamentals may have helped create a "bubble" in the price (Newell 2011).

Additional research should help to clarify these matters, but the emerging consensus is that although futures markets may contribute to very short-term price volatility, they are incapable of creating persistent price changes. Put another way, without a futures market, prices might not rise quite as high, but they also might stay high longer. Speculators are not a group with a common objective; one may attempt to move the market higher but another will be acting to move it lower.

\section{Oil futures markets in Asia as an instrument for security}

For crude oil buyers or sellers or for refiners, futures markets are a fundamental form of insurance; hedging is a way of buying a fallback position on tactical moves in the market and limiting losses. For Asia, the problem with the NYMEX and ICE futures markets as they stand is that they are ultimately so thin and so distantly related to the markets they serve. A Japanese refiner taking positions in WTI and Brent is buying some insurance against movements in prices in his own crude slate, but major futures markets operating locally based on crudes of interest in the region would be much more useful.

The DME Dubai/Oman contract does offer a logical alternative to NYMEX WTI or to ICE Brent. As discussed before, almost all Middle Eastern oil moves 
to Asia, so a futures contract based on two Middle Eastern crudes with long histories of spot trading offers an important option for buyers in Asia who wish to hedge their exposures. Although the DME has been successful and is now firmly established, it is a puzzle that it has not become a rival in size to NYMEX or ICE. After all, the Middle East-to-Asia oil trade is now the largest oil flow in the world. DME is dominated by physical trade compared to NYMEX or ICE where paper trade is the rule. Companies in Asia should be encouraged to use DME to hedge as its connection to the Asian market is direct while Brent is distant and WTI is at least for a few years disconnected from the world oil market.

There is a larger question here than individual company hedging, however. In November of 2012, Japan announced plans to open a futures market in LNG by 2014. LNG buyers seldom need to hedge. Contracts run for long terms and are very specific, usually take-or-pay with tight ranges of volume, so opportunities for hedging are limited. Japan is hoping to create a real market in LNG, one in which the futures price will create a market indicator that sellers cannot ignore when offering contracts.

One contribution NYMEX and ICE futures markets have made is to provide public, open price benchmarks. The prices may be volatile, but the sheer number of transactions means that they are not subject to manipulation (as opposed to certain thin spot markets). Once a futures market is established and trading at a high rate, it becomes difficult for sellers to ignore. DME has not crossed this threshold. Rather than setting prices for the region, it is still a place where buyers go to procure physical crude.

It is both amusing and disturbing that the NYMEX WTI contract is no longer a market indicator and in Asia, the largest oil market, there is no established, highly traded market indicator. The only price clarity is provided by the ICE Brent contract - a group of crudes produced on the other side of the world. A major futures market east of Suez would have many benefits, but one of the biggest would be to establish Asian-driven pricing that would help control pricing behavior and link it to a market large enough that manipulation would be impossible. The DME seemed to hold out this promise and may still work at that level but not until paper trades rather than wet barrels play a major role.

If the DME can't succeed as a market indicator - and that remains to be seenwhat other possibilities are there? The only crude with the volume and potential to step into this role is the Russian Federation's Eastern Siberia-Pacific Ocean (ESPO) pipeline crude. This is a crude oil with an increasing volume of exports into East Asia that is lower in sulfur than many and therefore arguably a better match to Asian crudes, though not to Asian crude imports.

ESPO is a possible basis for a futures market, but there are many unresolved questions about how such a market would be structured. The way ESPO is priced today, most of the contracts are based on Dubai and Murban-two Middle Eastern crudes. In any case, a futures market price east of Suez would greatly improve clarity in Asian oil pricing. It matters little whether the basis is DME, or ESPO, or both. The problem is not the basis of the contract-Dubai and Oman are perfect representatives of Asian imports - the problem is that importing 
companies in Asia have chosen not to use the DME for hedging, and noncommercial participants are still on the sidelines.

\section{Summary of policy recommendations}

\section{Oil product subsidies}

In general, overall price subsidies are less of a problem in Asia today than in past as many of the most egregious issues have been addressed. Pricing levels still, however, remain a challenge in some economies. A more subtle problem is differential pricing among different fuels as it often creates unpredicted distortions. If social welfare is the goal, oil-pricing policies are a very crude tool. Pricing above external-market levels can have adverse effects if carried too far, but pricing above the external market can also have benefits in terms of supporting the development of other resources and slowing the growth in demand for oil.

\section{Oil stockpiles and oil-sharing arrangements}

Oil stockpiles are a useful cushion against extreme fluctuations in the market; in fact, keeping low levels of stock might even be characterized as bad business practice. The big threat in today's market is not targeted cutoffs of oil supplies as this is no longer a practical proposition. Today the problem is one of price spikes, and there is no doubt that strategic reserves can help counter them.

To date, however, strategic oil reserves have not generally been used to their full potential. In the Republic of Korea, the borrow-and-repay option is an excellent union of national strategy and tactical considerations, and the concept of allowing major exporting countries to store oil locally is one that could enhance oil security while offering commercial advantages. The concept in Japan of allowing other countries to participate in their national strategic oil reserve is also important. Regional or multi-country reserves may make more sense than national stockpiling.

There is nothing wrong with oil-sharing agreements, but the problem that they anticipate - the cutoff of supply to a single country - is improbable in today's market. Such agreements are still useful in the event of natural disasters, and some sort of oil-sharing or drawdown agreement needs to be in place for sharing centralized tanks.

\section{Unconventional gas}

The gas supply is perhaps the greatest unknown in future Asian oil demand. It is to everyone's benefit to characterize Asia's unconventional gas and potential shale liquid resources as soon as possible.

\section{Refining configuration}

Most Asian refineries are poorly equipped to deal with the super-heavy crudes of the Americas - the largest remaining undeveloped oil resources. This does not 
mean that there should be a regional policy initiative on refining, but crude exports from the Middle East and Africa will not be sufficient to cope with growing demand.

\section{Harmonization of product specifications}

Oil cannot flow freely when there are differing product specifications; fungibility would be greatly increased if there were some degree of standardization. This does not mean that every country must adopt a uniform set of specifications, but it should be possible to agree on where limits are needed.

\section{Overseas investment and trading}

Overseas investment and trading by Asian companies are sometimes advocated as a way of obtaining dedicated oil resources. There are many other potential benefits. Overseas expansion by Asian oil companies should be encouraged to enhance energy security.

\section{Consumer-producer dialogue}

Asia now consumes about $76 \%$ of all Middle Eastern oil exports, yet Asian buyers pay premiums. The time may be ripe to have a multilateral discussion on terms and guarantees. Obviously a discussion with all buyers is not practical, but if even a few of the largest buyers (the PRC, India, Japan, and the Republic of Korea) opened a dialogue, there could be room for reducing uncertainty on both sides of the table. Furthermore, although it is a delicate issue, the security of Middle Eastern exporters is now more important to Asian importers than to the US. This issue has not been widely recognized, but it is reaching a stage where it needs to be discussed.

\section{Futures markets east of Suez.}

Futures markets have transformed how business is done in oil, but there is not yet a benchmark futures market east of Suez. The DME is up and running, yet it hasn't become a touchstone for pricing or even hedging because there aren't enough paper transactions. Even though Dubai and Oman are excellent representatives of Asian imports from the Middle East, the DME is still underused. There are options for other futures markets such as ESPO; the problem is not the crude basis but that trading on those markets remains underdeveloped. The result is that events in the North Sea affect Asian prices more than dynamics within Asia do. Rather than fearing the futures markets, Asian governments should be encouraging companies to use them for hedging. Whether it is DME, or ESPO, or both, flourishing futures markets in Asia would help to ensure fair pricing and to moderate long-term price fluctuations.

Asia is already the world's largest oil-importing region, larger than North America and Europe combined. In any scenario, this disproportionate role seems 
bound to increase which will make Asia a region increasingly dependent on oil imports and will make oil security a prominent economic and political issue. With this great dependency, however, comes a massive increase in market power. Asia is now the center of the world oil market, but the world - and Asia-have yet to realize it.

\section{References}

Asian Development Bank (ADB). 2013. Asian Development Outlook: Asia's Energy Challenge. Manila: ADB.

Bamberger, C. 2004. IEA: The First 30 Years, Volume 4. Paris: Organisation for Economic Co-operation and Development (OECD)/International Energy Agency.

Bastiani, P., J. Heywood, and C. Hope. 2012. US CAFE Standards: Potential for Meeting Light-Duty Vehicle Fuel Economy Targets, 2016-2025. Cambridge, MA: MIT Energy Initiative. http://web.mit.edu/sloan-auto-lab/research/beforeh2/files/CAFE_2012.pdf (accessed February 2014).

British Petroleum (BP). 2012. BP Statistical Review of World Energy, 2011. London: BP. http://www.bp.com/statisticalreview (accessed February 2014).

Bullis, K. 2012. Shale Oil Will Boost US Production, but it Won't Bring Energy Independence. MIT Technology Review. 15 November. http://www.technologyreview.com/ news/507446/shale-oil-will-boost-us-production-but-it-wont-bring-energy-independence/ (accessed February 2014).

Burns, J. 2012. Natural Gas in Transport: Tomorrow's Fuel Today. Presentation at the 17th International Conference and Exhibition on Liquefied Natural Gas (LNG 17). Houston. 16-19 April. http://www.gastechnology.org/Training/Documents/LNG17proceedings/7-5-James_Burns_354.pdf (accessed February 2014).

Chung, J. 2013. Asian Petrochemical Feedstock Market Outlook. Paper presented at LPGC Japan 2013 Exchange Seminar. Tokyo. 31 January. http://www.lpgc.or.jp/corporate/ exchange/seminar2013presentation/9_jiwon_chung_opis.pdf (accessed February 2014).

Commodities Now. 2009. EIA Launches Energy and Financial Markets Initiative. 9 September. http://www.commodities-now.com/news/power-and-energy/655-eia-launchesenergy-and-financial-markets-initiative.html (accessed February 2014).

Deal, A. 2012. What Set of Conditions Would Make the Business Case to Convert Heavy Trucks to Natural Gas? A Case Study. Tulsa, OK: National Energy Policy Institute. http://nepinstitute.org/publications/what-set-of-conditions-would-make-the-business-caseto-convert-heavy-trucks-to-natural-gas- $\%$ e $2 \% 80 \% 93$-a-case-study/ (accessed February 2014).

Eilperin, J. and S. Mufson. 2012. Obama Administration Rejects Keystone XL Pipeline. Washington Post. 18 January. http://articles.washingtonpost.com/2012-01-18/national/ 35440450_1_keystone-xl-kerri-ann-jones-oil-sands

FACTS Global Energy (FGE). 2012a. Spring 2012 Asia-Pacific Oil Databook I: Supply, Demand, and Prices. London: FGE.

—. 2012b. Fall 2012 Asia-Pacific Oil Databook I: Supply, Demand, and Prices. London: FGE.

- 2012c. FGE Databook Database System. London: FGE.

- 2012d. Fall 2012 Asia-Pacific Oil Databook III: Refinery Configuration and Construction London: FGE.

Frankel, P. 1946. Essentials of Petroleum. New York: Frank Cass and Company. 
Government of the United States, Energy Information Administration (EIA). 2009. How Much Does it Cost to Produce Crude Oil and Natural Gas? EIA Online November review. http://www.eia.gov/tools/faqs/faq.cfm?id=367\&t=5 (accessed February 2014).

—. 2012. Annual Energy Outlook, 2012. http://www.eia.gov/forecasts/archive/aeo12/ (accessed February 2014).

—. 2013. US Exports of Crude Oil and Petroleum Products. EIA Online. http://www.eia. gov/dnav/pet/pet_move_exp_dc_NUS-Z00_mbblpd_a.htm (accessed February 2014).

Government of Canada, National Energy Board (NEB). 2011. Canada's Energy Future: Energy Supply and Demand Projections to 2035. http://www.neb-one.gc.ca/clf-nsi/ rnrgynfmtn/nrgyrprt/nrgyftr/2011/nrgsppldmndprjctn2035-eng.html (accessed February 2014).

Hook, L. 2011. Asia Moves to Shore Up Strategic Oil Reserves. Financial Times. 2 March. http://www.ft.com/cms/s/0/7fec8ae8-44fe-11e0-80e7-00144feab49a.html\# axzz2gWKNfatN (accessed February 2014).

International Energy Agency (IEA). 2008. IEA World Energy Outlook 2008. Paris: Organisation for Economic Co-operation and Development (OECD)/IEA.

—. 2012a. Energy Balances of OECD Countries. Paris: Organisation for Economic Co-operation and Development (OECD)/IEA.

—. 2012b. Energy Balances of Non-OECD Countries. Paris: Organisation for Economic Co-operation and Development (OECD)/IEA.

- 2012c. IEA World Energy Outlook 2012. Paris: Organisation for Economic Co-operation and Development (OECD)/IEA. http://www.worldenergyoutlook.org/ publications/weo-2012/ (accessed February 2014).

- 2012d. Energy Statitics of OECD Countries. Paris: Organisation for Economic Co-operation and Development (OECD)/IEA.

- 2012e. Energy Statistics of Non-OECD Countries. Paris: Organisation for Economic Co-operation and Development (OECD)/IEA.

- 2013. Oil Information 2013. Paris: Organisation for Economic Co-operation and Development (OECD)/IEA.

International Energy Forum (IEF). 2012. IEF Introductory Paper. IEA-IEF-OPEC Symposium on Energy Outlooks. Riyadh. 23-24 January. http://www.ief.org/_resources/ files/events/2nd-iea-ief-opec-symposium-on-energy-outlooks/introductory-paper.pdf (accessed 31 March 2014).

Jickling, M, R. Millar, and N. Nerurkar. 2011. Speculation, Fundamentals, and Oil Prices. Washington, DC: Congressional Research Service. http://www.hsdl.org/?view\&did= 718960 (accessed February 2014).

Kang, D. and J. Lee. 2007. Japan- [Republic of] Korea Relations: Treading Water, Little Progress. Comparative Connections. 9 (2). pp. 147-157. http://csis.org/files/media/csis/ pubs/0702qjapan_korea.pdf (accessed February 2014).

Kelley-Detweiler, P. 2012. Acceleration of the Natural Gas Highway. Forbes. 13 November. http://www.forbes.com/sites/peterdetwiler/2012/11/13/acceleration-of-the-natural-gashighway/ (accessed February 2014).

Kootungal, L. 2012. 2012 Worldwide Refining Survey. Oil and Gas Journal. 110 (12).

Mackenzie, K. 2012. Marginal Oil Production Costs are Heading Toward \$100/Barrel. Financial Times—FT Alphaville. 2 May. http://ftalphaville.ft.com/2012/05/02/983171/ marginal-oil-production-costs-are-heading-towards-100barrel/? (accessed February 2014).

Marasigan, F. and P. Isla. 2011. Oil-Sharing Deals Pitched for Philippines. Business Mirror. 3 March. http://www.abs-cbnnews.com/business/03/06/11/oil-sharing-dealspitched-philippines (accessed February 2014). 


\section{David Isaak}

Medlock, K. and A. Jaffe. 2009. Who is in the Oil Futures Market and How Has it Changed? Houston, TX: Rice University, Baker Institute for Public Policy.

Meech, R. 2010. Emission Control Areas (ECAs). Presentation at the International Maritime Organization Regional Workshop on the Ratification and Implementation of Marpol Annex VI. Athens. 26-27 October. http://www.euromedtransport.eu/Fr/image. php?id=2174 (accessed February 2014).

Newell, R. 2011. Energy and Financial Markets Overview: Crude Oil Price Formation. IEA presentation to the American Society of Petroleum Engineers, Capital Section. Washington, DC. 23 February. http://www.eia.gov/pressroom/presentations/newell_ 02232011.pdf (accessed February 2014).

Nicholas, F. 2009. ASEAN Energy Cooperation: An Increasingly Daunting Challenge. Paris: Institut Francais des Relations Interantionales (Ifri). http://www.ifri.org/?page= contribution-detail\&id=5481\&id_provenance $=103 \&$ provenance_context_id=16.\&style= big\&lang=uk (accessed February 2014).

Platts. 2013. Shell proceeds with FEED for LNG import facility in Philippines. Platts Oilgram News. 2 July. http://www.platts.com/latest-news/natural-gas/singapore/shellproceeds-with-feed-for-lng-import-facility-27146929 (accessed February 2014).

Warwick, G. 2012. LNG Propulsion: A Cool Idea? Aviation Week Online. 19 March. http://www.aviationweek.com/Blogs.aspx?plckBlogId=Blog:a68cb417-3364-4fbf-a9dd4feda680ec9c\&plckPostId=Blog\%3Aa68cb417-3364-4fbf-a9dd-4feda680ec9cPost $\%$ 3A00f49124-7f6b-4fec-9bdb-fae7095ba3b1 (accessed February 2014).

World Bank. 2013a. World Bank Development Indicators Database Online. http://data. worldbank.org/indicator/EP.PMP.SGAS.CD (accessed 31 January 2013)

- 2013b. Commodity prices have weakened in response to new capacity. World Economic Prospects. Washington, DC. World Bank. http://web.worldbank.org/WBSITE/ EXTERNAL/EXTDEC/EXTDECPROSPECTS/EXTGBLPROSPECTSAPRIL/0, contentMDK:23419347 menuPK:9210356 pagePK:2470434 piPK:4977459 theSite PK:659149,00.html (accessed February 2014). 


\title{
3 Energy security, sustainability, and affordability in Asia and the Pacific
}

\author{
Norberto Fueyo, Antonio Gómez, and \\ César Dopazo
}

\section{Introduction}

Energy security is a multifaceted concept that is often used as an umbrella term encompassing the interconnected aspects of an energy policy. Sovacool (2012) defines it as “... equitably providing available, affordable, reliable, efficient, environmentally benign, proactively governed, and socially acceptable energy services to end users" and further defines four "interconnected criteria or dimensions": availability, affordability, efficiency, and stewardship. Vivoda (2010) proposes an energy security assessment instrument comprising 11 dimensions and 44 attributes. In consultation with dozens of experts in Asia and elsewhere, Sovacool (2011) has identified 20 dimensions. Scheepers et al. (2006) note the need to develop security supply standards for the European Union and its members and suggest a model that includes two quantitative indicators - the supply/ demand index and the crisis capability index - and some qualitative considerations. Supply/demand includes final energy demand, production, and transport and primary energy supply. Crisis capability combines the risk of supply interruptions with the capability to overcome them. In both cases, the indexes are quantitative, but they combine objective information (such as energy balances or checklists) with subjective information (weighing factors, scoring rules). They can be combined via simple addition (whether weighted or not) into a single security of supply index.

In this chapter, energy security means self-sufficiency and diversification, energy sustainability means energy efficiency and low carbon emissions, and energy (electricity) affordability is measured as the ratio of the cost of electricity to per capita income. Security thus corresponds with Sovacool's availability, and sustainability combines his dimensions of efficiency and stewardship (protecting the natural environment, communities, and future generations). This definition of security may be regarded as narrow as diversification is used as a proxy for resilience or resistance to shocks, but it is purely for the purpose of quantification; wider definitions are also justified. 
We calculate energy security, sustainability, and affordability from 2010 to 2035 for Asian Development Bank (ADB) Asian and Pacific members using projections from the ADB business-as-usual (BAU) scenario (ADB 2003) for five indicators: primary energy intensity (PEI), carbon dioxide $\left(\mathrm{CO}_{2}\right)$ intensity of the primary energy mix (CIX), energy self-sufficiency (ESS), the affordability of electricity (EOL), and primary energy diversification (DIV). These indicators have a number of key properties:

- They are quantitative because qualitative information is usually not objective, increases uncertainty, and may sacrifice credibility.

- They are simple because it is easier to understand a simple indicator than to trust a complex one.

- They are equally applicable to economies for which a wealth of public data on their energy sectors (past, present, or future) exists and to those for which owing to their size or other circumstances public data are scarce.

- They allow for comparisons among economies and over time.

- They are easy to aggregate regionally to show the effects of integration.

- For consistency with other chapters, they largely rely on data provided by ADB (ADB 2013).

The calculations for the indicators appear in the next section.

We then assess the potential benefits of integrating the energy systems regionally and compare the indicators for Asia and the Pacific with those for Africa, Europe, Latin America, the Middle East, North America, and the Russian Federation. Our final analysis compares the BAU scenario, the Asian Century (ACS; Kohli, Sharma, and Sood 2011) coupled with the BAU scenario, and the Asian Century/alternative scenario in 2035. We offer conclusions and policy recommendations at the end of the chapter.

\section{Indicators}

\section{Primary energy intensity}

The PEI in year $t\left(P E I_{t}\right)$ is the primary energy demand (PED) in year $t\left(P E D_{t}\right)$ divided by the gross domestic product (GDP):

$$
P E I_{t}(\text { Toe } / \$ 1000)=P E D_{t} / G D P_{t}
$$

where Toe is tons of oil equivalent. Projections for PED and GDP from 2010 to 2035 are from ADB (2013).

\section{Carbon dioxide intensity of the primary energy mix}

The CIX is a measure of the environmental impact of the energy sector and is calculated as the $\mathrm{CO}_{2}$ emissions from fossil fuels $\left(\mathrm{CO}_{2 t}\right)$ divided by PED $\left(P E D_{t}\right)$ : 


$$
C I X_{t}\left(\mathrm{TCO}_{2} / \mathrm{Toe}\right)=\mathrm{CO}_{2 t} / P E D_{t}
$$

where $\mathrm{TCO}_{2}$ is tons of $\mathrm{CO}_{2}$.

Projections for $\mathrm{CO}_{2}$ emissions and PED from 2010 to 2035 are from ADB. Note that the $\mathrm{CO}_{2}$ emission intensity of an economy (CEI) can be calculated as the product of $P E I_{t}$ and $C I X_{t}$ :

$$
C E I_{t}\left(\mathrm{TCO}_{2} / \$ 1000\right)=P E I_{t} \times C I X_{t}
$$

\section{Energy self-sufficiency}

The ESS indicator $\left(E_{S S}\right)$ gauges the energy independence of a country or region. A value of 1 means it can meet all of its PED with indigenous resources while a 0 indicates complete reliance on energy imports. The index takes into account that the infrastructure to produce and transport energy takes many years to plan and develop.

The index is calculated as follows:

$$
E S S_{t}=\sum_{r}^{P} x_{r, t}+\sum_{f}^{N} x_{f, t} F_{f, t}\left\{\begin{array}{l}
\text { if } \frac{R_{f, t}}{C_{f, t}}>T, \\
\text { if } 1<\frac{R_{f, t}}{C_{f, t}}<T,
\end{array}\right.
$$

where

- $\quad x_{r, t}$ is the share of renewable energy sources $r$ (hydro, wind, solar) in primary energy consumption in year $t$;

- $x_{f, t}$ is the share of conventional fuel $f$ (coal, oil, gas, and nuclear) in primary energy consumption in year $t$;

- $\quad P$ is the number of renewable resources, and $N$ is the number of conventional ones;

- $\quad R_{f, t}$ are the national reserves of fuel $f$ in year $t$;

- $C_{f, t}$ is the primary energy consumption of fuel $f$ in year $t$;

- $\quad F_{f, t}$ is a security factor that depends on the reserves to consumption ratio for fuel $f$ in year $t$ (see below);

- $\quad T$ is the typical timescale (in years) required to change the energy consumption structure of an economy.

The factor $F_{f, t}$ compares the reserves for fuel $f$ with annual consumption; if reserves will last longer than $T$ years, their contribution to security is 1 ; between $T$ years and 1 year, the factor $F_{f, t}$ is employed to decrease the contribution to 0 if reserves will last less than 1 year. The timescale $T$ is taken as 10 years. 
The national reserves of fuel $f$ in year $t, R_{f, t}$, are calculated as:

$$
R_{f, t}=R_{f, t 0}-\sum_{t 0}^{t-1} C_{f, t}
$$

where $R_{f, t 0}$ are the national reserves of fuel $f$ in the base year (2010).

Reserves decrease using the consumption rate, not the production rate, and do not account for exports. There are several reasons for this. From a practical standpoint, exports are impossible to forecast accurately, and estimating export levels is feasible but controversial, particularly in the long term. From a conceptual viewpoint, exports offer some compensation in exchange for the future loss of self-sufficiency.

Projections for the share of renewable and conventional fuel sources $\left(x_{r, t}, x_{f, t}\right)$ and the primary energy consumption of fuel $f$ in year $t$ were obtained from ADB. National reserves in the base year 2010 are from the United States Energy Information Administration (EIA 2013).

\section{Primary energy diversification}

The DIV indicator $\left(D I V_{t}\right)$ measures the degree of diversification of energy sources. When all primary energy is from one source the DIV is 0 ; when energy comes equally from all primary sources considered (coal, oil, gas, nuclear, hydro, and others ${ }^{1}$ ) it is 1 . It is calculated as:

$$
D I V_{t}=-\frac{\sum_{i=1}^{N} x_{y, t} \ln x_{y, t}}{\ln N}
$$

where

- $\quad x_{y, t}$ is the share of energy source $y$ in primary energy consumption in year $t$;

- $\quad N$ is the number of energy sources considered (coal, oil, gas, nuclear, hydro, and others).

The same equation is used to calculate power (electricity) sector diversification.

Projections for the share of energy source $y$ were calculated from ADB.

\section{Affordability of electricity}

The affordability indicator for electricity is the fraction of per capita GDP that a household must spend to buy a fixed amount of electricity (e.g., 1,000 kilowatt hours per capita per year). Actual electricity consumption is not constant across economies but is highly correlated with GDP per capita. This is partly indicative of an affordability constraint: consumers buy the electricity or the equipment to use it that they can afford. This constraint is relaxed by using a constant amount of electricity across economies to obtain a metric that renders a fair comparison of affordability.

\footnotetext{
${ }^{1}$ This is the "others" category in ADB which encompasses renewables.
} 
The cost of electricity is assessed using either tariffs for households or the (estimated) levelized electricity cost (LEC). The indicator for the affordability of electricity based on tariffs (EOT) is defined as:

EOT $(\%)=$ Cost of 1000 kilowatt hours at household prices $/$ GDP per capita

where the household tariffs are those prevailing for electricity consumption under 100 kilowatt hours/month. These tariffs were collected from several sources (Fueyo, Gómez, and Dopazo 2013).

Because tariffs cannot be forecast, the EOT indicator cannot be used for the future. The expected electricity outlay based on LEC (EOL) is therefore calculated as:

$$
E O L_{t}(\%)=1000 \text { kilowatt hours } \times L E C_{t} / G D P \text { per capita }{ }_{t}
$$

where $L E C_{t}$ is the levelized electricity cost (2010 \$/kilowatt hour) for an economy (or region) in year $t$.

The LEC is calculated using the following equation:

$$
L E C=\sum_{i=1}^{N} x_{i}\left[\frac{a_{i} I_{i}}{F C_{i} \cdot 8760}+O M_{i}+\frac{P_{i} \cdot 0.0036}{\eta_{i}}\right]
$$

where:

- $\quad x_{i}$ is the share of technology $i$ (coal, oil, natural gas, nuclear, hydro, and renewables) in the total electricity generation of an economy/region;

- $a_{i}$ is the amortization factor of technology $i$, defined by $a_{i}=r \frac{1}{1-(1+r)^{-N_{i}}}$, where $r$ is the interest rate and $N_{i}$ is the lifetime of the technology (years);

- $\quad I_{i}$ is the capital or investment cost for technology $i$ (2010 \$/kilowatt);

- $\quad F c_{i}$ is the capacity factor of technology $I$;

- $O M_{i}$ is the operation and maintenance cost of technology $i(2010$ \$/kilowatt hour);

- $\quad P_{i}$ is the fuel price for technology $i$ (2010 \$/gigajoule). National fuel prices are used until the national fuel reserves for technology $i$ are depleted, then international fuel prices are used;

- $\quad \eta_{i}$ is the efficiency of technology $i$.

The GDP per capita for each economy in 2012 is from the International Monetary Fund (IMF 2013). For 2035, GDP is calculated as:

GDP per capita $\left.\right|_{2035}=$ GDP per capita $\left.\right|_{2012} \times(1+\text { GDP per capita growth }(\%))^{23}$

where GDP per capita growth (\%) is the annual average per capita growth from 2012 to 2035 reported in ADB. For regions, the GDP per capita is calculated by aggregating national GDPs and dividing by the regionally aggregated population.

The data for each technology $i$ (investment costs, capacity factors, operation, and maintenance costs) and on the trends in fuel prices (coal, oil, natural gas) are from several well established references. 


\section{Indexes from 2010 to 2035}

We computed the indicators from 2010 to 2035 for ADB Asian members using the projections for macroeconomic and energy parameters from the ADB BAU scenario.

\section{Energy sustainability}

The sustainability of a national energy system is measured using PEI which summarizes the energy efficiency of the economy as a whole, and CIX which indicates the environmental performance of the energy system. In general, the energy efficiency of an economy increases as it develops, thus the PEI in most will decrease usually by more than $20 \%$ from 2010 to 2035 (Figures 3.1, 3.2, and 3.3). Those with the highest intensities in 2010 (Figure 3.1) will experience the most dramatic improvements, e.g., Bhutan, the People's Republic of China (PRC) Myanmar, Turkmenistan, and Uzbekistan. Noteworthy exceptions to this are the Kyrgyz Republic and Mongolia (Figure 3.3).

Remarkably, the CIX will increase in most economies from 2010 to 2035 (Figures 3.4, 3.5, and 3.6) as the environmental performance of their energy systems deteriorates. In less developed countries, fossil fuels will increasingly displace traditional, carbon-neutral fuels such as biomass and agricultural residues which offers certain advantages (dependability and better indoor environments) but increases net $\mathrm{CO}_{2}$ emissions. The CIX decreases moderately in the developed group (Australia, Japan, and New Zealand) from 2010 to 2035 (Figure 3.6). The Republic of Korea has the largest reduction at $20 \%$ due to greater use of $\mathrm{CO}_{2}$-free sources such as nuclear and renewables, but it is nevertheless small; the main contribution to the overall reduction in $\mathrm{CO}_{2}$ emissions comes from improvements in PEI.

Trends in both indicators are graphed in Figure 3.7; the named end of each curve indicates the likely position in 2035 while the opposite end marks the situation in 2010. Economies moving towards the lower left-hand corner of the graph exhibit the sought-after behavior of decreasing both their PEI and CIX, but the trajectories in Figure 3.7 reflect a large decrease in PEI and a significant increase or only a moderate decrease in CIX. For example, Uzbekistan will substantially improve its energy efficiency by decreasing its PEI from 2.3 Toe/\$million in 2010 to about 0.6 Toe/\$million in 2035; however, the curve is nearly vertical, indicating little change in the CIX. In Bangladesh, on the other hand, energy intensity decreases slightly while the CIX increases substantially.

\section{Energy security}

ESS will notably decrease in Central Asia in the BAU scenario (Figure 3.8). In 2010, the indicators in almost all members were greater than 0.7 (Figure 3.9) but will be less than 0.5 in 2035 for the majority (Figure 3.10). This means that in 2035 , domestic resources will meet less than 50\% of annual energy needs (based on 2010 fuel reserves and not accounting for exports). Especially relevant is energy security in Uzbekistan which will deteriorate because of the depletion of its gas reserves. 


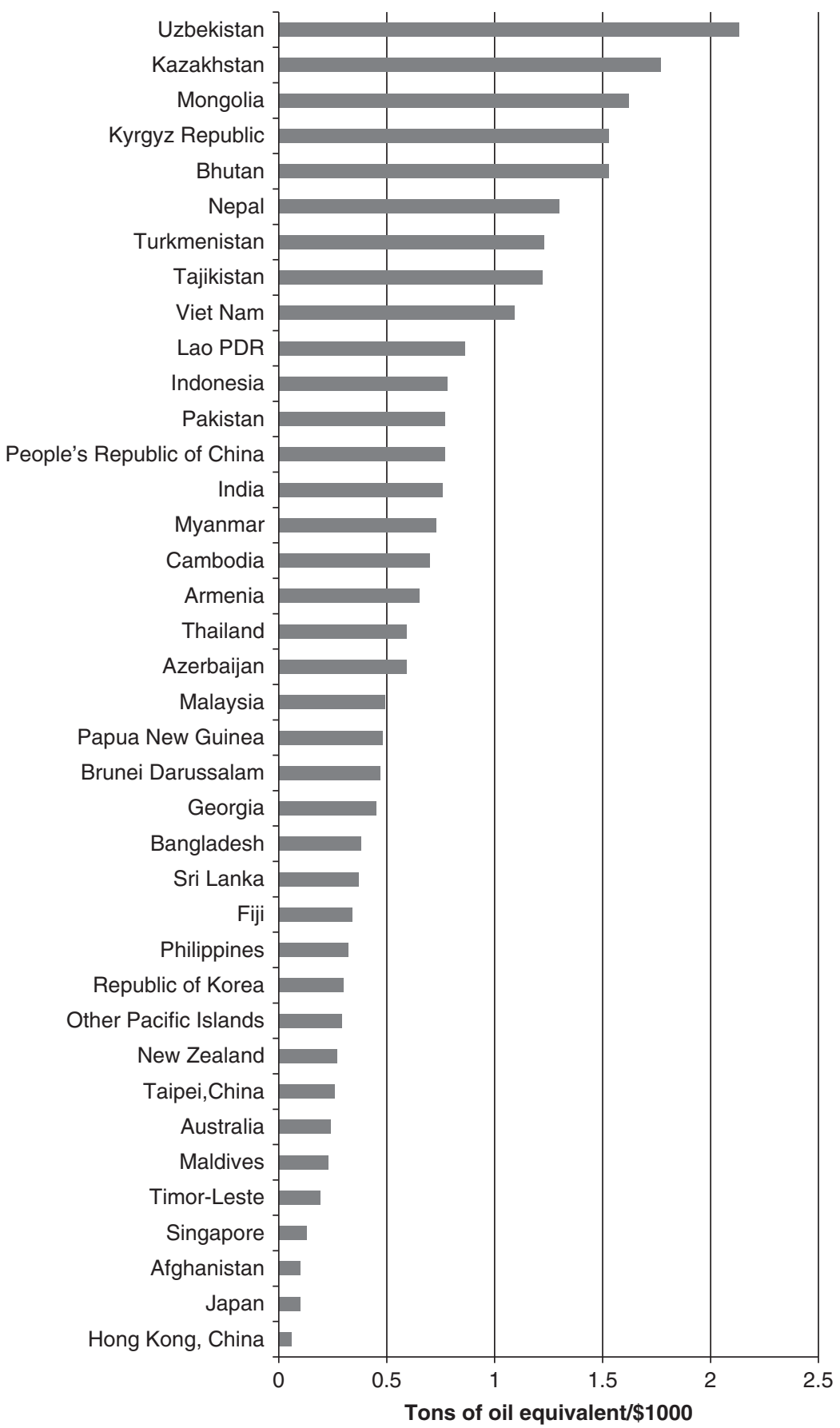

Figure 3.1 Primary energy intensity in 2010

Source: Authors' calculations with data from ADB (2013).

Note: Lao PDR = Lao People's Democratic Republic. 


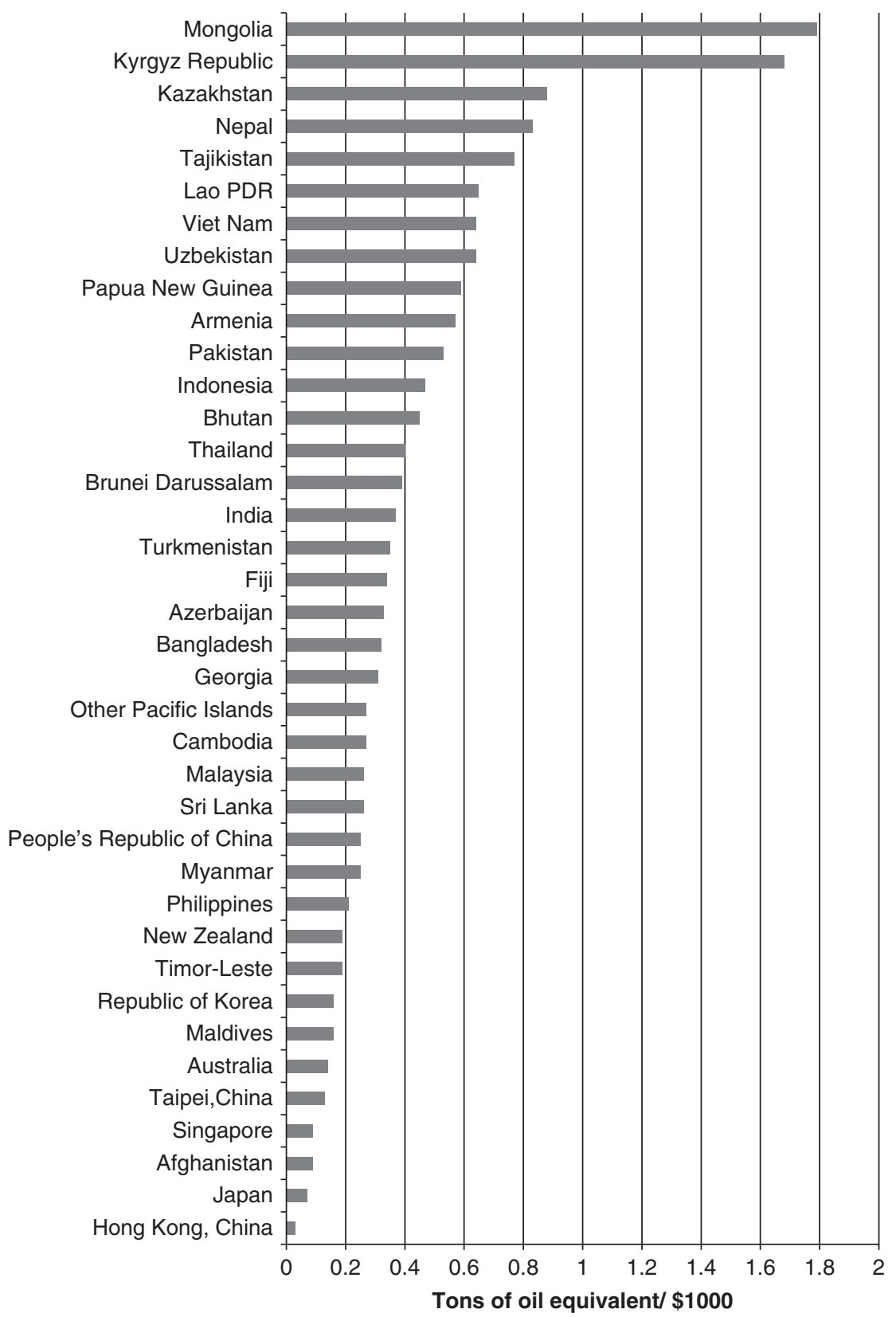

Figure 3.2 Primary energy intensity in 2035

Source: Authors' calculations with data from ADB (2013).

Note: Lao PDR = Lao People's Democratic Republic. 


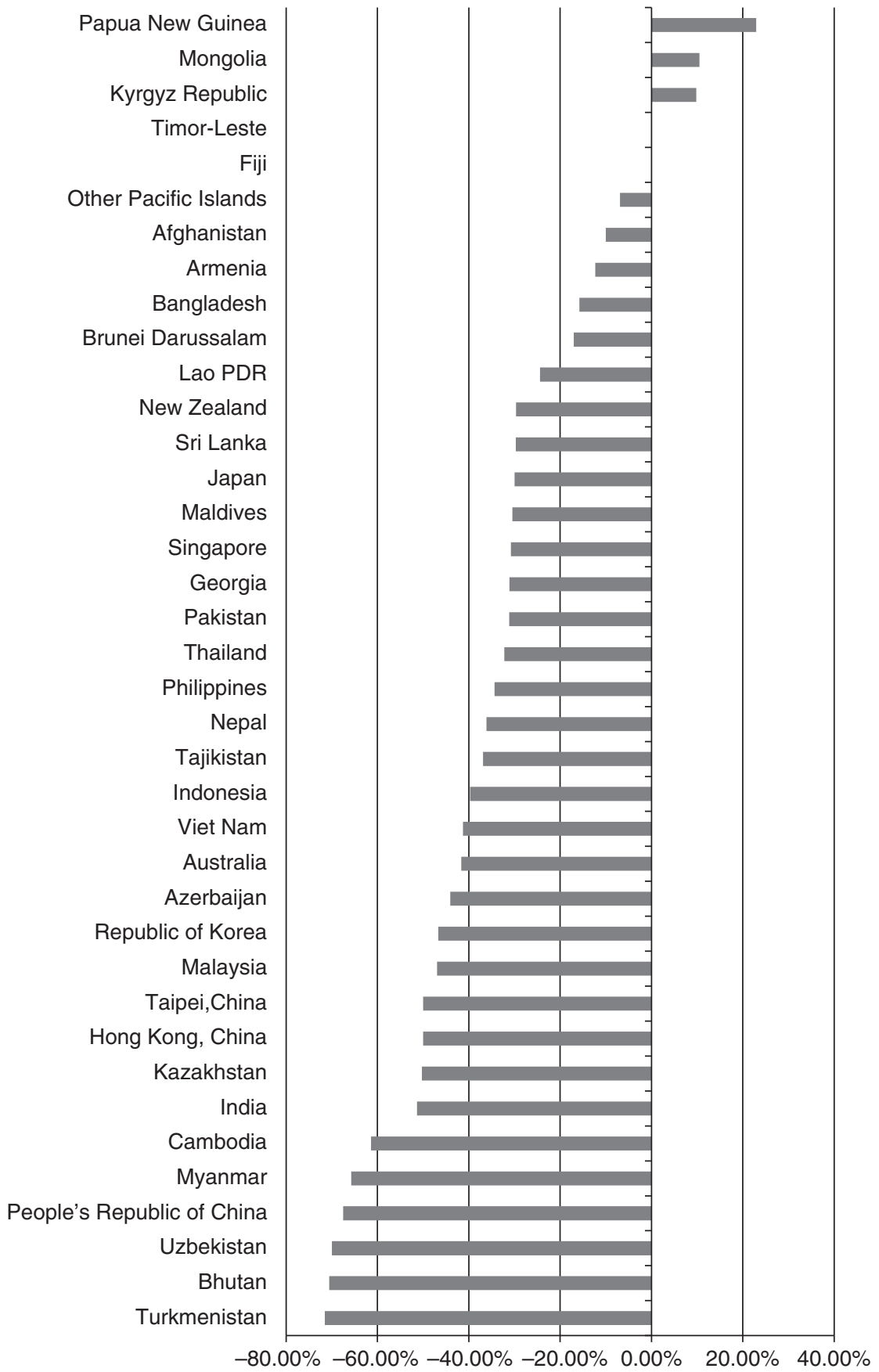

Figure 3.3 Change in primary energy intensity, 2010-2035

Source: Authors' calculations with data from ADB (2013).

Note: Lao PDR = Lao People's Democratic Republic. 


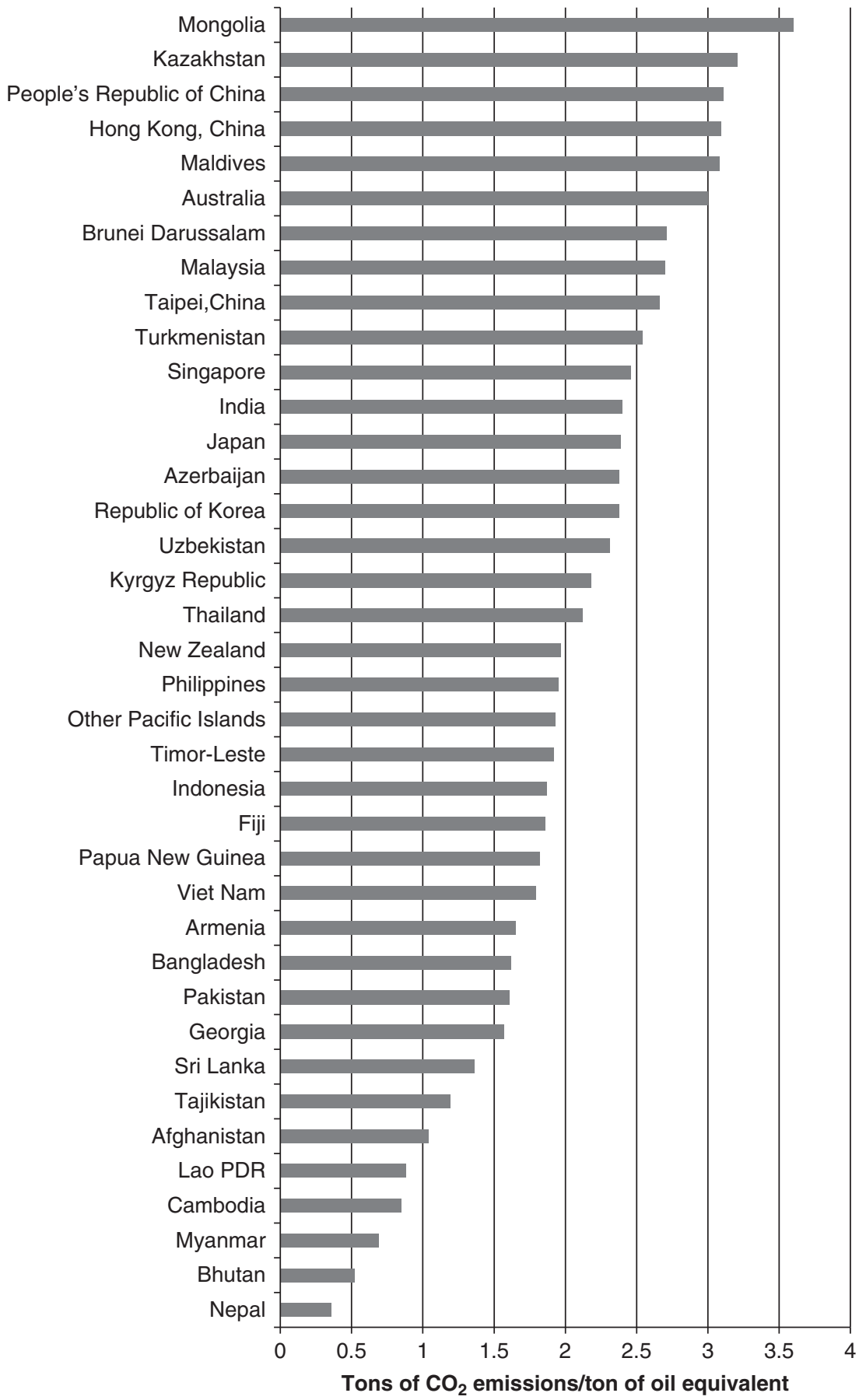

Figure 3.4 Carbon dioxide intensity of the primary energy mix in 2010

Source: Authors' calculations with data from ADB (2013).

Note: Lao PDR = Lao People's Democratic Republic. 


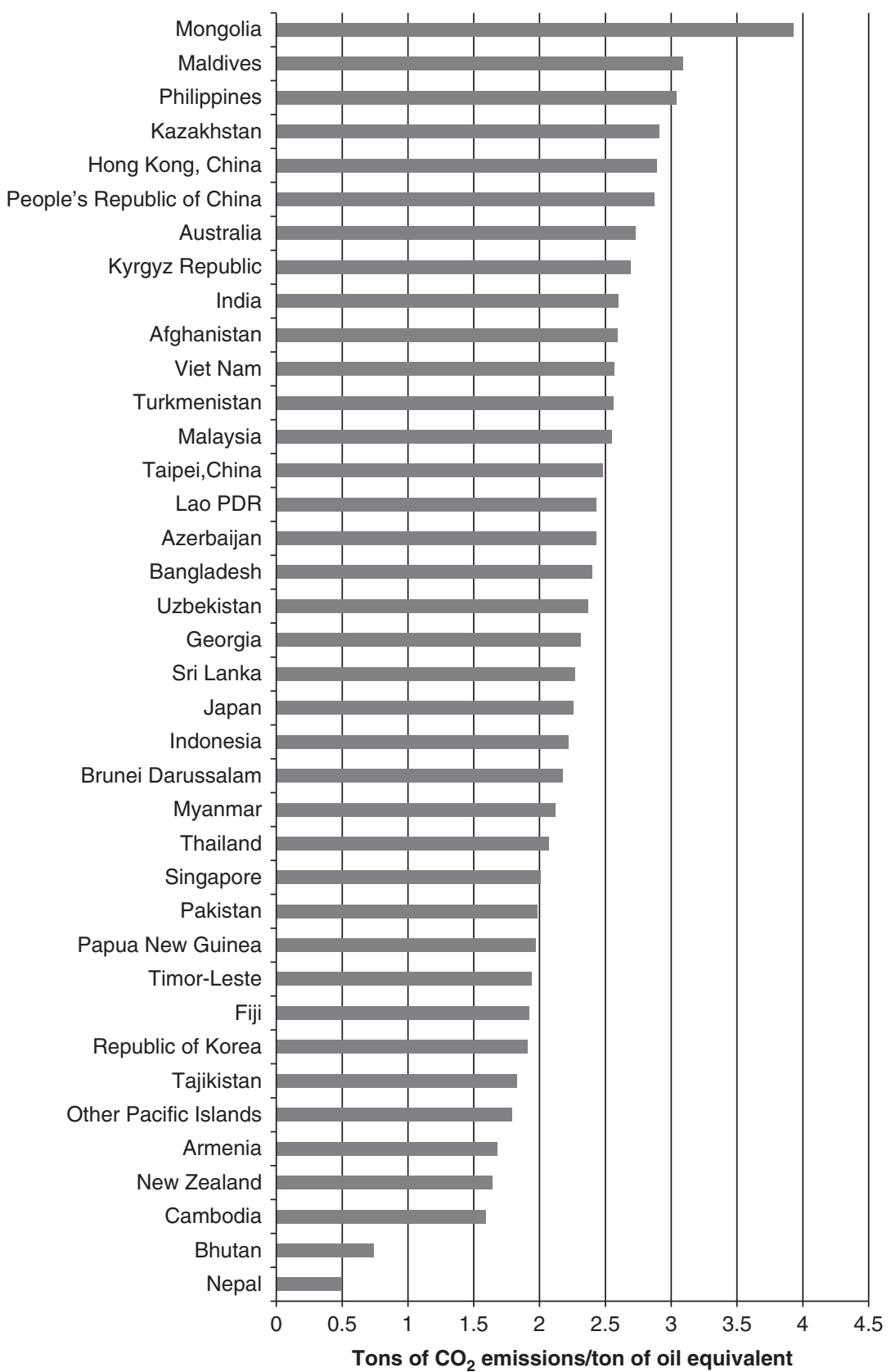

Figure 3.5 Carbon dioxide intensity of the primary energy mix in 2035

Source: Authors' calculations with data from ADB (2013).

Note: Lao PDR = Lao People's Democratic Republic. 


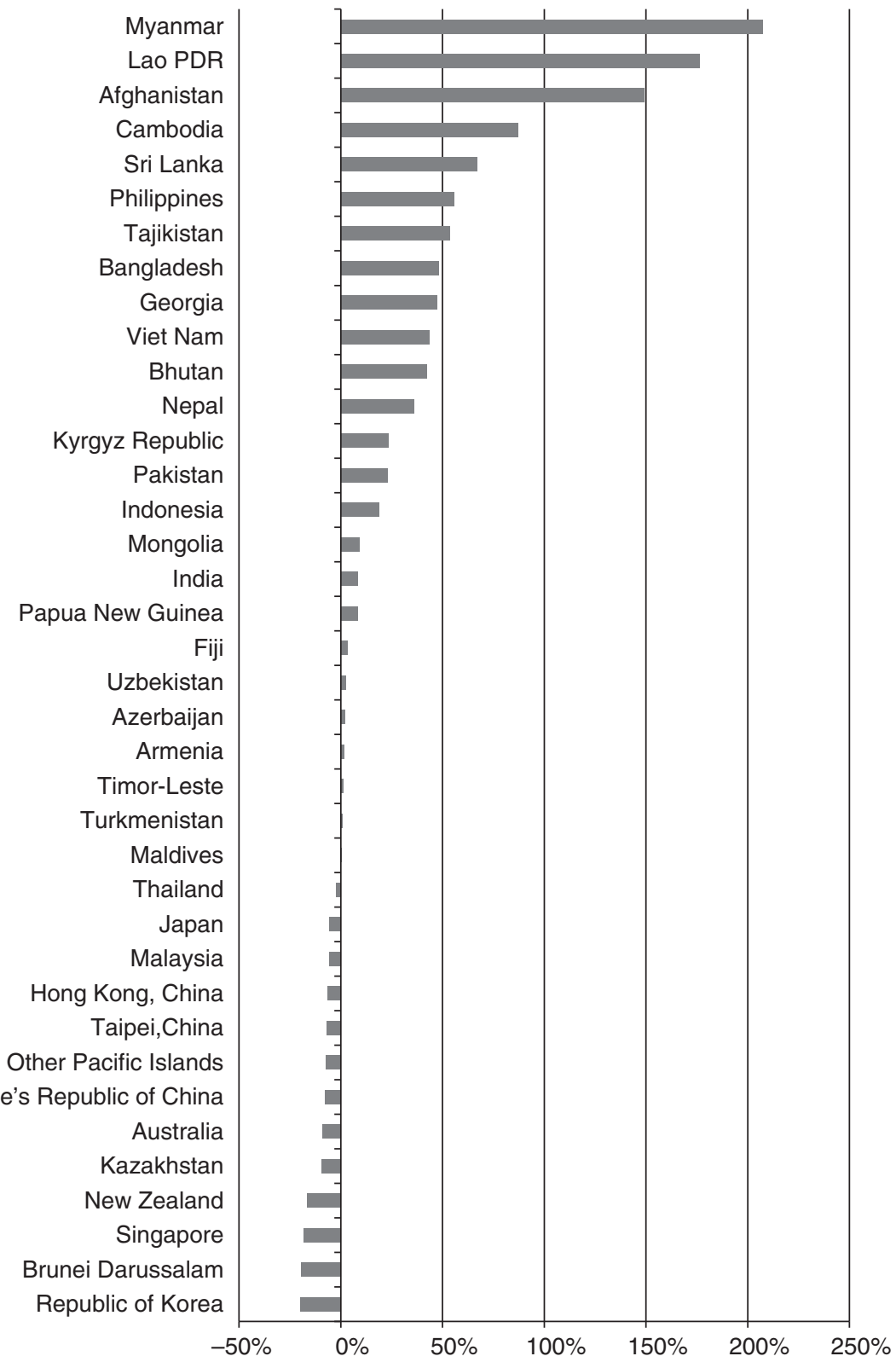

Figure 3.6 Change in carbon dioxide intensity of the primary energy mix, 2010-2035 Source: Authors' calculations with data from ADB (2013).

Note: Lao PDR = Lao People's Democratic Republic. 

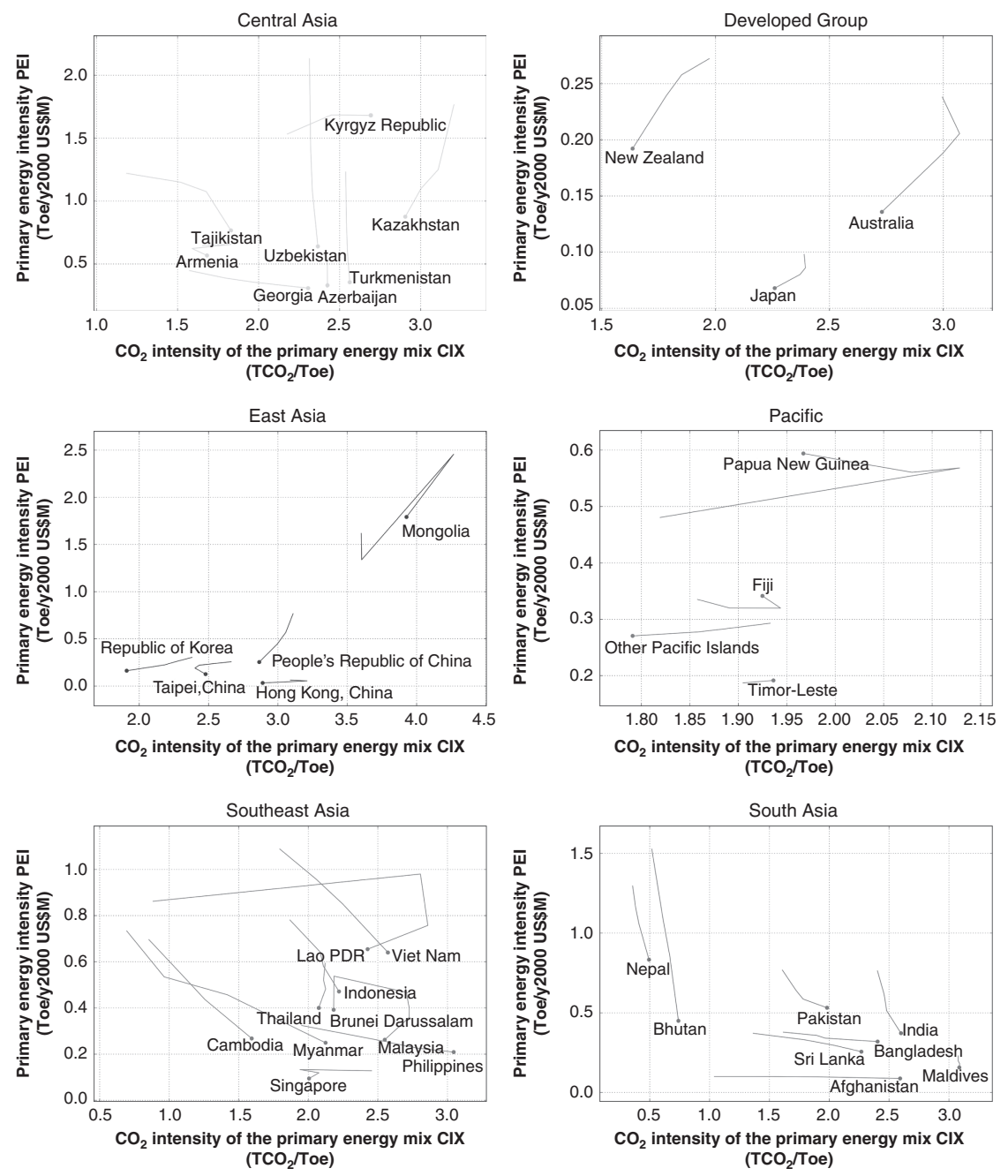

Figure 3.7 Primary energy intensity versus carbon dioxide intensity of the primary energy mix, 2010-2035

Source: Authors' calculations with data from ADB (2013).

Note: Lao PDR = Lao People's Democratic Republic; $\mathrm{TCO}_{2}=$ tons of $\mathrm{CO}_{2} ;$ Toe $=$ tons of oil equivalent.

In contrast, the DIV is maintained at the 2010 levels in most economies (see Figures 3.11 and 3.12). A DIV value less than 0.5 is a low level of diversification with the share of a single fuel resource in the PED greater than 70\%. Central Asia will not significantly change the structure of its energy systems. The low level of diversification in the power sector there should be noted, particularly in the case of former Soviet republics. 


\section{Norberto Fueyo, Antonio Gómez, César Dopazo}

In the developed group (Australia, Japan, and New Zealand) the ESS will decrease except in Japan where the larger contribution of renewable energy (mainly wind and solar) will improve self-sufficiency. The DIV has high values in 2010 and will change only slightly from 2010 to 2035 (Figure 3.8).

In East Asia, the ESS will decrease substantially in the PRC (Figure 3.8). In Hong Kong, China; the Republic of Korea; Mongolia; and Taipei,China, the ESS shows little change from 2010 to 2035. Except in the PRC and Mongolia, the
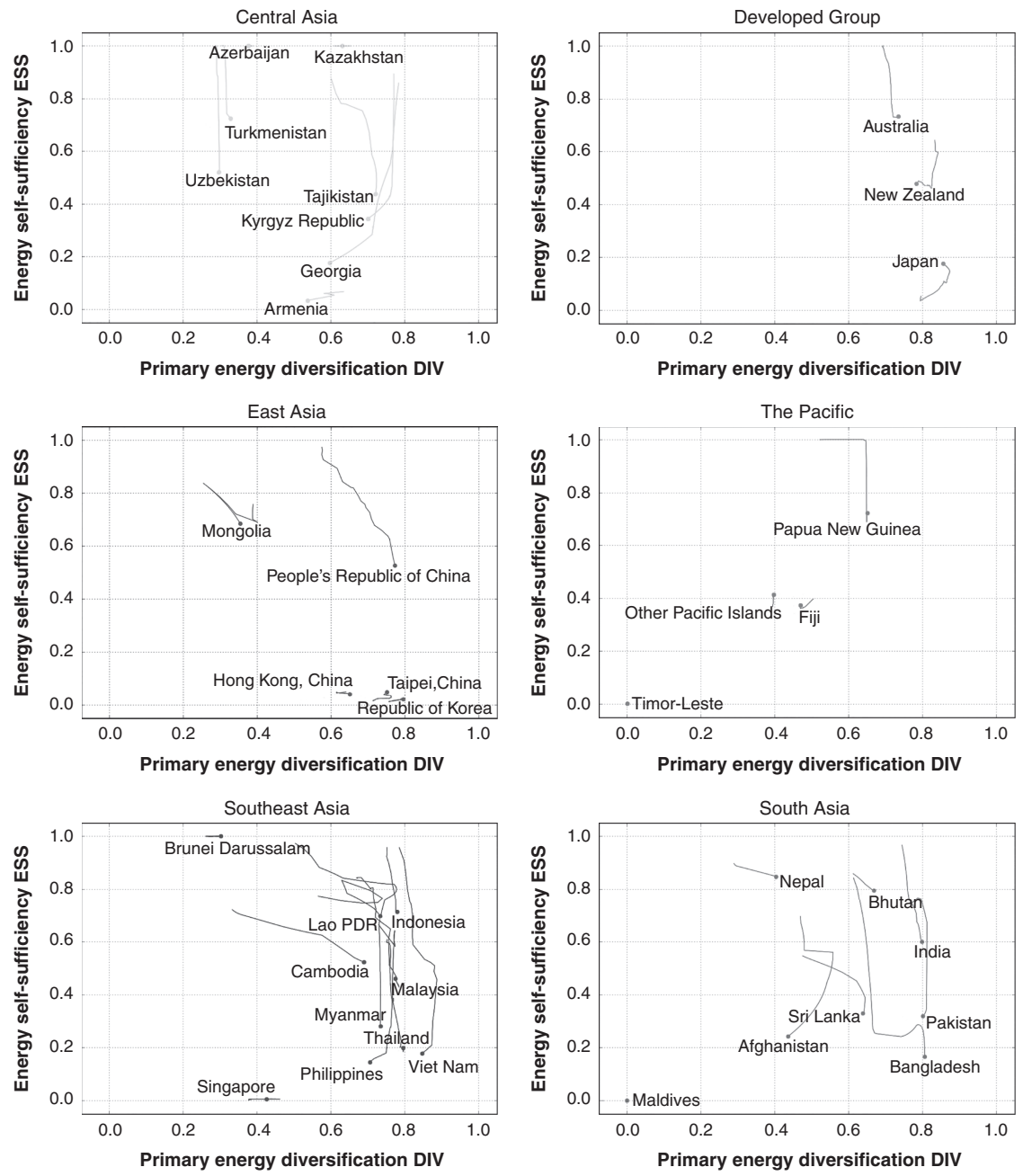

Figure 3.8 Energy self-sufficiency vs primary energy diversification, 2010-2035 (named end $=2035$ )

Source: Authors' calculations with data from ADB (2013).

Note: Lao PDR = Lao People's Democratic Republic. 


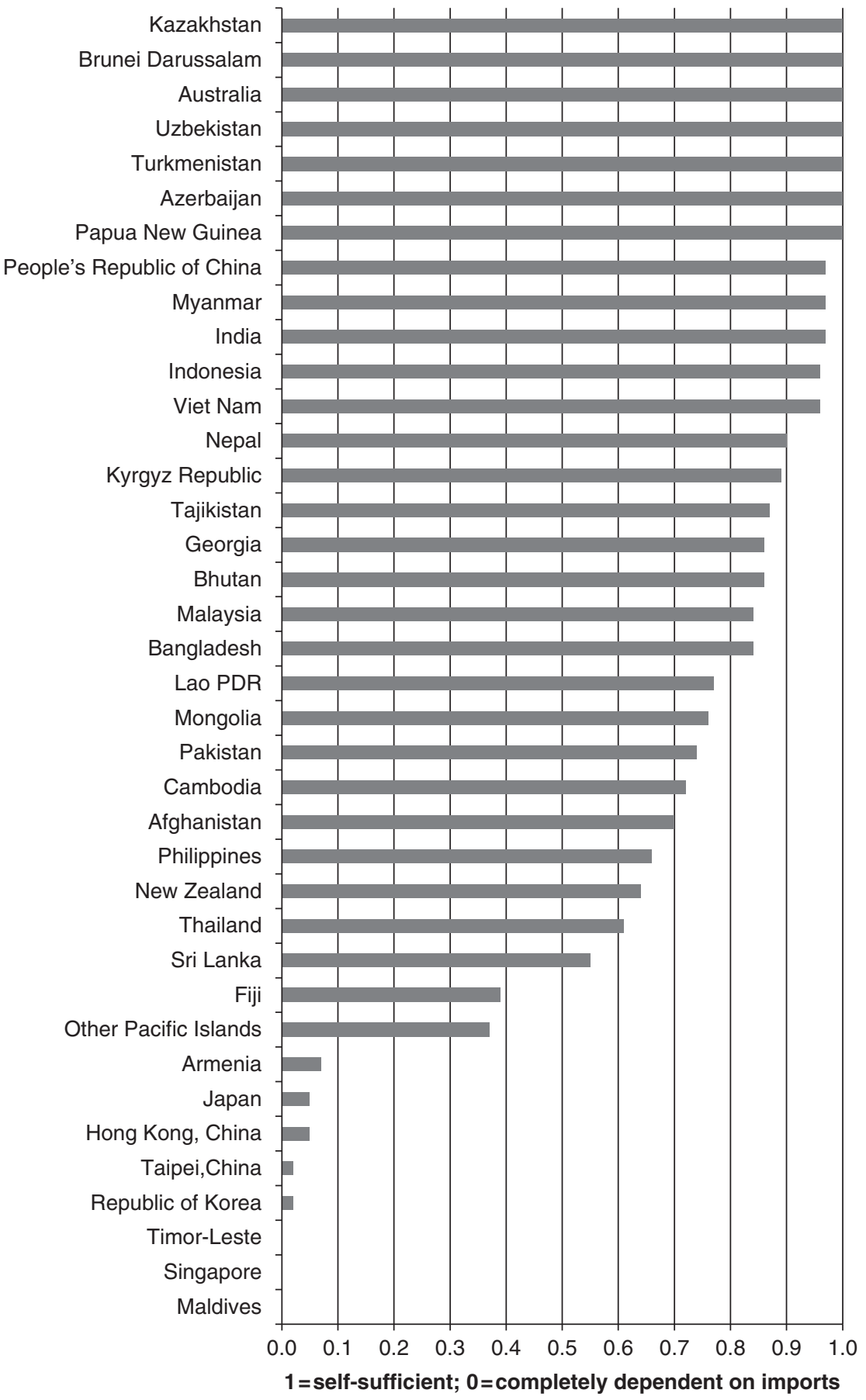

Figure 3.9 Energy self-sufficiency in 2010

Source: Authors' calculations with data from ADB (2013).

Note: Lao PDR = Lao People's Democratic Republic. 


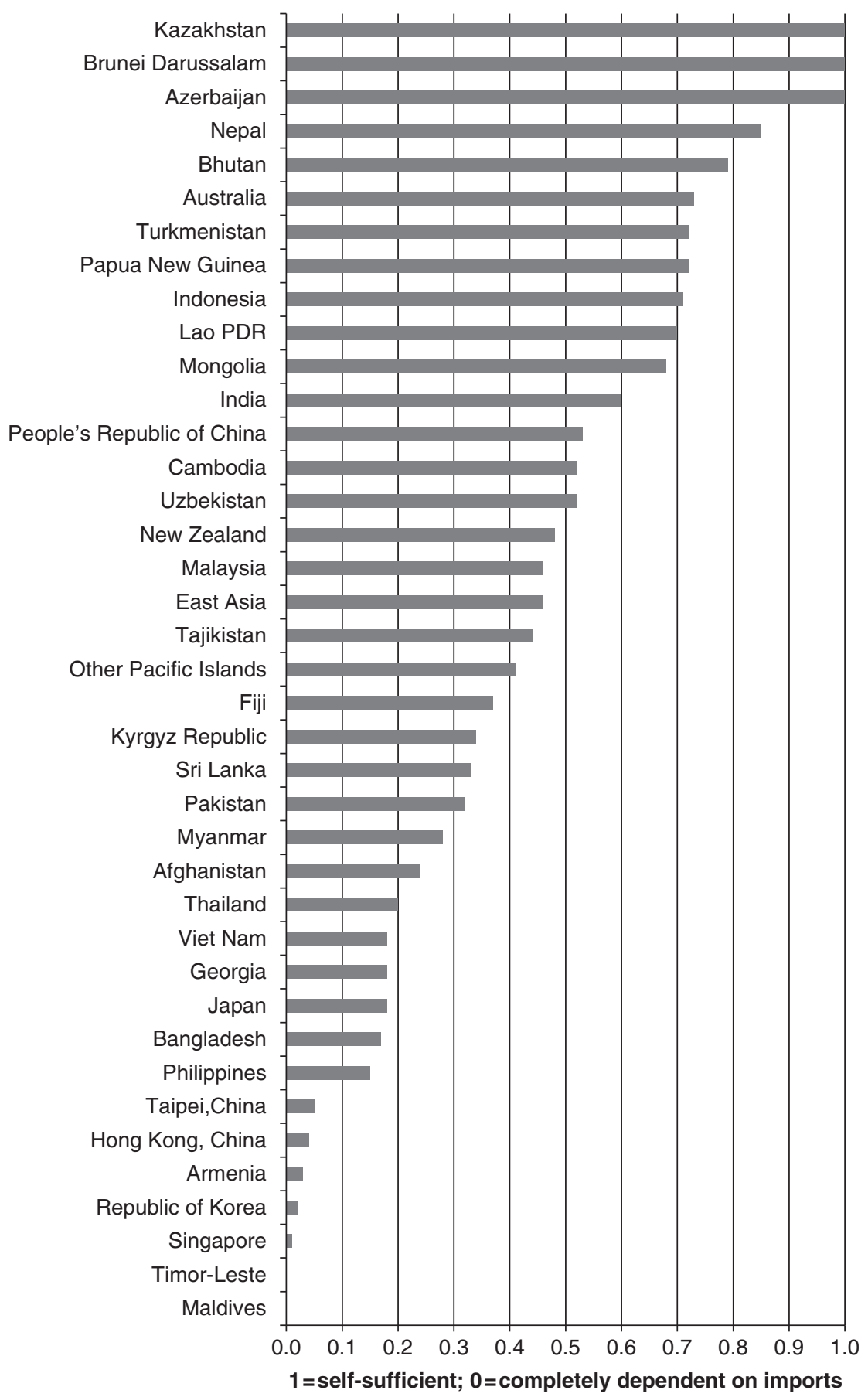

Figure 3.10 Energy self-sufficiency in 2035

Source: Authors' calculations with data from ADB (2013).

Note: Lao PDR = Lao People's Democratic Republic. 


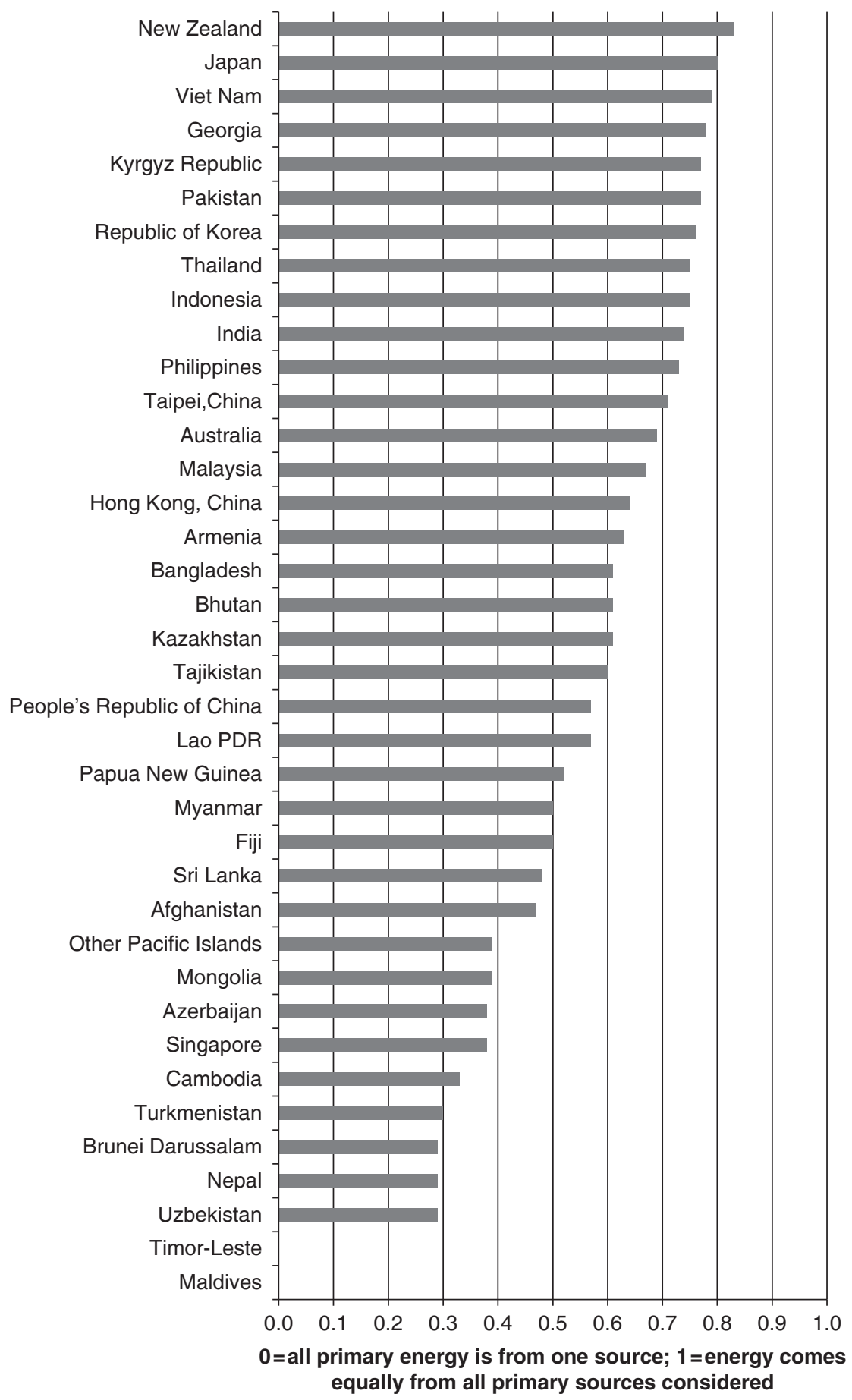

Figure 3.11 Primary energy diversification in 2010

Source: Authors' calculations with data from ADB (2013).

Note: Lao PDR = Lao People's Democratic Republic. 


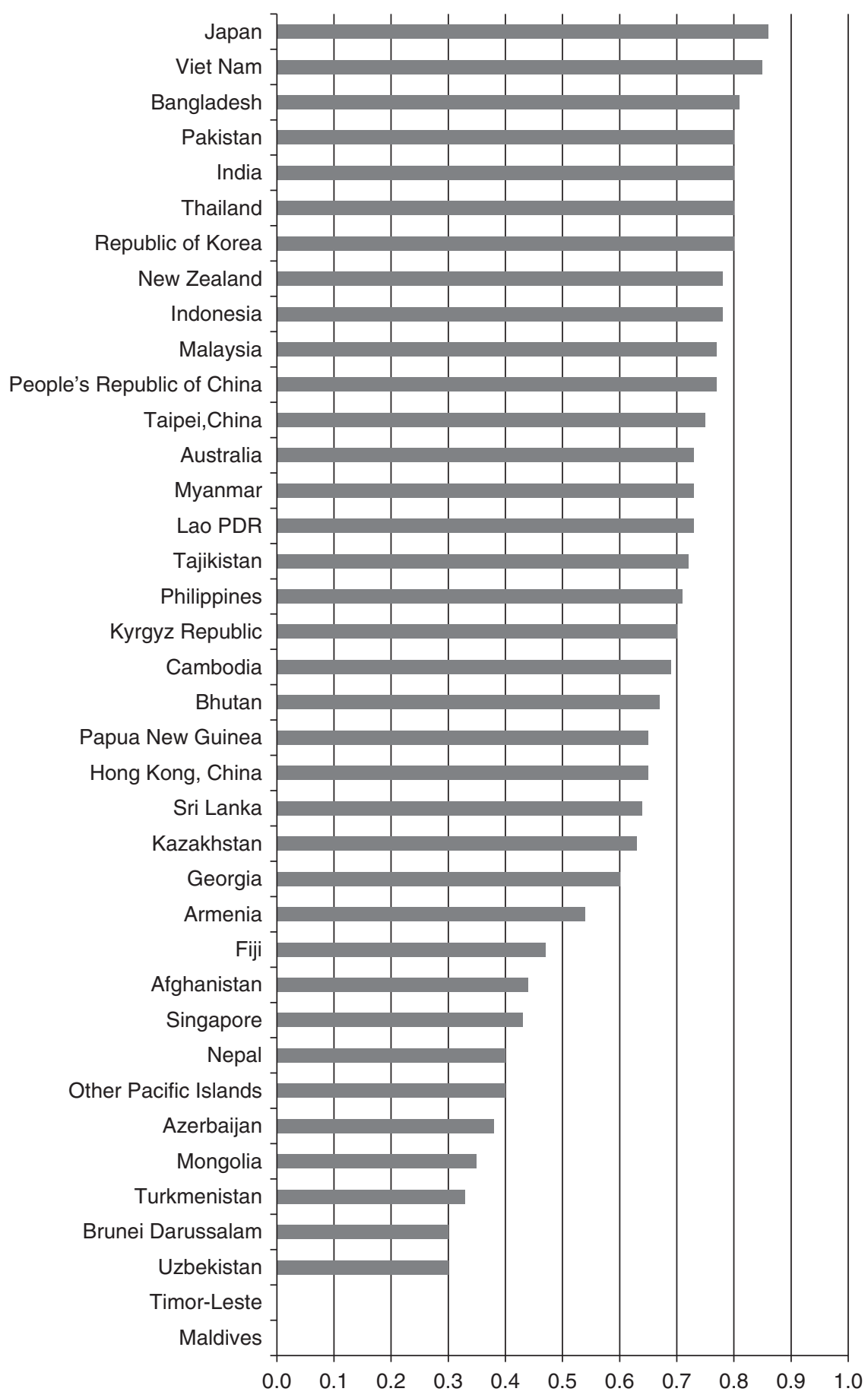

Figure 3.12 Primary energy diversification in 2035

Source: Authors' calculations with data from ADB (2013).

Note: Lao PDR = Lao People's Democratic Republic. 
ESS has very low values indicating a significant dependence on energy imports. The DIV shows little change except in the PRC where it increases due to greater contributions from gas, nuclear, and renewables (wind and solar).

Pacific countries will generally follow the trends observed in Asia; the ESS will decrease while the DIV will increase slightly. Timor-Leste has very low ESS and DIV values since its energy system is based mainly on oil imports. In other Pacific islands, the ESS will increase slightly because of increases in the share of renewables in PED.

In Southeast Asia, the ESS will decrease substantially from 2010 to 2035 . The PED will increase five-fold with coal, oil, and natural gas growing the most. While using these fuels will improve the DIV in some, it will be at the expense of ESS.

In South Asia, the ESS in Afghanistan, Bangladesh, Bhutan, India, Maldives, Nepal, Pakistan, and Sri Lanka will decrease, though in Bhutan and Nepal it will remain almost unchanged since hydro and biomass waste will still be the main contributors to their energy systems in 2035. Although coal reserves in India and Pakistan will still be substantial in 2035, the depletion of oil and natural gas reserves (especially in Pakistan) will cause a decrease in the ESS. In Bangladesh, the ESS will deteriorate because of the progressive reduction of coal and natural gas reserves and the decrease in the share of traditional fuels (biofuel and biomass waste) in PED in favor of greater consumption of gas and oil. Afghanistan and Sri Lanka show a similar trend with traditional fuels replaced by oil and coal $(67 \%$ in 2010 to $17 \%$ in 2035 in Afghanistan and 51\% to 31\% in Sri Lanka). The energy system in Maldives is based exclusively on oil; this is the reason for its low ESS and DIV values.

\section{Affordability}

The affordability of electricity for households is estimated as the expected electricity outlay, i.e., the fraction of per capita GDP spent to buy a certain amount of electricity. This is computed based on tariffs for households (EOT) and based on LEC (EOL). The former can be used only for the present or for the past while the latter can be calculated for the past, present, or future since it uses the structure of the power sector and fuel costs.

Figure 3.13 demonstrates that affordability is directly related to economic development; in general, it will improve, as development improves (Figures 3.14-3.18). Some factors can decrease affordability notably introducing new and more expensive power generation technologies, a rise in fuel prices, and the depletion of local reserves requiring imports.

In Central Asia, Armenia, Azerbaijan, Georgia, and Kazakhstan will considerably improve affordability (Figure 3.19) as they experience significant economic growth from 2010 to 2035 that will decrease their EOL; however, their electricity systems are based on different resources. Armenia and Georgia have negligible fossil fuel reserves; power generation is based on hydro in Georgia and on a combination of hydro and nuclear energy in Armenia. Azerbaijan and Kazakhstan base their power generation on indigenous gas and coal, respectively. In the Kyrgyz Republic, Tajikistan, and Uzbekistan, economic growth is not sufficient to substantially improve affordability. 


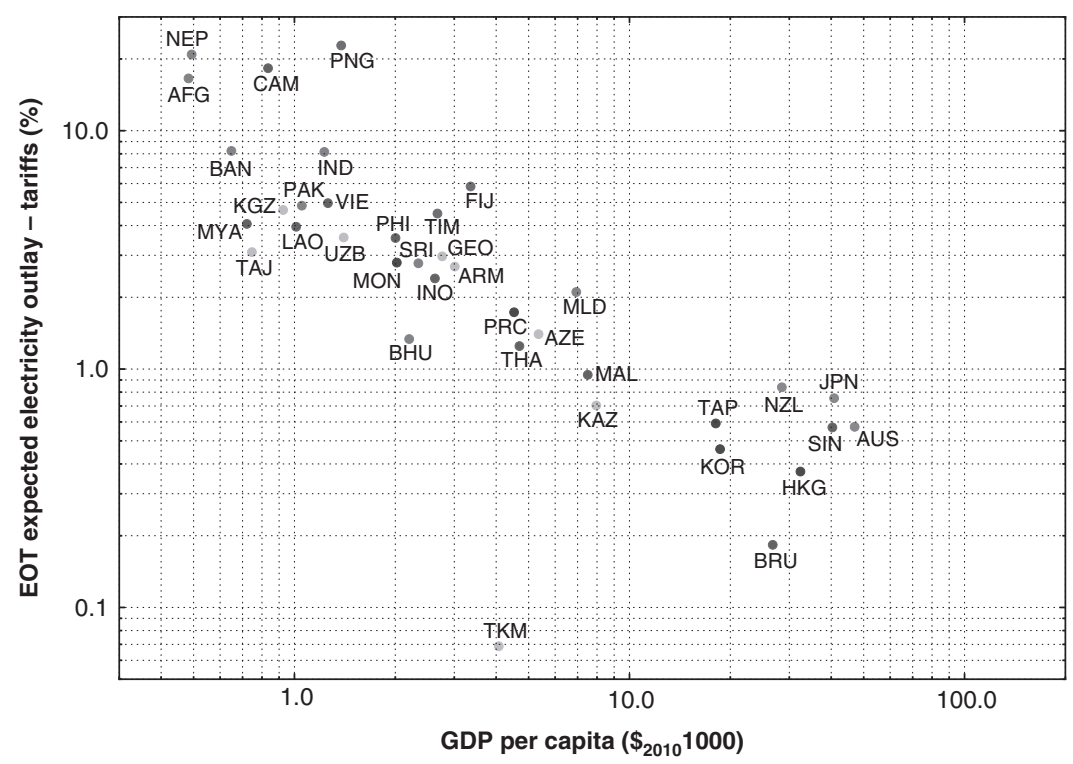

Figure 3.13 Expected electricity outlays based on tariffs in 2012

Source: Authors' calculations with data from ADB (2013), IMF (2013) and other sources (Fueyo et al. 2013).

Note: $\mathrm{AFG}=$ Afghanistan; ARM = Armenia; AUS = Australia; AZE = Azerbaijan; BAN = Bangladesh; $\mathrm{BHU}=$ Bhutan; $\mathrm{BRU}=$ Brunei Darussalam; $\mathrm{CAM}=$ Cambodia; FIJ $=$ Fiji; GDP $=$ gross domestic product; GEO = Georgia; HKG = Hong Kong, China; IND = India; INO = Indonesia; JPN = Japan; KAZ $=$ Kazakhstan; KOR $=$ Republic of Korea; KGZ $=$ Kyrgyz Republic; LAO $=$ Lao People's Democratic Republic; MAL = Malaysia; MLD = Maldives; $\mathrm{MON}=$ Mongolia; MYA = Myanmar NEP = Nepal; NZL = New Zealand; PAK = Pakistan; PNG = Papua New Guinea; $\mathrm{PHI}=$ Philippines; $\mathrm{PRC}=$ China, People's Republic of; SIN = Singapore; SRI = Sri Lanka; TAP = Taipei,China; TAJ = Tajikistan; THA = Thailand; TIM = Timor-Leste; TKM = Turkmenistan; UZB = Uzbekistan; VIE = Viet Nam.

In the developed group, affordability will remain nearly constant and even decrease slightly in Australia (Figure 3.19). Japan will increase its share of renewables (wind and solar) in the power system which translates into a higher overall LEC; however, this will be offset by economic growth and by a reduction in fossil fuel imports. Australia and New Zealand will increase their shares of natural gas and renewables in power generation which will result in a higher LEC in 2035, but economic growth will reduce the impact on affordability. Australia, Japan, and New Zealand will have the highest share of renewables (wind and solar) in the power sector in 2035 at $16.1 \%, 27.6 \%$, and $27.4 \%$ respectively.

In East Asia, affordability will improve considerably everywhere but especially in Mongolia and the PRC (Figure 3.19). Power generation in both countries in 2035 will be based on local coal, although in the PRC the contribution of coal will be reduced from $78 \%$ in 2010 to $58 \%$ in 2035 due to the increased penetration of natural gas, nuclear, and renewables. In Hong Kong, China; the Republic of Korea; and Taipei,China, the power mix will change only moderately; coal will be reduced in 


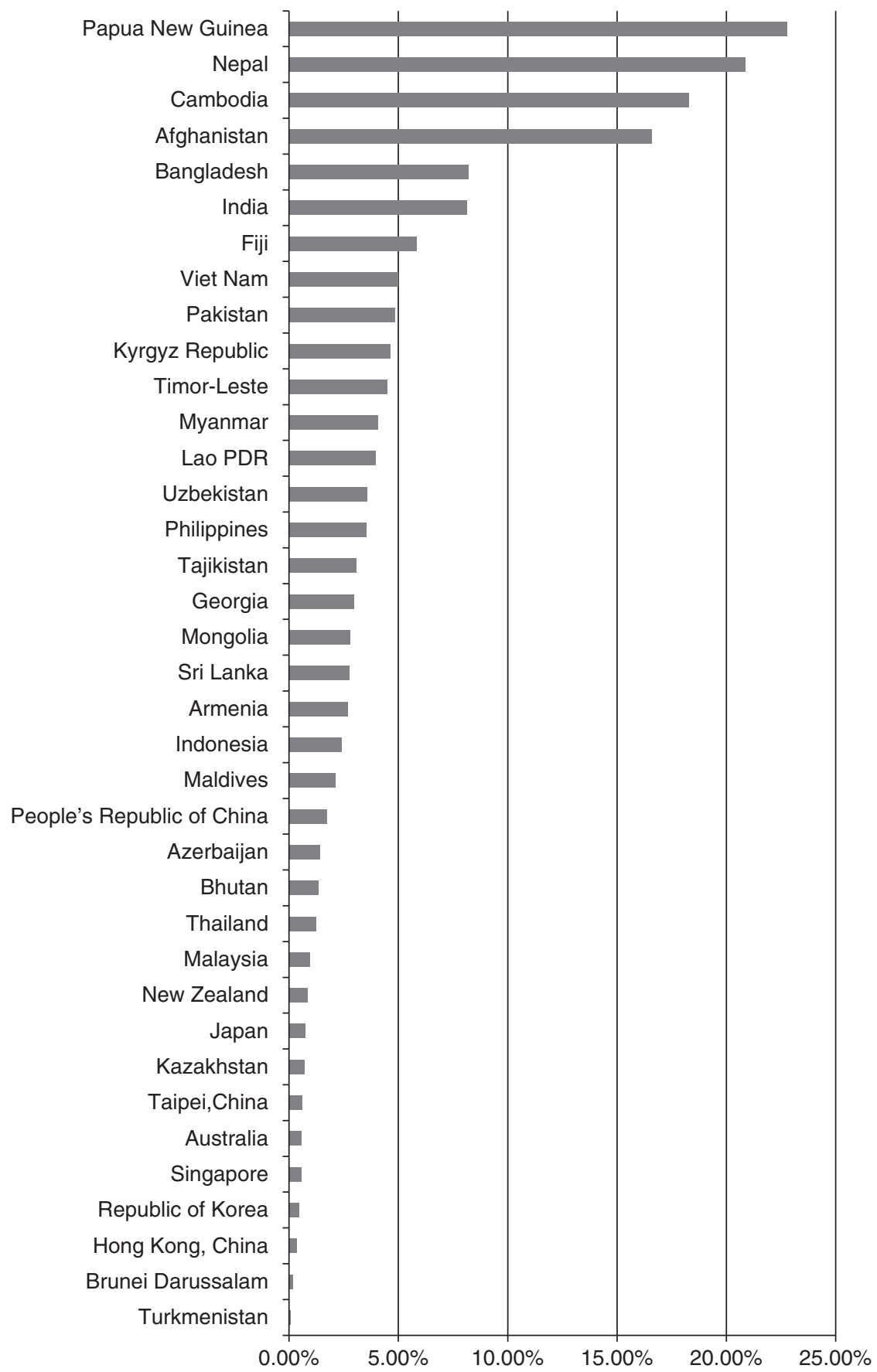

Figure 3.14 Expected electricity outlays based on tariffs in 2012

Source: Authors' calculations with data from ADB (2013), IMF (2013) and other sources (Fueyo et al. 2013).

Note: Lao PDR = Lao People's Democratic Republic. 

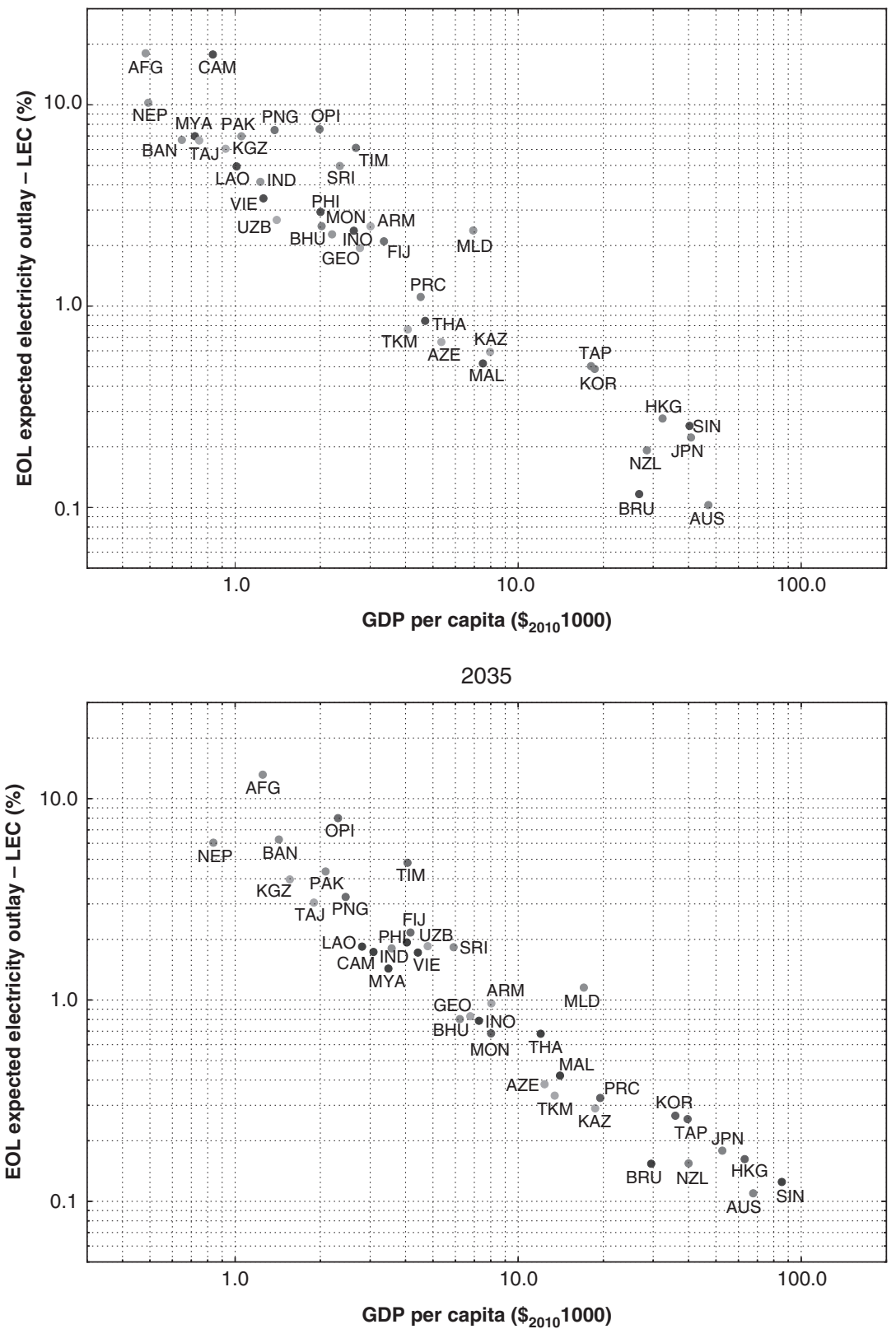

Figure 3.15 Expected electricity outlays based on levelized electricity cost in 2012 and 2035 Source: Authors' calculations with data from ADB (2013) and IMF (2013).

Note: $\mathrm{AFG}=$ Afghanistan ARM = Armenia; $\mathrm{AUS}=$ Australia $; \mathrm{AZE}=$ Azerbaijan $; \mathrm{BAN}=$ Bangladesh; BHU $=$ Bhutan; $\mathrm{BRU}=$ Brunei Darussalam; CAM $=$ Cambodia; FIJ $=$ Fiji; GDP $=$ gross domestic product; $\mathrm{GEO}=$ Georgia; HKG = Hong Kong, China; IND = India; INO = Indonesia; JPN = Japan; KAZ $=$ Kazakhstan; KOR $=$ Republic of Korea; KGZ = Kyrgyz Republic; LAO = Lao People's Democratic Republic; MAL = Malaysia; MLD = Maldives; MON = Mongolia; MYA = Myanmar; $\mathrm{NEP}=$ Nepal NZL $=$ New Zealand OPI $=$ Other Pacific Islands; PAK = Pakistan; PNG = Papua New Guinea; PHI $=$ Philippines; PRC $=$ China, People's Republic of; SIN $=$ Singapore; SRI $=$ Sri Lanka; TAP = Taipei,China; TAJ = Tajikistan; THA = Thailand; TIM = Timor-Leste; TKM = Turkmenistan; $\mathrm{UZB}=$ Uzbekistan; VIE $=$ Viet Nam. 


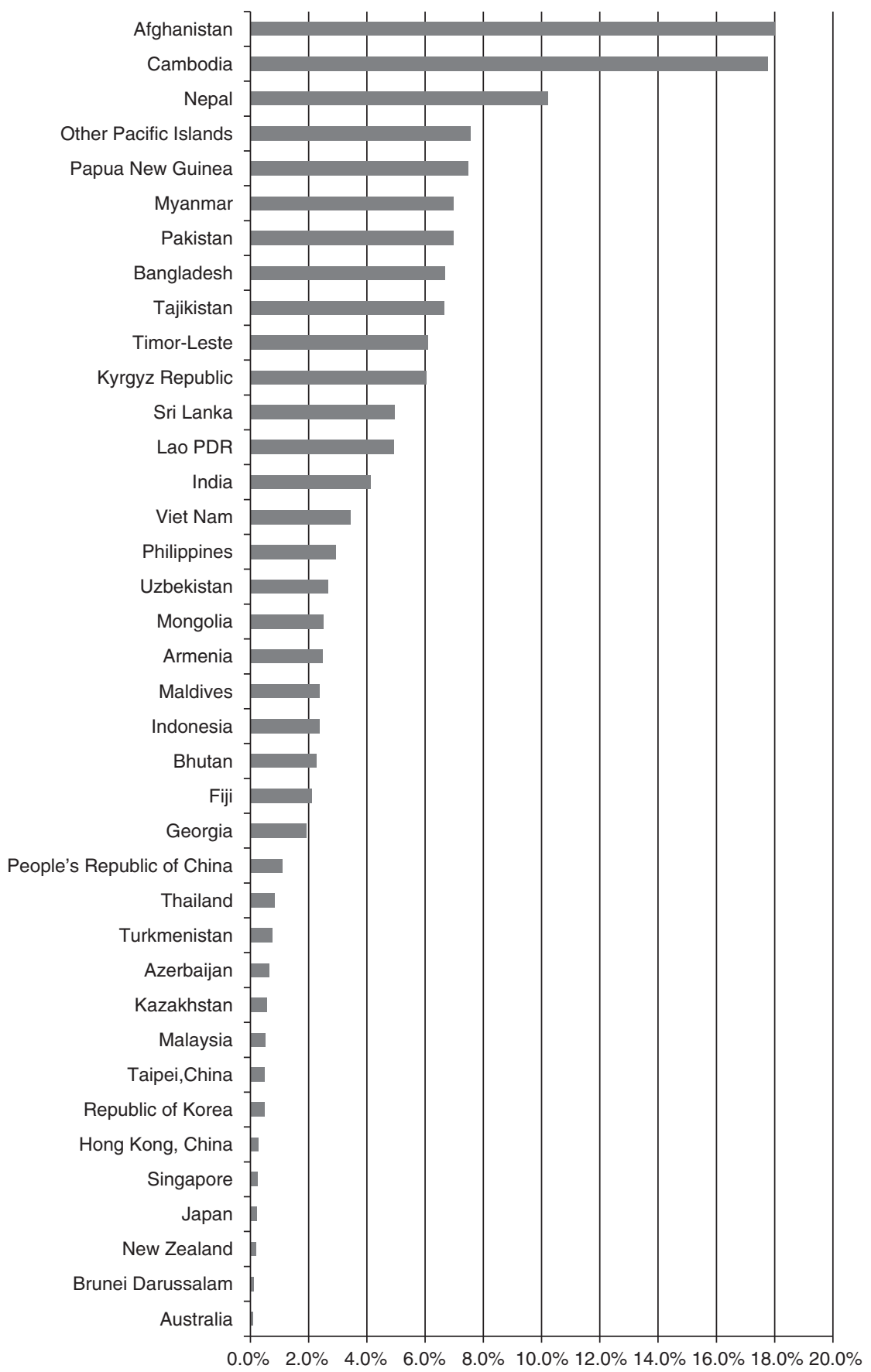

Figure 3.16 Expected electricity outlays based on levelized electricity costs in 2012 Source: Authors' calculations with data from ADB (2013) and IMF (2013).

Note: Lao PDR = Lao People's Democratic Republic. 


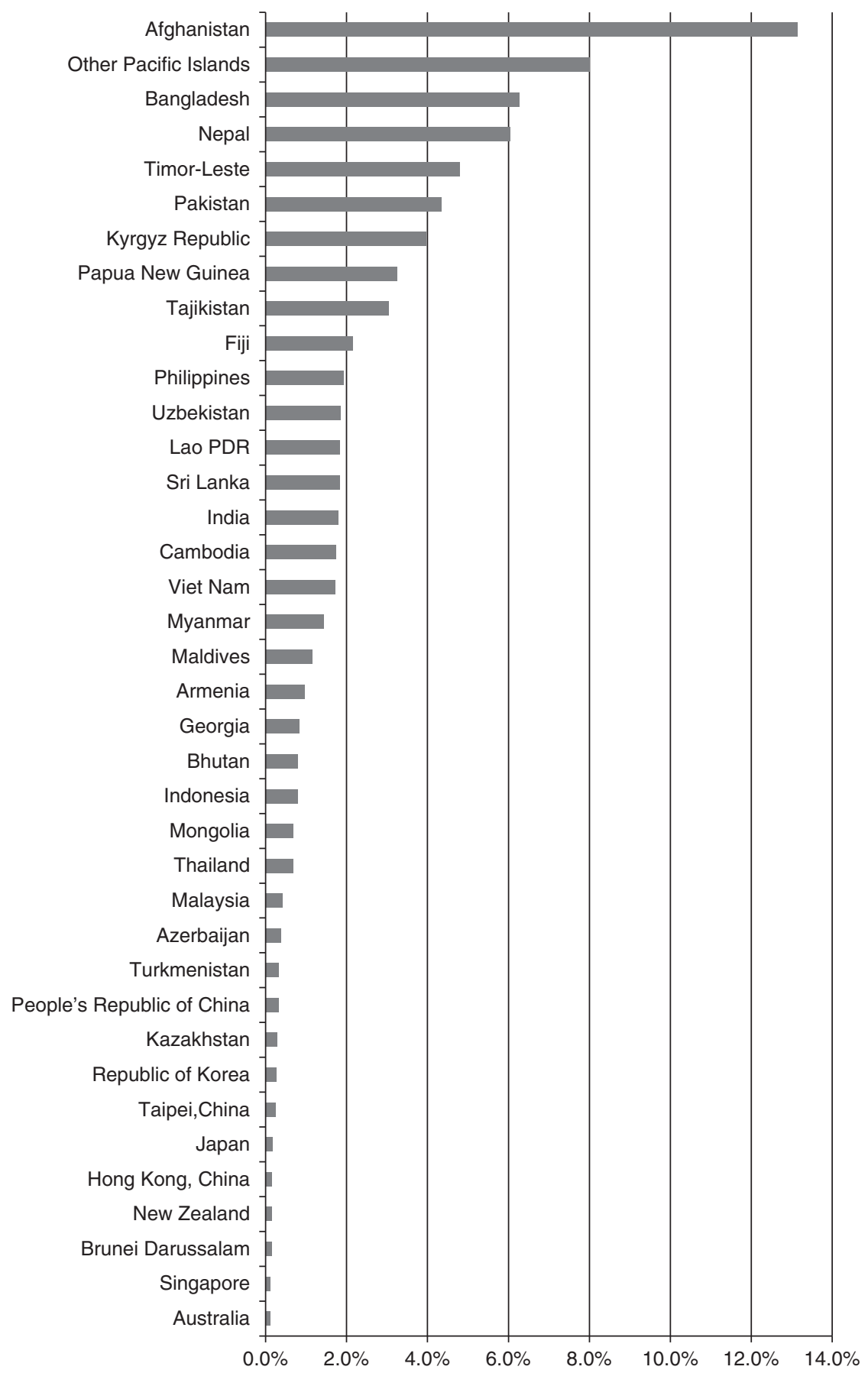

Figure 3.17 Expected electricity outlays based on levelized electricity cost in 2035 Source: Authors' calculations with data from ADB (2013) and IMF (2013).

Note: Lao PDR = Lao People's Democratic Republic. 


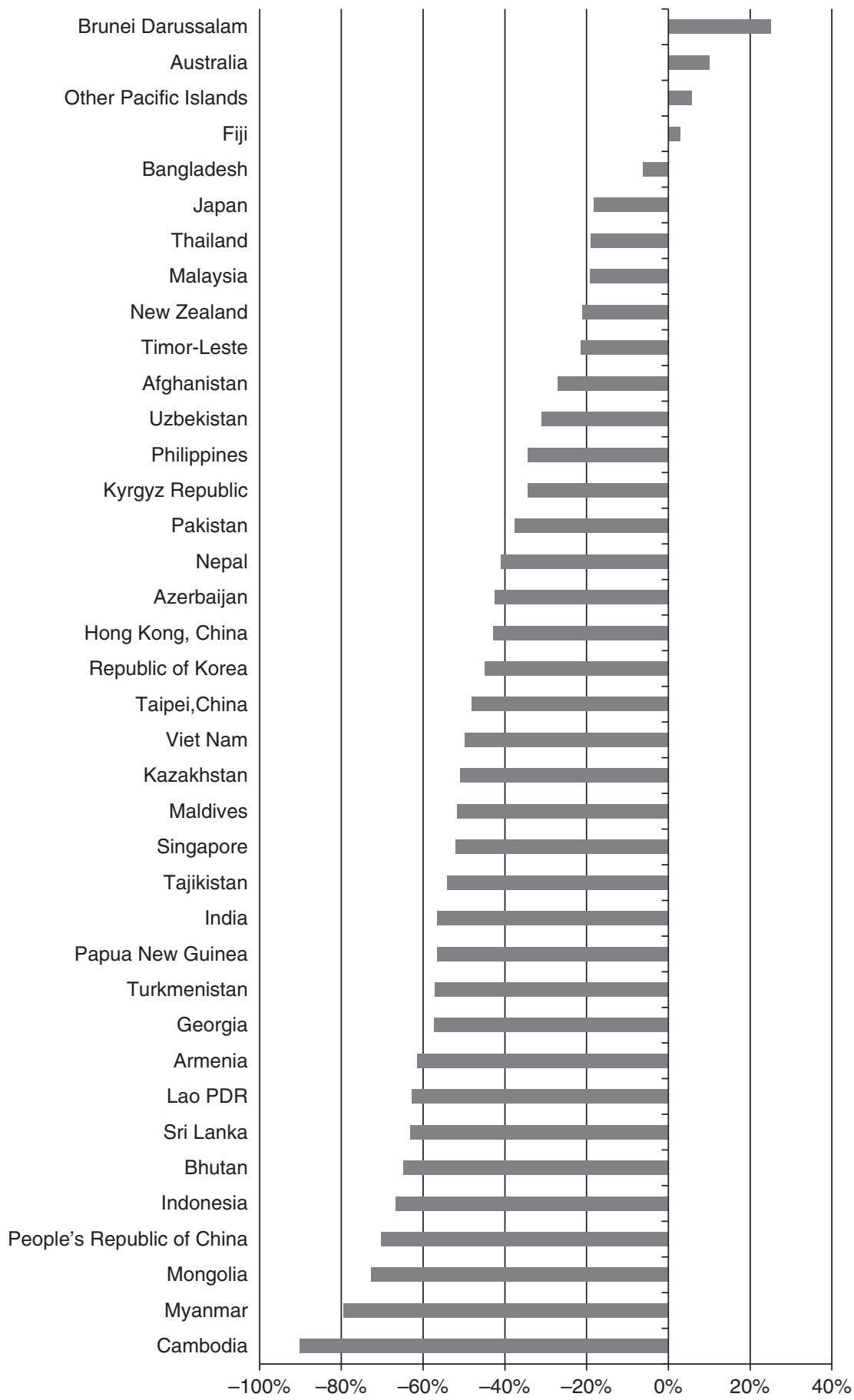

Figure 3.18 Change in expected electricity outlays based on levelized electricity cost, 2012-2035

Source: Authors' calculations with data from ADB (2013) and IMF (2013).

Note: Lao PDR = Lao People's Democratic Republic. 

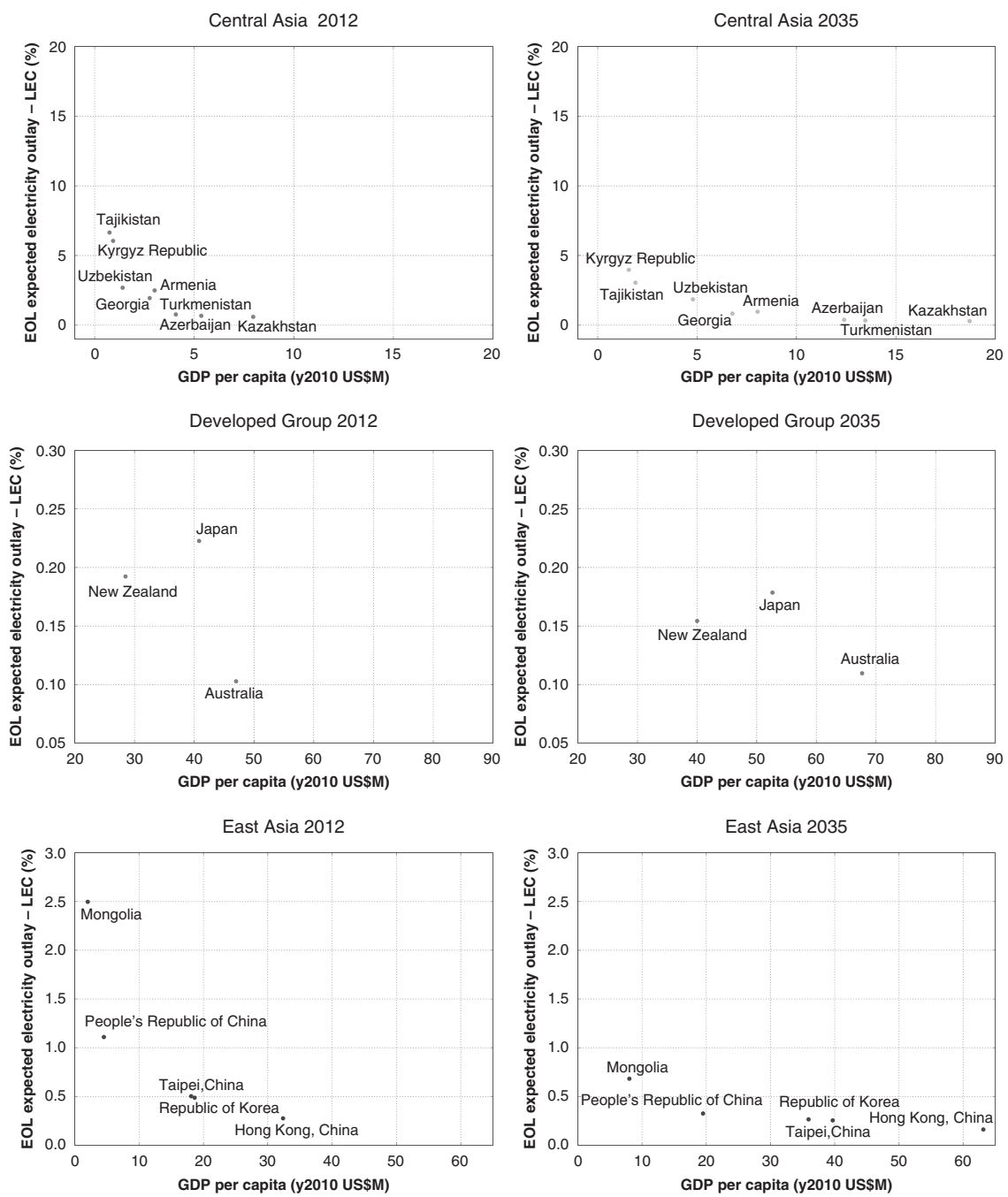

Figure 3.19 Expected electricity outlays based on levelized electricity cost in Central Asia, the Developed Group, and East Asia, 2012-2035

Source: Authors' calculations with data from ADB (2013) and IMF (2013).

Note: GDP $=$ gross domestic product.

favor of natural gas and nuclear in the Republic of Korea, natural gas and renewables in Taipei,China, and natural gas in Hong Kong, China. Although the overall LEC in East Asia will increase due to the greater contribution of natural gas and renewables, substantial economic growth will offset it by a large margin.

In the Pacific, electricity affordability will improve in Papua New Guinea and Timor-Leste (Figure 3.20). In Papua New Guinea, oil generation capacity in 2010 

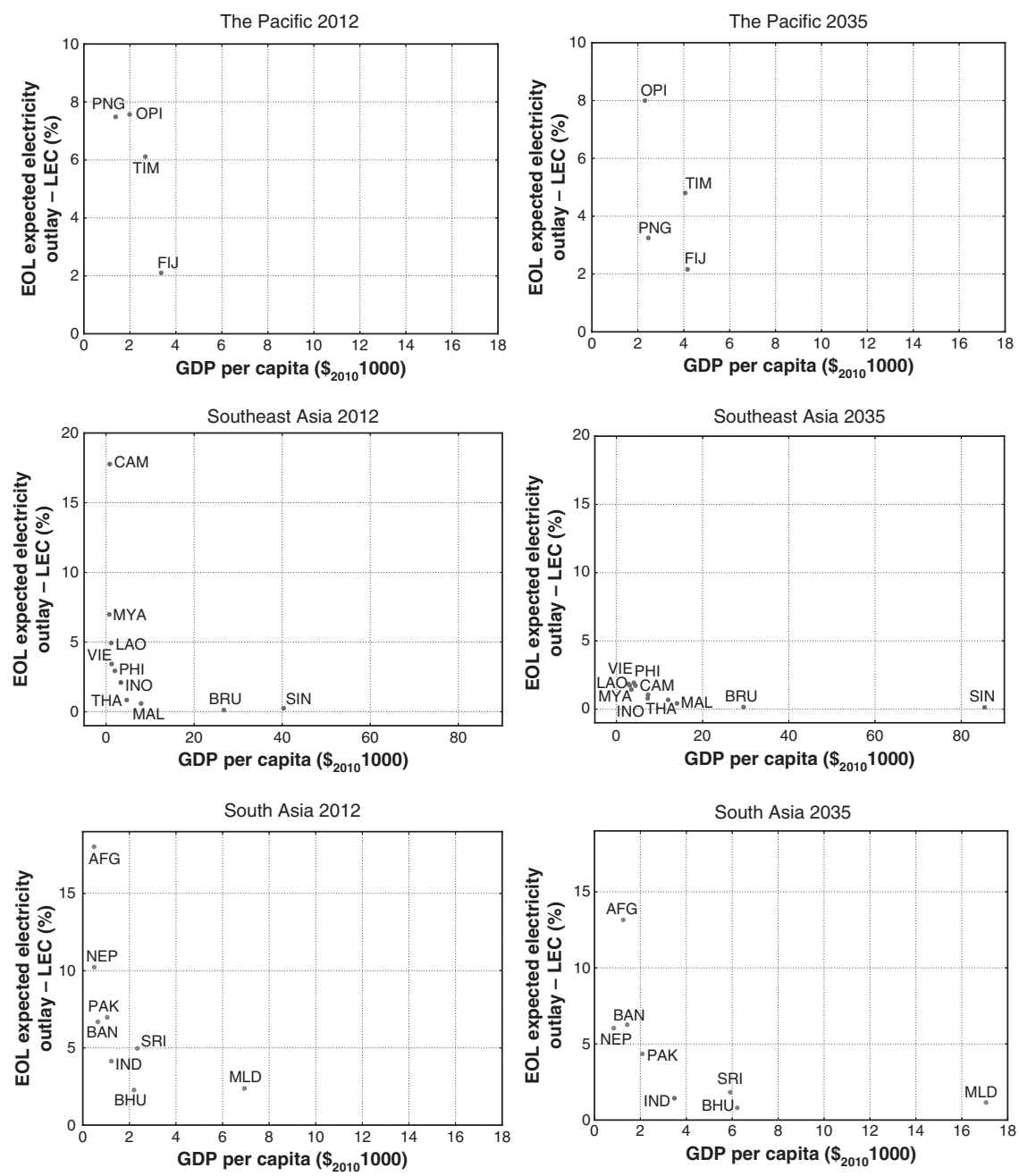

Figure 3.20 Expected electricity outlays based on levelized electricity cost in the Pacific, Southeast Asia, and South Asia, 2012-2035

Source: Authors' calculations with data from ADB (2013) and IMF (2013).

Note: $\mathrm{AFG}=$ Afghanistan; $\mathrm{ARM}=$ Armenia; $\mathrm{AUS}=$ Australia; $\mathrm{AZE}=$ Azerbaijan; $\mathrm{BAN}=$ Bangladesh; $\mathrm{BHU}=$ Bhutan; $\mathrm{BRU}=$ Brunei Darussalam; $\mathrm{CAM}=$ Cambodia; FIJ $=$ Fiji; GDP $=$ gross domestic product; $\mathrm{GEO}=$ Georgia; HKG $=$ Hong Kong, China; IND = India; INO = Indonesia; JPN = Japan; $\mathrm{KAZ}=$ Kazakhstan; KOR $=$ Republic of Korea; KGZ $=$ Kyrgyz Republic; LAO $=$ Lao People's Democratic Republic $;$ MAL $=$ Malaysia $;$ MLD $=$ Maldives $;$ MON $=$ Mongolia $;$ MYA $=$ Myanmar; $\mathrm{NEP}=$ Nepal; NZL = New Zealand; OPI = Other Pacific Islands; PAK = Pakistan; PNG = Papua New Guinea; PHI = Philippines; PRC = China, People's Republic of; SIN = Singapore; SRI = Sri Lanka; TAP $=$ Taipei,China; TAJ $=$ Tajikistan; THA $=$ Thailand; TIM = Timor-Leste; TKM = Turkmenistan; $\mathrm{UZB}=$ Uzbekistan; VIE $=$ Viet Nam . 
(54\% of the power system) will be replaced by local natural gas (53\% in 2035). This will reduce the LEC and together with economic growth will lead to a substantial improvement in affordability (Figure 3.18). In Timor-Leste, the power mix is based on imported oil and will not change from 2010 to 2035. Although the overall LEC will increase due to rises in oil prices, economic growth will produce a moderate improvement in affordability. In Fiji, the affordability indicator will change slightly between 2010 and 2035 (Figure 3.18) as the shares in the power sector of natural gas and renewables grow resulting in an LEC increase that will be offset by economic growth. In other Pacific islands, the power mix will still be based on oil imports by 2035; economic growth will not be sufficient to counter LEC increases due to rising oil prices.

In Southeast Asia, affordability will improve significantly in Cambodia, Indonesia, Lao People's Democratic Republic, and Myanmar (Figure 3.20) due to economic growth and to changes in their electricity mixes. Power generation in 2035 will be hydro and local gas in Myanmar, hydro and local coal in Indonesia and Lao People's Democratic Republic, and hydro in Cambodia. In Malaysia, the Philippines, Thailand, and Viet Nam, affordability will improve moderately. In 2035, their electricity mixes will be based on imported coal and natural gas except in Malaysia where local natural gas will be used. In Thailand, the main source for electric power will be natural gas (59.3\%) which will also supply $44.2 \%$ of power in Malaysia while in the Philippines and Viet Nam it will be coal $(70.1 \%$ and $42.9 \%$, respectively). The decrease in EOL in Viet Nam will be due to economic growth. In Brunei Darussalam and Singapore, the power mix in 2035 will still be based on natural gas (local in Brunei Darussalam and imported in Singapore) as it was in 2010; however, the EOL will improve for Singapore and deteriorate for Brunei Darussalam due to economic growth. Singapore will have an annual average increase in GDP per capita of 3.3\% from 2010 to 2035 while Brunei Darussalam will nearly stagnate with an annual average increase in GDP per capita of $0.4 \%$.

In South Asia, there will be significant improvements in affordability for Bhutan, India, Maldives, Nepal, Pakistan, and Sri Lanka (Figures 3.18 and 3.20). In Bhutan, India, Maldives, and Nepal, the electricity mix will change very slightly between 2010 and 2035. In Bhutan and Nepal, the power system will be based almost exclusively on hydro energy in 2035; in India local coal (64\%) and hydro energy ( $8 \%$ ) will produce more than $70 \%$ of the total electricity generated; in Maldives electricity will be still generated with oil in 2035 (99\%); improvements in affordability will be brought about mainly by economic growth. In Pakistan and Sri Lanka, both economic growth and changes in the generating structure will contribute to a decrease in EOL. In Pakistan, oil-based power generation will be replaced by gas (from $30 \%$ in 2010 to $43 \%$ by 2035) and hydro (from $29 \%$ in 2010 to $35 \%$ by 2035). Although gas will be imported, its lower cost compared to oil will contribute to a lower overall LEC. In Sri Lanka, the share of oil in the electricity mix will decrease from $58 \%$ in 2010 to $29.8 \%$ in 2035 in exchange for coal that will contribute $47.3 \%$ of power generation in 2035 (compared with $0 \%$ in 2010). Although both oil and coal will be imported in Sri Lanka, the cost of coal is lower, so the overall LEC will be reduced. In Bangladesh, the electricity mix in 2010 based on local natural gas $(87.4 \%)$ will shift to a mix 
with sizable contributions from local coal (41.8\%), imported oil (16.2\%), and imported natural gas $(32.0 \%)$. Dependence on fossil fuel imports increases the LEC; therefore, the improvement in affordability will not be as substantial as in other economies (Figure 3.18). In Afghanistan, power generation will depend on oil imports in 2035 which will significantly increase the cost of electricity. The EOL will therefore decrease moderately in spite of economic growth.

\section{The benefits of integration}

We calculated aggregate indicators for each region in a similar manner to assess the implications on sustainability, security, and affordability of regional policies and of regionally integrated energy systems.

\section{Sustainability}

When computed as a regional aggregate, the PEI will decrease for all regions (Figure 3.21) except for the Pacific (Fiji, Papua New Guinea, Timor-Leste, and other Pacific islands). This decrease is substantial in regions with high energy intensities in 2010, i.e., Central Asia, East Asia, South Asia, and Southeast Asia. In the developed group (Australia, New Zealand, and Japan), the reduction in PEI will be quite modest.

The CIX will, however, increase in general from 2010 to 2035 (Figure 3.21). This increase will be considerable in Southeast Asia and South Asia where traditional

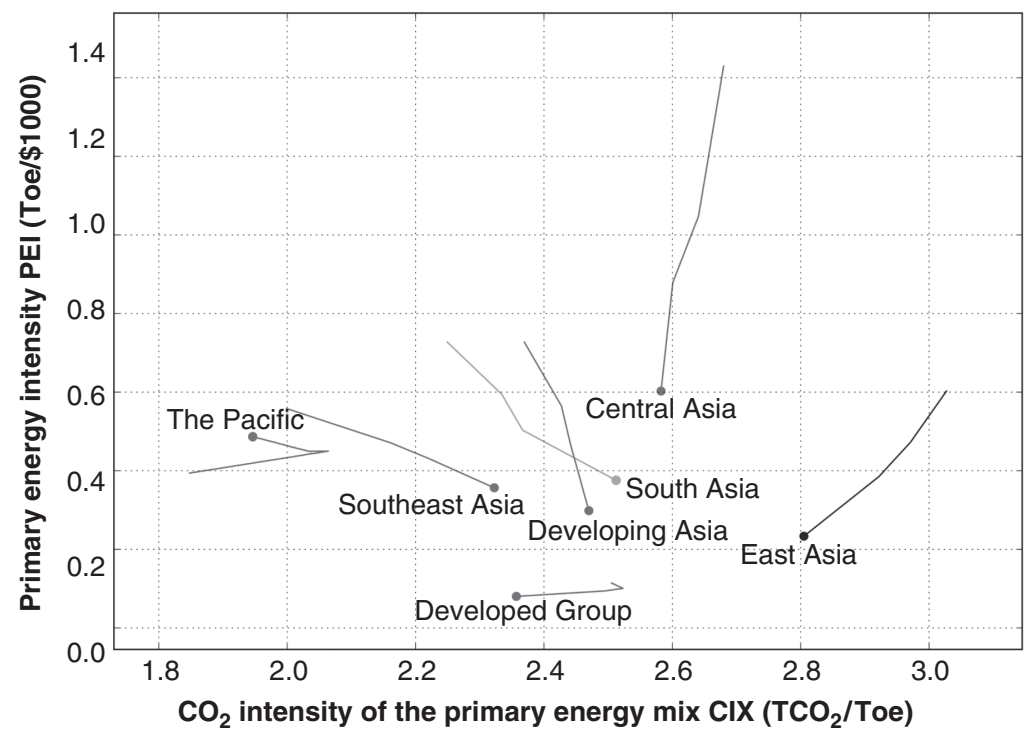

Figure 3.21 Regional primary energy intensity vs carbon dioxide intensity of the primary energy mix, 2010-2035 (named end = 2035)

Source: Authors' calculations with data from ADB (2013).

Note: $\mathrm{CO}_{2}=$ carbon dioxide; $\mathrm{TCO}_{2}=$ tons of $\mathrm{CO}_{2} ; \mathrm{Toe}=$ tons of oil equivalent. 


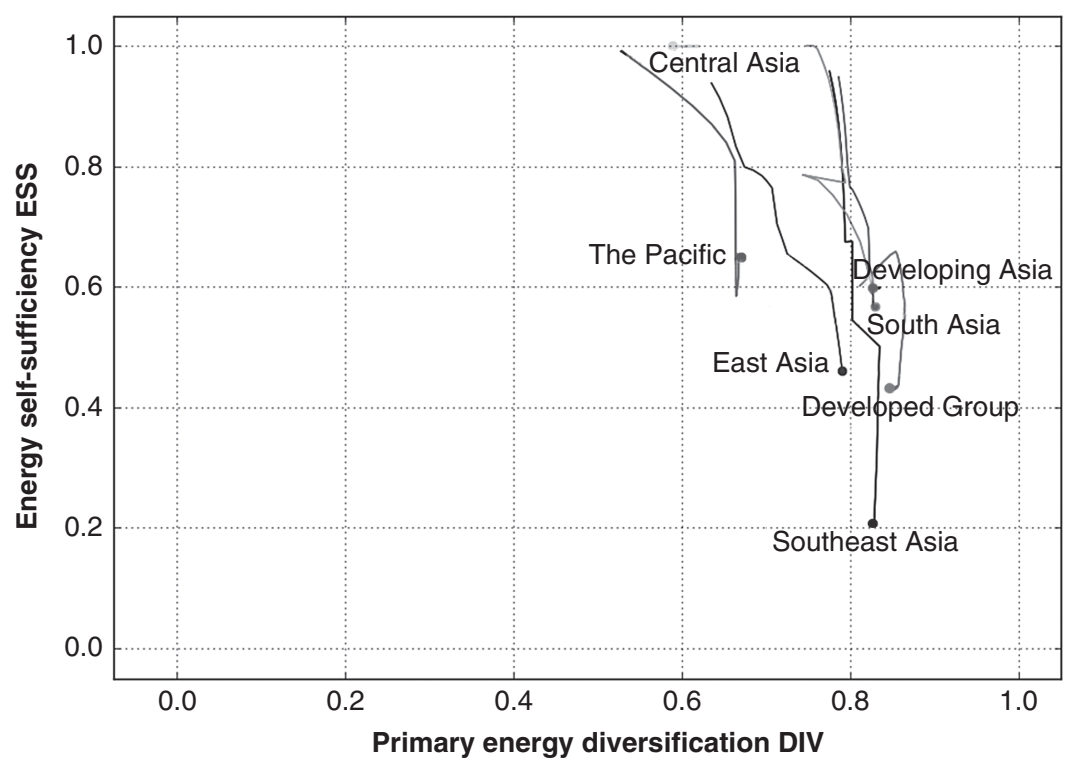

Figure 3.22 Regional energy self-sufficiency vs primary energy diversification, 2010-2035 (named end $=2035)$

Source: Authors' calculations with data from ADB (2013).

Note: for ESS, 1 = self-sufficient; 0 = completely dependent on imports; for DIV 0 = all primary energy is from one source, 1 = energy comes equally from all primary sources considered.

fuels will be replaced by fossil fuels. In Central Asia and the Pacific, this indicator will change slightly since the primary energy mix will remain similar to that in 2010. In East Asia, the CIX is reduced significantly due to the increase in the share of natural gas from $4.6 \%$ to $14.5 \%$ and of nuclear from $2.6 \%$ to $6.4 \%$ and the corresponding reduction in coal from $62.5 \%$ to $48.5 \%$. For the developed group, the CIX improves since the share of coal and oil decreases while the shares of gas and renewables (wind and solar) will grow from $18.1 \%$ to $24.5 \%$ for gas and from $3.3 \%$ to $14.6 \%$ for renewables.

\section{Security}

The ESS will deteriorate in all regions except for Central Asia (Figures 3.22 and 3.23). The decrease is especially significant in East Asia where ESS is reduced from 0.9 to 0.46 and in Southeast Asia where it drops from 0.88 to 0.20 . This means that East Asia will meet approximately $46 \%$ of its energy demand with local resources in 2035, and that Southeast Asia will meet only 20\%. In the developed group, South Asia, and the Pacific, the deterioration in ESS will not be as severe. 
Central Asia

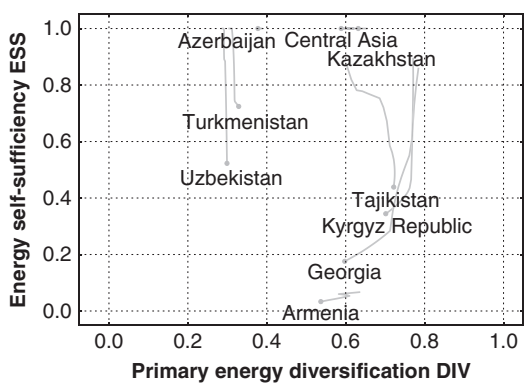

East Asia

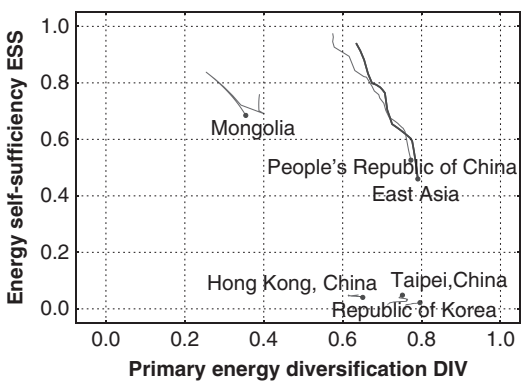

Southeast Asia

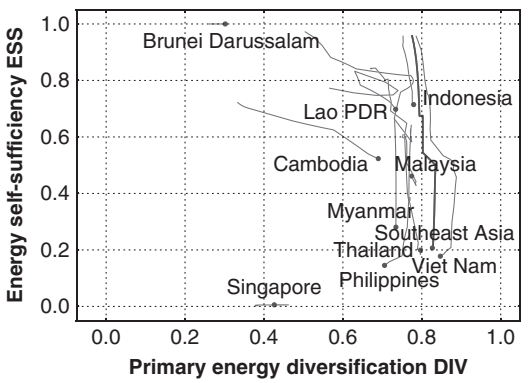

Developed Group

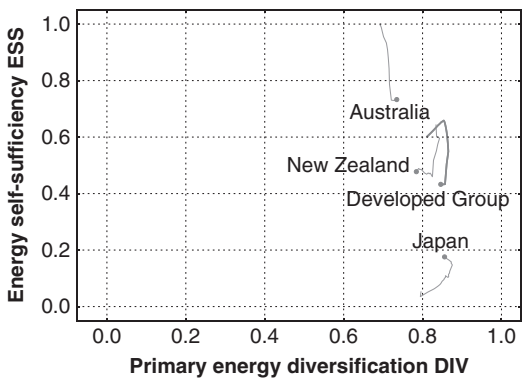

The Pacific

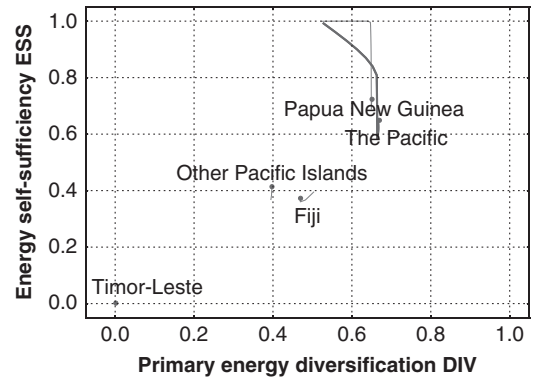

South Asia

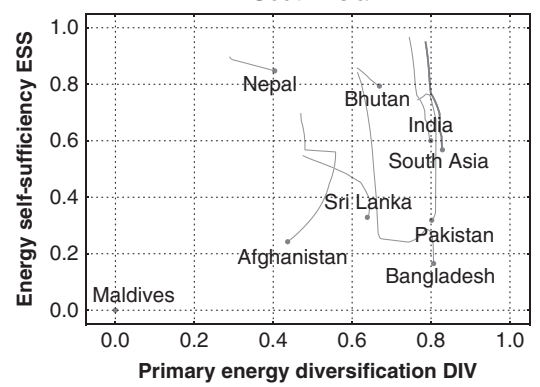

Figure 3.23 Energy self-sufficiency vs primary energy diversification by region, 2010-2035 (named end $=2035)$

Source: Authors' calculations with data from ADB (2013).

Note: for ESS, 1 = self-sufficient; 0 = completely dependent on imports; for DIV 0 = all primary energy is from one source, $1=$ energy comes equally from all primary sources considered. Lao PDR $=$ Lao People's Democratic Republic.

The overall energy security indicator for developing Asia will decrease from 1.0 in 2010 to 0.59 in 2035, mainly due to dependence on external oil. If no new reserves are added to the currently proven ones, imports will have to meet demand. The DIV will, however, remain substantially at 2010 levels for all regions (Figures 3.22 and 3.23). 

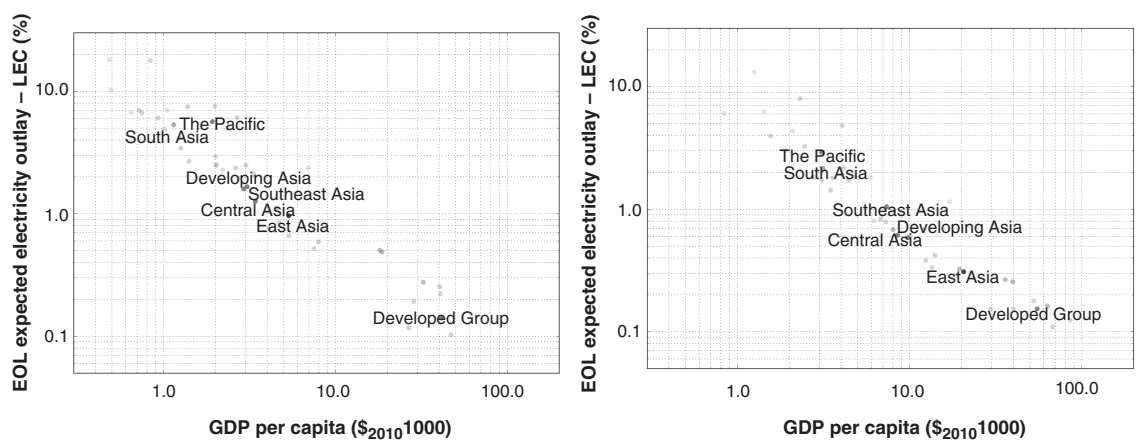

Figure 3.24 Regional expected electricity outlays based on levelized cost of electricity, 2012-2035

Source: Authors' calculations with data from ADB (2013) and IMF (2013).

Note: GDP = gross domestic product, LEC = levelized electricity cost.

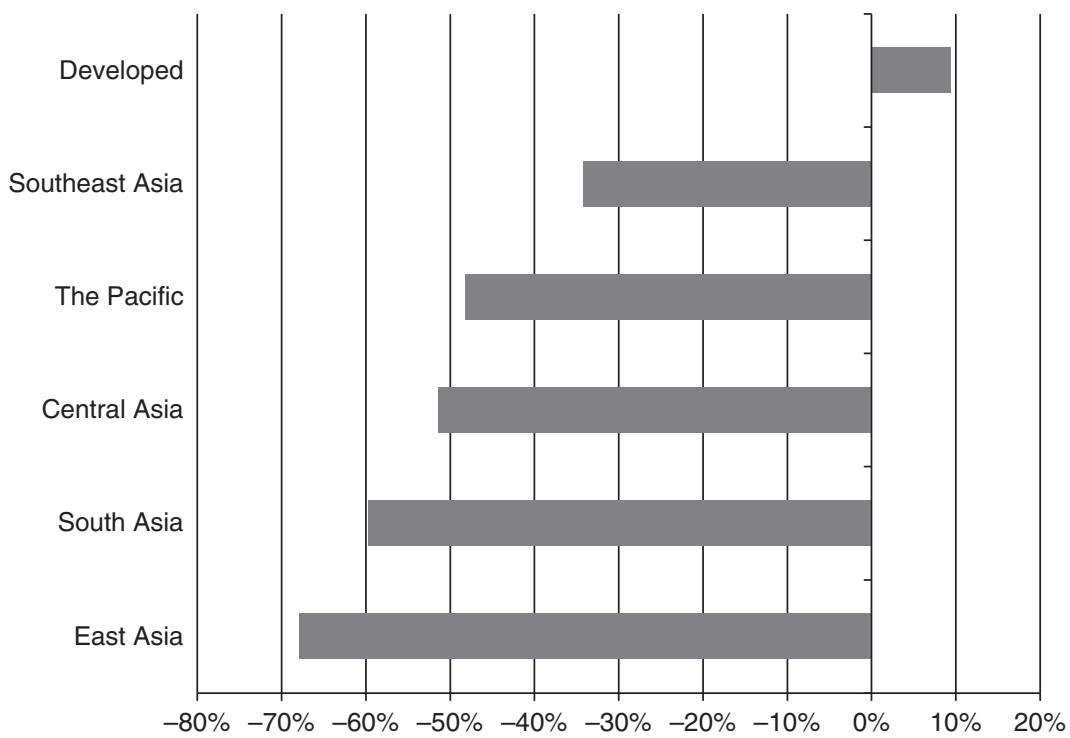

Figure 3.25 Regional change in expected electricity outlays based on levelized cost of electricity, 2012-2035

Source: Authors' calculations with data from ADB (2013) and IMF (2013).

\section{Affordability}

Affordability usually increases with development; therefore, the lowest expected electricity outlays based on EOL are found in the developed group (Figure 3.24). Central Asia, South Asia, and the Pacific have the highest EOL. 
From 2012 to 2035, affordability will improve in all regions except in the developed group where it decreases slightly (Figure 3.25). East Asia has the highest increase in affordability; in Central Asia, South Asia, and the Pacific, the improvement is also substantial.

\section{Benefits of integration}

Based on the foregoing analysis, this section summarizes the benefits afforded by integrating energy systems regionally in terms of both security and affordability.

\section{Security}

From the analysis of ESS, Central Asia offers the most distinct benefits for regional integration. Considered separately, the ESS of most economies will decrease substantially from 2012 to 2035 , but the aggregate regional security indicator will remain high due to the fossil fuel reserves in Azerbaijan, Kazakhstan, and Turkmenistan.

In East Asia and South Asia, the aggregate ESS indicator is largely influenced by the PRC and India, respectively. In East Asia, regional integration can improve the security of the Republic of Korea and of Taipei,China especially regarding coal. Large coal reserves in the PRC and Mongolia can help meet demand for the share of coal in their primary energy mix to be $16 \%$ and $27 \%$ in 2035 , respectively. A parallel situation is in South Asia where large coal reserves in India can help improve the energy security of Sri Lanka whose coal share in the primary energy mix will be $24 \%$ in 2035. Afghanistan and Pakistan would improve their energy security with better integration with Central Asia which has important oil and gas reserves. Despite the significant fossil fuel reserves in Indonesia and Malaysia, in Southeast Asia ESS will deteriorate significantly from 2012 to 2035 even as a regional aggregate.

In the developed group, the large coal and uranium reserves in Australia can improve the energy security of Japan whose coal and nuclear share in the primary energy mix in 2035 will be $24 \%$ and $4.5 \%$, respectively. In the Pacific, the fossil fuel reserves of Papua New Guinea would improve the energy security of Fiji, Timor-Leste, and other Pacific islands.

Another noticeable benefit of regional integration would be an increase in the diversification of the power systems (Figure 3.26). In most areas, the diversification of the power sector is larger regionally than nationally. In Central Asia and Southeast Asia, the improvement in diversification is quite noteworthy. Some economies base power generation largely on a single source (for instance coal in Kazakhstan, natural gas in Turkmenistan, or hydro in Tajikistan). Aggregating national systems not only increases diversification but also results in a balanced power sector with most of the conventional technologies contributing significantly to the aggregate.

Integrating national power systems into regional systems can have advantages in addition to that of increased diversification. The large-scale deployment of intermittent renewable energy (e.g., wind and solar) poses additional challenges for managing power systems (such as following demand or regulating frequencies). 


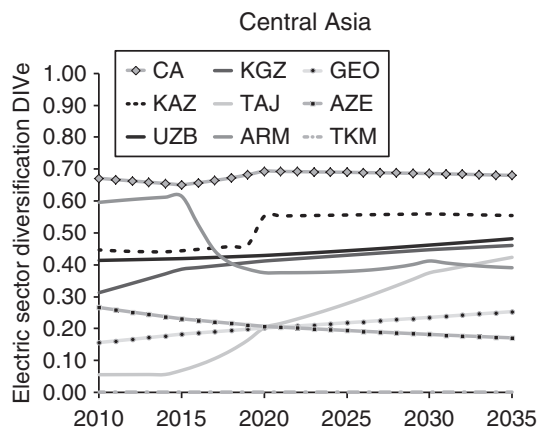

Developed Group

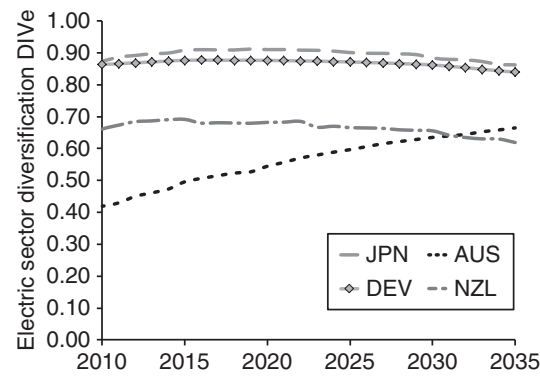

East Asia

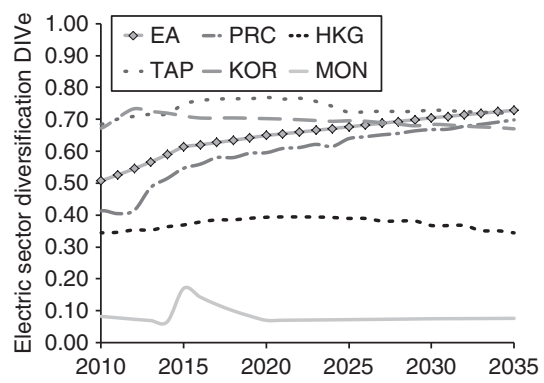

The Pacific

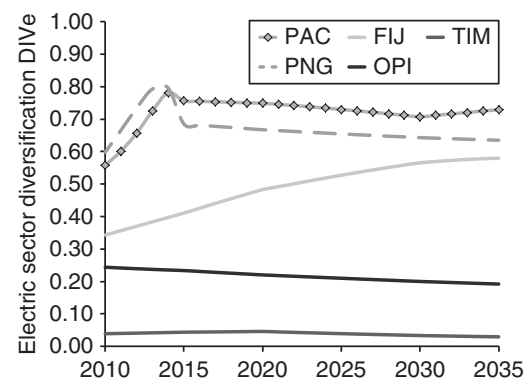

Southeast Asia
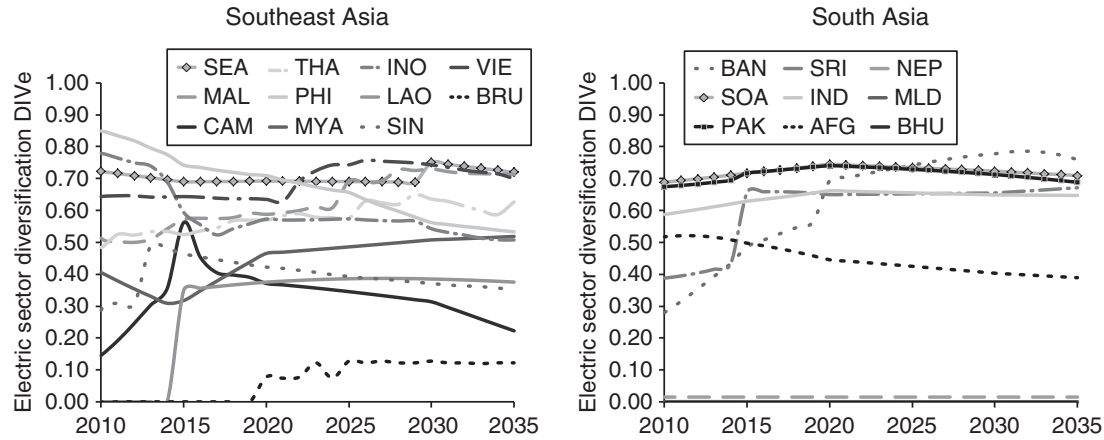

Figure 3.26 Change in the power (electricity) sector diversification indicator, 2010-2035 Source: Authors' calculations with data from ADB (2013).

Note: $\mathrm{AFG}=$ Afghanistan; $\mathrm{ARM}=$ Armenia $\mathrm{AUS}=$ Australia; $\mathrm{AZE}=$ Azerbaijan; $\mathrm{BAN}=$ Bangladesh; $\mathrm{BRU}=$ Brunei Darussalam; $\mathrm{BHU}=$ Bhutan $; \mathrm{CA}=$ Central Asia $\mathrm{CAM}=$ Cambodia; $\mathrm{DEV}=$ developed group; $\mathrm{EA}=$ East Asia; FIJ = Fiji; $\mathrm{GEO}=$ Georgia HKG $=$ Hong Kong, China; INO = Indonesia; $\mathrm{IND}=$ India; JPN $=$ Japan; KAZ $=$ Kazakhstan $; \mathrm{KGZ}=$ Kyrgyz Republic; LAO $=$ Lao People's Democratic Republic; MAL = Malaysia; MLD = Maldives; $\mathrm{MON}=$ Mongolia; MYA $=$ Myanmar; NEP = Nepal; NZL = New Zealand; OPI = Other Pacific Islands; PNG = Papua New Guinea; PAC = The Pacific; PAK $=$ Pakistan; PRC $=$ People's Republic of China; KOR $=$ Republic of Korea; PHF = Philippines; SEA $=$ Southeast Asia; SIN $=$ Singapore; $\mathrm{SOA}=$ South Asia; SRI $=$ Sri Lanka; TAJ = Tajikistan; TAP = Taipei,China; THA = Thailand; TIM = Timor-Leste; TKM = Turkmenistan; $\mathrm{UZB}=$ Uzbekistan; VIE $=$ Viet Nam. 


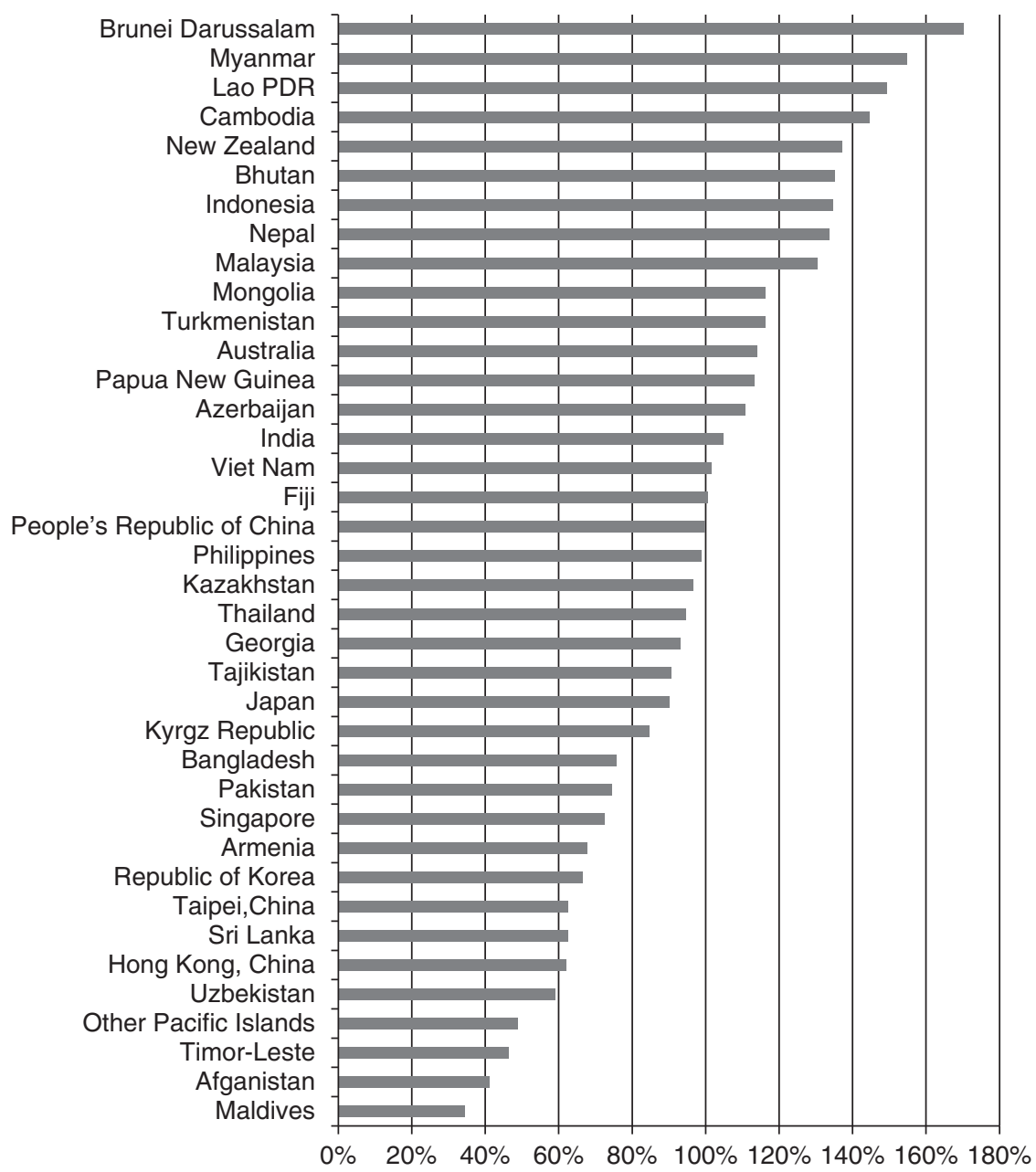

Figure 3.27 Ratio of regional levelized electricity cost to national levelized electricity cost in 2035

Source: Authors' calculations with data from ADB (2013) and IMF (2013).

Note: Lao PDR = Lao People's Democratic Republic.

Regionally integrating the power grid renders the system more manageable for larger shares of renewables (e.g. more than 20\%). Countries with a large share of renewables (e.g., Denmark) need high-capacity, international power grid interconnections to manage the system. In Asian countries with a large fraction of hydropower (Bhutan, Kyrgyz Republic, Lao People's Democratic Republic, Myanmar, Nepal, and Tajikistan), regional integration will help avoid the effect 

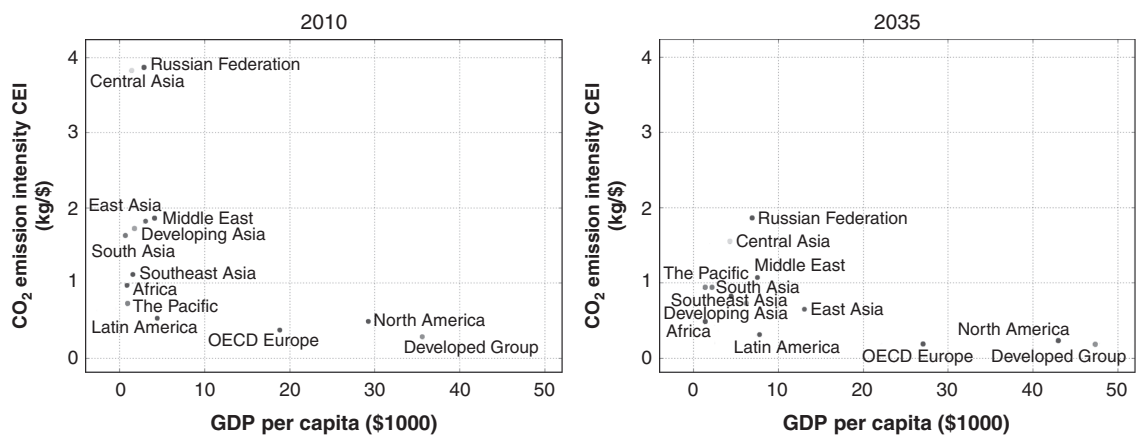

Figure 3.28 Carbon dioxide emission intensity in Asia and the Rest of the World in 2010 and 2035

Source: Authors' calculations with data from ADB (2013), IEA (2010) and IMF (2013).

Note: $\mathrm{CO}_{2}=$ carbon dioxide; $\mathrm{GDP}=$ gross domestic product; $\mathrm{kg}=$ kilogram.
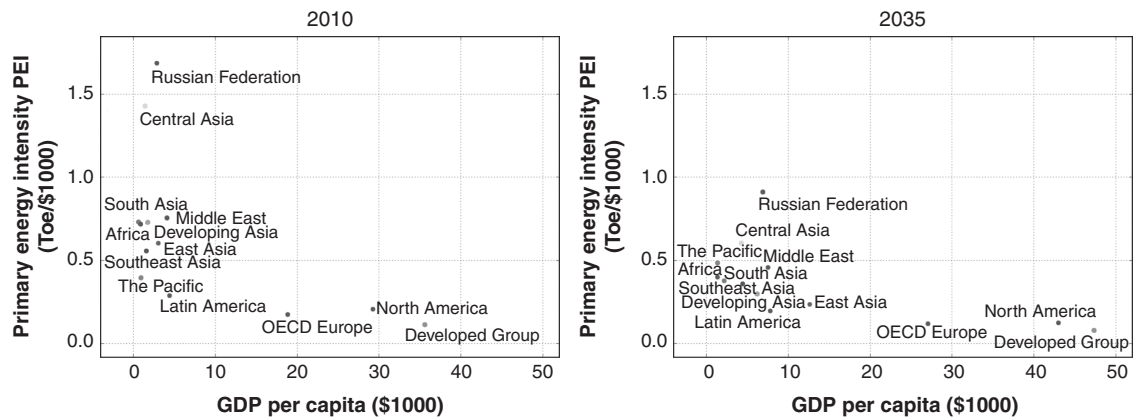

Figure 3.29 Primary energy intensity in Asia and the Rest of the World in 2010 and 2035 Source: Authors' calculations with data from ADB (2013), IEA (2010) and IMF (2013).

Note: GDP $=$ gross domestic product; Toe $=$ tons of oil equivalent.

on the energy system of dry years and will assist with the harmonization of competing uses for inland water (e.g., power in winter and irrigation in summer).

\section{Affordability}

Regional integration would alleviate the cost of importing fuels for economies without indigenous fuel resources like islands (Maldives, Sri Lanka, Taipei,China, and Timor-Leste) and for those whose fossil fuel reserves will be depleted by 2035 (Afghanistan, Bangladesh, Japan, Republic of Korea, Pakistan). In those economies, the regionally aggregated LEC is lower than the national LEC (Figure 3.27). Economies with fossil fuel reserves (Australia, Azerbaijan, Brunei Darussalam, 

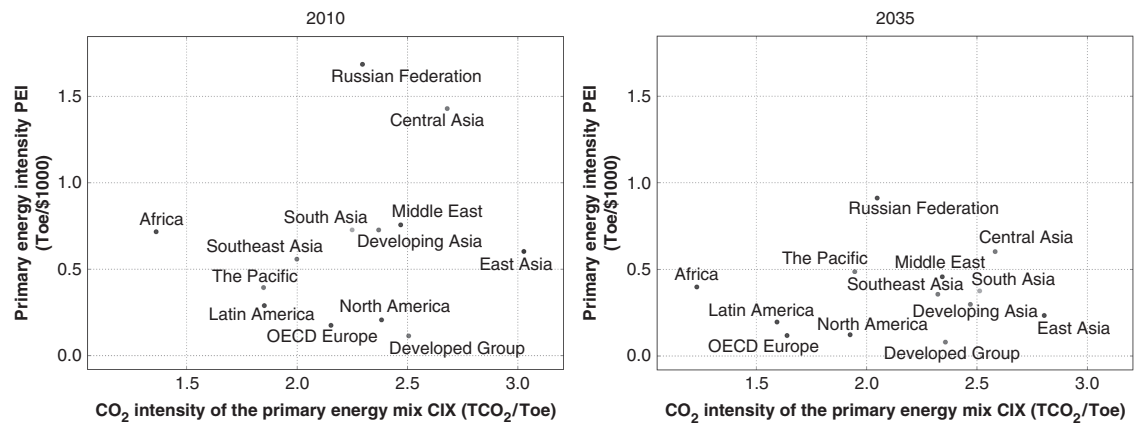

Figure 3.30 Primary energy intensity and carbon dioxide intensity of the primary energy mix in Asia and the Rest of the World in 2010 and 2035

Source: Authors' calculations with data from ADB (2013) and IEA (2010).

Note: GDP = gross domestic product; Toe $=$ tons of oil equivalent.

Indonesia, Mongolia) or those with power systems based on hydro (Bhutan, Lao People's Democratic Republic, Myanmar, Nepal) will not improve affordability through regional integration.

\section{International benchmarking}

In this section, we compare the energy indicators calculated for Asia with those in Africa, Latin America, the Middle East, North America, Organisation for Economic Co-operation and Development (OECD) Europe, and the Russian Federation using the forecasts for the new policies scenarios in The World Energy Outlook 2010 (IEA 2010). This is considered as a BAU scenario, but it takes into account the latest policy commitments on greenhouse gas emissions and renewable targets.

\section{Sustainability}

The current CEI of Asia is one of the highest in the world surpassed only by those of the Russian Federation and the Middle East (Figure 3.28). It is approximately four times as high as the CEI in Europe or North America, three times as high as Latin America and twice that of Africa. It varies from the Pacific with a CEI similar to that of Latin America to Central Asia which has a CEI closer to the Russian Federation's. The CEI in Asia will be reduced by $50 \%$ in 2035 from 2010 levels, but as a similar reduction is expected in the rest of the world, the relative difference will remain largely unchanged. The significant reduction in the CEI in the East Asia is noteworthy, but the CEI will increase in the Pacific.

As stated previously, PEI is strongly correlated with economic growth (Figure 3.29). In 2010, the PEI of Asia was four times as high as that of Europe or North 
2010
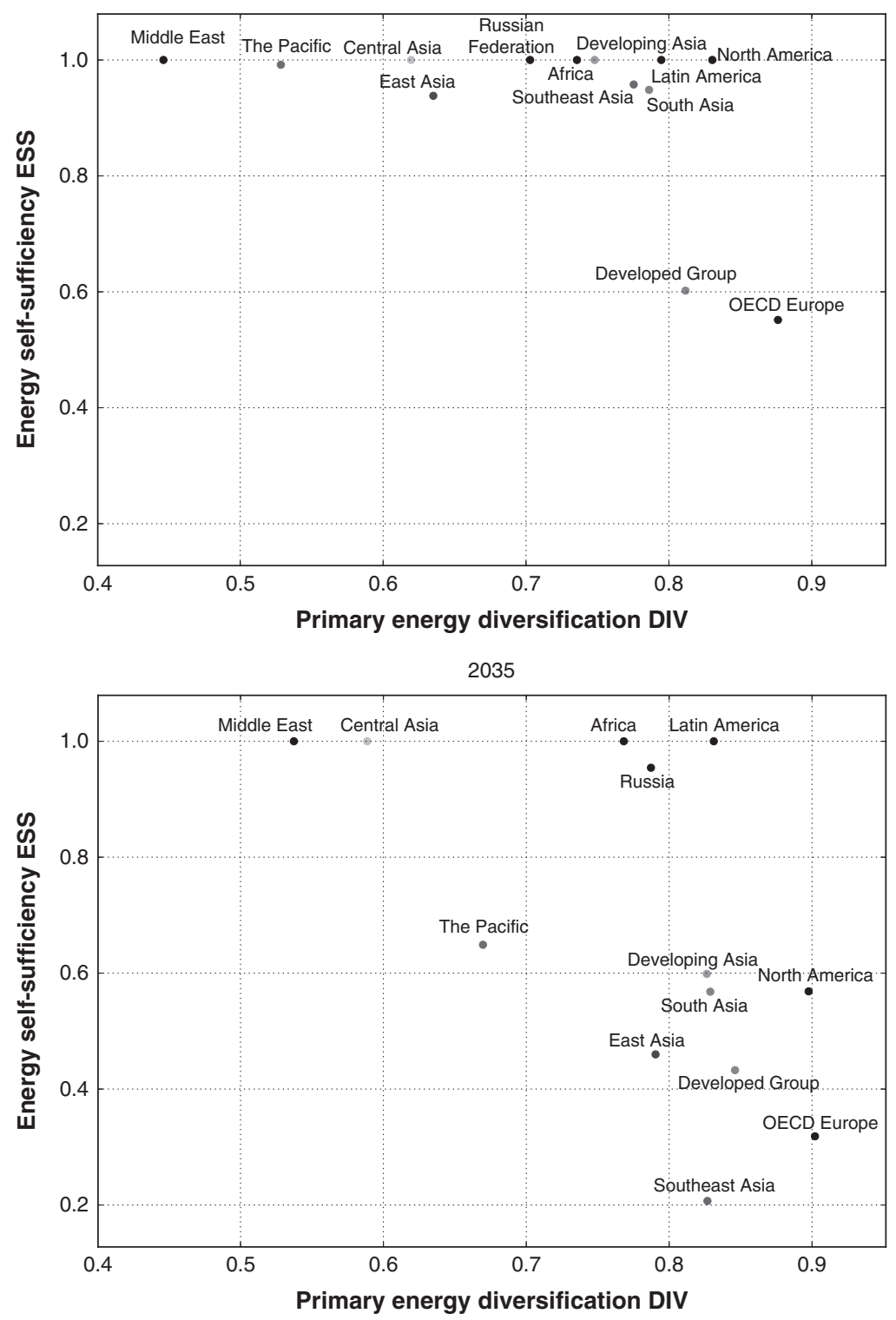

Figure 3.31 Energy self-sufficiency and primary energy diversification in Asia and the Rest of the World in 2010 and 2035

Source: Authors' calculations with data from ADB (2013) and IEA (2010). 

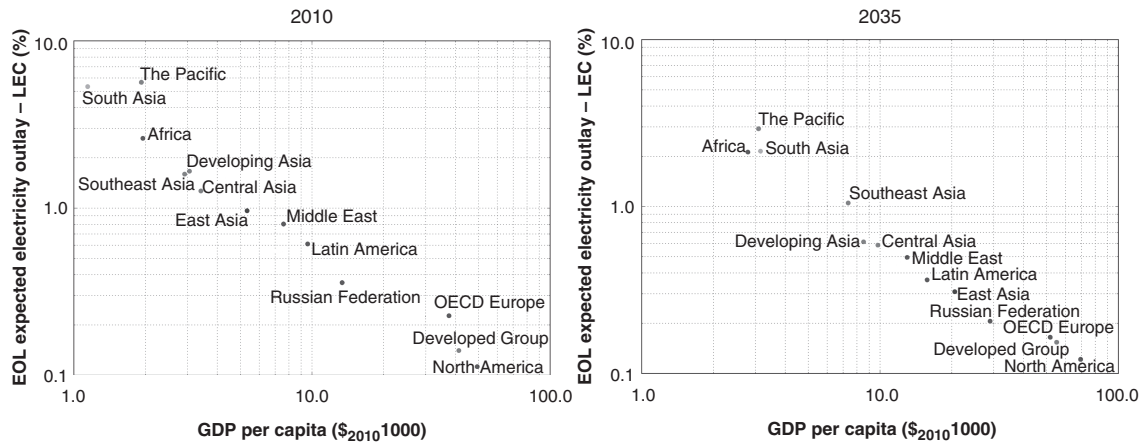

Figure 3.32 Expected electricity outlay in Asia and the Rest of the World in 2010 and 2035 Source: Authors' calculations with data from ADB (2013), IEA (2010) and IMF (2013).

Note: GDP $=$ gross domestic product; LEC $=$ levelized electricity cost.

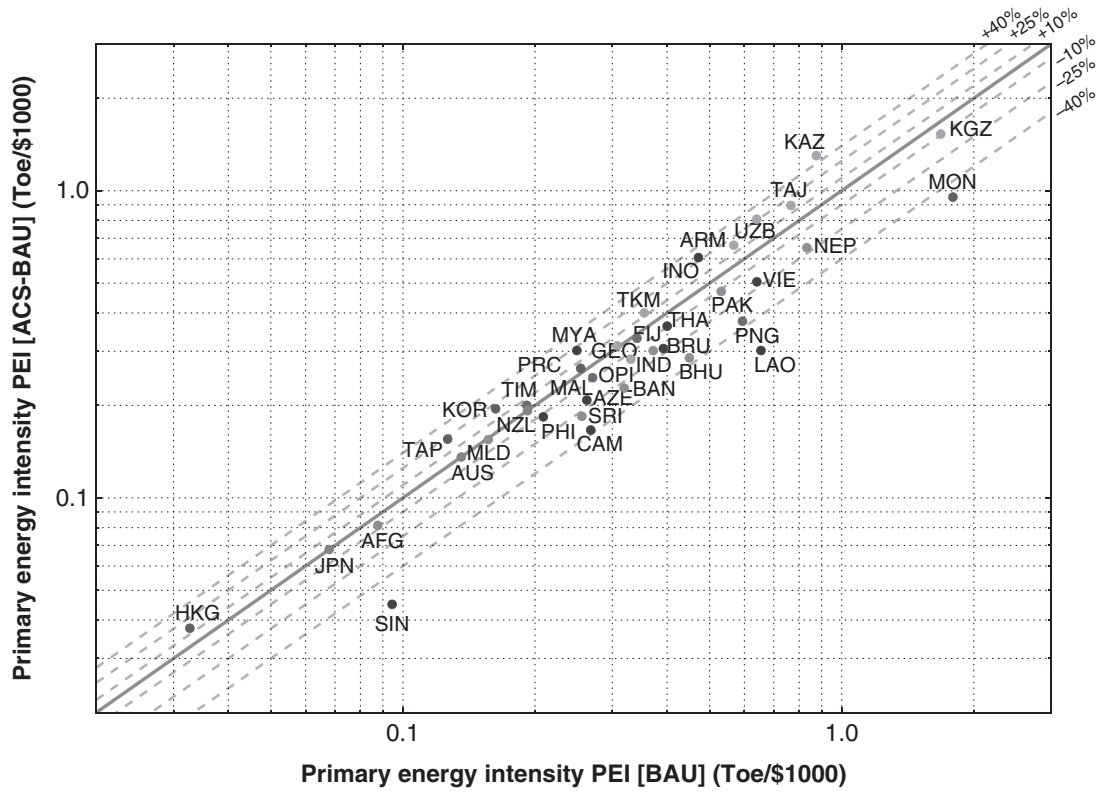

Figure 3.33 Primary energy intensity in business-as-usual scenario vs Asian Century/ business-as-usual scenario

Source: Authors' calculations with data from ADB (2013).

Note: $\mathrm{AFG}=\mathrm{Afghanistan} ; \mathrm{ARM}=$ Armenia; $\mathrm{AUS}=$ Australia ; AZE = Azerbaijan; $\mathrm{BAN}=$ Bangladesh; BHU $=$ Bhutan; $\mathrm{BRU}=$ Brunei Darussalam; $\mathrm{CAM}=$ Cambodia; FIJ $=$ Fiji; GDP $=$ gross domestic product; $\mathrm{GEO}=$ Georgia; HKG = Hong Kong, China; IND = India; INO = Indonesia; JPN = Japan; KAZ $=$ Kazakhstan; KOR $=$ Republic of Korea; KGZ = Kyrgyz Republic; LAO = Lao People's Democratic Republic; MAL = Malaysia; MLD = Maldives; MON = Mongolia; MYA = Myanmar; $\mathrm{NEP}=$ Nepal NZL $=$ New Zealand OPI $=$ Other Pacific Islands; PAK = Pakistan; $\mathrm{PNG}=$ Papua New Guinea; PHI $=$ Philippines; PRC $=$ China, People's Republic of; SIN $=$ Singapore; SRI $=$ Sri Lanka; TAP $=$ Taipei,China; TAJ $=$ Tajikistan; THA $=$ Thailand; TIM = Timor-Leste; TKM = Turkmenistan; Toe $=$ tons of oil equivalent; UZB $=$ Uzbekistan; VIE $=$ Viet Nam. 
America, twice that of Latin America, and similar to Africa's. PEI also varies substantially in developing Asia. The Pacific had a PEI of 0.49 Toe/\$1000 in 2010 while for Central Asia it was 1.43. By 2035, the PEI will decrease to a greater extent in Asia than in other parts of the world due to greater economic growth. It will be $25 \%$ lower than Africa's, and it will be closer to that in Latin America but nearly three times that of the developed world. East Asia will have the greatest reduction.

This significant reduction in PEI in Asia will not, however, be matched by a similar reduction in CEI due to the fact that the CIX will remain high compared with the other regions of the world (Figure 3.30). The high CIX is the result of substituting traditional fuels with fossil fuels, a high reliance on coal, and the low penetration of renewable energy sources (as forecast in the scenarios).

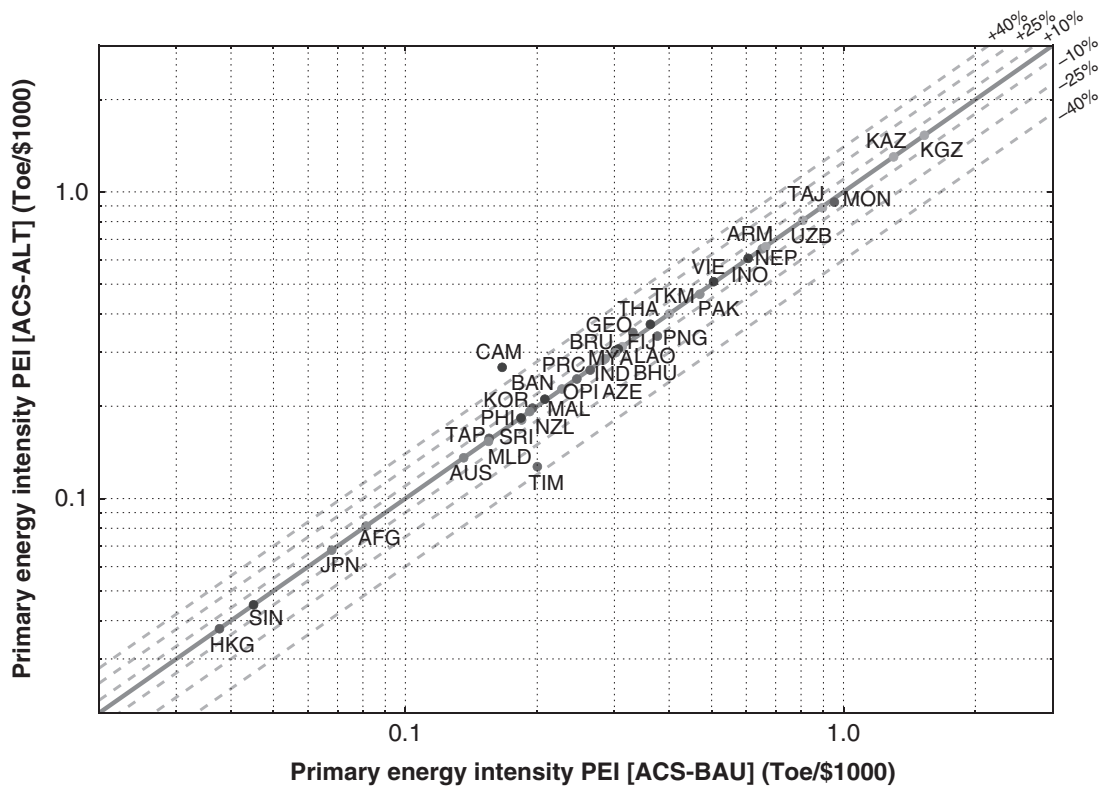

Figure 3.34 Primary energy intensity in Asian Century/alternative scenario vs Asian Century/business-as-usual scenario

Source: Authors' calculations with data from ADB (2013).

Note: $\mathrm{AFG}=$ Afghanistan; $\mathrm{ARM}=$ Armenia; $\mathrm{AUS}=$ Australia AZE = Azerbaijan; $\mathrm{BAN}=$ Bangladesh; $\mathrm{BHU}=$ Bhutan; BRU = Brunei Darussalam; CAM = Cambodia; FIJ = Fiji; GDP = gross domestic product; GEO = Georgia; HKG = Hong Kong, China; IND = India; INO = Indonesia; JPN = Japan; KAZ = Kazakhstan; KOR = Republic of Korea; KGZ = Kyrgyz Republic; LAO = Lao People's Democratic Republic; MAL = Malaysia; MLD = Maldives; $\mathrm{MON}=$ Mongolia; $\mathrm{MYA}=$ Myanmar; NEP = Nepal; NZL = New Zealand; OPI = Other Pacific Islands; PAK = Pakistan; PNG = Papua New Guinea; PHI = Philippines; PRC = China, People's Republic of; SIN = Singapore; SRI = Sri Lanka; TAP = Taipei,China; TAJ = Tajikistan; THA = Thailand; TIM = Timor-Leste; TKM = Turkmenistan; Toe $=$ tons of oil equivalent; $\mathrm{UZB}=$ Uzbekistan; VIE $=$ Viet Nam. 


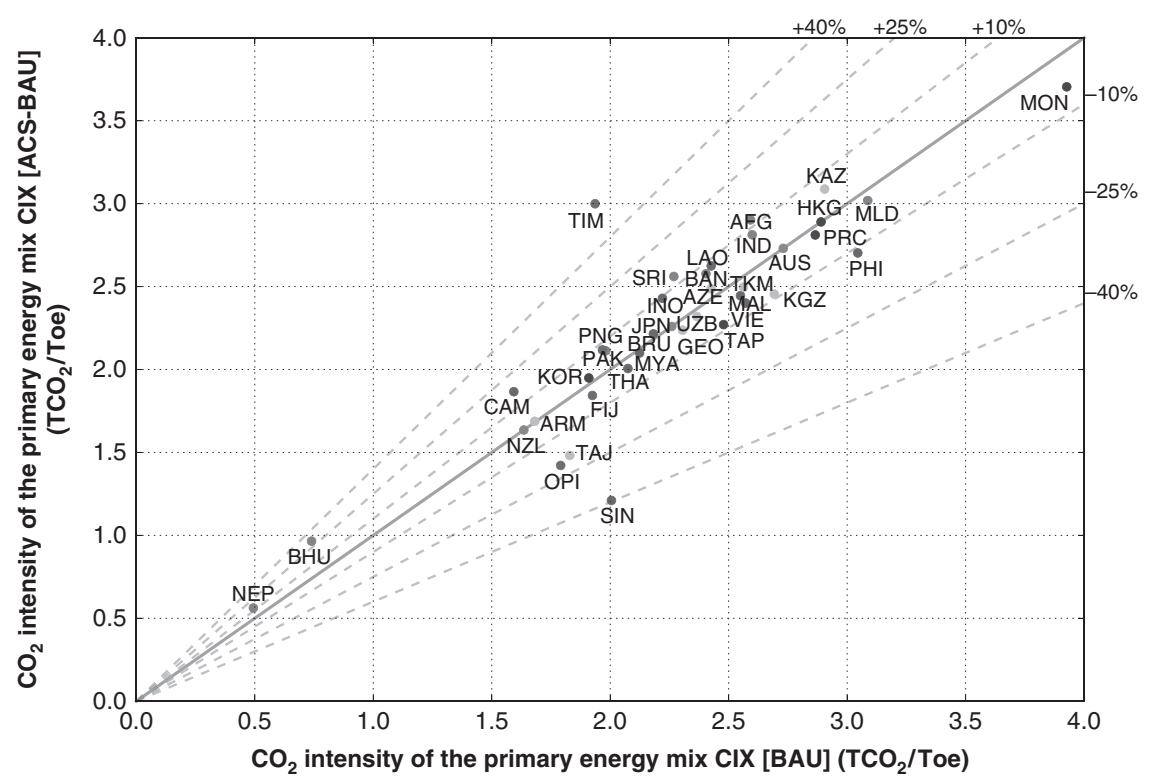

Figure 3.35 Carbon dioxide intensity of the primary energy mix in business-as-usual scenario vs Asian Century/business-as-usual scenario

Source: Authors' calculations with data from ADB (2013).

Note: See Figure 3.34 for the abbreviations. $\mathrm{CO}_{2}=$ carbon dioxide; $\mathrm{TCO}_{2}=$ tons of $\mathrm{CO}_{2}$; Toe $=$ tons of oil equivalent.

\section{Security}

Overall, the ESS in Asia deteriorates considerably between 2010 and 2035 (Figure 3.31). Although the region was nearly energy independent in 2010, the indicator will fall to 0.59 by 2035 ; only about $60 \%$ of the energy demand will be met with local resources. This is substantially more than in Europe and similar to North America. In contrast, Africa, Central Asia, Latin America, the Middle East, and the Russian Federation will maintain their high ESS values. DIV will, however, increase in Asia and will be only slightly less than in developed countries.

\section{Affordability}

Energy affordability is tightly coupled to economic growth. In 2010, the EOL in Asia was 16 times that of North America, 8 times that of Europe, and 3 times that of Latin America (Figure 3.32). In contrast, it was nearly half that of Africa.

By 2035, energy will be much more affordable in Asia because of strong economic growth. The EOL will be four times that of Europe and North America and twice that of Latin America, but it will vary substantially. In East Asia it will be $0.31 \%$ which is lower than that in Latin America and the Middle East, and in South Asia it will be $2.15 \%$, similar to Africa. 


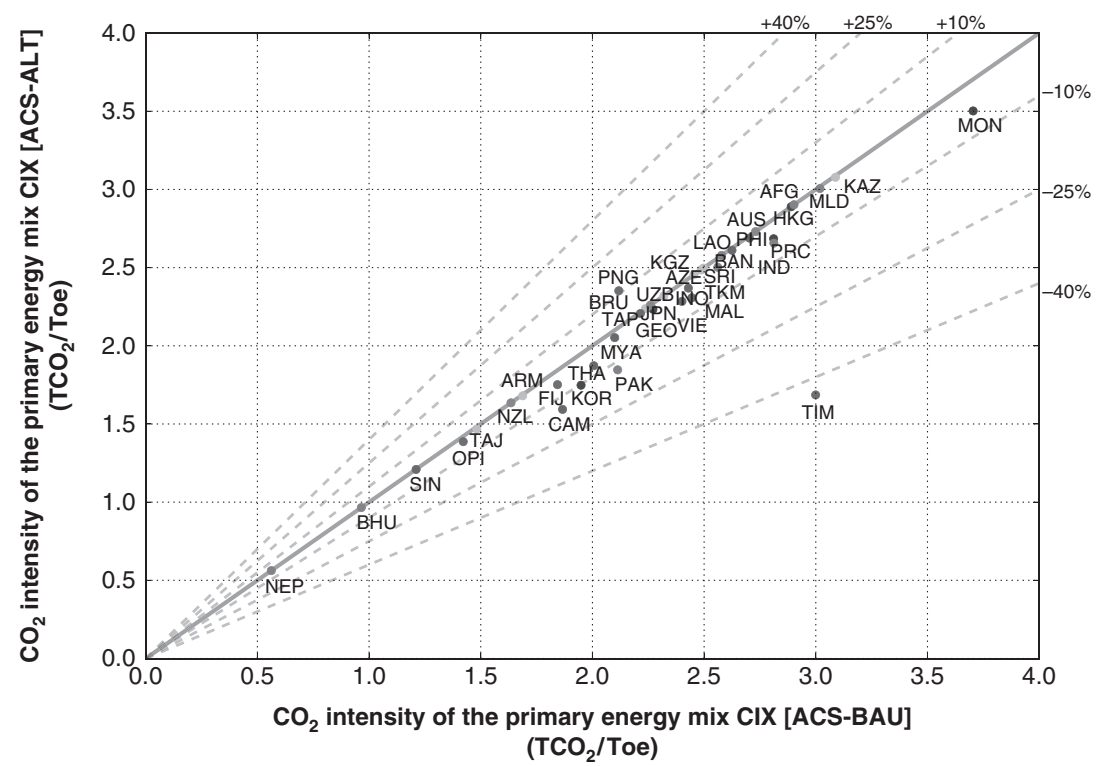

Figure 3.36 Carbon dioxide intensity of the primary energy mix in Asian Century/alternative scenario vs Asian Century/business-as-usual scenario

Source: Authors' calculations with data from ADB (2013).

Note: $\mathrm{AFG}=$ Afghanistan; $\mathrm{ARM}=$ Armenia; $\mathrm{AUS}=$ Australia $; \mathrm{AZE}=$ Azerbaijan; $\mathrm{BAN}=$ Bangladesh; $\mathrm{BHU}=$ Bhutan; $\mathrm{BRU}=$ Brunei Darussalam; $\mathrm{CAM}=$ Cambodia $; \mathrm{CO}_{2}=$ carbon dioxide; $\mathrm{FIJ}=$ Fiji; $\mathrm{GDP}=$ gross domestic product; $\mathrm{GEO}=$ Georgia; $\mathrm{HKG}=$ Hong Kong, China; IND = India; INO = Indonesia; JPN = Japan; KAZ = Kazakhstan; KOR $=$ Republic of Korea; KGZ = Kyrgyz Republic; LAO = Lao People's Democratic Republic; MAL $=$ Malaysia; MLD $=$ Maldives; MON $=$ Mongolia; MYA $=$ Myanmar; NEP = Nepal; NZL = New Zealand; OPI = Other Pacific Islands; PAK = Pakistan; PNG = Papua New Guinea; $\mathrm{PHI}=$ Philippines; $\mathrm{PRC}=$ China, People's Republic of; $\mathrm{SIN}=$ Singapore; $\mathrm{SRI}$ = Sri Lanka; TAP $=$ Taipei,China; TAJ = Tajikistan; THA = Thailand; TIM = Timor-Leste; TKM = Turkmenistan; $\mathrm{TCO}_{2}=$ tons of $\mathrm{CO}_{2}$; Toe $=$ tons of oil equivalent; $\mathrm{UZB}=$ Uzbekistan; VIE $=$ Viet Nam.

\section{Alternative scenarios}

In this section, we compare the security, affordability, and sustainability indicators for the following scenarios (ADB 2013).

- $\quad$ Business as usual (BAU). The baseline.

- Asian Century/BAU (ACS-BAU). Energy demand is derived from the macroeconomic parameters for the Asian Century (Kohli, Sharma, and Sood 2011) with national energy sectors following a BAU trend.

- Asian Century/alternative (ACS-ALT). The macroeconomic parameters are the same, but there is an increased emphasis on renewable and nuclear energy and on additional energy efficiency measures.

All figures in this section are for 2035. 


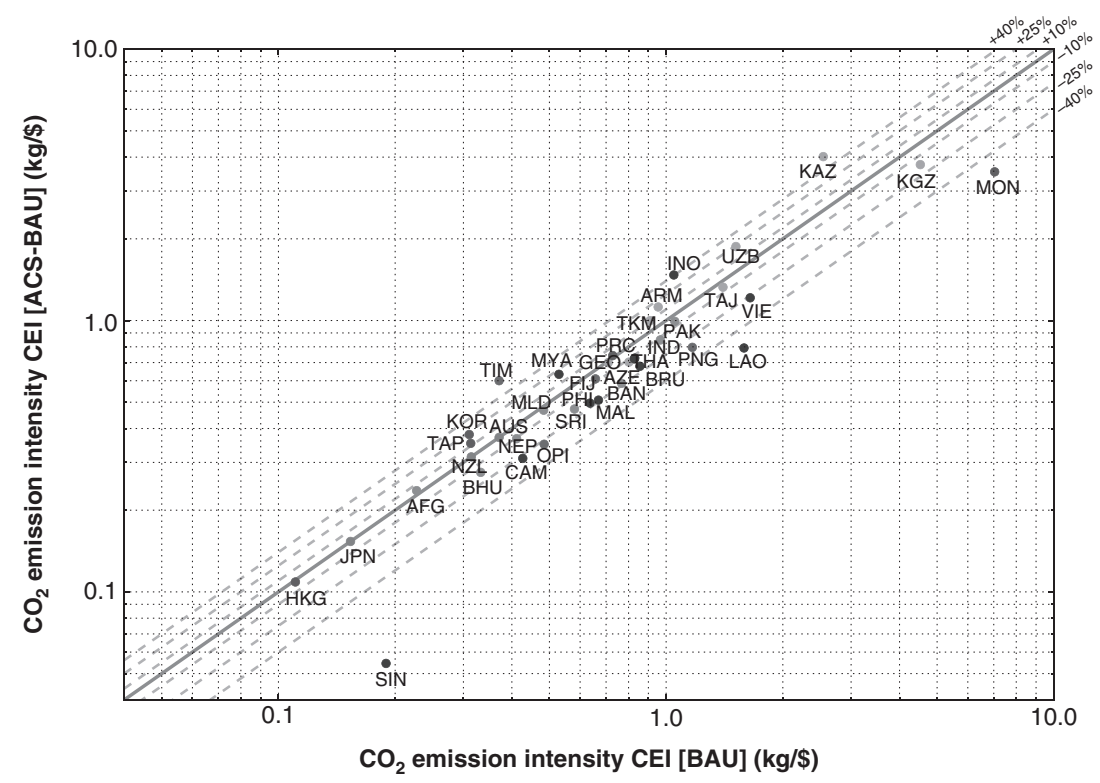

Figure 3.37 Carbon dioxide emission intensity in business-as-usual scenario vs Asian Century/business-as-usual scenario

Source: Authors' calculations with data from ADB (2013).

Note: See Figure 3.36 for the abbreviations. kg = kilogram.

\section{Impact on sustainability}

As a general trend, the PEI for Asia and the Pacific in 2035 is less in ACS-BAU than in the BAU scenario (Figure 3.33) because GDP growth is usually faster under the ACS-BAU hypotheses and PEI generally decreases with development. The PEI is, however, greater in ACS-BAU than in BAU in parts of East Asia (PRC; Hong Kong, China; Republic of Korea; and Taipei,China) and in Central Asia (Armenia, Kazakhstan, Tajikistan, Turkmenistan, and Uzbekistan). Except for the PRC, this is because growth is faster in the BAU scenario than in ACS-BAU. In the PRC, economic growth is slightly faster in ACS-BAU than in BAU, but so is the increase in energy consumption. As a consequence, the PEI in the PRC is $3.9 \%$ higher in ACS-BAU compared with BAU. The overall PEI in Asia in 2035 does not change significantly between ACS-BAU (276 Toe/\$1000) and BAU (278 Toe/\$1000).

In most economies, the PEI is slightly lower in ACS-ALT than in ACS-BAU due to additional energy efficiency measures; however, the differences are very small (Figure 3.34). The main exception is Cambodia where the PEI in 2035 is higher under ACS-ALT. This is because economic growth in Cambodia is greater under ACS-BAU.

There is no single regional trend in CIX when the BAU scenario and ACSBAU are compared (Figure 3.35). $\mathrm{CO}_{2}$ intensity increases in ACS-BAU in less 


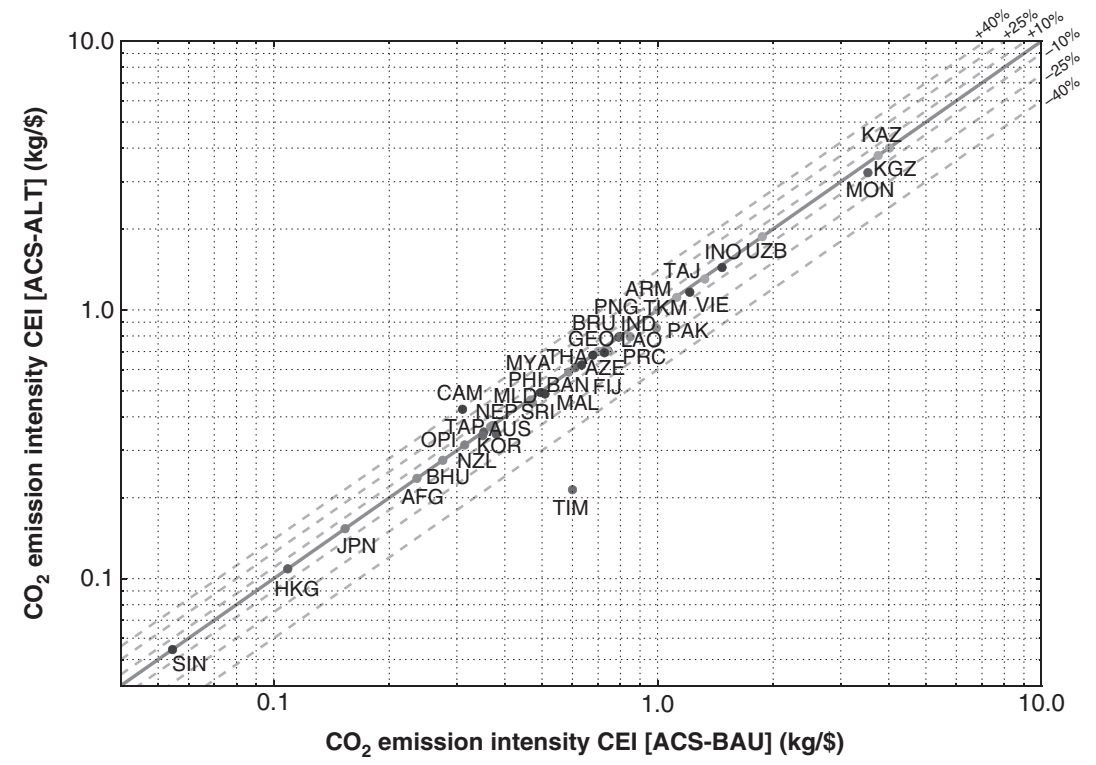

Figure 3.38 Carbon dioxide emission intensity in Asian Century/alternative scenario vs Asian Century/business-as-usual scenario

Source: Authors' calculations with data from ADB (2013).

Note: $\mathrm{AFG}=$ Afghanistan ARM = Armenia; $\mathrm{AUS}=$ Australia AZE = Azerbaijan; $\mathrm{BAN}=$ Bangladesh; $\mathrm{BHU}=$ Bhutan; $\mathrm{BRU}=$ Brunei Darussalam; $\mathrm{CAM}=$ Cambodia $\mathrm{CO}_{2}=$ carbon dioxide; FIJ $=$ Fiji; $\mathrm{GDP}=$ gross domestic product; $\mathrm{GEO}=$ Georgia; $\mathrm{HKG}=$ Hong Kong, China; IND = India; INO = Indonesia; JPN = Japan; KAZ = Kazakhstan; kg = kilogram; KOR = Republic of Korea; KGZ = Kyrgyz Republic; LAO = Lao People's Democratic Republic; MAL = Malaysia; MLD = Maldives; MON $=$ Mongolia; MYA $=$ Myanmar; NEP $=$ Nepal; NZL $=$ New Zealand; OPI $=$ Other Pacific Islands; PAK $=$ Pakistan; PNG $=$ Papua New Guinea; PHI $=$ Philippines; PRC $=$ China, People's Republic of; SIN $=$ Singapore; $\quad$ SRI $=$ Sri Lanka; TAP $=$ Taipei,China; TAJ $=$ Tajikistan; THA $=$ Thailand; TIM = Timor-Leste; TKM = Turkmenistan; UZB = Uzbekistan; VIE = Viet Nam.

developed economies due to substituting traditional carbon-neutral fuels with fossil fuels. In some of the more developed economies, the CIX increases due to the larger contribution of coal. The CIX is lower for most economies under ACSALT than ACS-BAU due to the increased contribution of renewables and nuclear (Figure 3.36).

The difference in CEI between ACS-BAU and BAU is similar to that for PEI. In East Asia and Central Asia, the CEI is generally higher under ACS-BAU than BAU while the trend is the opposite one in the rest of Asia (Figure 3.37). Overall, the CEI in developing economies does not change substantially under different scenarios (ACS-BAU 739 tons of $\mathrm{CO}_{2} / \$ 1000$ vs. BAU 747 tons of $\left.\mathrm{CO}_{2} / \$ 1000\right)$. 


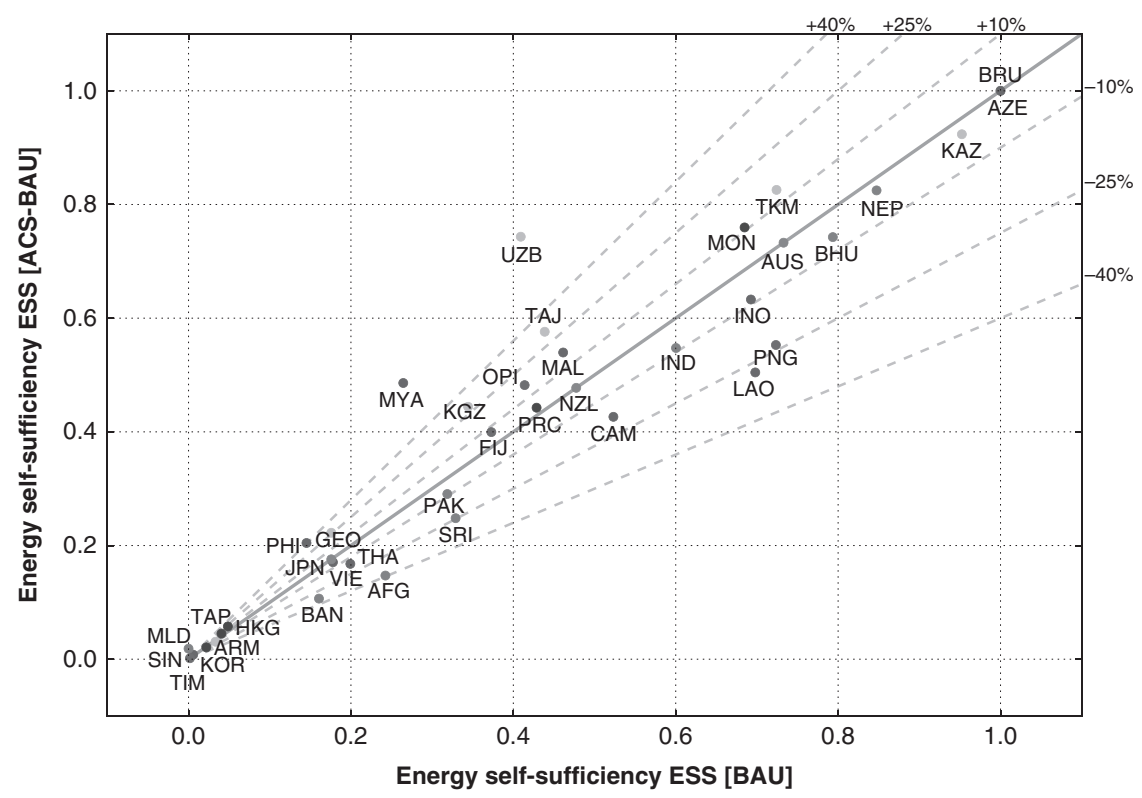

Figure 3.39 Energy self-sufficiency in business-as-usual scenario vs Asian Century/ business-as-usual scenario

Source: Authors' calculations with data from ADB (2013).

Note: See Figure 3.38 for the abbreviations.

The CEI is lower in nearly all economies under ACS-ALT as compared to ACS-BAU due to the lower CIX values (Figure 3.38). Cambodia does not follow this trend due to the greater value of its PEI under ACS-ALT. Overall, the CEI under ACS-ALT (702 tons of $\mathrm{CO}_{2} / \$ 1000$ ) is $5.0 \%$ lower than ACS-BAU (739 tons of $\left.\mathrm{CO}_{2} / \$ 1000\right)$.

\section{Impact on security}

There is no single trend for changes in ESS between BAU and ACS-BAU (Figure 3.39). Generally, ESS deteriorates where ACS-BAU assumes significantly higher growth rates than BAU (such as India, Lao People's Democratic Republic, or Sri Lanka) since an increase in primary energy demand depletes indigenous fuels at a faster pace. The reverse is also true for economies that grow faster under BAU than ACS-BAU. ESS logically remains the same throughout the region for ACS-ALT compared with ACS-BAU (Figure 3.40).

The aggregated ESS index for the region is substantially similar for all scenarios: 0.598 for BAU, 0.594 for ACS-BAU, and 0.60 for ACS-ALT. Primary 


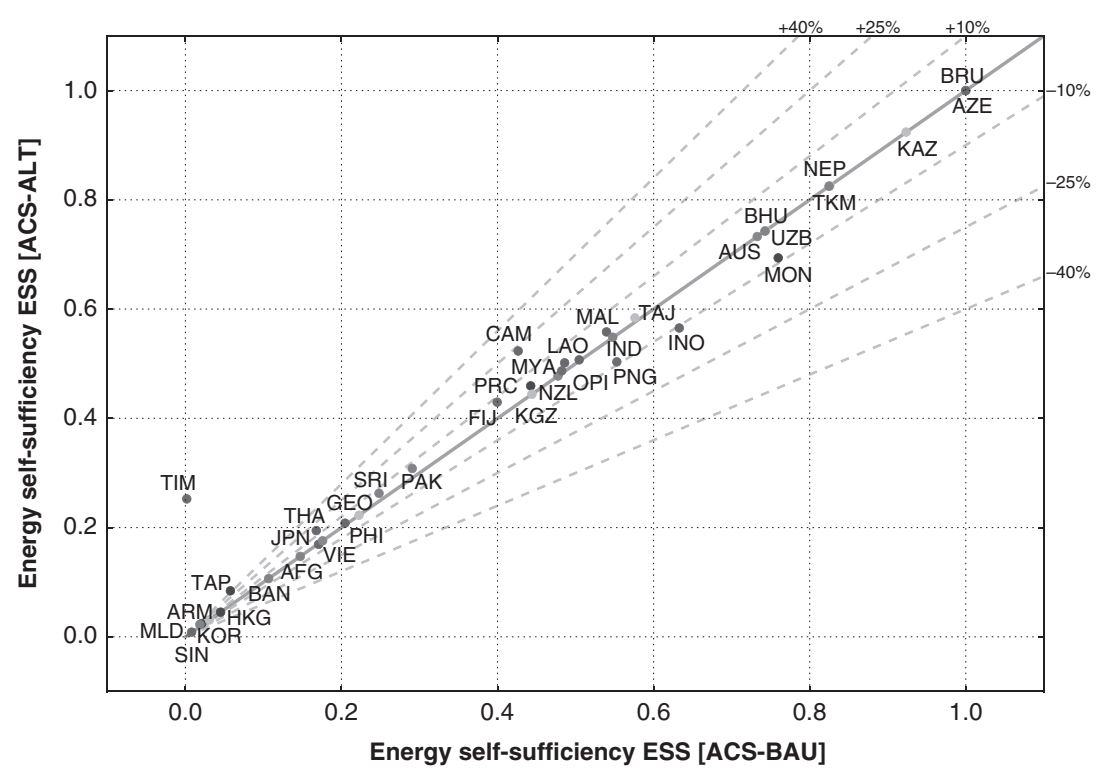

Figure 3.40 Energy self-sufficiency in Asian Century/alternative scenario vs Asian Century/ business-as-usual scenario

Source: Authors' calculations with data from ADB (2013).

Note: $\mathrm{AFG}=$ Afghanistan; $\mathrm{ARM}=$ Armenia; $\mathrm{AUS}=$ Australia; $\mathrm{AZE}=$ Azerbaijan; $\mathrm{BAN}=$ Bangladesh; BHU $=$ Bhutan; BRU $=$ Brunei Darussalam; CAM $=$ Cambodia; FIJ $=$ Fiji; GDP $=$ gross domestic product; $\mathrm{GEO}=$ Georgia; HKG = Hong Kong, China; IND = India; INO = Indonesia; JPN = Japan; $\mathrm{KAZ}=$ Kazakhstan; KOR $=$ Republic of Korea; KGZ $=$ Kyrgyz Republic; LAO $=$ Lao People's Democratic Republic; MAL = Malaysia; MLD = Maldives; MON = Mongolia; MYA = Myanmar; $\mathrm{NEP}=$ Nepal; NZL $=$ New Zealand OPI $=$ Other Pacific Islands; PAK = Pakistan; PNG = Papua New Guinea; PHI = Philippines; PRC $=$ China, People's Republic of; SIN $=$ Singapore; SRI $=$ Sri Lanka; TAP = Taipei,China; TAJ = Tajikistan; THA = Thailand; TIM = Timor-Leste; TKM = Turkmenistan; $\mathrm{UZB}=$ Uzbekistan; VIE $=$ Viet Nam.

energy consumption is higher for ACS-BAU than for BAU, but the increase is supplied by coal, the fossil resource with the largest reserves in Asia. The introduction of renewables and nuclear in the ACS-ALT scenario improve ESS with respect to ACS-BAU, but not significantly.

DIV in 2035 does not change significantly between BAU and ACS-BAU (Figure 3.41) given that they both are business-as-usual for the energy sector. In ACS-ALT, the DIV in 2035 increases slightly (Figure 3.42) due to the increased contribution of renewables and nuclear at the expense of fossil fuels. For Mongolia and Timor-Leste, the DIV increases substantially under ACS-ALT through the introduction of renewables in their energy mixes that are currently dominated by coal and oil, respectively. 


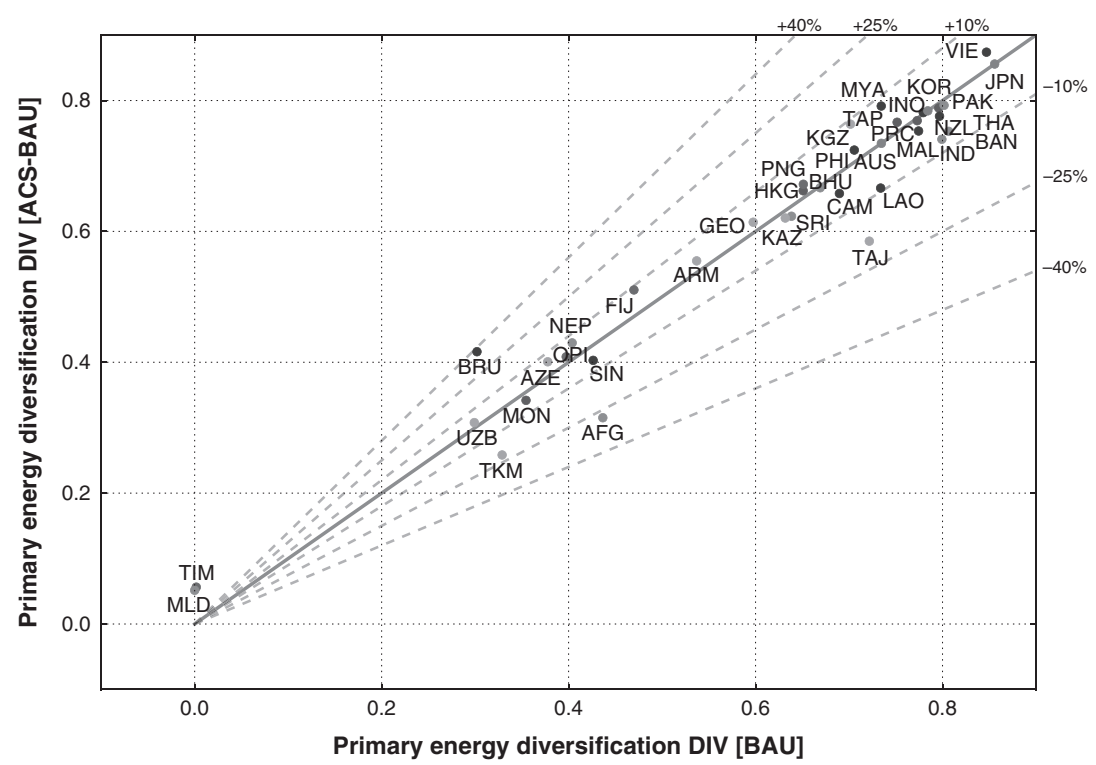

Figure 3.41 Primary energy diversification in business-as-usual scenario vs Asian Century/ business-as-usual scenario

Source: Authors' calculations with data from ADB (2013).

Note: See Figure 3.40 for the abbreviations.

\section{Impact on affordability}

The EOL in 2035 is generally lower under ACS-BAU than BAU (Figure 3.43) since the power mix is similar in both cases but GDP per capita is larger under ACS-BAU. The trend is reversed where growth is higher under BAU (Armenia, Kazakhstan, Turkmenistan, and Uzbekistan). The EOL is similar for ACS-BAU and for ACS-ALT since the amount of (expensive) renewable power introduced is moderate and so is its impact on cost (Figure 3.44). For Cambodia and Mongolia, growth is higher for ACS-BAU than for ACS-ALT which reflects on the EOL. For Timor-Leste, the introduction of additional hydroelectricity in ACS-ALT reduces oil imports and the LEC (and hence EOL).

\section{Conclusions and policy recommendations}

\section{Sustainability}

The PEI will decrease as economies develop in line with universal trends; additional targeted policies may afford additional improvements. The CIX will, however, decrease only in East Asia and the developed group. In other ADB members 


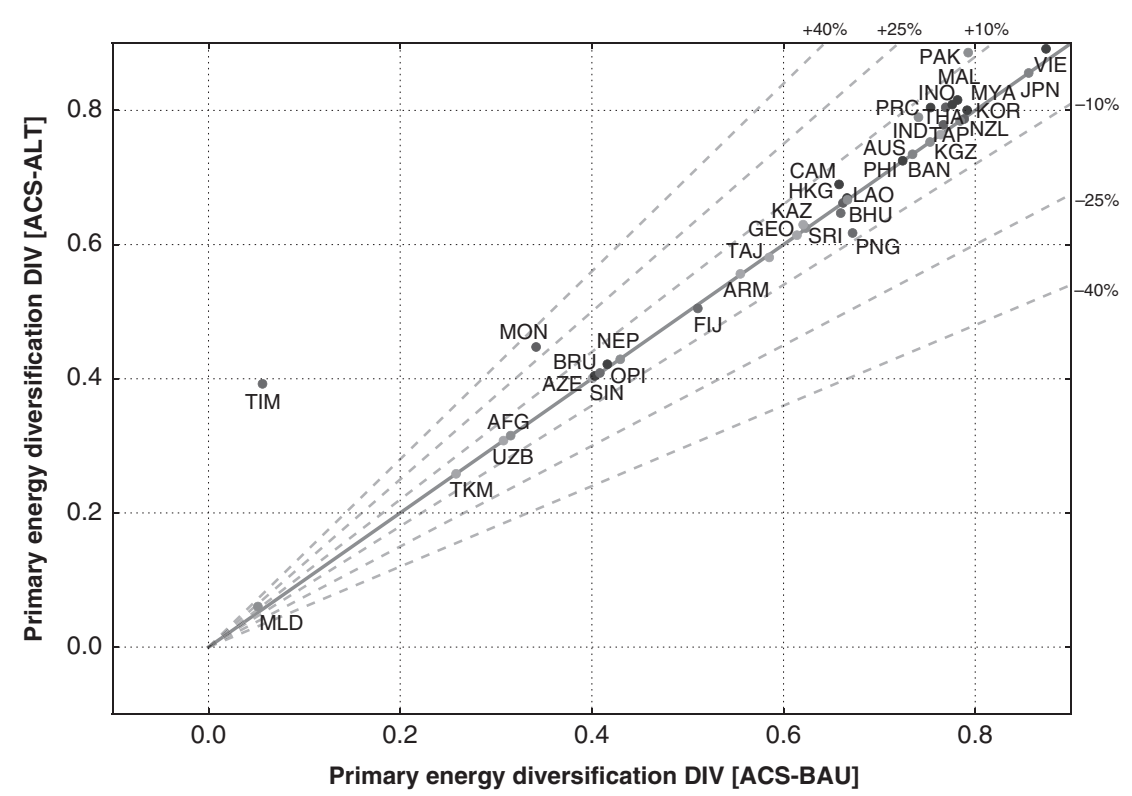

Figure 3.42 Primary energy diversification in Asian Century/alternative scenario vs Asian Century/business-as-usual scenario

Source: Authors' calculations with data from ADB (2013).

Note: $\mathrm{AFG}=$ Afghanistan; $\mathrm{ARM}=$ Armenia; $\mathrm{AUS}=$ Australia; $\mathrm{AZE}=$ Azerbaijan BAN = Bangladesh; $\mathrm{BHU}=$ Bhutan; $\mathrm{BRU}=$ Brunei Darussalam; $\mathrm{CAM}=$ Cambodia $; \mathrm{FIJ}=$ Fiji; GDP $=$ gross domestic product; GEO = Georgia; HKG = Hong Kong, China; IND = India; INO = Indonesia; JPN = Japan; $\mathrm{KAZ}=$ Kazakhstan; KOR $=$ Republic of Korea; KGZ $=$ Kyrgyz Republic; LAO $=$ Lao People's Democratic Republic; MAL = Malaysia $;$ MLD $=$ Maldives $;$ MON $=$ Mongolia $;$ MYA $=$ Myanmar; NEP = Nepal; NZL = New Zealand; OPI = Other Pacific Islands; PAK = Pakistan; PNG = Papua New Guinea; PHI $=$ Philippines; PRC $=$ China, People's Republic of; SIN $=$ Singapore; SRI $=$ Sri Lanka; TAP = Taipei,China; TAJ = Tajikistan; THA = Thailand; TIM = Timor-Leste; TKM = Turkmenistan; $\mathrm{UZB}=$ Uzbekistan; VIE $=$ Viet Nam.

it will increase largely due to the continuing displacement of carbon-neutral fuels (such as biomass) with more convenient fossil fuels. Additional policies will be required to decrease the contribution of oil and coal in favor of gas, nuclear, and renewables.

Coal is the fossil fuel with the largest reserves in the region and therefore is the main contributor to $\mathrm{CO}_{2}$ intensity. In the BAU scenario, the coal contribution to the primary energy mix will decrease only slightly from $46.4 \%$ in 2009 to $40.2 \%$ in 2035; and the oil contribution will remain virtually unchanged at $24.6 \%$ in 2009 and $24.1 \%$ in 2035. These moderate reductions are the reason for the poor performance of the CIX indicator.

Shale gas can contribute to the improvement of the CIX, but so can renewables and nuclear energy in the electricity sector. The latter should be combined with 


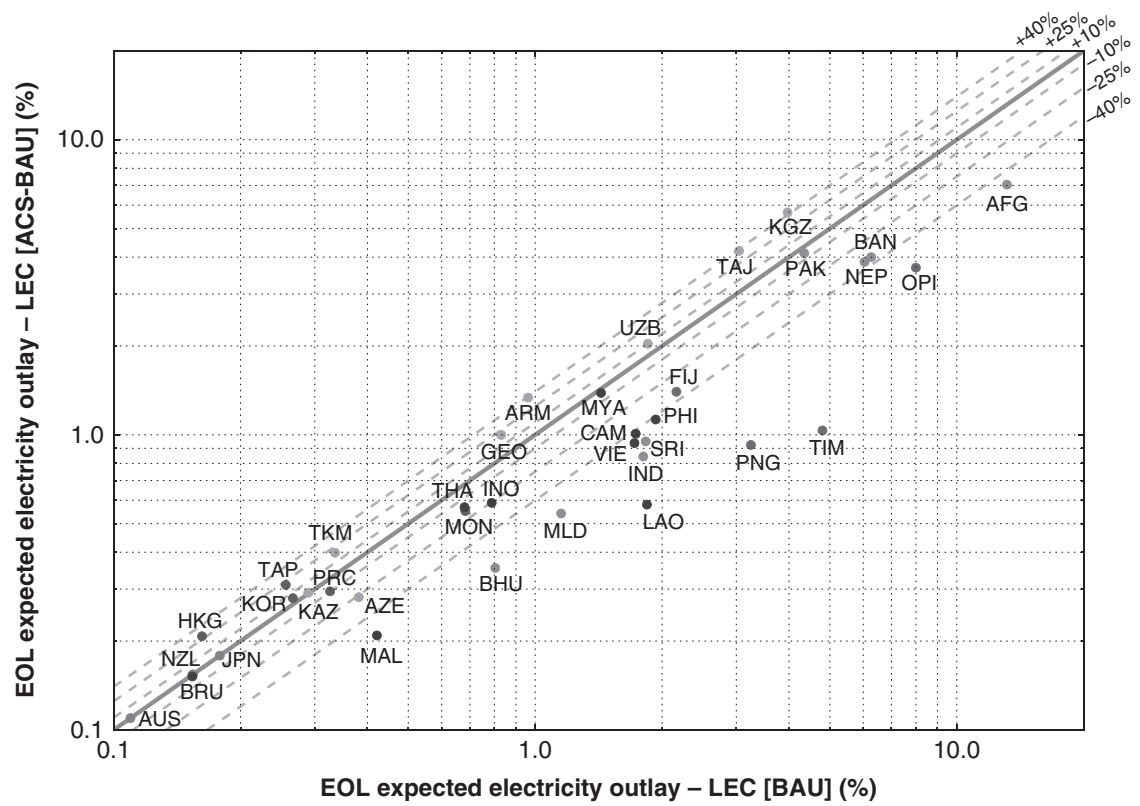

Figure 3.43 Expected electricity outlay in business-as-usual scenario vs Asian Century/ business-as-usual scenario

Source: Authors' calculations with data from ADB (2013) and IMF (2013).

Note: See Figure 3.42 for the abbreviations. LEC $=$ levelized electricity cost.

an increased share of electricity in the final energy mix as electrification is a common development trend.

\section{Security}

The ESS in the region will decrease substantially from $100 \%$ in 2009 to $59.8 \%$ in 2035. Current oil reserves will be depleted (even without exports outside the region) by 2019, and gas will nearly be by 2035. Japan, however, will more than triple its ESS indicator from 0.05 currently to 0.17 in 2035 due to increased reliance on renewable sources (wind, solar).

Oil and shale gas may therefore play an important role in maintaining energy self-sufficiency. Additionally, the region possesses substantial uranium reserves (Australia, the PRC, India, Kazakhstan, Mongolia, and Uzbekistan) that are not being utilized.

The DIV - one of the main contributors to the resilience of the energy systems - will not change significantly from 2010 to 2035 as the introduction of renewables or nuclear is rather limited in the BAU scenario. 


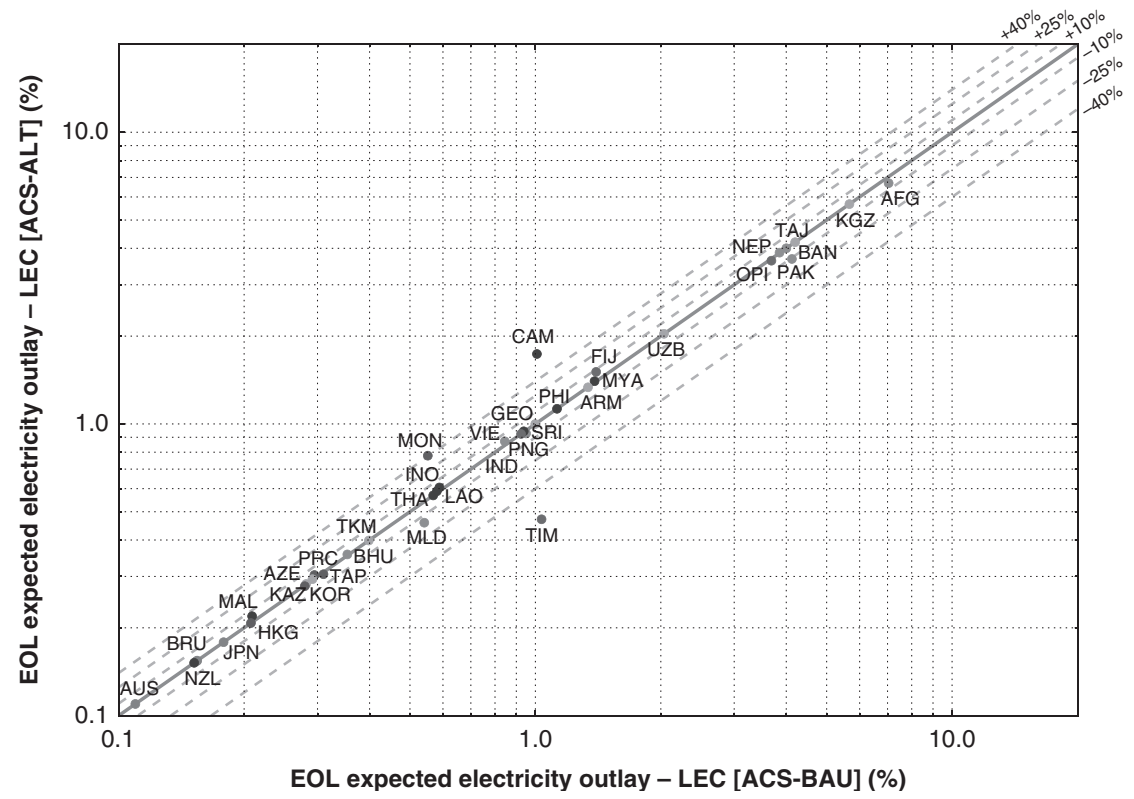

Figure 3.44 Expected electricity outlay in Asian Century/alternative scenario vs Asian Century/business-as-usual scenario

Source: Authors' calculations with data from ADB (2013) and IMF (2013).

Note: $\mathrm{AFG}=$ Afghanistan; $\mathrm{ARM}=$ Armenia; $\mathrm{AUS}=$ Australia; $\mathrm{AZE}=$ Azerbaijan; $\mathrm{BAN}=$ Bangladesh; $\mathrm{BHU}=$ Bhutan; $\mathrm{BRU}=$ Brunei Darussalam; $\mathrm{CAM}=$ Cambodia; FIJ $=$ Fiji; GDP $=$ gross domestic product; $\mathrm{GEO}=$ Georgia; HKG $=$ Hong Kong, China; IND = India; INO = Indonesia; JPN = Japan; KAZ $=$ Kazakhstan; KOR $=$ Republic of Korea; KGZ $=$ Kyrgyz Republic; LAO = Lao People's Democratic Republic; LEC = levelized electricity cost; MAL = Malaysia; MLD = Maldives; MON = Mongolia; MYA $=$ Myanmar; NEP $=$ Nepal; NZL $=$ New Zealand; OPI $=$ Other Pacific Islands; PAK = Pakistan; PNG = Papua New Guinea; PHI = Philippines; PRC = China, People's Republic of; $\mathrm{SIN}=$ Singapore; $\mathrm{SRI}=$ Sri Lanka; TAP $=$ Taipei, China; TAJ $=$ Tajikistan $; \mathrm{THA}=$ Thailand; $\mathrm{TIM}=$ Timor-Leste; TKM = Turkmenistan; UZB = Uzbekistan; VIE = Viet Nam.

\section{Affordability}

Electricity affordability will improve substantially as the economies in Asia grow. By 2035 , it will increase by more than $20 \%$ in most and by $50 \%$ or more in Armenia; Bhutan; Cambodia; the PRC; Georgia; India; Indonesia; Kazakhstan; Lao People's Democratic Republic; Maldives; Mongolia; Myanmar; Papua New Guinea; Singapore; Sri Lanka; Taipei,China; Tajikistan; Turkmenistan; and Viet Nam.

Economies with few fossil fuel reserves will have more affordability issues in 2035 as they will need to resort to more capital-intensive power generation technologies (such as renewables) or to importing fuel for conventional generation. South Asia, Central Asia, and Southeast Asia have the worst affordability and may need additional tariff support (for instance through lifeline tariffs) to 
ensure inclusiveness. Affordability in East Asia, however, will improve substantially. In 2035, there will still be a gap in affordability between developed and developing Asia; but it will diminish with respect to 2010. The BAU scenario assumes a small penetration of renewables; further increases in the renewable share are likely to worsen affordability.

\section{Regional cooperation}

Regional cooperation can generally increase energy security (self-sufficiency and diversification) and affordability. The key to successful integration may be seeking win-win situations whereby an energy supplier collects benefits in addition to monetary compensation. Some examples are the exchange of energy for energy expertise (e.g., in renewables or clean coal in the case of Kazakhstan); of energy for diversity (and hence resilience); or the energy-water exchange in Central Asia.

For power systems, the best opportunities for integration are in Central Asia where a regional power system would be more diversified than any single national system because their individually dominant power generation technologies are complementary. In Southeast Asia, regional integration could increase the diversification of the power systems of Cambodia, Indonesia, Lao People's Democratic Republic, Myanmar, Singapore, and Viet Nam. Bhutan and Nepal would greatly benefit from integration in South Asia.

\section{References}

Asian Development Bank (ADB). 2013. Asian Development Outlook: Asia's Energy Challenge. Manila: ADB.

Fueyo N., A. Gómez, and C. Dopazo C. 2013. Sources of Electricity Tariffs in Asia and the Pacific. Available upon request from Norberto.Fueyo@unizar.es.

Government of the United States, Department of Energy, Energy Information Administration (EIA). 2013. International Energy Statistics. http://www.eia.gov/cfapps/ipdbproject/ IEDIndex3.cfm (accessed February 2014).

International Energy Agency (IEA). 2010. World Energy Outlook 2010. Paris: Organisation for Economic Co-operation and Development/IEA.

International Monetary Fund (IMF). 2013. World Economic Outlook Database http://www. imf.org/external/pubs/ft/weo/2012/01/weodata/index.aspx (accessed November 2012).

Kohli, H. S., A. Sharma, and A. Sood. 2011. Asia 2050: Realizing the Asian Century. SAGE Publications.

Scheepers, M., A. Seebregts, J. de Jong, and H. Maters. 2006. EU Standards for Energy Security of Supply. Energy Research Centre of the Netherlands.

Sovacool, B. K. 2011. Evaluating Energy Security in the Asia Pacific: Towards a More Comprehensive Approach. Energy Policy. 39 (11). pp. 7472-7479.

- 2012. Energy Security: Challenges and Needs. Wiley Interdisciplinary Reviews: Energy and Environment. 1 (1). pp. 51-59.

Vivoda, V. 2010. Evaluating energy security in the Asia-Pacific region: A novel Methodological Approach. Energy Policy. 38 (9). pp. 5258-5263. 


\title{
4 Energy access and energy security in Asia and the Pacific
}

\author{
Benjamin K. Sovacool
}

\section{Introduction}

This chapter explores energy access, energy poverty, and energy development as energy security concerns confronting Asia and the Pacific. Improved access to energy services is arguably the key defining characteristic of economic development. Lack of access to energy and energy poverty contribute to hunger, with women and children spending long hours gathering fuels rather than earning incomes. The health consequences are dire with indoor air pollution associated with traditional energy use responsible for more deaths each year than those from malaria and tuberculosis (Holdren and Smith 2000). Environmentally, energy poverty forces its victims to harvest more polluting and less energy-dense fuels such as woody biomass or charcoal often causing land degradation, deforestation, and the contamination of soil and water resources. Such depletion instigates conflicts over land, decreases food supply, diminishes sources of traditional medicine, and accelerates malnutrition, all of which involve various dimensions of energy security.

\section{Defining energy poverty and access}

\section{The energy ladder}

As there is no simple definition of poverty, conceptualizing "energy poverty" is a somewhat arduous process. Recent work, including the United Nations Development Programme (UNDP 2010a) Human Development Report 2010, noted that poverty is not a static or fixed state but rather a multidimensional concept encompassing caloric intake, life expectancy, housing quality, literacy, access to energy, and a variety of other factors. Poverty is frequently expressed from an income perspective as earning less than $\$ 2$ per day adjusted for purchasing power parity. Under this definition, a shocking $40 \%$ of the global population is poor (D'Agostino 2010).

Sticking with the UNDP's multidimensional notion of poverty, its non-income dimensions such as health, education, and living conditions can be just as important as sources of employment or wages. Within this list of non-income dimensions, two energy indicators are found: electricity (having no electricity constitutes poverty) and cooking fuels (relying on wood, charcoal, and/or dung 
for cooking constitutes poverty). This conception of energy poverty has been confirmed by the International Energy Agency (IEA) and other multilateral organizations which state that energy poverty is comprised of lack of access to electricity and reliance on traditional biomass fuels for cooking (International Energy Agency, United Nations Development Programme, United Nations Industrial Development Organization 2010; Jones 2010).

Thus, UNDP explicitly defines energy poverty as the “. . . inability to cook with modern cooking fuels and the lack of a bare minimum of electric lighting for reading or for other household and productive activities at sunset" (Gaye 2007). The Asian Development Bank (ADB) takes a slightly broader approach to defining energy poverty and says that it is "the absence of sufficient choice in accessing adequate, affordable, reliable, high-quality, safe and environmentally benign energy services to support economic and human development" (Masud, Sharan, and Lohani 2007).

The most common concept illustrating energy poverty involves the "energy ladder." One study defines the energy ladder as ". . . the percentage of population among the spectrum running from simple biomass fuels (dung, crop residues, wood, and charcoal) to fossil fuels (kerosene, natural gas, and coal direct use) to electricity" (Holdren and Smith 2000). The idea implies that the primary types of energy used in rural areas or developing countries can be arranged on a "ladder" with the "simplest" or most "traditional" fuels and sources such as animal power, candles, and wood at the bottom with the more "advanced" or "modern" fuels such as electricity or refined gasoline at the top. The ladder is often described in terms of efficiencies with the more efficient fuels or sources moving higher up. For example, kerosene is three to five times more efficient than wood for cooking, and liquefied petroleum gas is five to ten times more efficient than crop residues and dung (Barnes and Floor 1996). Table 4.1 depicts the energy ladder as discussed in a variety of academic studies (see International Energy Agency, United Nations Development Programme, United Nations Industrial Development Organization (2010); Jones 2010; Legros et al. 2009; Cook et al. 2005; International Energy Agency 2004; and Barnes and Floor 1996).

The Advisory Group on Energy and Climate Change - an intergovernmental body composed of representatives from businesses, the United Nations, and research institutes - divided energy access into incremental categories. The first category is basic human needs met with both electricity consumption of 50-100 kilowatt-hours $(\mathrm{kWh})$ per person per year and 50-100 kilograms $(\mathrm{kg})$ of oil equivalent or modern fuel per person per year (or the ownership of an improved cookstove). Second are productive uses such as access to mechanical energy for agriculture or irrigation, commercial energy, or liquid transport fuels. Consumption here rises to $500-1,000 \mathrm{kWh}$ per year plus $150 \mathrm{~kg}$ of oil equivalent. Third is modern needs which include the use of domestic appliances, cooling and space heating, hot and cold water, and private transportation which in aggregate result in the consumption of about $2,000 \mathrm{kWh}$ per year and $250-450 \mathrm{~kg}$ of oil equivalent. Table 4.2 illustrates this sequential ordering quite clearly (United Nations Development Programme 2010b). 


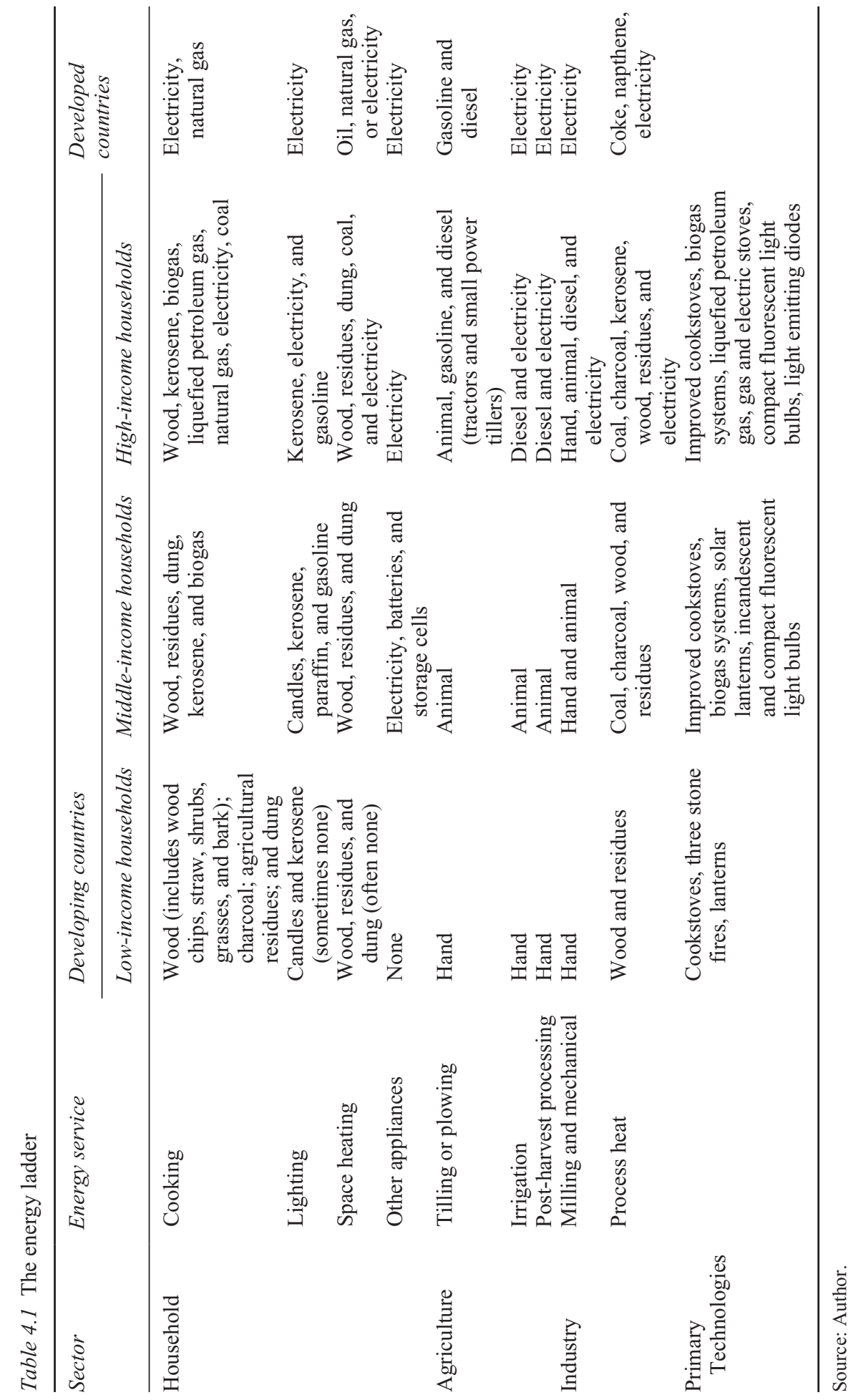




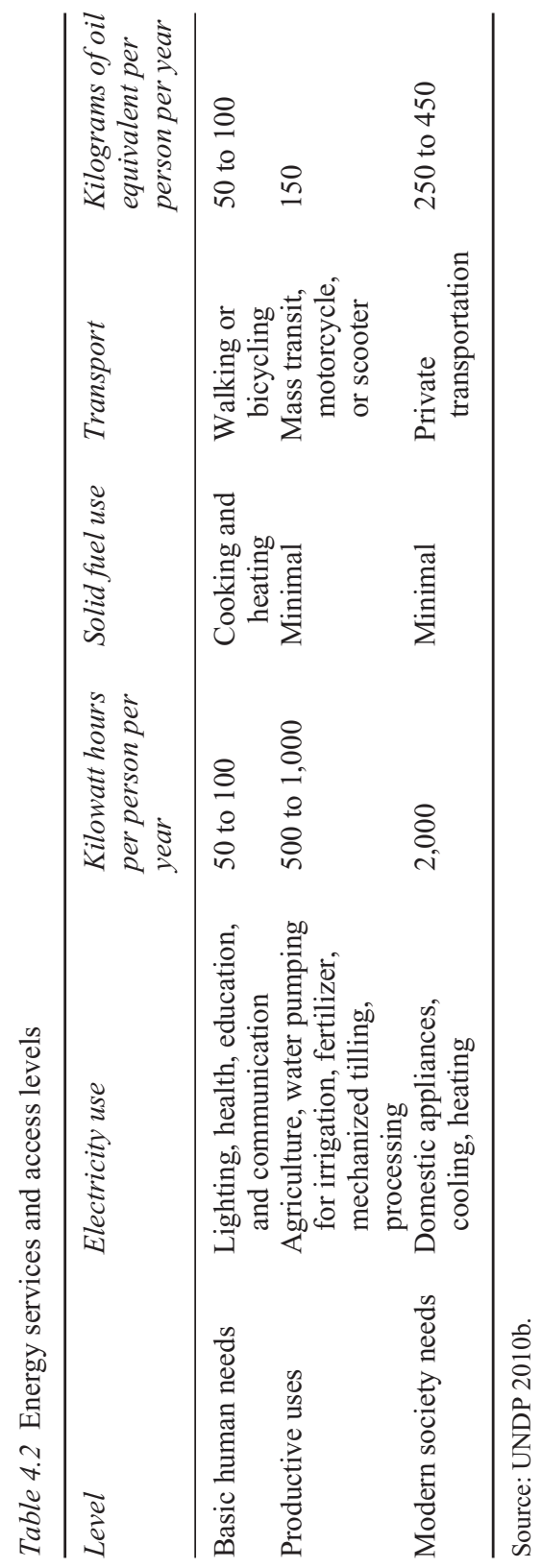




\section{Benjamin K. Sovacool}

\section{Measuring energy poverty}

Notwithstanding these complexities, IEA, the World Health Organization (WHO), and various United Nations organizations have done a remarkable job compiling statistics on energy poverty both in terms of those without access to electricity as well as those dependent on traditional fuels.

According to the most recent data available as of 2009, 1.4 billion people lack access to electricity - $85 \%$ of them in rural areas - and almost 2.7 billion people remain reliant on woody biomass fuels for cooking. The numbers are broken down in Table 4.3. An additional 1 billion people have access only to unreliable or intermittent electricity networks (United Nations Development Programme 2010b: 7). Put another way, the poorest $75 \%$ of the global population still use only $10 \%$ of global energy (Bazilian et al. 2011).

In Asia specifically, energy access oscillates noticeably. The People's Republic of China (PRC) alone accounts for about 30\% of the electricity generated for the entire region, and five countries-Australia, the PRC, India, Japan, and the Republic of Korea- account for $77 \%$ of electricity generated. When broken down

Table 4.3 Number and share of population without access to modern energy services, 2009

\begin{tabular}{|c|c|c|c|c|}
\hline & \multicolumn{2}{|c|}{ Without access to electricity } & \multicolumn{2}{|c|}{$\begin{array}{l}\text { Dependent on traditional } \\
\text { solid fuels for cooking }\end{array}$} \\
\hline & $\begin{array}{l}\text { Population } \\
\text { (million) }\end{array}$ & $\begin{array}{l}\text { Share of total } \\
\text { population (\%) }\end{array}$ & $\begin{array}{l}\text { Population } \\
\text { (million) }\end{array}$ & $\begin{array}{l}\text { Share of total } \\
\text { population (\%) }\end{array}$ \\
\hline Africa & 587 & 58 & 657 & 65 \\
\hline Nigeria & 76 & 49 & 104 & 67 \\
\hline Ethiopia & 69 & 83 & 77 & 93 \\
\hline DR Congo & 59 & 89 & 62 & 94 \\
\hline Tanzania & 38 & 86 & 41 & 94 \\
\hline Kenya & 33 & 84 & 33 & 83 \\
\hline $\begin{array}{l}\text { Other Sub-Saharan } \\
\text { Africa }\end{array}$ & 310 & 68 & 335 & 74 \\
\hline North Africa & 2 & 1 & 4 & 3 \\
\hline Asia & 675 & 19 & 1,921 & 54 \\
\hline India & 289 & 25 & 836 & 72 \\
\hline Bangladesh & 96 & 59 & 143 & 88 \\
\hline Indonesia & 82 & 36 & 124 & 54 \\
\hline Pakistan & 64 & 38 & 122 & 72 \\
\hline Myanmar & 44 & 87 & 48 & 95 \\
\hline $\begin{array}{l}\text { Rest of developing } \\
\text { Asia }\end{array}$ & 102 & 6 & 648 & 36 \\
\hline Latin America & 31 & 7 & 85 & 19 \\
\hline Middle East & 21 & 11 & 0 & 0 \\
\hline Developing countries & 1,314 & 25 & 2,662 & 51 \\
\hline World & 1,417 & 19 & 2,662 & 39 \\
\hline
\end{tabular}

Source: IEA, UNDP, and UNIDO 2010. 
into per capita figures, houses in Australia or New Zealand consume 100 times more electricity than those in Bangladesh and Myanmar (United Nations Economic and Social Commission for Asia and the Pacific 2010). Table 4.4 breaks down electrification numbers for more than 100 countries around the globe.

Table 4.4 Global national, rural, and urban electrification numbers

\begin{tabular}{|c|c|c|c|}
\hline \multirow[t]{2}{*}{ Country } & \multicolumn{3}{|c|}{$\begin{array}{l}\% \text { Population with electricity } \\
\text { access (most recently } \\
\text { available data) }\end{array}$} \\
\hline & National & Rural & Urban \\
\hline Korea, Republic of & 100.0 & 100.0 & 100.0 \\
\hline Kuwait & 100.0 & 100.0 & 100.0 \\
\hline Lao People's Democratic Republic & 55.0 & 42.0 & 84.0 \\
\hline Lebanon & 99.9 & 99.3 & 100.0 \\
\hline Lesotho & 16.0 & 6.0 & 44.0 \\
\hline Liberia & 3.3 & 1.0 & 7.0 \\
\hline Libya & 99.8 & 99.0 & 100.0 \\
\hline Madagascar & 19.0 & 5.0 & 53.0 \\
\hline Malawi & 9.0 & 5.3 & 25.0 \\
\hline Malaysia & 99.4 & 98.0 & 100.0 \\
\hline Maldives & 100.0 & 100.0 & 100.0 \\
\hline Mali & 17.4 & 3.7 & 48.7 \\
\hline Marshall Islands & 74.5 & 32.3 & 92.1 \\
\hline Mauritania & 30.1 & 2.0 & 47.0 \\
\hline Mauritius & 99.4 & 99.0 & 100.0 \\
\hline Mexico & 98.5 & 96.1 & 99.7 \\
\hline Micronesia & 54.0 & $\ldots$ & $\ldots$ \\
\hline Mongolia & 67.0 & 36.0 & 90.0 \\
\hline Morocco & 97.0 & 96.0 & 98.0 \\
\hline Mozambique & 11.7 & 6.3 & 21.0 \\
\hline Myanmar & 13.0 & 10.0 & 19.0 \\
\hline Namibia & 34.0 & 13.0 & 70.0 \\
\hline Nauru & 99.9 & $\ldots$ & 99.9 \\
\hline Nepal & 43.6 & 34.0 & 89.7 \\
\hline Nicaragua & 72.1 & 42.0 & 95.0 \\
\hline Niger & 9.3 & 1.5 & 47.2 \\
\hline Nigeria & 46.8 & 26.0 & 69.0 \\
\hline Niue & 99.0 & $\ldots$ & $\ldots$ \\
\hline Occupied Palestinian Territories & 99.7 & 99.4 & 99.8 \\
\hline Oman & 98.0 & 93.0 & 99.9 \\
\hline Pakistan & 57.6 & 46.0 & 78.0 \\
\hline Palau & 99.5 & 98.4 & 100.0 \\
\hline Panama & 88.1 & 72.0 & 94.0 \\
\hline Papua New Guinea & 10.0 & 5.0 & 42.8 \\
\hline Paraguay & 94.5 & 88.0 & 98.8 \\
\hline Peru & 76.9 & 28.0 & 96.4 \\
\hline Philippines & 86.0 & 65.0 & 97.0 \\
\hline Qatar & 98.7 & 70.0 & 100.0 \\
\hline
\end{tabular}

(Continued) 
138 Benjamin K. Sovacool

Table 4.4 (Continued)

\begin{tabular}{|c|c|c|c|}
\hline \multirow[t]{2}{*}{ Country } & \multicolumn{3}{|c|}{$\begin{array}{l}\text { \% Population with electricity } \\
\text { access (most recently } \\
\text { available data) }\end{array}$} \\
\hline & National & Rural & Urban \\
\hline Rwanda & 4.8 & 1.3 & 25.1 \\
\hline Saint Kitts and Nevis & 87.0 & & \\
\hline Saint Lucia & 99.0 & 98.5 & 100.0 \\
\hline St Vincent and Grenadines & 99.0 & 97.5 & 100.0 \\
\hline Samoa & 97.0 & & . \\
\hline Sao Tome and Principe & 48.5 & 33.7 & 61.6 \\
\hline Saudi Arabia & 99.0 & 95.0 & 100.0 \\
\hline Senegal & 42.0 & 18.0 & 74.7 \\
\hline Seychelles & 96.0 & $\ldots$ & . \\
\hline Sierra Leone & 5.1 & 0.1 & 12.7 \\
\hline Singapore & 100.0 & 100.0 & 100.0 \\
\hline Solomon Islands & 14.4 & 5.1 & 70.6 \\
\hline South Africa & 75.0 & 55.0 & 88.0 \\
\hline Sri Lanka & 76.6 & 75.0 & 85.8 \\
\hline Sudan & 31.4 & 19.0 & 47.5 \\
\hline Suriname & 78.6 & . & \\
\hline Swaziland & 29.7 & 20.2 & 65.2 \\
\hline Syrian Arab Republic & 92.7 & 84.0 & 100.0 \\
\hline Tanzania & 11.5 & 2.0 & 39.0 \\
\hline Thailand & 99.3 & 99.0 & 100.0 \\
\hline Timor-Leste & 22.0 & 10.5 & 52.0 \\
\hline Togo & 20.0 & 4.0 & 42.0 \\
\hline Tonga & 92.3 & 90.7 & 97.7 \\
\hline Trinidad and Tobago & 99.0 & 99.0 & 99.9 \\
\hline Tunisia & 99.5 & 98.5 & 100.0 \\
\hline Turkey & 100.0 & 100.0 & 100.0 \\
\hline Tuvalu & 98.0 & 95.0 & 100.0 \\
\hline Uganda & 9.0 & 4.0 & 42.5 \\
\hline United Arab Emirates & 100.0 & 100.0 & 100.0 \\
\hline Uruguay & 99.5 & 82.4 & 99.4 \\
\hline Vanuatu & 19.0 & 7.0 & 61.0 \\
\hline Venezuela & 99.0 & 85.0 & 100.0 \\
\hline Viet Nam & 89.0 & 85.0 & 99.6 \\
\hline Yemen & 38.2 & 22.0 & 75.0 \\
\hline Zambia & 18.8 & 3.3 & 47.0 \\
\hline Zimbabwe & 41.5 & 19.0 & 79.0 \\
\hline
\end{tabular}

Source: Sovacool 2011.

Note: ... = no data avalaible.

\section{Energy access as an energy security concern}

Energy poverty and deprivation result in four major, interrelated, negative energy security consequences: poverty, death, gender inequality, and environmental degradation. 


\section{Poverty and economic security}

Poverty and energy deprivation go hand-in-hand with energy expenses, accounting for a significant proportion of household incomes in many developing countries. Generally, 20\%-30\% of annual income in poor households is directly expended on energy fuels, and an additional $20 \%-40 \%$ is expended on indirect costs associated with collecting and using that energy such as healthcare costs, injuries, or loss of time. As a result, the poor pay on average eight times more for the same unit of energy than other income groups (Hussain 2011). In extreme cases, some of the poorest households directly spend $80 \%$ of their incomes obtaining cooking fuels (Masud, Sharan, and Lohani 2007). For example, one study looking at Asia noted that the poor typically pay more for energy needs yet receive poorer quality energy services due to inefficient and more polluting technologies with higher upfront costs as Figure 4.1 illustrates (Modi et al. 2005; WHO 2006). Table 4.5 also indicates how per capita consumption of energy can be correlated with poverty, with countries consuming fewer amounts of energy prone to higher rates of poverty.

\section{Household health}

Crisscrossing numerous household domains including maternal health, infant mortality, and disease epidemics, energy poverty has serious and growing public

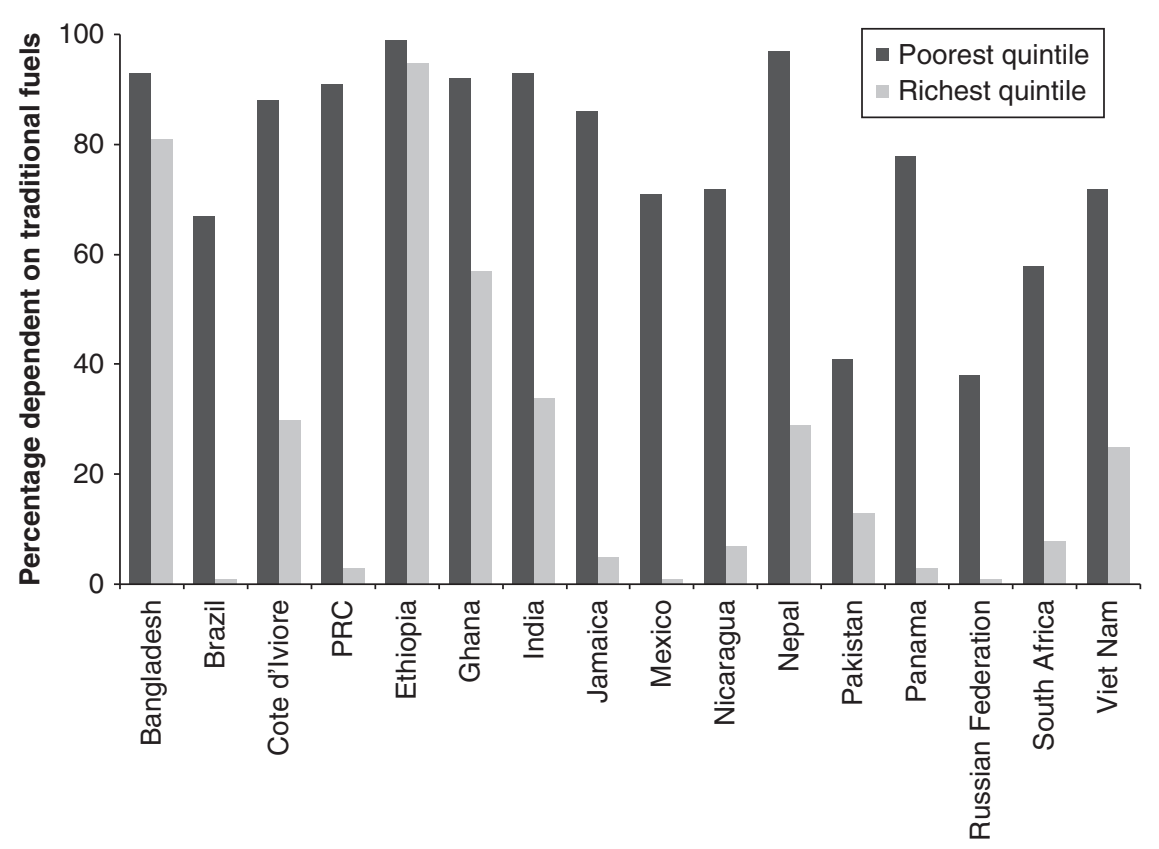

Figure 4.1 Energy access according to poorest and richest quintiles in selected countries Source: Modi et al. 2005; WHO 2006.

Note: PRC $=$ People's Republic of China. 
Table 4.5 Gross domestic product per capita and energy consumption and poverty in selected countries, 2002

\begin{tabular}{|c|c|c|c|c|}
\hline Country & $\begin{array}{l}\text { Gross domestic } \\
\text { product per } \\
\text { capita }\end{array}$ & $\begin{array}{l}\text { Electricity } \\
\text { consumption } \\
\text { per capita } \\
\text { (kilowatt hour) }\end{array}$ & $\begin{array}{l}\text { Commercial } \\
\text { energy } \\
\text { consumption } \\
\text { per capita } \\
\text { (kilogram of } \\
\text { oil equivalent) }\end{array}$ & $\begin{array}{l}\text { Population } \\
\text { below the } \\
\text { national } \\
\text { poverty line } \\
\text { (\%) }\end{array}$ \\
\hline United States & 36,006 & 13,241 & 7,725 & $\ldots$ \\
\hline Japan & 31,407 & 8,203 & 3,730 & \\
\hline $\begin{array}{l}\text { Republic of } \\
\text { Korea }\end{array}$ & 10,006 & 6,632 & 3,284 & $\ldots$ \\
\hline Brazil & 2,593 & 2,122 & 717 & 17.4 \\
\hline $\begin{array}{l}\text { People's Republic } \\
\text { of China }\end{array}$ & 989 & 1,139 & 561 & 4.6 \\
\hline South Africa & 2,299 & 4,313 & 2,649 & $\ldots$ \\
\hline India & 487 & 561 & 318 & 28.6 \\
\hline Ghana & 304 & 404 & 120 & 39.5 \\
\hline Uganda & 236 & 66 & 26 & 44.0 \\
\hline Kenya & 393 & 140 & 96 & 52.0 \\
\hline Senegal & 503 & 151 & 128 & 33.4 \\
\hline Malawi & 177 & 76 & 27 & 65.3 \\
\hline Chad & 240 & 12 & 5 & 64.0 \\
\hline Ethiopia & 90 & 30 & 29 & 44.2 \\
\hline Mali & 296 & 34 & 18 & 63.8 \\
\hline Niger & 190 & 41 & 33 & 63.0 \\
\hline
\end{tabular}

Source: Modi et al. 2005.

Note: . . = data not available.

health concerns related to indoor air pollution (IAP), physical injury during fuelwood collection, and lack of refrigeration and medical care in areas that lack electricity. By far the most severe of these is IAP. Most families without access to modern forms of energy cook and combust fuels directly inside their homes. Burning firewood, dung, and charcoal is physiologically damaging as it is like living within a giant smoking cigarette. Nearly $75 \%$ of people living in rural areas and $45 \%$ of the entire global population rely on wood and solid fuels for cooking (Legros et al. 2009), yet as WHO explains:

The inefficient burning of solid fuels on an open fire or traditional stove indoors creates a dangerous cocktail of not only hundreds of pollutants, primarily carbon monoxide and small particles, but also nitrogen oxides, benzene, butadiene, formaldehyde, polyaromatic hydrocarbons, and many other health-damaging chemicals.

(World Health Organization 2006)

There is a damaging spatial and temporal dimension to such pollution. Spatially, it is concentrated indoors in small rooms and kitchens so that many homes have 
exposure levels to harmful pollutants 60 times greater than the rate acceptable outdoors in city centers in North America and Europe (World Health Organization 2006). Temporally, the pollution from stoves is released at precisely the time when people are present cooking, eating, or sleeping, with a typical woman spending 3-7 hours a day in the kitchen (Masud, Sharan, and Lohani 2007).

Even when homes have chimneys and cleaner burning stoves (and most do not), combustion from solid fuels can result in acute respiratory infections, tuberculosis, chronic respiratory diseases, lung cancer, cardiovascular disease, asthma, low birth weights, diseases of the eye, and adverse pregnancy outcomes and can cause outdoor pollution in dense urban slums that can make air unfit to breathe and water undrinkable (Jin et al. 2006). Table 4.6 shows the most common, well established health impacts of IAP (World Health Organization 2006).

Strikingly, IAP ranks fourth on the global burden of disease risk factors at almost 5\% following high blood pressure (almost 8\%), tobacco smoking and secondhand smoke (about 7\%), and alcohol use (about 6\%) (Lim et al. 2012). It far outranks physical inactivity and obesity, drug use, and unsafe sex. In India and all of South Asia, cookstove smoke is the highest risk factor outranking smoking tobacco and high blood pressure. It ranks second in Sub-Saharan Africa, third in Southeast Asia, and fifth in East Asia. Air pollution from conventional cookstoves is therefore responsible for a shocking 4 million deaths each year, 3.5 million direct premature annual deaths, and 500,000 from "secondhand cookfire smoke" outdoors. This amounts to almost 11,000 deaths per day or almost 8 deaths per minute. The cost of this burden to national healthcare systems, which is not reflected in the price of fuelwood or energy, is an

Table 4.6 Health impacts of indoor air pollution

\begin{tabular}{llll}
\hline Health outcome & Evidence & Population & Relative risk \\
\hline $\begin{array}{c}\text { Acute infections of the } \\
\text { lower respiratory tract }\end{array}$ & Strong & Children aged 0-4 years & 2.3 \\
$\begin{array}{c}\text { Chronic obstructive } \\
\text { pulmonary disease }\end{array}$ & Strong & Women aged more than 30 years & 3.2 \\
& Moderate & Men aged more than 30 years & 1.8 \\
Lung cancer & Strong & Women aged more than 30 years & 1.9 \\
& Moderate & Men aged more than 30 years & 1.5 \\
Asthma & Specified & Children aged 5-14 years & 1.6 \\
Cataracts & Specified & Adults aged more than 15 years & 1.2 \\
Tuberculosis & Specified & Adults aged more than 15 years & 1.3 \\
\hline
\end{tabular}

Source: WHO 2006.

Note: "Strong" evidence means many studies of solid fuel use in developing countries supported with data from studies of active and passive smoking, urban air pollution, and biochemical and laboratory studies. "Moderate" evidence means at least three studies of solid fuel use supported by evidence from studies on active smoking and on animals. "Specified" means strong evidence for specific ages or groups. "Relative risk" indicates how many times more likely the disease is to occur in people exposed to indoor air pollution than in people not exposed. 
astonishing \$212 billion-\$1.1 trillion (United Nations Environment Programme, UNEP 2000). ${ }^{1}$

\section{Gender and education}

Energy poverty affects both genders and the educational opportunities available to children and adults. Gender impacts are primarily physical injuries collecting fuel and the health impacts of IAP; the costs of fuel, stoves, and healthcare; and the time needed for collecting fuel and water, cooking, and caring for sick children. Most of these burdens fall on women. Educational impacts relate to time spent out of school as well as to increased absenteeism due to illness (UNEP 2000).

The labor and time required for fuelwood collection depend on not only the availability of fuel but also on traveling distance, household size, and season. In the summer months when wood must be stockpiled for the winter, some women gather firewood twice a day with each trip taking two hours (Gaye 2007). In some developing countries, girls spend more than 7 times as many hours collecting wood and water than adult males and 3.5 times as many hours compared to boys the same age. In India, for instance, the typical woman spends 40 hours per month walking to collect fuel on 15 separate trips that can be more than 6 kilometers per round trip (Sangeeta 2008). This amounts to 30 billion hours annually ( 82 million hours per day) collecting fuelwood with an economic burden (including time invested and illnesses) of $\$ 6.7$ billion ( 300 billion rupees) per year (Reddy, Balachandra, and Nathan 2009).

In addition, current energy production entails occupational hazards that almost uniquely affect women as they suffer frequent falls, backaches, bone fractures, eye problems, headaches, rheumatism, anemia, and miscarriages from carrying weights of $40-50 \mathrm{~kg}$ which is nearly equal to their body weights. The energy needs of rural women can be further marginalized if men control community forests, plantations, or woodlots and if there are other "high value" wood demands on the community that displace their foraging grounds for fuel (Murphy 2001).

The educational impacts of energy poverty include absenteeism and increased illness. Numerous medical studies have documented a strong connection between the effects of IAP and acute respiratory infections in children which is the principal cause of absence from school in many countries. Modern energy access can therefore improve both education and gender equality as shown in Table 4.7 which depicts a variety of ways it can enhance the status of women by saving time and improving health.

For instance, one study in the Philippines noted that the odds of being illiterate are far greater for people without electric lighting (Porcaro and Takada 2005). Energy services can also enable schools to recruit and retain better qualified

${ }^{1}$ Figures have been updated to 2010 dollars. 
Table 4.7 Benefits of modern energy services for women

\begin{tabular}{|c|c|c|c|}
\hline \multirow[t]{2}{*}{ Energy source } & \multicolumn{3}{|l|}{ Benefits } \\
\hline & Practical & Productive & Strategic \\
\hline Electricity & $\begin{array}{l}\text { Pumping water, } \\
\text { reduced need to } \\
\text { haul and carry } \\
\text { mills for grinding, } \\
\text { improved } \\
\text { conditions at } \\
\text { home through } \\
\text { lighting }\end{array}$ & $\begin{array}{l}\text { Increased possibility } \\
\text { of activities during } \\
\text { evening hours, } \\
\text { refrigeration for food } \\
\text { production and sale, } \\
\text { power for specialized } \\
\text { enterprises and small } \\
\text { businesses }\end{array}$ & $\begin{array}{l}\text { Safer streets, } \\
\text { participation in } \\
\text { evening classes, } \\
\text { access to radio, } \\
\text { television, and the } \\
\text { Internet }\end{array}$ \\
\hline $\begin{array}{l}\text { Biomass } \\
\text { (improved } \\
\text { cookstoves) }\end{array}$ & $\begin{array}{l}\text { Improved health, } \\
\text { less time and } \\
\text { effort gathering } \\
\text { fuelwood, more } \\
\text { time for childcare }\end{array}$ & $\begin{array}{l}\text { More time for } \\
\text { productive activities, } \\
\text { lower cost of space } \\
\text { and process heating }\end{array}$ & $\begin{array}{l}\text { Improved } \\
\text { management of } \\
\text { natural forests }\end{array}$ \\
\hline Mechanical & $\begin{array}{l}\text { Milling and } \\
\text { grinding, } \\
\text { transport and } \\
\text { portering of water } \\
\text { and crops }\end{array}$ & $\begin{array}{l}\text { Increased variety of } \\
\text { enterprises }\end{array}$ & $\begin{array}{l}\text { Access to } \\
\text { commercial, } \\
\text { social, and political } \\
\text { opportunities }\end{array}$ \\
\hline
\end{tabular}

Source: Masud, Sharan, and Lohani 2007.

teachers (Porcaro and Takada 2005). Lighting from solar and microhydro technologies can extend the time children have to study at night and can also equip schools with computers and the Internet.

\section{Deforestation and climate change}

The environmental impacts of energy poverty include deforestation and changes in land use as well as greenhouse gas (GHG) emissions and black carbon. Because billions of people rely on biomass for cooking and heating, about 2 million tons of it is burned every day (WHO 2006). Where wood is scarce or the population is dense, reforestation does not match the demand for fuel resulting in deforestation, desertification, and land degradation. Even when trees are not felled, collecting dung, branches, shrubs, roots, twigs, leaves, and bark can deplete forest ecosystems and soils of much needed nutrients (Alam, Islam, and Huq 2000; Islam and Weil 2000). When wood supplies are scarce, people often switch to burning crops which threatens food security, and the deforestation and erosion caused by harvesting reduce the fertility of surrounding fields. One recent assessment attributed $6 \%$ of global deforestation to fuelwood collection (Velumail 2011).

In Bangladesh for example, trees and bamboo meet about $48 \%$ of all domestic energy requirements followed by agricultural residues at $36 \%$ and dung at $13 \%$ (Miah, Rashid, and Shin 2009). The destruction of forests to satisfy energy needs has reduced homestead forest cover to $8 \%$ of its original area (Miah, Rashid, and 


\section{Benjamin K. Sovacool}

Shin 2009) and natural forests by $50 \%$ in a single generation (Peios 2004). Similarly, about $4 \%$ of standing forests in the PRC are used for fuelwood and roughly $13 \%$ of cultivated land is used to grow fuelwood (Chan 2000).

Apart from environmental damage, fuelwood-driven deforestation increases the burden on collectors and farmers and increases fuel prices. As stockpiles are depleted, women and children must travel longer distances to collect fuel which requires more time and energy, and fuel collection often interferes with farming and other rural livelihoods that rely on trees for income (van der Horst, Hiemstra, and Hovorka 2008). Deforestation also causes significant price increases for fuelwood. As deforestation in Bangladesh has accelerated, the demand for wood has outpaced supply causing the price to increase from $\$ 0.35$ per bundle in 1980 to $\$ 1.27$ per bundle in 1991 and $\$ 1.69$ per bundle in 2007, which is nearly $50 \%$ of the typical rural annual household budget (Biswas, Bryce, and Diesendorf 2001).

Burning solid fuels in open fires and traditional stoves has significant effects on global warming due to the release of methane and carbon dioxide (Legros et al. 2009). Relying on biomass fuels and coal for cooking and heating is responsible for about $10 \%$ to $15 \%$ of global energy use making it a substantial source of GHG emissions (WHO 2006). One study projected that by 2050 the smoke from wood fires will release about 7 billion tons of GHGs into the atmosphere (Gaye 2007).

\section{The energy development index}

The IEA energy development index is composed of four indicators each of which "captures a specific aspect of potential energy poverty":

- Per capita commercial energy consumption which serves as an indicator of overall economic development.

- Per capita electricity consumption in the residential sector which serves as an indicator of the reliability of and consumer's ability to pay for electricity services.

- Share of modern fuels in total residential sector energy use which serves as an indicator of the level of access to clean cooking facilities.

- Share of population with access to electricity (International Energy Agency 2011a).

The latest results from the index suggest that energy poverty will remain a pertinent global issue over the next 30 years. Five of the "bottom 30 countries" are in Asia: Cambodia, the Lao People's Democratic Republic, Myanmar, Nepal, and Papua New Guinea. When projecting the future in the World Energy Outlook 2012, IEA estimated that almost 1 billion people will still be without electricity by 2030 and that 2.6 billion people will still be without clean cooking facilities (International Energy Agency, IEA 2012). In 2030, the number of people without clean cooking technologies in India will amount to twice the population of the 
United States (US), and overall the IEA forecast is that 39\% of people in Asia and the Pacific will lack access to modern cooking.

\section{Financing sustainable energy for all}

Although the technologies for providing sustainable energy for all (SE4ALL) electricity networks, diesel generators, improved cookstoves, microhydro dams, solar home systems, small-scale wind turbines, biogas digesters-are well understood, they need financial and institutional support to succeed. Achieving modern energy access requires technologies, financing instruments, and financing sources (IEA 2011b).

\section{Projections for financing required to achieve universal energy access}

In assessing the costs involved in universally extending access to energy services, IEA estimated in 2009 that $\$ 9.1$ billion was invested globally and that in the absence of any new policies or directions, the amount would rise to about $\$ 14$ billion each year from 2010 to 2030 . Most of this will be for extending national grids to urban areas. This level of investment- $\$ 280$ billion over 20 years - may sound significant, but it will still leave about 1 billion people without electricity by 2030 . Shockingly, with this investment, the number of people without clean cooking facilities will stay the same at 2.7 billion due to population growth. The IEA also estimated that about $\$ 76$ billion would be required to achieve universal access to clean cooking fuels by 2030 (an average of $\$ 3.8$ billion per year) and almost $\$ 1$ trillion would be needed for universal access to energy and electricity (an average of $\$ 50$ billion per year). That means the level of investment in 2009 must increase rapidly by a factor of five, but as of 2012 , only $3 \%$ of the total needed had been committed.

To reach these targets, IEA found that there is a role for numerous technologies and for both renewables and fossil fuels. Extending grids is the most suitable option for all urban areas and for around $30 \%$ of rural areas, but it is not a cost-effective option in more remote rural areas. Therefore, the remaining $70 \%$ of rural areas will have to be connected either with mini-grids ( $65 \%$ of this share) or with small, standalone, off-grid solutions (35\%). Globally, it is estimated that to ensure universal electricity access by 2030, out of a total generation requirement of 952 terawatt hours, $60 \%$ (572 terawatt hours) will be provisioned via mini-grid and isolated offgrid technology (Table 4.8). More interestingly, developing Asia accounts for almost two-thirds of the total additional investment required for clean cooking facilities, primarily ( $\$ 26$ billion) for biogas systems principally in the PRC and India.

Using different timeframes, and methodologies, the International Institute for Applied Systems Analysis Global Energy Assessment projects the need for \$36 billion to $\$ 41$ billion per year to achieve universal access to electricity and clean cooking, $\$ 259$ billion to $\$ 406$ billion to promote renewables, and an additional $\$ 258$ billion to $\$ 365$ billion per year to achieve energy efficiency improvements (Riahi et al. 2012). These estimates are summarized in Table 4.9. 
Table 4.8 Generation requirements for universal electricity access, 2030 (terawatt hours)

\begin{tabular}{lcccr}
\hline & On-grid & Mini-grid & Isolated off-grid & Total \\
\hline Africa & 196 & 187 & 80 & 463 \\
Developing Asia & 173 & 206 & 88 & 468 \\
People's Republic of China & 1 & 1 & 0 & 2 \\
India & 85 & 112 & 48 & 245 \\
Other Asian countries & 87 & 94 & 40 & 221 \\
Latin America $_{\text {Developing countries }}{ }^{\text {a }}$ & 6 & 3 & 1 & 10 \\
World & 379 & 3,993 & 171 & 949 \\
\hline
\end{tabular}

Source: IEA 2011b.

Note: ancludes Middle East countries.

Table 4.9 Annual investments required to achieve sustainable energy for all objectives (\$ billion in 2005)

\begin{tabular}{|c|c|c|c|c|}
\hline \multirow{2}{*}{$\begin{array}{l}\text { Annual energy } \\
\text { investments in: }\end{array}$} & \multicolumn{3}{|c|}{ Present (2010) } & \multirow{2}{*}{$\begin{array}{l}2010-2030 \\
\text { Annual investment } \\
\text { required to meet } \\
\text { SE4All goals }\end{array}$} \\
\hline & $\begin{array}{l}\text { Innovation } \\
R D \& D\end{array}$ & $\begin{array}{l}\text { Markets } \\
\text { formation }\end{array}$ & $\begin{array}{l}\text { Present } \\
\text { investment }\end{array}$ & \\
\hline Efficiency & $\gg 8$ & $\sim 5$ & 300 & $258-365$ \\
\hline Renewables & $>12$ & $\sim 20$ & 200 & $259-406$ \\
\hline Access & $<1$ & $<1$ & $\sim 9$ & $36-41$ \\
\hline All energy infrastructure & $>50$ & $<150$ & 1,250 & $1,260-1,680$ \\
\hline
\end{tabular}

Source: IIASA 2012.

Note: RD\&D = research, development, and demonstration; SE4ALL = sustainable energy for all.

$\sim$ refers to approximate estimates.

\section{The pro-poor public-private partnership model}

The pro-poor public-private partnership (5P) model is one useful vehicle for raising capital to finance energy access projects. Public-private partnerships have been widely used as a mechanism for engaging the private sector to deliver the infrastructure requirements of a state or of a quasi-government body. The underlying logic for establishing such partnerships is that both the public and the private sectors have unique characteristics that give them advantages in specific aspects of service or project delivery. These partnerships are characterized by sharing investments, responsibilities, risks, and rewards among partners.

Drawing on and expanding this logic, the 5P model has evolved to explicitly target poor communities that are often ignored by traditional public-private partnerships since supplying the poor can involve substantial business risks. As Figure 4.2 illustrates, the 5P model views the poor not only as consumers that receive benefits but also as partners in business ventures. It lies between 


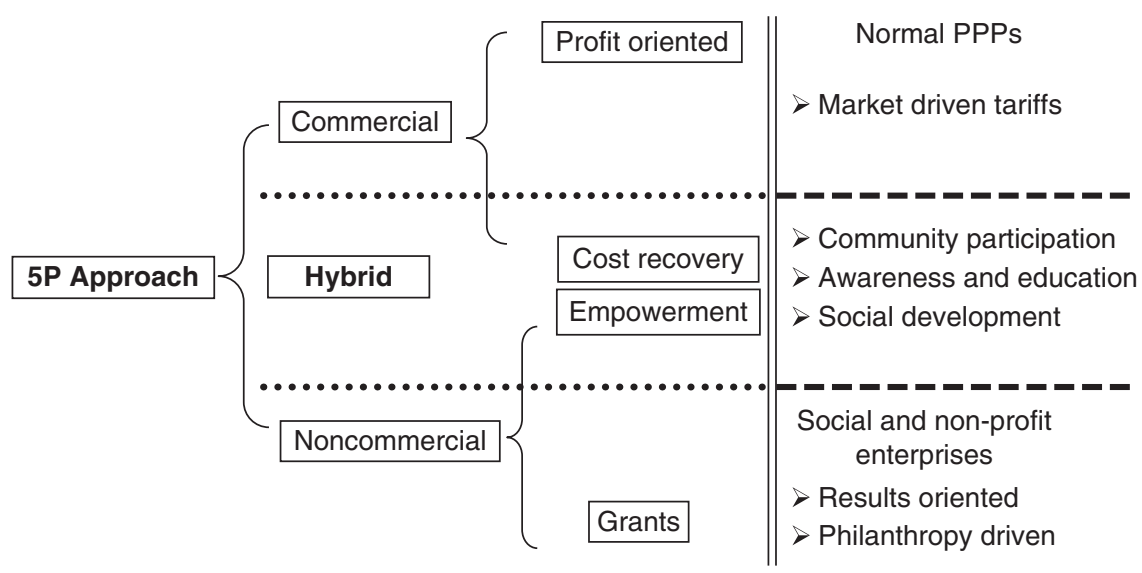

Figure 4.2 The pro-poor public-private partnership model

Source: Author.

Note: $5 \mathrm{P}=$ pro-poor public-private partnership, $\mathrm{PPP}=$ public-private partnership.

profit-oriented public-private partnerships and socially oriented grants and expands beyond the private sector to include development banks, equipment manufacturers, rural energy service companies, philanthropic organizations, community-based organizations, cooperatives, and households themselves. Each of these groups plays a different role: private sector participants can meet their corporate social responsibility obligations, utilities and energy companies can fulfill their obligations to deliver basic services, and communities and members of civil society can expand access to basic services. As United Nations Development Programme defines it, a 5P is one that, “. . . increases access of the poor to basic services by promoting inclusive partnerships between local government, businesses, community groups, nongovernment organizations, faith-based organizations, and others" (UNDP 2011).

The 5P model differs from an ordinary public-private partnership in three ways:

- It is participatory and involves a broad number of institutions instead of only one or two (government or government plus donor).

- The priority is social and economic development to help the poor, not necessarily to make a profit contrary to how most corporations and electric utilities operate.

- It is inherently cooperative rather than competitive and attempts to get partners to work together.

One example of the 5P approach is the Cinta Mekar microhydro project in West Java, Indonesia. The 120 kilowatt facility was built by a partnership of public, 
private, and community organizations, and the energy has been used to electrify village homes and produce revenue through exports to the national grid. Profits from the project are split equally between a private company, Hidropiranti Inti Bakti Swadaya, and the community itself represented by a village cooperative. Each month the hydro scheme generates about $\$ 3,300$ of gross income that is then channeled back to its investors (Tumiwa, Rambitan, and Tanujaya 2009).

\section{Household needs and off-grid programs}

Other types of public-private partnerships have attempted to expand energy access for household needs and through off-grid technologies. In 2006 and 2007, Indonesia created the Liquefied Petroleum Gas (LPG) Conversion Program as a substitute for kerosene in Indonesian households. It appointed the Ministry of Energy and Mineral Resources to lead the program and Pertamina, the stateowned oil and natural gas utility, as the sole program executor. Its initial goal was to convert 42 million households and micro-businesses nationally over 4 years. Under the program, every eligible household was given a 3-kg LPG canister, a coupon to fill that canister once for free, a single-burner stove, a hose, and a regulator. Pertamina conducted market assessments and built pressurized LPG terminals and filling stations to ensure reliability. In less than 3 years, Pertamina had distributed initial packages to more than 44 million households and small and medium-sized enterprises. Pertamina withdrew 5.3 million kiloliters of kerosene in 2009 and replaced it with 1.85 million tons of LPG, and Indonesia was able to save \$3 billion in decreased kerosene subsidies as of May 2010.

In Nepal, The UNDP Rural Energy Development Program offers an excellent example of how to rapidly diffuse microhydro facilities ranging from 10 to 100 kilowatts $(\mathrm{kW})$ with an average plant size of 25-30 kW. Program implementation was decentralized to local governments where district development committees and village development committees formed microhydro functional groups. The Alternative Energy Promotion Center, an autonomous body established in 1996 under the Ministry of Science and Technology, assumed overall management. The intended benefit was to provide customers currently dependent on kerosene and other fuels for lighting with reliable electricity. A secondary benefit came from promoting end-use activities such as cereal milling, rice husking, and mustard seed processing as well as replacing manual implements for carpentry with electrical machines and tools, though to prevent deforestation, project financing could not be used for sawmills. The program required communities wishing to build microhydro facilities to donate land for the construction of canals, penstocks, power houses, and distribution lines. Furthermore, villagers were required to contribute labor for related civil works.

As a result of these efforts, microhydro system coverage grew from only a few thousand homes in 25 districts in 2003 to 40 out of 51 target districts and 40,000 households in 2007 and more than 50,000 homes as of November 2010. The number of microhydro projects also jumped from 29 in 2003 to 280 in mid-2010. 
As of December 2007, a total of more than 90 projects with 1.5 megawatts (MW) of capacity had been completed providing access to 16,914 households meeting the original project goals almost 18 months ahead of schedule. By 2012, the program is expected to be operating in all 75 districts of Nepal with $6 \mathrm{MW}$ of capacity installed reaching more than one million people.

\section{Rural electrification}

The World Bank cites the PRC, the Lao People's Democratic Republic, Mongolia, the Philippines, Thailand, and Viet Nam as potential best practices for rural electrification. These six countries had the highest growth rates for electricity access from 2000 to 2009. Arguably, Bangladesh and Sri Lanka could also be included in this list.

The Philippines, for example, has an electrification rate of $89.7 \%$ which means that fewer than 9.5 million people lack access to electricity. This high rate stems from the aggressive National Electrification Act passed in 1969 that entrusted efforts to rural electric cooperatives that involved local communities as key elements of electrification efforts and massive amounts of government funding in the 1970s when 120 cooperatives served more than one million customers (United Nations Development Programme/World Bank Energy Sector Management Assistance Program 2002). Independent assessments have, however, indicated that many cooperatives face financial and operating challenges and are in debt, and that only $18.8 \%$ operate at a profit and are financially viable (United Nations Development Programme/World Bank Energy Sector Management Assistance Program 2002).

Over two-thirds of Laotian households today enjoy access-to-grid quality electricity, a vast improvement from 1995 when just one of every six families was connected, and coverage is envisaged to reach $90 \%$ by 2020 . How did this come about? First, the government made rural electrification a priority in the National Growth and Poverty Eradication Strategy (2006-2010) and committed the required resources. Then a comprehensive, sector-wide approach was adopted to carry out reforms, strengthen institutions, and build capacity which resulted in expanded generation capacity and distribution networks; improved operational efficiency; financial sustainability; and better service quality. Both grid and offgrid solutions were used to expand coverage. The government reformed tariffs including cross-subsidization in pricing and provided subsidies for the financial sustainability of the utility and for affordability for consumers. Capacity at the national utility was built in planning, design, implementation, and operation.

In addition, innovative methods were used to improve affordability for consumers. Villages were screened for clinics, schools, irrigation, and potential economic activities using gender-sensitive criteria and consultations. The Productive Use of Electricity Program was then launched to ensure income generation and extended social benefits. At the same time, the Power to the Poor Program was instituted to offer interest-free loans to poor households to pay for the upfront cost of connection. When the program was extended to already electrified villages, coverage increased from $80 \%$ to $98 \%$. Where off-grid solar systems were used to expand access, a hire-purchase scheme was implemented facilitating 
partial payments over a 10-year period making the systems accessible to the poor. Off-grid systems have covered about $2.5 \%$ of the households, particularly in inaccessible regions.

The tariff reforms carried out by the government coupled with capital subsidies have set the average energy price at $\$ 0.065$ per $\mathrm{kWh}$ against the cost of $\$ 0.05$ per kWh. System losses were reduced to $13 \%$ in 2009 from $20 \%$ in 2005 . Some of the key lessons from the Lao People's Democratic Republic experience are that (i) well-governed utilities can rapidly expand access with the private sector playing a complementary role; (ii) strong commitment from the government is critical; (iii) a combination of pricing and incentive mechanisms is necessary for financial sustainability and consumer affordability; (iv) strong commitment and capacity are a requisite for program managers; and (v) innovative, customized solutions are often required to reach the poor.

Even though they did not make the World Bank list, Bangladesh and Sri Lanka are also interesting cases. In 1971, 3\% of the total population of Bangladesh had access to electricity; today, approximately $53 \%$ has access. This success story is the result of a rural electrification program started in 1978 that created 70 rural cooperatives through which more than 50 million people are served.

At the end of the protracted civil war, Sri Lanka overwhelmingly re-elected President Mahinda Rajapaksa handing him a strong mandate to heal the country, rebuild the economy, and accelerate development. This has included an aggressive national electrification effort that has already connected more than $90 \%$ of households to the grid with an ambitious target of universal access to electricity between 2012 and 2015.

\section{Policy recommendations}

Based on the experiences in these case studies as well as those summarized by other research from the National University of Singapore (2011; see also Sovacool and Drupady 2012) and UNDP, at least five factors appear to be necessary in combination for programs and partnerships to successfully promote energy access and eradicate energy poverty.

\section{Select appropriate technology}

Successful programs frequently start small with pilot projects or with feasibility studies before initiating full-scale projects and scaling up to greater production or distribution volumes. They almost always choose appropriate technologies matched in quality and scale to the energy service desired. They set technical standards so only high-quality systems enter the marketplace, and they often possess culturally sensitive dissemination programs.

Feasibility studies and piloting are useful ways to identify market segments and determine if enough demand exists for renewable energy systems. Successful programs also have an orientation towards energy services matched in quality to end uses rather than technological deployment; they recognize technology not as an 
end itself but as a gateway to a particular energy service. The point is that different classes of people will put energy to use in different ways. In their work on energy poverty, Pachauri and Spreng (2008) identified numerous groups of people:

- tribal people and leaders;

- $\quad$ rural unemployed;

- landless peasants;

- traditional merchants and craft makers;

- $\quad$ peasants with small farms;

- the urban poor;

- $\quad$ servants; and

- blue-collar employees.

For these various groups, the services that energy delivers are far more important than the carrier itself. What matters is the relative importance users attach to it (Van Der Vleuten, Stam, and Van Der Plas 2007). A successful renewable energy project not only considers the appropriateness of the technology diffused for the needs of the target communities but also anticipates how these needs will change and grow over time and facilitates the transition to larger wattages or different technologies. As Amory Lovins mused many decades ago, "People do not want electricity or oil, nor such economic abstractions as 'residential services' but rather comfortable rooms, light, vehicular motion, food, tables, and other real things" (Lovins 1976).

Furthermore, programs that work tend to promote or harmonize rigorous technical standards to ensure renewable energy technologies perform as expected. This underscores the reliability component of energy access, and it also serves as a meaningful form of consumer protection. As one village leader told the author:

People will pay for energy services, just not for unreliability or unpredictability; they won't pay for electricity that is on when they don't need it or off when they do need it. Nor will they pay for electricity that has such erratic fluctuations in voltage that it fries appliances - that's what they don't want to pay for. But reliable, efficient service-yes, they want that.

Thus, successful programs strengthened technology in tandem with institutions and community awareness.

\section{Promote community participation}

Effective programs actively promote community ownership; in-kind contributions of labor, time, and other resources; and participatory decision making and planning. They tend to target minority groups in rural areas (such as female heads of households or children). They do not "give away" renewable energy technologies or over-subsidize technology or research. In essence, these attributes ensure 


\section{Benjamin K. Sovacool}

that households become involved in projects and that key stakeholders remain active.

Most of the successful case studies had local communities pay for renewable energy systems themselves and also saw local households or village leaders operate the technology. The projects had very high payback rates with more than $90 \%-99 \%$ of households repaying loans on time. Having local communities pay for renewable energy projects with their own funds means they expressed interest in and took responsibility for how the projects performed. They became not only passive consumers but active participants. As one respondent explained, "Classically, energy planners have seen the access question as one involving 'givers' and 'takers': the utility giving electricity or donors giving technology and the consumers taking it. This completely places the energy provider and consumer into a false dichotomy, one that successful programs break."

Contributions do not necessarily have to be financial. Communities and households can donate time (digging a canal), land (free property for the project site), or resources (wood for distribution poles). As the World Bank (1996) has noted, "Participation of local communities, investors, and consumers in the design and delivery of energy services is essential."

\section{Emphasize maintenance and after-sales service}

Successful programs strongly emphasize after-sales service and maintenance ensuring that technologies are cared for by rural populations or technicians. This can occur on the supply side through product guarantees, warranties, and assurances to buyback systems if communities are connected to the grid or on the demand side through training and free maintenance.

Once Grameen Shakti technicians in Bangladesh sell and install a solar home system, for example, they do not leave it up to the consumer to care for it. Grameen Shakti runs a buyback program in which clients can return their systems at a reduced price to the organization, and it gives free maintenance and training to all existing clients so that they can care and maintain their systems by themselves. They teach each user how to properly maintain the system and conduct minor repairs and also offer a free warranty for the first few years of operation. They view the needs of households and customers as "never ending" and train hundreds of technicians each year in renewable energy maintenance and the manufacturing of selected components.

The Renewable Energy Development Project in the PRC explicitly devolved maintenance authority to dealers. The Rural Electrification Project in the Lao People's Democratic Republic ensured that maintenance and battery replacement were formal parts of each program with responsibility clearly delegated to private sector participants. The Rural Energy for Access Project in Mongolia gave financial support for after-sales service call centers and the establishment of warranties. It created new centers to help herders maintain their systems, provide advice on battery charging, distribute spare parts, and honor warranties. The Renewable Energy Development Project in Nepal and the Energy Services Delivery Project 
in Sri Lanka utilized funds to hold microhydro maintenance training sessions. In Nepal, a small amount of every electricity tariff goes into a mandatory maintenance fund. In Sri Lanka, the project supported the creation of 80 permanent service and distribution centers with $\$ 5$ million committed from the private sector (these details are all summarized in Sovacool and Drupady 2012; Sovacool and Dworkin 2012; Sovacool 2012a,b).

\section{Couple energy services with incomes}

More effective programs couple and cultivate energy services with income generation and employment; they don't just wait for it to happen. They also sometimes offer scholarships and university training.

Grameen Shakti in Bangladesh offers a scholarship competition for the children of solar home system owners. It sponsors technical degrees in engineering and related fields for employees who commit to staying with the organization long term and has also done an excellent job linking its products and services to other local businesses and integrating its technologies with other programs. As one example, it connects the use of biogas units in homes and shops with the livestock, poultry, agriculture, and fishery industries. Clients wishing to own their own biogas unit can also purchase livestock, and clients who do not wish to use the fertilizer created as a byproduct from biogas units can sell it to local farmers, aquaculturists, and poultry ranchers. Similar links have been made in promoting Grameen Shakti solar panels, mobile telephones, compact fluorescent lamps, and light-emitting diode devices.

The Renewable Energy Development Project in the PRC offered nomadic herders tips on how they could use solar electricity not only for lighting but also to separate milk and cheese, charge mobile phones, and refrigerate yoghurt. In the Lao People's Democratic Republic, services put to use by solar panels have increased the business of restaurants, hotels, teahouses, and shops. In Mongolia, improved access to cellular telephony from the Rural Energy for Access Project has enabled herders to get better commodity prices for cashmere, meat, livestock, cheese, milk, yoghurt, and curd. In Nepal, the Renewable Energy Development Project has linked microhydro energy and the promotion of non-lighting uses of electricity including agro-processing, poultry farming, carpentry workshops, bakeries, ice making, lift irrigation, and water supply. In Sri Lanka, the Energy Services Delivery Project motivated many homeowners to begin new enterprises such as selling baked goods and vegetables, and existing shop owners to extend their operating hours after dusk.

The key lesson here is that successful programs did not just supply energy or electricity presuming people would know how to use it. They instead taught them how to put that energy to productive use. In essence, these projects succeeded because they promoted the types of economic activities that go hand-in-hand with modern energy enabling communities to form strong livelihood groups, to process agricultural commodities and crops, and to sustain small businesses and enterprises such as bars and restaurants (Jooijman-van Dijk and Clancy 2010). 


\section{Build local capacity}

Effective programs undertake capacity building, including strengthening the technical or managerial capacity of private and public firms, and educating villagers and communities about productive energy uses. Planners can neglect to build capacity because they think that their institutions already have sufficient expertise, because they choose to focus on the simpler act of deploying technology instead of the more difficult act of building human institutions, or in rare cases because of bias and corruption. Effective interventions have built private sector capacity through basic research grants; manufacturing and production loans; and efforts to standardize, certify, and test technology. Programs train staff at rural electricity companies, cooperatives, and manufacturers in setting tariffs, metering, billing, managing revenue, accounting, and auditing as well as in formulating business plans and advertising and marketing. Other private sector support can include staff recruitment and education, establishing rural outlets, and expanding inventory.

Public sector capacity can be strengthened by recruiting new staff, devising electrification and renewable energy deployment master plans, operating databases and new computer systems, and conducting feasibility studies and resource assessments. Assistance can enhance the ability to monitor and evaluate projects, to report results, arrange bulk purchases, and create or upgrade government research and testing laboratories. Community programs can educate households about energy and income generation.

In short, successful programs all undertook some degree of capacity building. Variants of this lesson include strengthening the technical or managerial capacity of domestic firms and institutions; outsourcing to international consultants when capacity is lacking; awarding research grants to manufacturers; improving the business practices of participating organizations; and emphasizing commercial viability and the ultimate goal of self-sustaining local markets for renewable energy and off-grid technology (Magradze, Miller, and Simpson 2007).

\section{References}

Alam, M. S., K. K. Islam, and A. M. Z. Huq. 2000. Simulation of Rural Household Fuel Consumption in Bangladesh. Energy 24 (8). 743-752.

Barnes, D. F. and W. M. Floor. 1996. Rural Energy in Developing Countries: A Challenge for Economic Development. Annual Review of Energy and Environment. 21. 497-530.

Bazilian, M., P. Nussbaumer, G. Gualberti, E. Haites, M. Levi, J. Siegel, D. M. Kammen, and J. Fenhann. 2011. Informing the Financing of Universal Energy Access: An Assessment of Current Financial Flows. Electricity Journal. 24 (7). 57-82.

Biswas, W. K., P. Bryce, and M. Diesendorf. 2001. Model for Empowering Rural Poor through Renewable Energy Technologies in Bangladesh. Environmental Science \& Policy. 4 (6). 333-344.

Chan, M. 2000. Air Pollution from Cookstoves: Energy Alternatives and Policy in Rural [People's Republic of] China. Pittsburg, PA: Carnegie Mellon University. 
Cook, C., T. Duncan, S. Jitsuchon, A. Sharma, and W. Guobao. 2005. Assessing the Impact of Transport and Energy Infrastructure on Poverty Reduction. Manila: Asian Development Bank.

D'Agostino, A. 2010. Energy Insecurity for ASEAN's BoP: The Un-electrified 160 Million. Presentation to the Energy Studies Institute-Ministry of Defence Workshop. Singapore. 5 October.

Gaye, A. 2007. Access to Energy and Human Development. United Nations Development Programme (UNDP) Human Development Report Office Occasional Paper. In Human Development Report 2007/2008. New York, NY: United Nations Development Programme.

Holdren, J. P., and K. R. Smith. 2000. Energy, the Environment, and Health. In T. Kjellstrom, D. Streets, and X. Wang, eds. World Energy Assessment: Energy and the Challenge of Sustainability. New York, NY: United Nations Development Programme. pp. 61-110.

Hussain, F. 2011. Challenges and Opportunities for Investments in Rural Energy. Presentation to the United Nations Economic and Social Commission for Asia and the Pacific (UNESCAP) and International Fund for Agricultural Development (IFAD) inception workshop Leveraging Pro-Poor Public-Private-Partnerships (5Ps) for Rural Development. Bangkok, Thailand. 26 September.

International Energy Agency. 2004. World Energy Outlook 2004. Paris: Organisation for Economic Co-operation and Development (OECD).

- 2011a. The Energy Development Index http://www.worldenergyoutlook.org/ resources/energydevelopment/measuringenergyanddevelopment/ (accessed February 2014).

- 2011b. Energy for All: Financing Access for the Poor. Paris: OECD.

- 2012. World Energy Outlook 2012. Paris: OECD.

International Energy Agency (IEA), United Nations Development Programme (UNDP), United Nations Industrial Development Organization (UNIDO). 2010. Energy Poverty: How to Make Modern Energy Access Universal? Paris: OECD.

International Institute for Applied Systems Analysis (IIASA). 2012. Global Energy Assessment. Cambridge, UK: Cambridge University Press.

Islam, K. R., and R. R. Weil. 2000. Land Use Effects on Soil Quality in a Tropical Forest Ecosystem of Bangladesh. Agriculture, Ecosystems and Environment. 79 (1). 9-16.

Jin, Y., X. Ma, X. Chen, Y. Cheng, E. Baris, and M. Ezzati. 2006. Exposure to Indoor Air Pollution from Household Energy Use in Rural [People's Republic of] China: The Interactions of Technology, Behavior, and Knowledge in Health Risk Management. Social Science \& Medicine. 62 (12). 3161-3176.

Jones, R. 2010. Energy Poverty: How to Make Modern Energy Access Universal? Special Early Excerpt of the World Energy Outlook 2010 for the United Nations General Assembly on the Millennium Development Goals. Paris: International Energy Agency/ OECD.

Jooijman-van Dijk, A. L., and J. Clancy. 2010. Impacts of Electricity Access to Rural Enterprises in Bolivia, Tanzania, and Viet Nam. Energy for Sustainable Development. 14 (1). 14-21.

Legros, G., I. Havet, N. Bruce, S. Bonjour, K. Rijal, M. Takada, and C. Dora. 2009. The Energy Access Situation in Developing Countries: A Review Focusing on the Least Developed Countries and Sub-Saharan Africa. New York, NY: World Health Organization and United Nations Development Programme. 
Lim S. S., T. Vos, A. D. Flaxman, G. Danaei, K. Shibuya, H. Adair-Rohani, M. Amann, H. R. Anderson, K. G. Andrews, M. Aryee, C. Atkinson, L. J. Bacchus, A. N. Bahalim, K. Balakrishnan, J. Balmes, S. Barker-Collo, A. Baxter, M. L. Bell, J. D. Blore, F. Blyth, C. Bonner, G. Borges, R. Bourne, M. Boussinesq, M. Brauer, P. Brooks, N. G. Bruce, B. Brunekreef, C. Bryan-Hancock, C. Bucello, R. Buchbinder, F. Bull, R. T. Burnett, T. E. Byers, B. Calabria, J. Carapetis, E. Carnahan, Z. Chafe, F. Charlson, H. Chen, J. S. Chen, A. T. Cheng, J. C. Child, A. Cohen, K. E. Colson, B. C. Cowie, S. Darby, S. Darling, A. Davis, L. Degenhardt, F. Dentener, D. C. Des Jarlais, K. Devries, M. Dherani, E. L. Ding, E. R. Dorsey, T. Driscoll, K. Edmond, S. E. Ali, R. E. Engell, P. J. Erwin, S. Fahimi, G. Falder, F. Farzadfar, A. Ferrari, M. M. Finucane, S. Flaxman, F. G. Fowkes, G. Freedman, M. K. Freeman, E. Gakidou, S. Ghosh, E. Giovannucci, G. Gmel, K. Graham, R. Grainger, B. Grant, D. Gunnell, H. R. Gutierrez, W. Hall, H. W. Hoek, A. Hogan, H. D. Hosgood III, D. Hoy, H. Hu, B. J. Hubbell, S. J. Hutchings, S. E. Ibeanusi, G. L. Jacklyn, R. Jasrasaria, J. B. Jonas, H. Kan, J. A. Kanis, N. Kassebaum, N. Kawakami, Y. H. Khang, S. Khatibzadeh, J. P. Khoo, C. Kok, F. Laden, R. Lalloo, Q. Lan, T. Lathlean, J. L. Leasher, J. Leigh, Y. Li, J. K. Lin, S. E. Lipshultz, S. London, R. Lozano, Y. Lu, J. Mak, R. Malekzadeh, L. Mallinger, W. Marcenes, L. March, R. Marks, R. Martin, P. McGale, J. McGrath, S. Mehta, G. A. Mensah, T. R. Merriman, R. Micha, C. Michaud, V. Mishra, K. Mohd Hanafiah, A. A. Mokdad, L. Morawska, D. Mozaffarian, T. Murphy, M. Naghavi, B. Neal, P. K. Nelson, J. M. Nolla, R. Norman, C. Olives, S. B. Omer, J. Orchard, R. Osborne, B. Ostro, A. Page, K. D. Pandey, C. D. Parry, E. Passmore, J. Patra, N. Pearce, P. M. Pelizzari, M. Petzold, M. R. Phillips, D. Pope, C. A. Pope III, J. Powles, M. Rao, H. Razavi, E. A. Rehfuess, J. T. Rehm, B. Ritz, F. P. Rivara, T. Roberts, C. Robinson, J. A. Rodriguez-Portales, I. Romieu, R. Room, L. C. Rosenfeld, A. Roy, L. Rushton, J. A. Salomon, U. Sampson, L. Sanchez-Riera, E. Sanman, A. Sapkota, S. Seedat, P. Shi, K. Shield, R. Shivakoti, G. M. Singh, D. A. Sleet, E. Smith, K. R. Smith, N. J. Stapelberg, K. Steenland, H. Stöckl, L. J. Stovner, K. Straif, L. Straney, G. D. Thurston, J. H. Tran, R. Van Dingenen, A. van Donkelaar, J. L. Veerman, L. Vijayakumar, R. Weintraub, M. M. Weissman, R. A. White, H. Whiteford, S. T. Wiersma, J. D. Wilkinson, H. C. Williams, W. Williams, N. Wilson, A. D. Woolf, P. Yip, J. M. Zielinski, A. D. Lopez, C. J. Murray, M. Ezzati, M. A. AlMazroa, and Z. A. Memish. 2012. A Comparative Risk Assessment of Burden of Disease and Injury Attributable to 67 Risk Factors and Risk Factor Clusters in 21 Regions, 1990-2010: A Systematic Analysis for the Global Burden of Disease Study 2010. Lancet. 380. 2224-2260.

Lovins, A. B. 1976. Energy Strategy: The Road Not Taken. Foreign Affairs. 55 (1). 65.

Magradze, N., A. Miller, and H. Simpson. 2007. Selling Solar: Lessons from More Than a Decade of Experience. Washington, DC: Global Environment Facility/International Finance Corporation.

Masud, J., D. Sharan, and B. N. Lohani. 2007. Energy for All: Addressing the Energy, Environment, and Poverty Nexus in Asia. Manila: Asian Development Bank.

Miah, D., H. Al Rashid, and M. Yong Shin. 2009. Wood Fuel Use in the Traditional Cooking Stoves in the Rural Floodplain Areas of Bangladesh: A Socio-Environmental Perspective. Biomass and Bioenergy. 33 (1). 70-78.

Modi, V., S. McDade, D. Lallement, and J. Saghir. 2005. Energy Services for the Millennium Development Goals. Washington, DC and New York, NY: World Bank Energy Sector Management Assistance Program and United Nations Development Programme.

Murphy, J. T. 2001. Making the Energy Transition in Rural East Africa: Is Leapfrogging an Alternative? Technological Forecasting \& Social Change. 6. 173-193. 
National University of Singapore, Lee Kuan Yu School of Public Policy. 2011. Energy Governance Case Studies. http://issuu.com/nuslkyschool/docs

Pachauri, S., and D. Spreng. 2008. Some Remarks on the Choice and Use of Indicators of Development. Presentation to the Clean Cooking Fuels and Technologies Workshop. Istanbul. 16-17 June.

Peios, J. 2004. Fighting Deforestation in Bangladesh. Geographical. 76 (3). 14.

Porcaro, J., and M. Takada. 2005. Achieving the Millennium Development Goals: The Role of Energy Services. New York: United Nations Development Programme.

Reddy, S. B., P. Balachandra, and H. S. K. Nathan. 2009. Universalization of Access to Modern Energy Services in Indian Households: Economic and Policy Analysis. Energy Policy. 37 (11). 4645-4657.

Riahi, K., F. Dentener, D. Gielen, A. Grubler, J. Jewell, Z. Klimont, V. Krey, D. McCollum, S. Pachauri, S. Rao, B. van Ruijven, D. P. van Vuuren, and C. Wilson. 2012. Energy Pathways for Sustainable Development. In The Global Energy Assessment: Toward a More Sustainable Future. Laxenburg, Austria: International Institute for Applied Systems Analysis (IIASA) and Cambridge University Press.

Sangeeta, K. 2008. Energy Access and its Implication for Women: A Case Study of Himachal Pradesh, India. Presentation to the 31st International Association for Energy Economics (IAEE) International Conference Pre-Conference Workshop on Clean Cooking Fuels. Istanbul. 16-17 June.

Sovacool, B. K. 2011. Developing Public-Private Renewable Energy Partnerships to Expand Energy Access. Bangkok: United Nations Economic and Social Commission for the Asia Pacific (UNESCAP).

—. 2012a. Deploying Off-Grid Technology to Eradicate Energy Poverty. Science. 338 (6103). pp. 47-48.

- 2012b. Design Principles for Renewable Energy Programs in Developing Countries. Energy \& Environmental Science. 5 (11). 9157-9162.

Sovacool, B. K. and I. M. Drupady. 2012. Energy Access, Poverty, and Development: The Governance of Small-Scale Renewable Energy in Developing Asia. New York: Ashgate.

Sovacool, B. K. and M. Dworkin. 2012. Overcoming the Global Injustices of Energy Poverty. Environment. 54 (5). 14-28.

Tumiwa, F., H. I. Rambitan, and O. Tanujaya. 2009. Cinta Mekar Micro-Hydro Power Plant: Giving Power to the People. Jakarta: Institute for Essential Services Reform.

United Nations Development Programme (UNDP). 2010a. Human Development Report 2010. New York, NY: UNDP.

—. 2010b. Energy for a Sustainable Future: The Secretary-General's Advisory Group on Energy and Climate Change Summary Report and Recommendations. New York, NY: UNDP.

—. 2011. Public Private Partnerships for Service Delivery. Johannesburg, South Africa: UNDP Capacity Development Group.

United Nations Development Programme/World Bank Energy Sector Management Assistance Program. 2002. Rural Electrification and Development in the Philippines: Measuring the Social and Economic Benefits. Washington, DC: World Bank.

United Nations Economic and Social Commission for Asia and the Pacific (UNESCAP). 2010. Lighting Up Lives: Pro-Poor Public Private Partnerships. Bangkok, Thailand: UNESCAP. United Nations Environment Programme (UNEP). 2000. Natural Selection: Evolving Choices for Renewable Energy Technology and Policy. New York, NY: UNEP.

van der Horst, G. H. and A. J. Hovorka. 2008. Reassessing the Energy Ladder: Household Energy Use in Maun, Botswana. Energy Policy. 36 (9). 3333-3344. 


\section{Benjamin K. Sovacool}

Van Der Vleuten, F., N. Stam, and R. Van Der Plas. 2007. Putting Solar Home System Programs into Perspective: What Lessons Are Relevant? Energy Policy. 35. 1439-1451. Velumail, T. 2011. Regional Context for Improving Access to Energy: Energy for Creating and Sustaining Livelihoods. Presentation to the United Nations Economic and Social Commission for Asia and the Pacific (UNESCAP) and International Fund for Agricultural Development (IFAD) inception workshop Leveraging Pro-Poor PublicPrivate-Partnerships for Rural Development. Bangkok, Thailand. 26 September.

World Bank. 1996. Rural Energy and Development for Two Billion People. Washington, DC: World Bank.

World Health Organization (WHO). 2006. Fuel for Life: Household Energy and Health. Geneva: WHO. 


\section{Part III}

\section{Energy and the environment}





\title{
5 The environment and energy security in Asia and the Pacific
}

\author{
Benjamin K. Sovacool
}

\section{Introduction}

This chapter explores the intersection of environmental constraints, climate change, and energy security in Asia and the Pacific. Although environmental sustainability has only recently emerged as an energy policy issue, the magnitude of energy impacts on environmental systems suggests strong links to energy security. The unchecked growth in fossil energy consumption and the ensuing acceleration of global climate change as well as related air and water pollution act as "threat multipliers" impinging on national security globally. These environmental dimensions are just a subset of a larger array of environmental concerns that threaten energy security including land pollution, forestry, and biodiversity loss (Brown and Dworkin 2011). Table 5.1 summarizes the four environmental dimensions of energy security in Asia and the Pacific discussed in this chapter: climate change, air pollution, water availability and quality, and land-use change.

\section{Climate change}

Climate change is a substantial energy security concern not only because direct flooding and natural disasters can damage power plants and transmission lines, disrupt the delivery of imported energy fuels, and destroy crops for biofuels but also because it has severe impacts on food security, health, and environmental refugees that can all lower the income base of Asian countries and add to government debt further complicating attempts at sound energy policymaking. Though climate change is certainly a global phenomenon, in many ways it is becoming an Asian problem. Figure 5.1 shows annual tons of carbon dioxide $\left(\mathrm{CO}_{2}\right)$ emissions from fuel combustion divided by the total national population for selected Asian countries; it indicates that emissions more than doubled from 1990 to 2010 in the People's Republic of China (PRC), Indonesia, Malaysia, Thailand, and Viet Nam.

Figure 5.2 indicates that when changes in land use are included, 4 of the top 10 emitters of greenhouse gases (GHGs) - PRC, Indonesia, India, and Japanare in Asia. $\mathrm{CO}_{2}$ emissions from the electricity supply sector in the $\mathrm{PRC}$ - mainly 
Table 5.1 Environmental dimensions of energy security in Asia and the Pacific

\begin{tabular}{|c|c|c|}
\hline Dimension & Link to energy security & $\begin{array}{l}\text { Energy contribution to the } \\
\text { problem }\end{array}$ \\
\hline Climate change & $\begin{array}{l}\text { Climate change is a "threat } \\
\text { multiplier" in terms of energy } \\
\text { security. } \\
\text { Mass migrations of refugees } \\
\text { seeking asylum from } \\
\text { ecological disasters could } \\
\text { destabilize regions of the world } \\
\text { threatening energy as well as } \\
\text { national security. }\end{array}$ & $\begin{array}{l}\text { A total of } 66.5 \% \text { of global } \\
\text { carbon dioxide emissions } \\
\text { come from energy supply and } \\
\text { transport. }\end{array}$ \\
\hline Air pollution & $\begin{array}{l}\text { Deterioration of environmental } \\
\text { conditions can negatively } \\
\text { impact human and ecological } \\
\text { health with significant } \\
\text { numbers of premature deaths } \\
\text { related to indoor and outdoor } \\
\text { air pollution and significant } \\
\text { expenditures lost in terms of } \\
\text { lost productivity and } \\
\text { healthcare. }\end{array}$ & $\begin{array}{l}\text { About } 80 \% \text { of global sulfur } \\
\text { dioxide emissions, } 80 \% \text { of } \\
\text { particulate matter emissions, } \\
\text { and } 70 \% \text { percent of nitrogen } \\
\text { oxide emissions come from } \\
\text { the energy and transport } \\
\text { sectors. }\end{array}$ \\
\hline $\begin{array}{l}\text { Water availability } \\
\text { and quality }\end{array}$ & $\begin{array}{l}\text { Lack of available safe drinking } \\
\text { water can destabilize the } \\
\text { security of a region. } \\
\text { Because fossil, hydro, and } \\
\text { nuclear power plants consume } \\
\text { large quantities of freshwater, } \\
\text { shrinking supplies of water } \\
\text { could threaten the ability to } \\
\text { provide electricity and the } \\
\text { ability of nations to feed } \\
\text { themselves. }\end{array}$ & $\begin{array}{l}\text { In all, } 25 \% \text { of global water } \\
\text { supply is lost due to } \\
\text { evaporation from reservoirs } \\
\text { and another } 10 \%-15 \% \text { of } \\
\text { global freshwater is used in } \\
\text { thermoelectric power plants. }\end{array}$ \\
\hline Land-use change & $\begin{array}{l}\text { Deforestation can cause social } \\
\text { dislocation, increase the cost of } \\
\text { fuelwood, destroy biodiversity, } \\
\text { and conflict with agriculture } \\
\text { and the preservation of nature } \\
\text { reserves. }\end{array}$ & $\begin{array}{l}\text { At least } 15 \% \text { of land-use } \\
\text { change is caused by the direct } \\
\text { clearing of forests for } \\
\text { fuelwood and the expansion } \\
\text { of plantations for energy } \\
\text { crops. }\end{array}$ \\
\hline
\end{tabular}

Source: Modified from Brown and Dworkin 2011.

coal-fired power plants - make up almost half of the total emissions generated by the country (Liu et al. 2011). In 1987, only $12 \%$ of emissions were due to industrial production, but that figure rose to $21 \%$ in 2002 and to $33 \%$ in 2005 (Weber et al. 2008). In Taipei,China emissions jumped from 160.5 million metric tons of $\mathrm{CO}_{2}$ equivalent in 1990 to 271.6 million in 2000, an increase of 5.3\% (Tsai and Chou 2005). One international assessment of the carbon footprints in 12 major metropolitan areas throughout the world in 2010 found that only 4 cities 


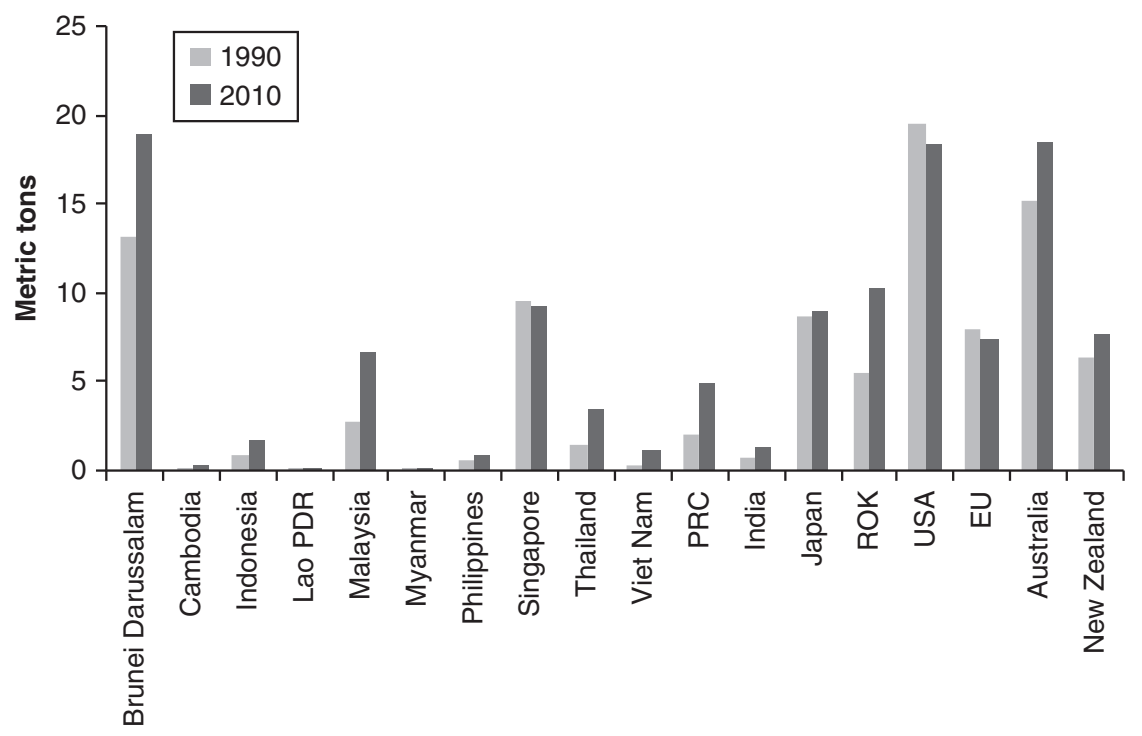

Figure 5.1 Per capita energy-related carbon dioxide emissions, 1990 and 2010 Source: Sovacool et al. 2011.

Note: PRC = People's Republic of China; EU = European Union; ROK = Republic of Korea; Lao $\mathrm{PDR}=$ Lao People's Democratic Republic; USA = United States.

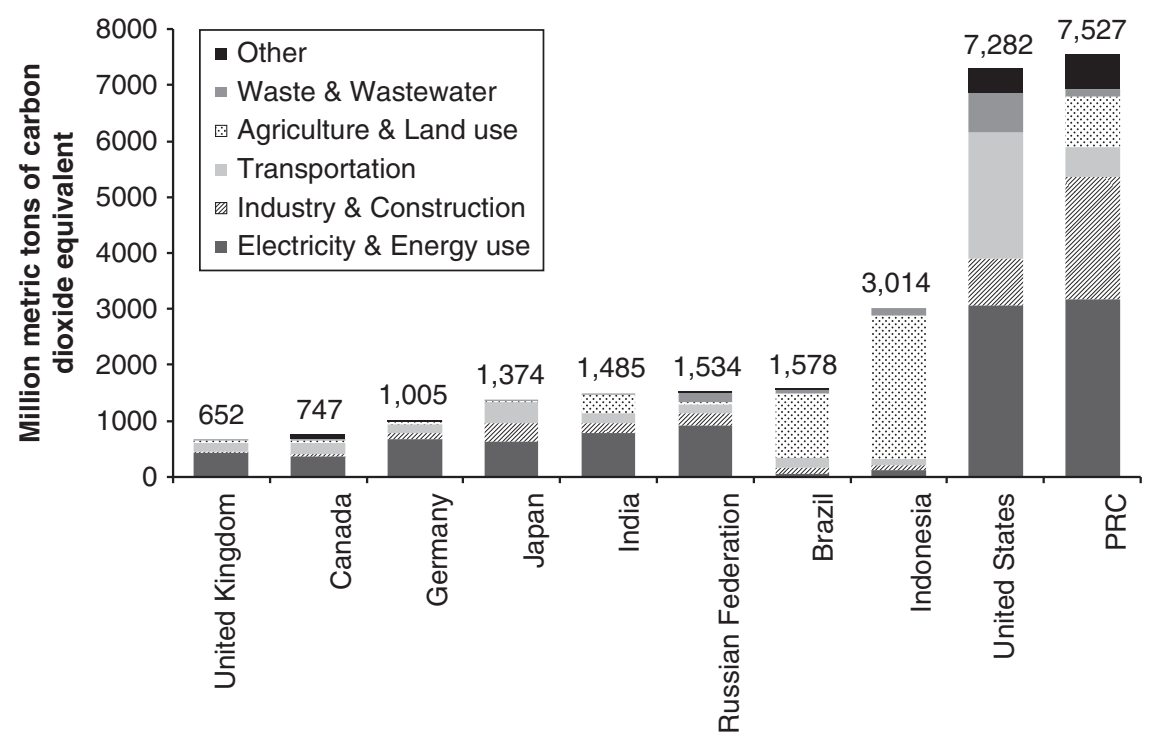

Figure 5.2 Share of greenhouse gas emissions in top ten countries, 2010

Source: Brown and Sovacool 2011.

Note: PRC = People's Republic of China. 


\section{Benjamin K. Sovacool}

were below the world average and that many major ones such as Seoul, Singapore, and Tokyo were already well above it. ${ }^{1}$

Unfortunately from a climate standpoint, the GHGs already emitted will threaten Asia with a staggering list of negative consequences. Because of their unique geography and climatology, low per capita incomes, and changing patterns of urbanization, Indonesia, the Philippines, Thailand, and Viet Nam are expected to lose $6.7 \%$ of combined gross domestic product (GDP) by 2100 if temperatures change as the Intergovernmental Panel on Climate Change predicts which is more than twice the rate of global average losses (Asian Development Bank 2009). Even uniform changes in climate will not affect Asia equally as Cambodia, Lao People's Democratic Republic, the Mekong River Delta, the Philippines, central Thailand, and Sumatra and Java in Indonesia are more at risk than wealthier countries such as Brunei Darussalam or Singapore (Yusuf and Francisco 2009; Government of Singapore 2008).

The PRC and India, for instance, could exhaust between $1 \%$ and $12 \%$ of their annual GDPs coping with climate refugees, changing disease vectors, and failing crops (Economics of Climate Adaptation Working Group 2009; Royal United Services Institute 2009; Center for Naval Analyses 2009). One study forecasts a $37 \%$ reduction in national crop yields by 2050 in the PRC if current climate trends continue (McMichael 2007). Some states in India such as Maharashtra are projected to suffer greater drought that will likely wipe out $30 \%$ of food production inducing $\$ 7$ billion in damages among 15 million small and marginal farmers (Economics of Climate Adaptation Working Group 2009). In India as a whole, farmers and fishers will have to migrate from coastal areas as sea levels rise and as they confront heat waves lowering crop output, and they will have to manage declining water tables from saltwater intrusion (Center for Naval Analyses 2009).

One wide-ranging survey of climate impacts in Asia and the Pacific from the United States Agency for International Development predicted the following, among other things:

- $\quad$ accelerated river bank erosion, saltwater intrusion, crop losses, and floods in Bangladesh that will displace at least 8 million people and destroy up to 5 million hectares of crops;

- more frequent and intense droughts in Sri Lanka crippling tea yields and reducing national foreign exchange and lowering incomes for low-wage workers;

- $\quad$ higher sea levels inundating half of the agricultural lands on the Mekong Delta causing food insecurity throughout Cambodia, Lao People's Democratic Republic, and Viet Nam;

\footnotetext{
${ }^{1}$ Global carbon footprint of 1.19 computed by dividing global emissions (28.1 billion tons of carbon dioxide) by the world population ( 6.4 billion) and again by 3.67 to convert carbon dioxide to carbon. Footprints include direct and responsible emissions from transport, buildings and industry, agriculture (when applicable), and waste (when applicable). See Sovacool and Brown 2010.
} 
- $\quad$ increased ocean flooding and storm surges inundating 130,000 hectares of farmland in the Philippines affecting the livelihoods of 2 million people;

- intensified floods in Thailand placing more than 5 million people at risk and causing $\$ 39$ billion to $\$ 1.1$ trillion in economic damages by 2050 (Government of the United States USAID 2010).

That study concluded that Asia and the Pacific will have more land threatened, more people damaged, and more economic damage from rising sea levels than any other part of the planet. Already, the region accounted for $85 \%$ of deaths and $38 \%$ of global economic losses due to natural disasters from 1980 to 2009 (United Nations Economic and Social Commission for Asia and the Pacific 2012).

Although these vulnerabilities are great, perhaps the most severe climate change impacts will befall small developing island states. Small island countries in the Pacific are at the ever-present mercy of natural disasters, especially cyclones and storm-induced floods that can damage energy infrastructure and reduce national incomes. Since the 1950s, the quantity and magnitude of natural disasters throughout the Pacific have increased significantly, and many countries lie in the path of Pacific cyclones. Table 5.2 also illustrates that a selection of

Table 5.2 Estimated economic and social impact of disasters in selected Pacific island economies, 1950-2008

\begin{tabular}{|c|c|c|c|c|c|c|}
\hline \multirow[t]{2}{*}{$\begin{array}{l}\text { Name of } \\
\text { economies }\end{array}$} & \multirow[t]{2}{*}{ Disasters } & \multirow[t]{2}{*}{$\begin{array}{l}\text { Losses } \\
(\$ 2008)\end{array}$} & \multicolumn{2}{|c|}{$\begin{array}{l}\text { Average } \\
\text { population } \\
\text { affected }(\%)\end{array}$} & \multicolumn{2}{|c|}{$\begin{array}{l}\text { Average } \\
\text { impact on } \\
\text { gross domestic } \\
\text { product (\%) }\end{array}$} \\
\hline & & & $\begin{array}{l}\text { Disaster } \\
\text { years }\end{array}$ & $\begin{array}{l}\text { All } \\
\text { years }\end{array}$ & $\begin{array}{l}\text { Disaster } \\
\text { years }\end{array}$ & $\begin{array}{l}\text { All } \\
\text { years }\end{array}$ \\
\hline American Samoa & 6 & $237,214,770$ & 5.81 & 0.61 & 7.76 & 0.82 \\
\hline Cook Islands & 9 & $47,169,811$ & 5.13 & 0.63 & 3.48 & 0.43 \\
\hline Fiji & 43 & $1,276,747,934$ & 5.39 & 2.74 & 3.48 & 0.78 \\
\hline French Polynesia & 6 & $78,723,404$ & 0.53 & 0.04 & 0.31 & 0.02 \\
\hline $\begin{array}{r}\text { Federated States } \\
\text { of Micronesia }\end{array}$ & 8 & $11,915,993$ & 6.20 & 0.65 & 0.82 & 0.09 \\
\hline Guam & 10 & $3,294,869,936$ & 1.97 & 0.28 & 10.13 & 1.42 \\
\hline Kiribati & 4 & 0 & 29.19 & 1.54 & 0.00 & 0.00 \\
\hline Marshall Islands & 3 & 0 & 6.40 & 0.22 & 0.00 & 0.00 \\
\hline New Caledonia & 15 & $69,623,803$ & 0.14 & 0.03 & 0.09 & 0.02 \\
\hline Niue & 6 & $56,461,688$ & 73.15 & 7.70 & 80.88 & 8.51 \\
\hline Papua New Guinea & 58 & $271,050,690$ & 0.69 & 0.36 & 0.14 & 0.07 \\
\hline Samoa & 11 & $930,837,187$ & 21.15 & 3.71 & 16.97 & 2.98 \\
\hline Solomon Islands & 21 & $39,215,686$ & 2.93 & 0.98 & 0.52 & 0.17 \\
\hline Tokelau & 4 & $4,877,822$ & 39.70 & 2.79 & & \\
\hline Tonga & 12 & $129,344,561$ & 21.32 & 3.37 & 5.76 & 0.91 \\
\hline Tuvalu & 5 & 0 & 3.19 & 0.28 & 0.00 & 0.00 \\
\hline Vanuatu & 36 & $406,402,255$ & 5.33 & 2.06 & 3.78 & 1.46 \\
\hline
\end{tabular}

Source: World Bank 2009. 
Pacific island countries has had no fewer than 257 disasters from 1950 to 2008 that have caused $\$ 6.8$ billion in damages (see Asian Development Bank 2005 and World Bank 2009). In the Solomon Islands, the Ministry of Environment, Conservation and Meteorology has warned that "energy production, utilization, conversion, and transportation" have been and will continue to be negatively affected by "droughts, floods, fires, storm surges, and cyclones" (Government of the Solomon Islands 2008). In Samoa, the earthquake and tsunami in September 2009 greatly damaged the Electric Power Corporation generation and distribution assets in the southern and eastern coastal areas of Upolu, Manono, and Savii. Damages included toppled power poles and fittings, cracked transformers, and destroyed hydroelectric dams (Government of Samoa 2011). With assets of only $\$ 163$ million and a net operating profit of $\$ 2.1$ million per year, the corporation has little revenue to draw from to address these types of damages. In Fiji, unexpected shortfalls in water have forced the country's hydroelectric dams to operate below full capacity increasing reliance on diesel imports and precipitating increases in electricity tariffs (Government of Fiji 2011).

\section{Air pollution}

Air pollution is an energy security concern in at least two respects: outdoor air pollution degrades human health and increases hospital admissions, and indoor air pollution from using traditional and stoves for cooking and heating causes premature deaths in women and children (see Chapter 4). Outdoor air pollution is significantly caused by energy production and use as about $80 \%$ of sulfur dioxide emissions, $80 \%$ of particulate matter emissions, and $70 \%$ percent of nitrogen oxide emissions come from the energy and transport sectors (World Resources Institute Earth Trends Database 2012).

The International Energy Agency (IEA) notes that air quality has become a serious problem for hundreds of Asian cities and towns. Bangkok, Ho Chi Minh City, Jakarta, Kuala Lumpur, and Manila suffer from air pollution due to increased vehicle use, rapid rates of industrialization and urbanization, a reliance on coal, and industries operating in close proximity to residential areas $(\mathrm{Olz}$ and Beerepoot 2010). The World Health Organization (WHO) estimates that 517,700 people in Asia die annually because of outdoor air pollution, 275,600 in the PRC alone. Of the 18 megacities worldwide with severe levels of total suspended particulate matter emissions, 10 are in Asia and 5 are in South Asia (Karachi, OsakaKobe, Dhaka, Beijing, Jakarta, Delhi, Shanghai, Kolkata, Mumbai, and Tokyo) (World Health Organization 2007).

Air pollution takes a substantial toll on national healthcare expenditures and GDP. In the Philippines, particulate matter pollution has been estimated to cause $\$ 432$ million in annual damages worth $0.6 \%$ of national GDP (World Bank 2002). In Thailand, particulate matter pollution causes at least $\$ 825$ million in damages worth $1.6 \%$ of GDP (World Bank 2002). In the context of electricity prices, the cost of air pollution adds as much as $\$ 0.0417$ per kilowatt to every unit of Thai electricity (Sakulniyomporn et al. 2011). In the PRC, particulate matter pollution 
causes from $\$ 63$ billion to $\$ 272$ billion in damages or as much as $3.3 \%$ to $7.0 \%$ of national GDP (Deng 2006; McMichael 2007). These numbers will undoubtedly rise with the growth in demand for automobiles in the PRC. In India, "It is now understood that rural outdoor air pollution is a significant problem with average levels of pollution in the Ganga River Basin, for example, being substantially above Indian and WHO health-based norms" (Venkataraman et al. 2010). In Cambodia, the rapid increases in vehicle operation have led to ambient concentrations of particulate matter that are "very high" with "likely severe impacts on the health of residents" (Asian Development Bank 2006).

Transportation is not the only cause of outdoor air pollution; burning coal for electricity and industrial uses contributes as well. The best example is the PRC. Coal is the most abundant and widely used fuel; the PRC already uses more of it than the European Union, Japan, and the United States (US) combined (Sovacool and Khuong 2011; Government of the United States EIA 2010). Coal meets more than $70 \%$ of the country's energy needs. The PRC is currently the world's biggest producer and consumer of coal producing 3.8 billion tons in 2011 (compared to 1.1 billion tons in the US) amounting to about half the world total (Biswas and Kirchherr 2012). Coal combustion provided $65 \%$ of the country's electricity in 1985 but that figure rose to more than $80 \%$ in 2006. From 2002 to 2007, demand for electricity grew by about $12 \%$, and more than 70,000 megawatts of capacity were brought online to meet it (Khuong and Sovacool 2010), a majority of which was coal fired. The PRC currently is constructing the equivalent of two $500 \mathrm{meg}-$ awatt coal-fired plants per week - a capacity comparable to the entire power grid in the United Kingdom (UK) every year. More than half of the coal production is used in the non-electricity sector. It provides $60 \%$ of chemical feedstock and $55 \%$ of industrial fuel. Nearly $45 \%$ of the national railway capacity is devoted exclusively to the transport of coal.

\section{Water quality and availability}

The United Nations (UN) reports that overall, agriculture is the largest user of freshwater but that the energy sector comes second with hydropower, nuclear power, and thermal power generation accounting for about $10 \%$ to $15 \%$ of global water consumption (United Nations Environment Program 2008). In addition, the UN estimates that the volume of water evaporated from reservoirs exceeds the combined freshwater needs of industry and domestic consumption which represent about $25 \%$ of global water use. As the UN concluded, hydroelectric dams therefore "greatly contribute to water losses around the world, especially in hot, tropical regions" (United Nations Environment Program 2008).

The energy sector consumes and contaminates water sources imposing costs on all water users from households and commercial enterprises to farmers and recreational users as well as on fish and marine mammals. Thermoelectric power plants - those relying on coal, oil, natural gas, biomass/waste, or uranium in nuclear reactors - take water from rivers, lakes, and streams to cool equipment before returning it to its source, and they consume it through evaporative loss. As 
Table 5.3 Water use (consumption and withdrawals) for selected power plants (gallons per kilowatt hour)

\begin{tabular}{|c|c|c|c|c|c|}
\hline & Withdrawals & Consumption & Withdrawals & Consumption & Total \\
\hline & \multicolumn{2}{|c|}{ (Combustion/downstream) } & \multicolumn{3}{|c|}{ (Production/upstream) } \\
\hline Nuclear & 43 & 0.4 & 0 & 0.11 & 43.5 \\
\hline Coal (mining) & 35 & 0.3 & 0.17 & 0.045 & 35.5 \\
\hline Coal (slurry) & 35 & 0.3 & 0 & 0.05 & 35.3 \\
\hline Biomass/waste & 35 & 0.3 & 0.03 & 0.03 & 35.3 \\
\hline Natural gas & 13.75 & 0.1 & 0 & 0.01 & 13.9 \\
\hline Solar thermal & 4.5 & 4.6 & 0 & 0 & 9.1 \\
\hline Hydroelectric & 0 & 0 & 0 & 4.5 & 4.5 \\
\hline Geothermal (steam) & 2 & 1.4 & 0 & 0 & 3.4 \\
\hline Solar PV & 0 & 0 & 0 & 0.3 & 0.3 \\
\hline Wind & 0 & 0 & 0 & 0.2 & 0.2 \\
\hline Energy efficiency & 0 & 0 & 0 & 0 & 0 \\
\hline
\end{tabular}

Source: Sovacool and Sovacool 2009b.

Note: PV = photovoltaic.

Table 5.3 shows, the average power plant uses about 25 gallons (95 liters) of water for every kilowatt hour generated (Sovacool and Sovacool 2009a). This means that the power consumed in 1 day in the average US home requires 775 gallons of water. Given that the world consumed about 17,000 terawatt hours of electricity in 2007, power plants ostensibly used 425 trillion gallons (1.61 quadrillion liters) of water that year. The water use of individual power plants is even more striking. A conventional 500 megawatt coal plant, for instance, consumes about 7,000 gallons (26,498 liters) of water per minute or the equivalent of 17 Olympicsized swimming pools every day (Sovacool and Sovacool 2009b).

Deficiencies in water supply and water quality already cause about 4,500 deaths throughout the world every day or 1.7 million deaths a year, $90 \%$ of which are to young children. More than 1 billion people lack access to clean water, and 2.6 billion do not have access to improved sanitation facilities (Schaefer 2008). Some rivers, aquifers, lakes, and other water sources are so polluted that it is more profitable for residents to remove plastic bottles and trash from them for recycling than it is to fish. The US Central Intelligence Agency believes that more than 3 billion people will be living in water-stressed regions around the world by 2015 (with a majority concentrated in North Africa and the PRC). Water tables for major grain producing areas in northern PRC are dropping at a rate of 5 feet per year, and per capita water availability in India is expected to drop by $50 \%$ to $75 \%$ over the next decade (Pope and Lomborg 2005).

Complicating this picture is climate change which is slowly but steadily altering precipitation and water patterns. For instance, if global warming induces the rise in sea levels that many climatologists and scientists expect, the intrusion of saltwater could contaminate freshwater aquifers possibly reducing potable water 
supplies by $45 \%$ (Smith and Ibakari 2007). Warmer temperatures resulting from global climate change will also increase energy demands in urban areas and require more intensive air-conditioning loads in turn raising the water needs for power plants. Hotter weather also increases the evaporation rates for lakes, rivers, and streams and thus accelerates the depletion of reservoirs and causes more intense and longer-lasting droughts as well as more wildfires that in turn need vast quantities of water to control (Sovacool and Sovacool 2009a).

\section{Land-use change}

As with climate change, air pollution, and water, the link between energy security and land-use change is complex. Energy production can affect land in many ways from converting forests into plantations for energy crops to access roads for dams and oil and gas facilities that open up areas to deforestation. One incredibly conservative estimate suggests that $15 \%$ of land-use changes are caused by clearing forests for fuelwood and for energy crop plantations (Dale, Efroymson, and Kline 2011). Figure 5.3 shows that most Asian countries saw a decline in their forest areas from 1990 to 2010 with significant decreases in Cambodia, Indonesia, Myanmar, and the Philippines. ${ }^{2}$

Forests can be a sink for GHG emissions but also a source depending on how they are managed. It is helpful to view forests through the lens of stocks and flows. The total stock of carbon in all tropical forests equals about 300 billion tons; through deforestation, about 1.5 billion tons are converted into 6 billion tons of $\mathrm{CO}_{2}$ that is emitted into the atmosphere (Boucher 2009). In other words, tropical forests alone contribute about $20 \%$ of overall anthropogenic $\mathrm{CO}_{2}$ emissions per year making them the largest emitter of carbon in the world after the energy sector (Houghton 2003). This amount is equivalent to the total emissions of the PRC or the US, and it is more than the emissions produced by every car, truck, plane, ship, and train on Earth.

Forestry is thus unique in its ability to fight climate change, but its benefits are reversible. A ton of carbon sequestered in a forest is not permanent and is a benefit to the atmosphere only if it remains stored. If a tree is felled or a forest is cleared, carbon is released and the temporary benefit reversed. Partly because of this aspect of forestry, tropical deforestation was excluded from the Kyoto Protocol as an eligible project class. Acknowledging that forests are decreasing at an alarming rate, the Copenhagen Accord produced (but not adopted) at the Fifteenth Conference of the Parties to the UN Framework Convention on Climate Change meeting in 2009 does, ". . . recognize the crucial role of reducing emissions from deforestation and forest degradation" (United Nations Framework Convention on Climate Change 2009). Yet the rate of deforestation worldwide

\footnotetext{
${ }^{2}$ Forest area is land under natural or planted stands of trees of at least 5 meters in situ, whether productive or not, and excludes tree stands in agricultural production systems (for example, in fruit plantations and agroforestry systems) and trees in urban parks and gardens.
} 


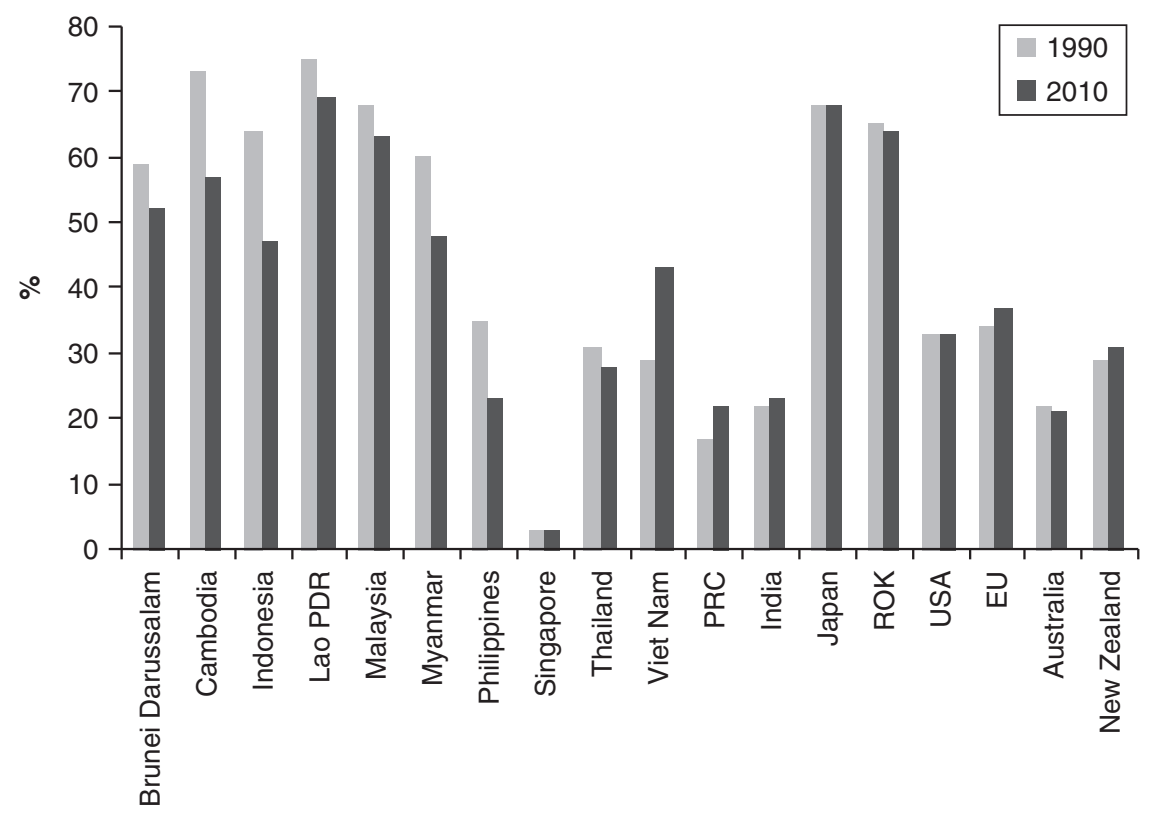

Figure 5.3 Forest area as a percent of land area in selected countries, 1990 and 2010

Source: Sovacool et al. 2011.

Note: PRC $=$ People's Republic of China; EU = European Union; ROK = Republic of Korea; Lao PDR $=$ Lao People's Democratic Republic $;$ USA = United States.

averaged 13 million hectares a year between 1990 and 2005 (out of a total forest coverage of about 4 billion hectares) (United Nations Food and Agricultural Organization 2006). Indonesia and Brazil accounted for about half the emissions from deforestation which also explains why they are (respectively) the third and fourth largest emitters of GHGs overall behind the PRC and the US. Table 5.4 shows that just nine countries, four of them in Asia, accounted for more than $80 \%$ of all GHG emissions from deforestation (Boucher 2008).

At least two main energy sources contribute to deforestation: fuelwood collection (see Chapter 4) and energy plantations for biofuels. Indonesia, Malaysia, and Thailand are the largest producers of palm oil in the world. The land-use changes taking place there involve converting peat lands, some of the richest carbon sinks in the world, to palm oil plantations. Some scholars and global institutions concerned with bioenergy recognize the environmental dilemmas that the large-scale production of palm oil can present by encroaching on protected areas, affecting water systems, displacing food production, and harboring unsustainable land-use practices that can not only cancel GHG emissions for decades but can also lead to widespread ecological despoliation (Keam and McCormick 2008; World Bank 2008a,b; Markevicius et al. 2010; Havlík et al. 2011; Comte et al. 2012). 
Table 5.4 Global leaders in carbon dioxide equivalent emissions from deforestation

\begin{tabular}{lc}
\hline Country & $\begin{array}{l}\text { Share of emissions } \\
\text { from deforestation (\%) }\end{array}$ \\
\hline Indonesia & 33.7 \\
Brazil & 18.0 \\
Malaysia & 9.2 \\
Myanmar & 5.6 \\
Democratic Republic of the Congo & 4.2 \\
Zambia & 3.1 \\
Nigeria & 2.6 \\
Peru & 2.5 \\
Papua New Guinea & 1.9 \\
Total & 80.8 \\
\hline
\end{tabular}

Source: Boucher 2008.

As a result of the twin pressures of fuelwood collection and biofuel production, in Southeast Asia as a whole deforestation has been 5 times the global average and 10 times the average for the rest of Asia (ASEAN Secretariat 2000). Indonesia alone is being deforested at a rate of 1.4 million hectares (3.5 million acres) a year with only 53 million hectares (131 million acres) of total forest area left (Indonesian Working Group on Underlying Causes of Deforestation and Forest Degradation 1999). Deforestation has helped promote the forest fires and peat land degradation that have made the country such a large emitter of GHGs (Speth 2008). Roughly $98 \%$ of the forest cover on Borneo and Sumatra will be "severely degraded" by 2012 and "completely gone" by 2022 (Nellemann et al. 2007). Illegal logging is difficult to control: $75 \%$ of timber is extracted illegally and illegal harvesting has been documented in 37 out of Indonesia's 41 national parks (Nellemann et al. 2007). Milling capacity exceeds legal limits by as much as a factor of five.

\section{Environmental impact of energy technology options}

Though admittedly qualitative, this section briefly assesses the environmental impacts of 13 energy systems on climate change, air pollution, water availability and quality, and land-use change. Table 5.5 summarizes them.

\section{Energy efficiency}

Energy efficiency and demand-side management — doing more with less, reducing energy consumption by substituting fuels and technologies and altering consumer behavior - is clearly the most environmentally benign way to address increases in demand for energy services. Energy efficiency can include practices as diverse as switching from conventional coal power plants to combined heat and power units, lowering thermostats, better maintaining industrial boilers, 
Table 5.5 Impacts of energy systems on climate change, air pollution, water availability and quality, and land-use change

\begin{tabular}{lllll}
\hline Energy system & Climate change & Air pollution & Water & Land use \\
\hline Energy efficiency & Minimal & Minimal & Minimal & Minimal \\
Nuclear power & Moderate & Minimal & Severe & Severe \\
Shale gas & Severe & Severe & Severe & Severe \\
Conventional coal & Severe & Severe & Severe & Severe \\
Clean coal & Moderate & Severe & Severe & Severe \\
Oil and gas & Severe & Severe & Severe & Severe \\
Hydroelectricity & Minimal & Minimal & Severe & Moderate \\
Wind energy & Minimal & Minimal & Minimal & Moderate \\
Solar photovoltaics & Minimal & Minimal & Minimal & Moderate \\
Solar thermal & Minimal & Minimal & Moderate & Moderate \\
Geothermal & Minimal & Minimal & Moderate & Moderate \\
Biomass & Minimal & Moderate & Moderate & Moderate \\
Biofuels & Minimal & Moderate & Severe & Severe \\
\hline
\end{tabular}

Source: Author.

and walking or cycling instead of driving. These actions not only involve very little damage to the environment, they can be cost effective as well as long as they are strategically implemented to avoid the rebound effect. On a global scale, the IEA reviewed large-scale energy efficiency programs and found that they saved electricity at an average cost of $\$ 0.032$ per kilowatt hour, well below the cost of supplying electricity from any source (International Energy Agency 2005).

\section{Nuclear power}

Nuclear power has minimal air pollution impacts as it is a combustion-free source of energy, but it does have moderate impacts on climate change and severe impacts for water and land use.

In terms of climate change, reprocessing and enriching uranium requires a substantial amount of electricity that is often generated from fossil fuel-fired power plants. Uranium milling, mining, and leaching; plant construction; and decommissioning all produce substantial amounts of GHGs. An assessment of 103 lifecycle studies of GHG-equivalent emissions for nuclear power plants found that the average $\mathrm{CO}_{2}$ emissions over the typical lifetime of a plant in 2005 were about 66 grams for every kilowatt hour or the equivalent of some 183 million metric tons of $\mathrm{CO}_{2}$ (Sovacool 2008). A second, follow-up, peer-reviewed study found that the best performing reactors had associated lifecycle emissions of 8 to 58 grams of $\mathrm{CO}_{2}$ per kilowatt hour but that other reactors emitted more than 110 grams (Beerten et al. 2009).

In terms of land use, nuclear power's most significant impacts arise from uranium mining and the storage of nuclear waste. Uranium is mined in three different ways - underground, open pit, and in-situ leaching — but uranium mining is 
very wasteful, regardless of the technique. To produce the 25 tons of uranium needed to operate a typical rector for a year, 500,000 tons of waste rock and 100,000 tons of mill tailings toxic for hundreds of thousands of years will be created along with an extra 144 tons of solid waste and 1,343 cubic meters of liquid waste (Sovacool 2011).

In terms of water, the nuclear industry has serious consequences both for human consumption and for the environment. Apart from the water-related impacts of uranium mining, three other stages of the nuclear fuel cycle-plant construction, plant operation, and nuclear waste storage-consume, withdraw, and contaminate water supplies. Moreover, a team of Indian scientists studying heated water discharges from the Madras Atomic Power Station noted that substantial additions of sodium hypochlorite to seawater decreased viable counts of bacteria and plankton by 50\% around the reactor site (Saravanan et al. 2008). A team of Korean marine biologists and scientists studied satellite thermal infrared images of the Younggwang Nuclear Power Plant and found that the thermal pollution plume extended more than 100 kilometers southward (Ahn et al. 2006). The researchers documented that the power plant directly decreased the dissolved oxygen content of the water, fragmented ecosystem habitats, reduced fish populations, and induced eutrophication.

\section{Shale gas}

Shale gas refers to natural gas extracted from gas shales, i.e., porous rocks that hold gas in pockets. Shale gas is captured by hydraulic fracturing or fracking, a process that shatters rocks by injecting water to release the gas. Shale gas has severe climate change, air, water, and land-use impacts.

New evidence has surfaced that the lifecycle of shale gas is more carbon intensive than previously thought (Jaramillo, Grifin, and Matthews 2007). Prior estimates of the carbon footprint of shale gas did not account for losses in processing and distribution, but the US Environmental Protection Agency took a nonpartisan look at the lifecycle of natural gas and its carbon equivalent emissions and doubled its previous estimate when it accounted for methane leaks from loose pipe fittings and methane vented from gas wells. When included, these losses make gas as little as $25 \%$ cleaner than coal from a carbon standpoint. Billions of cubic feet of natural gas are lost in the US each year-equivalent to the emissions from 35 million automobiles - seeping from loose pipe valves or venting from production facilities (Government of the United States Environmental Protection Agency 2010).

Furthermore, Nature cautions that $0.6 \%$ to $3.2 \%$ of the methane captured during hydrofracking can escape directly into the airshed (Lovett 2011). Other studies have noted that $3.6 \%$ to $7.9 \%$ of methane from shale gas production escapes into the atmosphere in venting and leaks which make methane emissions from shale gas between $30 \%$ and $100 \%$ greater than conventional natural gas (Howarth, Santoro, and Ingraffea 2011). These studies have noted, for example, that fugitive methane emissions are vented during the completion of wells, especially during 
the drill-out stage of new reserves. Venting and equipment leaks of methane are common, too, as the typical well has 55 to 150 different connections to equipment including heaters, meters, dehydrators, and compressors as well as vapor recovery systems that all can fail and leak. Processing to remove hydrocarbons and impurities such as sulfur is energy and carbon intensive, and shale gas needs more extensive processing to make it ready for existing pipelines. Shale gas is also prone to all of the environmental impacts of ordinary oil and natural gas production.

\section{Conventional coal}

The extraction of coal poses serious problems for communities and ecosystems near mining sites. Coal mining can remove mountaintops by clearing forests and topsoil before using explosives to break up rocks, pushing mine spoils into adjacent streams and valleys. This can cause acid drainage into river systems, destroy ecosystems, blight landscapes, and diminish water quality (Bernhardt and Palmer 2001; Palmer et al. 2010). One global assessment of the coal mining industry noted that common, "direct" impacts include:

fugitive dust from coal handling plants and fly ash storage areas; pollution of local water streams, rivers, and groundwater from effluent discharges and percolation of hazardous materials from the stored fly ash; degradation of land used for storing fly ash; and noise pollution during operation [in addition to] impacts on the health, safety, and well-being of coal miners; accidents and fatalities resulting from coal transportation; significant disruption to human life, especially in the absence of well-functioning resettlement policies; and impacts on the environment such as degradation and destruction of land, water, forests, habitats, and ecosystems.

(Chikkatur, Chaudhary, and Sagar 2011)

Another recent survey of global mining practices concluded that "a serious history of mining accidents" exists due largely to "widespread neglect of environmental safety and human security issues" and "sub-standard management activities"; it also noted an increase in trans-boundary pollution associated with mining and mineral prospecting and that more mines are opening in states with weak regulatory and governance regimes (United Nations Environment Program et al. 2005). A similar Word Bank study of mining practices noted that they "often have substantial environmental impacts" and have negative impacts on food security and the collection of clean water and on the health and time burdens of women (Eftimie, Heller, and Strongman 2009).

\section{Clean coal}

Clean coal has moderate climate impacts but like conventional coal, severe impacts on air, water, and land use. In terms of climate change, power plants with 
carbon capture and storage (CCS) can sequester much of their affiliated carbon underground; however, they can also

increase [GHG] emissions and air pollutants per unit of net delivered power and will increase all ecological, land-use, air-pollution, and water-pollution impacts from coal mining, transport, and processing, because the CCS system requires $25 \%$ more energy, thus $25 \%$ more coal combustion, than does a system without CCS.

(Government of the United Kingdom 2010)

Globally, coal mining activities have taken their toll on local environments and communities. Exploration involves drilling, clearing vegetation, trench blasting, and geophysical surveying that can result in habitat loss, sedimentation, and deforestation due to road development. Site preparation has been shown to fragment ecosystems, increase demand for water resources, change predation rates, and accelerate the chemical contamination of land. Mining operations require supporting infrastructure such as roads, electricity, processing facilities, and ports. Once closed, abandoned mines pose dangers in the form of physical injury, persistent contaminants in surface and groundwater, and acid drainage affecting hundreds of thousands of streams (Miranda 2004). Again, CCS requires more coal to produce each unit of electricity exacerbating all of these downstream impacts (Boute 2008).

\section{Oil and natural gas}

Many stages of the oil and gas fuel chain-exploration, onshore and offshore drilling, refining - pose serious environmental risks. Exploration necessitates heavy equipment and can be quite invasive as it involves "discovering" oil and gas deposits in sedimentary rock through various seismic techniques such as controlled underground explosions, special air guns, and exploratory drilling (Waskow and Welch 2005). The construction of access roads, drilling platforms, and their associated infrastructure frequently has environmental impacts beyond the immediate effects of clearing land as they open up remote regions to loggers and wildlife poachers. About 465 to 2,428 hectares of land (1,000 to 6,000 acres) are deforested for every 1 kilometer of new oil and gas roads built through forested areas around the world (Waskow and Welch 2005).

The production and extraction of oil and gas - which are themselves toxic as both contain significant quantities of hydrogen sulfide which is potentially fatal and extremely corrosive to equipment such as drills and pipelines - is even more hazardous. Drilling for oil and gas involves bringing large quantities of rock fragments, called "cuttings," to the surface. These cuttings are coated with drilling fluids called "drilling muds" that operators use to lubricate drill bits and stabilize pressure in oil and gas wells. The quantity of toxic cuttings and mud released for each facility is gargantuan ranging from 60,000 to 300,000 gallons per day. In addition to cuttings and drilling muds, vast quantities of water 
contaminated with suspended and dissolved solids are also brought to the surface creating what geologists refer to as "produced water" (Waskow and Welch 2005). Produced water contains lead, zinc, mercury, benzene, and toluene making it highly toxic often requiring operators to treat it with chemicals that increase its salinity and make it fatal to many types of plants before releasing it into the environment. The ratio of waste to extracted oil is staggering: every gallon of oil brought to the surface yields 8 gallons of contaminated water, cuttings, and drilling muds (Waskow and Welch 2005).

The next stage, refining, involves boiling, vaporizing, and treating extracted crude oil and gas with solvents to improve their quality. The average refinery processes 3.8 million gallons of oil per day, and about 11,000 gallons of its product $(0.3 \%$ of production) escapes directly into the local environment where it can contaminate land and pollute water (Waskow and Welch 2005).

Natural gas also has some environmental impacts unique to its fuel cycle. When not separated from oil deposits, it is often burned off at the well site, flared (combusted into $\mathrm{CO}_{2}$ and water vapor), or vented directly to the atmosphere. In all, $5 \%$ of world natural gas production- 150 billion cubic meters of natural gas, more than 2 billion tons of $\mathrm{CO}_{2}$ equivalent - is lost to flaring and venting each year making the gas industry responsible for roughly $10 \%$ of annual global methane emissions (Kirchgessner et al. 1997; Robison 2006). Methane is a GHG 21 to 23 times more potent than $\mathrm{CO}_{2}$ on a 100 -year timeframe, and its half-life is only 12 years meaning its instantaneous impact is much larger on the climate system. Methane is already the second largest contributor to anthropogenic GHG emissions after $\mathrm{CO}_{2}$ accounting for $16 \%$ of the total on a $\mathrm{CO}_{2}$-equivalent basis (IPIECA 2006). Researchers at the International Association of Oil and Gas Producers and the Society of Petroleum Engineers have calculated that the global average emission ratio for gas production is about 130 to 140 tons of $\mathrm{CO}_{2}$ equivalent for every 1,000 tons of production which is more than any other electricity fuel except oil and coal (Campbell and Bennett 2006).

\section{Hydroelectricity}

Hydroelectricity poses severe water impacts but only moderate land-use impacts and minimal climate change and air pollution impacts. For hydroelectric dams, the most extensively debated and complex environmental problems relate to habitat and ecosystem destruction, emissions from reservoirs, water quality, and sedimentation (World Commission on Dams 2000). All these concerns arise because a dam is a physical barrier interrupting water flows for lakes, rivers, and streams. Consequently, dams can drastically disrupt the movement of species and change upstream and downstream habitats. They also result in modified habitats with environments more conducive to invasive plant, fish, snail, insect, and animal species all of which may overwhelm local ecosystems. To maintain an adequate supply of energy resources in reserve, most dams impound water in extensive reservoirs; however, these reservoirs can also emit GHGs from rotting vegetation (Gagnon and van de Vate 1997). 
All forms of hydroelectric generation combust no fuel so they produce little to no air pollution in comparison with fossil fuel plants. One life-cycle assessment of hydroelectric facilities focused on the activities related to building dams, dykes, and power stations; decaying biomass from flooded land (where plant decomposition produces methane and $\mathrm{CO}_{2}$ ); and the thermal backup power needed when seasonal changes cause hydroelectric plants to run at partial capacity. It found that typical emissions of GHGs for hydropower were still 30 to 60 times less than those from fossil-fueled stations of the same size (Gagnon and van de Vate 1997).

\section{Wind energy}

Wind energy has moderate land-use impacts and minimal environmental impacts across the other three dimensions. Perhaps the most visible land-use concern associated with wind energy relates to the death of birds that collide with wind turbine blades which is termed "avian mortality." Onshore and offshore wind turbines present direct and indirect hazards to birds and to other non-avian species. Birds can smash into a turbine blade when they are fixated on perching or hunting and pass through its rotor plane; they can strike its support structure; they can hit part of its tower; or they can collide with its associated transmission lines. These risks are exacerbated when turbines are placed on ridges and upwind slopes; close to migration routes; and in fog, rain storms, and at night. Indirectly, wind farms can physically alter natural habitats, the quantity and quality of prey, and the availability of nesting sites (Sovacool 2009; Fielding, Whitfield, and McLeod 2006; Barclay, Baerwald, and Gruver 2007; Kunz et al. 2007a,b). Moreover, large, effective wind farms are sometimes highly land intensive. Large-scale utility wind turbines usually require one acre of land per turbine (Government of the United States Department of Energy 2004). When these big machines are built in densely forested areas or ecosystems rich in flora and fauna, they can fragment large tracts of habitat.

\section{Solar photovoltaics}

This form of solar energy has moderate land-use impacts and minimal environmental impacts across the other three areas. The land-use impacts center on the use of hazardous materials such as silicon which must be mined and can contaminate land when systems break down or are destroyed during hurricanes and tornadoes (Fthenakis and Alsema 2006; Fthenakis and Kim 2007; Fthenakis, Kim, and Alsema 2008). Chemical pollution has also occurred manufacturing solar cells and modules, and when not integrated into buildings, solar power plants need comparatively larger amounts of land than conventional energy sources (Fthenakis 2001).

\section{Solar thermal}

Solar thermal, or concentrated solar power, has many of the same climate and air benefits of solar photovoltaic systems. However, thermal and concentrated 
systems use much more water consuming and withdrawing similar amounts as a natural gas combined cycle power plant and also require amounts of land similar to solar photovoltaic power plants.

\section{Geothermal}

Geothermal facilities have moderate water impacts but minimal environmental impacts in the other areas. Geothermal plants can emit small amounts of hydrogen sulfide and $\mathrm{CO}_{2}$ along with toxic sludge containing sulfur, silica compounds, arsenic, and mercury (depending on the type of plant), though these can be controlled with pollution control equipment (Berinstein 2001). More significantly, geothermal systems require water during drilling and fracturing and are illsuited for deserts or arid regions (Green and Nix 2006). Extra land may also be required to dispose of waste salts from geothermal brines, and contamination of groundwater and freshwater can occur if plants are poorly designed (Duffield and Sass 2003).

\section{Biomass}

Biomass energy has minimal climate change impacts but moderate environmental impacts on air pollution, water, and land use. While biomass combustion has the advantage of not releasing any net $\mathrm{CO}_{2}$ into the atmosphere (and thus contributes little to the global inventory of GHGs), it releases measurable levels of a wide variety of pollutants into air, land, and water (Pimentel et al. 1994). The air pollution issues parallel aesthetic concerns about land use, smell, and traffic congestion. The combustion of biomass has been noted to release foul odors near some plants, and biomass fuel can contribute to traffic congestion when large amounts must be delivered by trucks (Karmis et al. 2005). When harvested improperly, generating electricity with agricultural wastes, forest residues, and energy crops such as sugar, legumes, and vineyard grain can strip local ecosystems of needed nutrients and minerals.

\section{Biofuels}

Biofuels raise severe climate, water, and land concerns but only moderately contribute to air pollution. As noted previously, the widespread use of biofuel crops can contribute to habitat destruction and deforestation (Mahapatra and Mitchell 1999). Biofuel production, like that for oil and gas, also involves a large amount of water. Furthermore, some GHGs such as nitrogen oxide, methane, and $\mathrm{CO}_{2}$ are emitted from nitrification and de-nitrification through the use of fertilizers, soil transformation, poorly drained soils, and motorized equipment; however, lifecycle GHG emissions are much lower for sugarcane ethanol than for gasoline with ethanol releasing 0.6 kilograms of $\mathrm{CO}_{2}$ per liter compared to 1 kilogram for gasoline (Cezar de Cerqueira Leite et al. 2009). However, one significant benefit, when compared with gasoline, is how ethanol affects air 
pollution. Although the combustion of ethanol in automobile engines is not benign - ethanol is a significant source of aldehyde emissions (similar to formaldehyde from gasoline) and peroxyacetyl nitrate pollution (an irritant to plants) - every kilometer fueled by ethanol releases less particulate matter, volatile organic compounds, lead, benzene (a carcinogen), 1-3 butadiene, sulfur oxide, and carbon monoxide than gasoline (Goldemberg, Coelho, and Guardabassi 2008).

\section{Conclusions}

No energy source is free of some type of environmental impact, though energy efficiency practices properly implemented are the most environmentally friendly. While renewable energy sources such as wind and solar have clear environmental benefits compared to conventional sources, they are not free of consequences. Even with the use of renewable resources, every kilowatt watt hour of electricity generated, every barrel of oil produced, every ton of uranium mined or cubic foot of natural gas manufactured produces a laundry list of environmental damage that may include radioactive waste and abandoned uranium mines and mills, acid rain and its damage to fisheries and crops, water degradation and excessive consumption, particulate pollution, and cumulative environmental damage to ecosystems and biodiversity through species loss and habitat destruction. In monetary terms, the social and environmental damage from just one type of energy - worldwide electricity generation - amounted to roughly $\$ 2.6$ trillion in 2010 (Brown and Sovacool 2011). This means that continuing along the businessas-usual path could result in an increased cost burden to governments as they become saddled with heavy public healthcare and environmental costs and the negative effects on economic competitiveness through loss of workforce productivity (Buckeridge et al. 2002; Von Klot et al. 2002). Put another way, if the increasing energy demands for the Asian Century scenario are met by the traditional mix of energy supply with current technologies, then the implications for the environment in terms of GHG emissions, green growth, global warming, and prices of fossil fuels would not be sustainable.

Policymakers must incorporate the cost of some of these negative environmental consequences of energy production and use into prices. At a bare minimum they should place a price on carbon and preferably other things like sulfur dioxide, nitrogen oxide, particulate matter, and water. A preponderance of evidence suggests that pricing energy more accurately will greatly improve the efficiency of the electricity industry, provide customers with proper price signals, reduce wasteful energy use, and most importantly, improve household incomes since they no longer have to waste as much time and money dealing with debilitating health issues caused by pollution (Sovacool 2009).

If policymakers desire to truly promote cleaner forms of energy, feed-in tariffs seem the best method to rapidly accelerate their adoption. One study analyzed renewable portfolio standards, green power programs, public research and development expenditures, system benefit charges, investment tax credits, production 
tax credits, tendering, and feed-in tariffs and found that only feed-in tariffs met the criteria for a truly effective policy tool (Sovacool 2010).

In the end, we must accept that current patterns of energy production and use have widespread and widely known negative impacts on the environment. As President Jimmy Carter once remarked when addressing the US Congress in 1976, to avoid a cycle of energy and climate crises, "We must face the prospect of changing our basic ways of living. This change will either be made on our own initiative in a planned way or forced on us with chaos and suffering by the inexorable laws of nature." It would be far better to implement carbon taxes, to incorporate the cost of negative environmental consequences into energy prices, to pass feed-in tariffs, and to harness the powers of energy efficiency now in a proactive way rather than a few decades from now when forced to by crises.

\section{References}

Ahn Y.-H., P. Shanmugam, J.-H. Lee, and Y. Q. Kang. 2006. Application of Satellite Infrared Data Mapping of Thermal Plume Contamination in Coastal Ecosystem of Korea. Marine Environmental Research. 61. pp. 186-201.

Asian Development Bank (ADB). 2005. Climate Proofing: A Risk-Based Approach to Adaptation. Manila: ADB.

—. 2006. Country Synthesis Report on Urban Air Quality Management: Cambodia. Manila: ADB.

- 2009. The Economics of Climate Change in Southeast Asia: A Regional Review. Manila: ADB.

Association of South East Asian Nations (ASEAN) Secretariat. 2000. Second ASEAN State of the Environment Report. Jakarta: ASEAN.

Barclay, R. M., R. E. F. Baerwald, and J. C. Gruver. 2007. Variation in Bat and Bird Fatalities at Wind Energy Facilities: Assessing the Effects of Rotor Size and Tower Height. Canadian Journal of Zoology. 85. pp. 381-387.

Beerten, J., E. Laes, G. Meskens, and W. D'haeseleer. 2009. Greenhouse Gas Emissions in the Nuclear Life Cycle: A Balanced Appraisal. Energy Policy. 37 (12). pp. 5056-5068.

Berinstein, P. 2001. Alternative Energy: Facts, Statistics, and Issues; New York, NY: Oryx Press.

Bernhardt, E. S. and M. A. Palmer. 2001. The Environmental Costs of Mountaintop Mining Valley Fill Operations for Aquatic Ecosystems of the Central Appalachians. Annals of the New York Academy of Sciences. 1223. pp. 39-57.

Biswas, A. and J. Kirchherr. 2012. Will [the People's Republic of] China Run Out of Water by 2030? China Daily. 29 November. http://www.chinadaily.com.cn/opinion/2012-11/ 29/content_15969860.htm. (accessed February 2014).

Boucher, D. 2008. Out of the Woods: A Realistic Role for Tropical Forests in Curbing Global Warming Washington, DC: Union of Concerned Scientists.

- 2009. Money for Nothing? Principles and Rules for REDD and Their Implications for Protected Areas. Washington, DC: Tropical Forest and Climate Initiative of the Union of Concerned Scientists. http:/www.ucsusa.org/assets/documents/global_warming/ Principles-and-Rules-for-REDD-and-their-Implications-for-Protected-Areas.pdf

Boute, A. 2008. Carbon Capture and Storage Under the Clean Development Mechanism: An Overview of Regulatory Challenges. Carbon \& Climate Law Review. 2 (4). pp. 339-352. 
Brown, M. A. and M. H. Dworkin. 2011. The Environmental Dimension of Energy Security. In B. K. Sovacool, ed. The Routledge Handbook of Energy Security. London: Routledge. pp. 176-190.

Brown, M. A. and B. K. Sovacool. 2011. Climate Change and Global Energy Security: Technology and Policy Options. Cambridge, MA: MIT Press.

Buckeridge, D. L., R. Glazier, B. J. Harvey, M. Escobar, C. Amrhein, and J. Frank. 2002. Effect of Motor Vehicle Emissions on Respiratory Health in an Urban Area. Environmental Health Perspectives. 110 (3). pp. 293-300.

Campbell, J. A. and W. Bennett. 2006. Environmental Performance in the E\&P Industry-2004. Presentation at the Society of Petroleum Engineers International Conference on Health, Safety, and Environment in Oil and Gas Exploration and Production. Abu Dhabi. April.

Center for Naval Analyses (CNA). 2009. Climate Change, State Resilience, and Global Security. CNA Conference Center: Alexandria, Virginia.

Cezar de Cerqueira Leite, R., M. R. L. Verde Leal, L. A. B. Cortez, W. M. Griffin, and M. I. G. Scandiffio. 2009. Can Brazil Replace 5\% of the 2025 Gasoline World Demand with Ethanol? Energy. 34. pp. 655-661.

Chikkatur, A. P., A. Chaudhary, and A. D. Sagar. 2011. Coal Power Impacts, Technology, and Policy: Connecting the Dots. Annual Review of Environment and Resources. 36. pp. 101-138.

Comte, I., F. Colin, J. K. Whalen, O. Grunberger, and J. P. Caliman. 2012. Agricultural Practices in Oil Palm Plantations and Their Impact on Hydrological Changes, Nutrient Fluxes and Water Quality in Indonesia: A Review. In D. L. Sparks, ed. Advances in Agronomy. Elsevier. pp. 71-124.

Dale, V. H., R. A. Efroymson, and K. L. Kline. 2011. The Land Use-Climate ChangeEnergy Nexus. Landscape Ecology. 26. pp. 755-773.

Deng, X. 2006. Economic Costs of Motor Vehicle Emissions in [the People's Republic of] China: A Case Study. Transportation Research. 11 (3). pp. 216-226.

Duffield, W. A. and J. H. Sass. 2003. Geothermal Energy: Clean Power from the Earth's Heat. Washington, DC: US Geological Survey.

Economics of Climate Adaptation Working Group. 2009. Shaping Climate-Resilient Development: A Framework for Decision-Making. New York, NY: Climate Works Foundation.

Eftimie, A., K. Heller, and J. Strongman. 2009. Gender Dimensions of the Extractive Industries: Mining for Equity. World Bank Extractive Industries and Development Series \#8. Washington, DC: World Bank.

Fielding, A. H., D. Whitfield, and D. McLeod. 2006. Spatial Association as an Indicator of the Potential for Future Interactions Between Wind Energy Development and Golden Eagles in Scotland. Biological Conservation. 131. pp. 359-369.

Fthenakis, V. M. 2001. Multilayer Protection Analysis for Photovoltaic Manufacturing Facilities. Process Safety Progress. 20. pp. 87-94.

Fthenakis, V. M. and E. Alsema. 2006. Photovoltaics Energy Payback Times, Greenhouse Gas Emissions, and External Costs. Progress in Photovoltaics Research and Applications. 14. pp. 275-280.

Fthenakis, V. M and H. C. Kim. 2007. Greenhouse-gas Emissions from Solar Electric and Nuclear Power: A Life-Cycle Study. Energy Policy. 35. pp. 2549-2557.

Fthenakis, V. M., H. C. Kim, and M. Alsema. 2008. Emissions from Photovoltaic Life Cycles. Environmental Science and Technology. 42. pp. 2168-2174.

Gagnon, L. and J. F. van de Vate. 1997. Greenhouse Gas Emissions from Hydropower: The State of Research in 1996. Energy Policy. 25. pp. 7-13. 
Goldemberg, J., S. Teixeira Coelho, and P. Guardabassi. 2008. The Sustainability of Ethanol Production from Sugarcane. Energy Policy. 36. pp. 2086-2097.

Government of Fiji, Fiji Electricity Authority. 2011. Annual Report. Suva.

Government of Samoa, Electric Power Corporation. 2011. Annual Report 2009-2010. Apia.

Government of Singapore, Ministry of the Environment and Water Resources. 2008. Singapore's National Climate Change Strategy. Singapore.

Government of the Solomon Islands, Ministry of Environment, Conservation and Meteorology. 2008. Solomon Islands National Adaptation Program of Action. Honiara.

Government of the United Kingdom, Department of Trade and Industry. 2010. The Energy Challenge. http://news.bbc.co.uk/2/shared/bsp/hi/pdfs/11_07_06_energy_review_ report. pdf (accessed February 2014).

Government of the United States, Department of Energy. 2004. Guide to Purchasing Green Power: Renewable Energy Certificates and On-Site Renewable Generation. Washington, DC: Department of Energy.

—. Energy Information Administration (EIA). 2010. [The People's Republic of] China. http://www.eia.gov/countries/index.cfm (accessed June 2012).

—. Environmental Protection Agency (EPA). 2010. Greenhouse Gas Emissions Reporting from the Petroleum and Natural Gas Industry. EPA Background Technical Support Document Washington, DC: EPA.

—. United States Agency for International Development (USAID). 2010. Asia Pacific Regional Climate Change Adaptation Assessment: Final Report Findings and Recommendations. Washington, DC: USAID.

Green, B. D. and R. G. Nix. 2006. Geothermal: The Energy Under Our Feet. Golden, CO: National Renewable Energy Laboratory.

Havlík, P., U. A. Schneider, E. Schmid, H. Böttcher, S. Fritz, R. Skalský, K. Aoki, S. De Cara, G. Kindermann, F. Kraxner, S. Leduc, I. McCallum, A. Mosnier, T. Sauer, and M. Obersteiner. 2011. Global Land-Use Implications of First and Second Generation Biofuel Targets. Energy Policy, 39 (10): 5690-5702.

Houghton, R. A. 2003. Emissions (and Sinks) of Carbon from Land-Use Change. Washington, DC: World Resources Institute and the Woods Hole Research Center.

Howarth, R. W., R. Santoro, and A. Ingraffea. 2011. Methane and the Greenhouse Gas Footprint of Natural Gas from Shale Formations. Climatic Change, 106: 679-690.

Indonesian Working Group on Underlying Causes of Deforestation and Forest Degradation (IWCUCD). 1999. The Underlying Causes of Deforestation and Forest Degradation. Jakarta: IWCUCD.

International Energy Agency (IEA). 2005. The Experience with Energy Efficiency Policies and Programs in IEA Countries: Learning from the Critics. Paris: IEA.

IPIECA (The global oil and gas industry association for environmental and social issues). 2006. Natural Gas as a Climate Change Solution: Breaking Down the Barriers to Methane's Expanding Role. Proceedings of the workshop. Washington, DC. 26 September.

Jaramillo, P., W. M. Grifin, and H. S. Matthews. 2007. Comparative Lifecycle Air Emissions of Coal, Domestic Natural Gas, LNG, and SNG for Electricity Generation. Environmental Science \& Technology. 41. pp. 6290-6296.

Karmis, M., J., Abiecunas, J. Alwang, S. Aultman, L. Bird, P. Denholm, and B. K. Sovacool. 2005. A Study of Increased Use of Renewable Energy Resources in Virginia; Blacksburg, VA: Virginia Center for Coal and Energy Research. 
Keam, S. and N. McCormick. 2008. Implementing Sustainable Bioenergy Production: A Compilation of Tools and Approaches. Gland, Switzerland: International Union for the Conservation of Nature.

Khuong, M. V. and B. K. Sovacool. 2010. Developing Asia and the Electricity Sector: Dynamics, Trends, and Policy Implications. East Asian Policy. 2 (3). pp. 81-95.

Kirchgessner, D. A., R. A. Lott, R. M. Cowgill, M. R. Harrison, and T. M. Shires. 1997. Estimate of Methane Emissions from the US Natural Gas Industry. Chemosphere. 35. pp. $1365-1390$.

Kunz, T. H., E. B. Arnett, W. P. Erickson, A. R. Hoar, G. D. Johnson, R. P. Larkin, M. D. Strickland, R. W. Thresher, and M. D. Tuttle. 2007a. Ecological Impacts of Wind Energy Development on Bats: Questions, Research Needs, and Hypotheses. Frontiers in Ecology and the Environment. 5. pp. 315-324.

Kunz, T. H., E. B. Arnett, B. M. Cooper, W. P. Erickson, R. P. Larkin, T. Mabee, M. L. Morrison, M. D. Strickland, and J. M. Szewczak. 2007b. Assessing Impacts of WindEnergy Development on Nocturnally Active Birds and Bats: A Guidance Document. Journal of Wildlife Management. 71. pp. 2449-2486.

Liu, T., T. Liu, G. Xu, P. Cai, L. Tian, and Q. Huang. 2011. Development Forecast of Renewable Energy Power Generation in [The People's Republic of] China and its Influence on the Greenhouse Gas Control Strategy of the Country. Renewable Energy. 36. pp. 1284-1292.

Lovett, R. 2011. Natural Gas Greenhouse Emissions Study Draws Fire. Published online 15 April 2011. http://www.nature.com/news/2011/110415/full/news.2011.242.html (accessed February 2014).

Mahapatra, A. K. and C. P. Mitchell. 1999. Biofuel Consumption, Deforestation, and Farm Level Tree Growing in Rural India. Biomass \& Bioenergy. 17. pp. 291-303.

Markevicius, A., V. Katinas, E. Perednis, and M. Tamašauskienè. 2010. Trends and Sustainability Criteria of the Production and Use of Liquid Biofuels. Renewable and Sustainable Energy Reviews, 14 (9): 3226-3231.

McMichael, A. J. 2007. Seeing Clearly: Tackling Air Pollution in [the People's Republic of] China. Lancet. 370 (9591). pp. 927-928.

Miranda, M. 2004. Mining and Critical Ecosystems: Mapping the Risks. Washington, DC: World Resources Institute.

Nellemann, C., L. Miles, B. P. Kaltenborn, M. Virtue, and H. Ahlenius (Eds.). 2007. The Last Stand of the Orangutan. State of Emergency: Illegal Logging, Fire, and Palm Oil in Indonesia's National Parks. Arendal, Norway: United Nations Environment Programme-GRID.

Olz, S. and M. Beerepoot. 2010. Deploying Renewables in Southeast Asia: Trends and Potentials. Paris: International Energy Agency.

Palmer, M. A., E. S. Bernhardt, W. H. Schlesinger, K. N. Eshleman, E. Foufoula-Georgiou, M. S. Hendryx, A. D. Lemly, G. E. Likens, O. L. Loucks, M. E. Power, P. S. White, and P. R. Wilcock. 2010. Mountaintop Mining Consequences. Science. 327. pp. 148-149.

Pimentel, D., G. Rodrigues, T. Wang, R. Abrams, K. Goldberg, H. Staecker, E. Ma, L. Brueckner, L. Trovato, C. Chow, U. Govindarajulu, and S. Boerke. 1994. Renewable Energy: Economic and Environmental Issues. BioScience. 44. pp. 42-48.

Pope, C. and B. Lomborg. 2005. The State of Nature: Our Roof is Caving In. Foreign Policy. 67.

Robison, D. 2006. Commercial Barriers to Natural Gas Capture, Supply, and Delivery. Presentation to the Natural Gas STAR International Conference. Washington, DC. 26 September. 
Royal United Services Institute (RUSI). 2009. Socioeconomic and Security Implications of Climate Change in [the People's Republic of] China. Washington, DC: Center for Naval Analyses.

Sakulniyomporn, S., K. Kubaha, and C. Chullabodhi. 2011. External Costs of Fossil Electricity Generation: Health-Based Assessment in Thailand. Renewable and Sustainable Energy Reviews. 15 (8). pp. 3470-3479.

Saravanan, P., A. Moushumi Priya, B. Sundarakrishnan, V. P. Venugopalan, T. S. Rao, S. Jayachandran 2008. Effects of Thermal Discharge from a Nuclear Power Plant on Culturable Bacteria at a Tropical Coastal Location in India. Journal of Thermal Biology. 33 (7). pp. 385-394.

Schaefer, M. 2008. Water Technologies and the Environment: Ramping Up by Scaling Down. Technology in Society. 30. pp. 415-422.

Smith, J. and M. Ibakari. 2007. Data Mining and Spatiotemporal Analysis of Extreme Precipitation and Northern Great Plains Drought. Presentation at the Geological Society of America Meeting. Denver, CO. 28-31 October.

Sovacool, B. K. 2008. Valuing the Greenhouse Gas Emissions from Nuclear Power: A Critical Survey. Energy Policy. 36 (8). pp. 2940-2953.

- 2009. Contextualizing Avian Mortality: A Preliminary Appraisal of Bird and Bat Fatalities from Wind, Fossil-Fuel, and Nuclear Electricity. Energy Policy. 37. pp. 2241-2248.

2010. A Comparative Analysis of Renewable Electricity Support Mechanisms for Southeast Asia. Energy. 35 (4). pp. 1779-1793.

- 2011. Contesting the Future of Nuclear Power. London: World Scientific Publishing.

Sovacool, B. K. and M. A. Brown. 2010. Twelve Metropolitan Carbon Footprints: A Preliminary Global Comparative Assessment. Energy Policy. 38 (9). pp. 4856-4869.

Sovacool, B. K. and V. M. Khuong. 2011. Energy Security and Competition in Asia: Challenges and Prospects for [the People's Republic of] China and Southeast Asia. In D. Jarvis and A. Welch, eds. ASEAN Industries and the Challenge from [the People's Republic of] China. New York: Palgrave Macmillan. pp. 210-229.

Sovacool, B. K. and Kelly E. Sovacool. 2009a. Preventing National Electricity-Water Crisis Areas in the US. Columbia Journal of Environmental Law. 34 (2). pp. 333-393.

- 2009b. Identifying Future Electricity Water Tradeoffs in the United States. Energy Policy. 37 (7). pp. 2763-2773.

Sovacool, B. K., I. Mukherjee, I. M. Drupady, and A. L. D'Agostino. 2011. Evaluating Energy Security Performance from 1990 to 2010 for Eighteen Countries. Energy. 36 (10). pp. 5846-5853.

Speth, J. G. 2008. The Bridge at the End of the World: Capitalism, the Environment, and Crossing from Crisis to Sustainability. New Haven, CT: Yale University Press.

Tsai, W. T. and Y. H. Chou. 2005. Overview of Environmental Impacts, Prospects and Policies for Renewable Energy in [Taipei,China]. Renewable and Sustainable Energy Reviews. 9. pp. 119-147.

United Nations Economic and Social Commission for Asia and the Pacific (UNESCAP). 2012. Low Carbon Green Growth Roadmap for Asia and the Pacific. Bangkok: UNESCAP.

United Nations Environment Program (UNEP). 2008. Vital Water Graphics: An Overview of the State of the World's Fresh and Marine Waters. 2nd Edition. Nairobi, Kenya: UNEP.

United Nations Environmental Programme (UNEP), United Nations Development Programme (UNDP), Organisation for Security and Co-Operation (OSCE), and North Atlantic Treaty Organization (NATO). 2005. Mining for Closure: Policies and 
Guidelines for Sustainable Mining Practice and Closure of Mines. Geneva: UNEP, UNDP, OSCE, and NATO.

United Nations Food and Agricultural Organization (FAO). 2006. Global Forest Resource Assessment. Rome: FAO.

United Nations Framework Convention on Climate Change, Copenhagen Accord, Article 6. 2009. http://unfccc.int/resource/docs/2009/cop15/eng/107.pdf (accessed February 2014).

Venkataraman, C., A. D. Sagar, G. Habib, N. Lam, and K. R. Smith. 2010. The Indian National Initiative for Advanced Biomass Cookstoves: The Benefits of Clean Combustion. Energy for Sustainable Development. 14. pp. 63-72.

Von Klot, S., G. Wölke, T. Tuch, J. Heinrich, D. W. Dockery, J. Schwartz, W. G. Kreyling, H. E. Wichmann, and A. Peters. 2002. Increased Asthma Medication Use in Association with Ambient Fine and Ultrafine Particles. European Respiratory Journal. 20 (3). pp. 691-702.

Waskow, D. and C. Welch. 2005. The Environmental, Social, and Human Rights Impacts of Oil Development. In Svetlana Tsalik and Anya Schiffrin, eds. Covering Oil: A Reporter's Guide to Energy and Development. New York NY: Open Society Institute. pp. 101-123.

Weber, C., Christopher L. Weber, Glen P. Peters, Dabo Guan, and Klaus Hubacek. 2008. The Contribution of Chinese Exports to Climate Change. Energy Policy. 36. pp. 3572-3577.

World Bank. 2002. Environment Monitor 2002. Air Quality (Philippines and Thailand Country Reports). Washington, DC: World Bank.

—. 2008a. Agriculture for Development World Development Report. Washington, DC: World Bank.

—. 2008b. Spending for Development: Making the Most of Indonesia's New Opportunities. Washington, DC: World Bank.

- 2009. Preparedness, Planning, and Prevention: Assessment of National and Regional Efforts to Reduce Natural Disaster and Climate Change Risks in the Pacific. Washington, DC: World Bank.

World Commission on Dams. 2000. Dams and Development: A New Framework for Decision-making. London: Earthscan.

World Health Organization (WHO). 2007. Air Quality Guidelines for Particulate Matter, Ozone, Nitrogen Dioxide and Sulfur Dioxide: Summary of Risk Assessment. Geneva: WHO.

World Resources Institute, Earth Trends Database accessed January 2012. http:// earthtrends.wri.org (accessed February 2014).

Yusuf, A. A. and H. A. Francisco. 2009. Climate Change Vulnerability Mapping for Southeast Asia. Singapore: International Development Research Centre. 


\title{
6 Macroeconomic impacts of energy efficiency improvements in Asia
}

\author{
Deepak Sharma, Suwin Sandhu, \\ and Suchi Misra
}

\section{Introduction}

Energy efficiency has lately emerged as a key policy strategy to address the twin challenges of energy security and climate change. According to the International Energy Agency (IEA), energy efficiency improvements could significantly reduce the burden of energy-import requirements, especially in import-dependent countries. Furthermore, they could contribute to more than half of the overall reduction in global greenhouse gas (GHG) emissions (IEA 2012a).

There is a widely held view that Asia is likely to be the main engine of global economic growth in the 21st century; this century is therefore often referred to as the Asian Century. This economic rise will bring with it, and perhaps will be driven by, an unprecedented demand for energy. According to the Asian Development Bank (ADB), meeting this demand is likely to be a megachallenge for the region (ADB 2011). To meet this challenge, various policy options and strategies have been and are being considered. Improving energy efficiency is one of them.

Several studies have been conducted to estimate the potential for energy savings and the carbon emission reductions associated with energy efficiency improvements in Asia. They tend, however, to be micro-assessments typically developing estimates of the lifecycle costs (or benefits) of specific measures to improve efficiency. While useful, such a focus precludes a deeper understanding of the macroeconomic - and hence policy-significant-impacts of alternative measures. For example, while a particular efficiency measure may result in large energy savings relative to others, it may be less attractive when looked at from broader macroeconomic considerations due to the complexity of underlying links with other sectors. This chapter will help overcome this limitation.

Furthermore, most existing studies tend to focus on analyzing the impacts of demand-side efficiency improvements, for example, the impacts of introducing energy efficient end-use appliances and vehicles or building codes. Significant energy losses, however, occur in the transformation and primary supply stages, particularly in the electricity sector. These stages therefore offer considerable opportunities for improving efficiency and, by implication, macroeconomic 
benefits. Therefore, this chapter equally emphasizes both demand and supply measures.

We examine the macroeconomic impacts of energy efficiency improvements especially policy trade-offs - on economic output, employment, trade balance, energy demand/intensity, energy security, and carbon dioxide $\left(\mathrm{CO}_{2}\right)$ emissions/ intensity in seven major Asian countries from 2010 to 2050: the People's Republic of China (PRC), India, Indonesia, Japan, Republic of Korea, Malaysia, and Thailand. In the recent report Asia 2050: Realizing the Asian Century, ADB considered these seven as the engines that would lead the region to prosperity (ADB 2011). Currently they collectively account for $78 \%$ of the Asian population, $87 \%$ of economic output, $88 \%$ of primary energy, and $90 \%$ of GHG emissions (ADB 2011, IEA 2012b, WRI 2012). They are significant globally as well as they account for $45 \%, 24 \%, 35 \%$, and $40 \%$ of the world's population, economic output, energy consumption, and GHG emissions, respectively (World Bank 2012).

\section{Methodological framework}

\section{Modeling approach}

The core methodology is energy-oriented input-output analysis for each of the seven countries based on Global Trade Analysis Project databases (Narayanan et al. 2012) as these tables are available in consistent (industry-classification) formats. These databases are extended by incorporating data from IEA, the World Bank and the United Nations (UN) to provide a disaggregated representation of energy production and consumption by sector as well as electricity generation using different technologies. The disaggregation enables an assessment of the economy-wide impacts of energy efficiency improvement policies.

The database for each of the seven economies contains links with other countries/ regions that enable an assessment of the regional trade implications of energy efficiency improvements. Table 6.1 presents the list of countries/regions, sectors, commodities, primary production factors, and final demand categories included in the model.

It is widely acknowledged that the traditional input-output model does not provide justifiable mechanisms for evaluating the impact of changes in technology due to the underlying assumption about the fixed proportionality of input-output coefficients. In reality, these coefficients are likely to change, for example, due to innovations, to alterations in consumer and producer preferences, or to policy adjustments (Rose 1984). This would have an impact on input prices and hence changes in technology through changes in factor inputs. Therefore, if one is to assess how energy efficiency improvements would influence technological change, one must make the input-output coefficients responsive to price changes. We achieve this by replacing the Leontief production function with more flexible production functions that allow for input factor substitutions in response to energy efficiency improvement policies (Sandu 2007). 


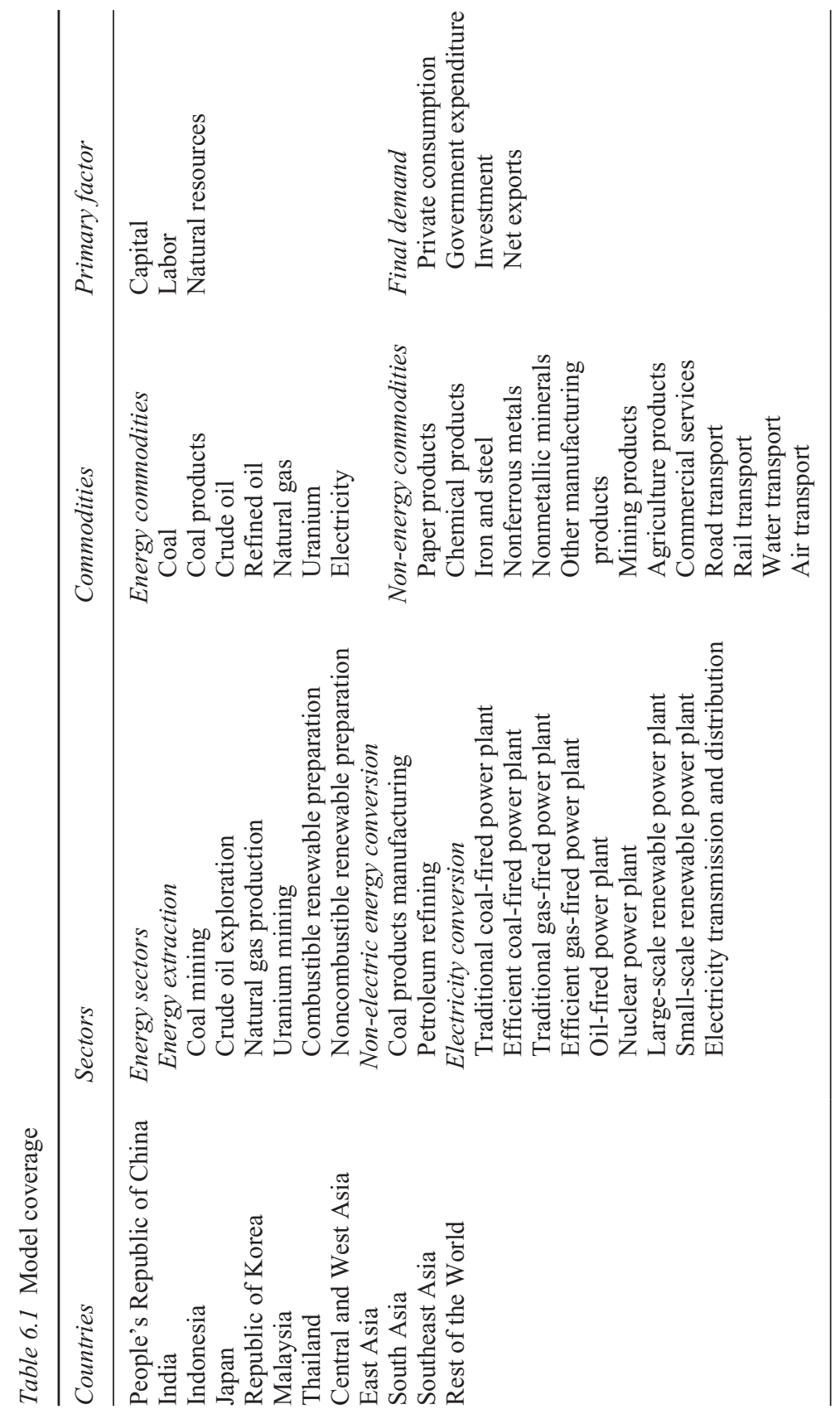




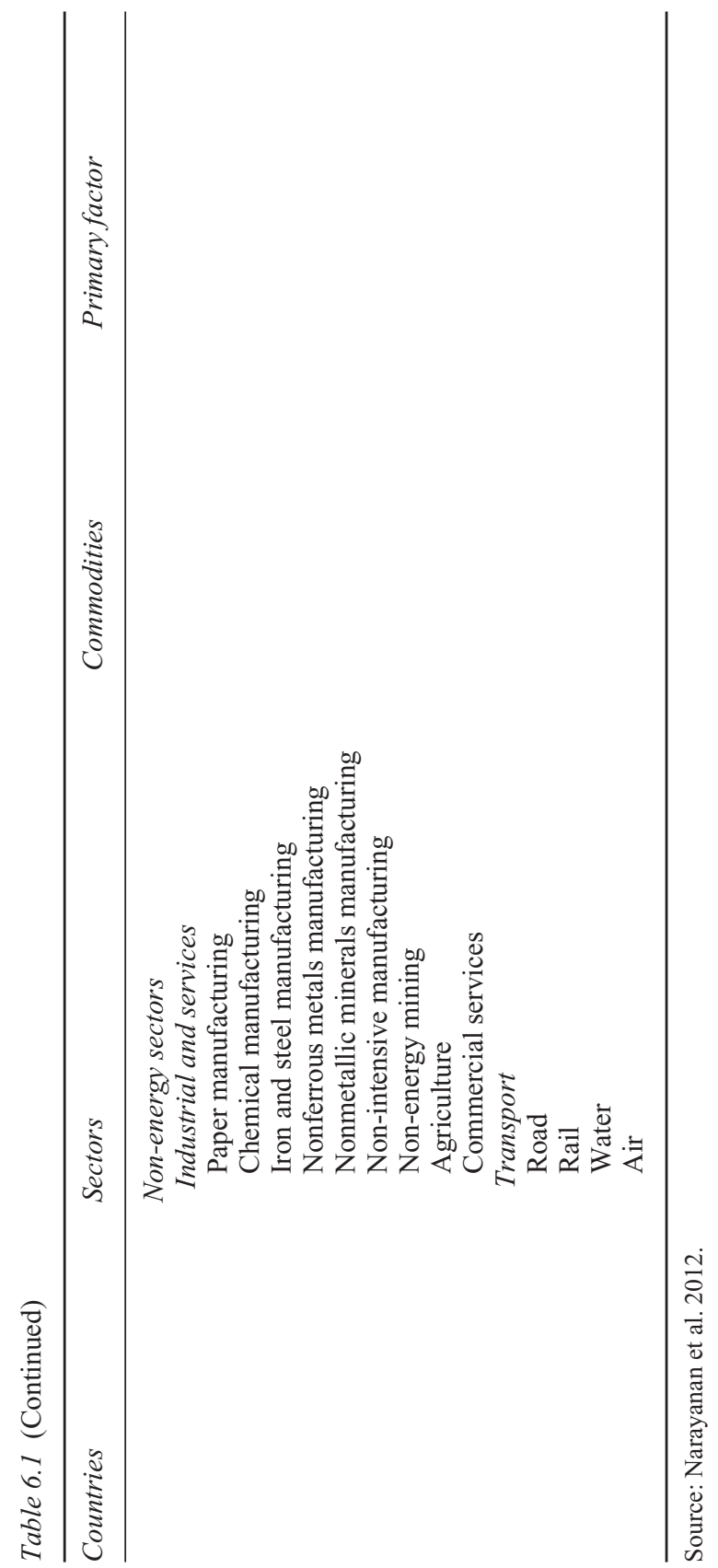




\section{Scenario descriptions}

We develop six scenarios up to 2050. Two reflect different economic growth and energy pathways for the region, namely the business-as-usual (BAU) scenario and the Asian Century scenario (ACS). The BAU scenario reflects a continuation of historic trends in economic and population growth in the absence of any significant changes to energy and economic policy settings or of other external shocks. The ACS, on the other hand, extends past success into the future by increasing economic growth by approximately $6 \%$ annually to 2050 which would then give the average Asian an income similar to that in Europe today (ADB 2011).

For each of these two economic growth scenarios, we develop three energy efficiency scenarios.

- The historic trend (HT) scenario assumes a continuation of historic, longterm energy efficiency improvement trends.

- The country policy (CP) scenario assumes energy efficiency will grow with the country's existing energy plans and policies.

- The best practice (BP) scenario assumes the aggressive implementation of efficiency measures based on energy efficiency improvement rates in Germany and Japan in the recent past.

These scenarios are summarized in Figure 6.1.

\section{Assumptions}

The key assumptions underlying BAU and ACS are summarized in Table 6.2. The population growth rates for 2011-2050 are taken from the UN Population Division (2012). The economic growth rates for 2011-2035 are based on APERC (2013), and for 2035-2050, they are estimated from population growth rates over this period, using an autoregressive integrated moving average forecasting model. The ACS assumes a considerably higher economic growth rate from 2011 to 2050, consistent with the ADB (ADB 2011).

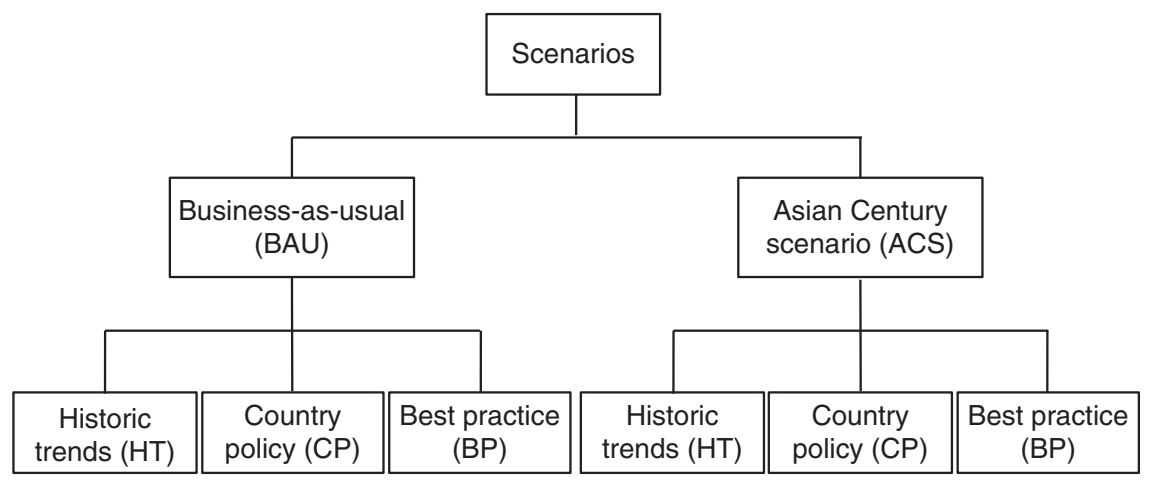

Figure 6.1 Energy efficiency scenarios

Source: Authors. 


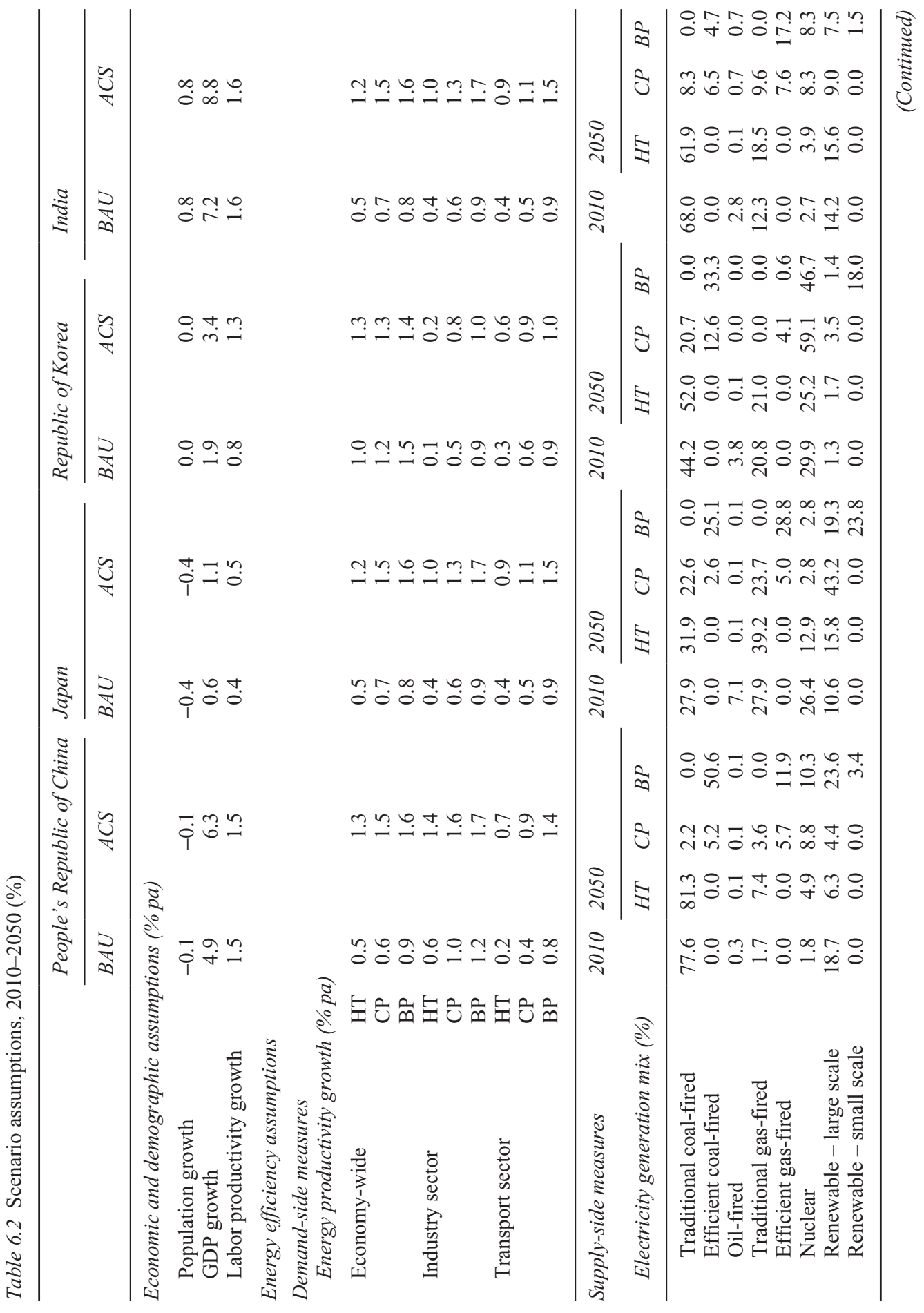




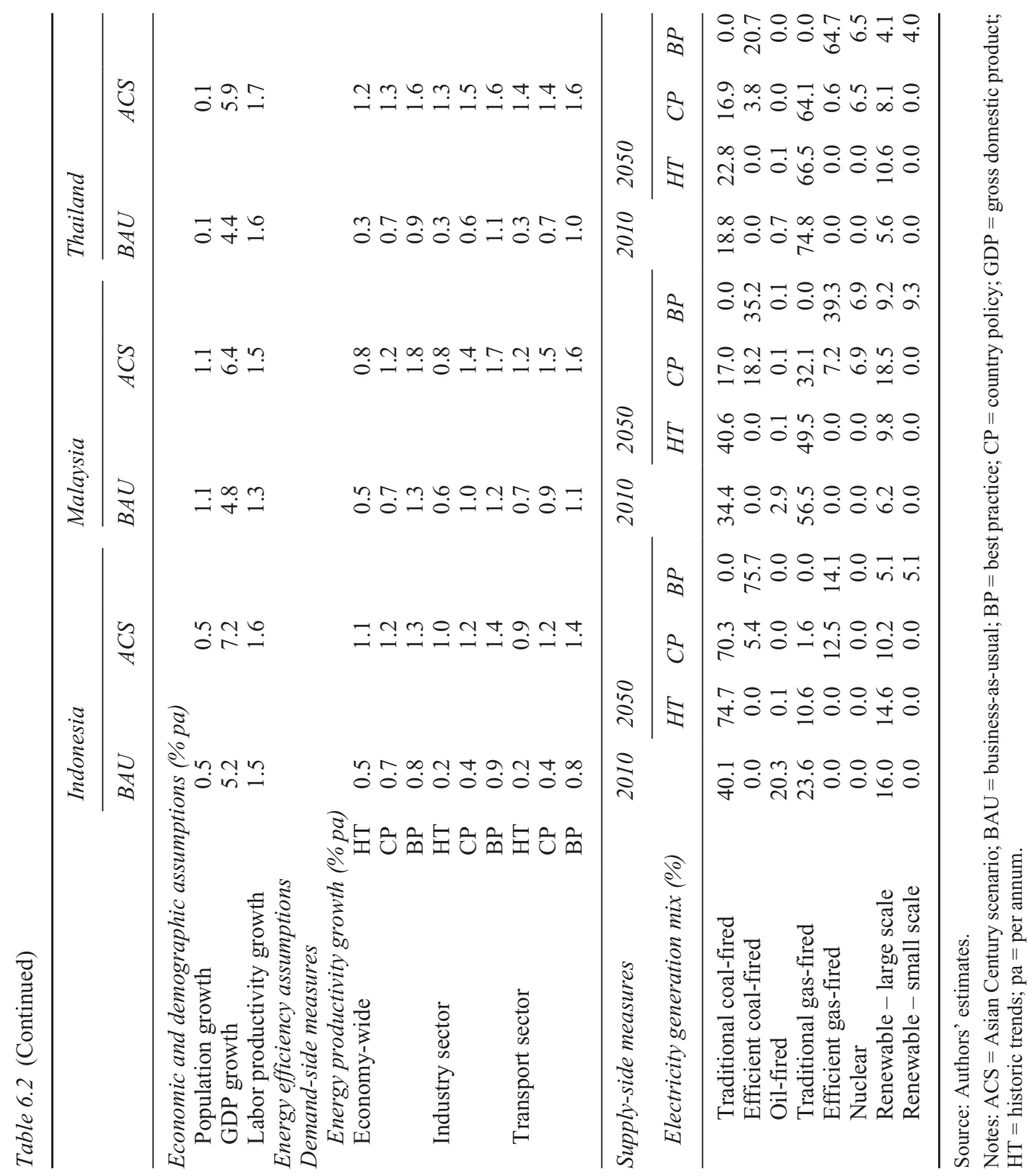


In the HT scenario, we make energy productivity growth projections for each of the seven countries to 2050 on the basis of the final energy consumption for the whole economy and for the industry and transport sectors. Final energy consumption is assumed to grow at long-term historical rates incorporating historic energy efficiency improvements provided by the IEA database for 1970-2010 (IEA 2012b). For the CP scenarios, energy productivity trends between 2010 and 2035 are estimated from the information published in the Asia Pacific Energy Research Centre energy outlook (APERC 2013). Beyond 2035, energy productivity is projected to grow at long-term trend rates reflecting ongoing energy efficiency improvement measures adopted by individual countries. For the BP scenarios, energy productivity trends are projected based on aggressive implementation of energy efficiency measures implemented in Germany and Japan.

These scenarios further consider available supply-side technology options specifically for the electricity sector. In the HT scenarios, it is assumed that future shares of different electricity generation technologies (coal, oil, gas, nuclear, and renewables) from 2011 to 2050 will grow at long-term historical rates as estimated from the IEA database (IEA 2012b). In the CP scenarios, these shares will follow the targets set by individual governments and are based on the Asia Pacific Energy Research Centre outlook. In the BP scenarios, it is further assumed that the traditional coal-fired and gas-fired power plants will be completely replaced by efficient plants by 2050 and that small-scale, distributed power plants based on renewable energy will play a greater role from 2020 onwards. Table 6.2 summarizes these assumptions.

\section{Macroeconomic impacts}

This section analyses the economic, social, energy, and environmental impacts of energy efficiency improvements in the seven countries. The attributes used in the analysis are in Figure 6.2.

The analysis is done on an annual basis from 2010 to 2050, but the results are discussed separately for the short term (2010-2025), medium term (2025-2035), and long term (2035-2050).

\section{Economic and social impacts}

\section{Economic growth}

The impacts of energy efficiency improvements on economic growth are shown in Figure 6.3. The HT outcomes are used as a benchmark for analyzing the CP and BP outcomes both for BAU and ACS.

Overall, energy efficiency improvements will be critical for ensuring longterm, sustainable economic growth for all seven countries, but the intensity and timing of the economic impacts will vary.

Energy efficiency policies (CP and BP scenarios) will result in modest reductions in the gross domestic product (GDP) for the PRC in the short to medium terms. 


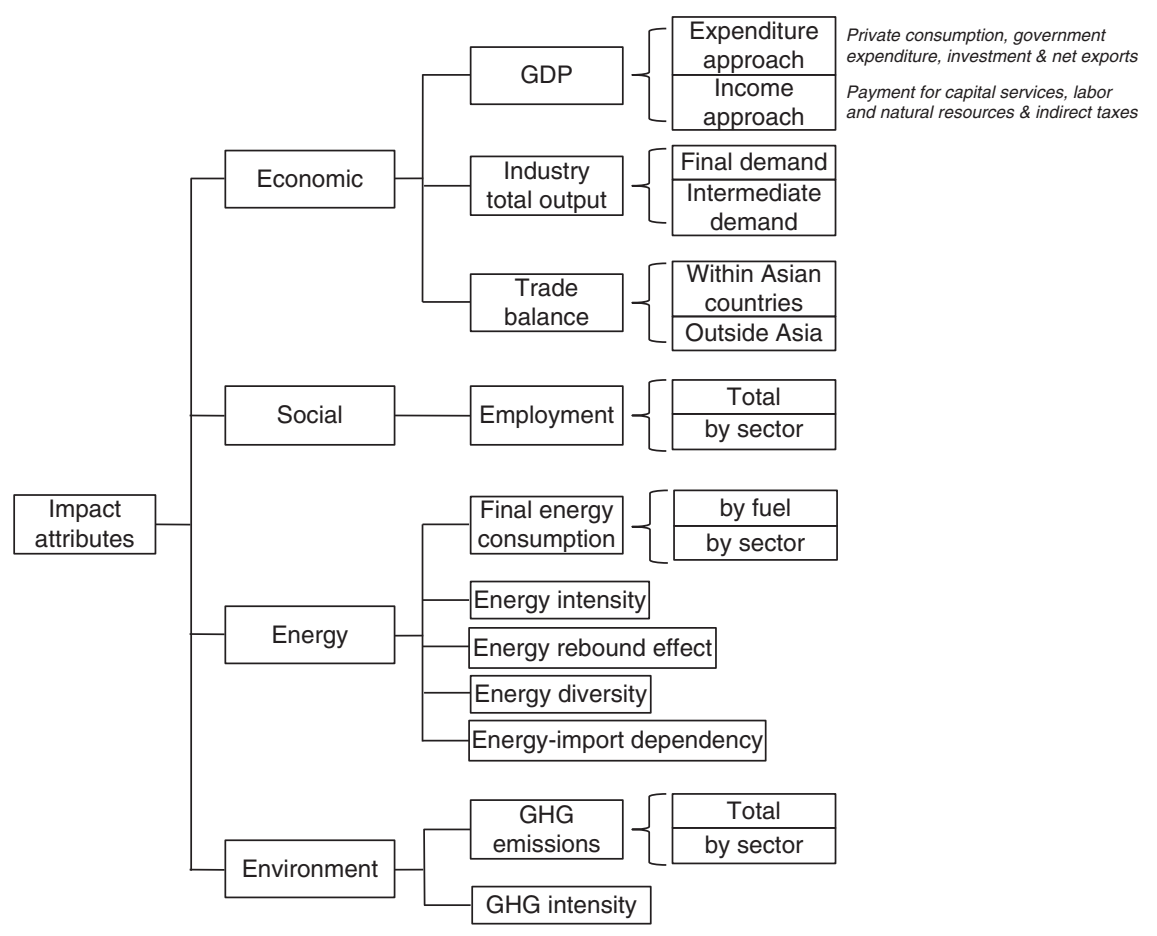

Figure 6.2 Attributes for assessing the impacts of energy efficiency improvements Source: Authors.

Note: GDP = gross domestic product; $\mathrm{GHG}=$ greenhouse gas.

In the long term, however, there will be appreciable GDP gains. For example, existing energy efficiency policies (CP) under ACS would result in a $0.04 \%$ loss of medium-term GDP and a $1.23 \%$ gain in long-term GDP compared with the HT scenario.

The Malaysian economy would apparently be adversely affected by energy efficiency policies. In the BAU-BP scenario the short-, medium-, and long-term GDP would decline by $1.17 \%, 1.88 \%$, and $3.29 \%$, respectively.

In contrast to the PRC and Malaysia, the other five countries would experience a net GDP gain from introducing energy efficiency measures. For example, existing country policies on energy efficiency would increase Indonesia's GDP by $0.25 \%$ in the short term, $0.43 \%$ in the medium term, and $0.76 \%$ in the long term compared to the HT scenario.

Introducing energy efficiency measures would have a positive impact on private consumption, government expenditure, and investment. Furthermore, these impacts would be evenly spread over the study period and will be particularly pronounced in the BP scenario. 

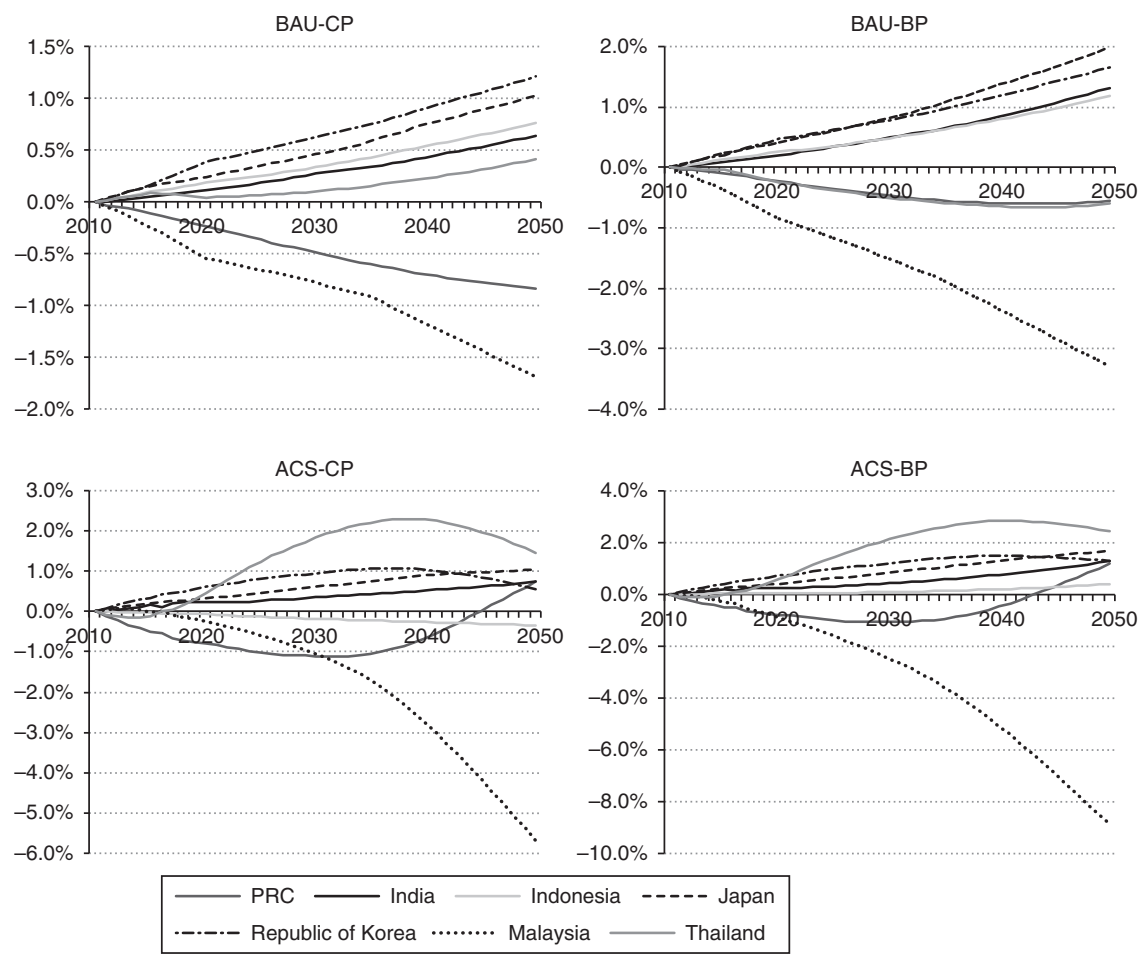

Figure 6.3 Changes in gross domestic product compared with historic trends scenarios

Source: Authors' estimates.

Note: $\mathrm{ACS}=$ Asian Century scenario; $\mathrm{BAU}=$ business-as-usual; $\mathrm{BP}=$ best practice; $\mathrm{PRC}=$ People's Republic of China; $\mathrm{CP}=$ country policy.

For India, adopting BP technology would cause private consumption in 2050 to increase by $0.55 \%$ and $0.90 \%$ in BAU and ACS, respectively. This compares rather favorably with the corresponding increases in the $\mathrm{CP}$ scenario of $0.13 \%$ in BAU and $0.34 \%$ in ACS.

It is worth noting that similar impacts would also be observed in the PRC and Malaysia where adopting energy efficiency policies would negatively impact medium-term GDP. For example, in Malaysia where GDP in ACS-BP would be $8.87 \%$ less in 2050, investment, private consumption, and government expenditure would, however, be $7.17 \%, 1.74 \%$, and $1.24 \%$ greater, respectively. This implies that net exports of goods and services for Malaysia would be more significantly negatively affected thus offsetting the gains obtained from other contributors to GDP.

In contrast to GDP based on expenditure, GDP based on income would produce mixed results. Income from capital services would be positively affected by introducing energy efficiency policies in all seven countries. For example, in the 
PRC income received from capital services in 2050 in ACS would be $1.73 \%$ greater in CP and $2.97 \%$ greater in BP compared with the HT scenario.

The impact of energy efficiency policies on "other income" would be mixed. Income from labor would be negatively affected in the PRC and India but positively affected in Japan, the Republic of Korea, and Malaysia. No significant impacts are observed for Indonesia and Thailand.

It is worthwhile to reiterate that this analysis is not limited to just adopting energy-efficient technologies in a strict technical sense but also includes adopting relatively expensive alternative technologies such as renewable sources and nuclear power for generating electricity. These are shown as supply-side measures in Table 6.2.

\section{Total industry output}

This attribute refers to the total intermediate and final output of domestic industry. The impacts of energy efficiency improvements are shown in Figure 6.4.

Except in Japan, the total output would be adversely affected by introducing energy efficiency policies, although it would be mostly felt by the intermediate sectors of the economy.

The most significant reduction in industry output would occur in Malaysia driven by reductions in both intermediate and final demand; this impact would be greatest in the BP scenario. Industry output in the PRC would also be significantly affected, particularly in the medium term where the total output in the CP and BP scenarios would be $2 \%$ to $3 \%$ less than in the HT scenario. The severity of the impact would, however, decrease in the long term (2050) to $1 \%$ and $2 \%$ for the CP and BP scenarios, respectively, when compared to the HT scenario. The impact would be less significant for Indonesia and the Republic of Korea. In both these countries, industry output in the $\mathrm{CP}$ and BP scenarios would decrease by $1 \%-1.5 \%$ compared with HT. As in the other countries, demand for intermediate uses would drive the reduction in output. The medium-term impact of energy efficiency policies on industry output would be almost neutral $(0.2 \%)$ for Japan and modest (1\%) for Thailand. Increased demand for final consumption would drive these gains.

The HT scenario suggests increasing trends in structural shifts in these countries, i.e., a move away from energy-intensive industries (including mining and manufacturing) toward the less energy-intensive service sector. These trends will accelerate with the introduction of energy efficiency policies (Table 6.3).

The importance of the service sector increases in all countries. This shift is particularly strong if the economies grow at an accelerated rate (as in ACS). For example, the share of the industry sector in the PRC would decrease from $61.3 \%$ in 2010 to $59.4 \%$ in 2050 in the BAU-HT scenario; it would further decrease to $56.1 \%$ in the ACS-HT scenario.

This transition from industry to services is particularly quick with stronger energy efficiency policies. Again for the PRC, the share of the industry sector would decrease to $55.3 \%$ in $\mathrm{CP}$ and $54.8 \%$ in BP compared with $56.1 \%$ in the HT scenario. While this transition would be gradual for most countries, for 


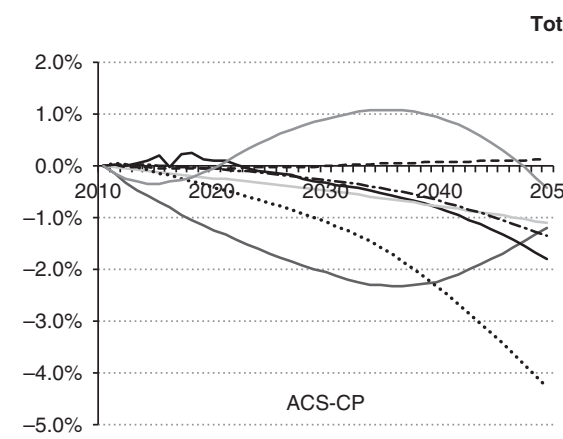

Total output
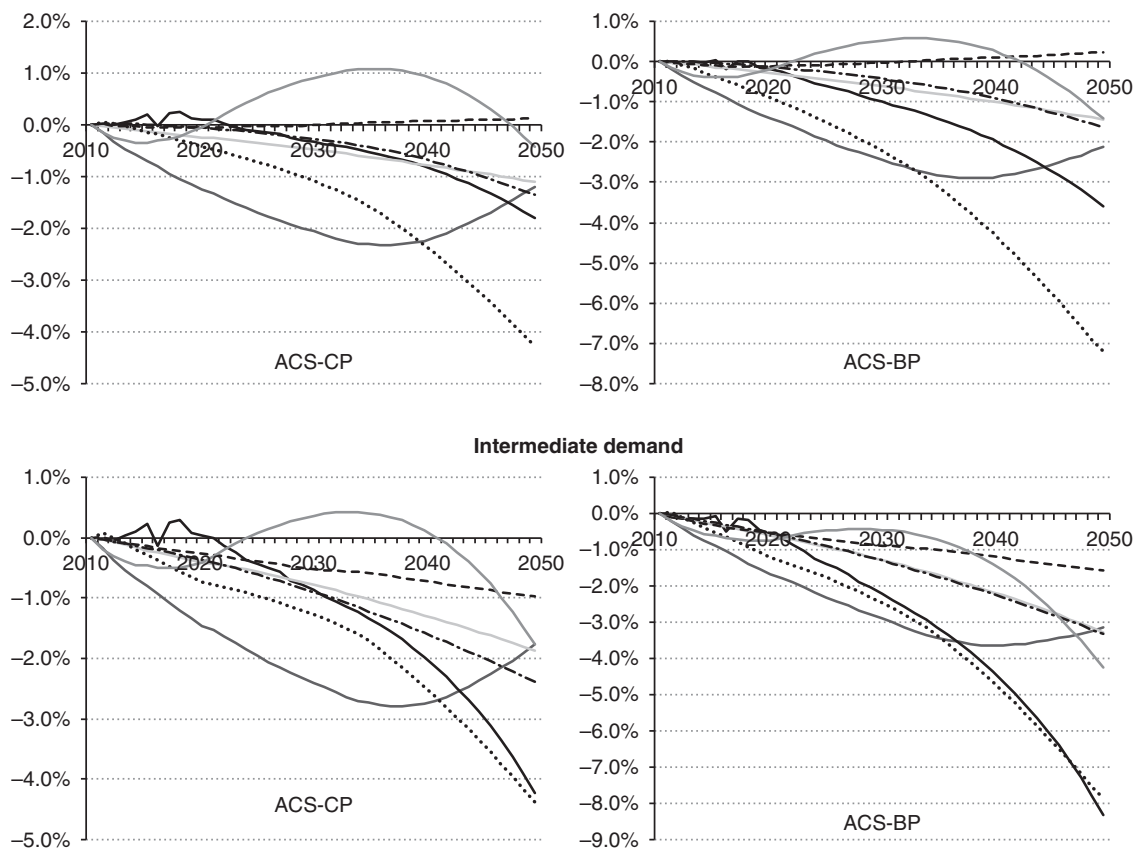

termediate demand

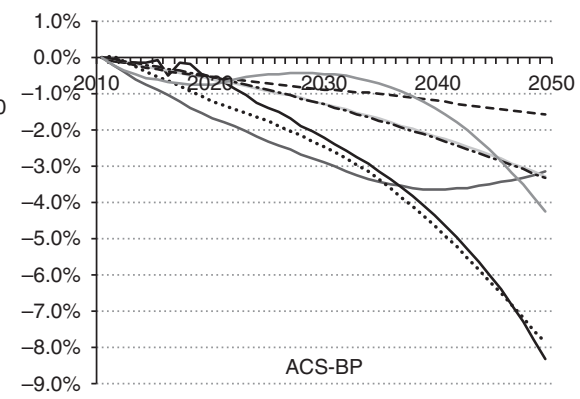

Final demand
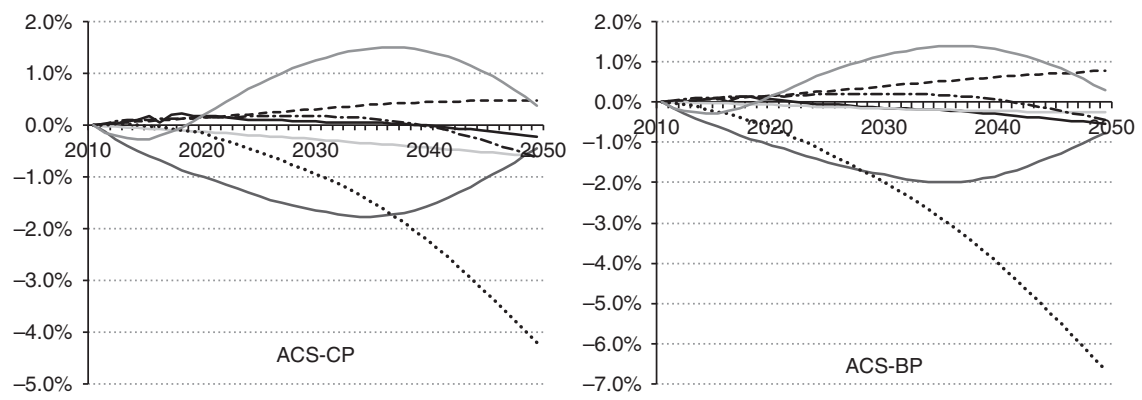

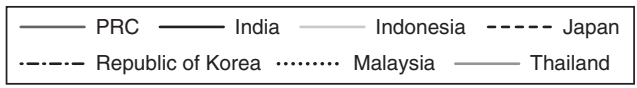

Figure 6.4 Changes in total output for Asian Century scenarios Source: Authors' estimates.

Note: $\mathrm{ACS}=$ Asian Century scenario; $\mathrm{BP}=$ best practice; $\mathrm{PRC}=$ People's Republic of China; $\mathrm{CP}=$ country policy.

Thailand and Indonesia the share of the industry sector would increase further in the medium term but would decrease in the long term.

The changes in the economic structures of Japan and to a lesser extent the Republic of Korea would be negligible which is not surprising as their economies are already very service oriented. 


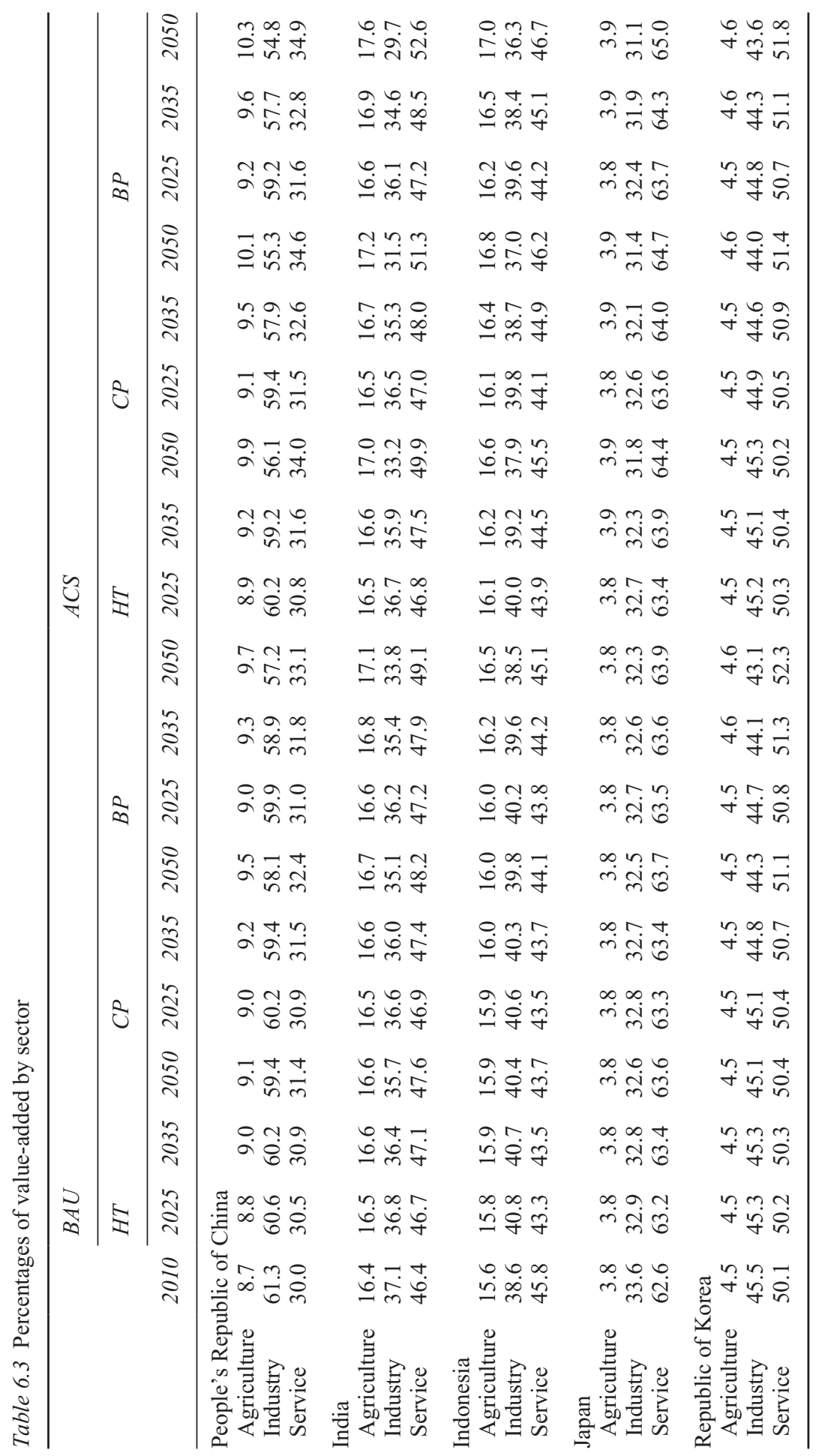




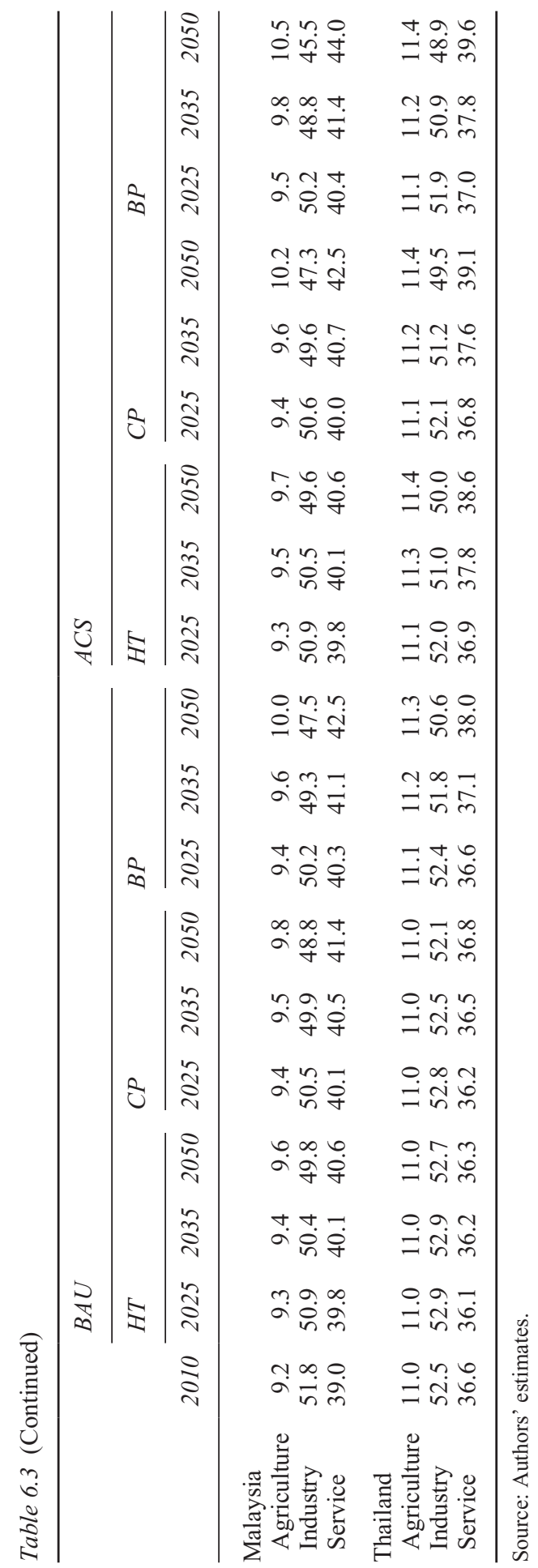




\section{Trade balance}

Energy efficiency policies would in general lead to a significant increase in trade within Asia and would reduce trade outside Asia. The effects would, however, differ across countries.

India would improve its total trade balance by about $\$ 120$ billion in 2050 in the BAU-CP scenario; its trade position would further improve by an additional $\$ 50$ billion in the BAU-BP scenario.

Indonesia and the Republic of Korea would also improve their trade balances; however, under ACS these improvements might not materialize. For example, while net trade in Indonesia and the Republic of Korea would increase by $\$ 31$ billion and $\$ 10$ billion respectively in 2050 in the BAU-CP scenario, in the ACS-CP scenario they would become net importers of goods and services ( \$96 billion and \$19 billion for Indonesia and the Republic of Korea, respectively).

In contrast, Thailand would become a net importer of goods and services by almost $\$ 50$ billion in 2050 if its economic growth continues at HT rates, but it would become a net exporter if the economy grows at the accelerated rate with a trade balance exceeding $\$ 50$ billion in 2050 .

Malaysia would be a big loser in terms of international trade as the trade balance in 2050 could deteriorate by $\$ 40$ billion to $\$ 315$ billion. The PRC would be the biggest loser ( $\$ 950$ billion in 2050 ) if its economy grows at a moderate rate, but under ACS this trend would reverse by 2040 putting the balance in positive territory ( $\$ 11$ billion in the CP scenario).

In terms of net trade in goods and services, the relative shares among different industries would vary considerably. Energy efficiency improvements would have a positive impact on mining and energy industries by reducing imports of products in energy-importing countries and increasing exports in energy-exporting countries. In the BAU scenario, imports of mining products in the PRC would decrease by $\$ 1,104$ billion in 2035 in CP compared with the HT scenario, and in Indonesia, the export of energy products would increase by $\$ 11.7$ billion in 2035 in BP.

Trade in manufactured products would be adversely affected by adopting energy efficiency measures in all countries except Japan. In ACS, net imports of manufactured products from the PRC would peak in 2040 (additional \$1,060 billion and \$1,260 billion in the CP and BP scenarios compared with HT) before improving slightly by 2050 though the PRC will still be a net importer of manufactured products.

While Thailand would also be a net importer of manufactured products in the BAU scenario - up to $\$ 50$ billion in 2050 - it could become a net exporter under ACS. Introducing energy efficiency policies would increase manufactured exports for Japan; ACS-BP would increase exports by \$46 billion in 2050.

\section{Employment}

The impact of adopting energy efficiency policies on employment will be significant and will differ across the countries (Figure 6.5). 


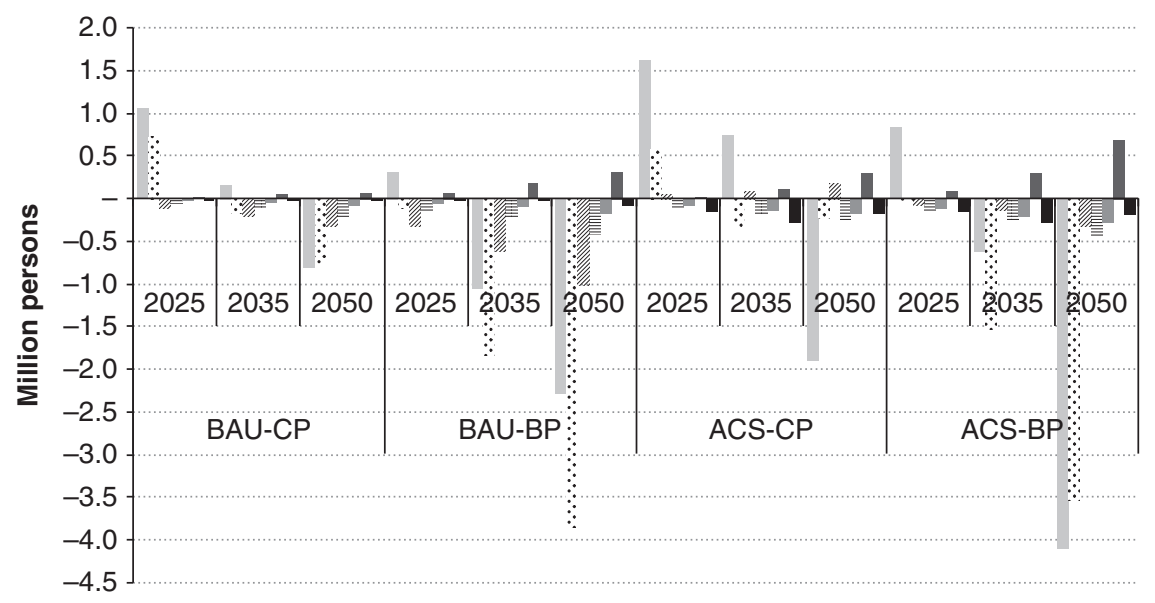

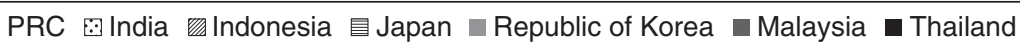

Figure 6.5 Changes in total employment

Source: UNESCAP 2012.

Note: $\mathrm{ACS}=$ Asian Century scenario; $\mathrm{BAU}=$ business as usual; $\mathrm{BP}=$ best practice; $\mathrm{PRC}=$ People's Republic of China; $\mathrm{CP}=$ country policy.

In the PRC, there will be a significant adverse impact on employment in the long term in ACS-CP and BP, but there may be modest employment gains in the short to medium terms. In India, the impact will be somewhat negative in ACS-CP at $0.02 \%$ ( 0.2 million) less than in HT. The number of unemployed would rise by 3.5 million in the ACS-BP scenario as more advanced technology requires less labor to operate.

The employment impacts will be much milder for Indonesia, Japan, the Republic of Korea, and Thailand. In Indonesia, long-term employment will be just $0.2 \%$ (0.3 million) less in the ACS-BP scenario; however, in the CP scenario, there will be a modest gain in employment. The employment impacts for Thailand will essentially be neutral in the BAU scenarios and somewhat negative ( 0.2 million) in the ACS scenarios.

The employment impacts will be largely positive for Malaysia at 0.7 million new jobs in ACS-BP compared with an increase of 0.3 million new jobs in ACS-CP.

Adopting energy efficiency policies would result in a shift in employment from energy and mining to manufacturing and services. For energy-rich countries, employment in energy and mining would decline. The most affected countries are likely to be Indonesia and Malaysia where energy and mining are major industries. These two countries are also net exporters of energy. For Malaysia in ACS, introducing BP would lead to a $32 \%$ reduction in employment in mining. 
This loss would, however, be offset by an increase of $15 \%$ in the service sector, $11 \%$ in the manufacturing sector, and $2 \%$ in the agriculture sector.

For energy-deficient countries, jobs would simply shift from the manufacturing sector to the service sector in all except the PRC and the Republic of Korea where the jobs would continue to be concentrated in the manufacturing sector.

\section{Energy impacts}

This section discusses the impacts of implementing energy efficiency policies (CP and BP) in terms of the energy attributes in Figure 6.2.

\section{Total final energy demand}

Table 6.4 shows final energy consumption under the six scenarios.

In the HT scenario, there will be a very large increase in final energy demand in the PRC, India, and Indonesia. In the PRC, the final energy demand (in BAU) would increase by more than five times from 1,520 million tons of oil equivalent (MToe) in 2010 to 7,900 MToe in 2050. Final energy demand for Indonesia would increase nearly 7-fold, and in India it would increase more than 13-fold from 449 MToe in 2010 to 6,043 MToe in 2050. This is largely due to the anticipated economic growth in these three countries. Energy consumption in the PRC would peak by the middle of the century; consequently the rate of growth in final energy demand will decrease.

Final energy demand will also increase in Malaysia and Thailand although at a much slower rate than in the PRC, India, and Indonesia. This is perhaps due to the fact that these two economies are in the upper-middle income group and hence require less energy to stay on their economic growth trajectories (see also Medlock 2009).

Japan would experience a modest decline in final energy demand, especially over the long term even though its economy will continue to grow. The low population growth rate appears to be the main reason for this. Final energy demand in the Republic of Korea would continue to grow at a much slower rate than in the other developing countries.

Accelerated economic growth under ACS would not lead to a uniform increase in final energy demand. While increased economic growth (compared with BAU) would increase energy demand in India, Indonesia, the Republic of Korea, and Malaysia even further, demand in the PRC, Japan, and Thailand would decline. This implies that the economic health of the former would continue to rely on the increased availability of energy while economic development in the latter might break the energy-economic growth connection.

There are significant contrasts in the impacts of HT, CP, and BP over the three time frames. In the $\mathrm{CP}$ and $\mathrm{BP}$ scenarios, introducing energy efficiency policies would lead to a modest slow-down in growth in energy demand in the short to medium term; the impact appears to be more significant in the long term, especially in ACS. There are also significant contrasts in the impacts across countries. 


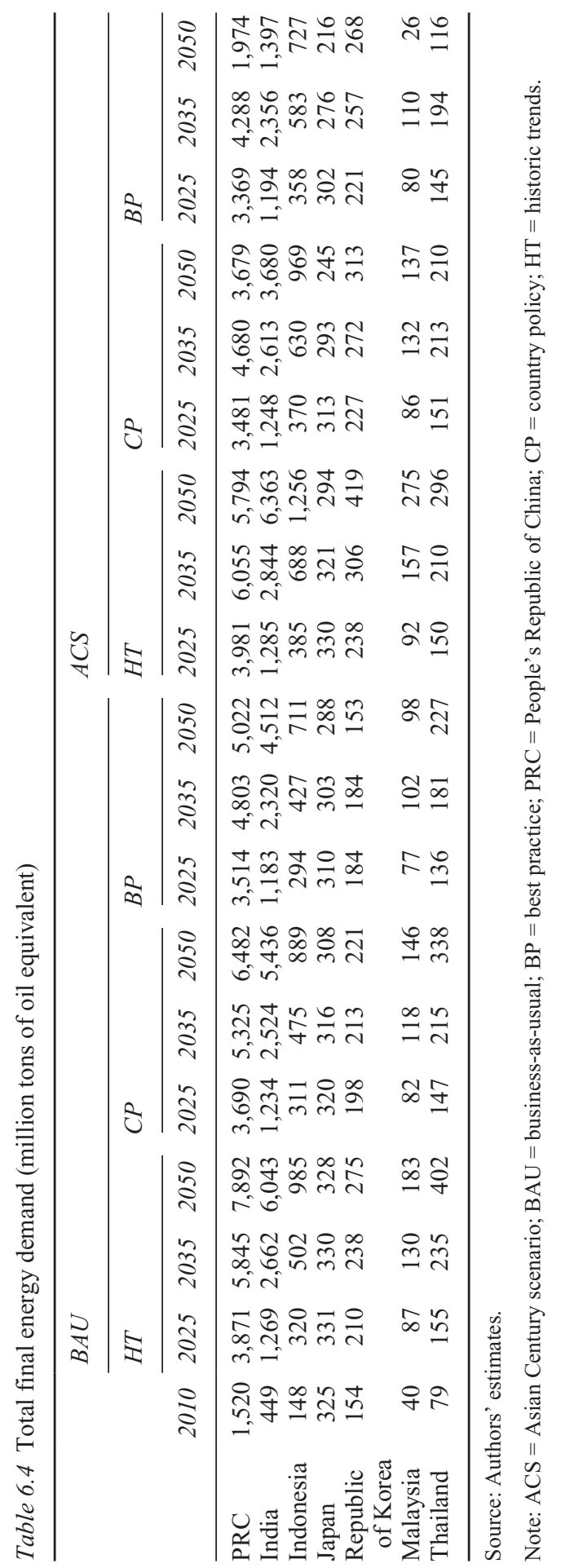


A modest deceleration of growth in energy demand would take place in Indonesia, the Republic of Korea, Malaysia, and Thailand over the short to medium term but would become more significant in the long term. In Indonesia, energy demand in the ACS-BP scenario would decreased by about $7 \%$ in 2025 , $15 \%$ in 2035 , and $42 \%$ in 2050 compared to demand in ACS-HT.

For Indonesia, the Republic of Korea, and Malaysia, greater energy savings will be achieved under ACS. Compared with the HT scenario, energy demand in BAU in Malaysia decreased by 5 MToe in CP and 10 MToe in BP in the short term; 12 MToe in CP and 28 MToe in BP in the medium term; and 37 MToe in $\mathrm{CP}$ and $85 \mathrm{MToe}$ in BP in the long term. The corresponding figures in ACS are 6 MToe and 12 MToe in the short term; 25 MToe and 47 MToe in the medium term; and 138 MToe and 249 MToe in the long term. In Thailand, there will be more energy savings in BAU in the short to medium term, but this trend will be reversed in ACS where savings will be only in the long term.

In the HT scenario, the total final energy demand for Japan would increase from 325 MToe in 2010 to 331 MToe in 2025 and then decrease slightly to 330 MToe in 2035 and 328 MToe in 2050. This is partly due to slower growth in GDP and population. In $\mathrm{CP}$ and $\mathrm{BP}$, final energy demand will steadily decrease in the short to medium term. In the long term, growth in energy consumption will slow down significantly. The reduction in ACS is more pronounced than in BAU, especially in the long term.

There are significant contrasts in energy consumption in the PRC and India depending on the scenario. Trends would be modest for Indonesia, the Republic of Korea, Malaysia, and Thailand reflecting their relatively low energy productivity compared with the most energy-productive countries in the world (Germany and Japan) and their ambitions to improve. This suggests that concerted efforts will be required if they want to catch up. In contrast, no appreciable difference in energy consumption is observed for Japan among the various scenarios reinforcing the status of Japan as an energy-efficient economy compared with the other six.

\section{Energy intensity}

Energy intensity denotes the energy intensiveness of the economy. In this chapter, it is expressed in terms of primary energy used, i.e., 1,000 tons of oil equivalent (kToe) to produce 1 million dollars (\$m) of GDP at 2010 prices.

There are considerable contrasts in 2010 in energy intensity across the seven countries. The PRC, India, and Thailand have relatively high energy intensities ranging between 342 and $467 \mathrm{kToe} / \$ \mathrm{~m}$ followed by Indonesia $(283 \mathrm{kToe} / \$ \mathrm{~m})$, Malaysia (279 kToe/\$m) and the Republic of Korea $(238 \mathrm{kToe} / \$ \mathrm{~m})$. Japan has the lowest energy intensity among these countries at $91 \mathrm{kToe} / \$ \mathrm{~m}$. Energy intensity trends for all six scenarios are shown in Figure 6.6.

From 2010 to 2050, there is a significant decrease in energy intensity in all countries most noticeably in currently energy-intensive PRC, India, Indonesia, and Thailand. The reduction is less significant in the Republic of Korea and 

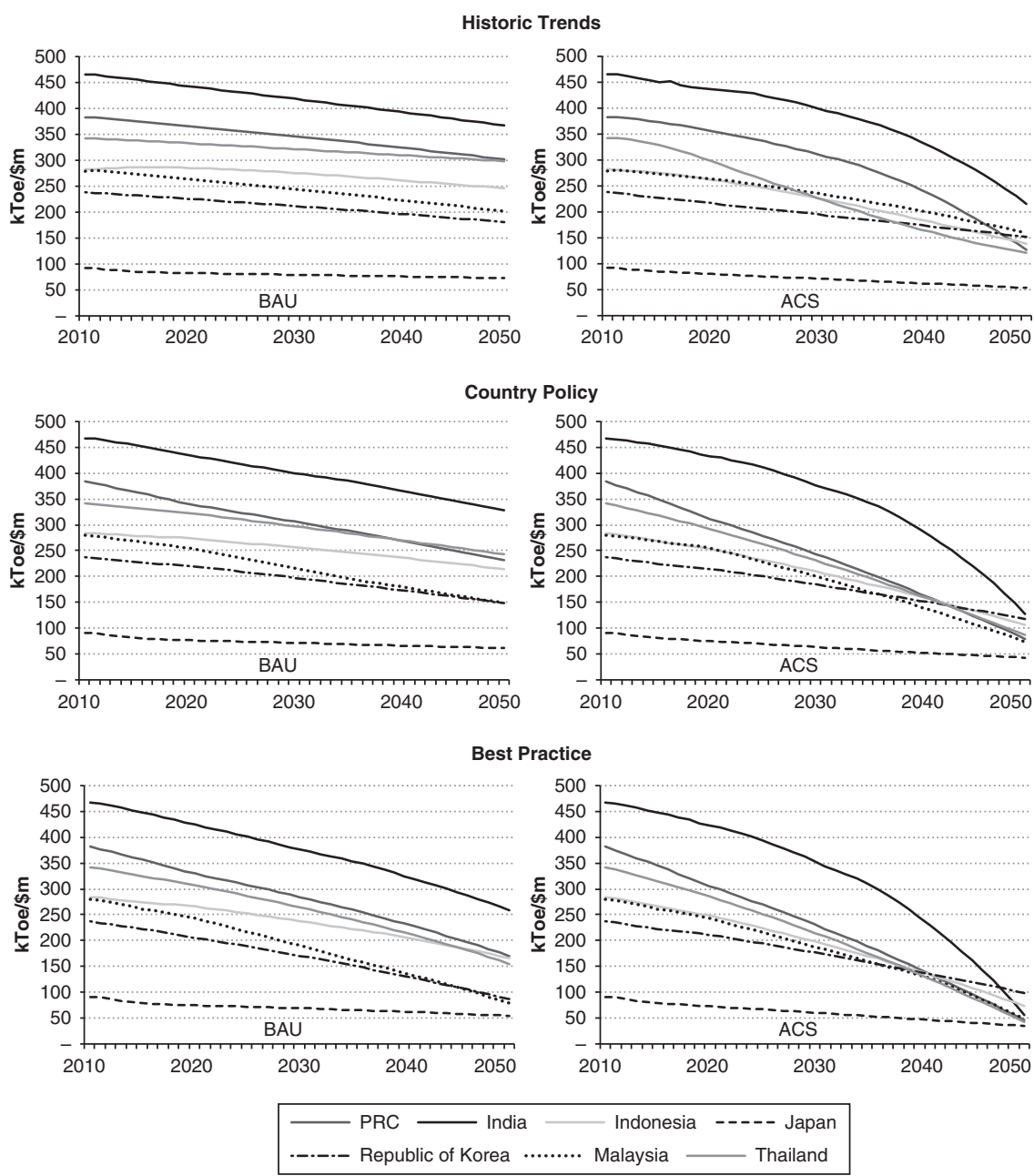

Figure 6.6 Energy intensity trends, 2010-2050

Source: Authors' estimates.

Note: $\mathrm{ACS}=$ Asian Century scenario; BAU = business-as-usual; PRC = People's Republic of China; $\mathrm{kToe}=1000$ tons of oil equivalent.

Malaysia. There is a modest reduction even in Japan, the most advanced economy in the group.

Energy intensity is likely to steadily decrease throughout the period. Under ACS, India is the only exception as most of the reduction would occur in the long term. Prior to 2035, energy intensity in India will decrease at an annual average rate of $1.3 \%$ in $\mathrm{CP}$ and of $1.7 \%$ in BP. After 2035, it will decline at an average rate of $6.4 \%$ per year in $\mathrm{CP}$ and $10.9 \%$ in $\mathrm{BP}$. 
The decline in energy intensity is generally more significant in ACS than in BAU. This implies that the sustained growth in the Asian economies depends on the efficient use of energy.

As a result of these trends, the energy intensities of these countries will converge. In the BAU scenarios, the convergence will take place in countries with similar energy-use patterns. The intensities for the PRC, India, Indonesia, and Thailand will converge in 2050. Similar trends are likely for the Republic of Korea and Malaysia. In ACS, the convergence will take place in all countries except Japan in the HT and CP scenarios where its energy intensity is the lowest. Under ACS-BP, however, the result would be a true convergence in energy intensities.

\section{Energy rebound effect}

The rebound effect arises from the behavioral response of the economy in which energy reductions from improvements in efficiency are partly or wholly offset by increased consumption. Estimates of the rebound effect in the seven countries are summarized in Figure 6.7.

In the BAU scenario, a very strong rebound effect is observed for the PRC and Malaysia, a moderate yet significant effect will occur in the Republic of Korea and Thailand, a still appreciable effect is observed for India and Indonesia, and the effect will be weak in Japan. The BP scenario generally shows a larger rebound than $\mathrm{CP}$ in all seven countries. More aggressive economic growth under ACS does not always lead to a lower rebound effect. Our analysis shows that this is true only in the PRC and Thailand in the CP scenario and in the PRC, Indonesia, and the Republic of Korea in the BP scenario.

Annual energy productivity growth rates for the PRC and Thailand in ACS-HT are $1.3 \%$ and $1.2 \%$, respectively compared with $0.5 \%$ and $0.3 \%$ in BAU-HT. For Japan and Malaysia, on the other hand, these values are $0.6 \%$ and $0.8 \%$ in
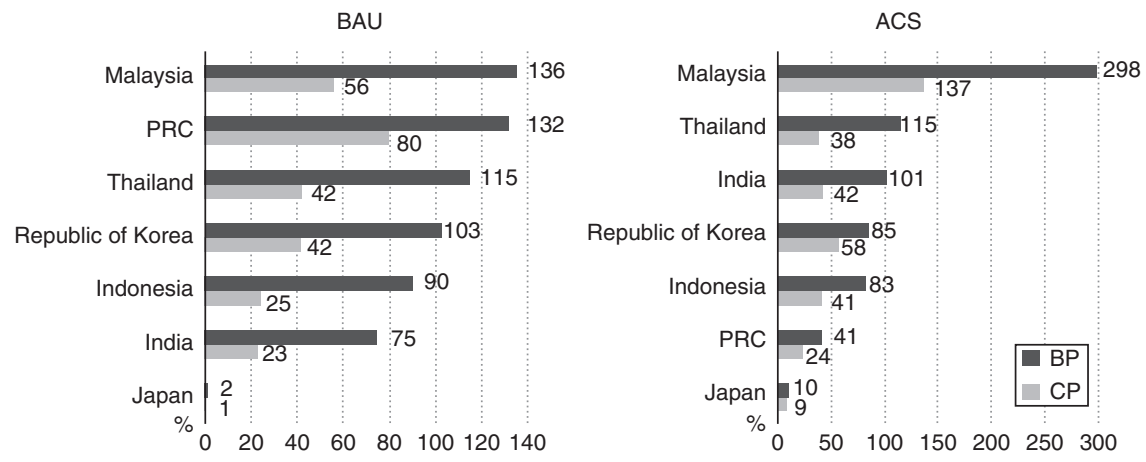

Figure 6.7 Energy rebound effect

Source: Authors' estimates.

Note: $\mathrm{ACS}=$ Asian Century scenario; $\mathrm{BAU}=$ business-as-usual; $\mathrm{BP}=$ best practice; $\mathrm{PRC}=$ People's Republic of China; $\mathrm{CP}=$ country policy. 
the ACS-HT scenario compared with $0.3 \%$ and $0.5 \%$ in the BAU-HT scenario. This means that more energy in ACS would be saved through energy productivity improvements leaving little room for further improvement from measures to increase demand-side efficiency.

The magnitude of the rebound associated with efficiency improvements in energy-intensive sectors is generally higher than in non-energy-intensive sectors. If the rates of efficiency improvements in energy-intensive sectors are high regardless of improvements in non-energy-intensive sectors, this would lead to a larger rebound. Take the Republic of Korea for example. The annual productivity growth from demand-side efficiency measures in the energy-intensive industry sector in ACS-CP is higher (0.6\%) than that in the BAU-CP scenario $(0.4 \%)$. In this case, the rebound is relatively larger in ACS at 58\% compared with $42 \%$ in the BAU scenario. In contrast, annual productivity growth from demandside efficiency measures in this sector in ACS-BP $(0.7 \%)$ is lower than in the BAU-BP scenario $(0.8 \%)$. Here, the rebound effect is lower in ACS at $85 \%$ compared with $103 \%$ in the BAU scenario.

The magnitude of the rebound effect differs from country to country possibly due to a combination of factors. A higher rate of energy productivity growth from energy efficiency measures generally leads to a larger rebound. Energy productivity from efficiency measures for Malaysia is assumed to grow by $28 \%$ ( $0.4 \%$ per year) in ACS-CP and by $48 \%$ (1\% per year) in ACS-BP. These rates are the highest of the seven. Countries that are likely to experience higher population and GDP growth are also expected to have larger rebounds. Both of these rates are assumed to be relatively high for Malaysia- $1.1 \%$ per year in population growth and 6.4\% per year in GDP growth-from 2010 to 2050.

Countries that can rely on domestic energy resources to meet their demands are likely to have a larger rebound than those that rely on energy imports (Sorrell 2009).

\section{Energy diversity}

We use the Herfindahl Index as a proxy for the diversity of a country's energy fuel mix (lower values suggest greater diversity). Estimates of the Herfindahl indices for the seven countries are summarized in Figure 6.8.

No noticeable improvement in energy diversity is observed except in the PRC where it will improve modestly in the medium to long term. Notwithstanding, the PRC would still be the least diverse of the seven due mainly the overwhelming reliance on coal and oil.

In India, energy diversity decreases in both the $\mathrm{CP}$ and $\mathrm{BP}$ scenarios. The index will increase from 0.301 in 2010 to 0.317 in CP and to 0.388 in BP in 2050 in part because of the increasing share of oil in primary energy consumption. Its share will increase from around 35\% in 2010 to more than 55\% in 2050.

Energy diversity will converge across countries except in the PRC. This suggests that the primary energy sources would remain broadly the same: coal and oil in India, Indonesia, and Japan, coal and nuclear in the Republic of Korea, oil and natural gas in Malaysia, and oil in Thailand. 


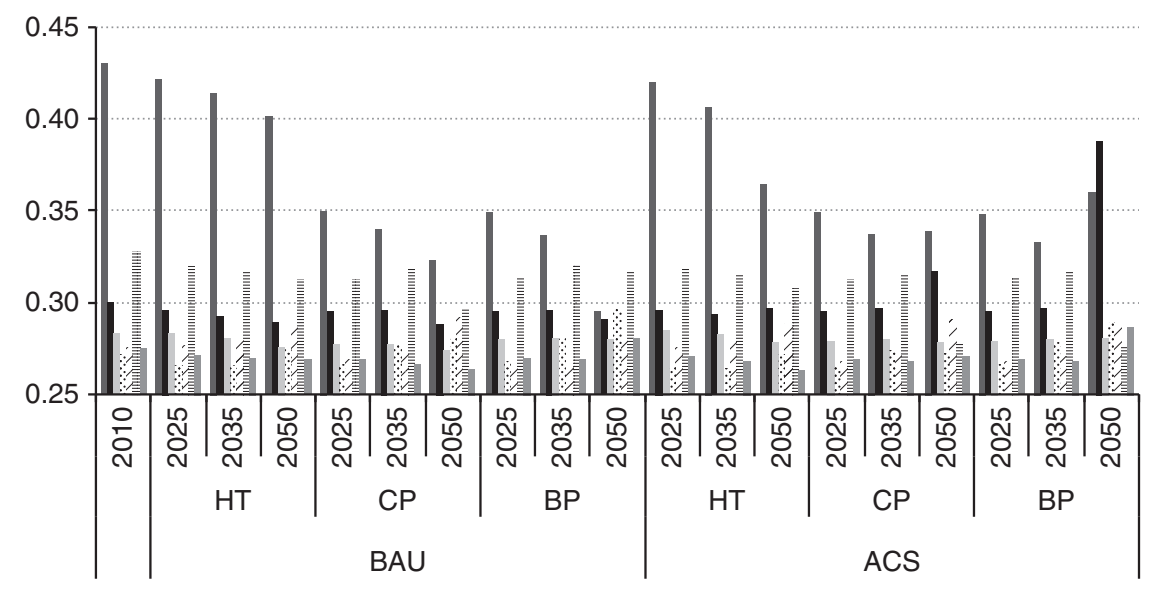

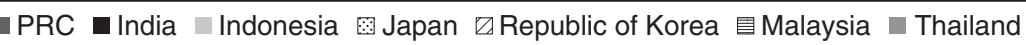

Figure 6.8 Herfindahl Index

Source: Authors' estimates.

Note: ACS = Asian Century scenario; $\mathrm{BAU}=$ business-as-usual; $\mathrm{BP}=$ best practice; $\mathrm{PRC}=$ People's Republic of China; $\mathrm{CP}=$ country policy; $\mathrm{HT}=$ historic trends.

In addition, contrasts in energy diversity throughout the study period will be minimal which suggests that energy efficiency policies would have little impact on the fuel mix.

\section{Energy-import dependency}

In this chapter, energy-import dependency is expressed in terms of the ratio of net energy imports to total primary energy consumption. Table 6.5 shows this indicator for the seven countries under the six scenarios.

Japan and the Republic of Korea are the most dependent as about $80 \%$ of their demands are met by imports. With the introduction of energy efficiency policies, noticeable improvements in dependence can be achieved for the Republic of Korea especially in the medium to long term, but dependence will remain high for Japan. This is probably due to differing attitudes towards nuclear energy in these two countries.

The energy-import dependence of Thailand is relatively modest (around 44\%); it will not noticeably improve particularly in the BAU scenario (still $44 \%$ ). Some improvement would be observed in ACS with dependency reduced to about $35 \%$. This is partly due to reduced energy demand as a result of more active energy efficiency policies.

The PRC and India depend less on imports though levels will increase in the PRC because of its increasing reliance on imported oil. In India, the level will 


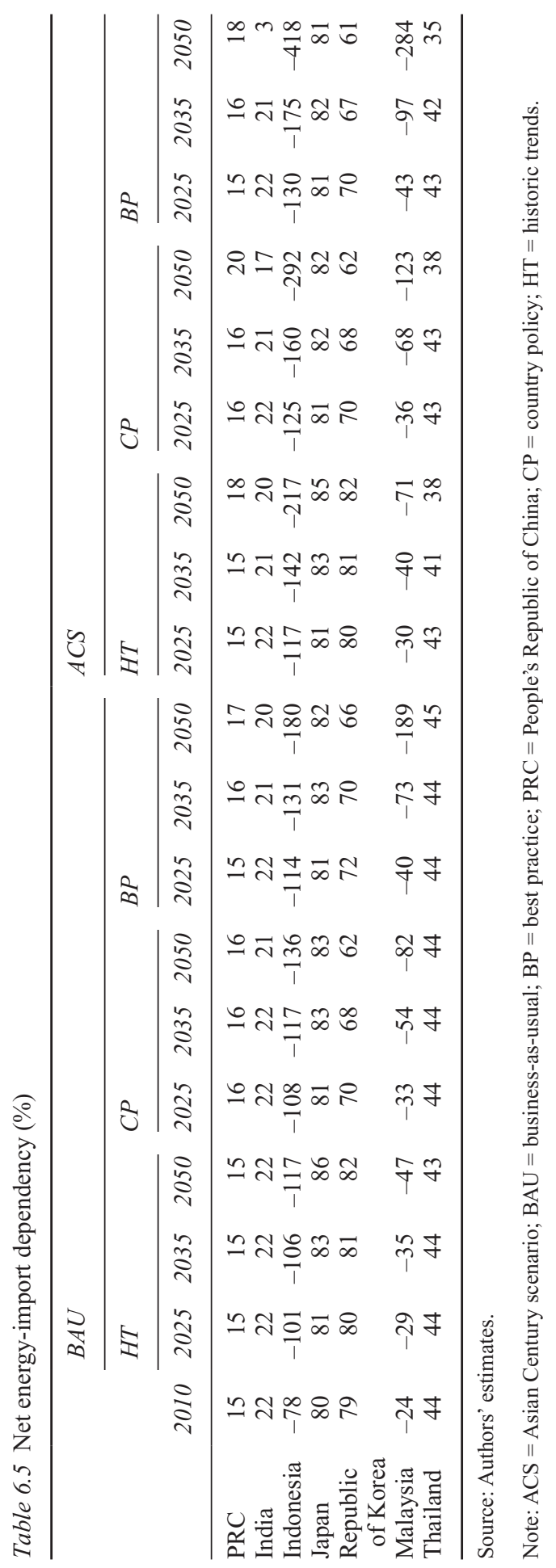


decrease slightly as a result of increased reliance on domestic coal, nuclear, and renewables.

As energy-exporting countries, Indonesia and Malaysia would be big winners from introducing energy efficiency policies. Under ACS-BP, for example, the ratio of net energy exports to consumption would improve from $77.6 \%$ in 2010 to $418 \%$ in 2050 for Indonesia and from $24.5 \%$ to $284 \%$ for Malaysia indicating an enhanced energy-export capacity.

\section{Environmental impacts}

This section discusses the environmental impacts of implementing energy efficiency policies in terms of GHG emissions and intensities.

\section{Greenhouse gas emissions}

Without energy efficiency improvement measures, total GHG emissions would increase significantly in most countries given the ongoing trends in economic growth and energy consumption (Table 6.6).

The PRC and India would experience a significant increase in total GHG emissions from 2010 to 2050 in HT, but emissions would be greatly reduced in CP and BP. In the PRC, BP would lead to a reduction in total GHG emissions by about $30 \%$ in 2035 and $53 \%$ in 2050 compared with the HT scenario. This is equivalent to avoided emissions of more than 21 billion tons in 2050 (18.422 billion tons in BP instead of 39.457 billion in HT).

From 2010 to 2050, a modest increase in total GHG emissions will occur in Indonesia, the Republic of Korea, Malaysia, and Thailand; however, it will be significantly offset by energy efficiency improvements. In Malaysia, BP would lead to a $34 \%$ reduction in total GHG emissions in 2035 and to a $60 \%$ reduction in 2050 compared to the HT scenario. This means that total GHG emissions in Malaysia would increase from 184 million tons in 2010 to 410 million tons in 2035 before dropping to 347 million tons in 2050. In the HT scenario, emissions would have reached 879 million tons in 2050 .

In the BAU scenario, total GHG emissions would be slightly higher in Japan in the long term. In ACS, emissions would increase only in the medium term (20102035 ) and would decline slightly after 2035. As in the other countries, emissions would be greatly reduced by introducing energy efficiency measures.

It is worth noting that adopting BP technologies would result in more significant reductions in total GHG emissions compared to the CP scenario. This impact would be more apparent in the long term. In India, implementing energy efficiency policies would result in a reduction of total GHG emissions in 2025 of $3.3 \%$ in the CP scenario and of $7.1 \%$ in the BP scenario compared to the HT scenario. The corresponding figures for 2035 are $3.7 \%$ and $11.8 \%$ and for 2050 are $11.0 \%$ and $32.6 \%$.

In addition in ACS, introducing energy efficiency measures would reduce total GHG emissions more significantly compared with the BAU scenario. In the PRC, 


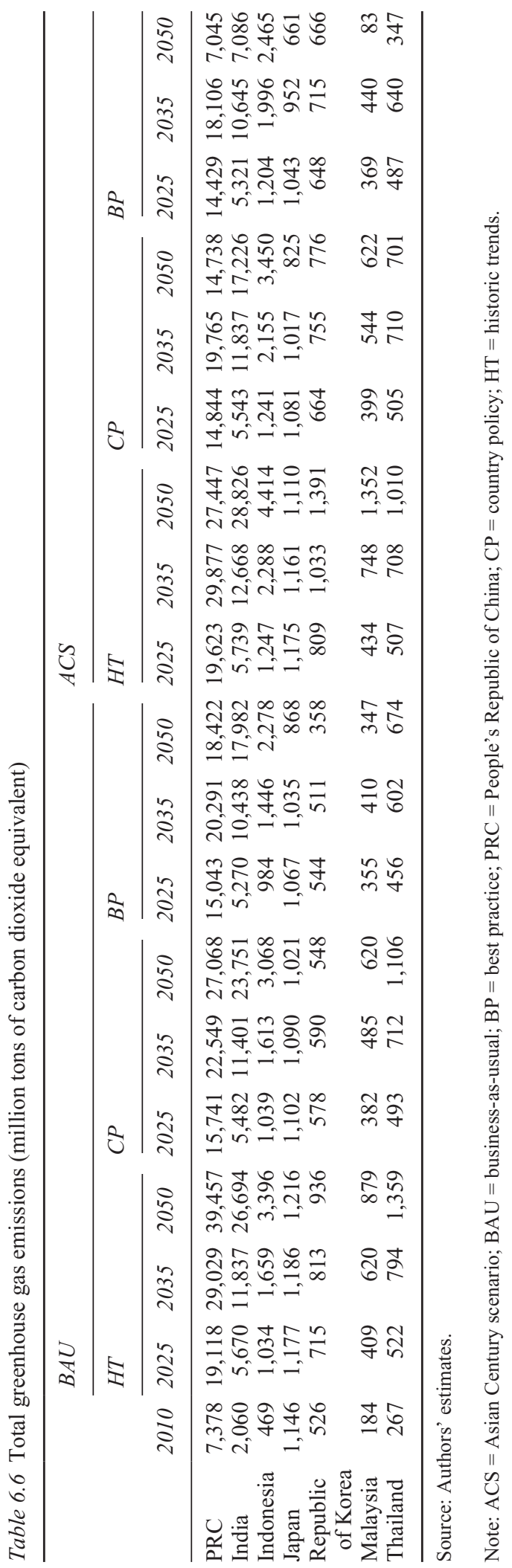


the improvement would be $17.7 \%$ in BP in 2025 in the BAU scenario compared to $24.4 \%$ in $\mathrm{ACS}$.

GHG emissions would also be reduced in energy-intensive sectors. Energy efficiency measures would result in a significant reduction in GHG emissions from the energy sector. In the PRC, CP would reduce GHG emissions by 5.158 billion tons in 2035 in the BAU scenario. This is approximately $80 \%$ of the total GHG emissions for the year.

The manufacturing and transport sectors are the most significant non-energy sectors contributing to GHG emissions; introducing energy efficiency policies would lead to modest reductions. In Malaysia, implementing aggressive measures would reduce GHG emissions by 25 million tons in the manufacturing sector and by 10 million tons in the transport sector in 2035 in the BAU scenarioapproximately $12 \%$ and $5 \%$ reductions, respectively.

\section{Greenhouse gas intensity}

In the context of this chapter, $\mathrm{GHG}$ intensity denotes the $\mathrm{CO}_{2}$ intensiveness of the economy. It is expressed in terms of kilograms $(\mathrm{kg})$ of $\mathrm{CO}_{2}$-equivalent $\left(\mathrm{CO}_{2}\right.$-eq) per dollar (\$) of GDP at 2010 prices. The trends in GHG intensity (Figure 6.9) are similar to those observed for energy intensity (see Figure 6.6).

There is a significant difference in 2010 in GHG intensity across the seven countries. The PRC and India have very high levels (more than $1.2 \mathrm{~kg} \mathrm{CO}$-eq/ $\$$ ), and intensities are also quite high in Indonesia, the Republic of Korea, Malaysia, and Thailand (more than $0.5 \mathrm{~kg} \mathrm{CO}_{2}$-eq $/ \$$ ). In contrast, Japan has a relatively low GHG intensity of approximately $0.2 \mathrm{~kg} \mathrm{CO}$-eq $/ \$$.

There will be a broad convergence in GHG intensity across countries in the long term except in Japan where emission intensity is already significantly lower than that in the others. This is particularly true in ACS where GHG intensity would grow from approximately 0.3 to $0.4 \mathrm{~kg} \mathrm{CO}$-eq $/ \$$ in the HT and CP scenarios. In the BP scenario, however, a fuller convergence is observed with GHG intensities for the six countries reaching the same level as Japan (below $0.2 \mathrm{~kg}$ $\mathrm{CO}_{2}$-eq/\$).

BP would have a more significant impact on GHG intensity than CP. In Indonesia, energy efficiency improvements in BAU would lead to a $22 \%$ reduction in GHG intensity in the CP scenario and to a $33 \%$ reduction in the BP scenario in 2035 compared with the HT scenario. In 2050, the corresponding reductions would be $31 \%$ and $47 \%$, respectively.

Energy efficiency policies would in general contribute to greater reductions in GHG intensity in ACS than in the BAU scenario. Existing energy efficiency policies in the PRC would result in a $10 \%$ reduction in GHG intensity in the BAU scenario and to a $22 \%$ reduction in ACS by 2050 .

\section{Policy trade-offs and implications}

We extend the discussion in the previous section by providing a more complete policy perspective. Specifically, we discuss policy trade-offs between 

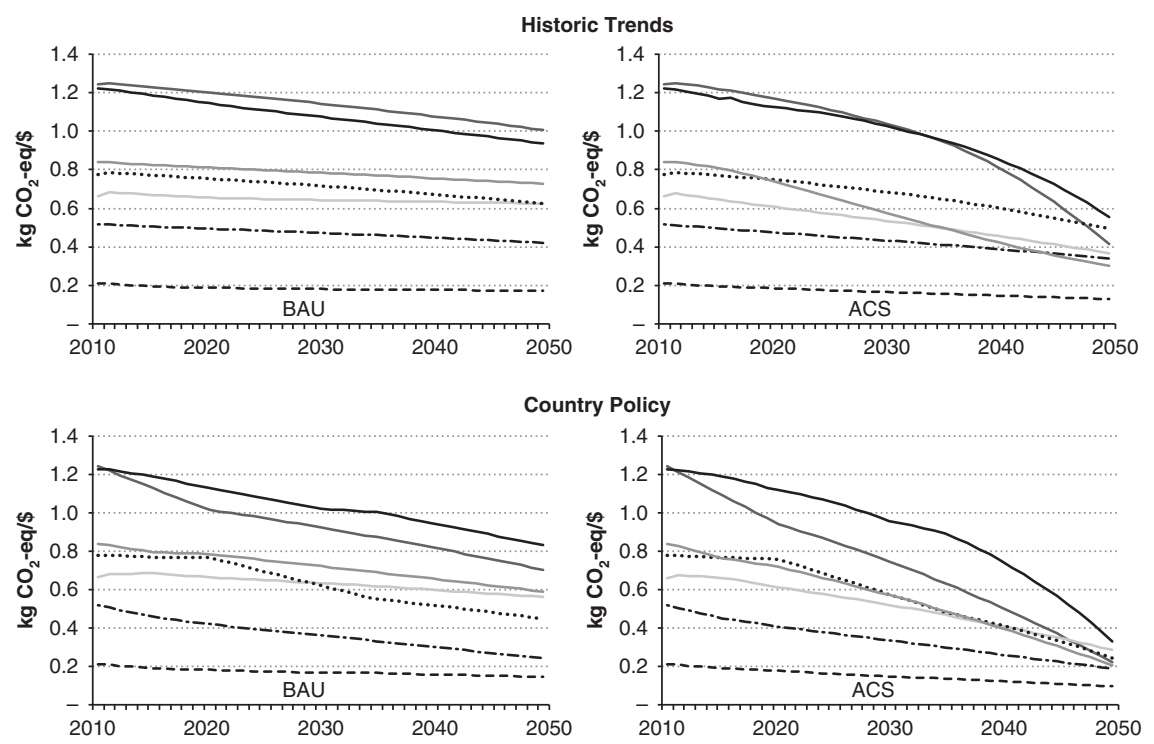

Best Practice
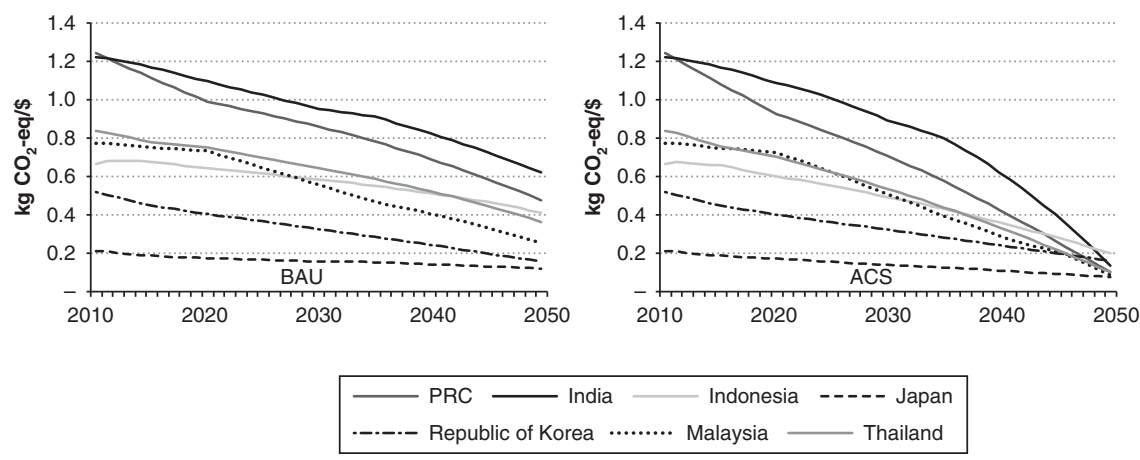

Figure 6.9 Greenhouse gas intensity trends, 2010-2050

Source: Authors' estimates.

Note: ACS = Asian Century scenario; BAU = business-as-usual; PRC = People's Republic of China; $\mathrm{kg} \mathrm{CO}_{2}$-eq/\$ = kilograms of carbon dioxide equivalent/dollar.

major attributes such as economic growth, primary energy requirements, and GHG emissions. The policy implications of the $\mathrm{CP}$ and $\mathrm{BP}$ scenarios on energy diversity and import dependency, employment, and trade balances are also discussed.

\section{The People's Republic of China}

Figure 6.10 summarizes key macroeconomic impacts and their policy implications for the PRC. 


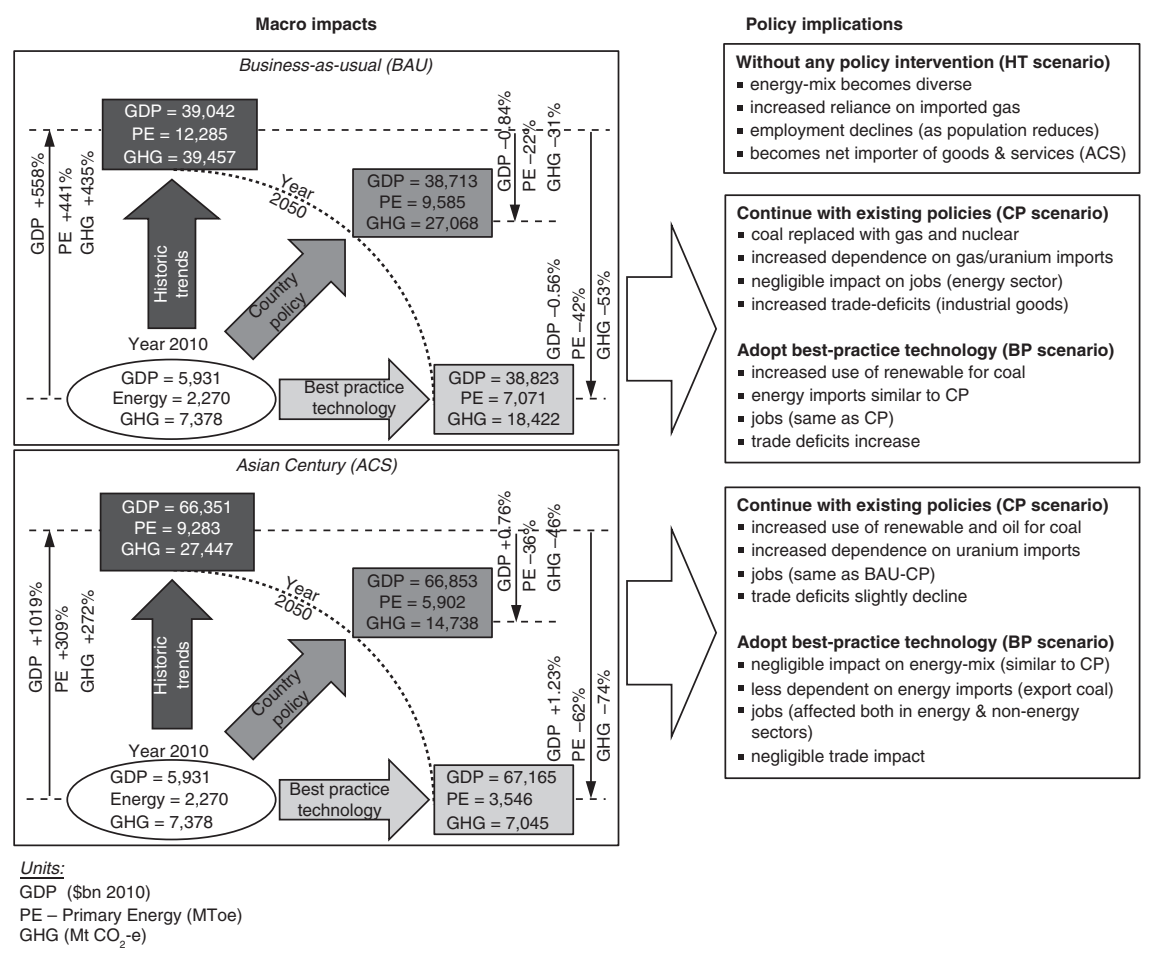

Figure 6.10 Summary of impacts and policy implications for the People's Republic of China Source: Authors.

Note: $\mathrm{ACS}=$ Asian Century scenario; $\mathrm{BAU}=$ business-as-usual; $\mathrm{BP}=$ best practice $\mathrm{CP}=$ country policy; $\mathrm{GDP}=$ gross domestic product; $\mathrm{GHG}=$ greenhouse gas; $\mathrm{HT}=$ historic trends; $\mathrm{PE}=$ primary energy. Units: $\mathrm{GDP}=2010$ \$billion; $\mathrm{GHG}=$ million tons of $\mathrm{CO}_{2}$ equivalent; $\mathrm{PE}=$ million tons of oil equivalent.

In the BAU-HT economic growth scenarios, the GDP over the next 40 years would increase more than six-fold (from $\$ 5,900$ billion to $\$ 39,000$ billion). If present energy efficiency trends continue, primary energy requirements will increase more than five-fold from 2.3 to 12.3 gigatons of oil equivalent (GToe), and GHG emissions will increase from 7.4 gigatons to 39.5 gigatons.

In ACS, the economy would be more than 11 times larger ( $\$ 66,400$ billion) than its current size. Surprisingly, however, primary energy requirements and GHG emissions would be less (9.3 GToe and 27.4 gigatons, respectively) than those in the BAU scenario. This implies that energy productivity improvements could make major contributions to sustainable economic growth. Efficiency improvements should therefore be a major focus of energy policies.

Continuing present energy efficiency trends (HT) to 2050 would slightly diversify the energy mix in both BAU and ACS. Coal and renewable energy would be partly replaced by natural gas and to a smaller extent by nuclear and oil. 
This improvement will, however, be at the expense of increased reliance on imported energy, particularly natural gas. Employment would be less reflecting mainly a declining population after reaching its peak in 2025 (UN 2012b). The trade position will be reversed; the PRC will become a net importer of industrial goods.

The severity of these impacts could be reduced by adopting a suite of policy measures aimed at improving demand and supply efficiency and increasing the use of alternative electricity generating technologies and fuels. By pursuing currently planned policies, the PRC could reduce its primary energy requirements by $36 \%$ and GHG emissions by $46 \%$. To achieve this, a concerted effort to reduce the share of coal in the country's energy mix (from $60 \%$ currently to $47 \%$ in BAU and $35 \%$ in ACS) is needed. Coal would be replaced by other energy sources in an approximately equal proportion which would lead to increased use of gas and nuclear power and hence an increased reliance on natural gas and uranium imports.

In BP, primary energy demand could be reduced by $62 \%$ and GHG emissions by $74 \%$. In addition to an increased use of natural gas and nuclear power (CP scenario), the use of renewable energy would also rise to $17 \%$ (currently $12 \%$ ). The share of coal would drop to just $26 \%$ in ACS thus potentially making the PRC a net exporter of coal by 2050 .

Compared with the HT scenarios, the impact on GDP of adopting energy efficiency policies would be small. While the impact would be negative in the BAU scenario (GDP will reduced by $0.84 \%$ in CP and $0.56 \%$ in BP), it would be positive in ACS. These macroeconomic impacts along with the impacts discussed above suggest that the policies in the $\mathrm{CP}$ and $\mathrm{BP}$ scenarios should emphasize reducing primary energy demand and reducing GHG emissions while minimizing the negative impacts on the economy.

$\mathrm{CP}$ and $\mathrm{BP}$ will have a limited ability to improve employment. In fact, up to $0.55 \%$ of jobs could be lost in these scenarios compared with HT. Job losses in the energy sector due to declining demand would be partly offset by new jobs in the non-energy sectors, particularly in the industry sector. This implies that introducing energy efficiency policies (CP and BP scenarios) would result in a transfer of employment as well as income for labor from the energy to the non-energy sectors.

Finally, introducing energy efficiency policies would raise the trade deficit in the BAU scenario, but this may not be bad especially if it contributes to rebalancing world trade patterns that have caused economic problems in the recent past. The trade deficits would largely result from increased imports of industrial goods; however, under ACS, the impacts would be negligible, and energy efficiency policies would have modestly positive impacts.

\section{India}

Figure 6.11 summarizes key macroeconomic impacts and their policy implications for India.

In the BAU-HT scenarios, there would be a more than 16-fold increase in the GDP over the next four decades from $\$ 1,700$ billion in 2010 to $\$ 28,500$ billion in 2050. If current energy efficiency trends continue, primary energy requirements 


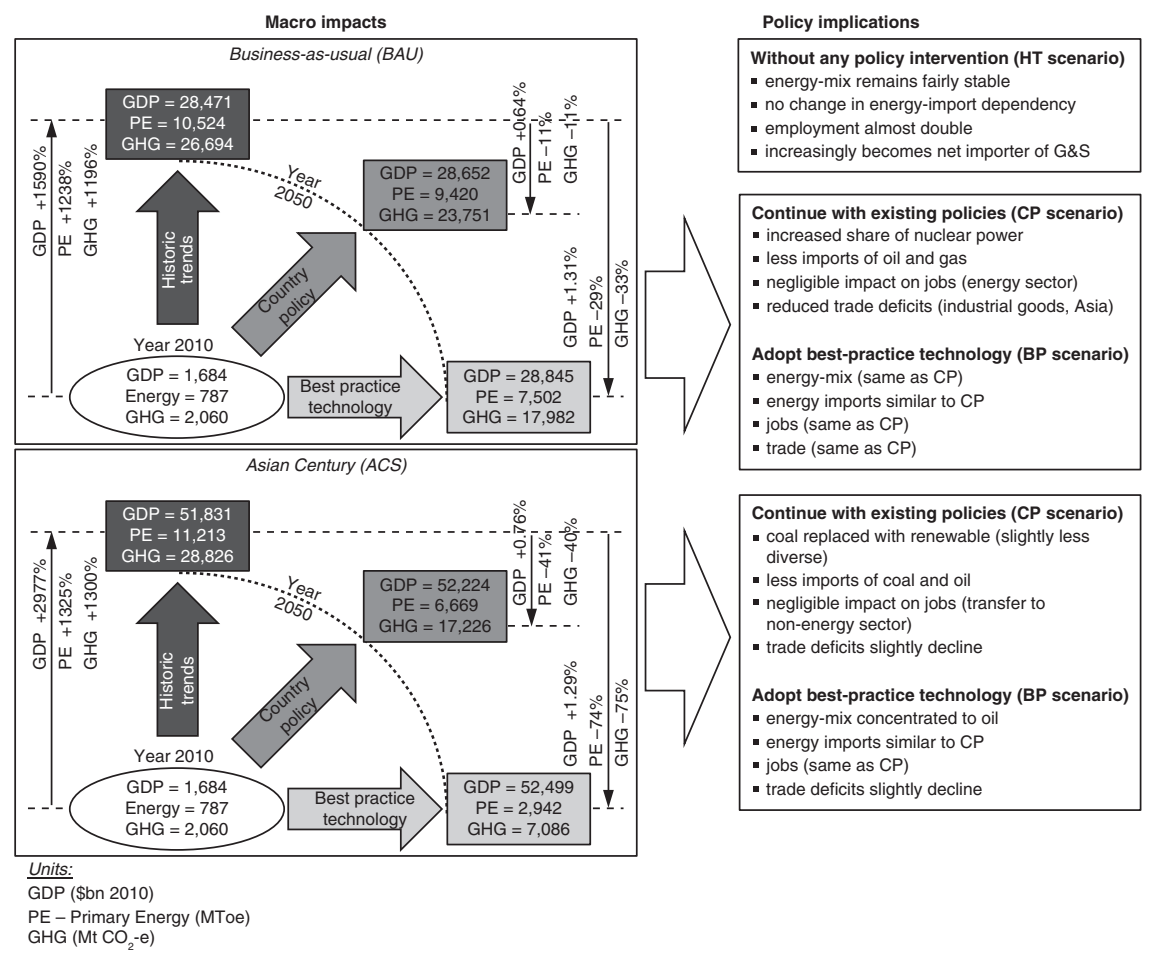

Figure 6.11 Summary of impacts and policy implications for India

Source: Authors.

Note: $\mathrm{ACS}=$ Asian Century scenario; $\mathrm{BAU}=$ business-as-usual; $\mathrm{BP}=$ best practice $\mathrm{CP}=$ country policy; $\mathrm{GDP}=$ gross domestic product; $\mathrm{GHG}=$ greenhouse gas; $\mathrm{HT}=$ historic trends; $\mathrm{PE}=$ primary energy. Units: $\mathrm{GDP}=2010$ \$billion; $\mathrm{GHG}=$ million tons of $\mathrm{CO}_{2}$ equivalent $\mathrm{PE}=$ million tons of oil equivalent.

will increase more than 13 -fold from 0.8 GToe to 10.5 GToe, and GHG emissions will increase more than 12-fold from 2 gigatons to 26.7 gigatons.

In ACS, the GDP would increase spectacularly by more than 30 times to $\$ 51,800$ billion. In contrast with the PRC, however, primary energy requirements and GHG emissions would be higher at 11.2 GToe and 28.8 gigatons than in the BAU scenario. The continuation of present energy efficiency trends to 2050 would not have any observable impact on the energy mix or on energy-import dependency. Job numbers would, however, double reflecting a growing population and increasing personal wealth. In addition, India would become a net importer of goods and services.

The severity of these impacts could be reduced by adopting a suite of policy measures aimed at improving demand and supply efficiency and increasing the use of alternative electricity generating technologies and fuels. By pursuing 
existing and currently planned policies, India could reduce its primary energy requirements and GHG emissions by nearly $40 \%$. To achieve this, a concerted effort directed at increasing the share of nuclear in the power generating mix will be needed (from 3\% currently, to $8 \%$ in both BAU and ACS). Coal-fired power plants would also need to be partly replaced by gas-fired plants. This would lead to an increased use of gas and nuclear power and hence increased natural gas and uranium imports. In BP, primary energy demand and GHG emissions could each be reduced by nearly $75 \%$. The share of coal-fired power plants in total electricity generation would drop to $62 \%$ (in both ACS and BAU) in 2050 .

Compared with the HT scenarios, the impact of adopting energy efficiency policies on the GDP would be modestly positive. Unlike the PRC, the GDP would be positively affected both in the BAU (by $0.64 \%$ in CP and $1.31 \%$ in BP) and in ACS (by $0.76 \%$ in CP and $1.29 \%$ in BP). These macroeconomic impacts along with the impacts noted above imply that the policies in the $\mathrm{CP}$ and BP scenarios should emphasize reducing primary energy demand and GHG emissions while promoting economic growth.

The CP and BP scenarios will have a limited ability to improve employment. Up to $0.5 \%$ of jobs could be lost in these scenarios in comparison with the HT scenario. Similar to the PRC, the job losses in the energy sector due to declining demand would be partly offset by new jobs in the non-energy sectors, particularly in the industry sector. This implies that adopting energy efficiency policies would result in a transfer of employment as well as income for labor from the energy to the non-energy sectors.

Finally, in terms of trade balance, introducing higher energy efficiency targets would reduce trade deficits in both BAU and ACS because of the increase in industrial output and its export potential. However, additional surpluses from the industry sector would come at the expense of increasing trade deficits in the service sector.

\section{Indonesia}

Figure 6.12 summarizes key macroeconomic impacts and their policy implications for Indonesia.

In the BAU-HT scenarios, the GDP would increase more than 7-fold from $\$ 7$ billion to $\$ 5,400$ billion by 2050 . If present energy efficiency trends continue, primary energy requirements will increase more than 6-fold from 0.2 GToe to 1.3 GToe, and GHG emissions will increase nearly 7-fold from 0.5 gigatons to 3.4 gigatons.

In ACS, the economy will be 17 times larger ( $\$ 12,100$ billion). Primary energy requirements and $\mathrm{GHG}$ emissions would be 1.65 GToe and 4.4 gigatons higher than in the BAU scenario. The continuation of present energy efficiency trends to 2050 would not have a noticeable impact on the country's energy mix. An increased use of coal will be accompanied by reduced use of oil and of renewable energy. Given that Indonesia has its own coal resources, there would be no 


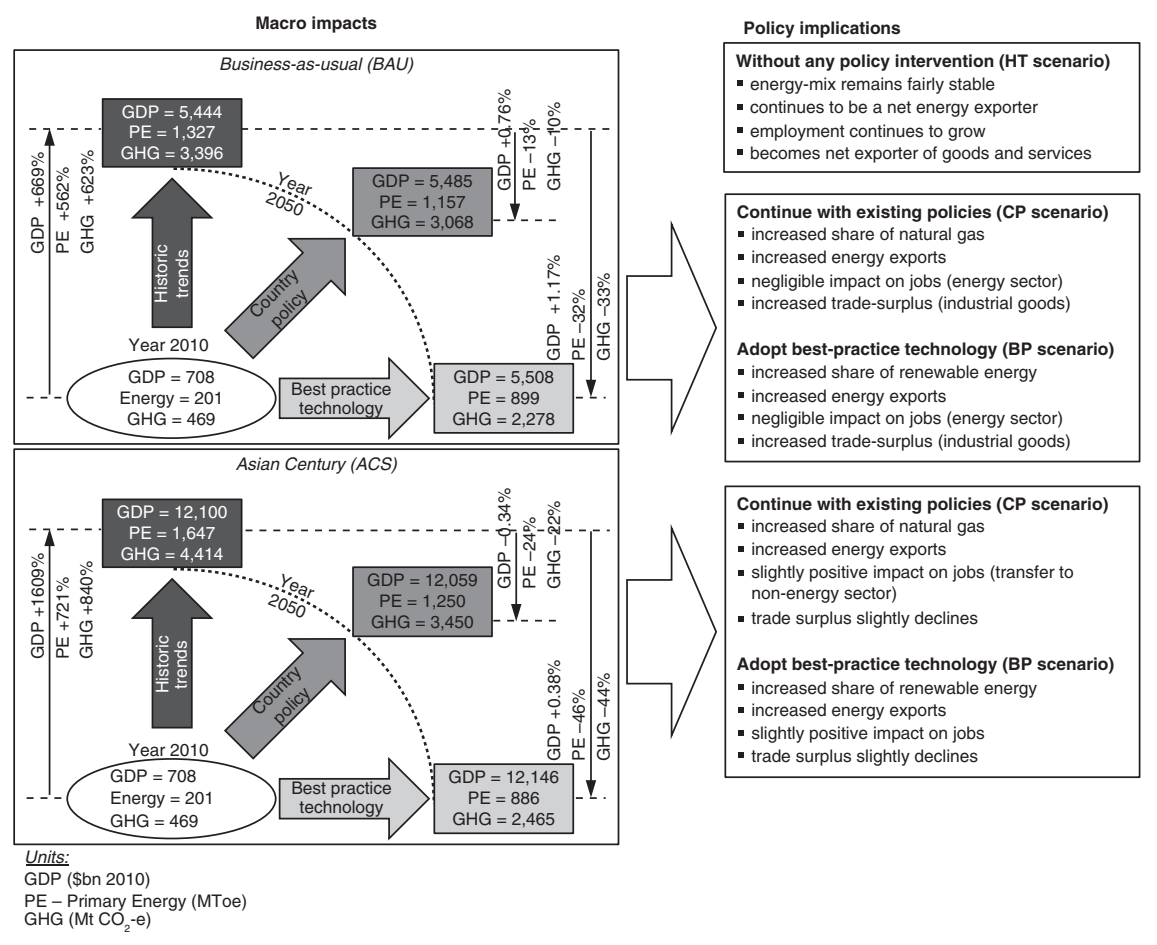

Figure 6.12 Summary of impacts and policy implications for Indonesia

Source: Authors.

Note: $\mathrm{ACS}=\mathrm{Asian}$ Century scenario; $\mathrm{BAU}=$ business-as-usual; $\mathrm{BP}=$ best practice $\mathrm{CP}=$ country policy; $\mathrm{GDP}=$ gross domestic product; $\mathrm{GHG}=$ greenhouse gas; $\mathrm{HT}=$ historic trends; $\mathrm{PE}=$ primary energy. Units: $\mathrm{GDP}=2010$ \$billion; $\mathrm{GHG}=$ million tons of $\mathrm{CO}_{2}$ equivalent; $\mathrm{PE}=$ million tons of oil equivalent.

significant impact on energy-import dependency. Jobs would grow in consonance with the growing population and personal incomes. In addition, Indonesia would become a net exporter of goods and services, a major factor driving GDP.

In CP, Indonesia could reduce its primary energy requirements by $24 \%$ and its GHG emissions by $22 \%$. To achieve this, a significant effort is needed to promote the use of natural gas for BAU and renewable energy for ACS. In BP, the primary energy demand could be reduced by $46 \%$ and GHG emissions by $44 \%$. The share of coal in the total energy mix would be further reduced and that of renewable energy would increase in both ACS and BAU.

The impact of adopting energy efficiency policies on the GDP compared with the HT scenario will be modestly positive except in the BAU-CP scenario where it will be negative. In ACS, the impact of continuing with existing policies would lead the economy to contract by $0.34 \%$ compared with the HT scenario while adopting BP technologies would cause it to expand by $0.38 \%$. 
These macroeconomic impacts and the impacts discussed above suggest that policies in the BP scenario should emphasize reducing primary energy demand and GHG emissions while contributing to economic gains.

The impact of these policies on job creation would, however, be negligible; in fact, jobs will be $0.8 \%$ fewer than in the HT scenario. Even in ACS, introducing existing policies would lead to a mere $0.1 \%$ increase in jobs in 2050 . The number of job losses in the energy sector due to declining demand would be partially offset by additional jobs in the non-energy sectors, but this will happen only if the economy grows very rapidly as in ACS. This implies that adopting energy efficiency policies in the CP and BP scenarios would result in some transfer of employment and wages from the energy to the non-energy sectors.

Finally, introducing higher energy efficiency targets would improve the trade surplus in BAU and ACS although higher growth would take place in CP. This improvement will occur due to increased exports of energy resources. Additional surpluses would also come from the industry sector.

\section{Japan}

Figure 6.13 summarizes macroeconomic impacts and their policy implications for Japan.

The economy is likely to grow at a slow rate over the 40 -year period. In the BAU-HT scenarios, the GDP would increase by just $27 \%$ (from $\$ 5,500$ billion to $\$ 7,000$ billion) by 2050 . If the present energy efficiency trends continue, primary energy requirements will not grow (currently 0.5 GToe), but GHG emissions would grow by $6 \%$ from 1.15 gigatons to 1.22 gigatons.

In ACS, economic growth for Japan would be $56 \%$ greater (GDP $\$ 8,600$ billion) in HT than its current size. Similar to the PRC, its primary energy requirements and GHG emissions would be less at 0.46 GToe and 1.1 gigatons. This implies that improvements in energy productivity could significantly promote economic growth and hence should be the focus for policymakers.

If present energy efficiency trends continue to 2050, there would be no appreciable change in the overall energy mix; however, there would be increased reliance on natural gas imports as the share of nuclear decreases. Employment (jobs) would increase modestly in line with GDP, and the trade balance would continue to improve as exports of goods and services increase.

In the CP scenario, Japan could reduce its primary energy requirements by $23 \%$ and GHG emissions by $26 \%$. For generating electricity this will, however, require reducing reliance on fossil fuels and nuclear power and increasing the use of renewable energy thus also reducing reliance on energy imports. If Japan adopts the BP scenario, primary energy demand could be reduced by $37 \%$ and GHG emissions by $41 \%$.

Even though Japan is an energy-efficient economy, it could benefit from energy efficiency policies. Its GDP would be positively affected both in BAU (increasing by $1 \%$ in $\mathrm{CP}$ and $2 \%$ in $\mathrm{BP}$ ), and $\mathrm{ACS}$ (increasing by $1.1 \%$ in $\mathrm{CP}$ and $1.7 \%$ in $\mathrm{BP}$ ). 


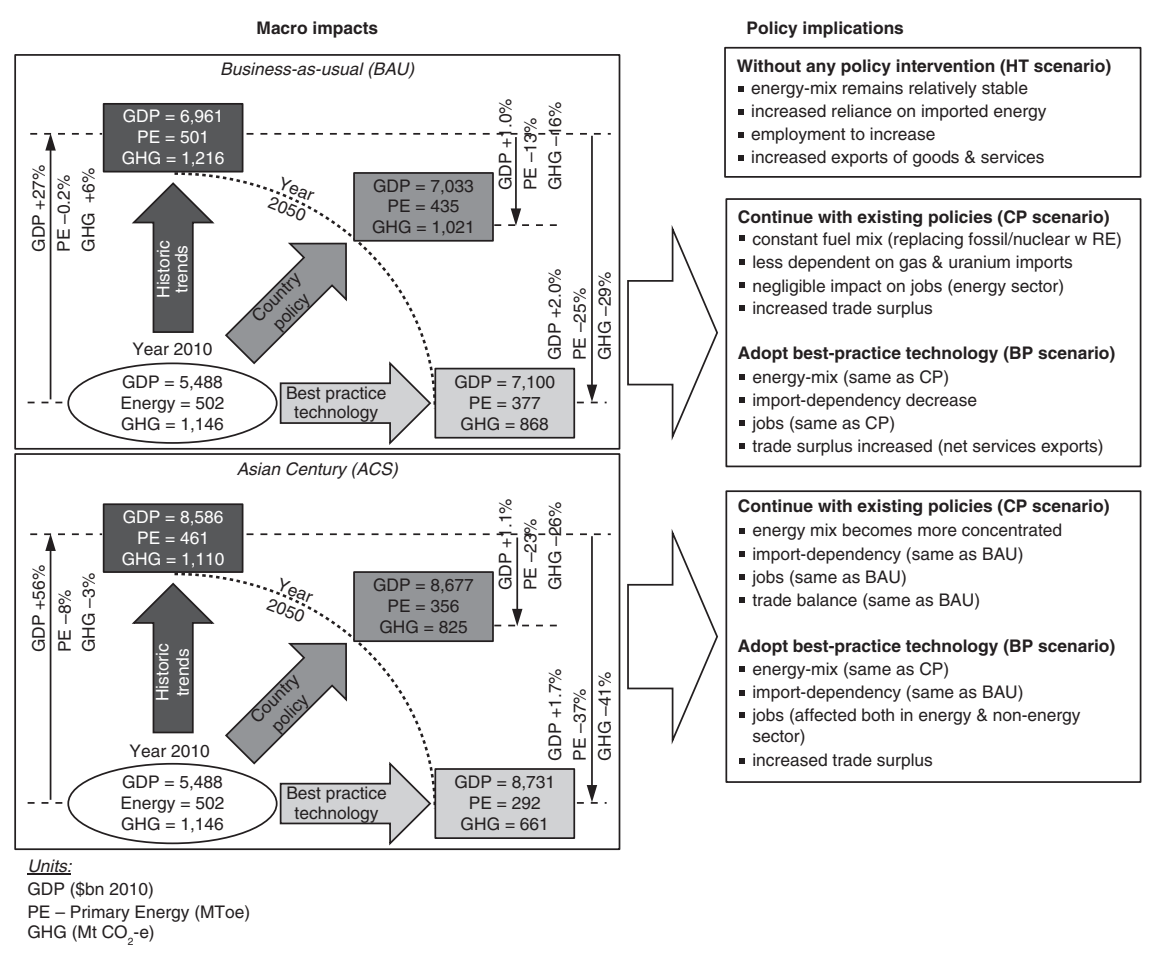

Figure 6.13 Summary of impacts and policy implications for Japan

Source: Authors.

Note: $\mathrm{ACS}=$ Asian Century scenario; $\mathrm{BAU}=$ business-as-usual; $\mathrm{BP}=$ best practice; $\mathrm{CP}=$ country policy; $\mathrm{GDP}=$ gross domestic product; $\mathrm{GHG}=$ greenhouse gas; $\mathrm{HT}=$ historic trends; $\mathrm{PE}=$ primary energy. Units: $\mathrm{GDP}=2010$ \$billion; $\mathrm{GHG}=$ million tons of $\mathrm{CO}_{2}$ equivalent; $\mathrm{PE}=$ million tons of oil equivalent.

The trade balance will improve in both BAU and ACS with higher growth in BP as the industry sector increases output for international markets. In fact, in the BAU scenario, Japan could become a net exporter of services in the long term.

\section{The Republic of Korea}

Figure 6.14 summarizes macroeconomic impacts and their policy implications for the Republic of Korea.

In the BAU-HT scenarios, the GDP would more than double (from $\$ 1,000$ billion to $\$ 2,200$ billion) in the next 40 years. If present energy efficiency trends continue, primary energy requirements will increase by $66 \%$ from 241 MToe to 400 MToe and GHG emissions will increase by $78 \%$ from 526 million tons to 936 million tons. In ACS, economic output would triple to $\$ 4,100$ billion. To support this growth, primary energy requirements would have to increase by $145 \%$ 


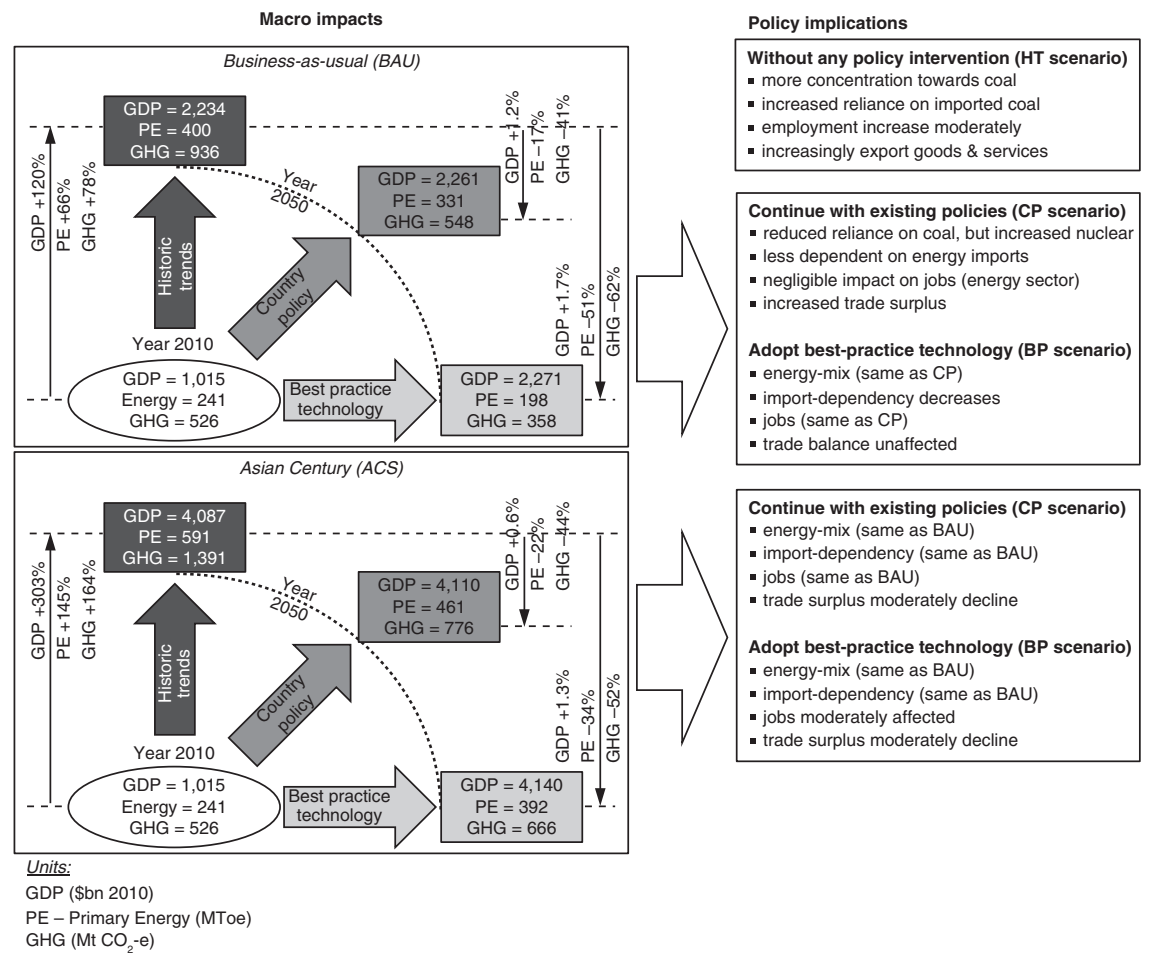

Figure 6.14 Summary of impacts and policy implications for the Republic of Korea Source: Authors.

Note: $\mathrm{ACS}=$ Asian Century scenario; $\mathrm{BAU}=$ business-as-usual; $\mathrm{BP}=$ best practice $\mathrm{CP}=$ country policy; $\mathrm{GDP}=$ gross domestic product; $\mathrm{GHG}=$ greenhouse gas; $\mathrm{HT}=$ historic trends; $\mathrm{PE}=$ primary energy. Units: $\mathrm{GDP}=2010$ \$billion; $\mathrm{GHG}=$ million tons of $\mathrm{CO}_{2}$ equivalent; $\mathrm{PE}=$ million tons of oil equivalent.

to 591 MToe and GHG emissions would increase by $164 \%$ to 1.4 gigatons. Continuing current energy efficiency trends to 2050 would reduce energy diversity leading to increased dependence on imported coal. Overall, however, aggressive energy efficiency would improve the trade balance and provide moderate employment gains.

In $\mathrm{CP}$, primary energy requirements will decrease by $22 \%$, and GHG emissions will decrease by $44 \%$. To achieve this, coal must be substituted with nuclear; the share of nuclear will increase from $13 \%$ in HT to $33 \%$ in CP. This will reduce dependence on imported coal. In BP, primary energy requirements could be reduced by $51 \%$ and GHG emissions by $62 \%$. Unlike other countries, these reductions would occur in the BAU scenario. The share of coal-fired power plants in total electricity generation would decrease to $62 \%$ in both ACS and BAU; however, the magnitude of the impact on energy diversity and energyimport dependency would be the same as in the other scenarios. 
Compared with HT, the GDP would be positively affected by adopting energy efficiency policies. From 2010 to 2050 in BAU, GDP will increase by $1.2 \%$ and $1.7 \%$ in the CP and BP scenarios, respectively, and in ACS, growth will be $0.6 \%$ and $1.1 \%$ in the $\mathrm{CP}$ and $\mathrm{BP}$ scenarios, respectively.

Overall, the employment impacts of energy efficiency policies will be modestly negative. There will be 1.1\% fewer jobs in ACS-BP compared with ACS-HT; this is equivalent to 0.3 million persons in 2050 (around $0.6 \%$ of the estimated population). Moreover, the number of job losses in the energy sector due to declining demand would be partially offset by new jobs in the non-energy sectors particularly in the service sector.

Introducing higher energy efficiency targets would improve the trade balance, particularly in the BAU scenario as the industry sector increases output for international markets; however, if BP is adopted, increasing exports of industrial goods would be offset by increasing imports of services.

\section{Malaysia}

Figure 6.15 summarizes macroeconomic impacts and their policy implications for Malaysia.

In the BAU-HT scenarios, GDP would increase more than 6-fold by 2050 from $\$ 200$ billion to $\$ 1,400$ billion. In HT, primary energy requirements would increase more than 4-fold from 66 MToe to 304 MToe, and GHG emissions would increase from 184 million tons to 879 million tons. In ACS, the economy would be more than 11 times greater at $\$ 2,700$ billion, but primary energy requirements and GHG emissions would be higher compared with BAU by 450 MToe and 1.4 gigatons.

If present energy efficiency trends continue to 2050 (HT), there would be a noticeable impact on the energy mix but no significant impact on energy-import dependency. Job numbers would double reflecting population growth and increasing wealth. In addition, Malaysia would become a net exporter of goods and services, a major factor in the GDP.

By pursuing currently planned policies (CP), Malaysia could reduce its primary energy requirements by $53 \%$ and GHG emissions by $54 \%$. To achieve this, the share of renewable energy in the primary energy mix must increase from $3 \%$ currently to $7 \%$ in 2050 . In BP, primary energy demand could be reduced by $75 \%$ and GHG emissions by $74 \%$. The share of coal in the total energy mix would decrease and would be replaced by nuclear (in both ACS and BAU).

Compared with the HT scenarios, the impact of adopting energy efficiency policies on GDP would be significant. It will increase by $1.7 \%$ in BAU-CP or by $8.9 \%$ in ACS-BP. These impacts suggest that the policies in the BP scenario would be most beneficial for Malaysia.

These policies will also be favorable in terms of creating jobs as they could add up to $2.8 \%$ more in ACS-BP compared with the HT scenario. The job losses in the energy sector due to declining demand would be more than offset by new jobs in all non-energy sectors, specifically in the service sector. 


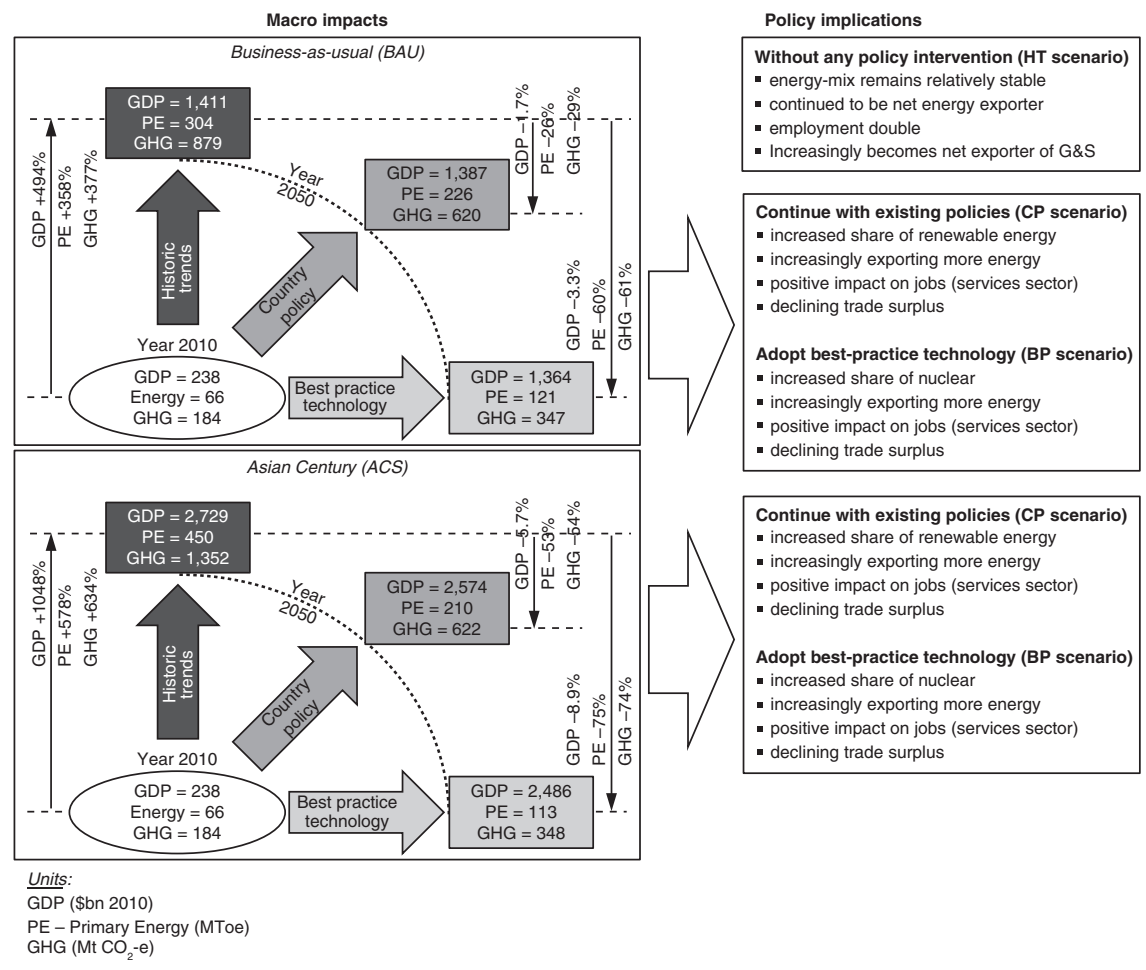

Figure 6.15 Summary of impacts and policy implications for Malaysia

Source: Authors.

Note: $\mathrm{ACS}=$ Asian Century scenario; $\mathrm{BAU}=$ business-as-usual; $\mathrm{BP}=$ best practice $\mathrm{CP}=$ country policy; $\mathrm{GDP}=$ gross domestic product; $\mathrm{GHG}=$ greenhouse gas; $\mathrm{HT}=$ historic trends; $\mathrm{PE}=$ primary energy. Units: $\mathrm{GDP}=2010$ \$billion; $\mathrm{GHG}=$ million tons of $\mathrm{CO}_{2}$ equivalent; $\mathrm{PE}=$ million tons of oil equivalent.

Finally, introducing higher energy efficiency targets would affect the trade balance. Malaysia is likely to become a net importer of services; currently it is a net exporter.

\section{Thailand}

Figure 6.16 summarizes macroeconomic impacts and their policy implications for Thailand.

In the BAU-HT scenarios, the GDP would increase by more than five times from $\$ 300$ billion in 2010 to $\$ 1,900$ billion in 2050 . Primary energy requirements will increase significantly from 109 MToe to 557 MToe, and GHG emissions will increase from 0.3 gigatons to 1.4 gigatons. In ACS, the GDP will be $\$ 3300$ billion; however, primary energy requirements and GHG emissions would 


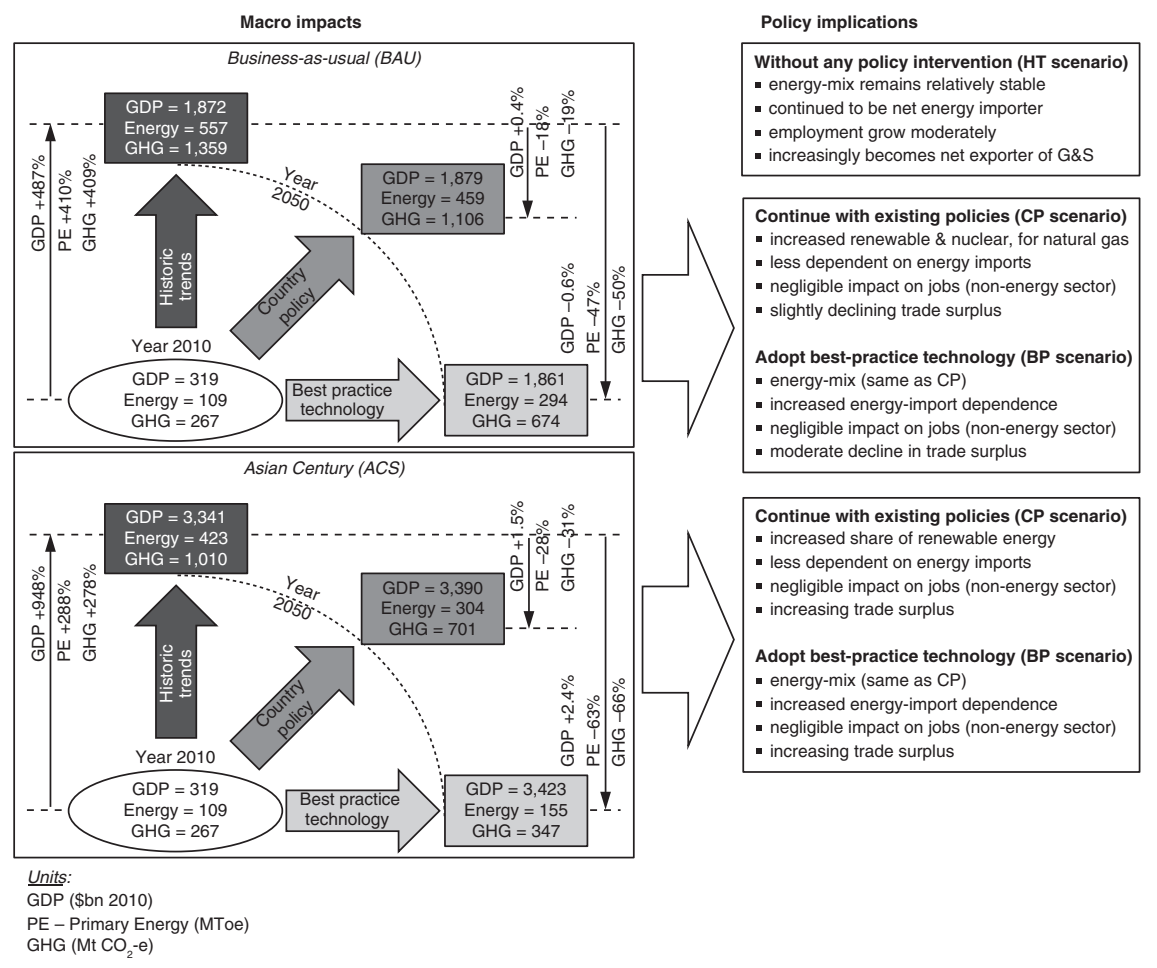

Figure 6.16 Summary of impacts and policy implications for Thailand

Source: Authors.

Note: $\mathrm{ACS}=$ Asian Century scenario; $\mathrm{BAU}=$ business-as-usual; $\mathrm{BP}=$ best practice $\mathrm{CP}=$ country policy; $\mathrm{GDP}=$ gross domestic product; $\mathrm{GHG}=$ greenhouse gas; $\mathrm{HT}=$ historic trends; $\mathrm{PE}=$ primary energy. Units: $\mathrm{GDP}=2010$ \$billion; $\mathrm{GHG}=$ million tons of $\mathrm{CO}_{2}$ equivalent; $\mathrm{PE}=$ million tons of oil equivalent.

decrease by 423 MToe and 1.0 gigatons compared with the BAU scenario. This implies that improving energy productivity would contribute significantly to economic growth and should therefore be a focus of the energy policy.

The HT scenario will have a minimal impact on the overall energy mix. Thailand will continue to be a net energy importer given its reliance on imported fossil fuels. The number of jobs would increase moderately in line with increasing GDP. The trade balance would improve considerably in the BAU scenario due to increased exports of goods and services. In ACS, the country would become a net importer of services, but it would export more industrial goods and agricultural commodities.

By pursuing currently planned policies (CP scenario), Thailand could reduce its primary energy requirements by $28 \%$ and GHG emissions by $31 \%$. To achieve this, a significant effort will be needed to reduce the share of imported fossil 
energy and to increase the share of renewable energy for generating electricity. The share of nuclear power would also increase; it will create the need to import uranium. If the country adopts the BP scenario, primary energy demand could be reduced by $63 \%$ and GHG emissions by $66 \%$.

Compared with the HT scenarios, the impact of adopting energy efficiency policies on the GDP would be favorable similar to the impact in India and Japan. The GDP would increase in ACS by $1.5 \%$ in CP and $2.4 \%$ in BP. Implementing current policies under the BAU scenario would also provide a $0.4 \%$ gain in GDP. These impacts suggest that policies in the CP and BP scenarios would result in reduced primary energy demand and GHG emissions while maintaining (in fact enhancing) economic growth.

These polices will have a marginally negative impact on employment as there will be $0.45 \%$ fewer jobs compared with the HT scenario, but jobs lost in the energy sector due to declining demand would be more than offset by new jobs in other sectors particularly agriculture, industry, and services. ACS would have a higher positive impact on employment.

Higher energy efficiency targets would improve the trade balance particularly in ACS as all non-energy sectors increase their outputs for international markets.

\section{Summary}

The policy trade-offs among key economic, energy, and environmental attributes over the long term vary across countries. Reductions in energy demand and in GHG emissions would accompany higher GDP growth in all cases in India, Japan, and the Republic of Korea. In the PRC, Indonesia, and Thailand there would be positive impacts on GDP in some cases and negative impacts in others. Malaysia, on the other hand, would face negative impacts on GDP under all the scenarios though some attributes like employment would improve with the implementation of policies. Care must therefore be taken in selecting appropriate energy efficiency targets to achieve policy objectives.

\section{References}

Asia Pacific Energy Research Centre (APERC). 2013. APEC Energy Demand and Supply Outlook 5th Edition. Tokyo: APERC.

Asian Development Bank (ADB). 2011. Asia 2050: Realizing the Asian Century. Manila: ADB.

International Energy Agency (IEA). 2012a. World Energy Outlook. Paris: Organisation for Economic Co-operation and Development.

—. 2012b. World Energy Statistics. Paris: Organisation for Economic Co-operation and Development.

Medlock III, K. B. 2009. Energy Demand Theory. In J. Evans and L. C. Hunt, eds. International Handbook on the Economics of Energy. Cheltenham: Edward Elgar.

Narayanan, B., A. Aguiar and R. McDougall, eds. 2012. Global Trade, Assistance, and Production: The GTAP 8 Data Base. Center for Global Trade Analysis, Purdue University, IN. 


\section{Deepak Sharma, Suwin Sandhu, Suchi Misra}

Rose, A. 1984. Technological Change and Input-Output Analysis: An Appraisal. SocioEconomic Planning Sciences. 18 (5). pp. 305-318.

Sandu, S. 2007. Assessment of Carbon Tax as a Policy Option for Reducing Carbondioxide Emissions in Australia, PhD Dissertation. Sydney: University of Technology.

Sorrell, S. 2009. Jevons' Paradox Revisited: The Evidence for Backfire from Improved Energy Efficiency. Energy Policy. 37. pp. 1456-1469.

World Bank. 2012. World Development Indicators. http://data.worldbank.org/data-catalog/ world-development-indicators (accessed February 2014).

World Resources Institute (WRI). 2012. Climate Analysis Indicators Tool Version 8.0.

United Nations (UN). Economic and Social Commission for Asia and the Pacific (ESCAP), Statistical Division. 2012. ESCAP Data Centre: Employment. http://www.unescap.org/ stat/data/statdb/DataExplorer.aspx (accessed February 2014).

- Department of Economic and Social Affairs, Population Division. 2012. World Population Prospects: The 2012 Revision. http://esa.un.org/unpd/wpp/index.htm (accessed 31 March 2014). 


\section{Part IV \\ Options for energy supply and integration}





\title{
7 Diversification of energy supply \\ Prospects for emerging energy sources
}

\author{
Michael M. D. Ross
}

\section{Introduction}

As Asia develops, its demand for energy is expected to grow (ADB 2013). Current forms of supply may be insufficient or may be unacceptable from an energy security or environmental perspective. To fill the gap, a range of emerging energy sources has been proposed. ${ }^{1}$ Their prospects depend on the available resources, costs compared with competing alternatives, environmental impacts, and investment and infrastructure requirements.

Unconventional gas, photovoltaics, and wind power have developed rapidly over the past two decades and are seen as promising avenues for Asia. Questions related to the extent of the Asian resource, the capacity of Asian economies to exploit the resource, and the environmental impacts of fracking dominate discussions about unconventional gas. In contrast, wind and photovoltaics draw on strong resources and have limited environmental impacts but are hindered by high — but declining — capital costs. These issues are examined in this chapter.

\section{Unconventional gas}

Shale gas, tight gas, and methane from coal deposits (see Appendix to this chapter) are the forms of unconventional gas discussed here. Shale gas has transformed the North American gas supply (Figure 7.1) and merits special attention. Tight gas has a longer history of exploitation but is unlikely to have the same impact as shale. Methane from coal has not seen explosive growth like shale gas but has nevertheless progressed over the past two decades.

Unconventional forms of gas, particularly shale gas, have been most thoroughly developed in North America. Before exploring their prospects in Asia, the North American situation will be surveyed.

\section{How revolutionary is shale gas?}

In North America, the "shale gas revolution," it is claimed, has been a "game changer": over a few years, unconventional sources of gas, previously ignored by

\footnotetext{
${ }^{1}$ Information on other emerging energy sources in Asia available from Ross 2013.
} 


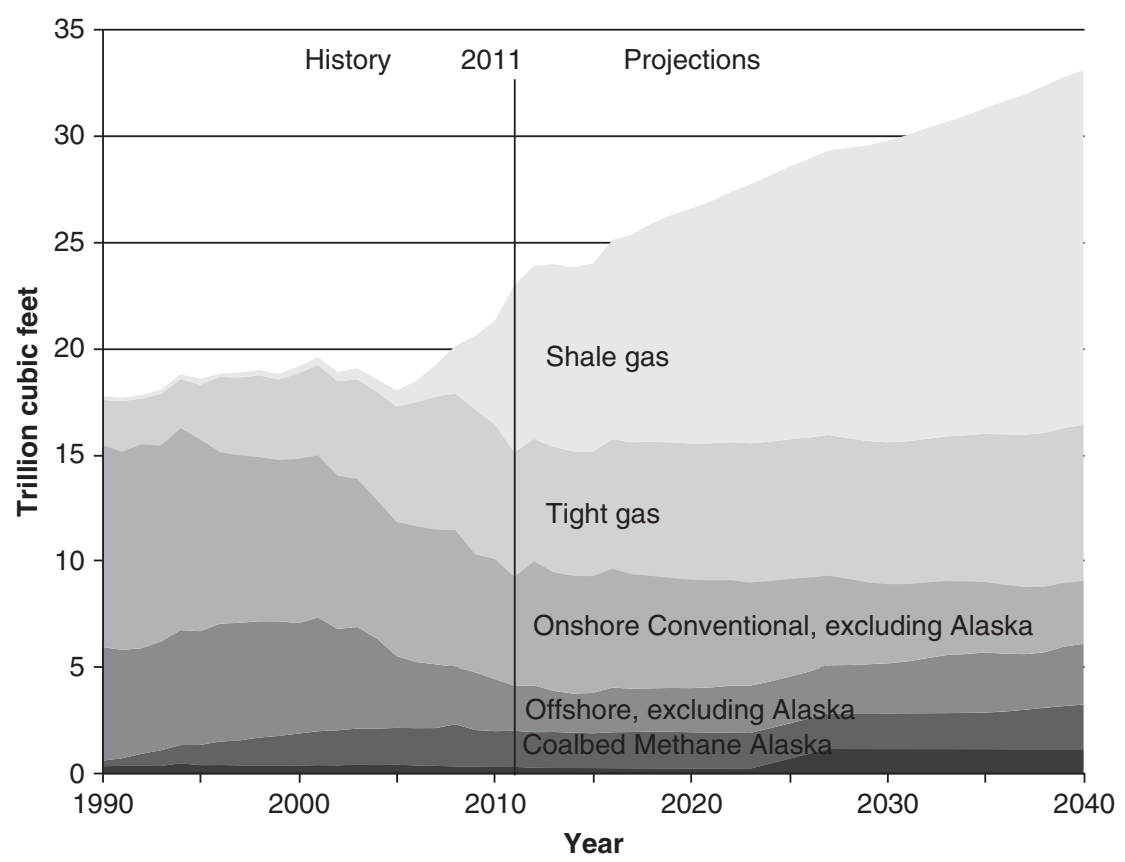

Figure 7.1 Dry natural gas production by source in the United States (trillion cubic feet per year)

Source: Government of the United States, EIA 2012c.

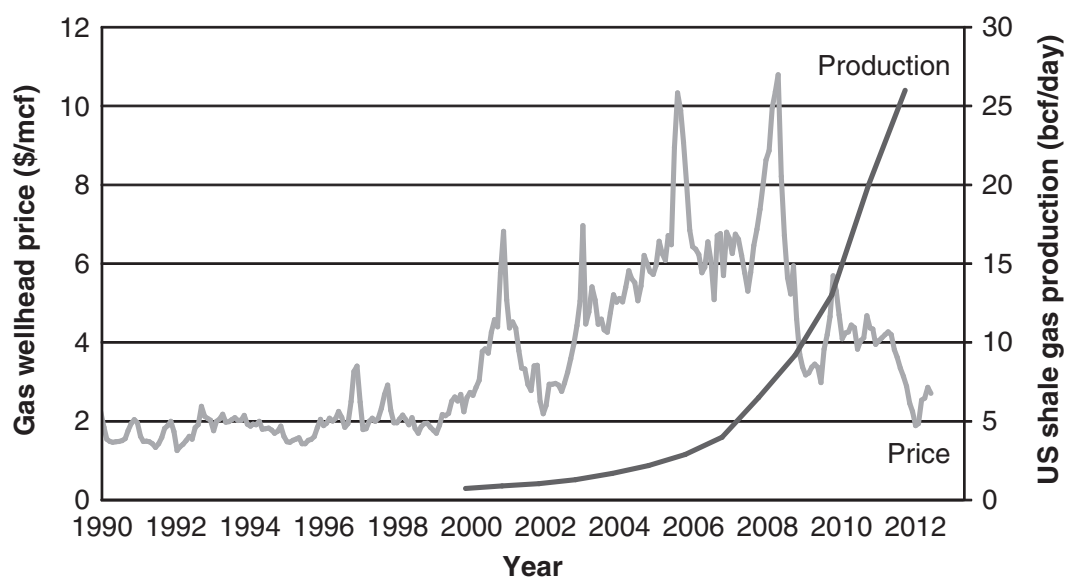

Figure 7.2 Natural gas price at the wellhead and shale gas production in the United States Sources: Government of the United States, EIA 2012a and 2012b; Hughes 2000-2012.

Note: Total dry natural gas production in the United States in 2012 was around 63 billion cubic feet/ day (bcf/day). 
the major oil and gas companies, have significantly expanded supply, causing prices - and imports - to tumble (Figure 7.2). Advanced drilling techniques (notably horizontal drilling and fracking) have made it possible to extract gas at high production rates from vast shale formations at a price that is competitive with conventional gas.

If vast shale gas reservoirs can be tapped at prices less than $\$ 3.00 /$ million cubic feet, this is indeed revolutionary; there are, however, caveats.

- Many shale gas wells may not be profitable at these low prices (Fontevecchia 2012). Supply is strong despite low prices because of gas associated with drilling for more valuable oil and natural gas liquids (Government of the United States, EIA 2012c; Parkinson 2012; Tertzakian 2012).

- Depletion rates are very quick (Figure 7.3). A conventional gas well might produce at a fairly steady rate for 30 to 40 years while gas flows through the interconnected pores of the formation. The low permeability of shale, however, impedes surrounding gas from rapidly replenishing the fractures, so production declines drastically in a few years. Short lifetimes require new wells every few years just to compensate for those in decline. According to one analysis, replacing declining North American shale wells costs around $\$ 90$ billion per year, yet the wells may be producing a cash flow of only \$50 billion per year (Parkinson 2012).

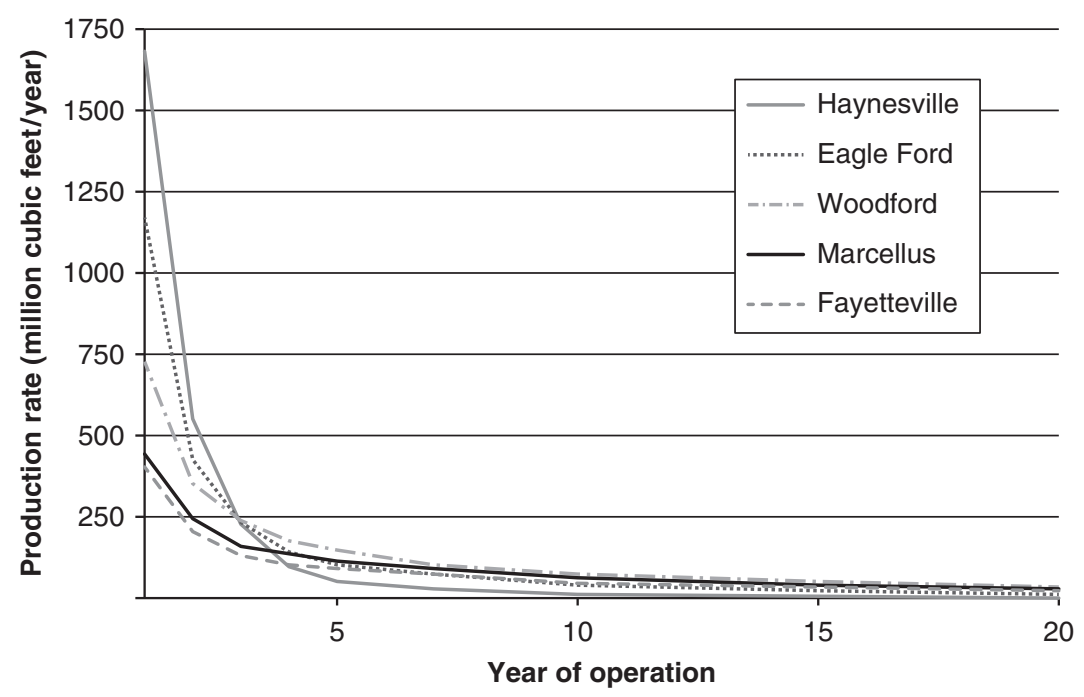

Figure 7.3 Average production profiles for shale gas wells in major shale plays in the US by years of operation

Source: Government of the United States, EIA 2012d.

Note: $E U R=$ estimated ultimate recovery. 
- The total amount of gas yielded - the estimated ultimate recovery rate-is often low. For the best wells, rates range from 1 billion to 3.6 billion cubic feet; elsewhere they may be considerably lower (Government of the United States, EIA 2011b and EIA 2012d).

- Low prices may justify drilling only in "sweet spots" - the places where the estimated ultimate recovery rates are high. Over time, the sweet spots are tapped out, and new drilling moves to less productive areas (Government of the United States, EIA 2012d).

In light of this, the United States (US) Energy Information Administration (EIA) foresees Henry Hub gas prices below \$4.10/million cubic feet through 2018 and then rising slowly to $\$ 5.55 /$ million cubic feet by 2030 . They believe that accelerated drilling for oil and natural gas liquids will yield sufficient associated gas to keep prices down in the short term and that advances in drilling efficiency will permit them to stay fairly low in the medium term (Government of the United States, EIA 2012c). Figure 7.4 shows that their projections are sensitive to the estimated ultimate recovery rates rates, which are highly uncertain for future wells.

Outside of the EIA, many industry analysts foresee post-glut prices of $\$ 4.50$ to $\$ 6.00 /$ million cubic feet (Medlock et al. 2011; Fontevechhia 2012; McGlade, Sorrell, and Speirs 2012). Even in the US, with the longest history of shale gas, there is still significant uncertainty.

At these prices, shale gas does look revolutionary, but only in the context of the years immediately preceding the boom. Looking back further in Figure 7.2,

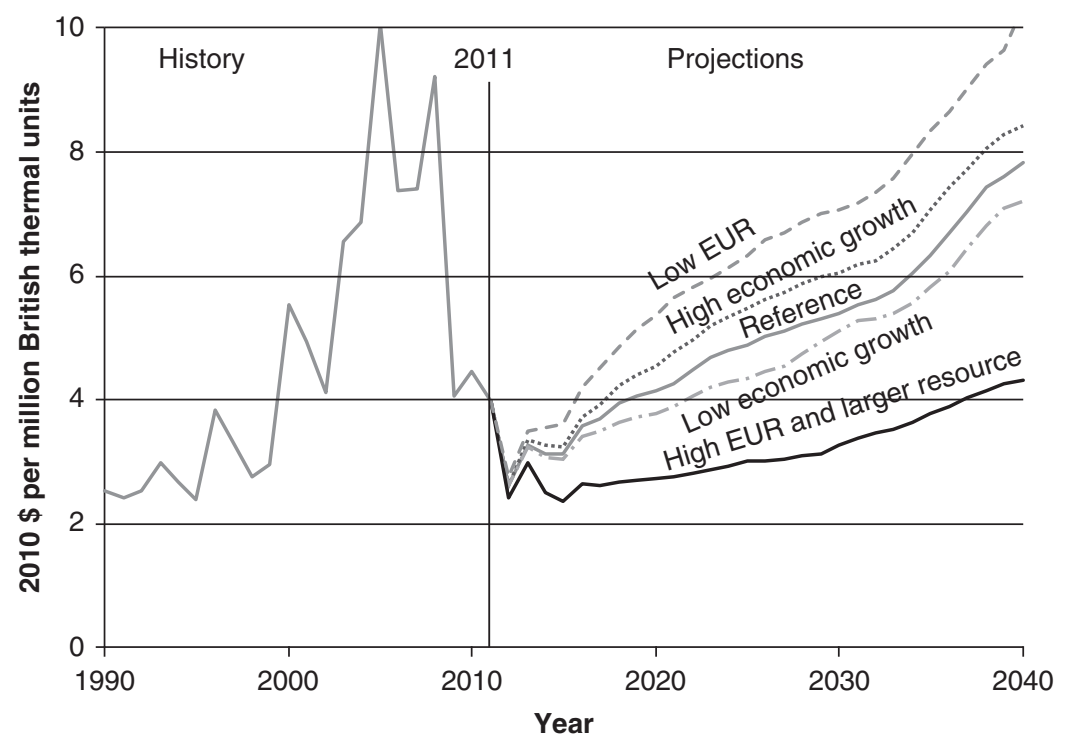

Figure 7.4 Annual average Henry Hub spot natural gas prices

Source: Government of the United States, EIA 2012d.

Note: EUR = estimated ultimate recovery. 
projected prices continue the trend of the 1990s and early 2000s. Arguably, the real upset of the last decade has not been the shale gas "revolution" but rather the magnitude of the jump in oil prices (Figure 7.5).

Even in the higher price scenarios for North America, shale gas will be cheaper than liquified natural gas (LNG) imports and some sources of conventional gas. This has stimulated interest in shale gas in many parts of Asia.

\section{Resources in Asia}

There is a lot of unconventional gas in Asia, but where it is and how much of it can technically be recovered is far from certain (IEA 2012a,b; Rogner 1997; McGlade, Sorrell, and Spiers 2012). Large parts of the continent lack information from past exploration and seismic surveys, ${ }^{2}$ and a reliable assessment simply

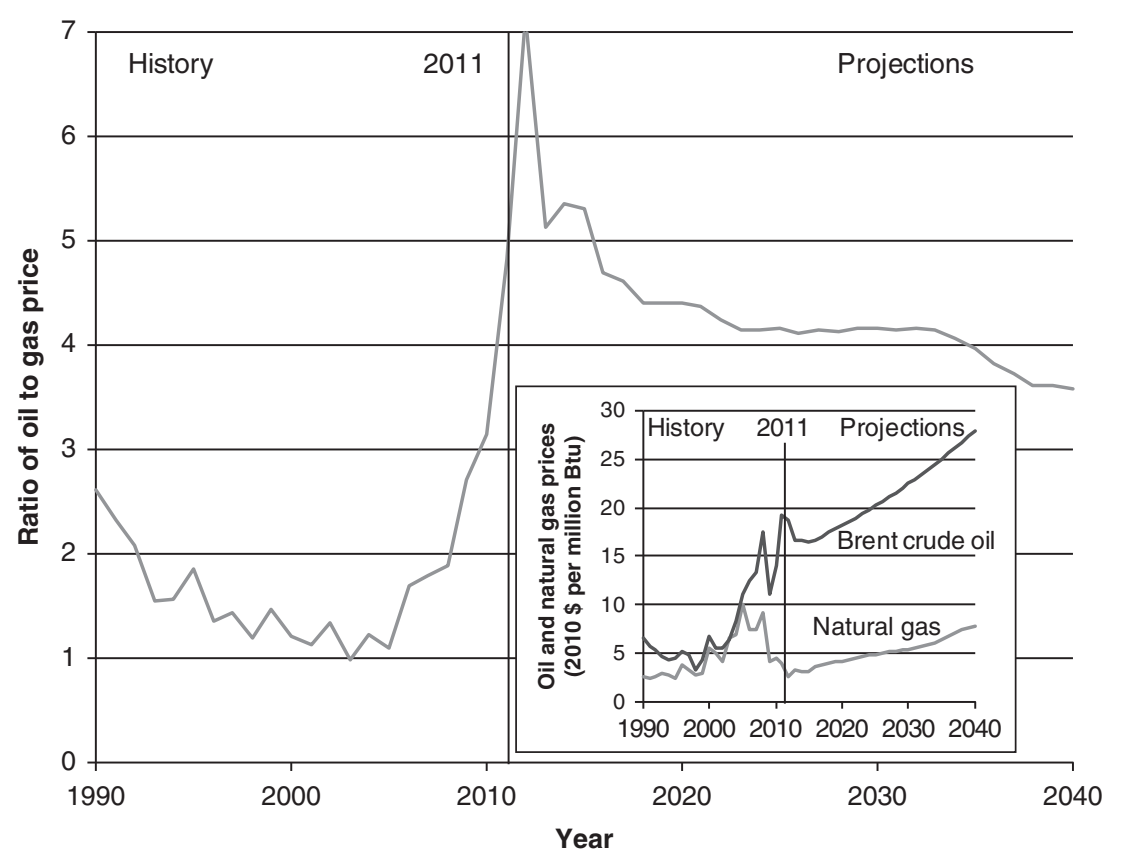

Figure 7.5 Ratio of Brent crude oil price to Henry Hub natural gas price on an energy equivalent basis

Source: Adapted from Gruenspecht (2012) using data from Government of the United States, EIA 2012d.

Note: $\mathrm{Btu}=$ British thermal unit.

${ }^{2}$ Even where exploration has been extensive, there is much uncertainty. For example, the EIA estimates of the technically recoverable resource for the US changed from 347 to 827 trillion cubic feet and back to 482 trillion cubic feet in its Annual Energy Outlook 2010, 2011, and 2012 (Government of the United States, EIA 2012d). 
Table 7.1 Regional estimates of unconventional gas in Asia

\begin{tabular}{lccc}
\hline & $\begin{array}{l}\text { Coal bed methane } \\
\text { (gigatons of } \\
\text { oil equivalent) }\end{array}$ & $\begin{array}{l}\text { Shale gas } \\
\text { (gigatons of } \\
\text { oil equivalent) }\end{array}$ & $\begin{array}{l}\text { Tight gas } \\
\text { (gigatons of } \\
\text { oil equivalent) }\end{array}$ \\
\hline South Asia & 1 & 0 & 5 \\
Centrally planned Asia & 31 & 90 & 9 \\
Other Pacific Asia & 0 & 8 & 14 \\
\hline
\end{tabular}

Source: Rogner 1997.

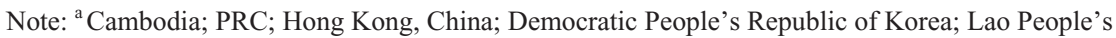
Democratic Republic; Mongolia; Viet Nam.

does not exist for most Asian countries. Furthermore, different assessment methods and assumptions yield widely varying estimates, so comparisons of the resource in different countries may be misleading or meaningless where the estimates originate in different studies. ${ }^{3}$

\section{Subregional assessments}

Table 7.1 provides estimates of unconventional gas in place for three subregions in Asia. Although this assessment is dated, it is still used as a point of departure for some detailed appraisals (IEA 2012b).

\section{Country assessments for shale gas}

To date, the EIA has made the only basin-by-basin, publicly available study for shale gas using a consistent methodology across different countries (Government of the United States, EIA 2011a). The countries studied were selected because they "demonstrate some level of relatively near-term promise" and had basins that "have a sufficient amount of geologic data for resource analysis." Countries were excluded if they had substantial conventional gas resources that would be preferentially exploited or if there was an expectation that necessary markets and infrastructure would not be built in a meaningful time frame. The PRC, India, and Pakistan satisfied these criteria (Table 7.2).

PEOPLE'S REPUBLIC OF CHINA

The shale gas resource is the largest in the world at nearly $20 \%$ of the world total, but the exact size of the technically recoverable resource remains uncertain (Table 7.3).

\footnotetext{
${ }^{3} \mathrm{~A}$ comprehensive and up-to-date discussion of these issues is provided in McGlade, Sorrell, and Spiers 2012.
} 
Table 7.2 Shale gas resources in promising Asian countries

\begin{tabular}{lclll}
\hline & $\begin{array}{l}\text { Proven } \\
\text { conventional } \\
\text { gas reserves } \\
\text { (gigatons of } \\
\text { oil equivalent) }\end{array}$ & $\begin{array}{l}\text { Technically } \\
\text { recoverable } \\
\text { shale gas } \\
\text { resources } \\
\text { (gigatons of } \\
\text { oil equivalent) }\end{array}$ & $\begin{array}{l}\text { Fraction of } \\
\text { total shale } \\
\text { resources of } \\
34 \text { countries }\end{array}$ & $\begin{array}{l}\text { Shale gas } \\
\text { studied } \\
\text { rank among } \\
\text { studied }\end{array}$ \\
$\begin{array}{lccll}\text { studies } \\
\text { People's Republic } \\
\text { of China }\end{array}$ & 2.8 & 33.1 & $19.3 \%$ & 1 \\
$\begin{array}{l}\text { India } \\
\text { Pakistan }\end{array}$ & 1.0 & 1.6 & $1.0 \%$ & 15 \\
World & 0.8 & 1.3 & $0.8 \%$ & 17 \\
\hline
\end{tabular}

Source: Government of the United States, EIA 2011a.

Note: "The "countries" include Western Sahara and a grouping of countries in Europe together holding less than 0.5 gigatons of oil equivalent of shale gas. $\mathrm{NA}=$ not applicable.

Table 7.3 Estimates of technically recoverable shale gas resources in the People's Republic of China

\begin{tabular}{lll}
\hline Source of estimate & $\begin{array}{l}\text { Resource (gigatons } \\
\text { of oil equivalent) }\end{array}$ & Reference \\
\hline EIA/ARI & 33.1 & EIA 2011a \\
$\begin{array}{l}\text { PRC National Petroleum } \\
\quad \text { Corporation }\end{array}$ & 28.1 & Nakano et al. 2012 \\
$\begin{array}{l}\text { PRC Gov. Ministry of } \\
\text { Land and Resources }\end{array}$ & 23.0 & IEA 2012a \\
Research paper & $13.8-22.9$ & Jia et al. 2012 \\
Research paper & 6.0 & Medlock et al. 2011 \\
\hline
\end{tabular}

Note: PRC = People's Republic of China; EIA/ARI = Energy Information Administration based on a study by Advanced Resources International.

Instead of a single, highly uncertain estimate, one study sensibly suggests providing a range that for the PRC was 1.5 to 36.5 gigatons of oil equivalent (GToe) with a best estimate of 19.4 GToe (McGlade, Sorrell, and Spiers 2012).

The EIA/ARI study appraises two marine deposited sedimentary basins, the Sichuan and the Tarim, that it believes to have "excellent potential" for shale gas development. It also introduces five other basins with non-marine deposited shales that it deems "sizeable but less prospective" (Government of the United States, EIA 2011a). The locations are shown in Figure 7.6.

\section{SUBCONTINENT}

The shale gas resources of India and Pakistan have received less attention and are more uncertain than those of the PRC. The EIA/ARI study identified five 


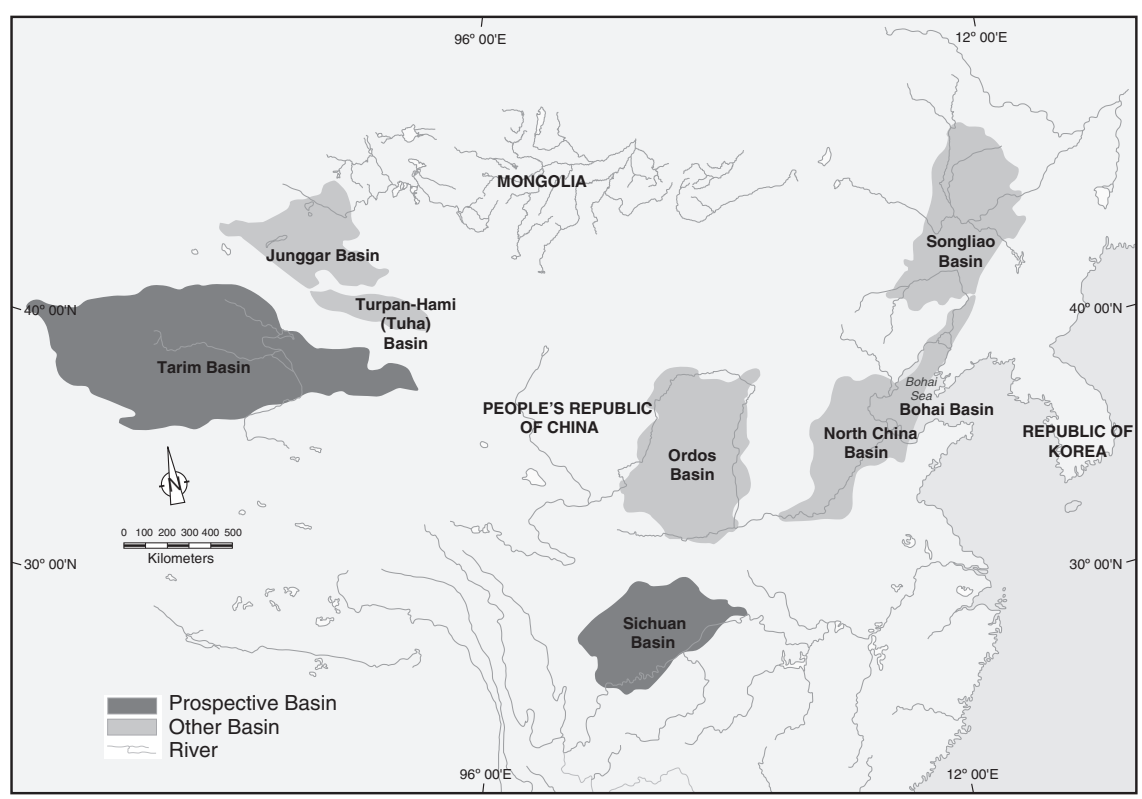

Figure 7.6 Major shale basins of the People's Republic of China

Source: Approximation based on the Government of the United States, EIA 2011a.

priority basins (in dark shading in Figure 7.7) and identified several others (light shading) that were either unsuitable for gas production or lacked the data required for a resource assessment. It estimated the risked gas in place for these basins to be 7,536 million tons of oil equivalent (MToe) for India and 5,346 MToe for Pakistan; it estimated the technically recoverable resources to be 1,653 MToe and 1,323 MToe. Table 7.4 shows the wide range in estimates of India's technically recoverable resources.

INDONESIA

Shale gas resources may be substantial (Dittrick 2012) but have been subjected to scant independent scrutiny. An oft-cited but elusive study by the Bandung Technical University apparently estimated the "resource" at 26 GToe (Wah 2011), although it is unclear if this is gas in place or technically recoverable resource (the former seems more likely). The resource is concentrated in Papua and in Sumatra. The Ministry of Energy and Mineral Resources advertises 8.7 GToe of "shale gas potential" (Focus Reports 2012). Companies are already announcing assessments of their production sharing contract areas (Bintang 2012). 


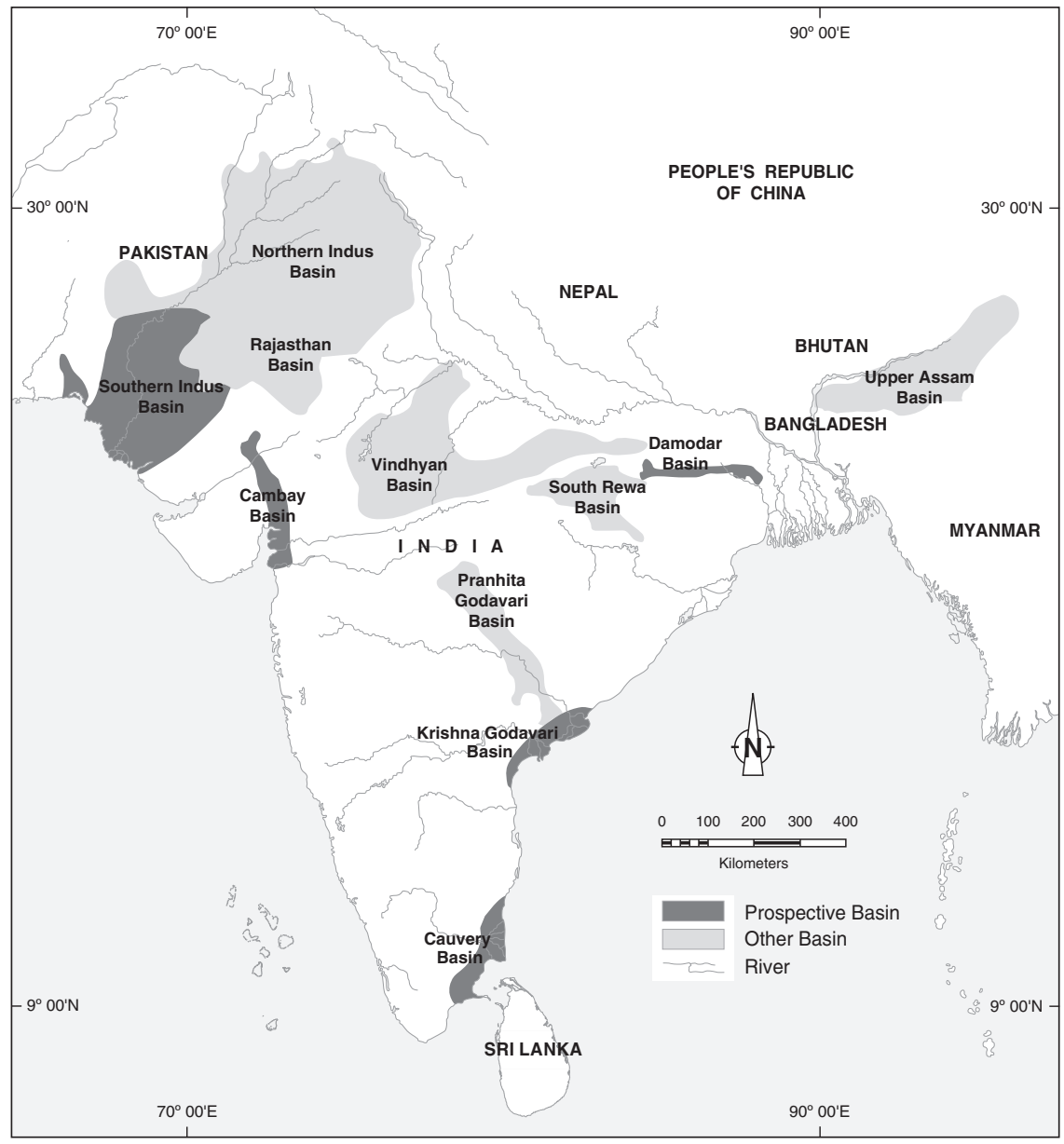

Figure 7.7 Shale gas basins of India and Pakistan

Source: Approximation based on the Government of the United States, EIA 2011a.

Table 7.4 Estimates of technically recoverable shale gas resources in India

\begin{tabular}{lll}
\hline Source of estimate & $\begin{array}{l}\text { Resource (million tons } \\
\text { of oil equivalent) }\end{array}$ & Reference \\
\hline $\begin{array}{l}\text { EIA/ARI (Cauvery, Krishna } \\
\text { Godavar, Cambay, Damodar) }\end{array}$ & 1635 & EIA 2011a \\
$\begin{array}{l}\text { EIA/ARI (Cauvery, Krishna } \\
\text { Godavar, Cambay) }\end{array}$ & 1453 & EIA 2011a \\
$\begin{array}{l}\text { USGS (Cauvery, Krishna } \\
\text { Godavar, Cambay) }\end{array}$ & 159 & USGS 2011 \\
\hline
\end{tabular}

Source: Author.

Note: ARI = Advanced Resources International, Inc.; EIA = Energy Information Administration; USGS $=$ United States Geological Survey. 
OTHERS

There is little publicly available information on the rest of Asia (McGlade, Sorrell, and Spiers 2012). One study inferred from the total lack of reports that there is no shale gas in the Republic of Korea. There is interest in Kazakhstan (RFERL 2012), but resource assessments are not yet available. Cursory assessments for Azerbaijan, Malaysia, Mongolia, Turkmenistan, Uzbekistan and Viet Nam may exist (Hart Energy Research Group 2011) but are not public and will be uncertain due to lack of data.

\section{Country assessments for coal bed methane and coal mine methane}

There is no study of the coal bed methane (CBM) resource that applies a consistent methodology across all countries. Countries have, however, published their own data for CBM resources and methane emissions from operating mines (Government of the United States, EPA 2010); the results for Asia are summarized in Table 7.5. The figures often rely on approximate methods and incomplete data, and it is unlikely that all the countries use the same definition for "resource"; probably these figures should be considered gas in place. Undoubtedly the PRC, Indonesia, and India have vast resources. ${ }^{4}$

Table 7.5 Annual methane emissions from operating coal mines and coal bed methane resources

\begin{tabular}{lcc}
\hline & $\begin{array}{l}\text { Estimated coal mine methane } \\
\text { emissions from operating } \\
\text { mines in 2010 (kilotons } \\
\text { of oil equivalentyear) }\end{array}$ & $\begin{array}{l}\text { Coal bed methane } \\
\text { resources } \\
\text { (gigatons of } \\
\text { oil equivalent) }\end{array}$ \\
\hline $\begin{array}{l}\text { People's Republic } \\
\text { of China }\end{array}$ & 9,873 & 33.7 \\
$\begin{array}{l}\text { India } \\
\text { Indonesia }\end{array}$ & 1,481 & $1.8-3.1$ \\
Kazakhstan & $32(2005)$ & $8.7-11.8$ \\
Mongolia & $899(2009)$ & $0.6-0.8$ \\
Pakistan & 2.7 & $\ldots$ \\
Philippines & $64(1993-1994)$ & Unknown but \\
Republic of Korea & 15 & 0.015 \\
Viet Nam & 75 & $\ldots .15-0.25$ \\
\hline
\end{tabular}

Source: Government of the United States, EPA 2010.

Note: ... = no data available.

\footnotetext{
${ }^{4}$ Mongolia may also have very large resources, but these have not been appraised, nor, based on the country's natural gas infrastructure, are they likely to be developed soon.
} 
For annual methane emissions from existing coal mines, one unrefined approach that at least offers consistency is to use estimates published in GHG inventories; this is, in fact, the source of many of the estimates in Table 7.5. This approach with updated data yields Table 7.6 (Government of the United States, EPA 2011).

\section{PEOPLE'S REPUBLIC OF CHINA}

The PRC's resources are the likely the largest in Asia outside of the Russian Federation with around 34 GToe of gas in place at depths above 2,000 meters; ${ }^{5}$ this is comparable to the country's conventional gas resources and ranks it second or third in the world. There may be an additional 46 GToe at depths of 2,000 to 4,000 meters, but any development of this resource is likely to be well in the future. Rather, near- to medium-term development will target coal at 300 to 1,500 meters where up to $60 \%$ of the resource $(17-20 \text { GToe })^{6}$ is expected to be found (PRC University of Petroleum 2008). Estimates of the technically recoverable resource range from 8.3 GToe (IEA 2012b) to 10.0 GToe (Jia 2012), although uncertainty in the recovery rate suggests it could be anywhere from 3.4 to 17 GToe (PRC University of Petroleum 2008).

Table 7.6 Annual methane emissions from operating coal mines, 2010

\begin{tabular}{lc}
\hline & $\begin{array}{l}\text { Estimated coal mine } \\
\text { methane emissions from } \\
\text { operating mines in 2010 } \\
\text { (kilotons of oil equivalentyear) }\end{array}$ \\
\hline Myanmar & 19 \\
People's Republic of China & 19,331 \\
India & 1,710 \\
Indonesia & 252 \\
Kazakhstan & 871 \\
Lao People's Democratic Republic & 6 \\
Mongolia & 13 \\
Democratic People's Republic of Korea & 691 \\
Pakistan & 71 \\
Philippines & 26 \\
Republic of Korea & 52 \\
Thailand & 26 \\
Uzbekistan & 6 \\
Viet Nam & 387 \\
Rest of non-Organisation for Economic & 6 \\
Co-operation and Development Asia & \\
\hline
\end{tabular}

Source: Government of the United States, EPA 2011.

\footnotetext{
${ }^{5}$ Estimates range from 9.7 to 45.9 GToe, with many estimates in the vicinity of 34 GToe (PRC University of Petroleum 2008).

${ }^{6} \mathrm{Gao} 2012$ cites a figure of 10 GToe.
} 
The Shanxi-Shaanxi-Inner Mongolia region is likely the richest in CBM with around $55 \%$ of the total (PRC University of Petroleum 2008). It contains the Ordos Basin identified in Figure 7.6 and the Qinshui Basin slightly to the east. The north of the Ordos Basin and the Qinshui Basin each hold around $5 \mathrm{GToe}^{7}$ and are the two richest CBM "belts" in the country (PRC University of Petroleum 2008). The eastern and western margins of the Ordos Basin hold at least an additional 3 GToe, and the total resource of the Ordos basin has been estimated as high as 17 GToe (PRC National Petroleum Corporation 2013). Xinjiang ${ }^{8}$ and Guizhou also contain large basins (Figure 7.6).

\section{INDONESIA}

Coal bed methane resources appear to be large but have seen only modest development so are still quite uncertain. The gas-in-place at depths between 500 and 4,500 meters has been estimated to be as large as 11.8 GToe; the authors of that assessment suggested that the technically recoverable resource might be 1.3 GToe, equal to one-third of the country's conventional gas reserves. The most promising area was South Sumatra with an estimated 4.8 GToe of gas-in-place between 300 and 1,000 meters. A similar quantity is estimated for the Barito and Kutei coal beds of Kalimantan. Other areas of Sumatra and Kalimantan also contain CBM; only around $1 \%$ of the identified resource was located off these two islands (Figure 7.8; Stevens and Hadiyanto 2004).

\section{INDIA}

Coal bed methane in place has been estimated as high as 4.2 GToe (Ojha et al. 2011) or even 5.2 GToe (Dart Energy 2013) with the Gondwana Basin the most promising area, particularly the Jharia Coalfield (Ojha et al. 2011). This area is the Damodar Basin shown in Figure 7.7.

\section{KAZAKHSTAN}

The Karaganda Basin has been identified as the area holding the vast majority of the country's CBM (Umarhajieva, Mustafin, and Alekseev 2003).

\section{Country assessments for tight gas}

Assessments of tight gas resources are yet scarcer than those for shale gas and CBM. Confusingly, it is sometimes included with either conventional gas or

\footnotetext{
${ }^{7}$ Gao 2012 cites a figure of 3.3 GToe for the Qinshui Basin.

${ }^{8}$ Although the coal resources in Xinjiang are large, PRC University of Petroleum (2008) suggests that outside of some more promising pockets the methane bearing properties are poor making exploitation difficult.
} 


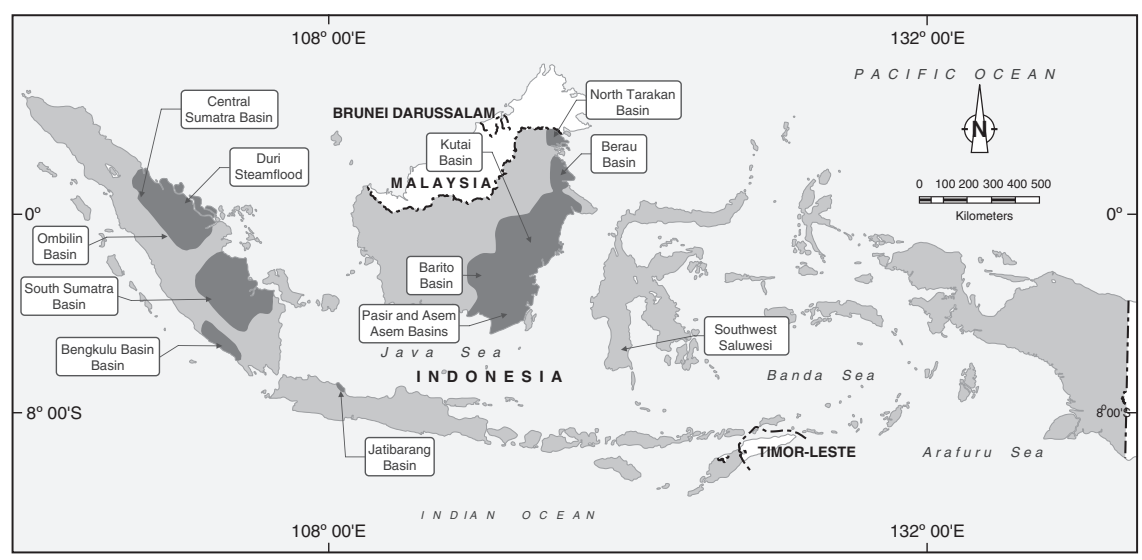

Figure 7.8 Indonesian coal bed methane basins

Source: Approximation based on ADB 2003.

shale gas (Pearson 2012). For the PRC, tight gas in place is estimated at 20.2 GToe (Zou 2012). The technically recoverable resource was estimated to be 8.1-11.1 GToe in one study (Jia, Zheng, and Zhang 2012), but only 2.8 GToe in another (IEA 2012b). The latter is almost certainly proven reserves (Dai, Ni, and Wu 2012). Indonesia's technically recoverable tight gas has been estimated to be around 1 Gtoe (IEA 2012b). Significant resources exist in Pakistan (Natural Gas Asia 2012a) and India (Petroleum Economist 2010), but independent assessments are not available.

\section{Current status in Asia}

The status can be summarized as follows.

1 Development lags behind the US.

2 The PRC leads followed by India and Indonesia.

3 The PRC has successfully exploited tight gas; India, Indonesia, and Pakistan are moving in that direction.

4 CBM has a relatively long history in the PRC; India, Indonesia, and Kazakhstan have also developed projects.

5 The PRC, India, Indonesia, Kazakhstan, and Pakistan have plans for or have expressed interest in developing shale gas.

\section{People's Republic of China}

With gas projected to supply $10 \%$ of national energy requirements by 2020 , conventional production failing to keep up, coal's environmental downsides 
becoming untenable, and the enticing example of expanding shale gas production in the US, there is much interest in the PRC's vast unconventional resources (Nakano et al. 2012; PRC Greentech Initiative 2012). Tight gas already accounted for $5 \%$ of gas production in 1990 . By 2010, this had risen to over 20 MToe, or a quarter of the country's output (Dai, Ni, and Wu 2012). ${ }^{9}$ Around half comes from the vast Sulige Field in the north of the Ordos Basin. Despite successes, there are suggestions that fracking for tight gas "needs perfecting" and that the cost of production is high. Nevertheless, production is expected to expand modestly, reaching 28 MToe in 2020 (Xinhua 2009).

Coal mine methane (CMM) and CBM resources have also been under development for several decades with mixed results (Gao 2012). Mine safety and GHG emissions concerns are largely responsible for the country's efforts to capture CMM. Drained CMM expanded 10-fold from 2000 to 2011 reaching 8.3 GToe annually and capturing around $60 \%$ of emissions.

CMM utilization has not expanded as quickly as its capture, however: captured methane is often flared. Only 3.0 GToe is productively used, fueling 900 megawatts of power generating plants and 4,000 vehicles, among other uses (Huang 2010; 2012). One executive pointed out that for a coal company, "Methane is a meaningless business compared to coal profits." The large number of small mines, with limited expertise and access to pipelines, adds to the challenges (PRC Greentech Initiative 2012). The 35\% utilization factor for CMM in 2010 was much less than the $60 \%$ targeted by the Eleventh Five-Year Plan (Gao 2012).

In 2005, 328 CBM surface wells were drilled which was more than the combined total for all prior years (Huang 2010). In 2006, the Eleventh Five-Year Plan enthusiastically called for 4.6 GToe in 2010 (Gao 2012), but despite drilling more than 5,000 wells and rapidly expanding output (Figure 7.9), production was only 1.3 Gtoe (Huang 2012). This has been variously blamed on lack of financing, limited access to gas pipeline infrastructure (Gao 2012), mining rights conflicts, ${ }^{10}$ and a monopoly market structure (PRC Greentech Initiative 2012).

By 2015, the Twelfth Five-Year Plan anticipates annual production of 14.7 MToe of CBM, capture of 12.8 MToe of CMM, and utilisation of $60 \%$ of the captured CMM - the (unattained) target set in the Eleventh plan (Huang 2012).

In support of these ambitious goals, and reflecting the higher costs for unconventional gas (PRC Greentech Initiative 2012), since 1996 both national and state governments have offered a range of incentives including a 2-year tax holiday and a $50 \%$ tax reduction in the subsequent 3 years, a 218 yuan/Toe $(\$ 35 /$ Toe $)$ CMM utilisation subsidy from the central government, additional state government subsidies, exemption from value-added taxes, exemption from import duties on CBM equipment, priority access to pipelines, and unregulated pricing (Gao 2012).

\footnotetext{
${ }^{9}$ In comparison, US tight gas production is well over 130 MToe/year.

${ }^{10}$ Between national oil and gas companies holding CBM rights and local mining groups holding mining rights.
} 


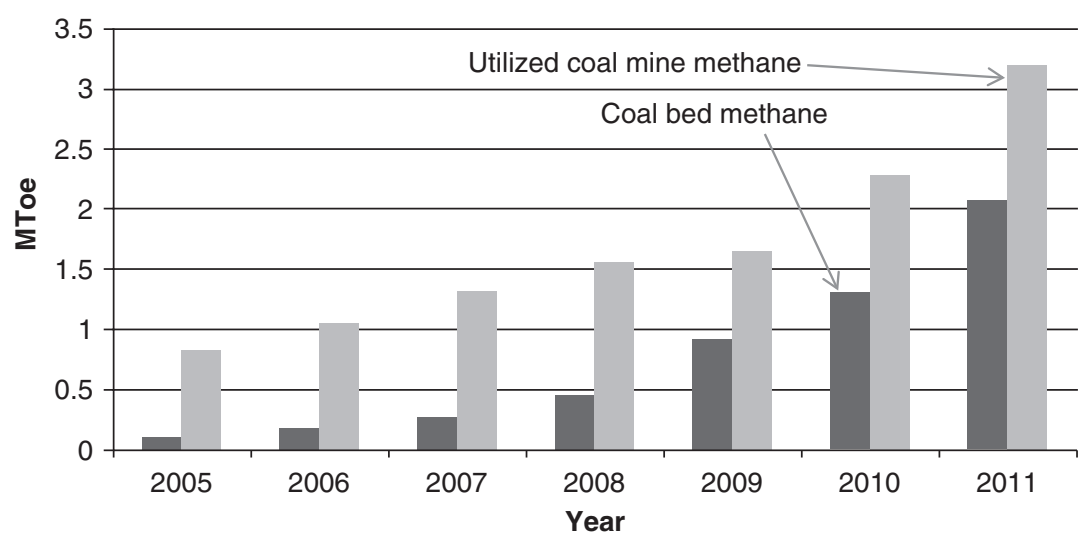

Figure 7.9 Coal bed methane production and coal mine methane capture and utilization in the People's Republic of China

Source: Huang 2012.

Note: MToe $=$ million tons of oil equivalent.

The PRC has much less shale gas experience, with the study of the resource starting only in 2004. Hydraulic fracturing, using US technology, did not occur until 2010; horizontal drilling and the first opportunity for commercial ventures to bid on the rights to develop shale gas blocks followed in 2011 (Tao and Louvel 2012). Commercial production started in 2012 (Katakey, Sethuraman, and Aibing 2012).

Regulations require that foreign firms interested in shale gas development find national counterparts; this should help local firms to acquire technology and expertise. State oil companies admit that their "... technology and experience still lag behind Western oil companies, but [... ] we can hire them to work for us" (EIU 2011). PRC firms have also invested heavily in Australian, Canadian, and US shale gas plays (Nakano et al. 2012) although this may be more for profit and to secure supply than for technology transfer (PRC Greentech Initiative 2012).

The Twelfth Five-Year Plan sets high expectations for shale gas development of 6 MToe in 2015 and 46-73 MToe in 2020, although the 2015 production estimates of the national oil companies amount to around half that (Gao 2012). Thus, the current thinking is that shale gas will overtake tight gas and CBM as the major source of unconventional gas.

To achieve these goals, the government is likely to encourage shale gas production in a manner similar to CBM, in part because the wellhead prices required for profitability will be on the high end of conventional gas prices (Medlock, Jaffe, and Hartley 2011). The Ministry of Land and Resources may subsidize shale gas production at a rate of $250-330$ yuan/Toe $(\$ 40-\$ 50 /$ Toe) (PRC Greentech Initiative 2012). 


\section{India}

India has exploited its conventional gas resources since the $1970 \mathrm{~s}$ but is a net importer of gas: in 2011, gas production of 42 MToe could not match domestic consumption of 56 MToe (BP 2012). The desire to find alternatives to imports has bolstered interest in unconventional gas.

India has been slower than the PRC to exploit its CBM resources (Nakano et al. 2012). Although a policy was drafted in 1997 and the first auction of development rights was held in 2001, commercial production did not start until 2007 (Government of the United States, EPA 2010). In 2011, production was still less than 0.1 MToe; the government foresees this increasing to 1.3 MToe annually by 2016 or 2017 (Government of India, Ministry of Petroleum and Natural Gas 2012).

The state-controlled Oil and Natural Gas Corporation drilled the first Indian shale gas wells in 2011(Nakano et al. 2012), but in 2012 the chairman of the company estimated that it ". . . may be four to five years before commercial drilling starts ... if [the People's Republic of] China and Australia can talk more about their reserves and production, it is because they have been working on this for a while now" (Katakey 2012b). Beyond technical challenges, regulations and approval from the environment ministry will be required before auctions of blocks and production can take place (Nakano et al. 2012).

Indian oil and gas firms, like their PRC counterparts, have looked abroad for shale gas technology, expertise, and investment opportunities (Nakano et al. 2012). For example, the Oil and Natural Gas Corporation has partnered with ConocoPhillips to develop shale gas resources in both India and North America (Katakey 2012a). India's indigenous oil and gas service industry is not advanced as that of the PRC, and the hiring of outside expertise is more common (Nakano et al. 2012).

\section{Indonesia}

Indonesia has a long-established conventional gas industry that produced 69 GToe in 2011, around half of which was exported. Domestic gas consumption is rising rapidly, however, and meeting expanding domestic demand while having sufficient supply to export-especially given declining output in existing conventional wells (Wah 2011) — will be a challenge. This has stimulated interest in the potentially vast unconventional resources.

Progress has been slow, however. For example, licences to exploit CBM were not awarded until 2007 (Government of the United States, EIA 2013), and commercial production did not occur until 2011 (CBM Asia Development Corp 2013). Nevertheless, the country is targeting production of 4.7 MToe in 2015, 9.5 MToe in 2020, and 14.2 MToe in 2025; production will almost certainly fall short of the near-term targets (Wah 2011). There is no shale gas production; indeed, the government has yet to award the first blocks to investors (Government of the United States, EIA 2013). The government is expected to encourage unconventional gas 
production by offering favorable profit-sharing arrangements (Oxford Business Group 2012).

\section{Kazakhstan}

Kazakhstan has a conventional oil industry more than a century old and is a significant coal producer and natural gas exporter (Government of the United States, EIA 2012b). It is also a relatively old hand at CBM: production started in 2000 (Government of the United States, EPA 2010) although quantities appear to be small. At the end of 2012, the government funded a study to investigate the shale gas resource, the legal and regulatory framework for its exploitation, and its potential impacts on the energy market (Trend News Agency 2012).

\section{Prospects for a shale gas revolution in Asia}

Many in government and industry expect an Asian echo of the North American shale gas boom. In this view, unconventional gas will be produced in Asia in large quantities at prices only slightly higher than projected for North America (e.g., for the PRC \$190 to \$240/Toe) (Medlock 2012). But there are differences between Asia and North America that may slow the growth of shale gas production. Moreover, some analysts predict shale gas costs considerably higher than in North America.

The challenges that preoccupy the pessimists include the following (environmental concerns are discussed separately).

\section{DIFFERENT, MORE CHALLENGING GEOLOGICAL CONDITIONS}

There is significant geological variety in gas shales, and some are easier to exploit than others. Many shales in the PRC appear to be smaller, deeper, more complex, and more clayey (making fracturing difficult) than those of North America (Lelyveld 2012; Kim and Yu 2012; Katakey, Sethuraman, and Aibing 2012). Indian shale formations are similarly complex (Jain, Sharma, and Agarwal 2012), a fact underlined by the discrepancy between United States Geological Survey and EIA/Advanced Resources International, Inc. assessments of the resource. This will require more wells for a given level of gas production (IEA 2012b) and impede using North American techniques (Kim and Yu 2012).

\section{LACK OF GEOLOGICAL DATA}

Shale gas production requires a good understanding of the geology of the region. In North America, good data accumulated over decades of conventional drilling and seismic surveys are available for large prospective areas (Stevens 2010; Butkiewicz 2012). This is generally lacking in Asia (Jain, Sharma, and Agarwal 2012). 


\section{LESS-DEVELOPED GAS SERVICE INDUSTRY}

North America's onshore gas service industry is large and technologically advanced, with expertise derived from over a century of conventional exploration and production (Butkiewicz 2012). This has been a key ingredient in the shale gas revolution because it allows the large number of wells necessary to be drilled quickly, economically, and with continuous improvements in efficiency. In comparison, the gas industry in Asia is smaller, less experienced, and still lacks some of the technology and expertise that have proven necessary in North America (Kim and Yu 2012; Nakano et al. 2012). Partly as a consequence, the PRC is drilling around 50 shale gas wells per year, whereas US drilling peaked at 1,300 wells per month (Katakey 2012b).

\section{TECHNOLOGY AND KNOWLEDGE}

The PRC and India have partnered with Western gas companies to access their shale gas technology and expertise. Undoubtedly, the technology can be imported, but it may be expensive, leading to "stubbornly high" production costs (Lelyveld 2012). Furthermore, the knowledge required by each drilling team to reliably fracture a deep horizontal well is much harder to import; the insight needed to successfully develop new techniques for particular geological conditions yet more so (Holditch and Madani 2010; Stevens 2010). This took years in North America; Asia may be no different (Gao 2012; Nakano et al. 2012).

\section{LACK OF A COMPETITIVE INDUSTRY WILLING TO TAKE RISKS}

The major oil and gas companies were latecomers to shale gas in North America. Smaller firms spurred by competition and willing to risk experimentation preceded them (Medlock 2012). Some believe that competition was necessary for the innovations that led to shale gas success (Stevens 2010). This is lacking in much of Asia, where state-owned companies dominate, and there appears to be a reluctance to experiment (Gao 2012; Jain, Sharma, and Agarwal 2012).

\section{DENSE POPULATIONS}

In the PRC, India, and other parts of Asia, many prospective areas for shale gas are heavily populated (Nakano et al. 2012; Gao 2012) heightening the likelihood of disruption and conflict (EIU 2011). Shale gas is highly disruptive in terms of traffic, noise, and dust. Pipelines (for collecting the gas) and roads to the wells also require space (Ground Water Protection Council and ALL Consulting 2009). These challenges are exacerbated where population density is high (Accenture 2012). There may be additional difficulties where the terrain is hilly or mountainous.

\section{SUBSURFACE RIGHTS}

In many places in North America, subsurface mineral rights are the property of the landowner; local opposition to shale gas has been muted in part because 
landowners see a direct financial benefit (Butkiewicz 2012; Gold and Kruk 2012; Stevens, 2010). In areas of Asia where subsurface rights do not reside with the landowner, this compensation will not automatically occur, and opposition may be stronger. Furthermore, it is often easier and quicker for a producer to negotiate with a private landowner than with a central government (Credit Suisse 2012).

\section{INSUFFICIENT PIPELINE NETWORK}

Nearly 500,000 kilometers of natural gas pipelines cover the US, allowing shale gas to be collected and distributed efficiently. In contrast, the PRC had 50,000 kilometers in 2010 and plans to expand this to 100,000 kilometers by 2015 (Gao 2012; Credit Suisse 2012; Kim and Yu 2012). There are fewer than 10,000 kilometers of trunk pipeline in India (Nakano et al. 2012), and most of its capacity has been contracted. This is expected to limit the areas where shale gas and CBM can be exploited (Kim and Yu 2012; Gao 2012).

\section{RESTRICTED ACCESS TO PIPELINES}

In North America, gas producers and pipeline owners are separate, permitting independent shale gas producers to transport their product by contracting with the pipeline. Elsewhere in the world, including the PRC and India, pipelines are typically owned by a major gas company which transports its product-and possibly nobody else's (Medlock 2012; Nakano et al. 2012; Gao 2012). In the PRC, for example, three national oil companies own nearly all the pipelines.

REGULATORY FRAMEWORK

The full framework for shale gas exploitation has yet to be defined in Asia (Nakano et al. 2012; EIU 2011).

\section{HISTORICAL PACE OF INDUSTRY DEVELOPMENT}

Some analysts have drawn a parallel between the sluggish growth of CBM in the PRC, India, and Indonesia and the prospects for shale gas (Gao 2012).

\section{COMPETITION FROM CBM, TIGHT GAS, AND IMPORTS}

In the PRC, for example, both tight gas and CBM are more developed than shale gas, and there have been calls to preferentially develop these resources (Dai, Ni, and Wu 2012; Natural Gas Asia 2012b).

The shale gas revolution will arrive eventually, but current plans may be overly optimistic. Significant production in the PRC will likely occur only around 2017 to 2020 (Credit Suisse 2012; Gao 2012) with Indian and Indonesian production following 5 years later. If shale gas costs in Asia prove to be high, production may not explode the way it has in North America. 


\section{Environmental challenges for shale gas}

Environmental challenges, which may prove especially acute in Asia, are another reason for caution. Shale gas and CBM exploitation are still relatively new, and considerable controversy surrounds their environmental and human health impacts. Several scientific studies of water contamination and fugitive methane emissions that appeared to conclusively resolve those issues have been found to be flawed in methodology and possibly tainted by conflict of interest (Hume 2012). The following is a synopsis of current concerns.

\section{WATER REQUIREMENTS}

Slick water hydraulic fracturing requires between 5 and 20 million liters of freshwater per well (Government of Western Australia, Department of Mines and Petroleum 2013b; Ramudo and Murphy 2010; Credit Suisse 2012; Gao 2012), and water resources are limited in much of Asia. The PRC and especially India both expect water demand to outstrip current supply by 2030 (Nakano et al. 2012).

In some areas, water will need to be transported over long distances, adding to costs. For example, the Tarim Basin, one of the two most promising areas of the PRC (Figure 7.6), is essentially desert; some assessments of shale gas potential discount the Tarim based on the cost of water (Medlock, Jaffe, and Hartley 2011).

In other areas, shale gas drilling will compete for water with other users such as agriculture. This may be the case in the Sichuan Basin, the second most promising area in the PRC and home to millions of farmers already struggling with water scarcity (Lelyveld 2012; Medlock, Jaffe, and Hartley 2011). The government may continue to prioritize residential and agricultural use (Gao 2012). Similar concerns apply in India and Pakistan but are generally absent in waterrich Indonesia.

\section{WATER CONTAMINATION}

In North America and Europe, concerns about water contamination have particularly alarmed those who oppose shale gas (Accenture 2012). The popular concern has been that the (generally undisclosed) chemicals used in fracking will migrate through the ground into groundwater (IEA 2012b). Water contamination may indeed be a real danger, but it is unlikely to occur that way as shale formations and the water table are generally separated by hundreds of meters of rock (Ground Water Protection Council and ALL Consulting 2009; Accenture 2012; MIT 2011; IEA 2012b). Improper well casing and cementing can, however, provide a path for shallower methane to migrate into groundwater; they may even leak fracking fluid, though this has not been demonstrated (Williams 2012; MIT 2011; Ramudo and Murphy 2010). Casings have been an element of natural gas wells for decades with few apparent mishaps, but shale gas may be different due to multiple fracking (rare in conventional operations) and the sheer quantities of water and additives used. 
Of the water injected during fracking, $15 \%-75 \%$ returns to the surface (Ramudo and Murphy 2010) containing not just the chemicals used for fracking, but contaminants liberated from the shale-including dissolved solids (salts) and even traces of naturally occurring radioactive materials (Accenture, Ground Water Protection Council and ALL Consulting 2009). To avoid contaminating surface water, the return water needs to be treated or disposed of safely. ${ }^{11}$

Several studies have examined these issues, but none so far has been conclusive. Ground and surface water contamination appears to be possible but infrequent (Williams 2012). In one study, 38 water contamination incidents were associated with 20,000 US shale gas wells between 2005 and 2009 (MIT 2011).

Water contamination may be a particular concern for Asia, where shale gas will be exploited in densely populated areas. In the Sichuan Basin, for example, water contamination could disrupt the livelihoods of millions of farmers (Lelyveld 2012). Furthermore, water treatment infrastructure is already strained, so shale gas operations may need to build their own treatment plants (Accenture 2012).

\section{FUGITIVE METHANE EMISSIONS}

Natural gas has long been promoted as a "green" fossil fuel because the GHG emissions associated with its combustion are roughly half those of coal or oil per unit of energy. On this basis, shale gas has been construed as a "bridge" to a lowGHG future.

Recently, however, several studies focusing on the methane that escapes into the atmosphere during production have questioned the green bona fides of natural gas in general and of shale gas in particular (Wigley 2011; Howarth, Santoro, and Ingraffea 2011). Since methane is 20 to 25 times more potent a GHG than carbon dioxide $\left(\mathrm{CO}_{2}\right)$ (though less persistent in the atmosphere $)^{12}$ these "fugitive" emissions may greatly increase the overall global warming impact of shale gas.

The level of fugitive emissions and the greenness of shale gas are disputed (Williams 2012; Forster and Perks 2012). For shale gas to cause less global warming than coal, fugitive emissions have to total less than 2.0\%-3.2\% (Wigley 2011; Alvarez et al. 2012), but an early study estimated fugitive emissions of 3.6\%-7.9\% and concluded that natural gas was no better than coal (Haworth, Santoro, and Ingraffea 2011). Various rebuttals suggested lower figures (2.2\%; Calthes et al. 2012), and most lifecycle assessments have found overall climate impacts $50 \%$ lower than estimated in that early study (Forster and Perks 2012).

The industry confirms that GHG emissions of shale gas production are worse than those of conventional gas, if only due to the heavy truck traffic and intensive drill site activity, but insists they are lower than those of coal (IEA 2012b; Forster

\footnotetext{
${ }^{11}$ A typical method is injection in a disposal well.

${ }^{12}$ Intergovernmental Panel on Climate Change figures for a 100-year timeframe. Over a timeframe of several decades, methane is far worse (Forster and Perks 2012).
} 
and Perks 2012). Fugitive emissions are, in reality, rarely measured, and where measurements have actually been taken, levels as high as $9 \%$ have been found (Tollefson 2013). ${ }^{13}$ This unresolved issue is one of great import for global climate change (CSSP 2010; IEA 2012b).

Another consideration is how efficiently gas or coal can be used, particularly for power generation (Wang, Ryan, and Anthony 2011). State-of-the-art combined cycle gas power plants achieve efficiencies in excess of $50 \%$. Their advanced coal counterparts cost more and achieve only 40\% efficiency (Research and Development Solutions 2010). As a result, even if shale gas were $25 \%$ worse than coal per unit of heat energy, it might be no worse than coal per unit of electricity generated.

Several conclusions can be drawn.

- Shale gas production is associated with higher GHG emissions than conventional gas production.

- Whether it is as bad as coal has not been ascertained but is not currently the expectation.

- If shale gas is as bad as some studies suggest, future regulations limiting GHG emissions could be a risk.

- Gas can be turned into electricity more efficiently than can coal thus reducing its emissions per unit of electricity, all other things being equal.

- Heavy reliance on natural gas will not contain GHG emissions to the levels necessary to limit climate change to acceptable levels (MIT 2011).

\section{EARTHQUAKES}

The tentative scientific conclusion at this point is that fracking has led to earthquakes, though too small to be of concern, and is unlikely to increase the likelihood of larger earthquakes. Re-injecting fracking wastewater into disposal wells, on the other hand, may generate earthquakes large enough to cause damage (Leith 2012; Williams 2012; IEA 2012b) ${ }^{14}$ If a major earthquake occurs in a populated area where there is fracking, the industry may be blamed with ramifications for government. Areas of the PRC, Indonesia, and other parts of Asia where shale gas might be produced are earthquake prone (Accenture 2012).

\section{LOCAL POLLUTION AND LAND IMPACTS}

Well operations may release volatile organic compounds that can be carcinogenic and contribute to respiratory problems (IEA 2012b); oil and gas drilling operations have been linked to serious air quality problems (Williams 2012). Shale gas drilling is a land-intensive, industrial activity (IEA 2012b); wells are numerous and tightly spaced, and drilling requires 900 to 1,200 truck visits per well (Ramudo

\footnotetext{
${ }^{13}$ This figure is for an oil and gas producing area, not specifically for shale gas.

${ }^{14}$ Curtailing this common wastewater disposal practice would require more costly water treatment methods (Accenture 2012).
} 
and Murphy 2010; MIT 2011). This leads to airborne dust, vehicle emissions, and noise (Ground Water Protection Council and ALL Consulting 2009; Accenture 2012). Furthermore, the drilling pad may involve flattening a site of 1-3 hectares (Ramudo and Murphy 2010; Ground Water Protection Council and ALL Consulting 2009) and cutting new roads through fields and forests. Pollution, habitat change, loss of farmland, forest fragmentation, erosion, and disfiguration of the landscape are very real local impacts of shale gas production.

Many of these challenges may have technological solutions. For example, water shortages may be sidestepped by using briny water instead of fresh, employing water recycling technologies, or even substituting supercritical nitrogen or propane for water (Medlock, Jaffe, and Hartley 2011; IEA 2012b). Other concerns, like water contamination and methane emissions, can be addressed through consistent use of best drilling practices. The International Energy Agency (IEA) and others have concluded that through new technology, best practices, monitoring, and transparency, shale gas can be exploited without significant environmental detriment (IEA 2012b). But there can be a gulf between possibility and actuality: safe nuclear plants and offshore drilling platforms exist, but so do Chernobyl and Deepwater Horizon.

Ensuring consistent application of best practices will be especially hard since unconventional gas operations will involve tens of thousands of geographically dispersed wells. This multiplies the opportunities for sloppy drilling, substandard well casings, and water spills. It also creates challenges for monitoring and identifying the source of an air or water contaminant, especially if it may dissipate very quickly (e.g., methane in the air), the "recipes" for fracking fluids remain secret, or it is released during drilling and migrates slowly underground. Furthermore, the transparency prescribed by the IEA is not a salient characteristic of all oil and gas companies (Lelyveld 2012); there have been transgressions in supposedly transparent North America (Williams 2012; Ramudo and Murphy 2010).

\section{Role in energy supply and power generation}

With uncertainty about both the size of the recoverable resource and the prospects for commercial production, projections of the future role of unconventional gas remain speculative. In Asia, the PRC was the only country selected for in-depth analysis by the IEA in their Golden Rules Report, which assumes all obstacles to shale gas are overcome (IEA 2012b). Combining the IEA's sunny projections of unconventional gas production with the Asian Development Bank (ADB) estimates of primary energy requirements under a business-as-usual scenario (ADB 2013), unconventional gas is slated to provide around 3\% of the country's energy in 2020 and $8 \%$ in $2035 .{ }^{15}$ Shale gas would account for $55 \%$ and CBM for $40 \%$ of this; unconventional gas would account for slightly over $80 \%$ of gas production.

\footnotetext{
${ }^{15}$ Under the IEA's estimates of primary energy requirements, unconventional gas would supply around $4 \%$ of the PRC's primary energy in 2020 and $11 \%$ in 2035.
} 
Despite the modest contribution of unconventional gas to the energy supply, the IEA accords it a significant role in energy security in the PRC as natural gas imports could be held to $20 \%-25 \%$ of consumption if unconventional gas booms but will grow to nearly $60 \%$ by 2035 if it does not. ${ }^{16}$ The $60 \%$ figure is alarming but needs to be viewed in the context of low overall reliance on natural gas: in 2035 , even the high estimate for imports would represent less than $6 \%$ of the total primary energy demand. Still, the PRC may not want its heavy dependence on oil imports to be repeated with natural gas (Credit Suisse 2012).

For 2035, the IEA sees India producing unconventional gas equal to $4 \%$ of its ADB total primary energy requirement. Around $75 \%$ of this would come from shale gas and the remainder from CBM; as in the PRC, unconventional gas would dominate total gas production. Even with this dramatic expansion, imports would still approach $50 \%$ of India's supply and would be only slightly larger in absolute terms if unconventional gas developed slowly (IEA 2012b). Thus, it would appear that with a limited resource and large total energy demand, unconventional gas may be an attractive business opportunity but not a panacea.

For Indonesia, unconventional gas production may exceed $8 \%$ of total primary energy requirements by 2035, split roughly equally between shale gas and CBM. Unconventional gas would account for less than $40 \%$ of total gas production (IEA 2012b).

The IEA expects that gas imports will be significantly more expensive than in-country unconventional gas production, so they will be a drag on the economy (IEA 2012b, Credit Suisse 2012). They also note that higher unconventional gas production may permit importers like the PRC and India to negotiate better prices, but it is not clear whether they need to actually produce large quantities or if the threat of expanded production might suffice.

It appears, therefore, that unconventional gas will make a limited contribution to the primary energy requirements of Asia through 2035.

Technically, there is no obstacle to unconventional gas playing a larger role in power generation in the longer term, particularly in the PRC, and substituting natural gas for coal in power stations near cities might provide some relief from mounting air pollution problems. In 2010, the contribution of natural gas to electricity generation was $27.4 \%$ in Pakistan, $23.6 \%$ in Indonesia, $12.3 \%$ in India, but only $1.6 \%$ in the PRC (ADB 2013). If in 2035 all unconventional gas in the PRC foreseen by the IEA in their Golden Rules scenario were used for power generation, it could supply around a third of the electricity requirement (as forecast by ADB).

The challenge for electricity generation will be price: using natural gas will likely remain more expensive than coal (IEA 2011a). In the PRC, for example, natural gas prices need to be below $\$ 260 /$ Toe $(\$ 0.24 /$ cubic meter) to compete with coal for electricity generation, absent carbon taxes (PRC Greentech Initiative

\footnotetext{
${ }^{16}$ This understates the difference between the two scenarios since the IEA assumes almost $25 \%$ lower natural gas demand if unconventional gas is not aggressively developed.
} 
2012). For similar reasons, coal's share of power generation is expected to rise in India with gas used by industry (Credit Suisse 2012). There may be a role for industrial backup generating units where the grid is unreliable to provide peak power and even combined heat and power. For importers of LNG like the Republic of Korea, the high price of natural gas will not justify substituting it for imported coal (Credit Suisse 2012).

The role of unconventional gas in power generation is likely to be in providing peak power (Credit Suisse 2012), which may be especially important when intermittent renewables - solar and especially wind - make a larger contribution to electricity generation (MIT 2011). Natural gas plants can compensate for rapid changes in the output of these renewables and have modest capital costs. In addition, gas-fired combined heat and power plants operating only during times of significant heat loads would maximize the benefit provided by natural gas although they would have high capital costs. Interest in such plants is growing, e.g., in the PRC (PRC Greentech Initiative 2012). They could also serve as renewable backup or peak power generating plants.

There is also room for more unconventional and natural gas use by end consumers, e.g., for heating and cooking. This has been given priority in the PRC over power generation, where heating is required and using coal degrades already bad air quality (PRC Greentech Initiative 2012). Natural gas could similarly reduce the use of coal-fired electricity for cooking and other small heating requirements as it can provide heat in these applications two to three times more efficiently than coal. It is reported that only $10 \%$ of the population in the PRC is currently connected to the natural gas distribution network, compared with an average of $40 \%$ worldwide (IEA 2011a).

While imported or unconventional natural gas is likely to be more expensive than coal, it will be competitive with oil; industries in gas importing economies are already contemplating switching. In places with a well-developed natural gas network, it might fuel vehicles (Government of the United States, EIA 2012d; MIT 2011). This will not engender the same air quality benefits as substituting for coal, however.

\section{Investment and infrastructure requirements}

In order to significantly expand the unconventional gas supply in Asia, five types of infrastructure will be required:

- $\quad$ gas wells;

- pipelines;

- drilling rigs and other equipment;

- $\quad$ roads, water trucks, water treatment facilities, and possibly water pipelines;

- $\quad$ LNG facilities and pipelines to import (and possibly export) gas.

The number of wells required to achieve a certain level of production-which will partly determine the requirements for drilling rigs, water transport, and 
treatment - is highly sensitive to ultimate recovery rates and well-decline rates; in Asia, both are unknown. ${ }^{17}$ According to the IEA Golden Rules scenario for drastic expansion of unconventional gas, the PRC will need to drill 300,000 unconventional gas wells by 2035 with annual requirements for 2,000 wells in the near term rising to 20,000 toward the end of the period. Credit Suisse arrived at similar numbers (Credit Suisse 2012). The IEA expects that the PRC would need to add nearly 1,600 rigs to its inventory over this period ${ }^{18}$ as few of the existing fleet are capable of horizontal drilling (Credit Suisse 2012). Local manufacturers are reportedly not yet able to build drilling rigs suitable for shale gas (Gao 2012). In comparison, the US has drilled 700,000 oil and gas wells of all types over the last 25 years and has 2,000 oil and gas drilling rigs (IEA 2012b). The IEA does not provide comparable figures for India, Indonesia, or other parts of Asia.

Horizontal shale gas wells in the US cost \$5 to \$10 million per well. The initial pilot wells in the PRC appear to cost \$11-\$15 million, but it is expected that prices will decline perhaps to $\$ 4$ million per well. On this basis, drilling 300,000 wells would cost $\$ 1.2$ trillion, ${ }^{19}$ but the IEA also notes that since Asian shales are deeper, wells will likely be more costly than in North America and estimates that a typical well will cost \$8 million (IEA 2012b). This would double the cost to \$2.4 trillion.

In its Golden Rules scenario for the PRC, the IEA foresees cumulative investment by 2035 of $\$ 400$ billion for unconventional gas wells, ${ }^{20} \$ 200$ billion for transmission and distribution (including for conventional gas), and $\$ 50$ billion for LNG facilities. For India, the comparable figures will be $\$ 220$ billion for wells, \$40 billion for transmission and distribution, and \$20 billion for LNG infrastructure. The rest of Asia will spend around $\$ 60$ billion for wells, $\$ 150$ billion for transportation and distribution, and \$20 billion for LNG infrastructure (2010 dollars; IEA 2012b).

\section{Risks}

While there is currently great enthusiasm for unconventional gas, there are risks associated with aggressively targeting these resources.

\section{PRODUCTION SHORTFALLS}

Enthusiasm for shale gas may create uncertainty about demand for alternatives and inhibit investment in conventional gas exploration, LNG terminals, pipelines,

\footnotetext{
${ }^{17}$ The IEA assumes an average recovery rate of 26 kilotons of oil equivalent ( 1 billion cubic feet) per well, with only $50 \%$ of the gas recovered after 3 years. These assumptions correspond to the performance of good North American shale plays, but as shown in Figure 7.3, may be optimistic for typical wells, even in North America.

${ }^{18}$ The IEA estimate is higher than some others, for example, Credit Suisse 2012 and Gao 2012.

${ }^{19}$ Assuming they are all horizontal wells; vertical wells might cost half as much (Credit Suisse 2012).

${ }^{20}$ It is unclear why the investment costs are one-sixth of what one would expect based on multiplying the estimate of the cost of a typical well and the number of wells to be drilled.
} 
and other energy infrastructure (Stevens 2010). If the geological, technological, infrastructural, and environmental obstacles facing unconventional gas prove insurmountable, it may be necessary to pay dearly to import gas and expand conventional gas production, or to fall back on coal and accept its environmental problems.

\section{DISTRACTS FROM ENERGY EFFICIENCY AND RENEWABLES}

The promise of abundant, "green" natural gas offered by unconventional resources is alluring, but natural gas is not GHG emission-free; it is clearly less green than renewables developed in a sustainable manner. Heavy reliance on shale gas may be better than heavy reliance on coal, but widespread combustion of shale gas will not permit the reductions in GHGs necessary to limit global climate change to 2 degrees Celsius above pre-industrial levels (IEA 2012b; Wigley 2011; MIT 2011). For this, efficiency and renewables will be required; shale gas distracts attention and investment from them (Credit Suisse 2012; KPMG 2011).

\section{RUNS AFOUL OF FUTURE GHG EMISSIONS REDUCTIONS EFFORTS}

If the GHG emissions associated with unconventional gas production prove to be at the higher end of current estimates, then it may be little better than coal. Currently, coal projects risk penalties from future GHG emissions regulations; heavy reliance on shale and other unconventional gas may entail similar risks (Medlock, Jaffe, and Hartley 2011).

\section{CAUSES LOCAL DISRUPTIONS AND ENVIRONMENTAL DEGRADATION}

Modern energy projects tend to have a direct impact on a fairly small proportion of the population which makes compensating them or simply ignoring their concerns feasible. Widespread exploitation of shale gas in populated regions of Asia will directly inconvenience a large number of people and may raise concerns about the availability of (clean) water, earthquakes, and disfiguration of the landscape.

\section{North American unconventional gas: implications for Asia}

Even if the obstacles to exploiting Asian unconventional gas are difficult to overcome, the enhanced North American supply has important ramifications.

\section{BARGAINING POWER FOR IMPORTERS}

Five years ago, there was widespread sentiment that natural gas supplies were declining and that in future there would be fierce competition for the dwindling resource. Feeling the need to lock in a long-term supply, importers were at the mercy of exporters (Medlock 2012). Now, with the prospect of North America 
exporting LNG, Asian importers have two bargaining chips. First, there is the expectation that LNG will be available near current prices in the medium term. Second, there is the implicit threat that if exporters are too greedy, importers will develop their indigenous shale gas supplies (Nakano et al. 2012). Overall, this suggests that indexing natural gas prices to oil prices, common in Asia, may weaken, to the benefit of gas importers (Medlock 2012).

\section{INVESTMENT AND BUSINESS OPPORTUNITIES}

Industries in the PRC, India, the Republic of Korea, and Malaysia participate in the North American (and Australian) shale gas boom through investments and partnerships or by supplying equipment.

\section{LNG MORE ATTRACTIVE}

With US imports falling and North America possibly exporting LNG, LNG (e.g., from Australia and Qatar) may become cheaper. Also, the possibility that the PRC and India will develop their own shale gas supplies means that there is uncertainty about their long-term import requirements which makes building pipelines risky and LNG more attractive (IEA 2012b).

\section{SUBSTITUTION OF GAS FOR OTHER FOSSIL FUELS IN INDUSTRY}

This is under study by, for example, several Japanese companies (Natural Gas Asia 2012c).

\section{DEPRESSED PRICES FOR COAL}

With US power generation quickly switching away from coal, US coal is looking for export markets. This will depress coal prices internationally making it yet more attractive for power generation despite its drawbacks (Credit Suisse 2012).

\section{Winners and losers}

With so much uncertainty about unconventional gas in Asia, it is dangerous to identify winners and losers, but there are some tentative conclusions. In the global context, it seems that on the whole Asia will be a net beneficiary of unconventional gas, mainly due to its sizable resources. Its good fortune exceeds that of Europe but is eclipsed by that of the North America.

Natural gas importers, notably the PRC, India, the Republic of Korea, Thailand, and Singapore, will be winners. Increased gas supply and more competition among exporters will grant importers a measure of bargaining power and will contain prices (IEA 2012b). Among gas importers, those able to exploit a sizeable indigenous unconventional gas resource (e.g., the PRC and perhaps India) will be the biggest winners. The indigenous resource will offset expensive imports, generate economic activity and employment, and spur industrial development. 
The impact of unconventional gas on exporters will depend on whether they have their own resources to exploit. Countries that do, like Indonesia and Kazakhstan, will suffer from lower prices but may gain in increased exports. If domestic consumption is relatively high and rising, as in Indonesia, unconventional gas will be a minor blessing. On the other hand, exporters without significant unconventional resources will see lower prices and new competitors, but no increase in volume. These likely include Azerbaijan, Malaysia, Turkmenistan, and Uzbekistan (Medlock, Jaffe, and Hartley 2011).

Countries with industries that can export equipment, expertise, and materials for unconventional exploration and drilling will also be winners. The PRC, the Republic of Korea, Malaysia, and perhaps India may benefit in this respect.

From a global perspective, the picture is mixed. Financially the benefit is clear, especially for consumers. If, in the absence of unconventional gas, energy would be supplied by coal, then likely there is an environmental benefit, too. If, however, the promise of cheap, abundant gas diverts efforts from keeping GHG emissions below the level necessary for preventing serious climate change, then we will all be losers; to what extent is currently unknown.

\section{Photovoltaics}

Photovoltaic technology has been used since the 1960s. Although safe, clean, extremely reliable, and requiring no fuel and little maintenance, it has long been too expensive to compete with conventional generation on the grid. That may be changing: the decades-long decline in module prices has accelerated in the last 5 years. This may have immense implications for Asia, where the solar resource is generally good though significant challenges related to high capital costs and the difficulties of siting and integrating large amounts of intermittent capacity into the grid remain. Meanwhile, photovoltaics are already cost effective off-grid, offering the cheapest electricity for hundreds of millions of Asians currently without power.

\section{Solar resource}

Figure 7.10 indicates the spatial variation of the solar resource across Asia. Higher latitudes and cloudier climates receive less solar radiation on average. Tilting the array towards the equator increases the sunshine received by the system, especially at higher latitudes. Tracking systems, which orient the array towards the sun, raise capacity factors ${ }^{21}$ in climates where there is little cloud cover.

Thus, the variation in solar radiation on the horizontal generally exaggerates the spatial variation in the output of tilted and tracking photovoltaic systems. In Figure 7.10 this is revealed by the capacity factor for fixed and tracking arrays at selected locations. For example, at $53.8^{\circ} \mathrm{N}$ in Kazakhstan, an optimally tilted fixed array produces nearly as much electricity as one in equatorial Papua New Guinea despite $35 \%$ less radiation on the horizontal.

\footnotetext{
${ }^{21}$ Capacity factor is the average output of a photovoltaic system as a percentage of its rated power.
} 


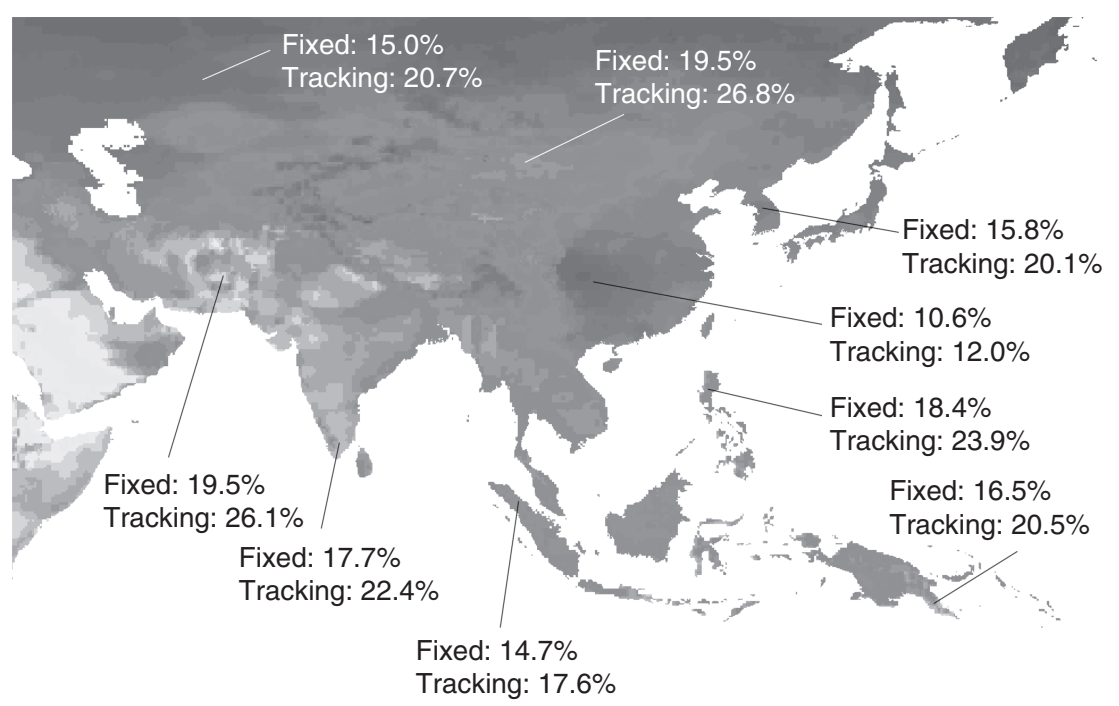

$2,500 \mathrm{kWh} / \mathrm{m}^{2}$ per year

$800 \mathrm{kWh} / \mathrm{m}^{2}$ per year

Figure 7.10 Asian solar resource

Source: Adapted from Meteotest; www.meteonorm.com

Note: Greyscale per year indicates annual radiation on the horizontal in kilowatt hours/square meter. For selected locations, the capacity factors for fixed tilt arrays and tracking photovoltaic systems are shown. Assumptions for capacity factor: fixed arrays are equator facing and tilted at an angle equal to the latitude; tracking arrays use two-axis tracking; grid-tied with inverter average efficiency of $94 \%$ and miscellaneous losses of $10 \%$. These calculations used US National Aeronautics and Space Administration satellite monthly climate data and RETScreen 4 software.

The most remarkable aspect of the solar resource is its very limited spatial variation. From the worst to the best site in Asia, the capacity factor for fixed arrays varies from $10 \%$ to $20 \%$. For the majority of sites across the continent, the capacity factor will be within a few percentage points of $16 \%$. There is no other energy resource that is so equitably distributed.

Solar energy can be used anywhere in Asia. Whether it makes sense to do so depends on the price of the system compared to the alternatives.

\section{Costs and market}

Photovoltaic technology, commercially available for decades, has become significantly cheaper over time. The cost of crystalline silicon photovoltaic modules - the component that turns sunlight into direct current—was around \$80/watt in 1977. By early 2008, it was \$4/watt (The Economist 2012); then it fell 50\% from 2008 to 2009 (Figure 7.11). Rapid declines have continued since then; currently modules can be had for $\$ 0.70 /$ watt. 


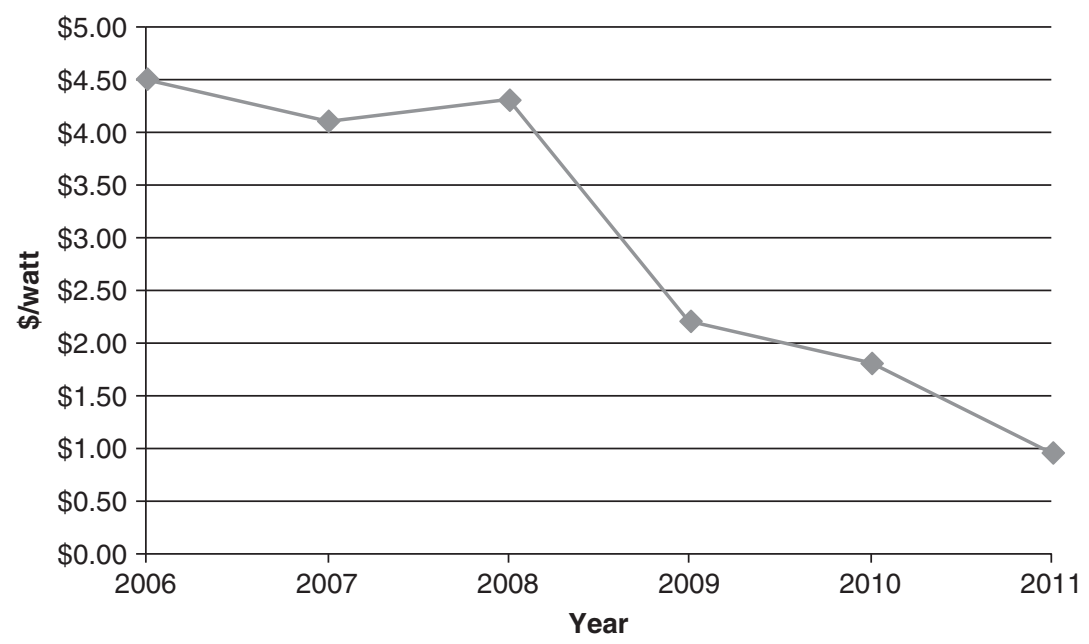

Figure 7.11 Crystalline silicon photovoltaic module prices (\$/watt by manufacturers in the People's Republic of China)

Source: Bazilian et al. 2012.

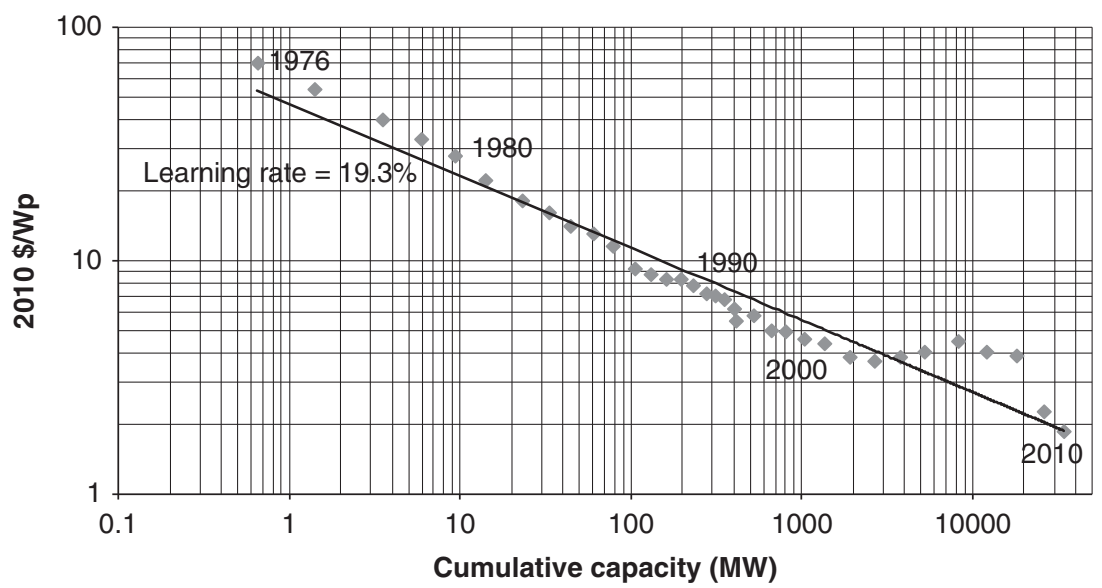

Figure 7.12 Photovoltaic module price as a function of installed capacity (\$/watt) Source: IEA 2011b; original figure from Breyer and Gerlach 2010.

Note: $\mathrm{MW}=$ megawatt; $\mathrm{Wp}=$ watt-peak.

The long-term decline in photovoltaic module prices follows a very quick learning curve: each doubling of cumulative installed capacity sees a roughly $20 \%$ reduction in price due to economies of scale and innovation. Figure 7.12 shows the price of modules as a function of installed capacity. Photovoltaics, aided by 


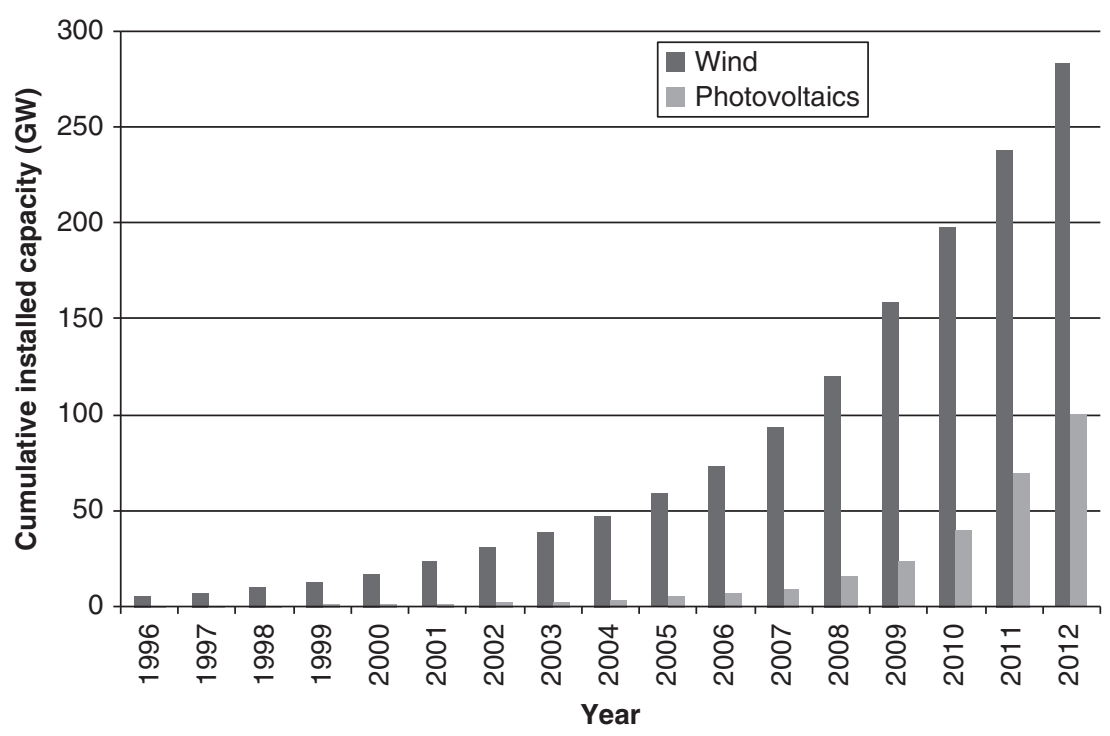

Figure 7.13 Cumulative installed photovoltaic and wind capacity, 1996-2012

Source: Data from EPIA 2012; GWEC 2013a; RETScreen 2013.

advances in semiconductor industry, have demonstrated the fastest learning curve of any energy technology (IEA 2011b).

Beyond the learning curve, Figure 7.12 reveals the massive increase in installed capacity since the year 2000 from about 1.5 gigawatts worldwide to just under 100 gigawatts by the end of 2012 (Barber 2012; iSuppli 2012). Most remarkably, from 2008 through 2012, the installed capacity jumped by an order of magnitude - an annual growth rate of 60\% (IEA PVPS 2012). This is clear in Figure 7.13, which compares the cumulative installed capacity of wind power, a more mature industry noted for its rapid growth, and photovoltaics. In 2006, photovoltaic installed capacity was equal to that of wind a decade earlier. By 2012, photovoltaics lagged wind by only 5 years.

One of the most important ramifications of the decline in module prices has been that the module no longer dominates system costs. Modules cost $\$ 0.70$ to $\$ 1.50$ /watt; in large, competitive markets (e.g., Germany), photovoltaic systems cost between $\$ 1.80$ and $\$ 2.50$ /watt for utility-scale systems (greater than 1 megawatt; Feldman et al. 2012; IEA 2011b; IEA PVPS 2012; Bazilian et al. 2012; Poissant 2012) and around $\$ 2.50$ /watt for residential systems under 10 kilowatts. ${ }^{22}$ Thus, the module now accounts for around half the cost of the system

\footnotetext{
${ }^{22}$ Prices are significantly higher in other markets, e.g., the US, particularly for residential systems (Feldman et al. 2012; Seel, Barbose, and Wiser 2013).
} 


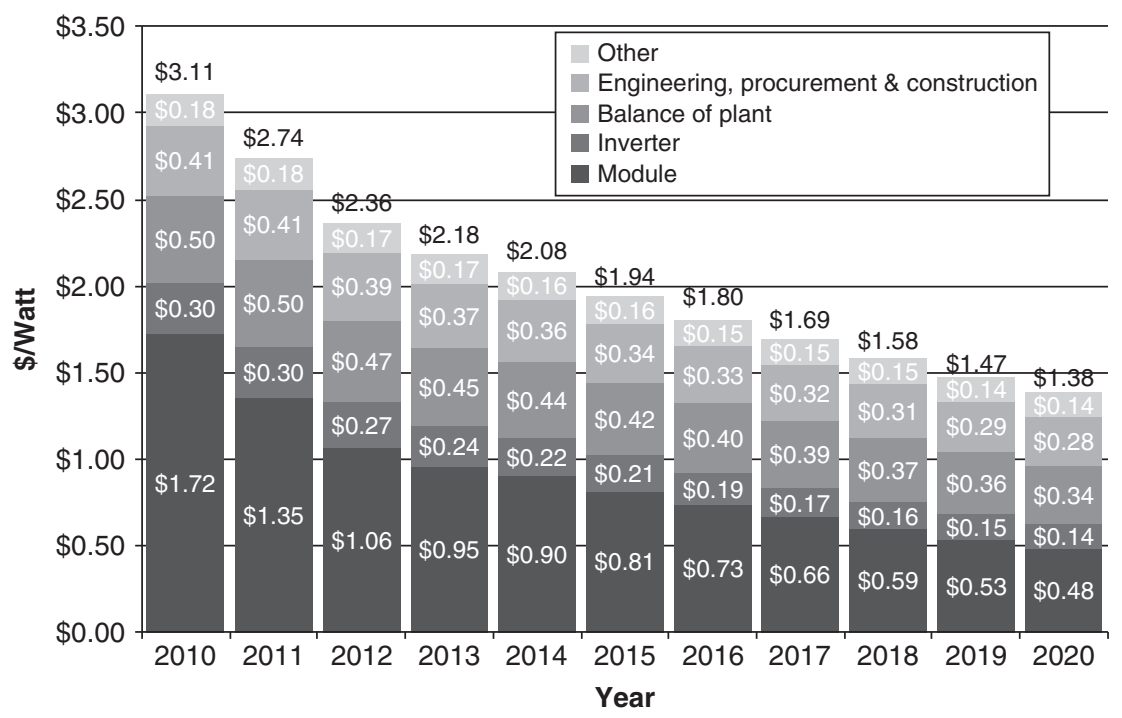

Figure 7.14 Utility-scale photovoltaic system price projections to 2020

Source: Reprinted from Liebreich 2011.

in the most cost-competitive markets and as little as $20 \%$ in less well-developed markets (Feldman et al. 2012).

Non-module costs include the inverter (around $\$ 0.30 /$ watt), racking and other hardware (around $\$ 0.20 / \mathrm{watt}$ ), installation and other project costs ( $\$ 0.20 /$ watt), and non-project costs (e.g., overhead) and profit (Seel, Barbose, and Wiser 2013). Module prices have a quicker learning curve than non-module costs, so the latter tend to grow in importance.

How will these prices evolve over time? Analysts tend to project prices based on the learning curve and assumptions about the expansion of the market (Breyer and Gerlach 2010). One set of projections for utility-scale photovoltaic system prices is shown in Figure 7.14; it appears valid for well-developed photovoltaic markets but optimisitic for small markets. Residential system costs are expected to follow a similar trajectory but remain $10 \%-50 \%$ more expensive than utilityscale systems unless widely integrated into building roofing and cladding.

Obviously, this cannot continue forever: there must be a floor price below which the system cannot be built. Recent estimates range from a low of $\$ 0.30$ /watt for photovoltaic modules and \$0.60/watt for installed systems (Breyer and Gerlach 2010).

\section{Cost effectiveness on-grid}

The levelized cost of energy (LCOE) takes into account capital and ongoing costs as well as the discount rate - an especially important consideration for technologies 
Table 7.7 Photovoltaic levelized cost of energy scenario assumptions

\begin{tabular}{|c|c|c|c|}
\hline & Low scenario & Middle scenario & High scenario \\
\hline Capacity factor & $20 \%$ & $16 \%$ & $10 \%$ \\
\hline Discount rate & $4 \%$ & $7 \%$ & $10 \%$ \\
\hline Maintenance costs ${ }^{\mathrm{a}}$ & \$20/(kW year) & $\$ 30 /(\mathrm{kW}$ year) & $\$ 50 /(\mathrm{kW}$ year $)$ \\
\hline Lifetime & 30 years & 25 years & 20 years \\
\hline $\begin{array}{l}\text { Deterioration over } \\
\text { lifetime }\end{array}$ & $20 \%$ & $20 \%$ & $20 \%$ \\
\hline
\end{tabular}

Source: Author.

Note: kW = kilowatt. ${ }^{\mathrm{a}}$ See Bazilian et al. 2012; Jacobi and Starkweather 2010.

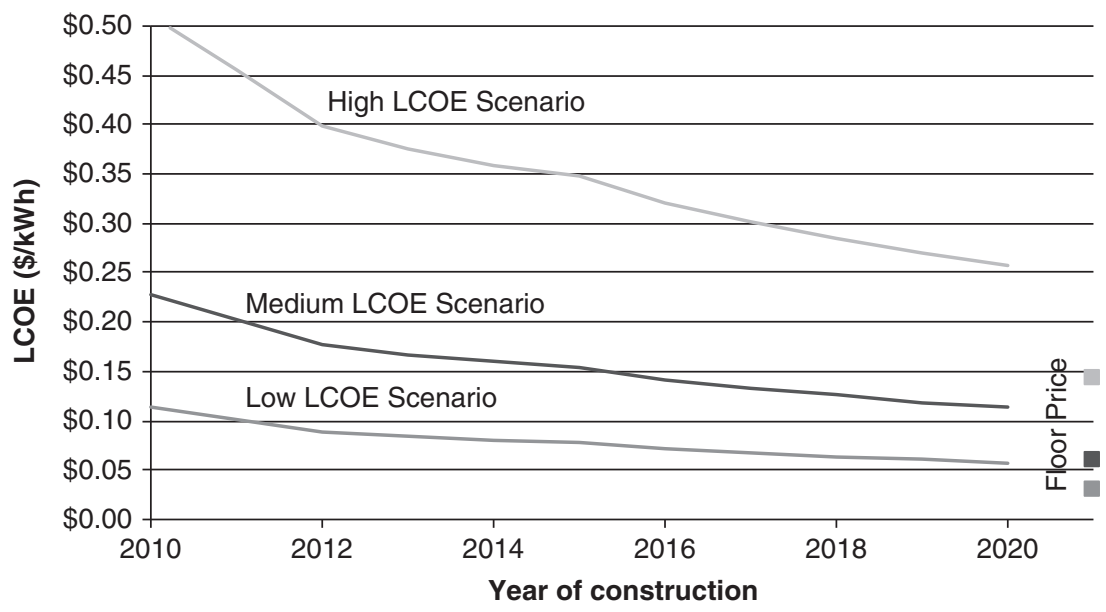

Figure 7.15 Levelized cost of energy for utility-scale photovoltaic systems constructed from 2010 to 2020

Source: Author.

Note: $\mathrm{kWh}=$ kilowatt hour; $\mathrm{LCOE}=$ levelized cost of energy.

like photovoltaics with high up-front but low ongoing costs. The simple LCOE (Government of the United States, NREL 2013) has been calculated under three scenarios (Table 7.7) using the photovoltaic system prices in Figure 7.14 and the floor price of $\$ 0.60 /$ kilowatt (Figure 7.15).

The sensitivity of LCOE to variations in parameters can be investigated by changing each input individually while holding the other parameters at the values for the medium LCOE scenario with 2015 prices (e.g., \$2.00/watt). The results are shown in Table 7.8 which also includes a row for varying the module cost while holding the non-module costs fixed at their 2015 levels. Note the following.

- The capacity factor is critical: good sites result in an LCOE half that of poor sites. 
Table 7.8 Sensitivity of photovoltaic levelized cost of energy to variations in input parameters

\begin{tabular}{|c|c|c|c|c|}
\hline & \multicolumn{2}{|c|}{ Range of parameter } & \multicolumn{2}{|c|}{$\begin{array}{l}\text { Range of levelized cost of } \\
\text { energy }\end{array}$} \\
\hline & Min & $\operatorname{Max}$ & Min & $\operatorname{Max}$ \\
\hline System cost & $\$ 1.38 / \mathrm{W}$ & $\$ 3.12 / \mathrm{W}$ & $\$ 0.113 / \mathrm{kWh}$ & $\$ 0.228 / \mathrm{kWh}$ \\
\hline Module cost & $\$ 0.30 / \mathrm{W}$ & $\$ 1.00 / \mathrm{W}$ & $\$ 0.120 / \mathrm{kWh}$ & $\$ 0.167 / \mathrm{kWh}$ \\
\hline Capacity factor & $10 \%$ & $20 \%$ & $\$ 0.123 / \mathrm{kWh}$ & $\$ 0.247 / \mathrm{kWh}$ \\
\hline Discount rate & $4 \%$ & $10 \%$ & $\$ 0.122 / \mathrm{kWh}$ & $\$ 0.190 / \mathrm{kWh}$ \\
\hline $\begin{array}{l}\text { Maintenance } \\
\text { costs }\end{array}$ & $\$ 20 / \mathrm{kW}$ & $\$ 50 / \mathrm{kW}$ & $\$ 0.147 / \mathrm{kWh}$ & $\$ 0.168 / \mathrm{kWh}$ \\
\hline Lifetime & 20 years & 30 years & $\$ 0.136 / \mathrm{kWh}$ & $\$ 0.168 / \mathrm{kWh}$ \\
\hline
\end{tabular}

Source: Author.

Note: $\mathrm{kWh}=$ kilowatt hour; $\mathrm{W}=$ watt.

- The module cost is of secondary importance: varying it by a factor of more than three changes the LCOE by only $30 \%$. Future reductions in the module cost cannot be counted on to materially reduce the LCOE.

- The discount rate plays a much larger role in the LCOE than either maintenance costs or lifetime.

Various organizations have forecast the LCOE for photovoltaic systems to 2030 under different sets of assumptions (Figure 7.16). The medium scenario in Figure 7.15 lies near the center of these estimates.

These figures can be compared with those from competing energy sources. This will vary from country to country within Asia. Estimates of the LCOE calculated under broadly similar assumptions to those used in Table $7.7^{23}$ were taken from an Organisation for Economic Co-operation and Development (OECD) study of existing and planned nuclear, coal, and gas plants in the Republic of Korea (a gas and coal importer) and the PRC (with strong domestic gas and coal supplies as well as hydro resources) (OECD 2010). Comparing Figures 7.17 and 7.18 with the scenarios in Table 7.7 and the 2030 estimates in Figure 7.16 we see that even by 2030 , photovoltaic-generated electricity will struggle to compete with large hydro, cheap coal, and cheap gas but may be attractive compared to generation using more expensive imported coal and gas, particularly in areas with a good solar resource. This illustrates that the cost effectiveness of photovoltaics depends on the solar resource, financing, and other particulars of the installation and on what the competing options are.

Calculating the LCOE for photovoltaic systems with the floor price of $\$ 0.60$ / kilowatt yields $\$ 0.031$ and $\$ 0.061 /$ kilowatt hour in the low and medium scenarios, respectively. For the Republic of Korea, this would be cheaper than gas and coal

\footnotetext{
${ }^{23}$ Discount rates of $5 \%$ and $10 \%$; simple LCOE calculation.
} 


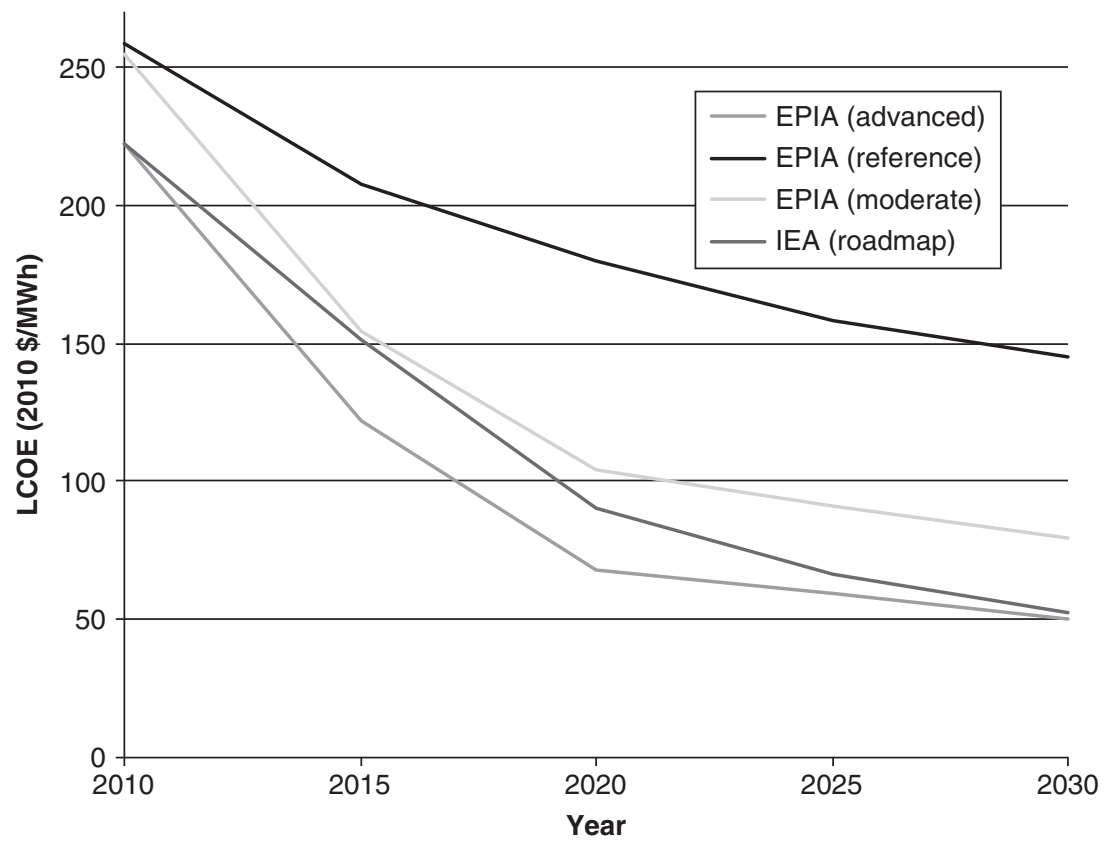

Figure 7.16 Estimates of levelized cost of energy for photovoltaic systems constructed from 2010 to 2030

Source: IRENA 2012a.

Note: EPIA = European Photovoltaic Industry Association; IEA = International Energy Agency; $\mathrm{LCOE}=$ Levelized Cost of Energy; MWh = megawatt hour.

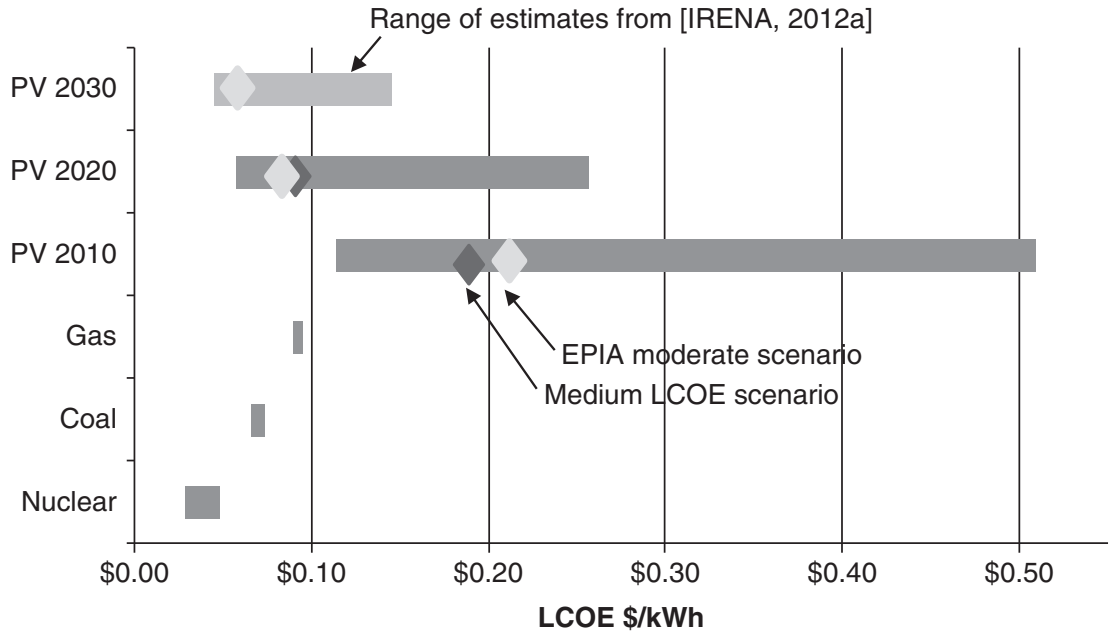

Figure 7.17 Levelized cost of energy for utility-scale photovoltaics versus gas, coal, and nuclear generation in the Republic of Korea

Source: Author; IRENA 2012a; OECD 2010.

Note: EPIA = European Photovoltaic Industry Association; $\mathrm{kWh}=$ kilowatt hour; $\mathrm{LCOE}=$ levelized cost of energy; $\mathrm{PV}=$ photovoltaic. 


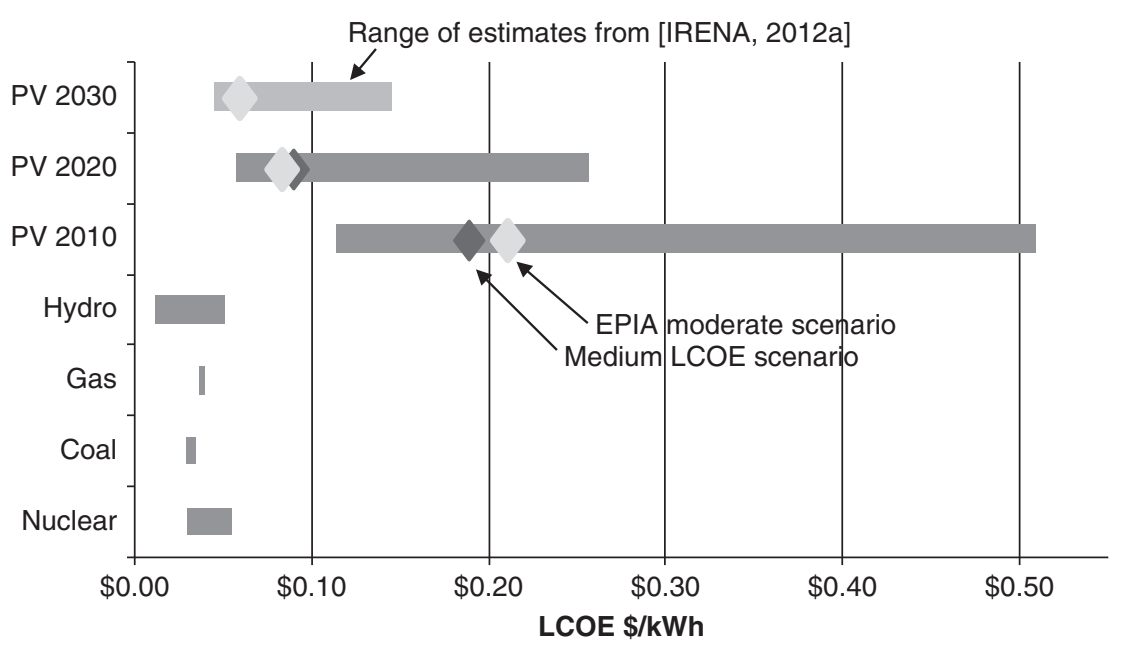

Figure 7.18 Levelized cost of energy for utility-scale photovoltaic versus hydro, gas, coal, and nuclear generation in the People's Republic of China

Source: Author; IRENA 2012a; OECD 2010.

Note: EPIA $=$ European Photovoltaic Industry Association; $\mathrm{kWh}=$ kilowatt hour; $\mathrm{LCOE}=$ levelized cost of energy; $\mathrm{PV}=$ photovoltaic.

and comparable to nuclear. For the PRC, it would be in the same range as coal, gas, nuclear, and the more expensive large hydro.

Comparisons of LCOE for intermittent renewables (e.g., wind and solar) and dispatchable forms of generation (e.g., coal and gas) are common but ignore costs for providing backup when the sun is weak and the wind is low (Government of the United States, EIA 2012d).

For photovoltaics connected to grids where air conditioning loads drive peak demand, there is a strong correlation between the availability of photovoltaic generation and the need for generation. Not only does this make it more reasonable to compare its LCOE to that of dispatchable generation, it suggests that photovoltaics will be in competition with more expensive, peaking forms of generation, e.g., natural gas. For countries with high natural gas prices (e.g., the Republic of Korea), this makes photovoltaics more cost competitive but leads to smaller GHG emissions reductions than if photovoltaics displaced coal.

While the LCOE of renewables is underestimated when intermittency raises integration costs, the LCOE for fossil fuel generation omits some costs, too. In particular, the uncertainty about future fossil fuel prices creates significant risk for thermal plants. ${ }^{24}$ Since the riskiness of an investment should be reflected in the discount rate, this suggests that the LCOE of photovoltaics should be calculated

\footnotetext{
${ }^{24}$ The OECD study assumes stable coal and gas prices.
} 
with a lower discount rate than that used for thermal plants (Awerbuch 1996). This is especially important for gas plants since their LCOE is most sensitive to fuel costs.

Similarly, fossil fuel generation is subject to risks associated with environmental externalities - e.g., GHG emissions and air pollution. Investors in a coal-fired power plant must consider the risk of future emissions penalties. This should be reflected in a higher discount rate. For example, the EIA uses a discount rate of $9.8 \%$ for LCOE calculations for coal without carbon capture and storage (CCS) and $6.8 \%$ for photovoltaics and coal with CCS (Government of the United States, EIA 2012d).

\section{Cost effectiveness off-grid}

Although they receive less attention than the on-grid market, many off-grid applications of photovoltaics have been cost effective for well over a decade. These include providing power to remote industrial systems and to people living in rural and remote areas.

In Asia, 800 million people lack grid electricity. ${ }^{25}$ They use kerosene or other liquid fuels (e.g., for lighting, small engines, and possibly cooking), locally collected wood and dung (e.g., for cooking), primary batteries (e.g., for radios and flashlights), and electricity generated by small reciprocating engines (e.g., for lighting, sound systems, and television) (Ross 1994).

Providing energy is expensive in these areas. Even though diesel or kerosene may cost around $\$ 1.00 /$ liter, they are used extremely inefficiently by appliances and small engines, so diesel-generated electricity may cost $\$ 0.50$ to $\$ 1.00 /$ kilowatt hour. Grid extension may easily cost $\$ 5,000 /$ kilometer and is difficult to justify where population densities are low, especially since per consumer electricity consumption in poor areas may be 1 kilowatt hour per day or less (Rolland 2012).

Photovoltaics can compete, especially where electricity requirements are modest. Systems may be small-lanterns or individual home systems of 30 to 300 wattsor may feed community mini-grids, possibly in combination with diesel generation. The potential off-grid requirement for photovoltaics is large: to supply a household of six consuming only 1 kilowatt hour of electricity per day, 40 to 50 watts of photovoltaic capacity per person would be required. Roughly 35 gigawatts of capacity - about a third of the total photovoltaic capacity currently installed worldwide - would be needed for the 800 million people lacking grid electricity in Asia.

For these systems, the cost of storage often equals or exceeds the cost of photovoltaics. The majority of electric loads-e.g., lighting and television-are required in the evening. The lead-acid batteries typically used for electric storage add around $\$ 0.15$ to $\$ 0.25$ per kilowatt hour of electricity stored. Furthermore,

\footnotetext{
${ }^{25}$ Most of these are in South Asia and to a lesser extent East Asia (Breyer and Gerlach 2010; Rolland 2012).
} 
lead-acid batteries have lifetimes of only 1 to 6 years, and lead is toxic. Lead recycling is essential, but procedures are not always followed safely in developing countries (Fuller 2009), and scrap battery collection services may be limited in remote areas. Financing these systems is challenging. Capital to purchase a photovoltaic system may be scarce, and effective discount rates are high necessitating rapid paybacks. Transaction costs for arranging small loans may be prohibitive.

While the cost of electricity is high in these regions, so is its perceived value. Electricity, electric lighting, and television are compelling symbols of modernity with great significance in underdeveloped regions (Ross 1994). Electric lighting may also be more convenient and cheaper than kerosene or oil lighting. It is important, however, not to overstate the value of electricity in terms of measurable development outcomes. The major health hazard associated with the existing energy supply - the use of open fires for cooking - is rarely addressed by photovoltaics. Adequate disposal of sewage and providing clean drinking water are likely to do far more good than electrification though they may not elicit the same enthusiasm.

Furthermore, electrification's impacts on a village's social fabric may be complex and unclear to an outsider. Migration to the city may be slowed through rural electrification; in near-subsistence economies, inequality may be amplified because those who have more money (e.g., the teacher or shopkeeper) can more easily pay for electricity; ostentatious displays of wealth (e.g., duelling televisions) may upset traditions; and the need to keep up with the neighbors may lead to indebtedness (Ross 1994).

\section{Limits to grid penetration}

The diminished output of a photovoltaic plant during night and cloudy weather implies that without storage the grid cannot be powered exclusively by photovoltaics: the penetration ratio, i.e., the fraction of electricity supplied by photovoltaics, is limited. The first challenge is not technical but economic: the LCOE of photovoltaic electricity is still higher than that of conventional generation. The second challenge is financial. Achieving a $10 \%$ penetration ratio for the 20,000 terrawatt hours of electricity that developing Asian countries are expected to consume in 2035 (ADB 2013) will require approximately 1,400 gigawatts of photovoltaic capacity. Even assuming a system cost of $\$ 1 /$ watt, this will cost a staggering $\$ 1.4$ trillion. ${ }^{26}$ Generating this same amount of electricity with a combined cycle gas turbine having a capacity factor of $85 \%$ would require a capital expenditure of $\$ 160$ billion. It is both a blessing and curse that included in the purchase price of a photovoltaic system is a 30 -year fuel contract.

The third challenge will be related to transmission and distribution infrastructure at high photovoltaic penetration ratios. This will be especially important in

\footnotetext{
${ }^{26}$ Ignoring all grid integration costs.
} 
the PRC because the eastern parts of the country where much of the population resides are much less sunny than the relatively uninhabited west. Building transmission capacity specifically for photovoltaics is especially expensive per unit of electricity transmitted: if dedicated solely to photovoltaic plants with a capacity factor of $20 \%$, the energy transmitted is only one-fifth that of a transmission line operated at capacity all the time. ${ }^{27}$

The fourth challenge is balancing fluctuating generation and loads. These difficulties become more acute as penetration ratios exceed $10 \%$ and rise to $20 \%$ or $30 \%$. To accommodate high photovoltaic penetration levels, more robust transmission and distribution networks may be required; better predictions of photovoltaic output may be needed by the balancing authority; intermittent generation may need to be accommodated by new generating capacity; thermal generation may cycle more; larger flows of energy between neighboring balancing areas may occur; and reserve generation (capable of coming on line in response to a contingency) may be needed (OECD 2010; Milligan et al. 2011).

Integration costs are hard to estimate, open to interpretation, and situation specific but have been found to be modest. For example, for wind ${ }^{28}$ penetration ratios of $20 \%$ to $25 \%$, integration costs are \$1-\$6/megawatt hour (OECD 2010). This is a small fraction of the $\$ 57 /$ megawatt hour LCOE for photovoltaics in 2020 in the low scenario calculated earlier.

Fortunately, the intermittency of photovoltaics is mitigated by several factors.

- Clouds pass over neighboring photovoltaic systems at different times reducing variability in average output.

- Unlike wind, sunshine is strongly correlated with peak loads, which occur during the day and when air conditioning requirements are high.

- The diurnal cycle is predictable.

- Sunshine is uncorrelated or even somewhat negatively correlated with other forms of intermittent generation like wind and run-of-river hydro generation.

The fifth challenge will be suitable land. Utility-scale generation is cheaper than small, distributed photovoltaic generation but requires large areas of land. With tightly packed photovoltaic arrays at ground level, and any shading drastically curtailing their output, the land cannot have other uses such as farming. This will be problematic in the highly populous regions of Asia. Large desert areas are superbly suited to photovoltaics, but transmitting electricity to cities may be costly.

Finally, at very high penetration levels (e.g., $40 \%-50 \%$ or more) of intermittent solar and wind generation, storage will become increasingly necessary in

\footnotetext{
${ }^{27}$ Where good solar and wind resources coincide such as Mongolia, photovoltaics and wind may share transmission lines as the temporal variation in output is largely uncorrelated. The utilization of transmission capacity can also be increased by adding a modest amount of dispatchable generation.

${ }^{28}$ Integration costs have been more extensively investigated for wind than for solar.
} 
order to shift significant amounts of energy over periods of hours or days. ${ }^{29}$ Current dedicated electric energy storage technology is too expensive to permit this. There are forms of storage already available to most grids. These will be insufficient at very high penetration ratios but have value at lower ratios.

- Hydro reservoirs can be considered large batteries; photovoltaic electricity preserves the energy in the reservoir for when the sun is not shining.

- Where air conditioning loads extend into the night, cool storage can cheaply store photovoltaic output. By running chillers harder than necessary when there is sun and storing cold in water or concrete, evening electricity consumption for cooling is reduced (Ross 1999).

While the long-term prospects for solar are good, based on the capital requirements alone it would be optimistic to expect it to supply more than $10 \%-20 \%$ of Asia's power by 2035. This is a significant contribution but is not enough to solve the looming environmental catastrophe of climate change. This will require more conservation and energy efficiency.

\section{Asia in the world market}

Around 100 gigawatts of photovoltaic capacity had been installed worldwide by the end of 2012. Due to strong demand in South and East Asia, Asia is replacing Europe as the world's main market. In 2013, 44\% of the world demand for photovoltaics will be in Asia (EnergyTrend PV 2013).

In 2012, the PRC installed 5 gigawatts of photovoltaic capacity- $15 \%$ of the world total-second only to Germany (7.6 gigawatts). India was not in the top 10 in 2007 but ranked 6th in the world in 2012 at 1.4 gigawatts - almost 5\% of the world total (Parkinson 2013). Optimistic analysts ${ }^{30}$ expect that in 2014 the PRC will install 10.6 gigawatts - nearly $25 \%$ of the world total - and be the largest market in the world. India will rank 5th with 2.9 gigawatts $-6 \%$ of the world total. Thailand ( 0.7 gigawatts) and the Republic of Korea ( 0.6 gigawatts) will be out of the top 10 but will show rapid growth (Parkinson 2013).

Other Asian economies such as Bangladesh; Indonesia; Malaysia; and Taipei, China also have significant markets including for off-grid electrification, and a number of them have announced or are planning feed-in tariff programs (Werner et al. 2011; EPIA 2012). On a per capita basis, small island nations with high electricity costs will no doubt be world leaders. Asians are also leaders in the production of photovoltaic equipment. The largest producer of cells, modules,

\footnotetext{
${ }^{29}$ Storage has benefits at lower penetration levels too. For example, a relatively small amount of storage can greatly enhance the ability of photovoltaics to reliably supply peak loads driven by air conditioning (Perez, Seals, and Stewart 1993; IEC 2011).

${ }^{30}$ The EPIA forecasts based on 2011 data are more modest that those reported here but also underestimated 2012 capacity additions (EPIA 2012).
} 
and polysilicon feedstock is the PRC with over $50 \%$ of the world's production (Choudhury 2012). Taipei,China and the Republic of Korea also rank in the top six.

\section{Environmental concerns}

No energy generating technology is free of environmental impact, but photovoltaics are close. Since it emits nothing during operation, the most serious concern is GHG emissions during manufacture which depend on the energy supply of the factory. Estimates of the life cycle emissions from photovoltaic systems (post-2000) range from 10 to 217 grams of $\mathrm{CO}_{2}$ equivalent/kilowatt hour with an average around 60 grams. For comparison, the operating emissions of electricity generation are around 400 grams $\mathrm{CO}_{2}$ equivalent/kilowatt hour for natural gas and 900 grams for coal. The energy required to manufacture a photovoltaic module can be generated by the module in as little as 1.5 years (Sherwani, Usmani, and Varun 2010).

Local impacts on land and vegetation, potentially causing erosion, may be a concern in large-scale systems, particularly where the site is leveled to facilitate installation and native vegetation is cut or removed to avoid shading. Roof-top installations are more benign.

Most photovoltaic modules are constructed of glass, processed silicon, aluminium, and a small amount of plastic. These components are relatively harmless for the environment.

\section{Winners and losers}

All of Asia has a good to excellent solar resource and stands to benefit from solar energy. Depending on access to capital, off-grid residents of remote and rural regions stand to benefit most. Currently, the PRC; the Republic of Korea; and Taipei,China are major manufacturers of photovoltaic technologies. If this continues, they will benefit from a growing manufacturing industry and related exports. As photovoltaic module prices decline, an increasing fraction of the cost goes to local installation companies. Thus, photovoltaics use a local energy resource that is purchased largely through a local industry, not energy imports.

There are few obvious losers. The exception may be investors in photovoltaic manufacturing: many companies operate at a loss and are likely to disappear in the next few years. If feed-in tariffs or other incentives are set too high, rate payers and taxpayers who subsidize photovoltaic production will also lose. Alternatively, if they are set too low, early adopters will effectively subsidize late adopters.

Two dangers associated with photovoltaics could undermine this rosy picture. First, the high capital costs may divert investment from other priorities and sectors of the economy. Second, even large, worldwide investments in photovoltaics will not be sufficient to address the looming climate catastrophe in an acceptable timeframe. If photovoltaics are percieved as a panacea for climate change and energy efficiency and conservation are ignored or suffer as a result, its emergence will constitute a Phyrric victory. 


\section{Wind energy}

The wind industry is larger and more mature than photovoltaics. While wind technology is still evolving, improving, and growing in importance, the kind of radical developments seen over the past 5 years in photovoltaics occurred over a decade ago for wind.

\section{Resource and capacity factor}

There is much greater geographic variation in the wind resource than in the solar resource, as suggested by Figure 7.19. Outside of the tropics, wind tends to be stronger (and steadier) at sea than on land. Figure 7.19 shows the resource in terms of wind speed measured at a height of 80 meters. The power of the wind is not proportional to its speed, however: it is related to the cube of the speed. This greatly amplifies the variability; sites with an average wind speed of 4 meters/ second have an abysmal resource; ones with 8 meters/second have a superb resource, with roughly eight times the energy.

Wind speed is the major determinant of the turbine capacity factor as illustrated in Figure 7.20. Turbines installed in the lighter areas that dominate Figure 7.19 would generally have capacity factors of $5 \%-15 \%$ that would make it hard to competitively generate electricity given the capital costs of wind farms. Areas with mean wind speeds in excess of 6 meters/second at a height of 80 meters are necessary to achieve capacity factors of $30 \%$ or higher. As a rule, wind speed

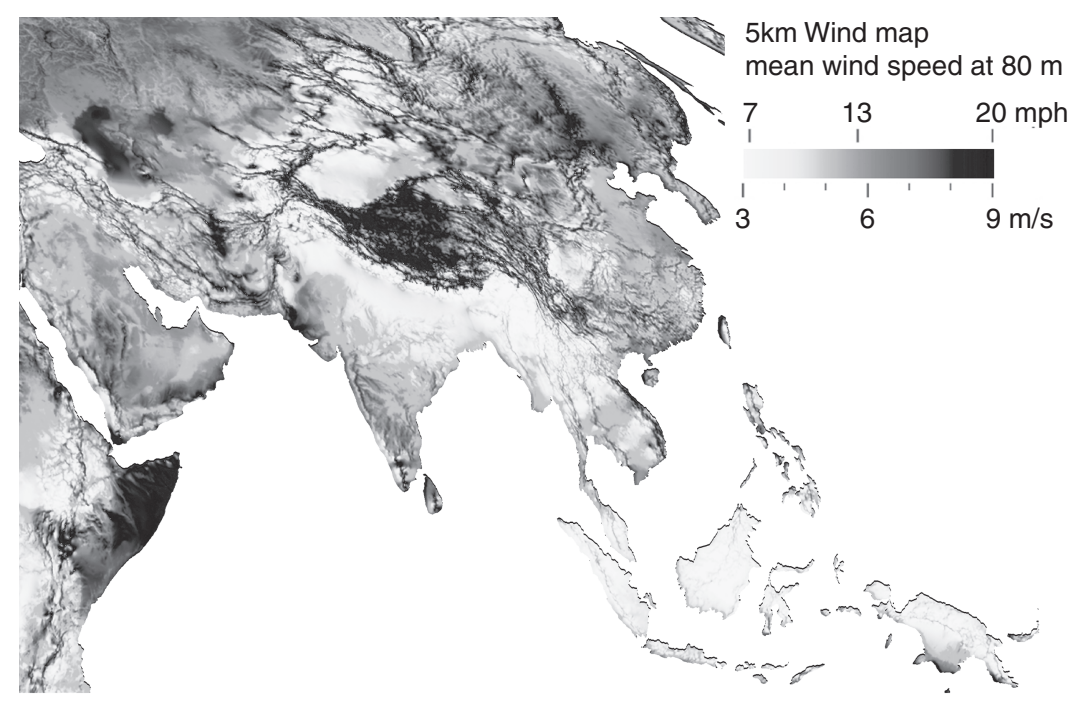

Figure 7.19 Mean wind speed at 80 meters

Source: Cropped and reprinted with permission from www.3tier.com (2011 3Tier Inc.).

Note: $\mathrm{km}=$ kilometer; $\mathrm{m}=$ meter; $\mathrm{m} / \mathrm{s}=$ meters per second. 


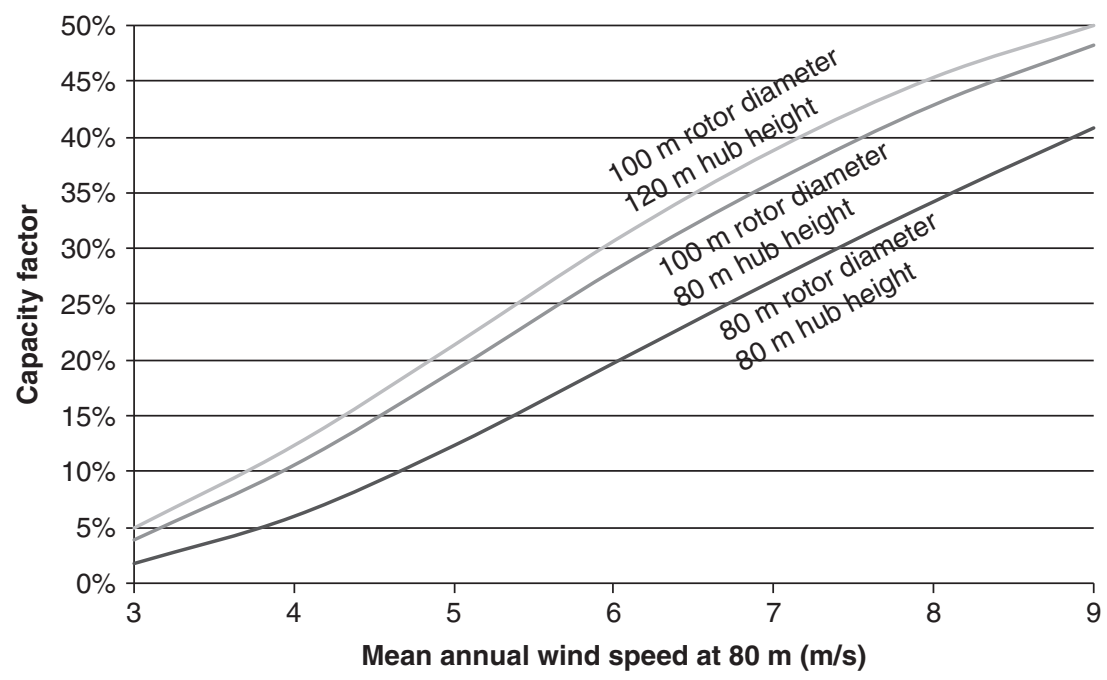

Figure 7.20 Capacity factor for three 1.8 megawatt turbines with different rotor diameters and hub heights

Source: Author.

Note: Calculated from published power curves for two 1.8 megawatt turbines available in 2013 from a single company, assuming wind speeds have a Weibull distribution with a shape factor of 2 , a wind shear exponent of 0.14 , wake losses of $5 \%$, airfoil losses of $3 \%$, miscellaneous losses of $4 \%$, and availability of $97 \% . \mathrm{m}=$ meter, $\mathrm{m} / \mathrm{s}=$ meters per second.

increases with measurement height. ${ }^{31}$ Thus, installing a turbine on a taller (more expensive) tower can improve the capacity factor as seen in Figure 7.20 for the turbine installed at 120 meters versus the turbine installed at 80 meters.

Figure 7.20 shows that the size of the rotor relative to the generator also influences the capacity factor. All the turbines in Figure 7.20 have a 1.8 megawatt generator and take their power rating from it, but the capacity factor is significantly improved when a 100 meter diameter rotor is used instead of an 80 meter one. The larger rotor captures more wind but also costs significantly more.

Turbines with oversized rotors have become more common in the past decade permitting the exploitation of sites with marginal wind resources. For example, to achieve a capacity factor of $30 \%$ with the 80 meter rotor turbine in Figure 7.20 requires a mean wind speed around 7.5 meters/second, i.e., a dark area in Figure 7.19. These areas are rare, especially when considering other constraints (access to transmission lines, proximity to loads). In contrast, the 100 meter rotor turbine can achieve this capacity factor at a mean wind speed only slightly higher than 6 meters/second, opening up all the mid-gray areas of Figure 7.19.

\footnotetext{
${ }^{31}$ The increase in wind speed with height is less significant over flatter surfaces, e.g., water.
} 


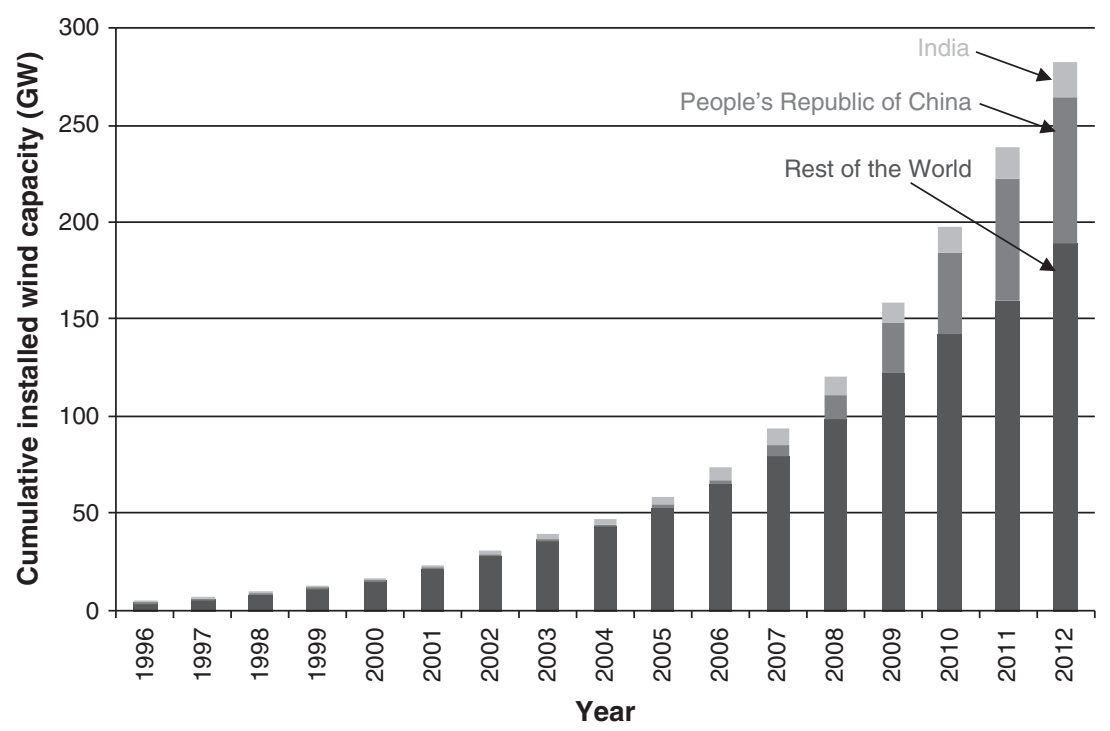

Figure 7.21 Global cumulative installed wind capacity, 1996-2012

Source: GWEC 2013a, The Windpower 2013.

Note: $\mathrm{GW}=$ gigawatt.

Due to the influence of rotor size and hub height, capacity factors cannot be superimposed on Figure 7.19: the capacity factor reflects design decisions, not just the wind speed. Typical capacity factors for recent onshore wind projects range from $20 \%-45 \%$ (IRENA $2012 \mathrm{~b}$ ).

\section{Global market}

Global growth in installed wind capacity, worldwide and in the PRC and India (the two largest Asian markets), is shown in Figure 7.21. In 2012, wind generated around 500 terawatt hours, about $2.5 \%$ of the world's electricity, and around 100 terawatt hours in the PRC alone (estimates derived from 2011 figures in GWEC 2013b). The PRC has more installed wind capacity than any other country (GWEC 2013a).

Asia's increasing importance in the global wind market is evident in Figure 7.22: it has been the largest market in the world since 2009 .

Although the PRC and India dominate the Asian market, the Republic of Korea and Taipei,China have installed around 0.5 gigawatts each, and most Asian nations have some wind projects as shown in Figure 7.23.

In most of Asia, the wind potential has barely been exploited. Figure 7.24 shows one assessment of the technical potential and compares it with capacity installed to date. The PRC and Mongolia could each install over 1 terawatt of 


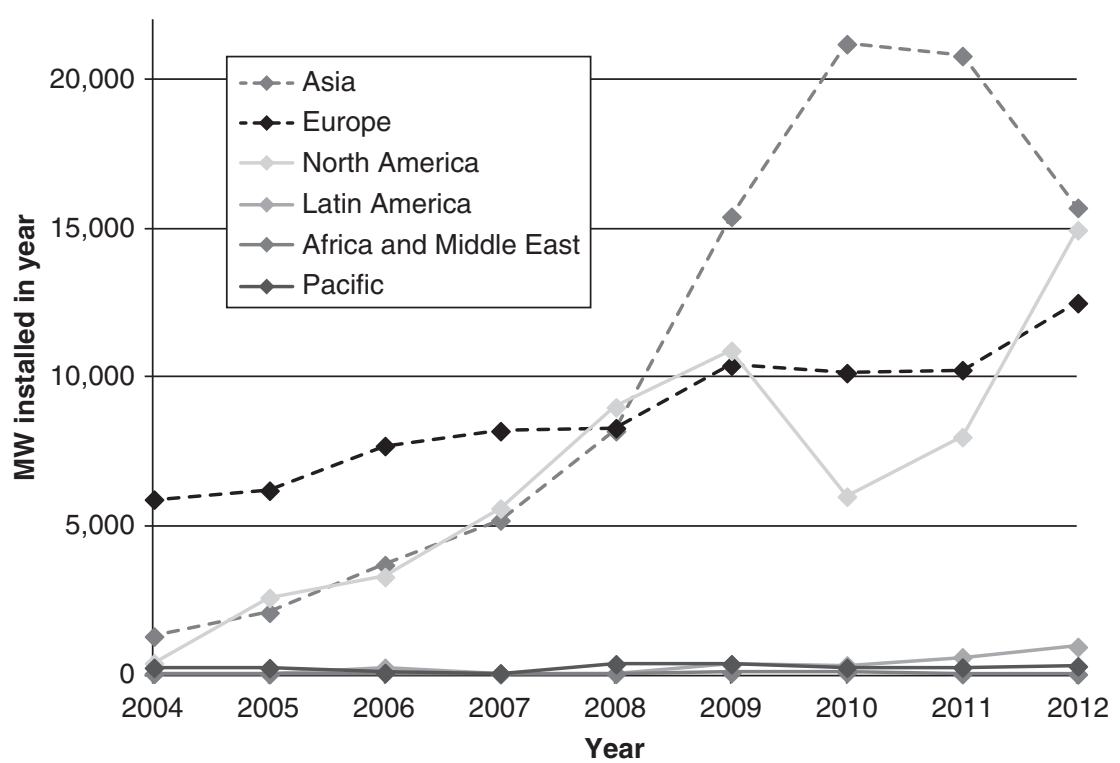

Figure 7.22 Wind capacity installed by continent, 2004-2012

Source: GWEC 2013a.

Note: $\mathrm{MW}=$ megawatt.

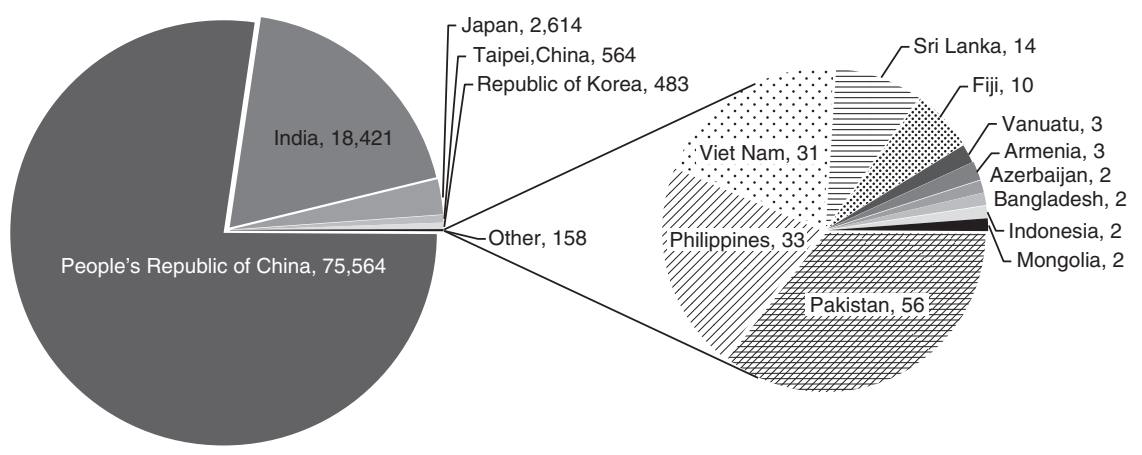

Figure 7.23 Total wind capacity as of 2012 in Asia (megawatts)

Source: GWEC 2013a and The Windpower 2013.

wind capacity, sufficient when combined to generate in excess of 4000 terawatt hours annually. This is roughly equal to the total electricity consumption in the PRC in 2010. Afghanistan, Kazakhstan, and Viet Nam could each install over 100 gigawatts. Only India has exploited more than $5 \%$ of its potential. Figure 7.24 emphasizes the unequal distribution of the wind resource. 


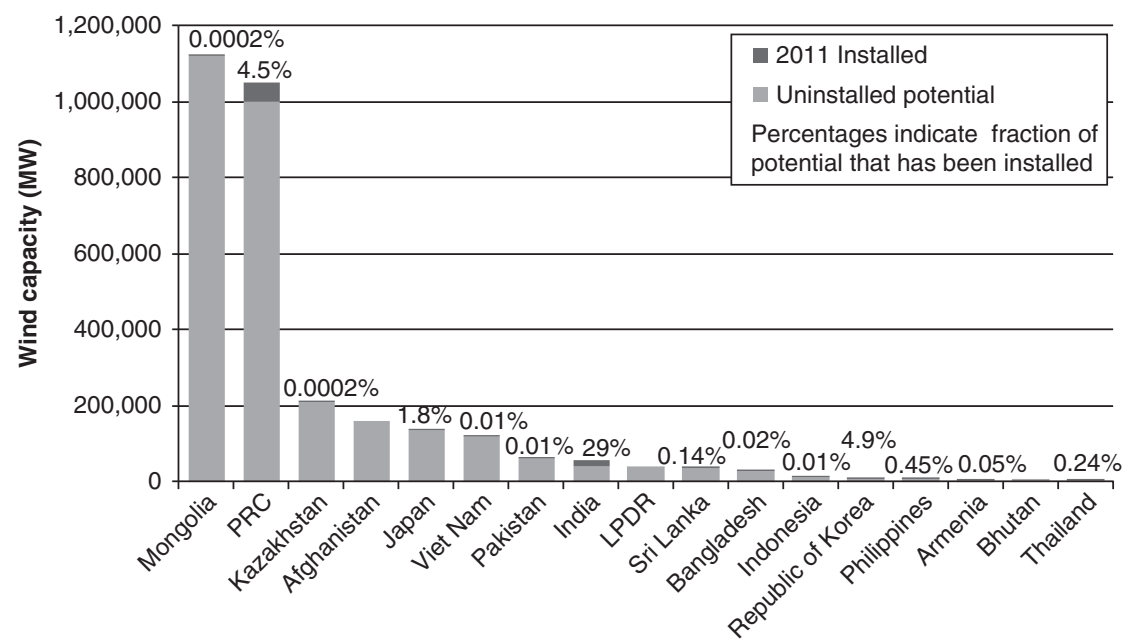

Figure 7.24 Installed capacity and technical potential for wind in Asia Source: Shah 2012.

Note: $\mathrm{MW}=$ megawatt; $\mathrm{PRC}=$ People's Republic of China; LPDR = Lao People's Democratic Republic.

\section{Costs $^{32}$}

Since wind is free, capital costs are the dominant consideration. Figure 7.25 shows the installed capital costs for projects between 1980 and 2005 in Denmark and the US, the two markets with the longest histories. Over this period, capital costs declined from $\$ 3,500 /$ kilowatt to $\$ 1,200 /$ kilowatt in constant dollar terms.

In Europe and North America, the trend of declining capital costs reversed between 2003 and 2008 and have plateaued or declined since then (Figure 7.26). In the PRC and India, however, domestic manufacturing, lower labor costs, and competition were able to keep project costs at $\$ 1,100$ to $\$ 1,500$ even when they peaked in Europe and the US (Lantz, Wiser, and Hand 2012; IRENA 2012b). In 2015 , Indian and PRC project costs are forecast to be as low as \$950-\$1,250/ kilowatt, slightly more than half those in North America or Europe (IRENA 2012b). In 2010, turbine prices in the PRC were half those in North America and one-third those in Japan and higher-cost European markets (Figure 7.27).

\section{Cost effectiveness}

The increase in North American and European costs in the mid-2000s (Figure 7.26) was counteracted by a rise in capacity factors (Figure 7.28) and a decline in

\footnotetext{
${ }^{32}$ This and the following two sections rely heavily on two excellent reviews: Lantz, Wiser, and Hand 2012 and IRENA 2012b.
} 


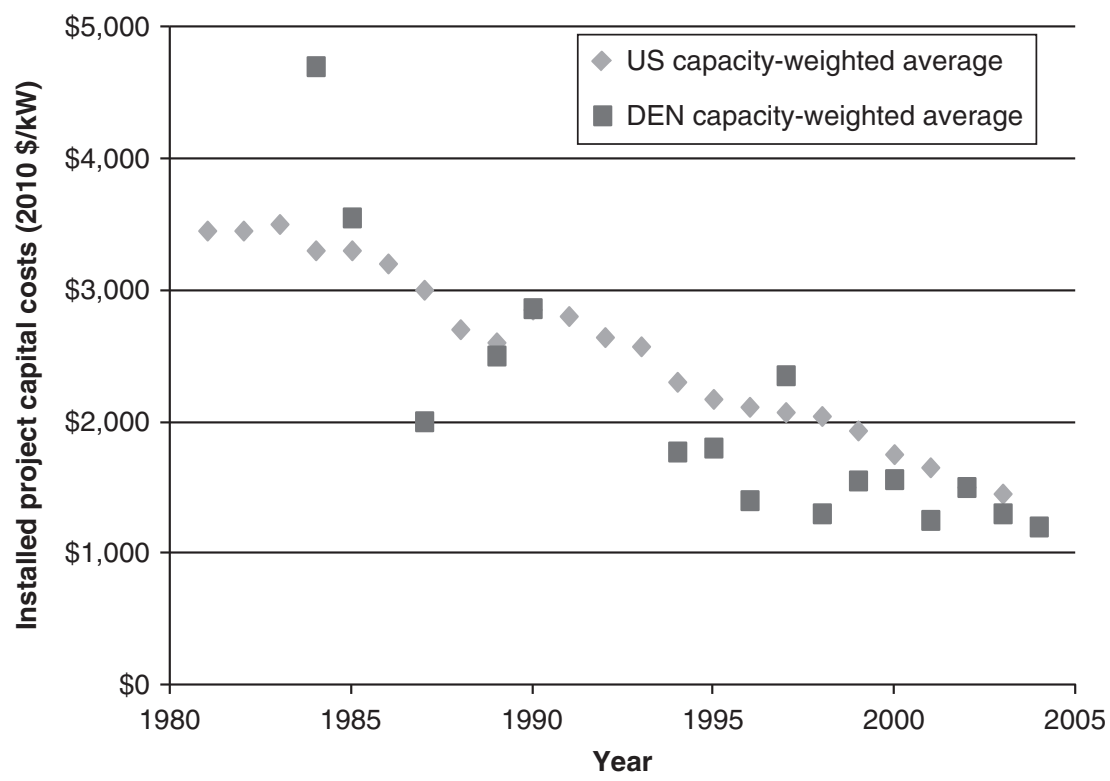

Figure 7.25 Wind project capital costs in Denmark and the United States, 1980-2005 Source: Lantz, Wiser, and Hand 2012.

Note: DEN = Denmark; $\mathrm{kW}=$ kilowatt; US = United States.

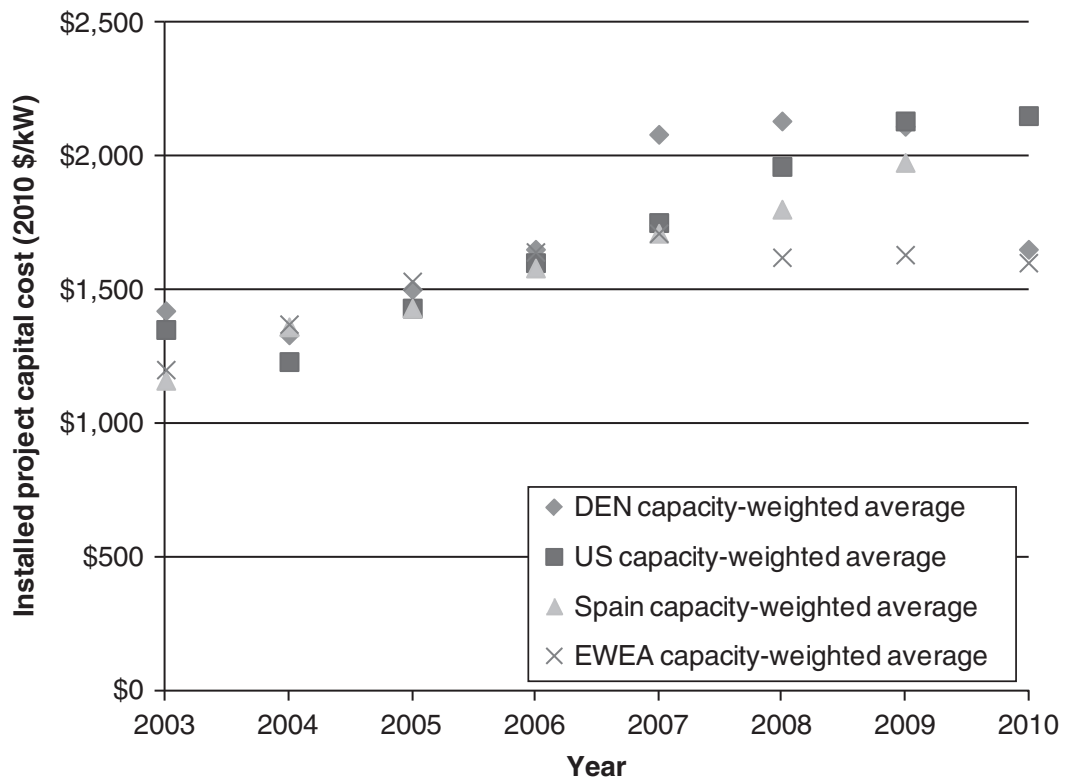

Figure 7.26 Wind project capital costs in Europe and the United States, 2003-2010 Source: Lantz, Wiser, and Hand 2012.

Note: DEN $=$ Denmark; EWEA $=$ European Wind Energy Association; US $=$ United States. 


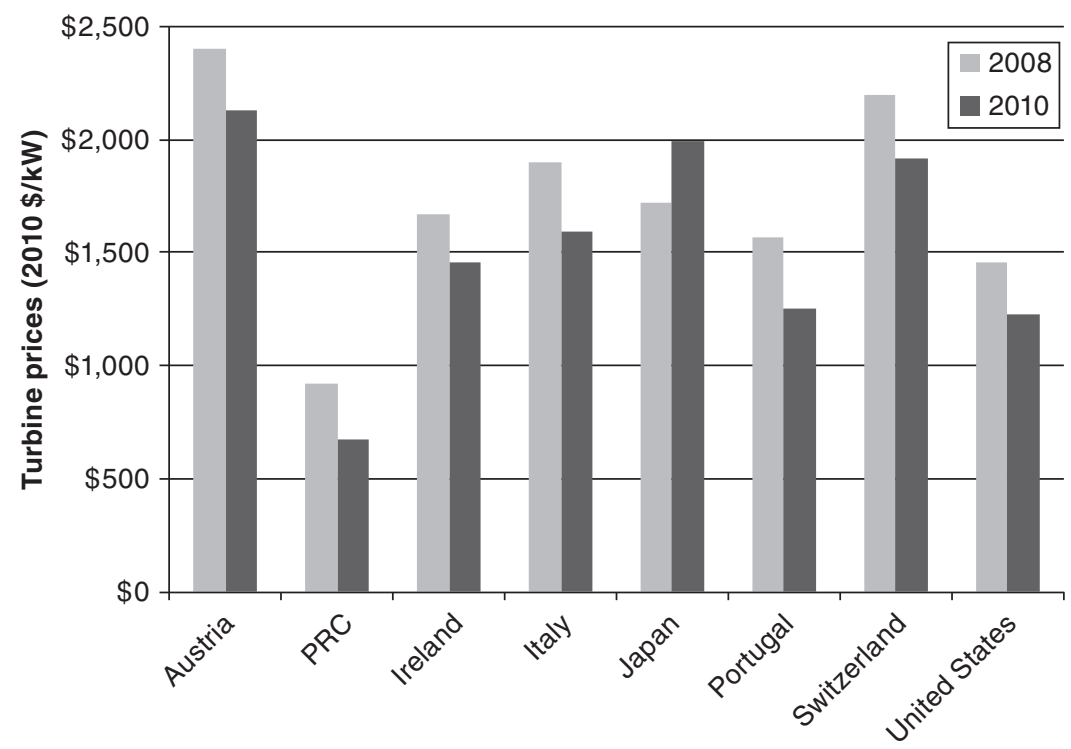

Figure 7.27 Turbine prices in 2008 and 2010 in selected countries Source: IRENA 2012b.

Note: $\mathrm{kW}=$ kilowatt; $\mathrm{PRC}=$ People's Republic of China.

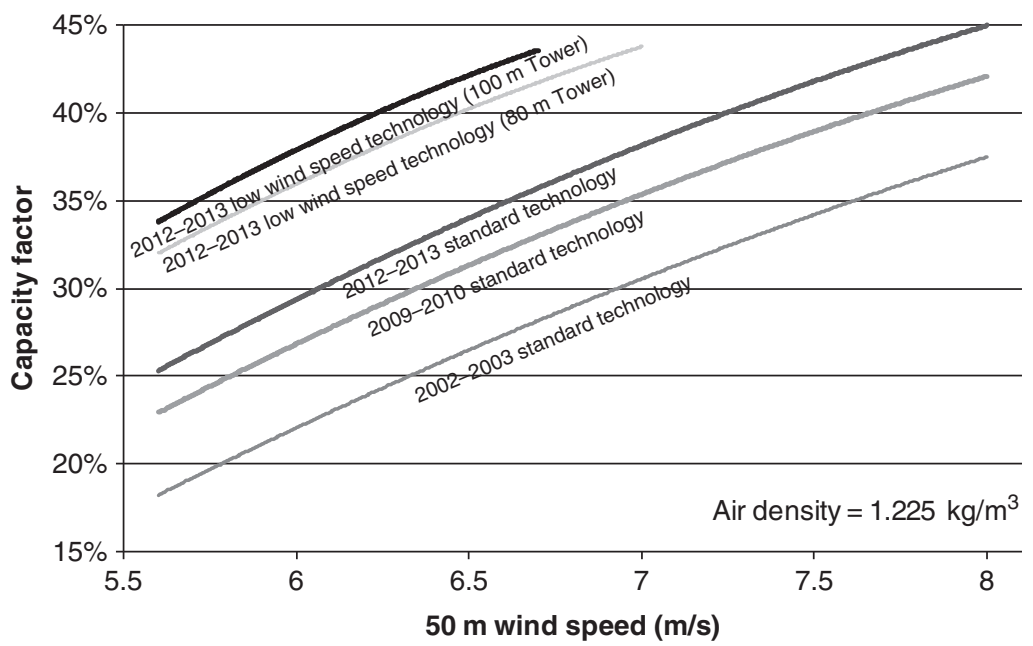

Figure 7.28 Capacity factors achieved by old and new turbine technology Source: Lantz, Wiser, and Hand 2012.

Note: $\mathrm{kg} / \mathrm{m}^{3}=$ kilogram per cubic meter; $\mathrm{m}=$ meter, $\mathrm{m} / \mathrm{s}=$ meters per second. 


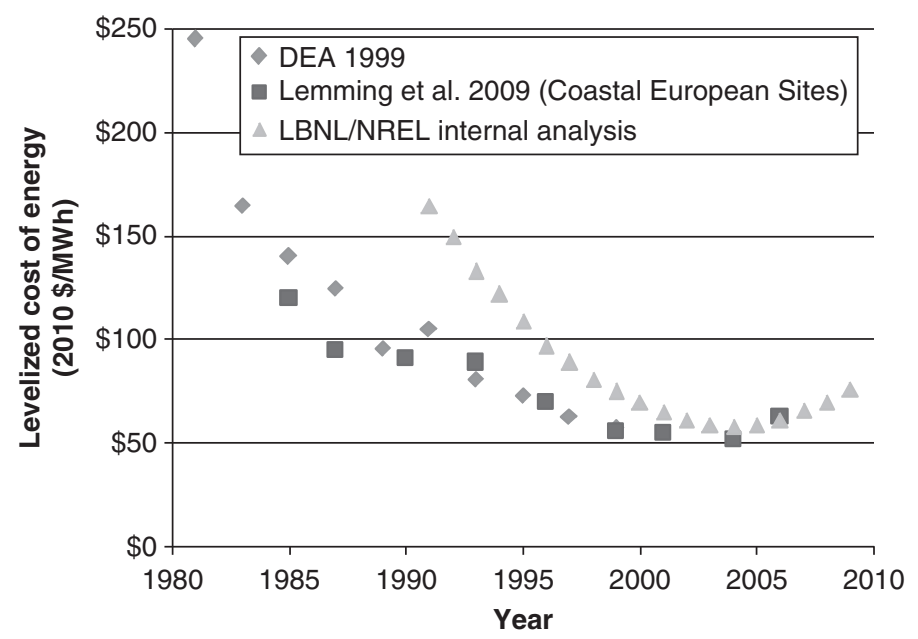

Figure 7.29 Estimated levelized cost of energy for onshore wind in North America and Europe, 1980-2010

Source: Lantz, Wiser, and Hand 2012.

Note: DEA = Danish Energy Agency; LBNL = Lawrence Berkeley National Laboratory; MWh = megawatt hours; NREL $=$ National Renewable Energy Laboratory.

operation and maintenance costs. The resulting rise in the LCOE for wind in these markets was relatively modest as seen in Figure 7.29, especially considering that once the best sites were developed, turbines were installed in weaker wind (Lantz, Wiser, and Hand 2012).

The lower installed costs in the PRC and India would suggest that the LCOE of wind should be $30 \%-45 \%$ lower there than in Europe and North America. Unfortunately, average capacity factors are also lower in Asia: for new wind farms, typical capacity factors are $25 \%-35 \%$ in Europe and $30 \%-45 \%$ in North America, but only $20 \%-30 \%$ in the PRC and India. As a result, their LCOE is comparable to that in Europe and North America.

The simple LCOE for wind energy is indicated in Table 7.9. The middle and high scenarios are similar to the range of estimates in IRENA 2012b. The low scenario might be considered the best possible outcome at a site with a very good wind resource.

Further reductions in the LCOE are possible although the already low costs in the PRC and India may make them hard to achieve (IRENA 2012b). Various estimates of these potential reductions have been made based on learning curve analyses, expert opinion, and engineering analysis. Based on a majority of the studies, a $20 \%-30 \%$ reduction in the LCOE is expected by 2030 (Lantz, Wiser, and Hand 2012). 
Table 7.9 Levelized cost of wind-generated electricity in the People's Republic of China and India, 2011

\begin{tabular}{llll}
\hline Item & Low scenario & Middle scenario & High scenario \\
\hline Installed cost $^{\mathrm{a}}$ & $\$ 1300 / \mathrm{kW}$ & $\$ 1375 / \mathrm{kW}$ & $\$ 1450 / \mathrm{kW}$ \\
Capacity factor $^{\mathrm{b}}$ & $40 \%$ & $30 \%$ & $20 \%$ \\
Discount rate & $4 \%$ & $7 \%$ & $10 \%$ \\
Maintenance costs & $\$ 0.005 / \mathrm{kWh}$ & $\$ 0.01 / \mathrm{kWh}$ & $\$ 0.015 / \mathrm{kWh}$ \\
Lifetime & 25 years & 25 years & 20 years \\
Levelized cost & $\$ 0.029 /$ & $\$ 0.055 /$ & $\$ 0.106 /$ \\
& kilowatt hour & kilowatt hour & kilowatt hour \\
\hline
\end{tabular}

Source: Author.

Notes: $\mathrm{kW}=$ kilowatt; $\mathrm{kWh}=$ kilowatt hour. ${ }^{\mathrm{a}}$ Based on a range of $\$ 1,300$ to $\$ 1,450 /$ kilowatt for typical installations in 2011 given in IRENA $2012 \mathrm{~b}$. ${ }^{\mathrm{b}}$ Based on a range of $20 \%-30 \%$ for typical installations in 2011 (IRENA 2012b) and recognizing that exceptional wind resource sites would result in capacity factors higher than typical. ${ }^{\mathrm{c}}$ Based on estimates of North American operation and maintenance costs of $\$ 0.005$ to $\$ 0.015 /$ kilowatt hour (IRENA 2012b).

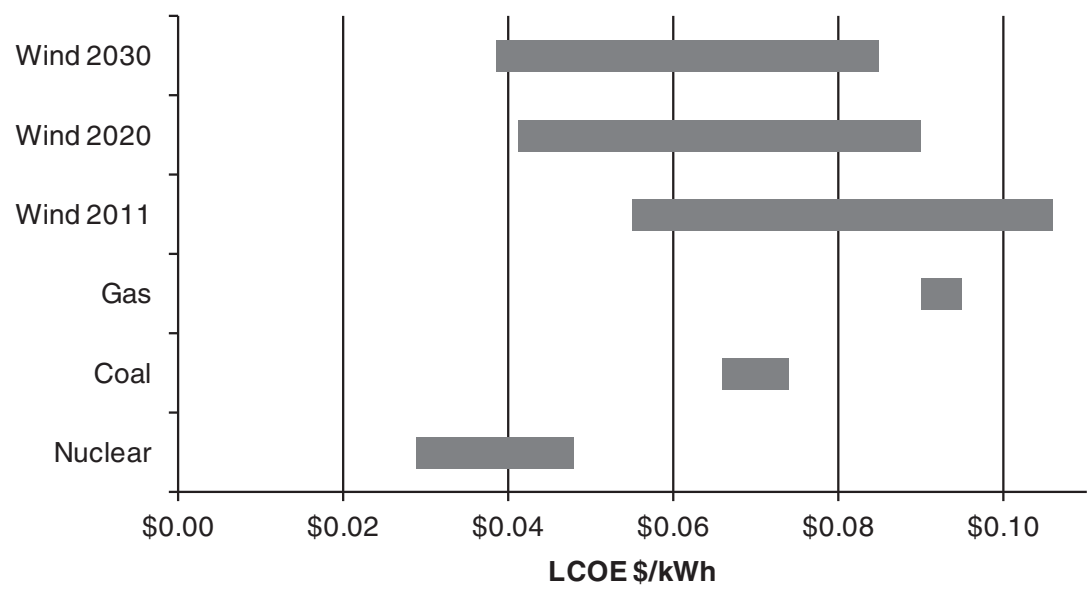

Figure 7.30 Levelized cost for wind-generated electricity versus gas, coal, and nuclear generation in the Republic of Korea in 2011, 2020, and 2030

Source: Author; OECD 2010.

Note: $\mathrm{kWh}=$ kilowatt hour; $\mathrm{LCOE}=$ levelized cost of energy.

Applying the projected decrease in the LCOE to the medium and high scenarios in Table 7.9, the LCOE for wind power at present, in 2020, and in 2030 can be compared to the LCOE for conventional forms of generation. This is done for the Republic of Korea in Figure 7.30 and for the PRC in Figure 7.31.

Wind generation is currently cheaper than photovoltaics. Good wind sites already beat expensive imported coal and gas in the Republic of Korea and will 


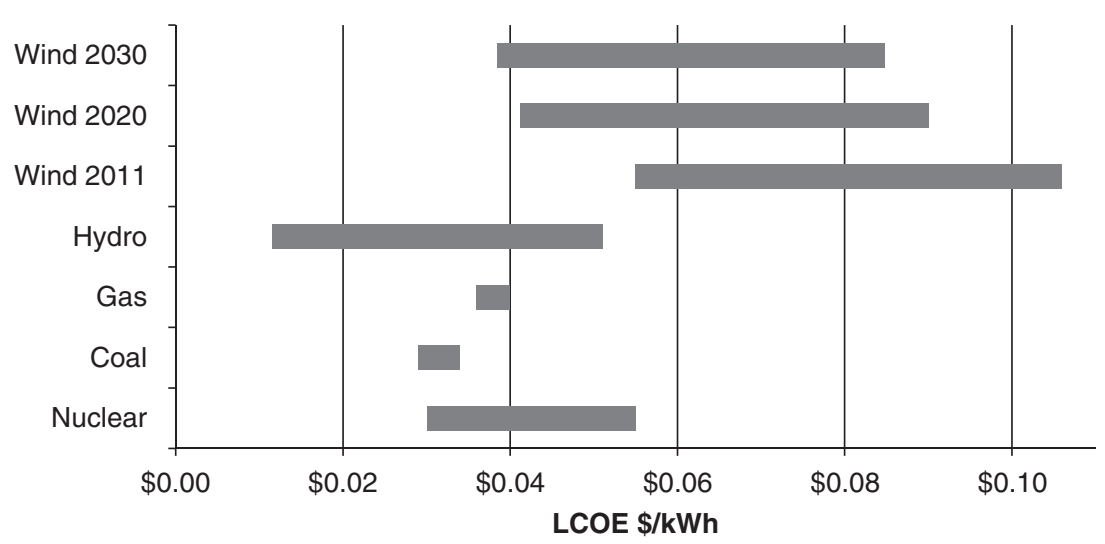

Figure 7.31 Levelized cost for wind-generated electricity versus large hydro, gas, coal, and nuclear generation in the People's Republic of China in 2011, 2020, and 2030

Source: Author; OECD 2010.

Note: $\mathrm{kWh}=$ kilowatt hour; $\mathrm{LCOE}=$ levelized cost of energy.

take on nuclear by 2020. In the PRC where inexpensive gas and coal are used, there is a modest price gap between wind and conventional forms of generation. As for photovoltaics, comparisons should recognize the difference in the value of dispatchable and intermittent generation but also the risks, absent for wind, of fuel cost escalation or future penalties levied on coal and gas emissions.

\section{Limits to grid penetration}

Wind power is growing rapidly in Asia, particularly in the PRC and India, but already some roadblocks to further growth are emerging. Many are the same challenges faced by photovoltaics.

The first challenge is economic. The LCOE for wind is generally still higher than that of conventional generation, although the gap is smaller than that for photovoltaics. The second challenge is financial. Because capacity factors are higher for wind than solar, the capital cost is lower but still huge-perhaps $\$ 900$ billion to purchase the 900 gigawatts of capacity necessary to achieve a 10\% penetration ratio for developing Asia in 2035.

Transmission and distribution infrastructure will be even more of a challenge for wind than for solar since large population centers are rarely windy. When constrained by lack of available transmission capacity, wind output must be curtailed, reducing capacity factors and increasing costs. Transmission and distribution infrastructure is already a problem in the PRC though the wind penetration ratio is only $2 \%$, largely because $25 \%$ of the country's capacity is installed 
in Inner Mongolia, far from major loads. As is true for photovoltaics, transmission capacity dedicated to wind power is expensive because of the variable output and modest capacity factors.

Technical difficulties arising from fluctuating generation are generally associated with penetration ratios above $15 \%-25 \%$. Such difficulties are already appearing in the PRC, but these reflect weaknesses in the grid and limitations of the wind turbine technology installed there prior to the recent implementation of grid connection standards. In contrast, wind penetration levels of $10 \%-20 \%$ have been achieved in Denmark, parts of northern Germany, Ireland, Portugal, and Spain without significant difficulties, though wind output is sometimes curtailed. Ireland, Portugal, and Spain are especially notable because they have limited interconnections with neighboring countries. Grid integration costs are generally modest, perhaps $\$ 1-\$ 6 /$ megawatt hour for wind penetration ratios of $20 \%-25 \%$ (OECD 2010), or 2\%-10\% of the cost of wind power at good sites.

The average output of geographically dispersed turbines varies less than the output of a single turbine. Unlike photovoltaics, wind can produce power at night. On the one hand, this means it is largely uncorrelated with peak loads and tends to offset cheap baseload generation rather than expensive peaking power. On the other, combined with geographic averaging, it can mean less variability and more efficient use of dedicated transmission capacity.

Land problems are different for wind and photovoltaics. Unlike photovoltaics, wind can be installed in actively farmed land or in forests; the turbines, access roads, and substations occupy just $1 \%-3 \%$ of the land. Good wind sites-with a strong resource, near transmission capacity, set back from dwellings, and unlikely to interfere with migrating birds and bats-are, however, limited, and once they are developed, attention turns to lesser sites. These will have poorer wind resources, higher development costs, or both. As for photovoltaics, storage may be necessary to accommodate very high penetration ratios of intermittent generation $(40 \%-50 \%$ or more). These considerations suggest that a penetration rate of $10 \%-20 \%$ for photovoltaics and wind combined will be difficult to achieve before 2035 .

\section{Offshore wind}

Turbines may also be sited in shallow lakes or seas. Interest in offshore wind has grown because the resource is better, coastal population centers may lack or have already developed all suitable onshore sites nearby, and very large offshore sites can accommodate very large turbines. There are also serious disadvantages. Construction and maintenance at sea are challenging, undersea foundations and power transmission are expensive, and turbines must withstand the harsh maritime environment. As a result, offshore wind is still expensive. Capital costs of $\$ 2,500 /$ kilowatt in the PRC are lower than in Europe $(\$ 4,000 /$ kilowatt) but twice those of onshore wind, and the capacity factors of some existing offshore projects are under $30 \%$. European maintenance costs are $\$ 0.025$ to $\$ 0.05 /$ kilowatt hour (IRENA 2012b). Offshore projects represent only around $2.5 \%$ of the global wind market (GWEC 2012a). 
Some analysts see considerable room for cost reductions in offshore wind, but recent trends have not been encouraging (Figure 7.32). The LCOE for offshore wind is $25 \%-75 \%$ higher than that for onshore wind and appears to be rising as sites are chosen further from shore. Turbines built specifically to withstand the rigors of the sea also inflate prices. One study concluded that offshore wind "will probably always be more expensive" than onshore wind (IRENA 2012b). The continued interest largely reflects European needs to find new wind sites to achieve ambitious renewable energy targets.

In 2011, the PRC's 260 megawatts of offshore demonstration projects were sufficient to rank it third in the world. Lackluster progress calls into question official targets of 5 gigawatts by 2015 and 30 gigawatts by 2020, however. The Republic of Korea is planning a 2.5 gigawatt offshore wind project (GWEC 2012a).

\section{Environmental concerns}

Wind energy has only minor environmental impacts.

- GHG emissions associated with turbine manufacture and project construction are around 3 to 45 grams of $\mathrm{CO}_{2}$ equivalent per kilowatt hour (Dolan and Heath 2012) compared with around 60 grams for photovoltaics, 400 grams

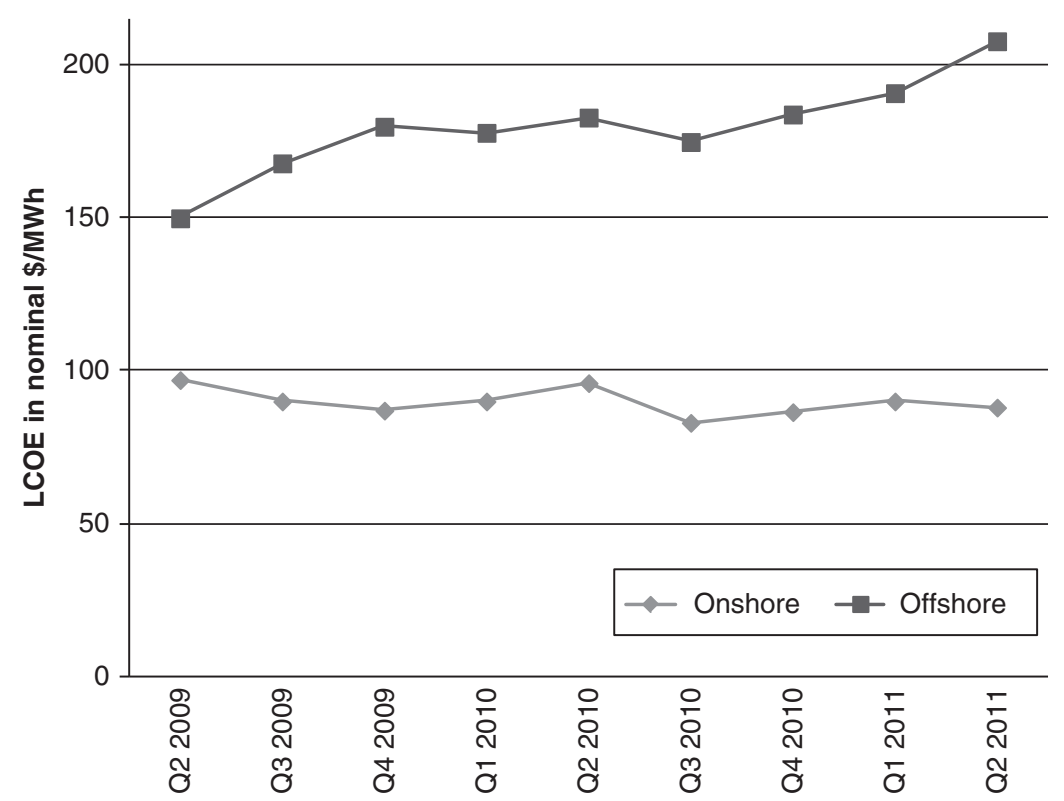

Figure 7.32 Average levelized cost of onshore and offshore wind generation, 2009-2011

Source: IRENA 2012b.

Note: $\mathrm{MWh}=$ megawatt hours; $\mathrm{Q}=$ quarter. 
for natural gas, and 900 grams for coal. Accommodating intermittent wind generation can lead to cycling and inefficiency in thermal plants, but this is unlikely to make wind as polluting as fossil fuels (Dolan and Heath 2012).

- $\quad$ Birds and bats, particularly migrating tree bats, can be killed in large numbers by a wind farm. For most species and most wind farms, the impact is minor compared with other threats including buildings, household cats, and habitat destruction. Nevertheless, wind farms sited in migratory pathways have been problematic, and there is uncertainty about the nature and scale of the problem for certain types of bats (NWCC 2010).

- Large wind farms can cause downstream turbulence that enhances the vertical movement of air and heat. As a result, local changes in climate, such as higher nighttime temperatures and cooler daytime temperatures, can be observed (Zhou et al. 2012).

Particularly in North America, there have been objections to noise and visual pollution associated with wind farms. Where turbines are set back from human habitation by half a kilometer or more, scientific evidence of adverse health impacts from noise pollution does not exist (Government of Australia, NHMRC 2010). Noise and visual pollution complaints are rare among people who earn revenues from turbines on their land.

\section{Asian wind industry}

By 2010, 4 of the top 10 wind turbine manufacturers were in the PRC, together producing around $30 \%$ of the world's turbines, though mainly for the domestic market. They generally build turbines and parts that can be traced to foreign designs and technology which may limit their ability to expand into foreign markets (Yang, Qian, and Cui 2012). Foreign manufacturers also have facilities in the PRC.

Wind manufacturing companies in India, both domestic and foreign, can build 10 gigawatts of capacity annually. One Indian company is in the top 10 manufacturers in the world. Taking advantage of low labor costs, parts (e.g., blades) are exported abroad (GWEC 2012b). Smaller wind industries including turbine and turbine part manufacturing exist in the Republic of Korea and Taipei,China (GWEC 2012a).

\section{Winners and losers}

While solar offers all Asian countries a clean energy alternative, some have been blessed with wind more than others. Mongolia has been blessed most of all; if the expensive transmission infrastructure can be built, wind could provide clean power to address its own serious air pollution problems and for export to the PRC. Mongolia is commissioning a 50 megawatt wind farm, a small first step in this direction (Kohn 2012). The PRC also has a strong onshore and offshore wind resource. Its manufacturing industry faces challenges but is large and supplies a giant domestic market. Afghanistan, Kazakhstan, and Viet Nam also have sizeable areas with a strong wind resource. Others have less bountiful resources but 
still have spots where the wind is good. India is an example. Although most of its landmass has modest winds, it has taken advantage of what it has and built a domestic wind industry. The Republic of Korea and Taipei,China have similar opportunities.

There are few losers from wind, especially if feed-in tariffs and other incentives are kept low and ratchet downwards over time. But like photovoltaics, wind cannot solve the serious climate problems that face Asia and the world and must not be permitted to detract from efficiency and conservation efforts.

\section{Appendix: Formation and exploitation of natural gas}

The methane in natural gas typically forms from organic matter contained in sedimentary rock layers. Over time, it may migrate out of these source rock layers. In some situations, it will enter rock formations that are both porous (i.e., containing many voids that the gas can fill) and permeable (i.e., the pores are interconnected, allowing gas to move through the rock). This may permit the gas to accumulate in reservoirs trapped under a cap of impermeable rock. If a well penetrates this reservoir, gas will flow out under its own pressure. This is "conventional" gas (see Figure 7A below).

Only a fraction of the gas ends up in conventional reservoirs, however. Some enters much less porous and less permeable formations. When they are penetrated by a well, little gas flows: the formation does not permit gas to migrate. This form

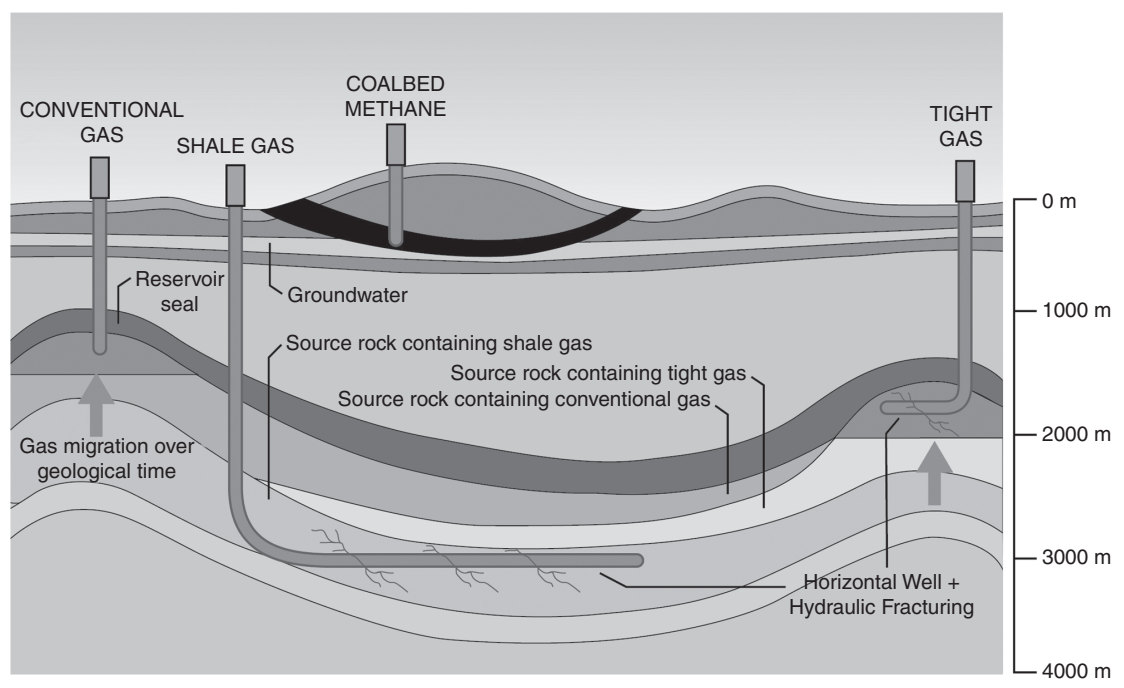

Figure $7 A$ Geology of conventional and unconventional gas

Source: Government of Western Australia, Department of Mines and Petroleum 2013a. Reprinted with permission. 
of "unconventional" gas is tight gas. Some gas also remains trapped in the source rocks, for example, as shale gas, a second form of unconventional gas. ${ }^{33}$

Due to the low permeability of the formation, tight gas and shale gas will not naturally flow into a well. Hydraulically fracturing, or "fracking," artificially increases its permeability allowing gas to flow. Typically, "slick water" fracking is used: large quantities of water mixed with lubricants, biocides, surfactants, corrosion inhibitors, scale inhibitors, and "proppants" are injected into the well, thus pressurizing the formation to between 340 and 540 times atmospheric pressure and breaking the rock (Ramudo and Murphy 2010). The proppants-often sand-enter the fractures and prevent them from reclosing (Government of Western Australia, Department of Mines and Petroleum 2013b).

After fracturing, the water, mixed with natural gas, flows back out of the well. Over a period of days to weeks, the water flow tails off and the gas picks up. The water is collected for treatment, storage, and disposal. It contains the chemicals originally injected into the well plus salts that were contained in the formation and sometimes even radioactive compounds. Some of the injected water remains in the ground.

Fracturing liberates the gas in a localized area of the formation. To liberate more gas, a large region must be fractured. This is achieved by multiple stage fracking in which the process is repeated 4 to 20 times (Ramudo and Murphy 2010) with each pressurization fracturing a new region of the formation.

Multiple fracking will have limited utility, however, if a vertical well passes through a horizontally situated gas-bearing formation. To further increase the area accessed by the well, "horizontal drilling" is used: the well descends vertically to the level of the formation and then turns to a horizontal orientation (Ground Water Protection Council and ALL Consulting 2009).

Geologists have long known of the existence of shale gas and tight gas, but they were not thought to be accessible at a reasonable cost. Over the last few decades, however, it has been shown that the combination of (multiple) fracking and horizontal drilling can sufficiently raise the permeability of resource-rich formations to liberate large quantities of gas at a cost that may be competitive with conventional gas (Medlock, Jaffe, and Hartley 2011).

Coal beds are a third source of unconventional gas. Methane is often adsorbed into the coal matrix and held in place by water pressure. When water is removed, the methane desorbs.

In a mine, the resulting gas is called coal mine methane (CMM). It is flammable, so operators try to drain it. If simply vented to the atmosphere, the methane, a potent greenhouse gas, will contribute to global climate change. The gas may instead be utilized, thought it may first require processing. Often it is simply flared. It is also possible to drill into a coal seam from the surface, remove the water, and induce production of natural gas. This is called coal bed methane

\footnotetext{
${ }^{33}$ Another distinguishing feature of shale is the extremely low permeability of the formation, orders of magnitude lower than for tight gas formations.
} 
(CBM). Often fracking is involved, and horizontal drilling may be used in deeper coal seams (IEA 2012b).

\section{References}

Accenture. 2012. Water and Shale Gas Development. Accenture.

Alvarez, R. A., S. W. Pacala, J. J. Winebrake, W. L. Chameides, and S. P. Hamburg. 2012. Greater Focus Needed on Methane Leakage from Natural Gas Infrastructure. Proceedings of the National Academy of Sciences. 109 (17). pp. 6435-6440.

Asian Development Bank (ADB). 2003. Indonesian Coalbed Methane: Task 1b: CBM Pilots, Data Base, and in-Country Capabilities. Manila: Advance Resources International, Inc.

—. 2013. Asian Development Outlook: Asia's Energy Challenge. Manila: ADB.

Awerbuch, S. 1996. New Economic Perspectives for Valuing Solar Technologies. Advances in Solar Energy, An Annual Review of Research and Development, vol 10. Boulder: ASES.

Barber, D. A. 2012. EPIA Report: Worldwide PV at 67.4 GW. Energy Trend PV. 10 February. http://pv.energytrend.com/research/research_solar_20120210.html (accessed 11 May 2014).

Bazilian, M., I. Onyeji, M. Liebreich, I. MacGill, J. Chase, J. Shah, D. Gielen, D. Arent, D. Landfear, and S. Zhengrong. 2012. Reconsidering the Economics of Photovoltaic Power. Bloomberg New Energy Finance. 16 May.

Bintang, H. 2012. NuEnergy's Sumatra Blocks Might Contain 6 TCF of Gas. Indonesia Today. 8 October.

Breyer, Ch. and A. Gerlach. 2010. Global Overview on Grid-Parity Event Dynamics. Proceedings of the 25th European Union Photovoltaic Solar Energy Conference/World Conference on Photovoltaic Energy Conversion-5. Valencia, Spain. 6-9 September.

BP. 2012. BP Statistical Review of World Energy 2012. London: BP.

Butkiewicz, L. 2012. The Shale Gas Revolution: Implications for US and Canadian Energy Policy and Asian Energy Security: An Interview with James Slutz. National Bureau of Asian Research. 4 September.

Calthes, L. M., L. Brown, M. Taam, and A. Hunter. 2012. A Commentary on the GreenhouseGas Footprint of Natural Gas in Shale Formations by R. W. Howarth, R. Santoro, and Anthony Ingraffea. Climatic Change. 113. pp. 525-535.

Coal Bed Methane (CBM) Asia Development Corp. 2013. Coal Bed Methane in Indonesia. http://www.cbmasia.ca/CBM-In-Indonesia (accessed February 2014).

[People's Republic of] China Greentech Initiative. 2012. The [People's Republic of] China Greentech Report 2012. Greentech Networks Limited.

[People's Republic of] China National Petroleum Corporation. 2013. Ordos Basin. http:// classic.cnpc.com.cn/en/press/publications/brochure/PageAssets/Images/pdf/19-Ordos\% 20Basin.pdf (accessed 11 May 2014).

[People's Republic of] China University of Petroleum. 2008. Feasibility Study of Coal Bed Methane Production in [the People's Republic of] China (EuropeAid/120723/D/SV/ $\mathrm{CN}$ ). European Union-[People's Republic of] China Energy and Environment Program.

Choudhury, N. 2012. [People's Republic of] China Dominates Top Ten Global Solar Manufacturers. PV-Tech. 27 March.

Credit Suisse. 2012. Connections Series: The Shale Revolution. 13 December.

Council of Scientific Society Presidents (CSSP). 2010. Letter, May 4, 2010. Retrieved from http://www.eeb.cornell.edu/howarth/CCSP\%20letter\%20on\%20energy\%20\&\% 20environment.pdf. Washington, DC (accessed 11 May 2014). 
Dai, J., Y. Ni, and X. Wu. 2012. Tight Gas in [People's Republic of] China and its Significance in Exploration and Exploitation. Petroleum Exploration and Development. 39 (3). pp. 277-284.

Dart Energy Ltd. 2013. India. http://www.dartenergy.com.au/page/Worldwide/India/ (accessed February 2014).

Dittrick, P. 2012. [People's Republic of] China Shale Gas Holds Great Promise, Shell Executive Says. Oil and Gas Journal. 5 June.

Dolan, S. L. and G. A. Heath. 2012. Life-Cycle Greenhouse Gas Emissions from UtilityScale Wind Power. Journal of Industrial Ecology. 16 (S1). pp. S136-S154.

Economist Intelligence Unit (EIU). 2011. Breaking New Ground: A Special Report on Global Shale Gas Developments. London, UK: Economist Intelligence Unit.

Energy Trend PV. 2013. TrendForce: PV Market to Flourish in Asia in 2013. EnergyTrend $P V$. http://pv.energytrend.com/research/20130107-4841.html (accessed February 2014).

European Photovoltaic Industry Association (EPIA). 2012. Global Market Outlook for Photovotlaics Until 2016. Brussels: European Photovoltaics Industry Association.

Feldman, D., G. Barbose, R. Margolis, R. Wiser, N. Darghouth, and A. Goodrich. 2012. Photovoltaic (PV) Pricing Trends: Historical, Recent, and Near-Term Projects. Washington, DC: United States Department of Energy.

Focus Reports. 2012. Indonesia: Re-energizing the Archipelago. In Indonesia Oil and Gas Report. October http://issuu.com/focusreports/docs/indonesia_oil_gas_report_ october_2012 (accessed February 2014).

Fontevecchia, A. 2012. Stick with Oil: Natural Gas Prices Still Far from Covering Production Costs. Forbes. 23 July.

Forster, D. and J. Perks. 2012. Climate Impact of Potential Shale Gas Production in the EU-Report for the European Commission DG CLIMA. AEA Technology PLC. 30 July.

Fuller, R. 2009. Lead Exposures From Car Batteries: A Global Problem. Environmental Health Perspectives. 117 (12). p. A535.

Gao, F. 2012. Will There Be a Shale Gas Revolution in [People's Republic of] China by 2020? Oxford Institute for Energy Studies. April.

Global Wind Energy Council (GWEC). 2012a. Global Wind Report Annual Market Update 2011. Brussels: Global Wind Energy Council.

—. 2012b. India Wind Energy Outlook 2012. Brussels: Global Wind Energy Council.

—. 2013a. Global Wind Statistics 2012. Brussels: Global Wind Energy Council.

—. 2013b. Wind in Numbers. http://www.gwec.net/global-figures/wind-in-numbers/ (accessed February 2014).

Gold, R. and M. Kruk. 2012. Will Shale Bonanza Be North America's Exclusive Prize? Wall Street Journal. 6 December.

Government of Australia, National Health and Medical Research Council (NHMRC). 2010. Wind Turbines and Health: A Rapid Review of the Evidence. Canberra: National Health and Medical Research Council.

Government of India, Ministry of Petroleum and Natural Gas. 2012. Production of Coal Bed Methane to reach 4 MMSCMD by 2016-2017. New Delhi: Press Information Bureau.

Government of the United States, Environmental Protection Agency (EPA). 2010. Coal Mine Methane Country Profiles. Coal Bed Methane Outreach Program. Washington, DC: Environmental Protection Agency.

—, - 2011. Draft Appendices to the Report Global Anthropogenic Non-CO2 Greenhouse Gas Emissions: 1990-2030 EPA 430-D-11-003. Washington, DC: Environmental Protection Agency. 
Department of Energy, Energy Information Administration (EIA). 2011a. World Shale Gas Resources: An Initial Assessment of 14 Regions Outside the United States. Washington, DC: Department of Energy.

—_ 2011b. Review of Emerging Resources: The US Shale Gas and Shale Oil Plays. Washington, DC: Department of Energy.

—_ 2012a. The US Surpassed [the Russian Federation] as World's Leading Producer of Dry Natural Gas in 2009 and 2010. http://www.eia.gov/todayinenergy/detail. cfm?id=5370 (accessed February 2014).

—__ 2012b. US Natural Gas Wellhead Price (Dollars per Thousand Cubic Feet). http://tonto.eia.gov/dnav/ng/hist/n9190us3m.htm (accessed February 2014).

— - 2012c. Annual Energy Outlook 2013 Early Release Overview. http://www.eia. gov/forecasts/aeo/er/pdf/0383er(2013).pdf (accessed February 2014).

—_- 2012d. Annual Energy Outlook 2012. http://www.eia.gov/forecasts/archive/ aeo12/pdf/0383(2012).pdf (accessed February 2014).

—_— 2013. Indonesia. http://www.eia.gov/countries/analysisbriefs/Indonesia/ indonesia.pdf. (accessed February 2014).

—. National Renewable Energy Laboratory (NREL). 2013. Simple Levelized Cost of Energy (LCOE) Calculator Documentation. http://www.nrel.gov/analysis/tech_lcoe_ documentation.html (accessed February 2014).

—. United States Geological Survey (USGS). 2011. Assessment of Potential Shale Gas Resources of the Bombay, Cauvery, and Krishna-Godavari Geologic Provinces, India, 2011. Fact Sheet 2011-3131. Washington, DC: Department of the Interior.

Government of Western Australia, Department of Mines and Petroleum. 2013a. Petroleum Fact Sheet: Gas Resource Types. http://www.dmp.wa.gov.au/documents/132499_ Resources_Type_Fact_Sheet.pdf (accessed February 2014).

— 2013 b. Natural Gas from Shale and Tight Rocks Fact Sheet: Hydraulic Fracture Stimulation: The Basics. http://www.dmp.wa.gov.au/documents/Hydraulic_fracture_ stimulation_the_basics.pdf (accessed February 2014).

Ground Water Protection Council and ALL Consulting. 2009. Modern Shale Gas Development in the United States: A Primer. Washington, DC: US Department of Energy.

Gruenspecht, H. 2012. Natural Gas Markets: Recent Changes and Key Drivers. Presentation at the LDC Gas Forum. Chicago, IL. 11 September.

Hart Energy Research Group. 2011. Global Shale Gas Study. Houston, TX: Hart Energy Publishing.

Holditch, S. A., and H. Madani. 2010. Global Unconventional Gas: It is There, But is It Profitable? Journal of Petroleum Technology. December. pp. 42-49.

Howarth, R. W., R. Santoro, and A. Ingraffea. 2011. Venting and Leaking of Methane from Shale Gas Development. Climatic Change. 106. pp. 679-690.

Huang, S. 2010. Great Potential for CBM/CMM Recovery and Utilization and Preferential Policies. Presentation at the Methane to Markets Partnership Expo. New Delhi, India. 3 March.

- 2012. Preferential Policy and International Action of CBM/CMM Development in [People's Republic of] China. Presentation at the Coal Mining Methane Abatement Seminar. Sydney, Australia. 4-5 September.

Hughes, D. Shale Gas Production By Play, 2000-2012. Hughes GSR, Inc. http://i.bnet. $\mathrm{com} / \mathrm{blogs} /$ shale-gas-production-by-play-2000-2012-hughes.jpg?tag=content;siu-container (accessed February 2014).

Hume, M. 2012. Fissures Appear in Scientists' Assurances About Safety of Fracking. The Globe and Mail. 9 December. 
International Electrotechnical Commission (IEC). 2011. Electrical Energy Storage White Paper. Geneva: International Electrotechnical Commission.

International Energy Agency (IEA). 2011a. World Energy Outlook 2011 Special Report: Are We Entering a Golden Age of Gas? Paris: International Energy Agency.

—. 2011b. Renewable Energy Technologies: Solar Energy Perspectives. Paris: International Energy Agency.

—. 2012a. World Energy Outlook 2012 Executive Summary. Paris: International Energy Agency.

_ 2012b. Golden Rules for a Golden Age of Gas: World Energy Outlook Special Report on Unconventional Gas. Paris: International Energy Agency.

IEA Photovoltaic Power Systems Programme (PVPS). 2012. Trends in Photovoltaic Applications. Survey Report of Selected IEA Countries Between 1992 and 2011. Report IEA-PVPS T1-21:2012. Paris: International Energy Agency.

International Renewable Energy Agency (IRENA). 2012a. Renewable Energy Technologies: Cost Analysis Series. Solar Photovoltaics. 1: Power Sector (4/5). Abu Dhabi: International Renewable Energy Agency.

—. 2012b. Renewable Energy Technologies: Cost Analysis Series. Wind Power. 1: Power Sector (5/5). Abu Dhabi: International Renewable Energy Agency.

iSuppli. 2012. Global Photovoltaic Market Will Finish Year with Slower Growth. IHS iSuppli Market Research. 16 November.

Jacobi, J. and R. D. Starkweather. 2010. Solar Photovoltaic Plant Operating and Maintenance Costs. ScottMaden. September.

Jain, T., A. Sharma, and A. Agarwal. 2012. Current Scenario and Future Prospects of Shale Gas in India. Search and Discovery Article 80276. 31 December.

Jia, C., M. Zheng, and Y. Zhang. 2012. Unconventional hydrocarbon resources in [People's Republic of] China and the prospect of exploration and development. Petroleum Exploration and Development. 39 (2). pp. 139-146.

Katakey, R. 2012a. ONGC to Study Conoco's US Shale Assets as It Seeks Deal. Bloomberg. 4 April.

—. 2012b. First Indian Shale Gas Seen in 4 Years, [People's Republic of] China Output Nears. Bloomberg.17 May.

Katakey, R., D. Sethuraman, and G. Aibing. 2012. [People's Republic of] China Shale Delay to Boost LNG Imports in Boon for Exxon: Energy. Bloomberg. 14 February.

Kim, A. and Z. Yu. 2012. [People's Republic of] China's Vast Shale Gas Potential Limited By Pipeline Infrastructure Obstacles. Financial Times. 18 March.

Kohn, M. 2012. Severely Polluted Mongolia Tries a Cleaner Power Source. New York Times. 3 December.

KPMG. 2011. Shale Gas: A Global Perspective. KPMG International.

Lantz, E., R. Wiser, and M. Hand. 2012. The Past and Future Costs of Wind Energy. Golden, CO: National Renewable Energy Laboratory.

Leith, B. 2012. Hydraulic Fracturing: The State of the Science. United States Geological Survey. www.usgs.gov/solutions/ppt/2012june08_leith.pptx (accessed February 2014).

Lelyveld, M. 2012. [People's Republic of] China Debates Shale Gas Growth. Radio Free Asia. 16 July.

Liebreich, M. 2011. Catalysing Investment in Low-Carbon, Climate Resilient Growth. Presentation at the Organisation for Economic Co-operation and Development (OECD) Workshop. Paris. 7 November.

Massachusetts Institute of Technology (MIT) Energy Initiative. 2011. The Future of Natural Gas. Boston, MA: Massachusetts Institute of Technology. 
McGlade, C., S. Sorrell, and J. Speirs. 2012. A Review of Regional and Global Estimates of Unconventional Gas Resources. In Unconventional Gas: Potential Energy Market Impacts in the European Union. European Commission Joint Research Centre.

Medlock, K. B., A. Myers Jaffe, and P. R. Hartley. 2011. Shale Gas and US National Security. Rice University: James A. Baker III Institute for Public Policy.

Medlock, K. 2012. Modelling the implications of expanded US shale gas production. Energy Strategy Reviews. 1. pp. 33-41.

Milligan, M., E. Ela, B.-M. Hodge, B. Kirby, D. Lew, C. Clark, J. DeCesaro, and K. Lynn. 2011. Cost-Causation and Integration Cost Analysis for Variable Generation. Golden, CO: National Renewable Energy Laboratory.

Nakano, J., D. Pumphrey, R. Price Jr., and M. A. Walton. 2012. Prospects for Shale Gas Development in Asia. Washington, DC: Centre for Strategic and International Studies. August.

National Wind Coordinating Collaborative (NWCC). 2010. Wind Turbine Interactions with Birds, Bats, and their Habitats: A Summary of Research Results and Priority Questions. Washington, DC: National Wind Coordinating Collaborative.

Natural Gas Asia. 2012a. Pakistan Has Substantial Unconventional Gas Reserves. http:// www.naturalgasasia.com/pakistan-has-substantial-unconventional-gas-reserves (accessed February 2014).

—. 2012b. [People's Republic of] China should prioritize CBM over shale gas. http://www.naturalgasasia.com/chian-should-prioritize-cbm-over-shale-gas (accessed February 2014).

_. 2012c. Asahi Kasei may use shale gas instead of crude oil. http://www.naturalgasasia. com/asahi-kasei-may-use-shale-gas-instead-of-crude-oil-6626 (accessed February 2014).

Ojha, K., B. Karmakar, A. Manda., and A. K. Pathak. 2011. Coal Bed Methane in India: Difficulties and Prospects. International Journal of Chemical Engineering and Applications. 2 (4). pp. 256-260.

Organisation for Economic Co-operation and Development (OECD). 2010. Projected Costs of Generating Electricity, 2010 Edition. Paris: OECD/International Energy Agency/Nuclear Energy Agency.

Oxford Business Group. 2012. Indonesia 2012: Into the Deep: Firms See Greater Potential in Coal Bed Methane Extraction. http://www.oxfordbusinessgroup.com/news/deep-firmssee-greater-potential-coal-bed-methane-extraction (accessed February 2014).

Parkinson, D. 2012. End to Low Natural Gas Prices Inevitable. The Globe and Mail. 10 September.

Parkinson, G. 2013. The Top Solar Countries: Past, Present, and Future. Renew Economy. 4 February.

Pearson, I. 2012. Introduction. In Unconventional Gas: Potential Energy Market Impacts in the European Union. European Commission Joint Research Centre.

Perez, R., R. Seals, and R. Stewart. 1993. Assessing the Load Matching Capability of Photovoltaics for US Utilities Based Upon Satellite-Derived Insolation Data. Record of the 24th IEEE Photovoltaic Specialists Conference. pp. 1146-1151.

Petroleum Economist. 2010. India's tight gas boost. http://www.petroleum-economist. com/Article/2735901/Indias-tight-gas-boost.html (accessed February 2014).

Poissant, Y. 2012. Photovoltaic Technology Specialist, CanmetENERGY-Varennes. Personal communication.

Radio Free Europe Radio Liberty (RFERL). 2012. Kazakstan to Tap Shale-Gas Potential. Radio Free Europe Radio Liberty. 14 March.

Ramudo, A. and S. Murphy. 2010. Hydraulic Fracturing: Effects on Water Quality. Ithaca, NY: Cornell University. 
Research and Development Solutions, LLC. 2010. Cost and Baseline Performance for Fossil Energy Plants. Volume 1: Bituminous Coal and Natural Gas to Electricity. United States Department of Energy: National Energy Technology Laboratory.

RETScreen. 2013. Status of Clean Energy Technologies. Natural Resources Canada. http:// www.retscreen.net/ang/status_of_clean_energy_technologies.php (accessed February 2014).

Rogner, H. H. 1997. An Assessment of World Hydrocarbon Resources. Annual Review of Energy and the Environment. 22. pp. 217-262.

Rolland, S. 2012. Continent of the Rising Sun: The Potential of Off-Grid PV in Asia. Energetica India. May.

Ross, M. M. D. 1994. Technology and Development in a Rural Indonesian Village: The Context for the Introduction of New Technology to Maruwei Satu. Waterloo, Ontario: Department of Systems Design Engineering University of Waterloo.

-1999. Optimal Utilization of the Electricity from Amorphous-Si Photovoltaics in Commercial Buildings. Helsinki: Helsinki University of Technology.

—. 2013. Emerging Energy Sources for Asia. Report to Asian Development Bank. http:// www.rerinfo.ca/documents/trADB2013EmerginEnergyAsia.pdf (accessed 31 March 2014).

Seel, J., G. Barbose, and R. Wiser. 2013. Why are Residential PV Prices in Germany So Much Lower than in the United States? Berkeley, CA: Lawrence Berkeley National Laboratory.

Shah, J. 2012. ADB Quantum Leap in Wind. Mongolian Renewable Energy. Ulaanbaatar. Sherwani, A. F, J. A. Usmani, and Varun. 2010. Life Cycle Assessment of Solar PV Based Electricity Generation Systems: A Review. Renewable and Sustainable Energy Reviews. 14 (1). pp. 540-544.

Stevens, P. 2010. The Shale Gas Revolution: Hype and Reality. London: Chatham House (The Royal Institute of International Affairs).

Stevens, S. H. and Hadiyanto. 2004. Indonesia: Coalbed Methane Indicators and Basin Evaluation. Paper prepared for a presentation to SPE Asia Pacific Oil and Gas Conference and Exhibition. Perth, Australia. 18-20 October.

Tao, J. and G. Louvel. 2012. Shale Gas: What is New in [People's Republic of] China? Natural Gas Asia. 16 April.

Tertzakian, P. 2012. Why Oil Prices Won't Follow Natural Gas. The Globe and Mail. 13 November.

The Economist. 2012. Daily Chart: Pricing Sunshine. 28 December.

The Windpower. 2013. Profiles for Asian Countries. www.thewindpower.net (accessed February 2014).

Tollefson, J. 2013. Methane Leaks Erode Green Credentials of Natural Gas. Nature. 493. p. 12.

Trend News Agency. 2012. Kazakhstan to hold comprehensive analysis of shale gas developing possibilities. Bloomberg Businessweek. 16 November.

Umarhajieva, N. S., R. K. Mustafin, and E. G. Alekseev. 2003. Central Kazakhstan Coalfields Potential for Development of Coalbed Methane Production Projects. Paper prepared for a presentation to the Third Annual Methane and Nitrous Oxide Mitigation Conference. Beijing. 17-21 November.

Wah, H. 2011. Indonesia's Opportunity in the Development of Unconventional Gas Resources. IndoGas 2011. Jakarta.

Wang, J., D. Ryan, and E. J. Anthony. 2011. Reducing the Greenhouse Gas Footprint of Shale gas. Energy Policy. 39. pp. 8196-8199. 
Werner, C., Ch. Breyer, A. Gerlach, and P. Adelmann. 2011. Global Overview on Cumulative Installed Photovoltaic Power. Paper prepared for a presentation to the Second Symposium on Small PV Applications. Ulm, Germany. 6-7 June.

Wigley, T. M. L. 2011. Coal to Gas: The Influence of Methane Leakage. Climatic Change. 108. pp. 601-608.

Williams, S. 2012. Discovering Shale Gas: An Investor Guide to Hydraulic Fracturing. Maryland, US: Sustainable Investments Institute.

Xinhua, M. 2009. Status and Development Prospects of [People's Republic of] China's Unconventional Natural Gas Exploration and Exploitation. Presentation at the the Ninth Sino-US Oil and Gas Industry Forum. Qingdao, People's Republic of China. 27-28 September.

Yang, C., W. Qian, and C. L. Cui. 2012. [People's Republic of] China's Wind-Power Industry: The Insider's View. Accenture.

Zhou, L., Y. Tian, S. B. Roy, C. Thorncroft, L. F. Bosart, and Y. Hu. 2012. Impacts of wind farms on land surface temperature. Nature Climate Change. 2. pp. 539-543.

Zou, C., R. Zhu, K. Liu, L. Su, B. Bai, X. Zhang, X. Yuan, and J. Wang. 2012. Tight gas sandstone reservoirs in [People's Republic of] China: characteristics and recognition criteria. Journal of Petroleum Science and Engineering. 88-89. pp. 82-91. 


\title{
8 Policy issues in Asia's power sector
}

\author{
Balancing economic growth \\ and sustainability
}

\author{
Jong Ho Hong, Changhun Kim, and \\ Heeyoung Shin
}

\section{Introduction}

World electricity demand is rising rapidly driven mainly by growth in Asia. It is projected to increase over 70\% between 2010 and 2035 (IEA 2012) with over half expected to come from the People's Republic of China (PRC) (38\%) and India $(13 \%)$, while Asia overall is expected to account for $64 \%$. With electricity demand in the PRC expected to grow $140 \%$ from 3,668 terawatt hours in 2010 to 8,810 terawatt hours in 2035 and in India by $255 \%$ from 693 terawatt hours in 2010 to 2,463 terawatt hours in 2035, Asia's portion of world electricity demand is projected to grow from $29 \%$ in 2010 to $43 \%$ in 2035 (IEA 2012). In 2010, the PRC and India accounted for $20 \%$ and $4 \%$ of the world total, respectively; this is projected to grow to $28 \%$ and $8 \%$, respectively (IEA 2012). Asia's importance in the power sector is therefore evident, especially the contributions of the PRC and India.

The growth in electricity demand is potentially destructive as greenhouse gas (GHG) emissions from the sector are a direct cause of climate change. According to a scenario by the International Energy Agency (IEA), assuming current policies on climate change are maintained global primary energy demand is projected to rise by one-third up to 2035 which results in a $50 \%$ probability of limiting the long-term average global temperature increase to 3.6 degrees Celsius relative to pre-industrial levels (IEA 2012). From 2000 to 2010, carbon dioxide $\left(\mathrm{CO}_{2}\right)$ emissions from Asia increased by $76 \%$, most of which came from developing Asia which showed a near two fold increase from 5,923 million tons of $\mathrm{CO}_{2}$ to 11,666 million tons (ADB 2013). Emissions from electricity generation are projected to increase annually by $2 \%$ from 2010 to 2020 , an increase of $21 \%$ overall in Asia (ADB 2013). With electricity and heat generation accounting for $41 \%$ of energy-related $\mathrm{CO}_{2}$ emissions (IEA 2012), reviewing short- and longterm policies for Asian power sectors is critical at this juncture.

It is also, however, important for the power sectors to provide for the growing electricity demands of their economies. As the increase in power consumption indicates, Asia's presence in the world economy will continue to grow with the PRC and India leading the way. The economy in the PRC is likely to surpass that 
of the United States (US) in the next two decades, and India's growth rate is forecast to pick up rapidly after 2030 becoming the next economic power house (Government of the United States, NIC 2012).

In this chapter, we examine the power sector of four Asian countries representing economic growth at different stages: the PRC, India, Japan, and the Republic of Korea. The PRC and India will be the center of development in the coming years while Japan is at the opposite end of the spectrum in terms of economic and power sector development. Despite a decrease in electricity consumption, Japan was still the third largest producer of electricity in 2010 (World Bank 2013). The Republic of Korea is at yet another juncture. By providing electricity below the cost of generation, it faces continued growth in demand that does not reflect the social cost of electricity.

In the first section of this chapter, the current status and future prospects of the electricity sectors are addressed. Next, key policy issues are discussed by country focusing on the area that is currently most critical. Lastly, policy recommendations are made that balance economic growth and sustainability goals.

\section{Current status and future prospects for electricity supply and demand}

\section{Overview}

\section{Growing energy and electricity demand in Asia}

According to the IEA World Energy Outlook 2012 New Policies Scenario, the portion of world primary energy demand in Asia is expected to increase from $38 \%$ in 2010 to $45 \%$ in 2035 as seen in Figure 8.1. The increase is greater for electricity as the report forecasts the Asian portion in the world electricity market will surge from $38 \%$ to $51 \%$ in the same period (Figure 8.2). Managing the energy and electricity sectors in Asia will be critical to continuing economic growth and to achieving sustainability goals for the world at large.

\section{Greenhouse gas emissions from power generation}

Reducing GHG emissions is an important item on the global agenda to mitigate climate change. Figure 8.3 shows the estimated GHG emissions from the electric power sector for each country. The absolute amounts of GHG emissions and rates of increase in the PRC and India are large compared to the other countries because they both use coal as the main power source, and coal has a relatively large emission factor. According to climatologists, to meet the goal of limiting the global increase in average temperatures to 2 degrees Celsius in the long term compared to pre-industrial levels, GHG concentrations in the atmosphere have to be limited to 450 parts per million of $\mathrm{CO}_{2}$ equivalent $\left(\mathrm{CO}_{2}\right.$-eq; EU Climate Change Expert Group for Science 2008). This will be impossible without future reductions in the PRC and India. 


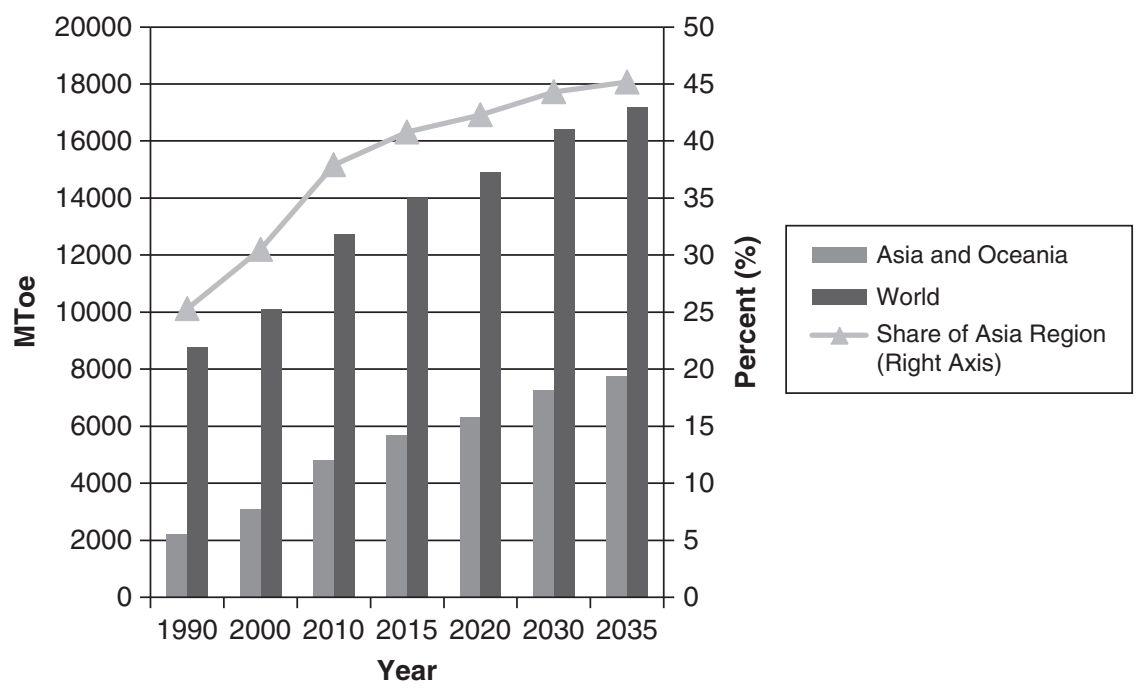

Figure 8.1 Primary world and Asian energy demand Source: IEA 2012.

Note: $\mathrm{MToe}=$ million tons of oil equivalent.

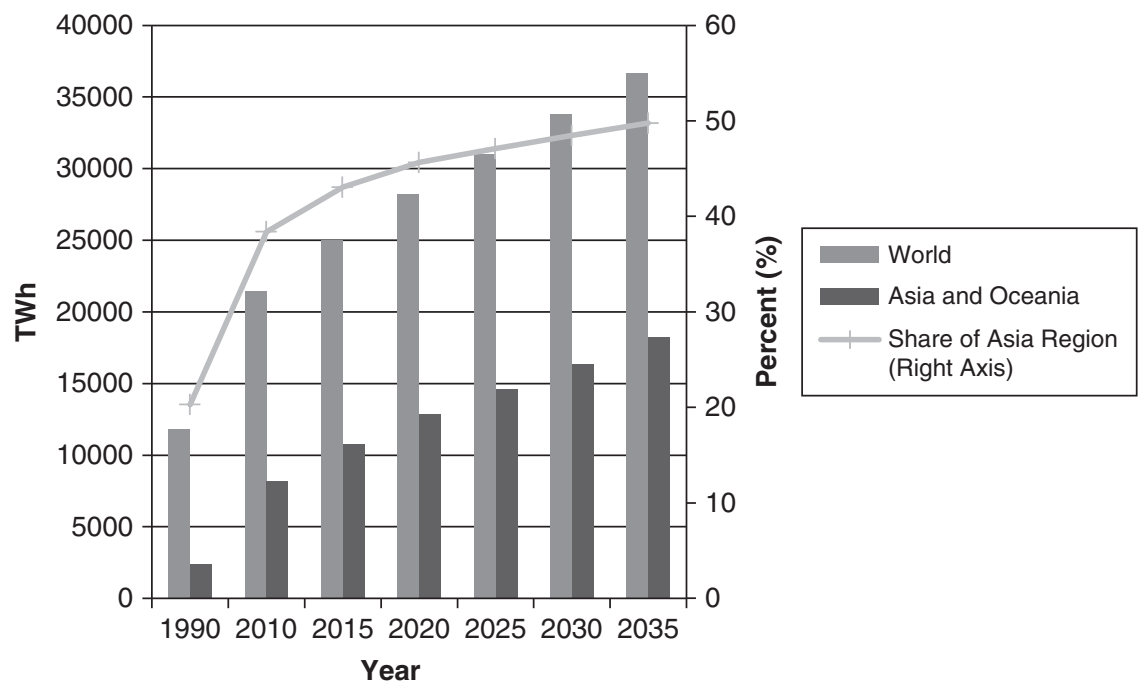

Figure 8.2 World and Asian electricity generation

Source: IEA 2012.

Note: $\mathrm{TWh}=$ terawatt hours. 


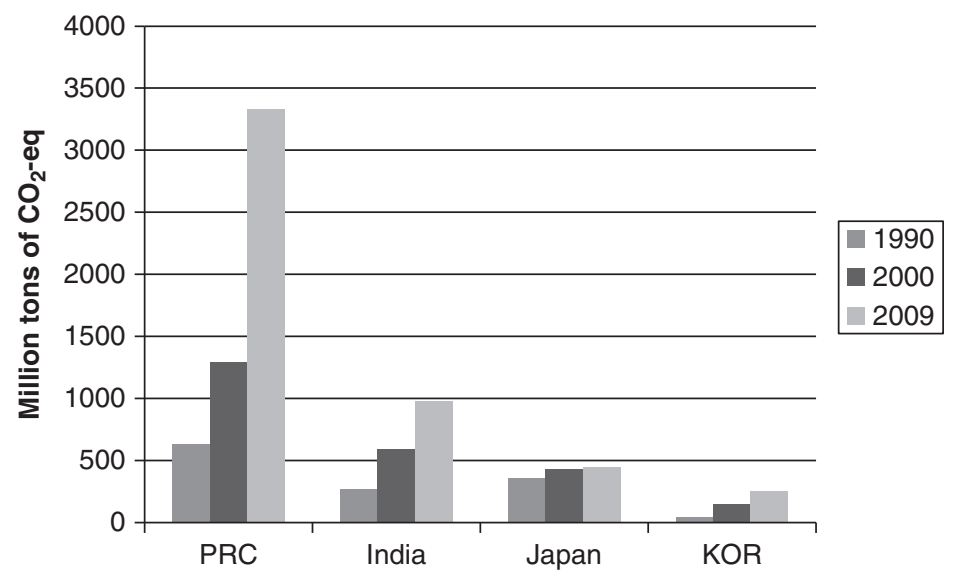

Figure 8.3 Estimations of greenhouse gas emissions from thermal power generation Source: ADB 2013.

Note: $\mathrm{PRC}=$ People's Republic of China; $\mathrm{CO}_{2}$-eq $=$ carbon dioxide equivalent; $\mathrm{KOR}=$ Republic of Korea.

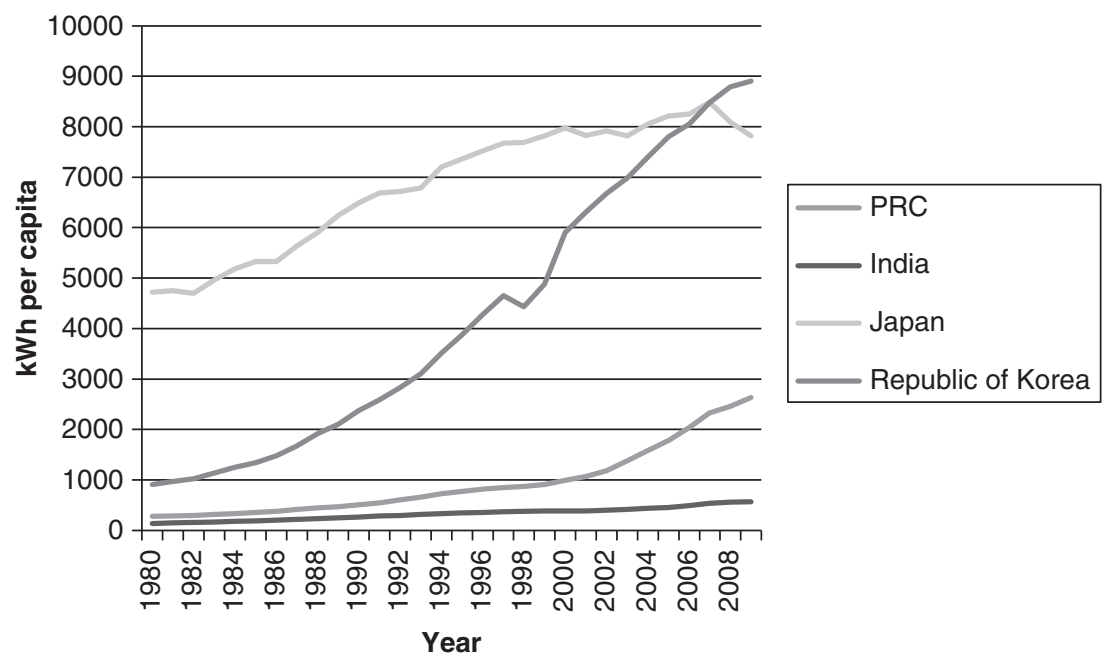

Figure 8.4 Electricity consumption per capita

Source: World Bank 2013.

Note: $\mathrm{PRC}=$ People's Republic of China; $\mathrm{kWh}=$ kilowatt hour.

Electric power consumption

The PRC and India constitute $62 \%$ of Asia's power consumption, but in terms of power consumption per capita they consume much less than Japan or the Republic of Korea. Figure 8.4 shows consumption per capita rising slowly and steadily in 


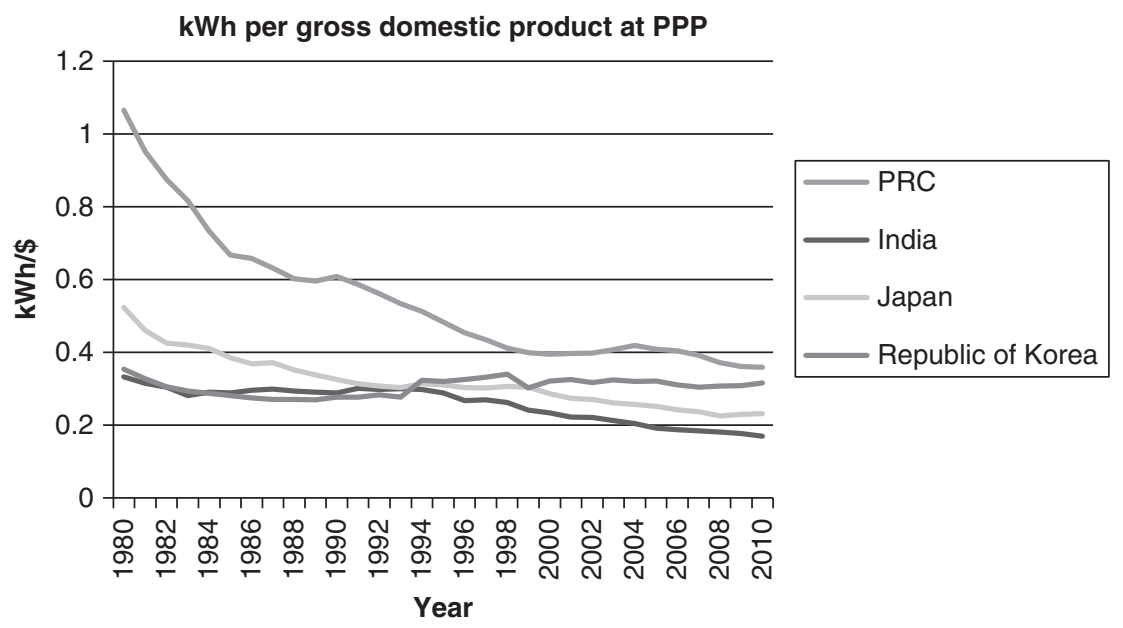

Figure 8.5 Electricity consumption by gross domestic product Source: World Bank 2013.

Note: $\mathrm{PRC}=$ People's Republic of China; $\mathrm{kWh}=$ kilowatt hour; PPP = purchasing power parity.

both the PRC and India though much faster in the former. While India is the fifth largest producer of electricity, its per capita consumption is one of the lowest. Over one third of the nation does not have access to electricity, and the supply is intermittent and unreliable for those that do. On the other hand, per capita consumption in the Republic of Korea rose at an alarming rate surpassing that of Japan signaling overuse. Per capita figures in Japan have decreased due to demand management and to improved efficiency. Electricity consumption per gross domestic product (GDP) at purchasing power parity shows improved efficiency in all countries except the Republic of Korea (Figure 8.5).

\section{The People's Republic of China}

The electricity sector has been channeling power to the private, commercial, and industry sectors to fuel the nation's economic growth. In 2010, total electricity generation stood at 4,208 terawatt hours with an average annual growth rate of 9.8\% from 1990 to 2010 (ADB 2013). The Asian Century scenario (ACS) of the Asian Development Bank (ADB) forecasts electricity demand will reach 9,593 terawatt hours in 2035 with the share of electricity in the total energy demand at final consumption increasing from $19.6 \%$ in 2010 to $28.1 \%$ in 2035 (Figure 8.6) (ADB 2013). The IEA World Energy Outlook 2012 shows a similar result: its central scenario forecasts 9,945 terawatt hours of electricity generation in the PRC in 2035, and the share of electricity reaches $30.6 \%$ of final energy consumption. 


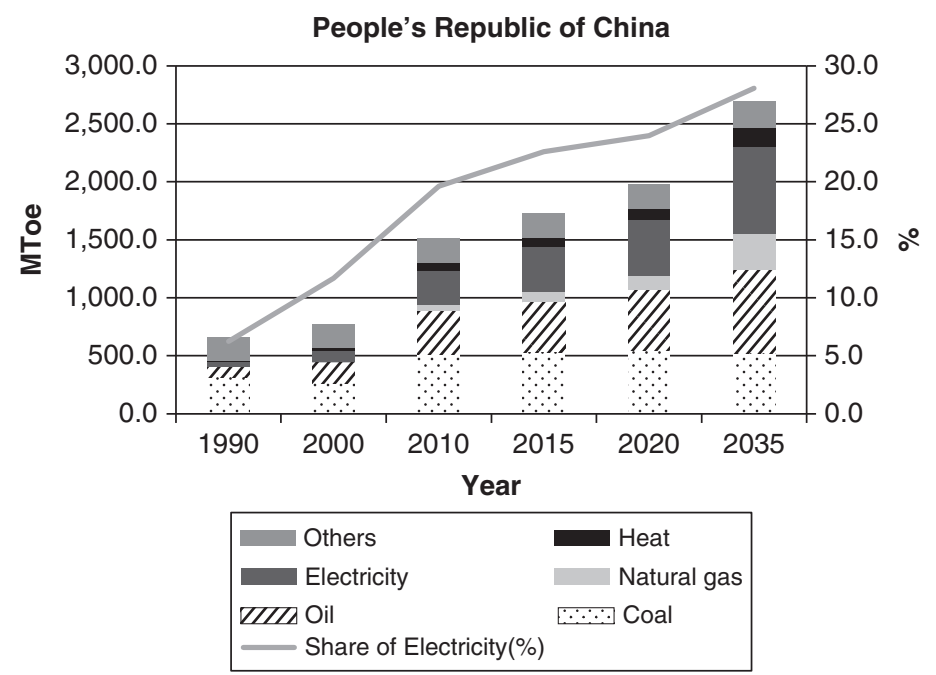

Figure 8.6 Final energy demand by energy source

Source: ADB 2013.

Note: $\mathrm{MToe}=$ million tons of oil equivalent.

The government's aggressive expansion of power plants explores hydroelectric potential to the fullest and coal-fired plants that run on a domestic supply. A foray into nuclear power and renewable energy was made to diversify the energy mix. In 2010, coal generation accounted for $78.8 \%$ of power production and hydro accounted for $17.2 \%$, together constituting $95.0 \%$ (Figure 8.7 ). Electricity generation will continue to grow in the coming years; the ACS estimates an annual growth of $4.2 \%$ between 2010 and 2020 , a somewhat slower growth rate compared to the past. It seems that while the economy will continue to grow, it will be affected by the global downturn as well.

\section{India}

The per capita energy and electricity consumption in India is one of the lowest in the world at 455 kilograms of oil equivalent per person of primary energy in 2004 which was around $26 \%$ of the world average of 1,750 kilograms (Government of India Planning Commission 2008). Energy and electricity demand will grow, however, along with the economy.

India's total power generation output was 960 terawatt hours in 2010; ACS projects this will reach 1,832 terawatt hours in 2020 . The average annual growth rate from 2010 to 2020 is $6.7 \%$ and is $7.6 \%$ from 2020 to 2030. As Figure 8.8 shows, electricity demand is expected to increase dramatically after 2020 though projections differ by organization. The World Energy Outlook 2012 proposes a 


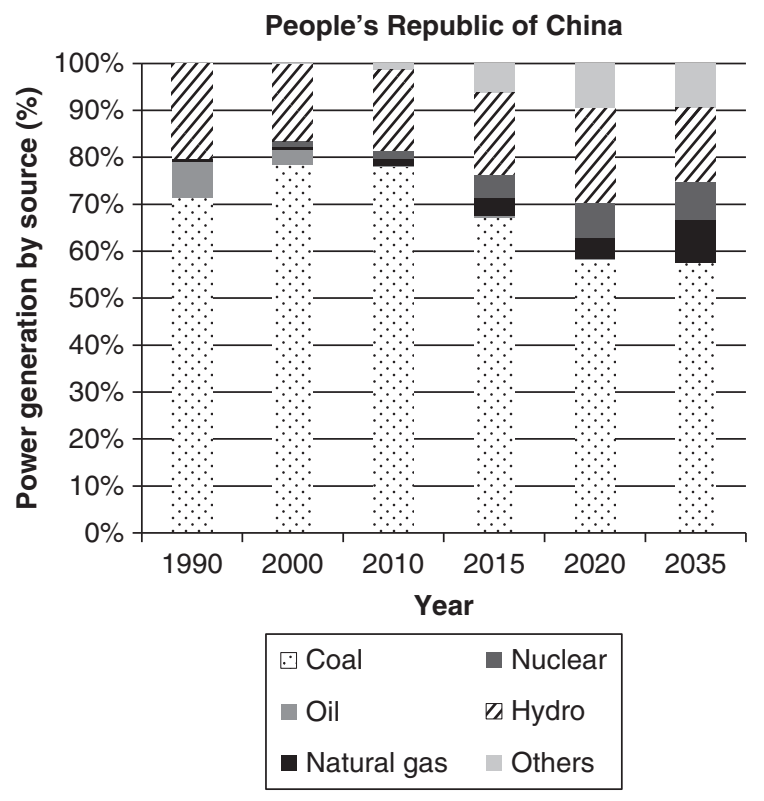

Figure 8.7 Projections of fuel mix in electricity generation (business-as-usual scenario)

Source: ADB 2013.

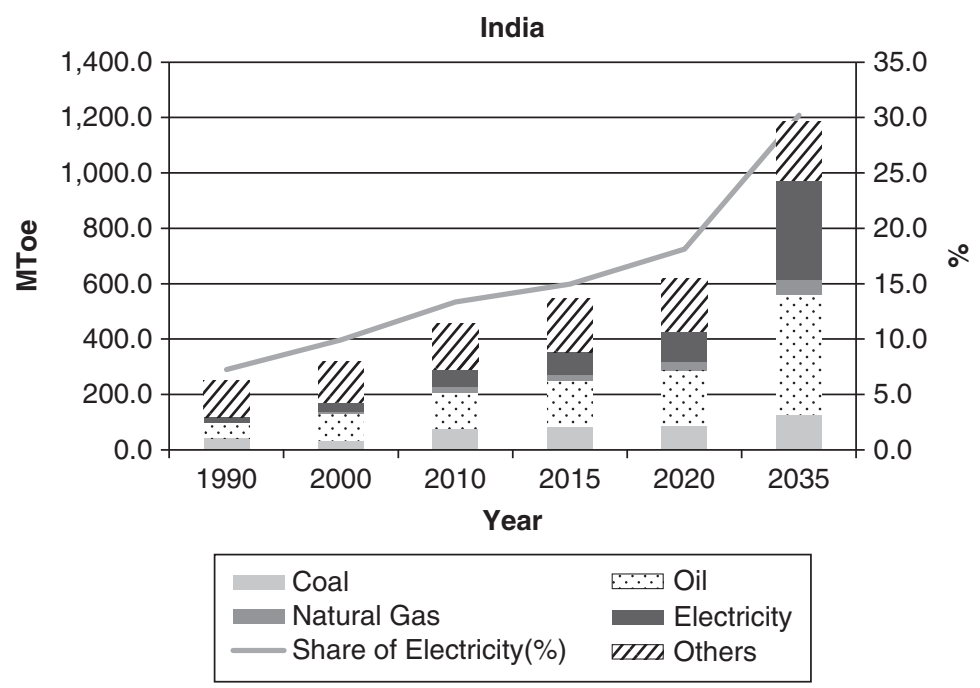

Figure 8.8 Final energy demand by energy source

Source: ADB 2013.

Note: $\mathrm{MToe}=$ million tons of oil equivalent. 
$5.1 \%$ compound average annual growth rate from 2010 to 2035 in its main scenario and $4.3 \%-5.4 \%$ of growth in other scenarios. The US Energy Information Administration (EIA 2011) projects an average annual growth of 3.9\% from 2008 to 2035 in its International Energy Outlook 2011.

In terms of energy mix, coal generation is the major source of electricity at $68.0 \%$ of power generation output; natural gas and hydro come next at $12.3 \%$ and $11.9 \%$, respectively (Figure 8.9 ). Coal will most likely provide the majority of power generation, but continued growth is unlikely and undesirable due to high emission factors. The shares of nuclear and renewable energy are projected to increase with nuclear growing from $2.7 \%$ in 2010 to $6.0 \%$ in 2020 . Renewable sources excluding hydropower were $2.3 \%$ of total power generation output in 2010 and will grow to $4.3 \%$ in 2020 according to ADB projections (ADB 2013).

\section{Japan}

Power production was 1,041 terawatt hours in 2009; it increased by an average of $1.2 \%$ annually between 1990 and 2009 (ADB 2013). Production is expected to remain stagnant from 2009 to 2020 at an average annual growth rate of $0.3 \%$ (Figure 8.10). The IEA projects $0.3 \%$ average annual growth from 2010 to 2035 in its main scenario while the EIA 2011 outlook predicts a slightly higher rate of $0.8 \%$ from 2008 to 2035 (EIA 2011).

Japan has a diverse fuel mix with no one source dominating; however, recent trends show a dramatic reduction in oil use and an increase in coal. In 1990, oil

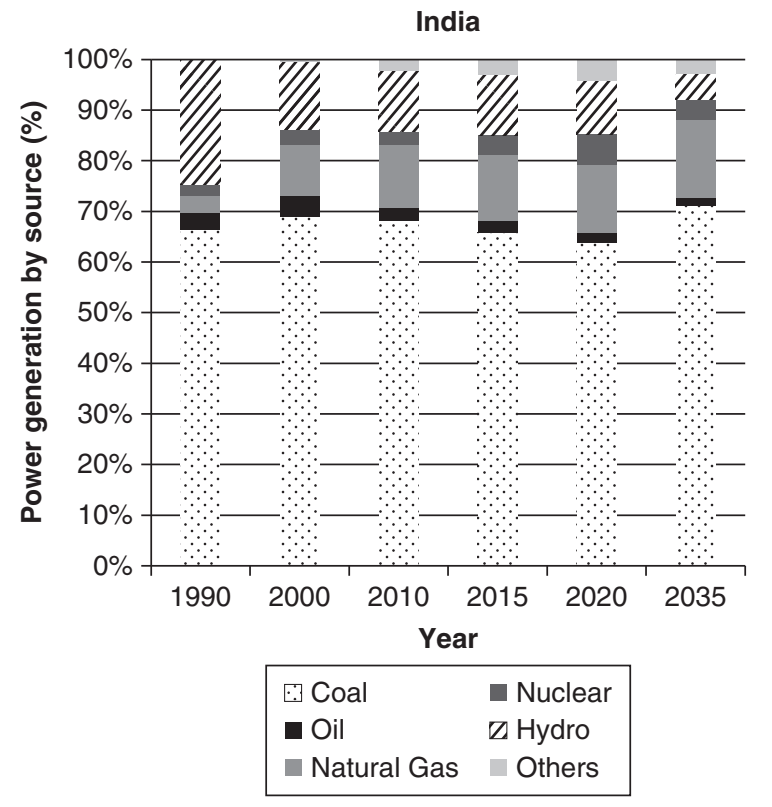

Figure 8.9 Projections of fuel mix in electricity generation (business-as-usual scenario) Source: ADB 2013. 
accounted for $14.0 \%$ of electricity generation while in 2009 it increased to $26.8 \%$ (Figure 8.11). In 2009, natural gas constituted $27.4 \%$ and nuclear $26.9 \%$, but the Fukushima Daiichi accident in 2011 forced the government to reduce the nuclear portion drastically to $0.5 \%$ in the second quarter of 2012 (Figure 8.12 ). Renewable
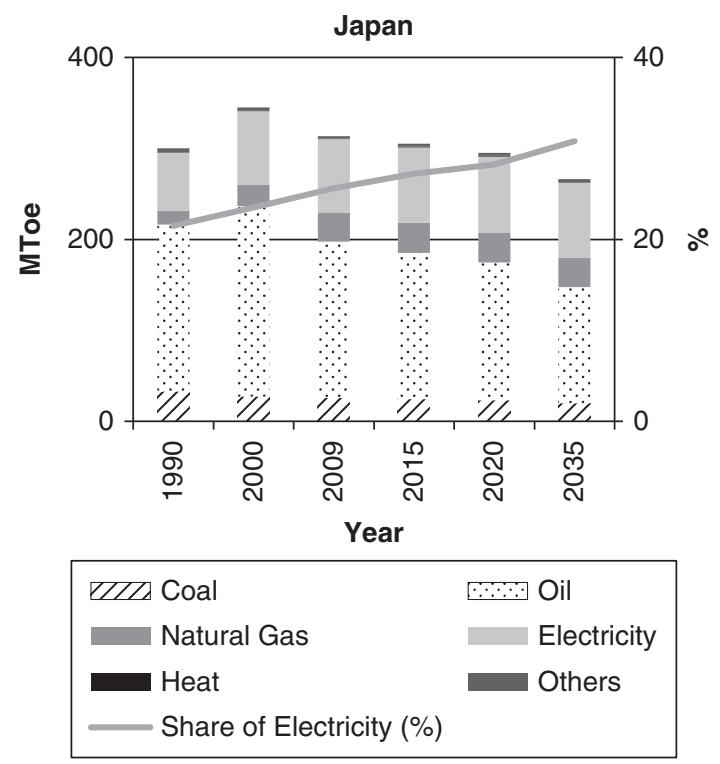

Figure 8.10 Final energy demand by energy source

Source: ADB 2013.

Note: MToe $=$ million tons of oil equivalent.

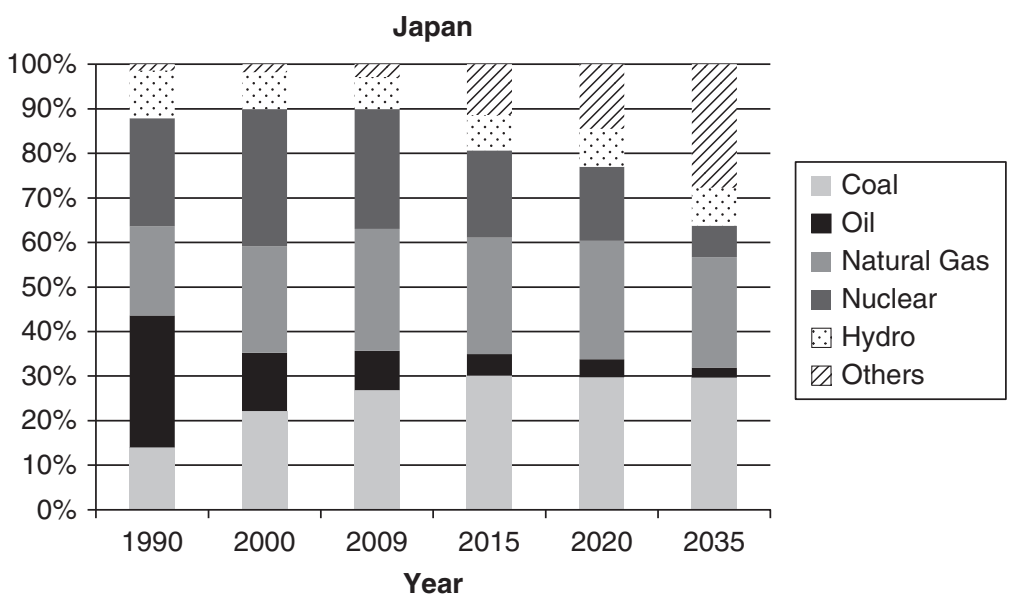

Figure 8.11 Projections of fuel mix in electricity generation (business-as-usual alternative scenario)

Source: ADB 2013. 


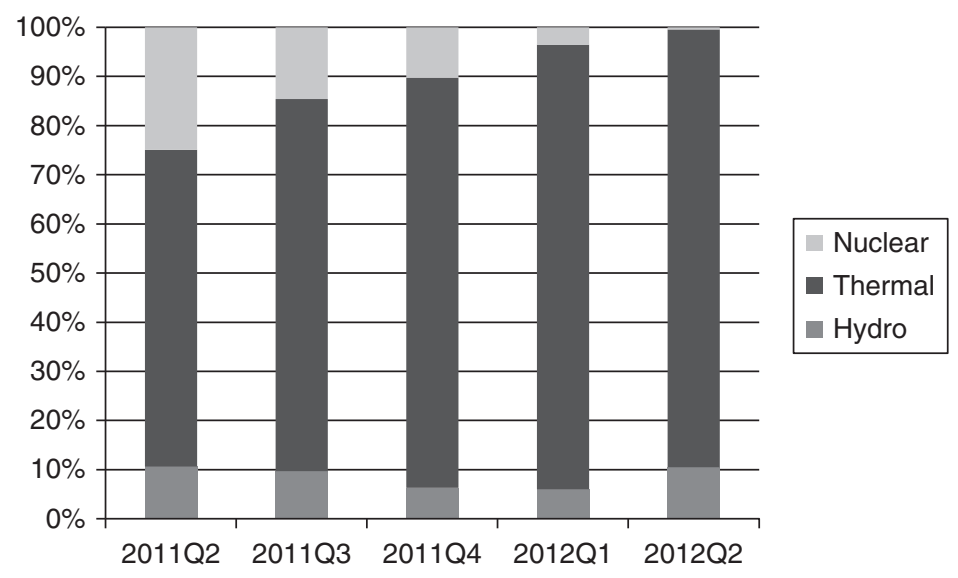

Figure 8.12 Japan's power generation mix after the Fukushima nuclear accident

Source: IEEJ 2012b.

Note: $\mathrm{Q}=$ quarter.

sources fueled $2.9 \%$ of total electricity generation in 2009. Japan has implemented a feed-in tariff to boost investment in renewables (Government of Japan Renewable Energy Policy Platform 2010), but whether this policy directive continues remains to be seen as the high price of renewables is a burden on the economy.

\section{Republic of Korea}

Electricity production totaled 496.7 terawatt hours in 2010 with an average annual growth rate of $8.1 \%$ from 1990 to 2010 ([Republic of] Korea Electric Association 2011). ADB projects that power production will slow down to an average annual growth rate of $0.9 \%$ from 2010 to 2020 and of $0.5 \%$ from 2020 to 2035 (ADB 2013). The proportion of electric power in the final energy consumption stage is expected to reach $27.7 \%$ in 2035 up from $24.5 \%$ in 2010 (Figure 8.13).

Growth projections differ by institution. According to the EIA, electricity demand is projected to grow at an average annual rate of $2.0 \%$ from 2008 to 2035 (Government of the United States, EIA 2012b), but the Fifth Basic Plan for LongTerm Electricity Supply and Demand released by the government in 2010 projects power demand to grow by an average of 3.1\% annually from 2010 to 2024 (Government of the Republic of Korea, National Energy Committee 2010).

The general trend in the generation mix points to an increase in nuclear power (Figure 8.14). The government started implementing an aggressive renewable portfolio standard policy in 2012 and aims to increase the portion of renewables to $10 \%$ in 10 years (Republic of Korea, Ministry of Knowledge Economy 2010), but whether this goal will be reached remains uncertain. The Sixth Basic Plan for Long-Term Electricity Supply and Demand relies on increased coal and gas generation capacity to meet demand, and the additional construction 


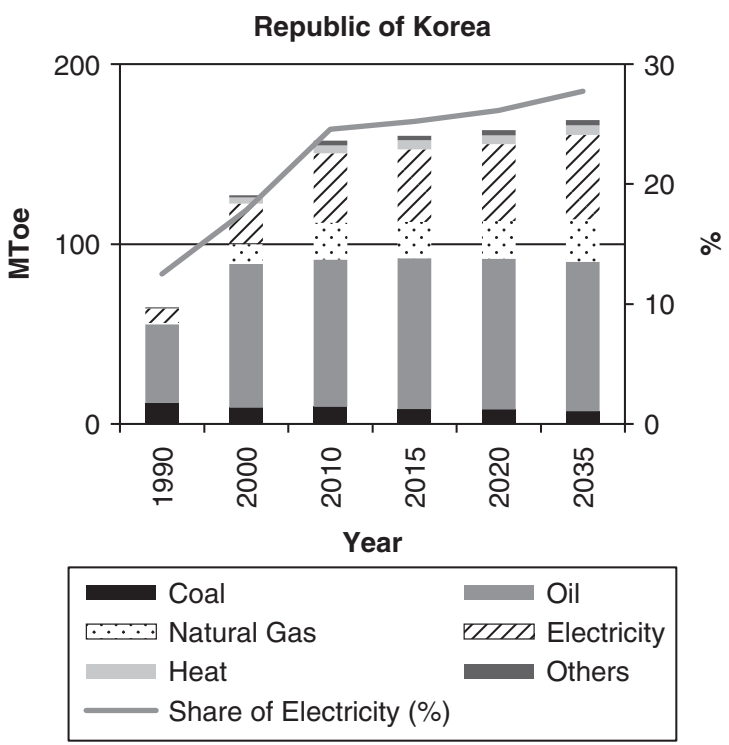

Figure 8.13 Final energy demand by energy source

Source: ADB 2013.

Note: MToe $=$ million tons of oil equivalent.

Republic of Korea

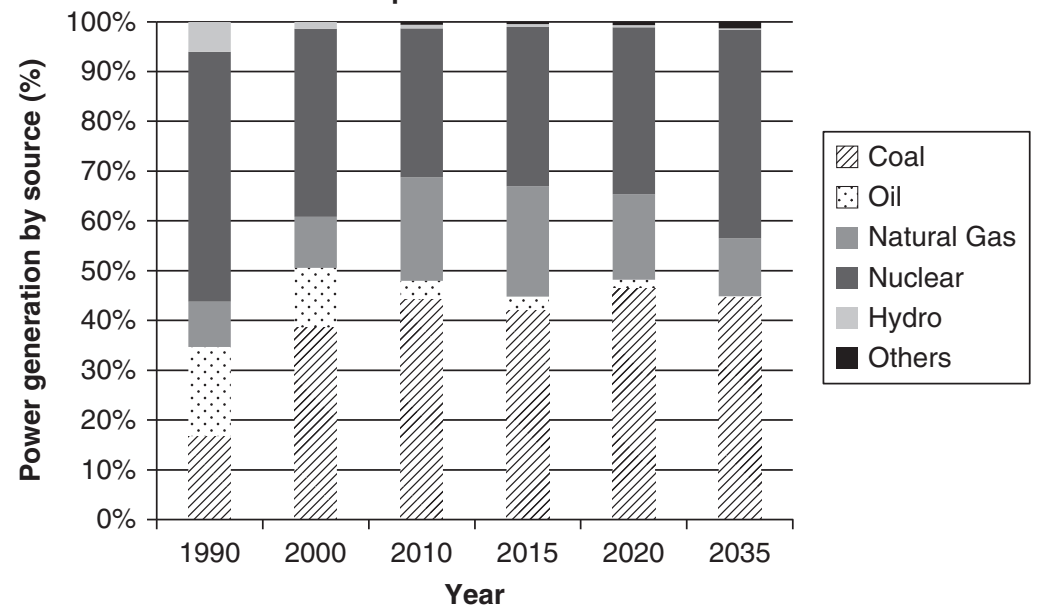

Figure 8.14 Projections of fuel mix in electricity generation (business-as-usual scenario) Source: ADB 2013.

of nuclear power plants remains undecided (Republic of Korea, Ministry of Knowledge Economy 2010). With the uncertainty surrounding power sector policy direction, it is difficult to make future projections based on current policy guidelines. 


\section{Key policy issues by country}

\section{People's Republic of China}

The combination of a growing industry sector, spreading electricity to rural areas, and adopting a modern lifestyle requiring more energy will continue to increase power consumption. The government has plans to build additional generation facilities and transmission infrastructure to meet growing demand. The energy mix and the efficiency of generation, transmission, distribution, and consumption will be the key to providing a stable and affordable power supply while at the same time curtailing future $\mathrm{CO}_{2}$ emissions to create a greener economy.

\section{Additional transmission infrastructure}

The government's energy plan has been very effective in providing for the country's electricity needs; however, the PRC suffers regional, seasonal, and intermittent shortages during the peak electricity months in summer and winter (Wu and $\mathrm{Fu}$ 2005). Improving inter-provincial transmission can reduce the risk of shortages and at the same time allow power plants to be built near coal mines. A total of $54 \%$ of coal power plants are located in the east while $19 \%$ are located in the coal-rich regions to the west (Zeng et al. 2012). The transfer of coal from the mines to the power stations requires energy; it would be more efficient to locate power plants closer to the mines and transmit electricity to the industrial centers. Hydro, wind, and solar resources are at various locations, and because their intermittency requires them to be coupled with other sources, transmission will be crucial to renewable energy development. The country is in the process of expanding 750 kilovolt lines that will improve transmission efficiency over long distances.

\section{Privatizing the electricity sector and higher prices}

The electricity sector has been undergoing a careful process of unbundling and incorporating and of applying market mechanisms to electricity distribution. In 1997, part of the Ministry of Power was transformed into the State Power Company, and from 1999 to 2000, six experimental electricity markets were established in cities and provinces. In 2002, generation was regrouped into five companies incorporating independent power producers and publicly listed companies. While the five companies were allotted similar assets, none has more than a $20 \%$ market share. Around $10 \%-20 \%$ of the generating capacity is owned by the grid companies to ensure reliable operation, frequency modulation, and peak load following, and $80 \%$ of the demand is traded on the electricity market based on long-term contracts while the rest is traded in the Electricity Dispatch and Trading Center (Wu and $\mathrm{Fu} 2005$ ).

In 2004, a scheme was introduced that links electricity prices with the price of coal. If during a cycle of six months the coal price rises $5 \%$ or more, the electricity price is likewise raised. However, while coal prices continue to rise, power 
producers are forced to limit what they charge as the National Development and Reform Commission, the country's top economic planning body, regulates power prices while coal prices are governed by the market. The power companies are left to shoulder the losses as the price to consumers is lower than production costs (Chung 2011). According to the State Electricity Regulatory Commission, the top five state-owned power companies lost approximately 60 billion yuan (\$10 billion) in thermal power generation from 2008 to 2011. They have been able to shoulder the losses through profits from other sources such as hydropower, but opportunities for greater efficiency could be realized through unbundling and flexible pricing schemes.

\section{Promoting renewable energy}

The PRC ranked first in the world for installed renewable capacity and third in terms of non-hydroelectric renewable capacity in 2010 (Government of the United States, EIA 2013). Hydroelectric resources were explored to the fullest with two large recent additions of the Three Gorges and Yellow River dams with 18.2 gigawatts of electricity $\left(\mathrm{GW}_{\mathrm{e}}\right)$ and $15.8 \mathrm{GW}_{\mathrm{e}}$ capacities, respectively. An IEA report indicates the PRC will account for $40 \%$ of the additional 710 gigawatts of global renewable energy capacity by 2017 (IEA 2012). The PRC also ranked first in the Ernst \& Young Renewable Energy Country Attractiveness Index in August 2012 and ranked first in terms of renewable energy investment in 2011, investing a total of $\$ 52$ billion. The Twelfth Five Year Plan stated that clean energy was one of the three key investment areas and set a target of a $17 \%$ reduction in $\mathrm{CO}_{2}$ emissions per unit of GDP (KPMG 2011). The Electricity Council projects wind generation capacity will reach 150 gigawatts in 2020 compared to 30 gigawatts in 2010; projections for solar are 24 gigawatts in 2020 compared to 0.26 gigawatts in 2010 (Zeng et al. 2012).

In the second quarter of 2012, the National Energy Bureau proposed a quota system for the renewable energy sector (Wu 2012). Under the quota, power companies generating more than 5 gigawatts are required to attribute $11 \%$ of installed capacity to renewable energy, and $6.5 \%$ of gross power generation will have to come from renewables. It also places a requirement on the grid companies to buy a specified amount of renewable energy by 2015 that ranges from $3.2 \%$ to $15 \%$. Also, each province will be given specific quotas to consume renewable energy. The provinces are categorized into four tiers based on renewable energy sources, economic aggregates, total electric power consumption, and electric power transmission capacity. A subsidy is given to grid companies providing connections to renewable sources as well; the amounts are between 0.01 yuan/kilowatt hour (\$0.002) and 0.03 yuan/kilowatt hour (\$0.006) depending on the length of the transmission line.

There are also feed-in-tariffs for solar and wind power. The nationwide policy for solar power started in 2011 guaranteeing a price of approximately $\$ 0.15 /$ kilowatt hour to generators (Liu 2011). A feed-in tariff for wind power has been in place since 2009 in four categories based on wind power potential and tariffs 
ranging from 0.51 yuan/kilowatt hour $(\$ 0.08)$ to 0.62 yuan/kilowatt hour $(\$ 0.10)$ (IRENA and GWEC 2012).

\section{Increasing nuclear power}

The government sees nuclear power as a way to reduce GHG emissions and has 28 plants under construction and more in the planning stage. Nuclear power was $1.8 \%$ of power generation output in 2010 with 17 nuclear power plants in operation (Government of the United States, EIA 2012b; World Nuclear Association 2013a). The target for 2020 was as high as $70-80$ gigawatt electrical $\left(\mathrm{GW}_{\mathrm{e}}\right)$, but following the Fukushima Daiichi accident, the State Council suspended approvals for new nuclear power stations, including those under construction, until safety checks were conducted. In October 2012, construction recommenced. Now the nuclear target for 2020 is $58 \mathrm{GW}_{\mathrm{e}}$ (World Nuclear Association 2013a).

According to a January 2011 report by the State Council Research Office which provides independent policy recommendations to the government, two major concerns were the type of reactors for future construction and the nuclear power workforce. With the focus on developing domestic nuclear power capabilities, Generation-II CPR-1000 units are under construction or on order instead of Generation-III AP-1000 reactors (see Chapter 9 Figure 9.9). While nuclear reactors may be built rapidly, developing a safety culture at the operational level takes time, and the council advised a slow rollout. The council also recommended that the National Nuclear Safety Administration be placed directly under the State Council Bureau as currently it is under the China Atomic Energy Authority (World Nuclear Association 2013a).

Whether nuclear power should be part of a sustainable energy mix is a highly debated question. It is green in terms of lower emissions, but safety and spent fuel storage concerns remain. The PRC should consider investing alternative options while cautiously expanding nuclear capacity.

\section{India}

The power sector has developed slowly compared to the economy. The blackout in July 2012 affected more than 600 million people raising concerns about energy infrastructure and the government's ability to manage the grid (Koyama 2012). The Central Electricity Agency continues to report power shortages while over one third of the population does not have access to electricity (Government of India Planning Commission 2008). Securing a reliable source of generation to meet growing consumption is the top priority.

\section{Insufficient capacity}

In 2010, the base-load requirement was 861,591 gigawatt hours but only 788,355 gigawatt hours were available (accounting for transmission loss), an 8.5\% deficit (Government of India Central Electricity Authority 2011). During 


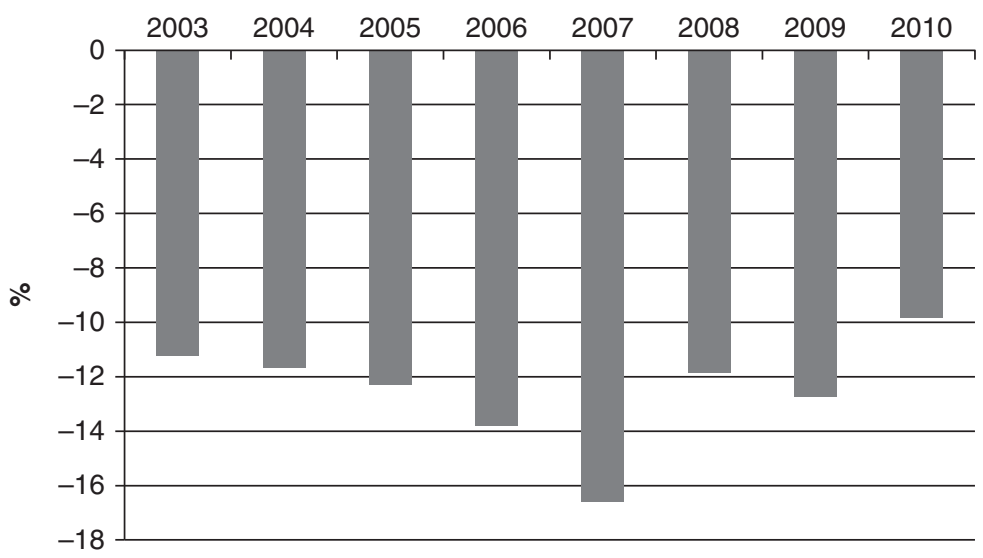

Figure 8.15 Supply shortage at peak times in India

Source: Government of India Ministry of Power 2011.

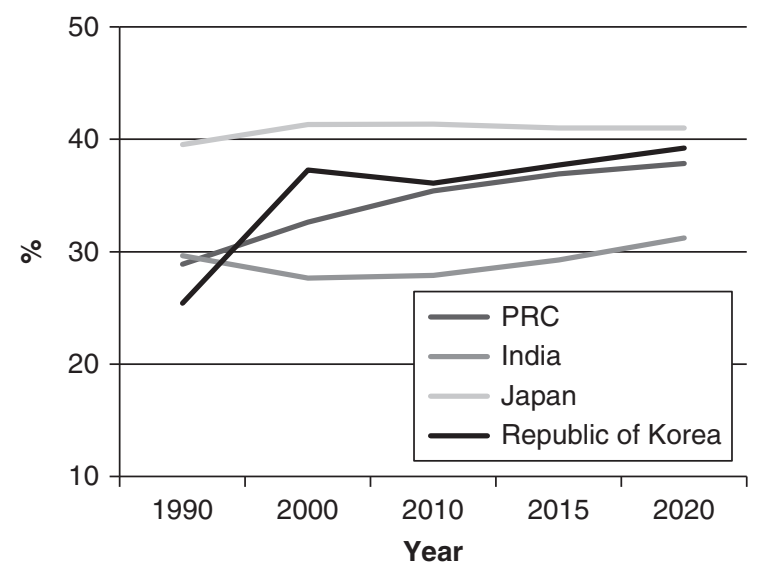

Figure 8.16 Coal thermal efficiency

Source: ADB 2013.

Note: PRC $=$ People's Republic of China.

peak loads, the demand was 122 gigawatts while availability was 110 gigawatts, a 9.8\% shortfall (Figure 8.15). India's main source for generating electricity is coal; however, the thermal efficiency of Indian coal generation is $27.9 \%$ which is less than the $35.4 \%$ in the PRC and the ADB average of $35.5 \%$ as indicated in Figure 8.16. Coal thermal efficiency in India has much room for improvement compared to the PRC, Japan, and the Republic of Korea. Increased efficiency will cut costs, reduce GHG emissions, and increase total generation output thereby reducing the need for additional power plants. 


\section{Reforming the coal industry}

India relied on coal for $68 \%$ of its electricity in 2010 (ADB 2013). While the abundant coal reserves within its borders make coal generation an inexpensive option, the plants cannot operate at full efficiency because of problems in the industry. The Coal Ministry verified over 285 billion tons of coal reserves as of 2011 (Government of India Ministry of Coal 2013), of which 55 billion tons are considered extractable (Kulkarni 2011). This should last over 100 years at current production rates of 550 million tons, yet coal production falls short of its demand and India imports more than 70 million tons of coal each year. Mining operations are crude, and coal transport is grossly inefficient as well (Arun 2012). While coal generation has a high emission factor and emits environmentally hazardous pollutants into the atmosphere, securing a stable domestic supply for pre-existing plants so that they may operate at full efficiency is the first step toward meeting growing electricity demand.

\section{Transmission losses}

Transmission losses need to be immediately addressed by state authorities and electricity suppliers. Non-technical losses consist primarily of theft, non-payment by customers, and errors in accounting and record keeping (Antmann 2009). While non-payment in poor areas is common and taken for granted in many parts of India, electricity theft by large residential, commercial, and industrial users may account for a significant portion of the losses (Antmann 2009). As seen in Figure 8.17, India's transmission losses exceed levels observed in other countries. The distribution of electricity is carried out by utility companies owned by state

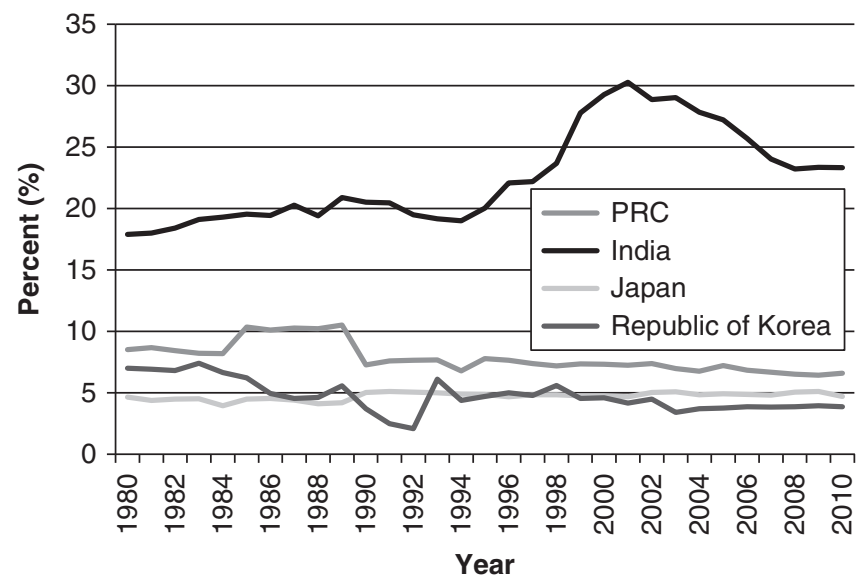

Figure 8.17 Electricity distribution losses

Source: Government of the United States, EIA 2012a.

Note: PRC $=$ People's Republic of China. 
governments; their aggregate technical and commercial losses stood at $27.15 \%$ in 2009 and 2010 (Government of India Central Electricity Authority 2011). A KPMG report in 2009 stated the losses were worth $\$ 6-\$ 8$ billion per year (KPMG 2009). Attempts to privatize distribution companies and unbundle the electricity sector to improve the situation have been effective: the privatization of North Delhi Power Limited and the restructuring of Andhra Pradesh State Electricity Board are models to follow. The former started with 53\% transmission losses in July 2002 and reduced them to $15 \%$ in 2009; the latter reduced transmission losses of $38 \%$ in 1999 to $20 \%$ in 2008 largely by reining in electricity theft (Antmann 2009).

\section{Using renewables}

India ranked fifth in new investment in renewable energy in 2011 (Frankfurt School of Finance \& Management 2012). On average in the first quarter of 2012, prices of wafers for solar cells dropped from just below \$1.00/watt in 2009 to $\$ 0.35 /$ watt and those of cells declined from $\$ 1.30 /$ watt in 2009 to $\$ 0.55 /$ watt (Bazilian et al. 2012). With the additional drop in installation costs, India experienced a spur of investment in solar photovoltaics. In the state of Rajasthan, the average tariff for all project bids under the second round of the National Solar Mission was as low as \$0.17/kilowatt hour (Government of India Ministry of New and Renewable Energy 2012). In 2009, the Jawaharlal Nehru National Solar Mission released plans to expand current capacity of 1,000 megawatts to 20,000 megawatts by 2022 (Government of India Ministry of New and Renewable Energy 2012). The state of Gujarat with annual sunshine of 5.6-6.0 kilowatt hours/square meter is showing a strong interest in solar power and is trying to solve the problem of power shortages with new installations. The government plans to build the world's largest solar power generation site with a capacity of 1,000 megawatts and in April 2012 completed a 605 megawatt capacity site in Charanka (Pathak 2012).

A locally distributed energy source can be the answer for the 400 million people who live without electricity. Although more expensive than coal generation, solar panels have the advantage of being able to provide power to areas not yet connected to the central grid. New approaches such as rooftop solar power and solar water heating systems are being explored as well.

The northern part of the country has vast potential for large-scale hydroelectric power generation. Recently, the government proposed a plan to construct 292 dams throughout the Indian Himalayas. Each dam would have a capacity of 7,000 to 11,000 megawatts and if completed, the country's hydropower capacity will be doubled accounting for about 6\% of energy demand in 2030 (Nuwer 2013).

\section{Increasing nuclear capacity}

India has developed a largely indigenous nuclear power industry and has the goal of having $14.6 \mathrm{GW}_{\mathrm{e}}$ of nuclear capacity installed by 2020 (World Nuclear Association 2013b). There are currently 20 operating nuclear power reactors with 
an installed capacity of 4,780 megawatts; six nuclear power reactors with an aggregate capacity of 4,800 megawatts are in various stages of construction (Nuclear Power Corporation of India Limited 2012). The target for additional capacity in the Twelfth Five Year Plan has been fixed at 88,538 megawatts with a nuclear target of 5,300 megawatts or $6 \%$ of the total (Government of India Planning Commission 2008). The Department of Atomic Energy plans to commission two 1,000 megawatt units at Kudankulkam, one 500 megawatt prototype fast breeder reactor at Kalpakkam, and two 700 megawatt indigenously-developed pressurized heavy water reactors each at Kakrapar and Rawat Bhata (Arun 2012). Including the present 4,780 megawatt reactors, total nuclear capacity will be 10,080 megawatts when these reactors are constructed. There is a plan to install a total of $700 \mathrm{GW}_{\mathrm{e}}$ by 2032 to meet $7 \%-9 \%$ GDP growth with nuclear targets as high as $63 \mathrm{GW}_{\mathrm{e}}$ (World Nuclear Association 2013b). In the Twelfth Five Year Plan, the target share of $\mathrm{GW}_{\mathrm{e}}$ for nuclear power in 2030 is set at $12 \%$ (Government of India Planning Commission 2008).

People living near proposed plant sites are, however, protesting. Mass demonstrations were carried out against the French-backed 9,900 megawatt Jaitapur Nuclear Power Project in Maharashtra and the 2,000 megawatt Koodankulam Nuclear Power Plant in Tamil Nadu. At the Jaitapur site, protests have continued since 2009, and in January 2013, thousands of villagers launched a protest against the project (Deshpande 2013). Local residents and anti-nuclear activists oppose the construction because, given the lack of transparency in the state-controlled nuclear energy industry, there is no way to ensure safety. A major objection to the Koodankulam project is that, "More than 1 million people live within a 30-kilometer radius which far exceeds Atomic Energy Regulatory Board stipulations. It is quite impossible to evacuate this many people quickly and efficiently in case of a nuclear disaster at Koodankulam" (Udayakumar 2011). Despite these public protests, India continues to develop its indigenous nuclear power sector and is pursuing the possibility of thorium nuclear reactors (World Nuclear Association 2013b).

\section{Japan}

Nuclear power policy after the Fukushima Daiichi accident

Mr. Nobuo Tanaka, Global Associate of the Institute of Energy Economics, Japan (IEEJ), stated in an interview in 2011 “. . . abundant and cheap energy is a thing of a past" (IEEJ 2012b). Indeed this seems to be the case for Japan, and perhaps the world will unwillingly follow in this direction. Japan has 50 main nuclear reactors with a total capacity of 44,215 megawatts (IAEA 2013). While nuclear accounted for $28 \%$ of power generation output in 2009 , this fell to $17 \%$ in 2011 following the accident as all nuclear reactors were shut down to undergo inspection and remained dormant afterwards (IEEJ 2010).

In the Basic Energy Plan announced in 2010 (Government of Japan, Ministry of Economy, Trade, and Industry 2010), nuclear power was to make up 50\% of 
electricity production by 2030 ; however, after the accident at Fukushima, the Revolutionary Energy and Environment Strategy, announced in 2012, planned to reduce nuclear and to phase it out in the 2030s (World Nuclear News 2012). These measures were not, however, formally adopted. The future of nuclear thus remains uncertain.

Although the government and industries plan to invest in renewables to displace nuclear, future prices for wind, geothermal, and photovoltaics have a wide range of uncertainty as indicated in Table 8.1. Though listed as 8.9+ yen/kilowatt hour, the cost of nuclear is estimated at 10.2 yen/kilowatt hour when damages are calculated at 20,000 billion yen. (In the table, they are calculated at 5,800 billion yen per model plant, exclusive of undefined costs.)

Following the Fukushima Daiichi accident, $80 \%$ of the Japanese public wanted to discontinue nuclear power despite the economic burden of generating power from fossil fuels or renewables. The Democratic Party was set on finding a way to replace current nuclear generation capacities; however, the Liberal Democratic Party's House of Councilors pledges for the elections in July 2013 included resuming the operation of nuclear power reactors. Currently, the only nuclear power generated is by reactors 3 and 4 at the Ohi plant.

\section{Feed-in tariffs to promote renewables}

Japan is aiming to diversify its generation portfolio by expanding renewable energy capacity and introduced a renewable portfolio standard in 2003. Electric power supplied by renewable energy more than doubled from approximately 4 billion kilowatt hours in fiscal year (FY) 2003 to 10 billion kilowatt hours in FY 2010. The expansion of renewable energy has, however, been slow compared to countries like Germany and Spain. In 2009, Japan introduced the surplus electricity purchase system. This led to an increase in residential photovoltaic power generation, but the scheme was limited to the sale of surplus power generated by solar photovoltaics. The portion of renewables, excluding hydropower, was limited to approximately 1\% in FY 2009 (Government of Japan, Ministry of Economy, Trade, and Industry 2012).

After the Fukushima accident, a feed-in tariff was passed with immense public support on 31 August 2011 and went into effect on 1 July 2012. The result was higher than expected installation rates of renewable energy technologies during six months of implementation. The internal rate of return forecast by the government was $6 \%$ for solar photovoltaic facilities with 10 kilowatts or greater installed capacity and $8 \%$ for wind power with 20 kilowatts or greater installed capacity. A total of 2,079 megawatts of renewable energy facilities began operating in FY 2012 (Government of Japan, Ministry of Economy, Trade, and Industry 2013). Solar photovoltaics dominate accounting for more than $75 \%$ of capacity. This is more than $\$ 2$ billion of investments. The government expects investments of $\$ 640$ billion in the renewable energy sector by 2030 with the feed-in tariff in place (Reuters 2012).

Critics point out that such tariffs impose high costs on electricity providers who are required to pay. The Agency for Natural Resources predicts the cost 


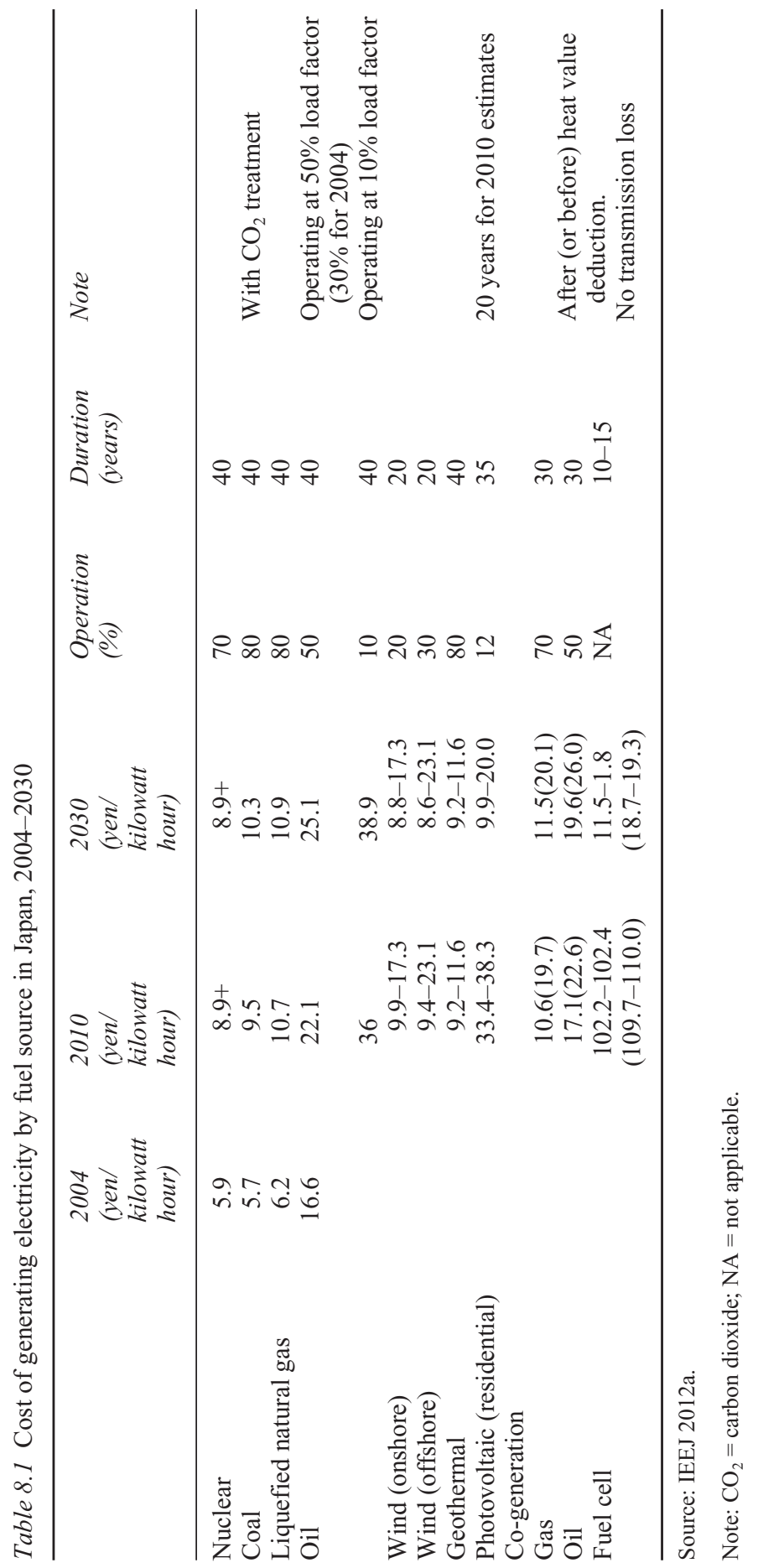


increase from the feed-in tariff to be from 0.2 to 0.4 yen/kilowatt hour $(\$ 0.02-$ $\$ 0.04 / \mathrm{kWh}$ ), which means average households consuming 300 kilowatt hours per month would have to pay an additional $70-100$ yen $(\$ 0.78-\$ 1.11)$ per month (Johnston 2012). When the feed-in tariff took effect in July 2012, consumers started paying an additional 0.22 yen/kilowatt hour $(\$ 0.024 / \mathrm{kWh})$ to utilities to cover the cost of the tariffs for FY 2012 (Government of Japan Ministry of Economy, Trade, and Industry 2012; Government of Japan, Agency for Natural Resources 2012).

As the installed capacity increases dramatically and the market matures, feed-in tariffs are ordinarily adjusted to reflect changes in the cost of production. Currently Japan's rate is more than twice that of France or Germany (Johnston 2012). Germany added 80 terawatt hours of renewable energy from 2000 to 2010 from wind, solar, and biomass, then during the first half of 2012 reduced its feed-in tariff on solar by half and stopped it altogether for large-scale power plants as the market matured.

Some criticize Japan's feed-in tariff for providing no guarantees for access to grid connections, a disadvantage for small-scale providers. Also, the segments accommodated within each technology are simple which limits variety. In Germany, onshore and offshore wind power sources are differentiated, and to promote small-scale installations wind power is categorized into five segments according to installed capacity. Japan's feed-in tariff, however, has the specific goal of large-scale renewable energy development over the first 3 years; progress to date indicates the policy has been very successful.

\section{Republic of Korea}

\section{Rising demand due to low prices}

There is a great deal of room for improvement in terms of demand management. The electricity price is the lowest among Organisation for Economic Co-operation and Development members and has stayed low despite the rise in fuel prices (IEA 2012). The cost of electricity for industries remains especially low; hence, demand has increased steadily over the years. Figure 8.4 shows consumption per capita increasing steadily and surpassing that in Japan. The price to consumers is set by the government at below production costs. Due to rising consumption, peak-time demand comes dangerously close to installed capacity, and there is a possibility of a blackout during summer and winter peak seasons.

In February 2013, the Ministry of Knowledge Economy announced the Sixth Basic Plan on Electricity Demand and Supply, an outline of an electricity policy from 2013 to 2028. In the plan, GHG emissions increase over $10 \%$ compared to the business-as-usual scenario announced in 2011. This contradicts the goals announced in 2009 of reducing GHG emissions by $30 \%$. According to the plan, heat generation will increase by 15.3 gigawatts by 2027 out of 29.570 gigawatts of total increased capacity. Demand management goals are set at 115,702 gigawatt hours, 37,154 of which come from increased efficiency and 78,548 from changes in the electricity price and the installation of smart grids. The growth in 


\section{Jong Ho Hong, Changhun Kim, Heeyoung Shin}

electricity demand is projected at an annual average of 3.4\% from 2013 to 2027 compared to the $3.1 \%$ annual growth from 2010 to 2024 assumed in the fifth plan. The new plan assumes electricity demand will reach 771,000 gigawatt hours by 2027.

\section{Prospects for nuclear power}

The Republic of Korea has continued on its nuclear expansion path despite the accident at Fukushima in neighboring Japan. Nuclear constituted 33\% of power generation output in 2009 , and the government planned to increase this to $41 \%$ by 2030 (Government of the Republic of Korea, National Energy Committee 2008). The economics of nuclear power remain highly debated with factors such as the cost of decommissioning, spent fuel storage, and insurance influencing levelized cost estimates. Anti-nuclear proponents argue that the costs related to nuclear power generation are grossly underestimated and that if the hidden costs are accounted for, nuclear power would not be economically viable. Nuclear power plant safety is also a major concern. Lapses in safety have led to unscheduled shut downs, and investigations revealed that unapproved parts were used in the plants. Government reports, however, view nuclear power as a green technology based on its low $\mathrm{CO}_{2}$ emission rates. In the Fifth Basic Plan, building nuclear power plants is seen as a part of an environmentally friendly electricity portfolio.

\section{Renewable energy policy}

Renewable energy currently accounts for less than $1 \%$ of total electricity generation and has been slow to develop. The government implemented a feed-in tariff from 2002 to 2011 (Lee and Yoon 2010) that boosted the development of solar photovoltaics, but the cost deterred it from continuing the policy. After much discussion, a renewable portfolio standard replaced the feed-in tariff and went into effect from 2012.

While the feed-in tariff was in place from 2002 to 2011, solar photovoltaic capacity increased exponentially from 200 kilowatts in 2004 to 347 megawatts in 2009. Likewise, government spending rose from 7.8 billion won ( $\$ 7.4$ million) in 2005 to 262.6 billion won ( $\$ 249$ million) in 2009 with more than $90 \%$ directed to solar (Electric Power Public Tasks Evaluation and Planning Center 2013). Eventually a cap was introduced as renewable energy installations increased at a faster rate than the government had anticipated. The rate of installation dropped from 257 megawatts in 2008 to 72 megawatts in 2009 (Shim 2012).

The renewable portfolio standard ambitiously aims to increase renewable energy 10\% in 10 years; however, results from 2012 show that the benefits of the policy may not materialize due to design flaws in the regulations as companies may choose the option of paying the fine instead of trying to meet the target (Shim 2012). The fine is up to $150 \%$ of the annualized averaged price of the renewable energy credit multiplied by the unfulfilled amount. The law leaves a loophole in that the structure of renewable energy credit markets makes them a 
buyer's market for the 13 electricity suppliers. Companies were given $30 \%$ room to put off meeting their targets for the first 3 years of the policy giving them the option of withholding purchase until the price of the credit drops.

At present the policy on the renewable portfolio standard needs to be readjusted to provide a realistic target for generators and to allow for fair trading in the renewable energy credit market. The scheme also needs to place more emphasis on small-scale projects. Additional measures that make grid connection the responsibility of power providers and not small-scale suppliers would encourage such developments.

Using feed-in tariffs to promote renewable energy is recommended along with changes in the portfolio standard policy. To do so, the first step would be increasing the budget allocated to promoting renewables two fold in the next 2 to 3 years, but in 2013, contrary to plans for green growth, the budget for renewable energy decreased by $15 \%$ compared to 2012 . Under these circumstances the renewable energy sector will lose its competitive edge compared with that in other economies that are investing heavily.

\section{Comparisons and policy recommendations}

Table 8.2 summarizes the features of the power sector indicators in the People's Republic of China, India, Japan, and the Republic of Korea.

\section{Improving electricity consumption per gross domestic product}

Referring back to Figure 8.5, electricity consumption per GDP for the PRC, Japan, and India show clear signs of decreasing while in the Republic of Korea it continues to rise. The PRC and Japan have concrete goals in place to improve efficiency. The PRC made provisions for a $16 \%$ reduction in energy intensity by 2015 (Ni 2012), and Japan has plans to achieve a 10\% reduction in electricity demand by 2030 (Murakami 2012). Energy efficiency investments often pay for themselves in terms of reduced fuel costs and generation capacity. The Republic of Korea and India should review such policies in the near future.

Demand management and increased efficiency in consumption are essential for reducing GHG emissions. Price controls, technological improvements, and using the most efficient source of energy will all play an important role. In the Republic of Korea, part of the problem is that government electricity demand projections assume continuous growth. The premises of such assumptions need to be reviewed.

\section{Reducing nuclear power}

In the search for cleaner and more reliable energy, nuclear was seen as an alternative to fossil fuel generation; however, Fukushima Daiichi showed that accidents do occur. Many countries have officially changed their nuclear power policies declaring eventual phase-outs or retractions of previous expansion schemes, but 


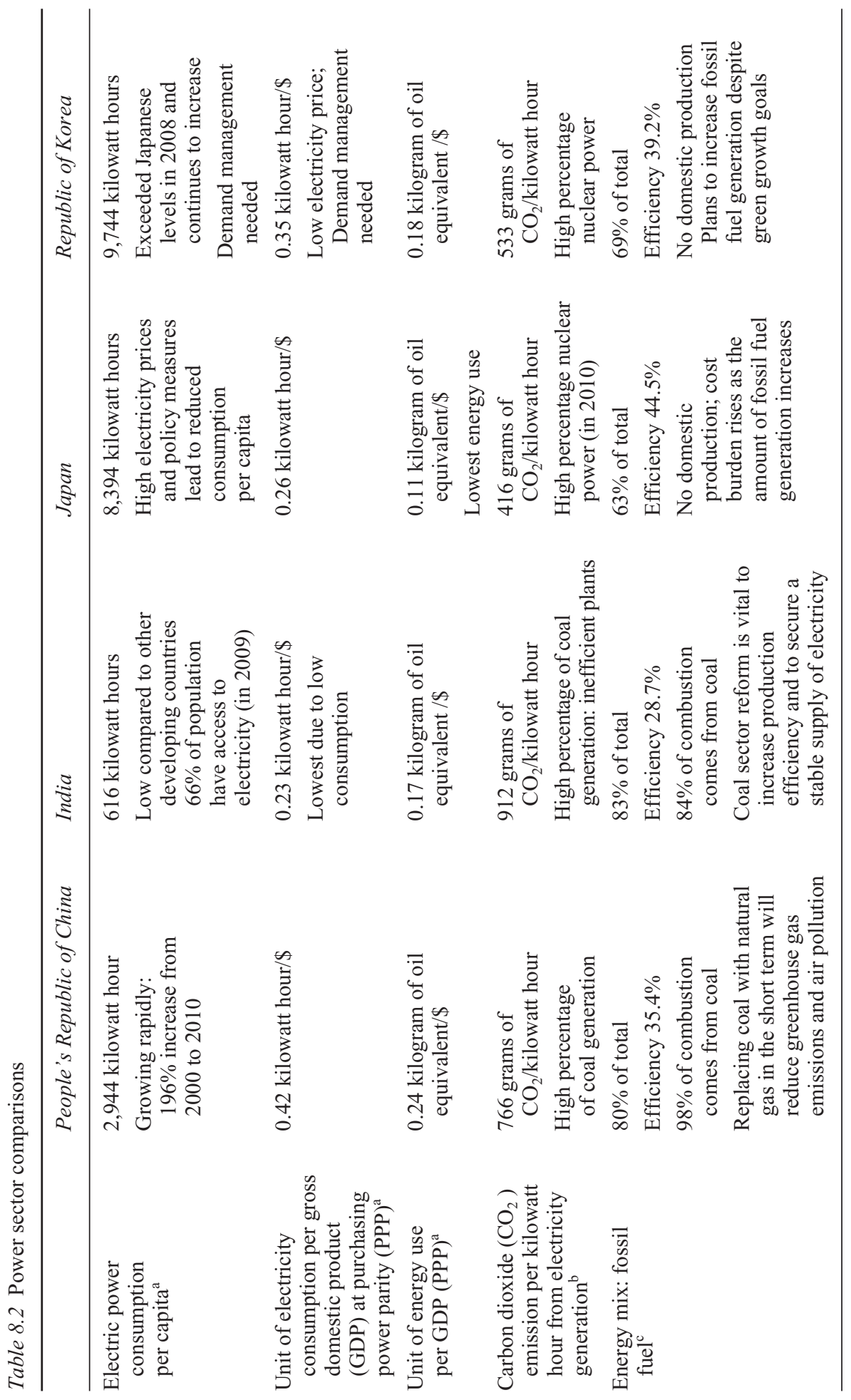




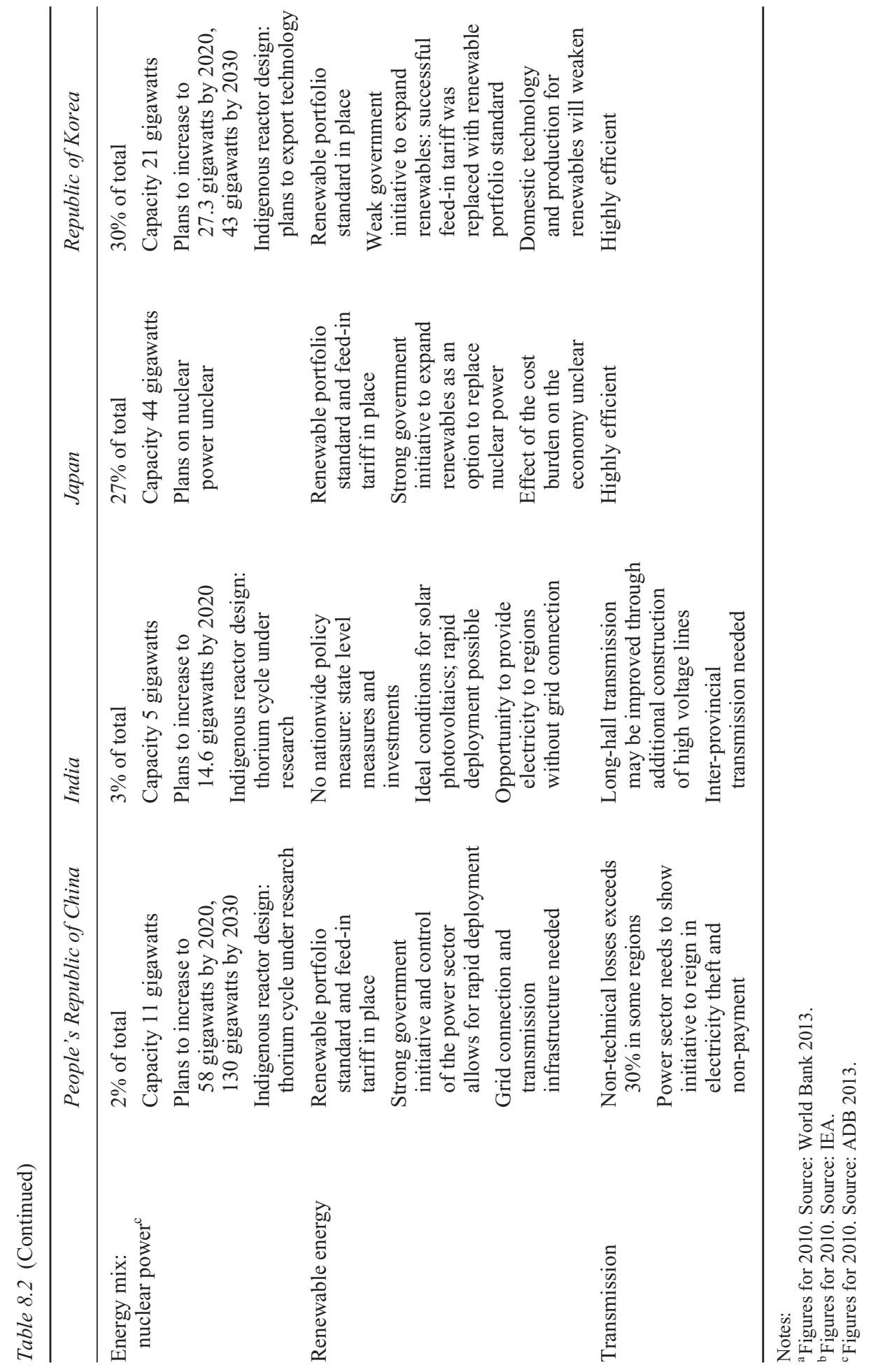


the PRC, India, and the Republic of Korea have plans to build additional nuclear power plants. For reasons of cost, safety, and sustainability, these countries should rethink their strategies for nuclear power.

The report released by Japan's Cost Verification Committee comparing generation cost by energy source yielded much higher costs per kilowatt hour for nuclear power. Once damage from nuclear accidents and subsidies to residents living near nuclear power plants are taken into account, nuclear is no longer an attractive option. Government authorities in these three countries need to make the information on calculating the cost of electricity by generation source public. When analyzing levelized costs of electricity, the cost of decommissioning and the unsolved problem of spent nuclear fuel storage must be considered.

Although the nuclear power target in the PRC was reduced following the Fukushima Daiichi accident, in October 2012 construction of new power plants resumed. The Indian government has had high hopes for its indigenous nuclear power program developing its own thorium cycle; however, public protests near reactor sites have been strong in their distrust of nuclear power safety. The nuclear targets in the Republic of Korea are extreme given what similar investments in energy efficiency could produce instead. Japan currently does not have a clear nuclear policy. Plans prior to 2011 need to be changed, and a sustainable energy mix concentrating on renewable energy should be devised. An official announcement outlining a gradual reduction in nuclear power is in order.

\section{Promoting renewable portfolio standards or feed-in tariffs}

In terms of market policies that stimulate the deployment of renewable energy technologies in the electricity sector, policy schematics can be broadly categorized into a price system in the form of feed-in tariffs and a quota system such as renewable portfolio standards. These two major policy directions are currently in place around the world with feed-in tariffs showing strong success in Germany and renewable portfolio standards in place in the US.

Feed-in tariffs guarantee a set price for renewable energy producers for a set period of time thus eliminating the uncertainty associated with selling electricity generated from renewable technologies to power companies; however, they do not guarantee a set percentage of renewables in the energy mix. Renewable portfolio standards set a minimum requirement for power generated from renewable technologies in the power generator's portfolios. They guarantee the goals set out by policymakers, and they encourage competition between technologies based on renewable energy credits.

Feed-in tariffs have been applied in 23 of the 28 European Union members, and Germany's Act on Granting Priority to Renewable Sources reframed in 2000 has proven them to be a most effective framework for promoting renewable technologies. Rapid increases in installed capacity from technological advancements tend to accelerate the pace of achieving grid parity, and economies of scale are made possible by the increase in demand. Overall, in terms of policy effectiveness, feed-in tariffs have proven to be an effective policy instrument in increasing 
the rate of diffusion of new technologies such as wind turbines and solar cells (Jacobsson and Lauber 2006).

In the renewable portfolio standard scheme, development may be slow compared to feed-in tariffs because the financial guarantee for the renewable energy providers is nonexistent; however, renewable portfolio standards have the advantage of giving clear signals to electricity generating companies thus providing certainty for future planning. The drawback of feed-in tariffs is the cost of implementation. In the Republic of Korea, they placed a financial burden on the government as the portion of renewable energy grew at a rate faster than expected. In fact, a survey of the 48 countries implementing feed-in tariffs suggests the policy tool is likely to be more suitable for advanced economies as many are located in Europe, e.g., Denmark, Germany, and Spain (Davies 2011).

\section{Conclusion}

Securing an affordable and reliable source of energy is vital for any economy. Electricity is increasingly becoming the preferred energy source, but managing the sector remains a difficult task. Balancing supply and demand while dealing with issues such as energy security and sustainability, policymakers face tough decisions concerning sector reform and energy mix. Improving energy efficiency should be a top priority everywhere; coal generation in developing economies can be improved, transmission losses can be reduced, and efficient consumption can be encouraged through demand management and appropriate price signals. In many cases, governments have expanded power generation capacity before investing in efficient generation and distribution.

Government policies promoting growth in renewable energy are a must in all stages of economic development. The economics of solar photovoltaics, wind, and other renewables are improving at a fast pace, and in some areas renewables are already at grid parity. Nevertheless, currently they remain expensive compared to fossil fuel thermal generation. With the full support of renewable energy industries, governments should also explore the option of replacing coal in thermal power plants with natural gas. The shale boom in the US will lead to lower natural gas prices in Asia; governments should maximize its potential by encouraging small-scale generation facilities. Together with distributed, small-scale, renewable energy generators, peak load demand on centralized facilities can be reduced.

In developed economies, governments should work toward implementing a market mechanism in the power sector. Electricity is often seen as a public good that must be available to all, but setting electricity prices below production costs leaves growing demand unchecked. The electricity sector currently is and will remain highly regulated by governments, but some flexibility needs to be introduced. By allowing market mechanisms to balance supply and demand through shifting electricity prices, efficiency on both ends can be improved.

As for nuclear power in Asia, governments must realize that recent developments require a review of pre-existing policies. The safety and economics of nuclear power should be re-examined. Public discourse on the subject must 
precede any policy decisions, and the costs associated with the entire life cycle of nuclear power plants must be analyzed. The impacts of nuclear power on current and future generations must be considered in full.

\section{References}

Antmann, P. 2009. Reducing technical and non-technical losses in the power sector. Background paper for the WBG Energy Strategy.

Arun, T. K. 2012. Despite Having One of the World's Largest Reserves of Coal, India is Unable to Dig it Up Fast Enough. The Economic Times. 14 June.

Asian Development Bank (ADB). 2013. Asian Development Outlook: Asia's Energy Challenge. Manila: ADB.

Bazilian, M., I. Onyeji, M. Liebreich, I. MacGill, J. Chase, J. Shah, D. Gielen, D. Arent, D. Landfear, and S. Zhengrong. 2012. Re-considering the Economics of Photovoltaic Power. White Paper. Bloomberg New Energy Finance.

Chung, O. 2011. Power Rationing Strikes [the People's Republic of] China Early. Asia Times. 20 May. http://www.atimes.com/atimes/China_Business/ME20Cb01.html (accessed February 2014).

Davies, L. 2011. Incentivizing Renewable Energy Deployment: Renewable Portfolio Standards and Feed-In Tariffs. KLRI Journal of Law and Legislation. 1 (1). pp. 39-91.

Deshpande, A. 2013, Villagers Court Arrest Against Jaitapur Nuclear Plant. The Hindu. 3 January. http://www.thehindu.com/news/national/villagers-court-arrest-against-jaitapurnuclear-plant/article4266213.ece (accessed February 2014).

Electric Power Public Tasks Evaluation and Planning Center of the Republic of Korea. 2013. Overview of Tasks and Funds (in Korean). January. http://www.etep.or.kr/home/ busi_info/result/pResultView.jsp (accessed February 2014).

European Union Climate Change Expert Group Science. 2008. The $2{ }^{\circ} \mathrm{C}$ target. http:// www.climateemergencyinstitute.com/uploads/2C_EU.pdf (accessed February 2014).

Frankfurt School of Finance \& Management and Bloomberg New Energy Finance. 2012. Global Trends in Renewable Energy Investment 2012. Frankfurt School of Finance \& Management.

Government of India, Ministry of Coal. 2013. Inventory of Coal Resources of India. http:// www.coal.nic.in/reserve2.htm (accessed February 2014).

- Ministry of New and Renewable Energy. 2012. Jawaharlal Nehru National Solar Mission Phase II Policy Document. http://mnre.gov.in/file-manager/UserFiles/draftjnnsmpd-2.pdf (accessed February 2014).

—. Ministry of Power, Central Electricity Authority. 2011. Load Generation Balance Report 2011-2012. http://www.cea.nic.in/reports/yearly/lgbr_report.pdf (accessed February 2014).

—. Planning Commission. 2008. Eleventh Five Year Plan 2007-2012. New Delhi: Oxford University Press.

Government of Japan. Japan Renewable Energy Policy Platform. 2010. Renewables Japan Status Report 2010. http://www.re-policy.jp/jrepp/JSR2010SMR20100427E.pdf (accessed February 2014).

—. Ministry of Economy, Trade, and Industry. 2010. The Strategic Energy Plan of Japan (Summary). http://www.meti.go.jp/english/press/data/pdf/20100618_08a.pdf (accessed February 2014). 
- Ministry of Economy, Trade, and Industry. 2012. Settlement of the Details of the Feed-in Tariff Scheme for Renewable Energy, Including Purchase Price and Surcharge Rates. http://www.meti.go.jp/english/press/2012/0618_01.html

—. Ministry of Economy, Trade, and Industry. 2013. Announcement Regarding the Present Status of Introduction of Facilities Generating Renewable Energy as of May 31. http://www.meti.go.jp/english/press/2013/0820_01.html (accessed February 2014).

—. Agency for Natural Resources and Energy. 2012. Feed-In Tariff Scheme in Japan. http://www.meti.go.jp/english/policy/energy_environment/renewable/pdf/summary 201207.pdf (accessed February 2014).

Government of the Republic of Korea. Ministry of Knowledge Economy. 2010. Renewable Portfolio Standards Implementation Decided for 2012 (in Korean). http://www.motie. go.kr/motie/ne/rt/press/bbs/bbsView.do?bbs_seq_n=59508\&bbs_cd_n=16 (accessed February 2014).

- National Energy Committee. 2008. First Master Plan for National Energy (in Korean). http://17naenc.pa.go.kr/include/download.asp?fname= $\% 5 \mathrm{~B} 18 \% 5 \mathrm{D} \% \mathrm{~B} 1 \% \mathrm{~B} 9 \% \mathrm{~B} 0 \% \mathrm{~A} 1 \%$ BF\%A1\%B3\%CA\%C1\%F6\%B1\%E2\%BA\%BB\%B0\%E8\%C8\%B9(2008-2030).pdf\& fnm $=\%$ B $1 \%$ B $9 \%$ B0 $\%$ A $1 \%$ BF $\%$ A $1 \%$ B3 $\%$ CA $\%$ C1\%F6\%B1\%E2\%BA $\%$ BB $\%$ B0 $\%$ E $8 \%$ C8\%B9(2008-2030).pdf (accessed February 2014).

—. National Energy Committee. 2010. Fifth Basic Plan for Long-Term Electricity Supply and Demand (in Korean). http://www.kgu.or.kr/download.php?tb=bbs_019\&fn $=\% \mathrm{C} 1 \% \mathrm{~A} 65 \% \mathrm{C} 2 \% \mathrm{~F} 7 \% \mathrm{C} 0 \% \mathrm{FC} \% \mathrm{~B} 7 \% \mathrm{C} 2 \% \mathrm{BC} \% \mathrm{~F} 6 \% \mathrm{~B} 1 \% \mathrm{DE} \% \mathrm{~B} 1 \% \mathrm{E} 2 \% \mathrm{BA} \% \mathrm{BB} \%$ B0\%Е8\%C $\% \%$ B9(101229).hwp\&rn=\%C1\%A65\%C2\%F7\%C0\%FC $\%$ B $7 \%$ C2\%BC $\%$ F6\%B1\%DE\%B1\%E2\%BA\%BB\%B0\%E8\%C8\%B9(101229).hwp (accessed February 2014).

Government of the United States. Energy Information Administration (EIA). 2011. International Energy Outlook 2011. Washington, DC: EIA.

—. Energy Information Administration (EIA). 2012a. Annual Energy Outlook 2012. Washington, DC: EIA.

—. Energy Information Administration (EIA). 2012b. Country Analysis Briefs. http:// www.eia.gov/countries/ (accessed February 2014).

—. Energy Information Administration (EIA). 2013. International Energy Statistics. http://www.eia.gov/cfapps/ipdbproject (accessed February 2014).

- National Intelligence Council (NIC). 2012. Global Trends 2030: Alternative Worlds. http://globaltrends2030.files.wordpress.com/2012/11/global-trends-2030-november2012. pdf (accessed February 2014).

Institute of Energy Economics Japan (IEEJ). 2012a. Japan Energy Brief No. 17. January 2012. http://eneken.ieej.or.jp/en/jeb/1201.pdf (accessed February 2014).

—. 2012b. Japan Energy Brief No. 18. March 2012. http://eneken.ieej.or.jp/en/jeb/1203. pdf (accessed February 2014).

International Atomic Energy Agency (IAEA). 2013. Nuclear Share of Electricity Generation in 2012. http://www.iaea.org/pris/WorldStatistics/NuclearShareofElectricity Generation.aspx (accessed February 2014).

International Energy Agency (IEA). 2012. World Energy Outlook 2012. Paris: IEA.

International Renewable Energy Agency (IRENA) and Global Wind Energy Council (GWEC). 2012. 30 Years of Policies for Wind Energy: Lessons from 12 Wind Energy Markets. IRENA. http://www.irena.org/DocumentDownloads/Publications/IRENA_ GWEC_WindReport_Full.pdf (accessed February 2014). 
Jacobsson, S. and V. Lauber. 2006. The Politics and Policy of Energy System Transformation explaining the German Diffusion of Renewable Energy Technology. Energy Policy. 34 (3). pp. 256-276.

Johnston, E. 2012. A Guide to Japan's New Feed-in Tariff. Fresh Currents. http:// www.freshcurrents.org/blog/2012/08/23/a-guide-to-japans-new-feed-in-tariff/ (accessed February 2014).

[Republic of] Korea Electric Association. 2011. Electricity Almanac 2011. Soeul.

Koyama, K. 2012. Background and Impacts of World's Largest Blackout in India. Special Bulletin. Tokyo: The Institute of Energy Economics, Japan (IEEJ).

KPMG. 2009. Think BRIC! India. KPMG International. http://www.kpmginstitutes.com/ global-energy-institute/insights/2010/pdf/think-bric-india.pdf?utm_source=page\&utm_ medium=/global-energy-institute/insights/2010/think-bric-india.aspx\&utm_campaign= download (accessed February 2014).

_. 2011. [People's Republic of] China 12th Five Year Plan Overview. KPMG Advisory (China) Limited. http://www.kpmg.com/cn/en/IssuesAndInsights/ArticlesPublications/ Documents/China-12th-Five-Year-Plan-Overview-201104.pdf (accessed February 2014).

Kulkarni, V. 2011. The Truth about India's Coal. The Hindu Business Line. 7 March. http:// www.thehindubusinessline.com/opinion/article1514900.ece?homepage=true (accessed February 2014).

Lee, H.-J. and S.-W. Yoon. 2010. Renewable Energy Policy in Germany and Its Implications for [the Republic of] Korea. Seoul: Korea Institute for International Economic Policy.

Liu, C. 2011. [People's Republic of] China Uses Feed-In Tariff to Build Domestic Solar Market. The New York Times. 14 September. http://www.nytimes.com/cwire/2011/ 09/14/14climatewire-china-uses-feed-in-tariff-to-build-domestic-25559.html?pagewanted $=1$ (accessed February 2014).

Murakami, T. 2012. Examining Japan's Energy Choices. Nippon.com. 10 September. http://www.nippon.com/en/in-depth/a01202/ (accessed February 2014).

Ni, V. 2012. [The People's Republic of] China Sets New Greenhouse Gas Emission Reduction Goals. China Briefing. 18 January. http://www.china-briefing.com/news/ 2012/01/18/china-sets-new-greenhouse-gas-emission-reduction-goals.html (accessed February 2014).

Nuclear Power Corporation of India Limited. 25th Annual Report 2011-2012. http://www. npcil.nic.in/main/AnnualReportDisplay.aspx (accessed February 2014).

Nuwer, R. 2013. Hobbled on Energy, India Ponders a Multitude of Dams. The New York Times. 7 January. http://green.blogs.nytimes.com/2013/01/07/hobbled-on-energy-indiaponders-a-multitude-of-dams/?_r=0\&pagewanted=print (accessed February 2014).

Pathak, M. 2012. Solar Boom Faces Challenges. Live Mint and The Wall Street Journal. 24 April. http://www.livemint.com/Politics/feKnOVKKTR3D4xUBAANYUL/Solar-boomfaces-challenges.html (accessed February 2014).

Reuters. 2012. Japan Sun Subsidy Fires Electric Spending Rush. 12 September. http:// in.reuters.com/article/2012/09/12/japan-energy-renewables-idINL3E8KB20G20120912 (accessed February 2014).

Shim, S. 2012. Renewable Portfolio Standard (RPS) in [the Republic of] Korea: How to Make It Work. Paper presented at the Construction, Building, and Real Estate Research Conference of the Royal Society of Chartered Surveyors. Las Vegas. 11-13 September. http://www.rics.org/Global/COBRA2012_Renewable_Portfolio_Korea_200912_dwl_aj. pdf (accessed February 2014). 
Udayakumar, S. P. 2011. Thirteen Reasons Why We Do Not Want the Koodankulam Nuclear Power Project. TRANSCEND Media Service. 29 August. https://www.transcend. org/tms/?p=14126 (accessed February 2014).

World Bank. 2013. World Development Indicators. www.data.worldbank.org (accessed 31 January 2013).

World Nuclear Association. 2013a. Nuclear Power in [People's Republic of] China. http:// www.world-nuclear.org/info/Country-Profiles/Countries-A-F/China-Nuclear-Power/\#. UjKou8ano40 (accessed February 2014).

—. 2013b. Nuclear Power in India. http://world-nuclear.org/info/Country-Profiles/ Countries-G-N/India/\#.UjMLp8ano40 (accessed February 2014).

World Nuclear News. 2012. "Innovative" Strategy to End Japanese Nuclear. 14 September. http://www.world-nuclear-news.org/NP_Innovative_strategy_to_end_Japanese_nuclear_ 1409121.html (accessed February 2014).

Wu, F. W. and S. Fu. 2005. [The People's Republic of] China's Future in Electric Energy. IEEE Power and Energy Magazine. 3 (4).

Wu, Qi. 2012. [People's Republic of] China Targets Grid-Access Bottleneck With Quota System. Wind Power Monthly. 1 June. http://www.windpowermonthly.com/article/ 1133694/china-targets-grid-access-bottleneck-quota-system (accessed February 2014).

Zeng, M. M., X. Song, Z. Xiaoli, and M. Mingjuan. 2012. [People's Republic of] China 12th Five Year Plan Pushes Power Industry in New Directions. Power Magazine. 1 January. http://www.powermag.com/gas/Chinas-12th-Five-Year-Plan-Pushes-PowerIndustry-in-New-Directions_4257.html (accessed February 2014). 


\title{
9 Nuclear power development in Asia
}

\author{
Holger Rogner and Kee-Yung Nam
}

\section{Introduction}

The accident at the Fukushima Daichii nuclear power plant in Japan after the extraordinary earthquake and tsunamis on 11 March 2011 ended several years of rapidly increasing construction starts of new plants and put the technology on a slower growth trajectory. While some governments have decided to phase out the use of nuclear power over the next decades, interest continues especially in large rapidly developing economies in Asia, in economies without significant indigenous fossil resources, and in jurisdictions that value the climate change mitigation benefits of nuclear power. This chapter surveys the rationale for pursuing nuclear power from the vantage points of economics, finance, safety and waste disposal, public acceptance, non-proliferation, and technical innovation.

\section{The global situation}

Electricity market liberalization and low fossil fuel prices during the 1990s and early years of the 21st century exposed nuclear power plant operators to previously unknown competition forcing them to better utilize their assets, to condense maintenance outages, and to reduce overhead costs by consolidating plants and numerous other administrative measures. The net results were low, short-run marginal generating costs as well as enormous performance improvements in the global fleet of reactors. Until the early 1990s, the load factor (the percentage of time a plant generates electricity to the grid at full capacity) hovered around $65 \%$. By 2005 , the global load factor had reached more than $80 \%$ which allowed continued growth in nuclear generation by $37 \%$ despite aggregate generating capacity expanding only $14 \%{ }^{1}$ Globally though, new plant construction was moving slowly as investors were alienated by uncertain, long-term marginal generating costs and the legacy of the 1986 Chernobyl accident, i.e., lack of government policy support and public acceptance (Rogner 2010). The overall safety performance in terms of scrams and radiation exposure to the workforce mirrored the good economic performance leading to license extensions of up to 20 years,

\footnotetext{
${ }^{1}$ The vastly improved utilization of existing capacity worldwide corresponds to the virtual construction of about 31,000 megawatts of generating capacity.
} 
power uprates by replacing aged equipment, and safety upgrades. Major new builds occurred in the People's Republic of China (PRC) and India and to a lesser extent in the Russian Federation.

Beginning in 2004, fossil fuel market prices exhibited both significant growth and intense volatility. Energy security, forgotten for two decades, was back on the political agenda. The climate change debate and the entry into force of the Kyoto Protocol in 2005 brought to the fore the need for low greenhouse gas (GHG) emitting technologies. Rising electricity demand in the developing world, energy security, climate change, volatile fossil fuel prices, and promising nuclear economics combined in an upward trend for nuclear power often referred to as the "nuclear renaissance." Countries with operating plants contemplated new builds while more than two dozen currently without nuclear power programs prepared to introduce the technology. By 2010, plant orders and construction starts (16 in 2010) reached levels not seen for a quarter of a century.

As of 31 December 2012, 437 plants were operating globally generating 2,484 terawatt hours (TWh) of electricity (2011) or $12.9 \%$ of the global supply, and 68 reactors were under construction. This was the most since the mid-1990s despite the sharp drop from 16 construction starts in 2010 to only 4 in 2011 (and a rebound to 7 in 2012). As in previous years, expansion and near- and long-term growth prospects remain centered in Asia (Figure 9.1). Of the 68 reactors under construction, 47 are in Asia as are 40 of the last 50 reactors that have been connected to the grid.

Until the turn of the century, nuclear power was a technology primarily used in industrialized economies; only a few in the developing world introduced nuclear power on a limited scale (Figure 9.1 left panel). Plants currently under

Units in operation: 437 $372.3 \mathrm{GW}_{\mathrm{e}}$

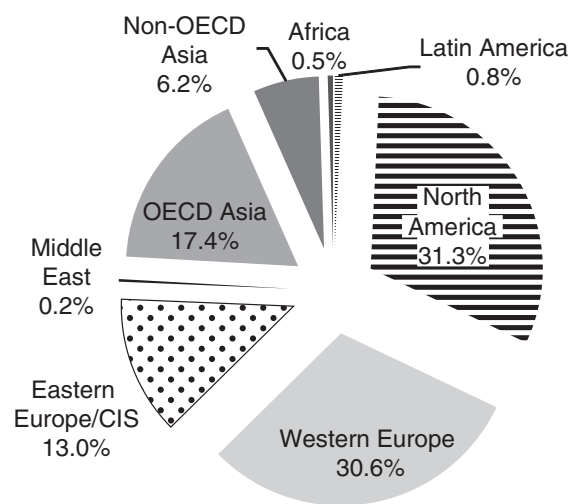

Units under construction: 68 $65.4 \mathrm{GW}_{\mathrm{e}}$

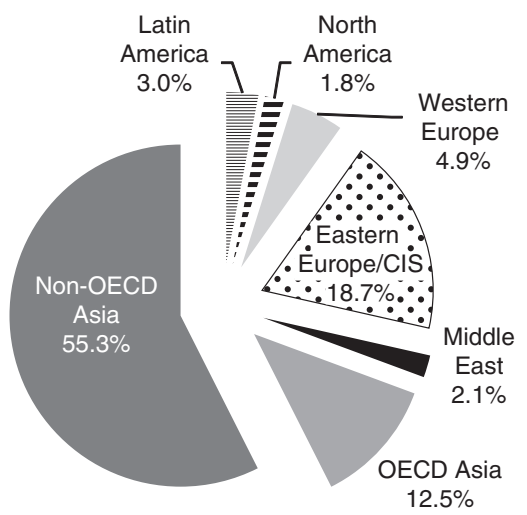

Figure 9.1 Regional distribution of nuclear power as of 31 December 2012 Source: IAEA 2013.

Note: $\mathrm{GW}_{\mathrm{e}}=$ gigawatts of electricity; $\mathrm{OECD}=$ Organisation for Economic Co-operation and Development; CIS = Commonwealth of Independent States. 
construction show a fundamental shift of momentum to Asia (Figure 9.1 right panel). The PRC and India have the fastest growing nuclear programs followed by the Russian Federation and the Commonwealth of Independent States. The rest of the world, particularly the traditional nuclear power countries of North America and Western Europe, has fallen behind Asia by a wide margin.

\section{The Fukushima Daiichi accident}

Before the accident, many countries without nuclear power programs expressed interest in adding nuclear to their electricity generation portfolios. A total of 12 decided to implement programs and started preparing the necessary infrastructure, 7 started preparations without a final decision, and more than 40 either considered programs or were interested in obtaining relevant information on the technology and its prerequisite infrastructure requirements. The Fukushima Daiichi accident re-ignited the debate about the role of nuclear power in the future global energy mix. Initial government policy responses, in large part fuelled by public pressure, pointed toward a more uncertain future for the technology. In the short run, the accident had a significant impact on construction starts in 2011 and 2012 as well as plant closures. In 2011, 13 reactors - 12 in an immediate response to the accident — were officially declared as permanently shut down. This was the highest number of shutdowns since 1990 after Chernobyl.

The immediate response of governments with nuclear power plants was to conduct comprehensive safety reviews - including reassessing the safety margins of all nuclear installations - and to improve the frameworks for dealing with nuclear accidents, for emergency preparedness, and for communication. Stress tests evaluated the capacity of plants to withstand extreme natural and anthropogenic events. Measures have been initiated to improve preparedness for prolonged power blackouts, to protect sources of backup electrical power, and to assure the availability of water for cooling even during severe multiple accidents. Emergency preparedness and response capabilities came under critical review in many cases causing radical revisions of worst-case assumptions for safety planning. In addition, many countries revisited their long-term energy development plans and policies and analyzed demand and supply options.

Several governments with operational nuclear power plants decided to phase out the technology over the next two decades. Within weeks after the accident, Germany renounced its September 2010 policy decision to extend the lifetime of its reactor fleet by an average of 12 years and closed for good eight nuclear reactors that were off-line for refuelling, maintenance, or repairs. Moreover, phasing out the remaining nine reactors was accelerated to 2022 which corresponds to an average lifetime of approximately 30 years. Belgium, Switzerland, and Taipei,China put nuclear phase-out policies in place after the Fukushima accident. Table 9.1 summarizes policy responses.

The Japanese government ordered the shutdown or blocked the restart of most reactors in the country to conduct mandatory two-phase stress tests. They further ceased all construction of new builds and decided to decommission Fukushima Daiichi units 1 to 4. By May 2011 (2 months after the accident), only 
Table 9.1 Policy responses to the Fukushima Daiichi accident

\begin{tabular}{|c|c|}
\hline Economy & Policy response \\
\hline Belgium, Germany, Switzerland & Nuclear phase out; no new builds \\
\hline Taipei,China & $\begin{array}{l}\text { Nuclear phase out announced but new plant } \\
\text { construction continues }\end{array}$ \\
\hline Japan & $\begin{array}{l}\text { Plants under construction suspended, Fukushima } \\
\text { units } 1-4 \text { to be decommissioned, remaining } \\
50 \text { plants successively shut down by } 5 \text { May } \\
2012 \text {; two restarts in July 2012; future use } \\
\text { of nuclear power contested; subsequently, } \\
\text { phase-out intentions by late 2030s announced }\end{array}$ \\
\hline People's Republic of China & $\begin{array}{l}\text { Awards of new construction licenses suspended } \\
\text { but lifted again in October } 2012\end{array}$ \\
\hline Belarus, Turkey, UAE & First plants ordered; UAE construction started \\
\hline $\begin{array}{l}\text { Chile, Indonesia, Malaysia, Morocco, } \\
\text { Thailand, Saudi Arabia, Viet Nam }\end{array}$ & $\begin{array}{l}\text { Active preparation with final decision delayed or } \\
\text { no final decision }\end{array}$ \\
\hline $\begin{array}{l}\text { Bangladesh, Egypt, Jordan, Ghana, } \\
\text { Nigeria, Poland }\end{array}$ & Continue preparing infrastructure \\
\hline Italy, Kuwait, Senegal, Venezuela & Plans to introduce nuclear power cancelled \\
\hline
\end{tabular}

Source: Authors.

Note: $\mathrm{UAE}=$ United Arab Emirates.

26 of the remaining 50 reactors were in operation; this number dropped to zero by 5 May 2012 when Tomari-3, the country's only reactor still in operation, was taken off the grid for maintenance and refuelling.

In June 2012, Prime Minister Noda announced the government's approval with the agreement of local authorities to restart units 3 and 4 at the Kansai Electric Power Company's Ohi plant in Fukui Prefecture. Both were shut down shortly after the accident for scheduled outages and have since successfully passed phase 1 of the mandatory stress test. After 2 months without nuclear power in Japan, Ohi-3 started generating electricity again on 5 July 2012 and was followed by Ohi-4 2 weeks later.

A white paper by the Japanese government published in the fall of 2011 announced a decrease in the nuclear share in the electricity mix in the medium to long term. The Energy and Environment Council prepared three scenarios for the share of nuclear power by 2030: $0 \%, 15 \%$, and $20 \%-25 \%$ (the share in 2010 was $29 \%$ ). These options were presented nationally at public hearings for comment and debate with the clear outcome a preference for the $0 \%$ option. In the New Energy Policy presented in September 2012, the government announced its intention to phase out nuclear energy as soon as possible after 2030.

Italy, Kuwait, Senegal, and Venezuela had stated intentions to explore the nuclear option or to introduce nuclear power, but after the accident they announced that they would no longer do so, and Indonesia, Malaysia, and Thailand said their plans would be delayed and reassessed. To date, however, though the accident has 
stimulated a lot of reflection about nuclear power, it has not led to a significant retraction in programs globally. The pre-March 2011 trend of power uprates and of renewed or extended licences for many operating reactors continued, for example, in Canada, Finland, France, Mexico, Spain, Slovakia, and the United States (US) (IAEA 2012a). Nuclear power remains an important option not only where there are existing nuclear power programs but also for developing economies with growing energy requirements. Those continuing with plans to expand or to introduce nuclear energy are determined to incorporate the lessons learned from the Fukushima-Daiichi accident.

\section{Asia and the Pacific: Asian Development Bank members}

Although the seven Asian Development Bank (ADB) members operating nuclear power reactors (Table 9.2) account for $23.7 \%$ of global nuclear generating capacity, their share of total nuclear electricity generation amounted to only $14.4 \%$ in 2012 which corresponds to a low load factor of only $43.5 \%$. This was the result of the continued shut-downs of 48 of Japan's fleet of 50 reactors throughout the year.

Overall, however, the region accounts for $69 \%$ of global nuclear generating capacity currently under construction. The PRC and to a lesser extent India dominate. Preparations for the introduction of nuclear power are most advanced in Bangladesh and Viet Nam with vendor arrangements already in place, but financing is still not fully disclosed or is uncertain in Bangladesh.

Table 9.2 Nuclear capacity and generation in Asian Development Bank member countries (as of 31 December 2012)

\begin{tabular}{|c|c|c|c|c|c|c|c|c|}
\hline & \multicolumn{2}{|c|}{$\begin{array}{l}\text { Reactors } \\
\text { in operation } \\
\text { on } 31 \text { Dec } \\
2012\end{array}$} & \multicolumn{2}{|c|}{$\begin{array}{l}\text { Reactors } \\
\text { under } \\
\text { construction }\end{array}$} & \multicolumn{2}{|c|}{$\begin{array}{l}\text { Nuclear } \\
\text { electricity } \\
\text { supplied in } \\
2012\end{array}$} & \multicolumn{2}{|c|}{$\begin{array}{l}\text { Total } \\
\text { operating } \\
\text { experiene } \\
\text { through } 2012\end{array}$} \\
\hline & $\begin{array}{l}\text { No of } \\
\text { Units }\end{array}$ & $\begin{array}{l}\text { Total } \\
M W_{e}\end{array}$ & $\begin{array}{l}\text { No of } \\
\text { Units }\end{array}$ & $\begin{array}{l}\text { Total } \\
M W_{e}\end{array}$ & $T W h$ & $\begin{array}{l}\% \text { of } \\
\text { total }\end{array}$ & Years & Months \\
\hline Armenia & 1 & 375 & & & 2.1 & 26.6 & 38 & 4 \\
\hline $\begin{array}{l}\text { People's } \\
\text { Republic } \\
\text { of China }\end{array}$ & 17 & 12,860 & 29 & 28,844 & 92.7 & 2.0 & 141 & 7 \\
\hline India & 20 & 4,391 & 7 & 4,824 & 29.7 & 3.6 & 377 & 3 \\
\hline Japan & 50 & 44,215 & 2 & 2,650 & 17.2 & 2.1 & 1,596 & 4 \\
\hline $\begin{array}{l}\text { Republic of } \\
\text { Korea }\end{array}$ & 23 & 20,739 & 4 & 4,980 & 143.5 & 30.4 & 404 & 1 \\
\hline Pakistan & 3 & 725 & 2 & 630 & 5.3 & 5.3 & 55 & 8 \\
\hline Taipei,China & 6 & 5,028 & 2 & 2,600 & 40.4 & 19.0 & 188 & 1 \\
\hline Total & 120 & 88,333 & 46 & 44,528 & 330.9 & 6.9 & 2,801 & 4 \\
\hline
\end{tabular}

Source: IAEA 2013.

Note: $\mathrm{MW}_{\mathrm{e}}=$ megawatts of electricity; $\mathrm{TWh}=$ terawatt hours. 
Viet Nam started preparing its nuclear program in 1995, and initial site evaluations took place in 2008. Preparations have closely followed International Atomic Energy Agency (IAEA) recommended guidelines, and the country has requested two IAEA-led integrated nuclear infrastructure review missions. Viet Nam has signed an agreement with the Russian Federation (Atomstroyexport) for the construction and financing of two 1,000 megawatts of electricity $\left(\mathrm{MW}_{\mathrm{e}}\right)$ reactors. A similar arrangement for another 2,000 $\mathrm{MW}_{\mathrm{e}}$ has been signed with Japan. Construction of the first plant is expected to start in 2014 with grid connection in 2020. The plants will be state owned by Electricity of Viet Nam with no private equity.

Bangladesh started planning for nuclear power in the early 1960s and started site evaluations in the mid-1990s. In May 2010, a nuclear cooperation agreement was signed with the Russian Federation for construction and operation as well as for nuclear fuel supply and the return of spent fuel. An agreement with Rosatom was signed in February 2011 for two 1,000 $\mathrm{MW}_{\mathrm{e}}$ reactors to be built at Rooppur by Atomstroyexport. A finance package arranged in August 2012 includes 85\% of the estimated $\$ 1.5$ billion cost for constructing the first unit funded by the Russian Federation with a repayment schedule of 28 years including a 10 -year grace period. Construction is expected to start in 2013 with operation in 2018.

Plans to add nuclear power in Thailand also date back several decades but were put aside when gas discoveries were rapidly developed in the 1980s. The 1986 Chernobyl accident then stalled nuclear ambitions. Plans to embark on a nuclear power program resurfaced in the early 2000s when natural gas production fell behind demand - primarily for electricity — and gas prices rose. Studies projecting growth in electricity demand of $7 \%$ per year for the next 20 years prompted the Thailand National Energy Policy Council to commission a feasibility study for a nuclear power program. In 2007, the council approved the Nuclear Power Development Plan for 2007-2021 including the construction of 4,000 $\mathrm{MW}_{\mathrm{e}}$ of nuclear generating capacity with a grid connection of the first plant in 20202021. Originally the government was to make a final decision in 2011 on starting construction in 2014, but in light of the Fukushima Daiichi accident, the government now envisages having 2,000 $\mathrm{MW}_{\mathrm{e}}$ of nuclear capacity on line by 2026 . The necessary nuclear infrastructure is under preparation following IAEA guidance. ${ }^{2}$

In Malaysia, the government formally decided to consider nuclear power in June 2009. In January 2011, the Malaysia Nuclear Power Corporation was commissioned to spearhead nuclear power development under the new Economic Transformation Programme. Post-Fukushima plans are to have a first plant commissioned in 2023 or 2024; preparatory work is on track.

\footnotetext{
${ }^{2}$ The IAEA recommends a phased, 19 milestone approach to establishing nuclear power capacity for newcomers. The milestones provide a framework to develop national nuclear infrastructure that (i) comprehensively recognizes and identifies the national commitments and obligations associated with introducing nuclear power; (ii) establishes and adequately prepares the entire national infrastructure needed to begin plant construction; and (iii) establishes all the necessary competences and capabilities to be able to regulate and operate a plant safely, securely, and economically (IAEA 2007).
} 
In response to the 1973 oil crisis, the Philippines decided to build the first of two units of the Bataan Nuclear Power Plant. Construction started in 1976 and was completed in 1984. Due to financial disputes and safety concerns related to earthquakes, it never became operational. At one point conversion to a natural gas-fired power plant was considered, but this proved impractical. Since then the plant has been mothballed. Energy security considerations have rekindled the government's interest in nuclear power, and plans to refurbish and upgrade the Bataan plant were studied but no definite conclusions were reached. Nevertheless, the 2008 national energy plan foresees $600 \mathrm{MW}_{\mathrm{e}}$ of nuclear power by 2025 with further capacity added afterwards.

In the late 1970s, Indonesia launched an initiative for a nuclear power program. Potential sites were evaluated in the late 1980s, and comprehensive feasibility studies were conducted. All sites assessed are located on the north shores away from the tectonic subduction zone. The government favors an independent producer approach to building and operating plants, but nuclear plans remain on hold given the current economic climate and the post-Fukushima effect. A prefeasibility study for a small, system-integrated modular advanced reactor (SMART) for electricity generation and seawater desalination has been undertaken, and floating plants offered by the Russian Federation on a fully serviced basis to provide electricity to smaller islands have been examined without making any final decisions.

The Republic of Korea launched its nuclear energy activities in the 1960s with a small research reactor. Construction of the first commercial reactor started in 1972. It was a Westinghouse pressurized water design on a turnkey contract with commercial operation commencing in 1978. During the 1980s the country successively increased the local content of its expanding construction program and built up a comprehensive national nuclear manufacturing capability. It also advanced nuclear technology research and development and within two decades progressed from a nuclear technology importing country to a technology holder and exporter. Despite the Fukushima Daiichi accident, nuclear energy remains a strategic priority, and domestic generating capacity is projected to increase from 20.7 gigawatts of electricity (GWe) in 2012 to $29 \mathrm{GW}_{\mathrm{e}}$ by 2020 and then to $39 \mathrm{GW}_{\mathrm{e}}$ by 2030 .

Nuclear power in Armenia dates back to the mid-1970s. As of 1980, two plants with $375 \mathrm{MW}_{\mathrm{e}}$ each were in operation. Although the plants endured a forceful earthquake with the epicenter just 75 kilometers from the site without damage and continued operating normally, both units were subsequently shut down in 1989 due to safety concerns regarding seismic vulnerability. One unit was restarted in 1995 due to a severe energy shortage and economic crisis. Since then, safety improvements have been implemented with international cooperation and support. The plant was scheduled for decommissioning in 2016 but as it supplied $33 \%$ of the country's total electricity in 2011 , it is now scheduled for closure in 2021. An agreement for the construction of at least one $1,000 \mathrm{MW}_{\mathrm{e}}$ reactor was reached between the Russian Federation (Rosatom) and Metzamorenergoatom in August of 2010 with the Russian Federation financing 50\% of the investment costs. Armenia guarantees the purchase of all the plant's electricity at commercial rates 
for 20 years. Construction is expected to start in 2013 with plant commissioning no later than 2020 .

The PRC operates 17 reactor units, 4 of which were connected to the grid since the Fukushima Daiichi accident. Another 29 reactor units are under construction and a further 42 units are in various planning stages including some of the world's most advanced designs. The civilian nuclear power program commenced in 1970 and by 2005 had shifted into a rapid development phase. Technology was initially imported from Canada, France, and the Russian Federation with increased local content with each new build. In all, 21 of the 29 units currently under construction by local manufacturers are based on French designs, but the Westinghouse AP1000 is likely to be the main basis of nuclear technology in the immediate future. The PRC has a full range of fuel-cycle facilities and is currently expanding them rapidly. Initially fuel for new reactors of foreign designs is supplied by the vendors, but eventually the PRC intends to be self-sufficient in fuel services including reprocessing.

After completing safety inspections of its potential sites for new nuclear builds, in the fall of 2012 the PRC government restarted the ambitious reactor building program that was suspended after the Fukushima accident. In late 2012, four new construction starts took place including a $200 \mathrm{MW}_{\mathrm{e}}$ high-temperature reactor. Nuclear power construction will be slower than the rapid expansion from 2005 to 2010 , but according to the government, there is no alternative to developing nuclear power, if the country wants to meet its economic development and carbon emission reduction goals. Nuclear generating capacity is expected to reach at least 40 gigawatts by 2015, and an expansion to 200 gigawatts by 2030 is under consideration.

India operates 20 plants, and 7 more of various designs are under construction including one fast breeder reactor. India expects to have 20 gigawatts of nuclear capacity on line by 2020 and 62 gigawatts by 2032 and aims to generate $25 \%$ of its electricity from nuclear power by 2050 . Its burgeoning program has been primarily based on indigenous technology and fuel-cycle developments. Because India is not a signatory to the Nuclear Non-Proliferation Treaty (NPT) due to its nuclear weapons program, it was excluded from access to and trade in nuclear plants or materials until 2009. As a result of these trade bans and the lack of indigenous uranium resources, India has been the forerunner in developing a nuclear fuel cycle to exploit its large reserves of thorium. India's self-sufficiency in nuclear energy extends from uranium and thorium exploration and mining through fuel fabrication, heavy water production, and reactor design and construction to reprocessing and waste management. It has a small fast breeder reactor and is building a much larger one. Under an agreement with the US in 2009, India has access to foreign technology and fuel which is expected to boost its nuclear power expansion plans considerably. ${ }^{3}$

\footnotetext{
${ }^{3}$ India agreed to separate its civil and military nuclear facilities and to place all its civil nuclear facilities under IAEA safeguards; in exchange, the US agreed to cooperate in civil nuclear technology.
} 
Pakistan's nuclear power program consists of three small reactors with a combined capacity of $725 \mathrm{MW}_{\mathrm{e}}$, but there are plans to increase this substantially. The first reactor was a heavy water reactor supplied by Canada in the early 1970s before the NPT entered into force, and the other two are of PRC origin and supplied under safeguards arrangements. The PRC also provided partial financing. With its nuclear weapons program, Pakistan is also outside the NPT and therefore is largely excluded from trade in nuclear plants or materials. Lack of access to foreign technology has impeded the development of civilian nuclear energy despite the fact that the reactors are under international safeguards. Since 2011, two $315 \mathrm{MW}_{\mathrm{e}}$ reactors have been under construction again with technical and financial support from the PRC, and discussions about a 1,000 $\mathrm{MW}_{\mathrm{e}}$ unit of PRC design are under way. In all, approximately $8,000 \mathrm{MW}_{\mathrm{e}}$ of nuclear power capacity is expected to be operational by 2030 .

\section{Nuclear power and green growth}

Nuclear power is controversial in the green growth debate. On the one hand it is a low GHG emitting technology supplying reliable baseload electricity; on the other hand, there is the risk of severe accidents and the perceived lack of a final solution to radioactive waste. As the Organisation for Economic Co-operation and Development (OECD) states, "Green growth requires a green engine. Improving the environmental performance of energy transformation and consumption is a cornerstone of any attempt towards green growth" (OECD 2011). Typical criteria for green energy include the following:

- highly secure supply;

- low local/regional air pollution;

- low GHG emissions;

- low threat to biodiversity and to human health/security;

- competitive generating costs;

- $\quad$ low material intensity (3Rs = reduce, reuse, recycle);

- low resource depletion;

- low waste volumes;

- low noise/visual pollution;

- low land requirements;

- high potential for innovation.

According to these criteria, nuclear energy could well qualify as a green energy technology; however, opponents point to its long-lived radioactive waste, the risk of severe accidents with long-term impacts, weapon proliferation concerns, and the lack of public acceptance. Table 9.3 summarizes arguments on both sides of the debate.

\section{Economic characteristics of nuclear power}

The economics of nuclear power are characterised by large, upfront capital costs but low and stable fuel and operating costs. In short, nuclear power is expensive to build 
Table 9.3 Pros and cons of nuclear power as a technology in support of green growth

\begin{tabular}{|c|c|}
\hline Arguments against nuclear power & Arguments in favor of nuclear power \\
\hline $\begin{array}{l}\text { Nuclear power is unsafe and risks are } \\
\text { excessive: it can never be made safe } \\
\text { enough }\end{array}$ & $\begin{array}{l}\text { Nuclear power on a life-cycle basis has an } \\
\text { excellent safety record compared with } \\
\text { alternatives }\end{array}$ \\
\hline $\begin{array}{l}\text { Diverts attention from energy efficiency } \\
\text { and renewables }\end{array}$ & $\begin{array}{l}\text { Expands electricity supplies ("connecting the } \\
\text { unconnected") }\end{array}$ \\
\hline $\begin{array}{l}\text { No solution for climate change mitigation } \\
\text { especially in the short run }\end{array}$ & $\begin{array}{l}\text { Reduces harmful emissions including } \\
\text { greenhouse gases }\end{array}$ \\
\hline $\begin{array}{l}\text { Transboundary consequences and issues } \\
\text { related to transport of spent fuel }\end{array}$ & Enhances energy security \\
\hline $\begin{array}{l}\text { Not economically viable: too expensive } \\
\text { and always depends on subsidies }\end{array}$ & $\begin{array}{l}\text { Competitive supplier of base-load electricity } \\
\text { at stable and predictable generating costs }\end{array}$ \\
\hline Nuclear weapon proliferation & Increases human and technological capital \\
\hline High externalities & Ahead in internalising externalities \\
\hline $\begin{array}{l}\text { Uranium resources last only a few } \\
\text { decades }\end{array}$ & $\begin{array}{l}\text { Nuclear power decoupled from any resource } \\
\text { constraints: no alternative uses for uranium }\end{array}$ \\
\hline $\begin{array}{l}\text { No long-term solution to high-level } \\
\text { nuclear waste }\end{array}$ & Wastes are managed \\
\hline Lacks public acceptance & Keeping options open for future generations \\
\hline
\end{tabular}

Source: Adapted from Rogner 2012.

but cheap to run. Variable operating costs, essentially fuel costs, are a comparative advantage of nuclear power especially when plants have been fully depreciated. The fact that nuclear power plants can be very profitable once their large, upfront capital costs have been paid off is reflected in the interest in renewing operating licenses. In the US, 70 of the 104 operating reactors have successfully requested and subsequently received 20-year license renewals. It costs considerably less to replace some nuclear components than to build any type of new generation-fossil, nuclear, or renewable - which makes license extensions highly profitable for nuclear operators. These investments usually also result in improved operating safety, power uprates, and/or higher output (e.g., new turbines or more efficient steam generators) all of which further improve overall economics. License extensions therefore have been targeted as potential revenue sources by governments.

The investment for a typical 1,000 $\mathrm{MW}_{\mathrm{e}}$ nuclear plant amounts to approximately $\$ 2.5$ to $\$ 8$ billion depending on design, location, and financing which accounts for $60 \%$ to $75 \%$ of total generation costs. In addition to high upfront capital costs, the long lead time for planning; the need for environmental impact assessments, licensing, and public hearings; the time needed for construction; the sensitivity of returns on interest rates; and regulatory changes all combine to create a relatively high risk for investors. In contrast, fossil fuel baseload electricity plants cost less to build but due to high fuel costs are more expensive to operate. Nuclear power requires investors with a long-term perspective; they are often public rather than private. There is, therefore, a legitimate role for governments to play if nuclear power is in the long-term public interest due to its climate change mitigation and supply security benefits. 
Financiers demand interest rates that are sufficient to compensate them for the risks involved. Recent experience with new builds in Finland and France with long construction delays and substantial cost overruns have alienated investors and fuelled the suspicion that nuclear power is simply too risky a proposition. More favorable experiences in the PRC and elsewhere with evidence that the same designs can be built according to schedule and on budget are often overlooked.

\section{A comparison of nuclear power investment and electricity generating costs}

Reliable capital cost data are generally difficult to obtain, especially for nuclear power. There are numerous reasons for this including proprietary concerns, definitions of what is included, cost escalation assumptions, interest rates, and vendor optimism in published cost quotations. Different cost data may simply reflect different definitions of costs, overnight costs, ${ }^{4}$ or overnight costs with interest during construction. Cost data are also highly dependent on site specifics, e.g., a green field site, a location with nuclear plants and associated infrastructure already in operation, or a site with high seismic activity. They may reflect different local content requirements, subsidies, or regulatory requirements. Figure 9.2 summarizes the overnight cost data without interest during construction of the OECD study "Projected Costs of Generating Electricity: 2010 Update" (IEA/NEA 2010).

Figure 9.2 (top panel) shows a large overlap and spread of specific investment costs for different electricity generating technologies typically explained by varying local conditions, technology designs, or regulatory and environmental constraints. The lower boundary represents the conditions in large developing countries such as the PRC and India while higher prices reflect particularly challenging site conditions in OECD countries. In part the lower costs in Asia reflect recent experience in building new reactors.

On a per unit size, nuclear power investment considerably exceeds the alternatives except large hydro (greater than 400 megawatt) plants (Figure 9.2 bottom panel). Small grid sizes in developing countries limit the integration of presently commercially available designs of $1,000 \mathrm{MW}_{\mathrm{e}}$ or more per unit. In the future, commercializing small and medium-sized reactors of $100 \mathrm{MW}_{\mathrm{e}}$ to $600 \mathrm{MW}_{\mathrm{e}}$ might become feasible and ease their financing and integration into smaller national power grids.

Long-run, marginal generating costs accounting for overnight costs; interest during construction; fuel, operating, and maintenance costs; and waste management and decommissioning are often used to rank investment alternatives. Figure 9.3 shows the ranges of levelized electricity cost (LEC) generation for real discount rates of 5\% and 10\%. LEC includes all cost components throughout a technology's life cycle-construction, operation and maintenance, fuel, waste

\footnotetext{
${ }^{4}$ Overnight cost often expresses what the investment would cost if it were built "overnight," i.e., as if money had no time value.
} 

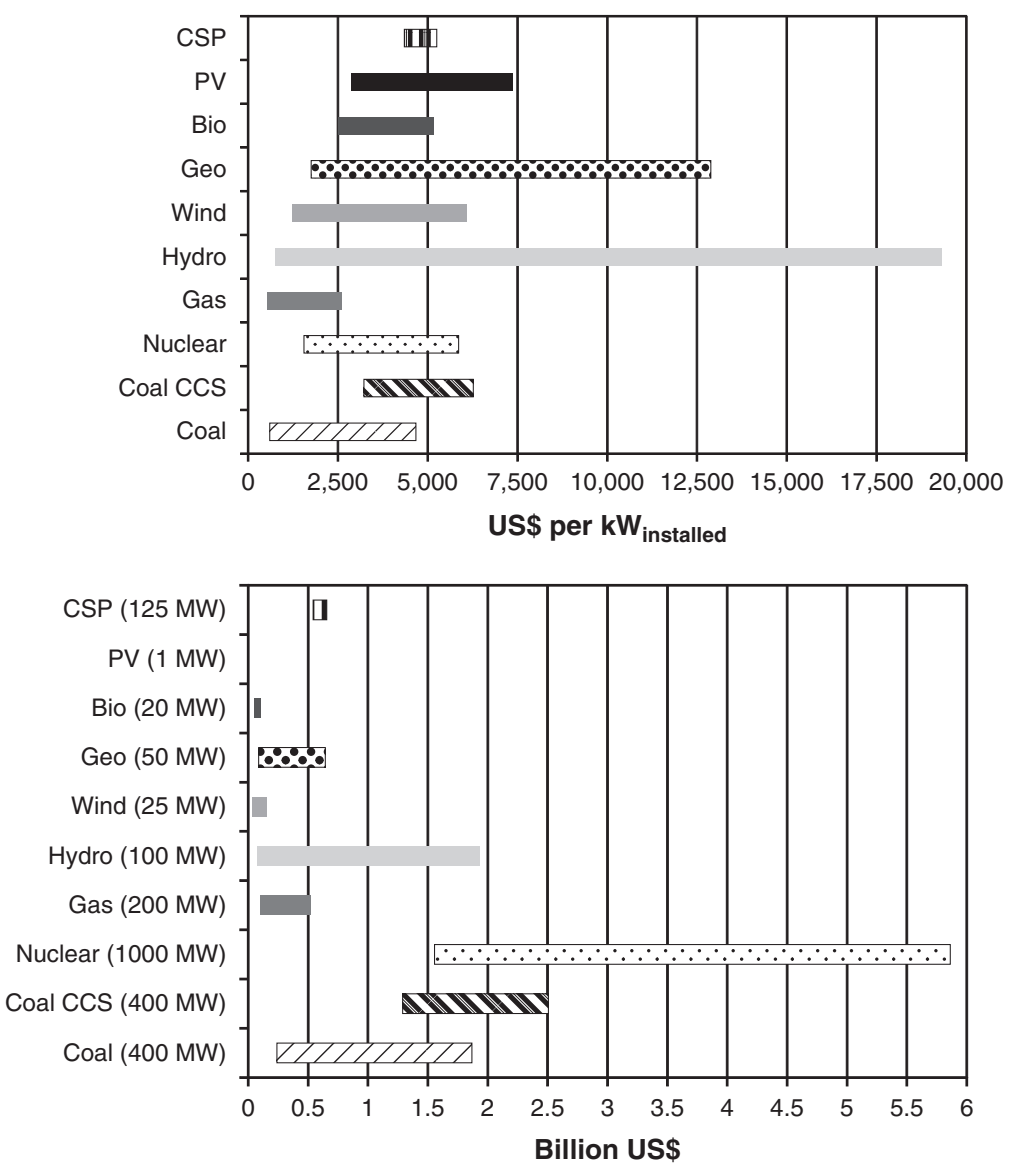

Figure 9.2 Overnight cost for 1,000 megawatts of electricity from various generating technologies (top) and for typical unit sizes (bottom)

Source: IEA/NEA 2010.

Note: $\mathrm{CSP}=$ concentrated solar power; $\mathrm{PV}=$ photovotaics; $\mathrm{Bio}=$ biomass; $\mathrm{Geo}=$ geothermal; $\mathrm{CCS}=$ carbon capture and storage; $\mathrm{MW}=$ megawatt; $\mathrm{kW}=$ kilowatt.

disposal, and decommissioning - and the expected kilowatt hours generated throughout the plant's operating life. It is one way to compare investment options. Other things being equal, the option with the lower LEC looks like the better one, but in reality, other things are never equal. For example, even if nuclear power has a lower LEC, too many of the costs are upfront and too much of the revenue is delayed.

At $5 \%$ discount rates and despite its capital intensiveness, nuclear power is among the least-cost baseload generating options. The actual order depends on national and local conditions such as fuel prices and labor and material markets 

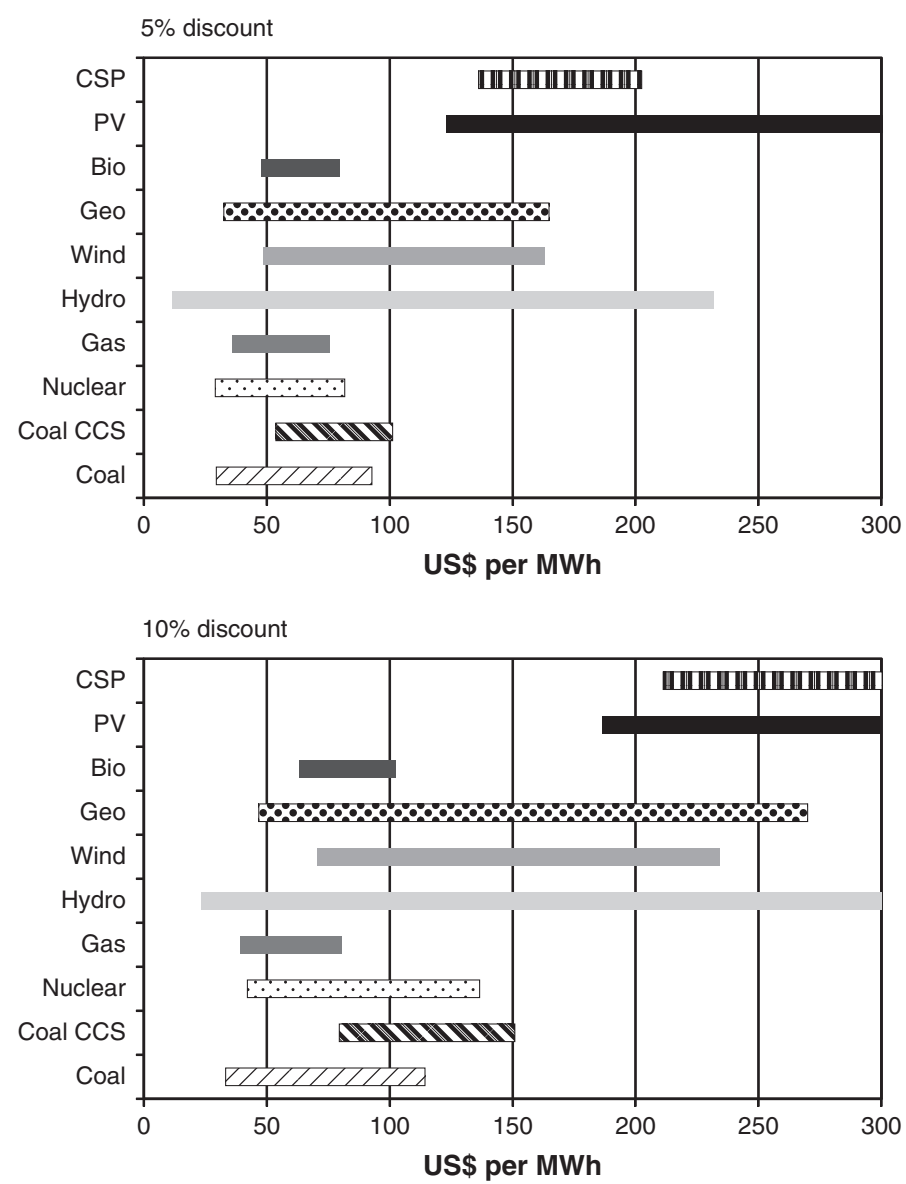

Figure 9.3 Levelized electricity cost of various generation options at discount rates of $5 \%$ and $10 \%$

Source: IEA/NEA 2010.

Note: $\mathrm{CSP}=$ concentrated solar power $; \mathrm{PV}=$ photovoltaics $; \mathrm{Bio}=$ biomass $; \mathrm{Geo}=$ geothermal; $\mathrm{CCS}=$ carbon capture and storage; $\mathrm{MWh}=$ megawatt hour.

and cannot be generalized. For example, in places with low-cost coal like Australia, certain parts of the PRC, the Russian Federation, and the US, coal outperforms nuclear power even when equipped with carbon capture and storage (CCS) technology. Hydro and wind power may be competitive for baseload generation per kilowatt hour, but their actual competitiveness depends on system integration (pump storage, spinning reserve structure, export-import links, transmission capacity) and backup requirements (especially for wind and solar) to compensate for intermittency. 
At the higher discount rate of $10 \%$, the competitiveness of nuclear power generally slips versus fossil generation. In some locations, coal technology with and without carbon abatement and combined cycle gas turbines provide the least-cost generation whereas nuclear power remains competitive with the non-coal and nongas alternatives. Any GHG emission penalty (carbon tax) or emission cap would improve the competitiveness of nuclear power relative to fossil fuel alternatives.

The competitiveness of nuclear also depends on the structure of the electricity market. Regulated markets generally offer better opportunities. Public ownership and direct government support and/or cost-plus rate structures enable nuclear operators to pass inefficient operation costs on to consumers. Liberalized markets are characterized by short-run marginal costs where inefficiencies are immediately penalized; however, deregulated markets are not proving particularly well fitted to green objectives as they are based on short-term profitability at the expense of long-term environment and resource management considerations (Rogner 2010).

\section{Energy security}

Once construction is completed and plant operation has commenced, nuclear power offers stable and predictable generating costs. The high capital cost is complemented by low resource, fuel, and operation and maintenance costs. The share of uranium cost is about $5 \%$; the remaining fuel costs include enrichment, fuel element fabrication, and spent fuel management (see Figure 9.4). Unlike coal and natural gas generation, doubling resource prices hardly affects the total generating costs of nuclear power. The decommissioning costs that are included in

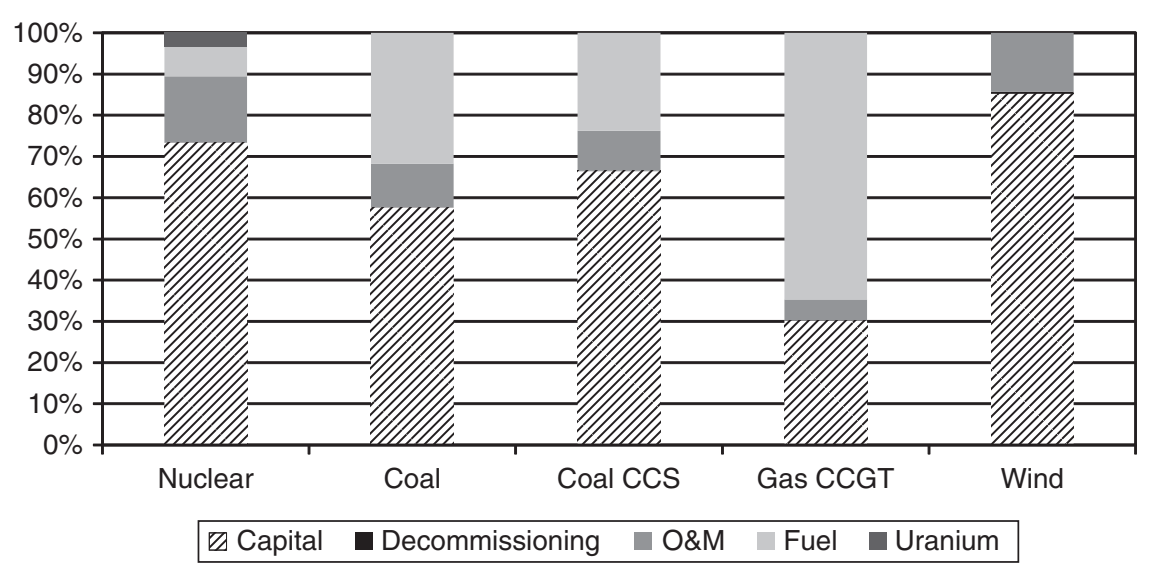

Figure 9.4 Shares of cost components in total generating costs at a $10 \%$ discount rate Source: adapted from IEA/NEA 2010 and NEA 2003.

Note: $\mathrm{CCS}=$ carbon capture and storage; $\mathrm{CCGT}=$ combined cycle gas turbine; $\mathrm{O \& M}=$ operation and maintenance. 
Figure 9.4 are not discernible either because they are either very low in actual terms (as in the case of wind) or are incurred so far in the future (e.g., 80 or more years for nuclear power) that discounting makes them quasi-invisible.

Nuclear energy enhances energy security not only due to its relative insensitivity to resource costs but also due to the fact that its low fuel volume allows for easy stock-piling, i.e., storing uranium for the entire lifetime of the plant on site. Long refuelling cycles of 18 to 24 months plus on-site storage of fuel elements for one refuelling event provide sufficient time to seek alternative suppliers in case the original supplier defaults. Moreover, fuel supply contracts are generally long term.

Energy security has been one of the main drivers for adopting nuclear power even where the cost was higher. Countries with limited domestic fossil resources have been willing to pay the premium for a secure, stable supply of energy to minimize dependency on fossil fuel imports (e.g., France, Japan, Republic of Korea, and Sweden). Emerging economies like the PRC and India also acknowledge that nuclear power is critical for energy security and to alleviate environmental concerns. Energy security has motivated many governments in countries currently without nuclear power to explore it alongside renewable technologies to diversify the mix (World Future Energy Summit 2012).

Uranium reserves and resources are abundant and available from many suppliers worldwide. Commercially, uranium is presently produced in 17 countries although fewer than half produce significant quantities. There is an internationally competitive uranium and fuel service market that makes monopolies virtually impossible. Uranium reserves and resources at production costs below $\$ 260$ per kilogram amount to 7.1 million tons (NEA/IAEA 2012), which is sufficient to fuel the existing fleet of reactors for more than 100 years and when considering all conventional uranium occurrences for 200 years. Reprocessing spent fuel and recycling unspent uranium and plutonium doubles the reach of each category. Fast breeder reactor technology can further increase uranium use 50 -fold or more (IAEA 2012b).

In addition to conventional uranium occurrences, there are enormous low and lowest concentration (unconventional) occurrences. Phosphates, carbonite, nonferrous ores, lignite, and black shists contain an estimated 17 million tons of uranium. The total mass of uranium in seawater is enormous and amounts to about 4.5 gigatons, dwarfing any other exhaustible energy resource. In short, uranium availability is no inherent constraint to the future growth of nuclear power.

\section{Environmental characteristics of nuclear power}

The full technology chain for nuclear energy covering uranium mining (open pit or underground), milling, conversion, enrichment (diffusion or centrifuge), fuel fabrication, power plant construction and operation, reprocessing, conditioning of spent fuel, interim storage of radioactive waste, and construction of the final repositories emits only a few grams of GHG per kilowatt hour of electricity. The bulk of GHG emissions are from plant construction (from cement and material production and component manufacturing) and in the upstream fuel stages with values between 1.5 and 20 grams of carbon dioxide $\left(\mathrm{CO}_{2}\right)$ equivalent/kilowatt 
Fossil electricity generation

(life cycle emissions)

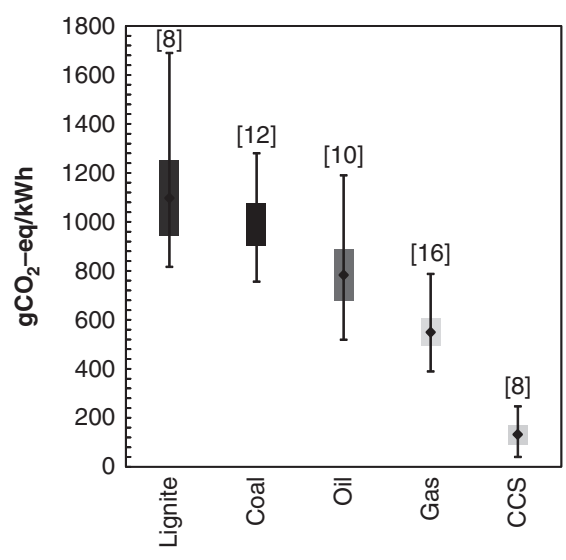

Non-fossil electricity generation (life cycle emissions)

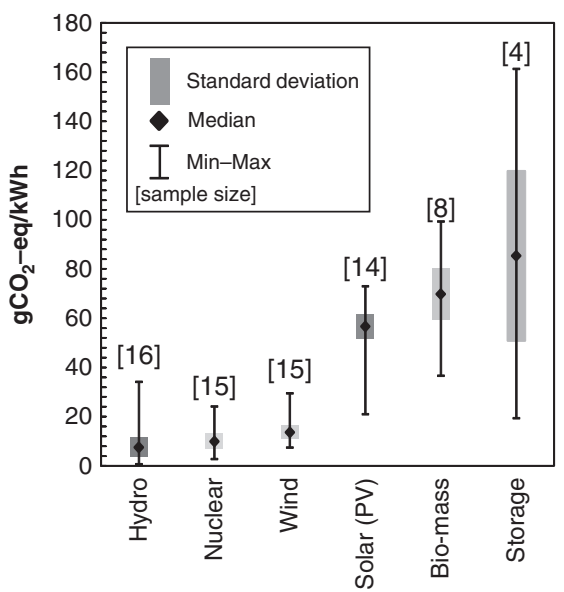

Figure 9.5 Life-cycle greenhouse gas emissions of various electricity generating options Source: Weisser 2007.

Note: $\mathrm{gCO}_{2}$ eq per $\mathrm{kWh}=$ grams of carbon dioxide equivalent per kilowatt hour; $\mathrm{Min}=$ minimum; $\mathrm{Max}=$ maximum $; \mathrm{CCS}=$ carbon capture and storage $\mathrm{PV}=$ photovoltaic.

hour. This range is largely due to the enrichment processes considered and the extent to which nuclear fuel recycling was accounted for. Gaseous diffusion, the technology widely used for enrichment in the past and still used in a few places, requires a substantial amount of electricity; however, the industry has been switching to gaseous centrifuge technology which requires only about $2 \%$ of the energy input needed for gaseous diffusion.

During the operational stage of the reactor, GHG emissions are negligible ranging between 0.74 and 1.3 grams of $\mathrm{CO}_{2}$ equivalent/kilowatt hour, the GHG emissions associated with decommissioning and waste management range between 0.46 and 1.4 grams, and cumulative emissions for the studies reviewed by Weisser (2007) lie between 2.8 and 24 grams. Figure 9.5 summarizes lifecycle GHG emissions for a range of power generation technologies and fuels and shows that nuclear power along with hydropower and wind is one of the lowest emitters. Coal-based generation, even if equipped with CCS, is estimated to emit one order of magnitude more GHGs per unit of electricity than the three truly low-carbon generating technologies: wind, hydro, and nuclear. These results are consistent with the conclusions of similar studies (IPCC 2007; 2011). ${ }^{5}$

\footnotetext{
${ }^{5}$ Several studies show higher ranges of GHG emissions for nuclear power (Sovacool 2008). These studies include assumptions that are no longer plausible, e.g., diffusion technology for enrichment or the extraction of low concentration uranium occurrence with standard mining technologies.
} 


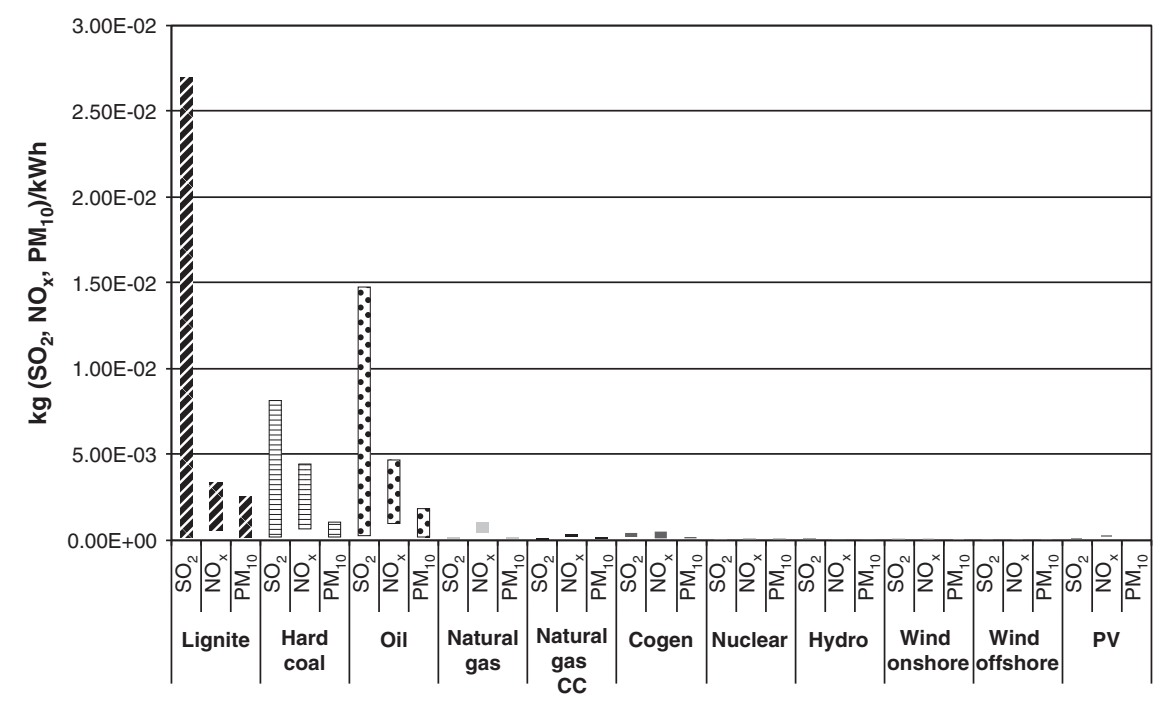

Figure 9.6 Air pollutants from selected energy chains

Source: Adapted from NEA 2007.

Note: $\mathrm{kg}=$ kilogram; $\mathrm{NOx}=$ nitrogen oxide; $\mathrm{SO}_{2}=$ sulphur dioxide; $\mathrm{PM10}=$ particulate matter with a diameter of 10 micrometers or less; $\mathrm{kWh}=$ kilowatt hour; $\mathrm{CC}=$ combined cycle; $\mathrm{PV}=$ photovoltaic.

In addition to mitigating climate change, nuclear plants also avoid air pollution and its negative health and environmental impacts as they emit virtually no air pollutants during operation (Figure 9.6). In contrast, fossil-based power plants are major contributors to air pollution causing poor air quality and haze that seriously limits visibility and reduces sunlight. The World Health Organization (WHO) has estimated that air pollution causes approximately 2 million premature deaths worldwide each year (WHO 2008).

Regional acidification from air pollution adversely affects ecosystems leading to reduced agricultural productivity and to undesirable impacts on freshwater fisheries and natural vegetation including forests. Acid rain also damages infrastructure, buildings, and historic and cultural monuments. The technology to reduce these emissions exists but at a cost.

\section{Critical issues in nuclear power development}

\section{Financing}

Finance is the key constraint to expanding nuclear power. Nuclear plants require the commitment of large amounts of capital over extended periods of time. The full upfront cost of a commercial plant including interest during construction, owner's cost, and contingencies can be $\$ 2$ billion to $\$ 5$ billion without cost 
escalation. Payback periods of 20 to 30 years or more are substantially longer than those of most other technologies, and expenditures commence up to 10 years or more before the first revenue is collected. Only a few private sector utilities or large institutional investors are willing and able to deal with the inherent uncertainties associated with such long payback periods.

Nearly all nuclear power plants operating today were financed and built in regulated utility markets, and much of the financing was provided by governments or with government backing or guarantees of some kind. Governments have also used regulatory power to permit utilities building new plants to partially finance construction with electricity tariffs. Government involvement and regulated markets guaranteed a firm customer base and sufficiently high electricity prices to assure an adequate commercial return. Under these conditions, cost overruns and project delays were covered by higher electricity prices and ultimately paid for by customers or from government budgets thus minimizing the risk to investors.

\section{Options}

Equity and debt are the basic elements of capital finance. To attract them, assurances are needed that the project is viable; that project revenues will cover costs with an adequate return; that the regulatory and fiscal climates are reasonably stable and not expropriative; that profits of foreign investors can be repatriated; that debt repayment is guaranteed; and that risks are properly allocated and managed. ${ }^{6}$

Equity is a more expensive source of finance than loans but is needed to establish project credibility especially if the sponsors have a poor record of cost control or low credit ratings, if the plant design is the first of a kind, or if the project is the first in a country. In addition to the investing utility, potential equity providers are governments, other utilities, large-scale electricity users, vendors, or commercial investors. Other utilities may wish to expand their portfolios by owning and selling their shares of electricity or by gaining experience with nuclear power. Large-scale electricity users that wish to secure long-term (and low-carbon) supplies at predictable costs may assume equity in a nuclear plant (the so-called Mankala model), a strategy practised in Finland. Vendors may participate as part of the sales package thus not only easing financing but also sharing risk.

Creditors are attracted by the creditworthiness of the project; if a government or another entity guarantees the debt, the risk of non-payment and hence the cost of debt falls significantly. Vendors have increasingly provided debt financing in support of their bids; this has become an important source of funding for many plants.

${ }^{6}$ Efficiently and properly allocating costs, risks, rights, and responsibilities among the responsible parties as well as a project structure that imposes serious discipline in cost and risk management is essential for successful financing whatever arrangements are made with regard to debt and equity. 


\section{Institutions}

There are three basic ways to structure the financing of a nuclear plant: government (sovereign), corporate (balance sheet), and limited recourse (including project) finance which shields sponsors' non-project assets from liability for obligations. The key differences among them are the ownership pattern they establish which in turn governs the degree to which they protect the interests of investors and creditors and the ways in which they allocate risk. For nuclear power this practically excludes non-recourse or limited recourse financing as it offers no collateral to lenders except the future income and assets of the project itself.

Government financing can either come straight from the annual budget, from government-issued securities (e.g., bonds), or from funds borrowed by the government in national or international capital markets. Where such financing is involved, a government utility will be the likely owner (and operator) of the plant. Direct government involvement-owning assets, equity participation, sharing risk, and providing various incentives including loan guarantees-imposes a degree of risk on the public sector itself (and thus on society at large). The government may also incur indirect or non-financial risks such as obligations to maintain infrastructure or to assume the liability for plant and site decommissioning and spent fuel waste management. Initial financing arrangements for a new plant might include some government funding for energy assessments and pre-construction studies, for nuclear regulatory and legal infrastructure, or for research and human resource development (IAEA 2008).

In the absence of budget resources, governments can create equity or dedicate collateral. For example, they can pledge receivables from creditworthy governmentowned industries (or from industrial customers in the case of a government-owned utility); dedicate a portion of their revenue streams (e.g., from mineral exports or taxes); pledge an asset like uranium reserves; or offer barter arrangements (e.g., trade financing for agricultural exports). Governments can also highlight the environmental and security benefits of nuclear power by pricing carbon emissions. Energy security and system reliability may also justify a government subsidy that would raise overall profitability.

\section{Private sector}

Corporate financing means financing the project from the utility's (and partners') own resources, i.e., from accumulated, undistributed past profits; from current revenue; or from loans taken against existing assets. From the perspective of lenders, balance-sheet financing secures their loans against all the assets of the utility and its partners, not just the investment project. Plant owners may be able to exclude a portion of their assets from serving as potential collateral by ringfencing parts of their corporate structures, but limiting the collateral increases the lenders' risks and thus raises the cost of finance.

The utility (and co-owners) assumes the bulk of the investment risk against the asset base. Any problems with the plant such as construction delays, completion, 
commissioning, or operational availability places these assets directly at risk. The financial sector tends to respond to a utility's nuclear investment decision by downgrading its credit rating and increasing its cost of borrowing across the board.

Schemes like public-private partnerships, build-operate-transfer, buildown-operate and their variations are not financing arrangements but instead define the ultimate ownership of a project. These schemes are usually based on long-term power purchase agreements with government or public sector counterparts that provide investors with a guaranteed price for the electricity (in essence a feed-in-tariff) over an extended period of time (typically up to 20 years). These agreements reduce market risks for investors but not construction completion risks or operational risks which are assumed by the public-private partnership or build-own-operate owners.

Public-private partnerships and build-own-operate schemes are basically non-recourse projects and until recently were not used for financing nuclear plants. This changed when the Russian Federation's Rosatom and the Government of Turkey agreed on a build-own-operate scheme for the four-unit Akkuyu Plant and to provide $100 \%$ initial equity in a Turkish company established for the purpose. While this arrangement is a first of its kind, it is likely to remain a scheme for deep governmental rather than for private sector involvement.

Many governments are eager to secure private sector involvement by providing risk mitigation schemes. Contracts for difference are long-term contracts to provide stable and predictable incentives for companies to invest in low-carbon generation including nuclear power. The United Kingdom (UK) energy bill of November 2012 states,

Generators will receive the price they achieve in the electricity market plus a "top up" from the market price to an agreed level (the "strike price"). Where the market price is above the agreed level, the generator would be required to pay back and thus ensure value for money and greater price stability for consumers.

(Government of the United Kingdom 2012)

Private sector financing for nuclear power is likely to require some kind of government involvement be it through tax credits, subsidies, assuming liability beyond design-based accidents, power purchase agreements, or contracts for difference given the high investment costs. With the availability of such support, infrastructure funds often acting on behalf of institutional investors such as pension funds or insurance companies have shown an interest in financing nuclear power projects.

Although relatively new on the financial scene, one of the largest funds (Macquarie Bank) has an overall capitalization of $\$ 22$ billion and finances infrastructure projects including power plants and uranium projects. One of the essential features of this type of finance is the decoupling of owners and operators with ownership entrusted to the funds. In a related vein, the Van Eck Global Fund 
and Standard \& Poor's Global Nuclear Energy Index offer more narrowly focused nuclear energy funds comprising a basket of nuclear energy companies. ${ }^{7}$

\section{Safety}

The essence of nuclear operating safety is protecting the population, workforce, and the environment from ionized radiation. It is the highest priority in plant design and operations, and under normal operations, radiation exposure from plants is very low compared with the average exposure from natural and other anthropogenic sources. Major sources of external exposure are cosmic rays from outer space and natural terrestrial radionuclides in the Earth's soil and in building materials like granite and marble, the so-called naturally occurring radioactive materials. The level of exposure to cosmic rays depends primarily on latitude and altitude. Exposure also arises from the intake of radionuclides in soil by inhalation (mainly radon) and ingestion (food and drinking water).

The release of radioactivity from naturally occurring materials is caused by many routine economic activities including mining, oil and gas production, geothermal energy use, or fossil fuel combustion. In the US, the annual radiation dose within 50 miles of a coal-fired power station is more than three times that within 50 miles of a nuclear power station (Government of the United States EPA 2012).

According to the latest report by the United Nations Scientific Committee on the Effects of Atomic Radiation (UNSCEAR), the average worldwide public radiological exposure from nuclear power and fuel cycle facilities is estimated to be only 2 microsievert $(\mu \mathrm{Sv})$ per person per year of operation compared with a global average of $2,420 \mu \mathrm{Sv}$ per year from natural sources, with a typical range of 1,000 to $13,000 \mu \mathrm{Sv}$ per year depending on location (UNSCEAR 2010; WHO 2012). Diagnostic medical examinations (X-rays) contribute some $400 \mu \mathrm{Sv}$ per year.

Things are different in severe nuclear accidents. Radioactive surface concentrations in the plant vicinity can be high and can last for years or decades, and decontamination is very expensive. In areas further away from the site of the accident, radiation may cause significant economic damage due to suspending activities like agricultural production and fishing.

The Three Mile Island accident was a partial core meltdown and resulted in the release of small amounts of radioactive gases into the environment with inconsequential health impacts. In contrast, the Chernobyl and Fukushima Daiichi accidents released large amounts of radioactive materials with significant social, economic, and environmental consequences; however, there have as yet been no radiation-related fatalities from the Fukushima accident. The latest

\footnotetext{
${ }^{7}$ Standard \& Poor's Global Nuclear Energy Index is comprised of 24 publicly traded companies and is designed to provide liquidity to the global nuclear energy sector. The index weight is distributed equally among nuclear energy production and energy materials, equipment, and services.
} 
analyses estimate the long-term fatalities associated with the Chernobyl accident at a cumulative 4,000 to 30,000 late-life cancer deaths (Garwin and Charpak 2001; Chernobyl Forum 2006). More fatalities per year are recorded in other industries like mining, coal mining, and oil exploration. "Coal plants are much deadlier: the fine-particulate air pollution they produce kills about 10,000 people each year in the United States alone" (von Hippel 2011). A comparison of aggregated, normalized, immediate fatality rates along the electricity chain between 1970 to 2008 ranks coal and hydro power as the most accident prone and shows nuclear power and natural gas have the lowest fatality rates (Burgherr, Eckle, and Hirschberg 2011).

In addition, non-radiation impacts can be significantly larger than radiation impacts. For example, "The severest consequences of the Chernobyl accident have been social in nature and are not a consequence of radiological events" (Gerasimova 2008). Altogether 335,000 persons were evacuated from severely contaminated areas. Most of these people did not return to their original homes and later suffered from depression and stress (Simmons 2012).

WHO recently released a report assessing radiation exposure for the first year following the Fukushima Daiichi accident. In the two areas with the highest impact in Fukushima Prefecture, the dose was between $10 \mu \mathrm{Sv}$ and $50 \mu \mathrm{Sv}$. In the rest of the prefecture, the dose was estimated to be between $1 \mu \mathrm{Sv}$ and $10 \mu \mathrm{Sv}$. Estimates for exposure in the rest of Japan range between $0.1 \mu \mathrm{Sv}$ and $1 \mu \mathrm{Sv}$ and for the rest of the world are below $0.01 \mu \mathrm{Sv}$ (WHO 2012). To put these numbers into context, Figure 9.7 shows the levels of exposure that people are normally

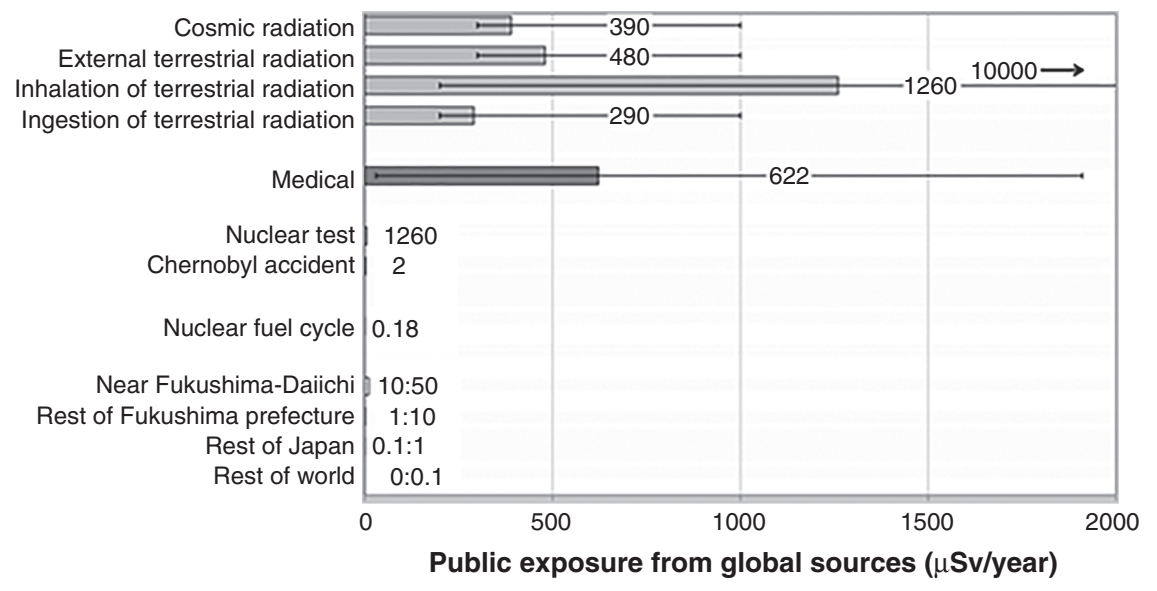

Figure 9.7 Public exposure to radiation from global sources (bars = averages; lines = typical ranges)

Sources: Adapted from UNSCEAR 2010; WHO 2012.

Note: $\mu \mathrm{Sv}=$ microsievert. 
subjected to. As mentioned earlier, worldwide exposure to natural radiation sources for an average individual is $2,420 \mu \mathrm{Sv}$ per year with a typical range of $1,000 \mu \mathrm{Sv}$ to $13,000 \mu \mathrm{Sv}$ per year.

The Chernobyl and Fukushima Daiichi events proved that severe accidents are not hypothetical and led to a widely held perception that nuclear power is inherently unsafe. Lessons learned from past accidents have, however, had profound impacts on the overall safety performance of nuclear plants through safety conventions, safety peer reviews, and safety improvements from technological changes and innovation (defence-in-depth engineering).

The IAEA Action Plan on Nuclear Safety (IAEA 2011) developed in response to the accident at Fukushima Daiichi aims to further strengthen nuclear operating safety globally, to improve transparency and accountability along the entire nuclear chain, to enhance emergency preparedness and the management of severe accidents, and to improve regulatory effectiveness.

\section{Nuclear waste management}

All electricity generation technologies generate waste. Fuel and material extraction, fuel preparation, equipment manufacturing, plant construction, and plant operation and decommissioning in one way or another generate byproducts and wastes. These wastes can vary widely in different electricity chains in terms of volume per kilowatt hour, toxicity, and longevity. In some cases, waste can simply be disposed in landfills while in others toxicity might require special treatment and shielding from the biosphere for thousands of years.

The nuclear energy chain produces radioactive waste of different levels of radiotoxicity. The high energy density of uranium results in relatively low waste volumes thereby enabling a fundamentally more equitable waste management strategy of confinement rather than dispersion. Low-level and intermediate-level waste account for the bulk of radioactive waste $(97 \%-98 \%)$ and represent only a small proportion of total radioactivity (about 8\%). Low-level waste (e.g., contaminated clothing such as protective shoe covers and floor sweepings) and intermediate-level waste (e.g., reactor water treatment residues, filters, or peripheral reactor components) arise mainly from routine facility maintenance and operations as well as fuel-cycle activities. Their radioactivity ranges from just above the natural background to more elevated levels. Disposal facilities for lowlevel and intermediate-level waste have been in operation for decades in many countries; in terms of volume, around $80 \%$ of all the nuclear waste created since the inception of the nuclear industry has already been sent for safe and controlled disposal.

It is the high-level waste that is controversial in the sustainable development and green growth debates. High-level waste represents $2 \%-3 \%$ of total nuclear radioactive waste but presents particular challenges in terms of its radiotoxicity and longevity. It is either spent nuclear fuel or separated waste from reprocessing the spent fuel. In the latter case, the separated fission products and minor actinides are treated as high-level waste (uranium and plutonium are then re-used as 
fuel in reactors). The spent fuel produced annually from the world's operating nuclear plants amounts to approximately 10,000 cubic meters and would cover a soccer field to a depth of 1.5 meters.

High-level waste will remain more radioactive than its natural surroundings for thousands of years and must be isolated from the biosphere until the level of radioactivity has decayed to natural background levels. Disposal facilities must be monitored and safeguarded for many generations. Ensuring the safety of such facilities and that their construction and operation are funded in a way that is fair are the two key concerns from the perspective of intergenerational equity.

From a safety perspective, the nuclear industry has practiced the safe, temporary surface storage of spent fuel for more than half a century. Over the last two decades, however, there have been major advances in creating the first operating disposal facility. Geological disposal has been recommended by most scientists as a preferred way of disposing of nuclear waste, although some advocate the reprocessing of fuel for re-use as reactor fuel. The Swedish Nuclear Fuel and Waste Management Company (SKB) has already applied for the permits needed for a final used-fuel repository. The earlier decision of Finland to proceed with the construction of its fifth reactor was intimately tied to the decision on a final spent-fuel repository; other countries (e.g., Canada and France) have set out timetables for developing geological disposal facilities.

The non-radioactive solid waste generated by different types of energy chains is displayed in Figure 9.8. Different waste types with different characteristics are aggregated including hazardous waste, lignite ash, and inert material landfill.

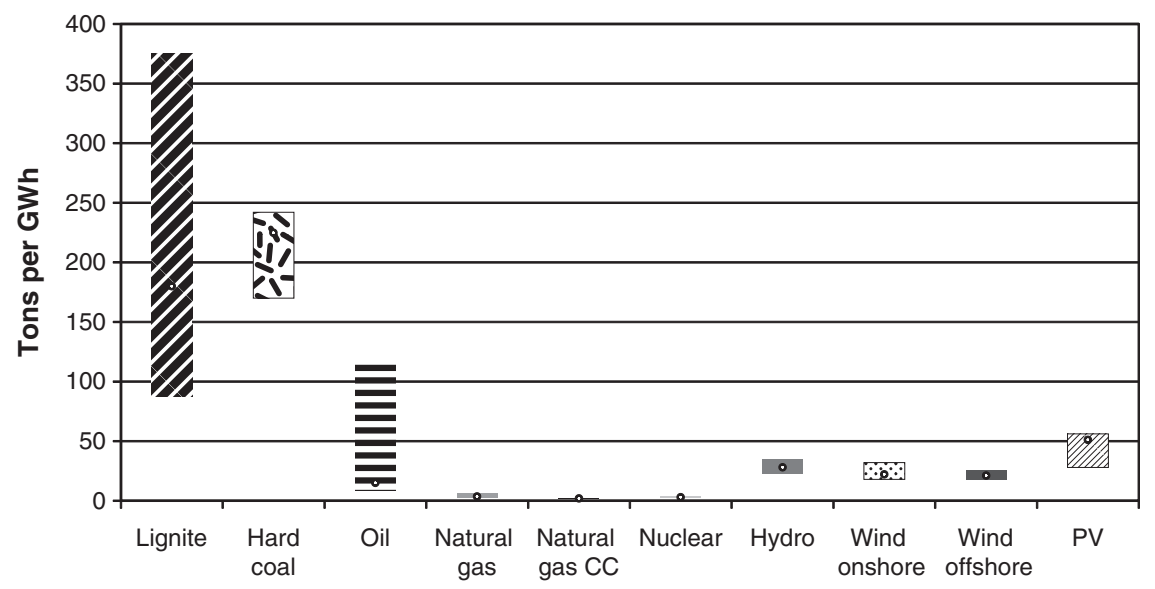

Figure 9.8 Non-radioactive solid wastes from various generation technologies (average = white dot)

Source: NEA 2007.

Note: $\mathrm{CC}=$ combined cycle gas turbine; $\mathrm{GWh}=$ gigawatt hour. 
Hard coal and lignite produce the highest amount of non-radioactive waste ${ }^{8}$ while the natural gas chain specifically combines cycle gas power plants to produce the lowest levels of non-radioactive waste. The nuclear energy chain produces radioactive waste, but low- and intermediate-level waste accounts for the largest amounts. Although small in comparison with total waste, photovoltaic cell manufacturing generates toxic and hazardous waste that requires confinement for thousands of years (ENEF 2010). Figure 9.8 shows nuclear non-radioactive waste (tons/gigawatt hour) is much lower than coal (lignite and hard) and renewables are comparable to natural gas.

\section{Non-proliferation and public acceptance}

\section{Non-proliferation}

The potential misuse of fissile materials for non-peaceful purposes is an anxiety specific to civilian nuclear power and its fuel cycle. It is a legacy from the dawn of the nuclear age that started with using nuclear weapons during World War II long before using nuclear power to generate electricity. Highly enriched uranium and plutonium are the concerns for nuclear weapon proliferation.

Nuclear plants, especially the currently dominating technology of light water reactors, are not the focus; rather their fuel-cycle components, enrichment, and reprocessing are the sensitive links to nuclear weapons. Without much modification, enrichment plants can enrich uranium beyond the 3\%-5\% U-235 required for fuelling nuclear power plants to weapons grade ( $90 \%$ or more). Reprocessing spent nuclear fuel-separating and accumulating plutonium - is the other route to weapons grade material.

From the outset, the existence of dual-use technologies has been a persistent concern in national and international politics. In the early 1950s, dozens of nuclear-armed states were predicted. In an effort to ban further proliferation, US President Eisenhower's "Atoms for Peace" initiative in 1953 united the international community to establish the IAEA in 1957 followed in 1970 by the NPT. Both the IAEA and the NPT seek to limit the further spread of nuclear weapons. The NPT provides the internationally binding legal backdrop for containing weapon proliferation while the IAEA has been entrusted with safeguarding civilian nuclear installations and verifying that nuclear technologies and materials are not diverted for military purposes.

Under the NPT, all non-nuclear-weapon states commit themselves not to acquire nuclear weapons and to accept IAEA inspections of all their nuclear activities. In return, the NPT grants these states the right to acquire, transfer, and develop the full spectrum of nuclear technology for peaceful purposes including the fuel cycle. The NPT also requires the five recognized nuclear weapon

\footnotetext{
${ }^{8}$ Coal ash contains considerable amounts of radioactivity from naturally occurring uranium and thorium in coal. The PRC is considering mining its vast coal ash deposit for uranium recovery.
} 
states - the PRC, France, the Russian Federation, the UK, and the US - to reduce their nuclear arsenals with the aim of accomplishing a world free of nuclear weapons.

Currently there are 190 signatories to the NPT, more than have ratified any other arms limitation and disarmament agreement. Only four states are outside the treaty: India, Israel, and Pakistan never joined, and the Democratic People's Republic of Korea has withdrawn. All four are known or believed to have active nuclear weapon programs. India, the Democratic People's Republic of Korea, and Pakistan have openly tested nuclear devices while Israel has not been clear about its domestic nuclear capabilities and intentions.

Bringing all reprocessing and enrichment under multinational control and considering multinational approaches to managing and disposing of spent fuel and radioactive waste would limit the number of such facilities (possibly to locations in recognized nuclear weapon states), make them easier to safeguard, and thus reduce the risk of diverting fissile materials. In 2004, an IAEA expert group concluded that multinational nuclear approaches to uranium enrichment, spent-fuel reprocessing, and waste management would have to assure current non-fuel cycle technology holders access to nuclear fuel as long as they are in full compliance with their safeguards and NPT obligations. Since then, numerous approaches have been proposed and debated ranging from assurances of supply by multi-government consortia to a fuel bank with the IAEA as a guarantor of last resort. One contentious issue in all approaches has been to what extent they would impinge on the individual right to develop a fuel cycle.

A first success is the International Fuel Bank which in 2009 passed the threshold of financial donations needed to move forward. The bank is designed to manage a physical stockpile of low enriched uranium and, under control of the IAEA, make fuel available on a non-political and non-discriminatory basis to countries that face politically motivated disruptions in supply. The uranium would be accessible by all states at market prices as long as they are in compliance with their nuclear safeguards obligations. The fuel bank contributes to non-proliferation as it provides a reliable nuclear fuel supply thus reducing the incentive to establish national enrichment facilities without limiting a country's right to developing its own fuel cycle technologies.

A situation not foreseen in the NPT is the appearance of non-state actors (terrorists and criminal groups). Preventing access to nuclear weapons or radioactive materials for malevolent purposes, therefore, has become an added challenge. Several United Nations Security Council resolutions aim at combating nuclear terrorism e.g., UN Resolution 1373 (2001) and UN Resolution 1540 (2004), and a number of both legally binding and non-legally binding instruments e.g., the Convention on the Physical Protection of Nuclear Material or the International Convention for the Suppression of Acts of Nuclear Terrorism address this concern. The IAEA is working with its 159 Member States to strengthen these instruments including measures to further protect nuclear facilities from sabotage and to improve controls over radiological sources. 


\section{Public acceptance}

Factors affecting the public acceptance of any technology fall into two categories: technology-specific (technical features, costs, real and perceived risks and benefits, and impacts on human health and the environment) and the socioeconomic context in which it is deployed. Shifts in both have affected and continue to affect public acceptance of nuclear power.

Among the technology-specific factors, the accidents at Three Mile Island and Chernobyl had devastating effects on public acceptance and established the impression that nuclear power is unsafe. This was further compounded by the lack of demonstrable solutions to nuclear waste disposal and anxiety about nuclear weapon proliferation and the physical security of nuclear installations. Since the turn of the millennium, the public attitude toward nuclear power has begun to swing slowly in the opposite direction, although this was in part reversed by the recent accident in Japan. More than 20 years of experience in safely and efficiently operating nuclear power plants have been instrumental in that change. In the broader socioeconomic context, climate change and the potential role in reducing GHG emissions, energy security, price stability, and progress in spent fuel management have helped to improve public confidence in nuclear power. In some places, however, public concerns about nuclear power remain a major obstacle.

Public acceptance begins with greater transparency in making political decisions, with clear and open public information, and with early stakeholder involvement. A great deal of public support can be mobilized through unbiased comparative analyses of all the options available showing that non-nuclear means of satisfying demand are technically, economically, or politically limited. The risks and benefits of nuclear power as well as the risks and benefits of non-nuclear alternatives must be presented in a neutral and transparent manner. Nuclear proponents have to listen and adequately respond to the public's concerns irrespective how irrational they may seem. Explaining "the facts" in defence of a decision already made - the decide-announce-defend approach — is ineffective. Effective stakeholder involvement in a project requires early engagement in all planning, evaluation, and deliberation before making a final decision (engage-deliberatedecide or consent as an act of informed decision making) (Meeskens 2013).

\section{Nuclear infrastructure}

Nuclear power requires a wide range of infrastructure to ensure that plants operate safely and effectively. Currently, most developing countries lack basic nuclear infrastructure. Key elements are a comprehensive nuclear law that regulates safety, security, safeguards, and liability; highly qualified and disciplined human resources; and efficiently and effectively managed institutions including an independent, competent nuclear regulatory entity, a deeply rooted safety culture, stakeholder involvement, long-term policies, solutions for nuclear waste management and eventual plant decommissioning, and well established and credible emergency preparedness. 
While infrastructure is not an insurmountable barrier to introducing nuclear power, it can involve lengthy preparations and require substantial financial commitment. Regional approaches to developing infrastructure may yield considerable benefits and may also include joint ownership of nuclear power plants.

\section{Technological Changes 9}

\section{Innovations}

The main focus of intensive nuclear technology research and development by vendors and research institutions around the world is reducing high upfront capital costs and improving safety. Most advanced plant designs available today or in the near future are evolutionary improvements on previous designs incorporating ongoing operational experience, component reliability, economic improvements, and advanced safety features. Building on proven designs minimizes technological and regulatory risks. They generally require little fundamental research and development, and as most of the system has already been licensed, evolutionary designs at most require engineering and confirmatory testing before licensing. Examples of commonly utilized elements of evolutionary design for improved economics are the following:

- $\quad$ simpler designs (reduced complexity), i.e., fewer components and cables and smaller seismic building volume with more functions based on natural forces and laws of physics to operate in the event of accidents (passive safety) rather than relying on engineered devices, operator actions, and the availability of electricity;

- shorter construction schedules reducing the financial charges that accrue without countervailing revenue;

- $\quad$ standardization and construction in series spreading fixed costs over several units;

- productivity gains in equipment manufacturing, field engineering, and construction;

- multiple unit construction at a single site;

- institutional arrangements;

- $\quad$ high localization factors.

Not surprisingly, research and development in many places focuses on advanced light water reactor designs, the design that currently accounts for $62 \%$ of reactors operating globally and $82 \%$ of reactors currently under construction. These reactor developments are labelled Generation III or Generation III+ designs. It appears that Generation III and III+ have become the designs of choice around the world after the Fukushima Daiichi accident due to their improved safety features (Figure 9.9).

\footnotetext{
${ }^{9}$ Based on the IAEA 2012 Nuclear Technology Review (IAEA 2012a).
} 


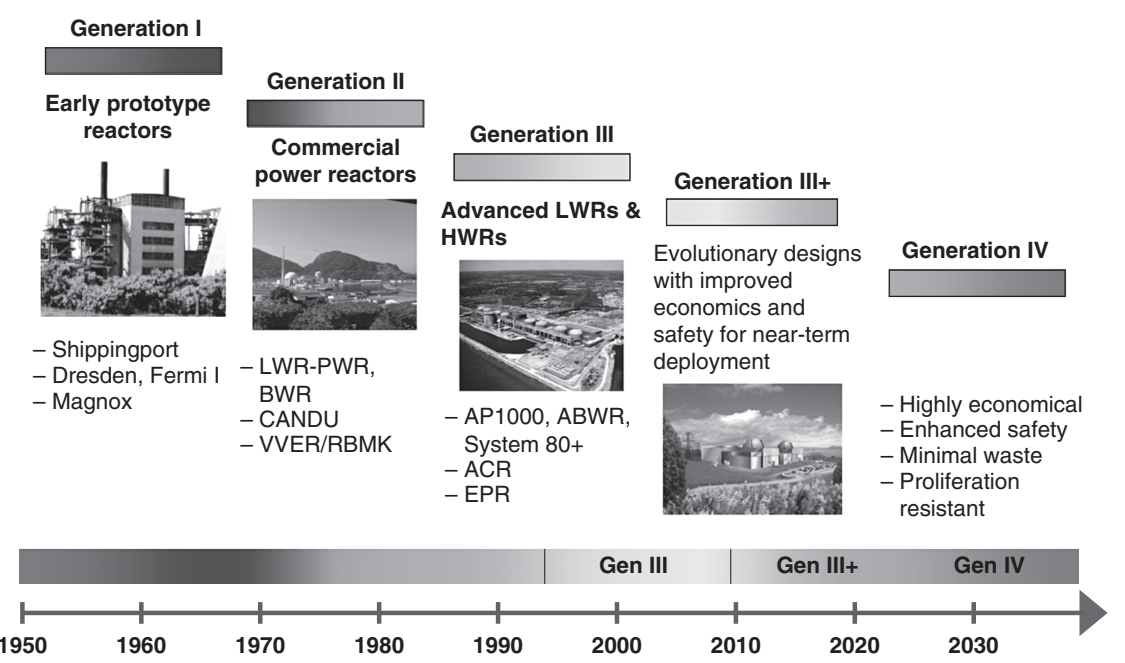

Figure 9.9 Classification of nuclear reactor generations

Source: Goldberg and Rosner 2011.

Note: $\mathrm{LWR}=$ light water reactor; $\mathrm{PWR}=$ pressurized water reactor; $\mathrm{BWR}=$ boiling water reactor; CANDU $=$ Canada Deuterium Uranium; VVER $=$ (vodo-vodyanoi) water-water power reactor; RMBK $=$ reaktor bolshoy moshchnosti kanalniy or high power channel-type reactor; HWR = heavy water reactor; $\mathrm{ABWR}=$ advanced boiling water reactor; $\mathrm{ACR}=$ advanced $\mathrm{CANDU}$ reactor; $\mathrm{EPR}=$ European pressurized reactor.

Research on fourth generation reactor technologies is carried out under a number of national and international initiatives. The latter include the Generation IV International Forum and the IAEA's International Project on Innovative Nuclear Reactors and Fuel Cycles (INPRO). Through a system of contracts and agreements, the forum coordinates research activities on six new generation nuclear energy systems selected in 2002: gas-cooled fast reactors, lead-cooled fast reactors, molten salt reactors, sodium-cooled fast reactors, supercritical water-cooled reactors, and very high temperature reactors. These six systems employ a variety of reactor, energy conversion, and fuel-cycle technologies. Their designs feature thermal and fast neutron spectra, closed and open fuel cycles, and a wide range of reactor sizes from very small to very large. Depending on their respective degrees of technical maturity, these systems are expected to become available for commercial use between 2030 and 2040. The two systems that are the focus of the most active research efforts are the sodium-cooled fast reactor and the very high temperature reactor. In 2011, a new task force was set up on safety design criteria for the sodium-cooled fast reactor taking into account its specific characteristics, the general safety approach of Generation IV reactors, and the lessons from the Fukushima Daiichi accident. 
Fast reactors have been under development for many years primarily as breeders. Plutonium breeding, together with fuel reprocessing and recycling, allows fast reactors to extract 60-70 times more energy from uranium than thermal reactors, a capability that will enable very substantial increases in nuclear power in the longer term. Fast reactors can also contribute to reducing plutonium stockpiles and to reducing the required isolation time for high-level waste by utilizing transuranic radioisotopes and transmuting some long-lived fission products.

The gas-cooled, high-temperature, gas pebble bed reactor design has been advanced as it has passive safety features meaning it can shut down safely in the event of total loss of cooling or station black-out without causing core meltdown or significant leakage of radioactive material. Modularity and small unit sizes also promise improved economic performance, and the high temperature allows the generation of non-electric energy services such as process heat for industries, desalination, and hydrogen production.

In the longer run, fundamentally new reactor configurations will be required based on innovative designs that integrate inherent operating safety features and waste disposal using previously generated radioactive waste as fuel and, by way of transmutation, convert nuclear waste or plutonium to less hazardous and shortlived isotopic substances. New designs feature passive safety features that do not require operator intervention and allow the reactor to shut down automatically in the event of emergencies.

\section{Small and medium-sized reactors}

According to the classification adopted by the IAEA, small reactors are those with an equivalent electric power of less than $300 \mathrm{MW}_{\mathrm{e}}$, and medium-sized reactors are those with an equivalent electric power of between $300 \mathrm{MW}_{\mathrm{e}}$ and $700 \mathrm{MW}_{\mathrm{e}}$. Small and medium-sized reactors are under development for all the principal reactor designs. At present, 13 are under construction in 6 countries: Argentina, PRC, India, Pakistan, the Russian Federation, and Slovakia.

Small and medium-sized reactors are of interest in developing countries where the electricity grids are too small to accommodate the unit sizes of currently commercially available designs. In industrialized countries, demand uncertainty coupled with potentially significant changes in daily and seasonal demand load profiles $^{10}$ make expanding or simply replacing existing reactors based on $1,000 \mathrm{MW}_{\mathrm{e}}$ to $1,700 \mathrm{MW}_{\mathrm{e}}$ units financially risky, especially in liberalized electricity markets. Small and medium-sized reactors reduce the upfront capital requirements per unit and are therefore easier to finance, they reduce investors' risk compared with larger units, and they also allow modular construction and in-shop manufacturing rather than in-the-field construction so they shorten the

\footnotetext{
${ }^{10}$ Demand uncertainty arises from demographic changes (aging populations), the impact of programs targeted at efficiency improvements and lower energy intensities, increasing the share of renewables, and the advent of smart grids.
} 
time to market substantially with potential savings in escalation charges and interest during construction. They also have a lower risk premium on borrowing costs. ${ }^{11}$

Private sector companies will undertake investments only if they are reasonably assured that the plant, once built, will be competitive with other sources of electricity. The operation of small and medium-sized reactors in cogeneration mode, e.g., electricity and desalination, would delink revenue generation from electricity load profiles, improve financial returns, and reduce risk.

\section{Outlook for nuclear power}

\section{Global}

The IAEA annually projects global nuclear power development up to 2030 with an outlook to 2050 based on a review of nuclear power projects and programs in Member States. These projections should be viewed as very general trends. Their validity must be constantly reviewed as energy and electricity demand and the role of nuclear power will depend on economic growth and structural economic change, demographic developments, technology performance and costs, energy resource availability and future fuel prices, and energy and environmental policies. The projections do, however, provide a plausible, indicative growth range of nuclear capacity regionally and worldwide (IAEA 2012c).

Figure 9.10 displays the historical expansion of nuclear generating capacity and the annual projections for 2020 and 2030 from 2005 to 2012. The low projection shown in the top panel accounts for new builds already firmly in the pipeline including scheduled retirements, planned uprates, and license renewals plus projects that can reasonably be assumed to materialize. The Fukushima accident was considered when the 2011 and 2012 projections were compiled as were the continued global financial and economic crises and associated uncertainties, especially in the short run. Nevertheless, the past drivers behind the use of nuclear energy (population and economic development, environmental protection and climate change, energy security considerations, and fossil fuel price volatility) have not changed and will continue to determine nuclear power development.

Additionally, the low projection does not automatically assume that ambitious targets for nuclear power growth in a Member State will necessarily be achieved. These assumptions are relaxed in the high projection (Figure 9.10, bottom panel) which is much more optimistic but still offers a plausible and technically feasible scenario that assumes that the current financial and economic crises will be overcome in the not too distant future and that past rates of economic growth and electricity demand, especially in East Asia, would essentially resume. In addition, the high case assumes the global implementation of stringent policies to mitigating climate change.

\footnotetext{
${ }^{11}$ The time to market is the period from the beginning of project planning to grid connection and revenue generation.
} 

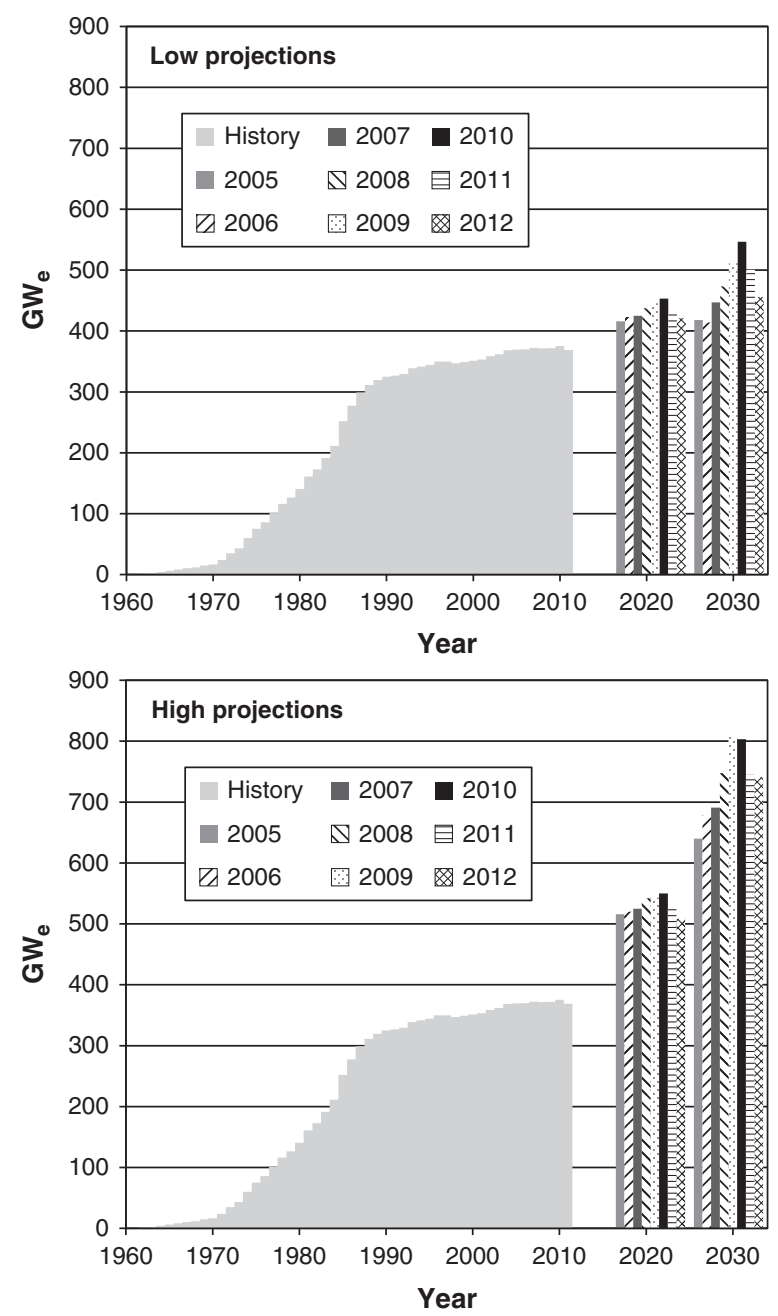

Figure 9.10 Annual projections of total nuclear generating capacity, 2005-2012 Source: IAEA 2012c.

Note: $\mathrm{GW}_{\mathrm{e}}=$ gigawatts of electricity.

The Fukushima accident has had an impact on worldwide prospects for nuclear power. Projections in 2012 for global nuclear power capacity in 2030 were $8 \%-16 \%$ lower than projections before the accident (Figure 9.10), but even in these lower projections, global capacity is projected to grow by $25 \%-100 \%$ by 2030. Thus, the accident is expected to delay growth but not to reverse it. Many countries that had been considering nuclear power are still very interested. For 
example, in 2012, the United Arab Emirates became the first country in 22 years to start constructing its first nuclear power plant.

More specifically, the low projection suggests a delay in nuclear new builds of about a decade, i.e., the 2030 projection in 2012 now falls in the range of preFukushima projections for the year 2020. The sharp drop in construction starts in 2011 and the modest rebound in 2012 were the consequence of suspending construction permits in several countries, the renewable directives in many jurisdictions, the emergence of potentially large amounts of relatively inexpensive shale gas, and the decline in public acceptance of nuclear power. The high projections for 2030 show a lower reduction in capacity than the low projections in both absolute and relative terms consistent with the overall more optimistic outlook on economic development, a new and effective binding international agreement on mitigating climate change, and the restoration of public confidence in nuclear technology.

\section{Asia and the Pacific}

The region with the most uncertainty about its nuclear future is the OECD Pacific in essence due to the reaction in Japan to the Fukushima Daiichi accident. Figures 9.11 and 9.12 reflect the uncertain role of nuclear power by 2030 from $44 \mathrm{GW}_{\mathrm{e}}$ to $90 \mathrm{GW}_{\mathrm{e}}\left(2010: 66.5 \mathrm{GW}_{\mathrm{e}}\right)$. The low projection assumes a long-term nuclear phase out in Japan and no new plant construction; the high projection assumes no phase out and a modest expansion. For comparison, the recent 2012 World Energy Outlook of the IEA reports between $71 \mathrm{GW}_{\mathrm{e}}$ (current policy scenario) and $87 \mathrm{GW}_{\mathrm{e}}$ (450 scenario) (IEA 2012).

In any case, the current nuclear power dominance of the OECD Pacific is set to wither by 2035. Growth in East Asia, essentially in the PRC, dwarfs all other regions. East Asia expands from $15 \mathrm{GW}_{\mathrm{e}}$ in 2010 to $100.5 \mathrm{GW}_{\mathrm{e}}$ (low) and $206 \mathrm{GW}_{\mathrm{e}}$ (high) in 2035. The 2012 World Energy Outlook foresees the PRC between $116 \mathrm{GW}_{\mathrm{e}}$ and $203 \mathrm{GW}_{\mathrm{e}}$ in capacity. In Central Western Asia/South Asia, nuclear expansion is led by India. Bangladesh is the only newcomer while Kazakhstan is expected to join the nuclear club again after $2025{ }^{12}$ Armenia and Pakistan are expected to expand their nuclear capacities from 2020 to 2035. The region will have $30.7 \mathrm{GW}_{\mathrm{e}}$ (low) and $60.5 \mathrm{GW}_{\mathrm{e}}$ (high) by 2035 (5.3 $\mathrm{GW}_{\mathrm{e}}$ in 2010).

Southeast Asia is currently without nuclear power plants and is thus the region with the most potential newcomers. Viet Nam is expected to have its first plant connected to the grid by 2020 in the high projection and in the early 2020 s in the low projection in the early 2020s. In the low projections, Malaysia and Thailand are the most likely to add nuclear power while in the high projection, Indonesia

\footnotetext{
${ }^{12}$ IAEA nuclear capacity projections are made country-by-country but only regional data are published. Country specific information was taken from the Word Nuclear Association to interpret IAEA projections.
} 


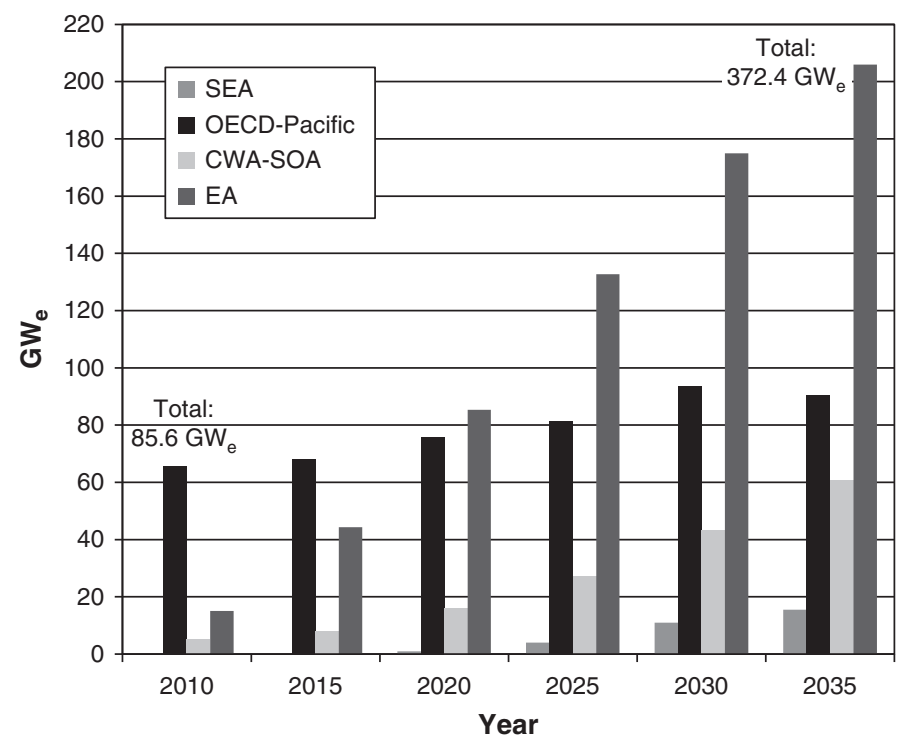

Figure 9.11 High projections for Asian Development Bank members

Source: IAEA 2012c.

Note: SEA = South East Asia: Brunei Darussalam, Cambodia, Indonesia, Lao People’s Democratic Republic, Malaysia, Myanmar, Philippines, Singapore, Thailand, Viet Nam; OECD Pacific = Australia, Japan, Republic of Korea, New Zealand; CWA = Central Western Asia: Afghanistan, Armenia, Azerbaijan, Georgia, Kazakhstan, Kyrgyz Republic, Pakistan, Tajikistan, Turkmenistan, Uzbekistan; SOA = South Asia: Bangladesh, Bhutan, India, Maldives, Nepal, Sri Lanka; EA = East Asia: PRC; Hong Kong, China; Mongolia; Taipei,China; $\mathrm{GW}_{\mathrm{e}}=$ gigawatts of electricity.

and the Philippines would as well. By 2035, the range of nuclear capacities projected for Southeast Asia is from $6 \mathrm{GW}_{\mathrm{e}}$ to $15.5 \mathrm{GW}_{\mathrm{e}}$.

The entire ADB region could expand from $86 \mathrm{GW}_{\mathrm{e}}$ of installed nuclear capacity to either $182 \mathrm{GW}_{\mathrm{e}}$ or $372 \mathrm{GW}_{\mathrm{e}}$. In the latter case, by 2035 it would have accumulated the same capacity the entire world had at the end of 2012. While technically possible, such a nuclear expansion would imply dedicated policy support everywhere without delay. Given the limited enthusiasm for the technology in several countries the time required for reflection and reconsideration of the nuclear option by many governments; and the need for detailed site explorations, impact analyses, and stakeholder involvement in decision making, the low projections reflect a more plausible nuclear future for the region. One of the main drivers behind the high projections is the assumption that stringent climate mitigation policies will take effect worldwide after 2020. If such a binding international environmental agreement can be negotiated and implemented by 2020, the future of nuclear may quickly shift to the high trajectory. 


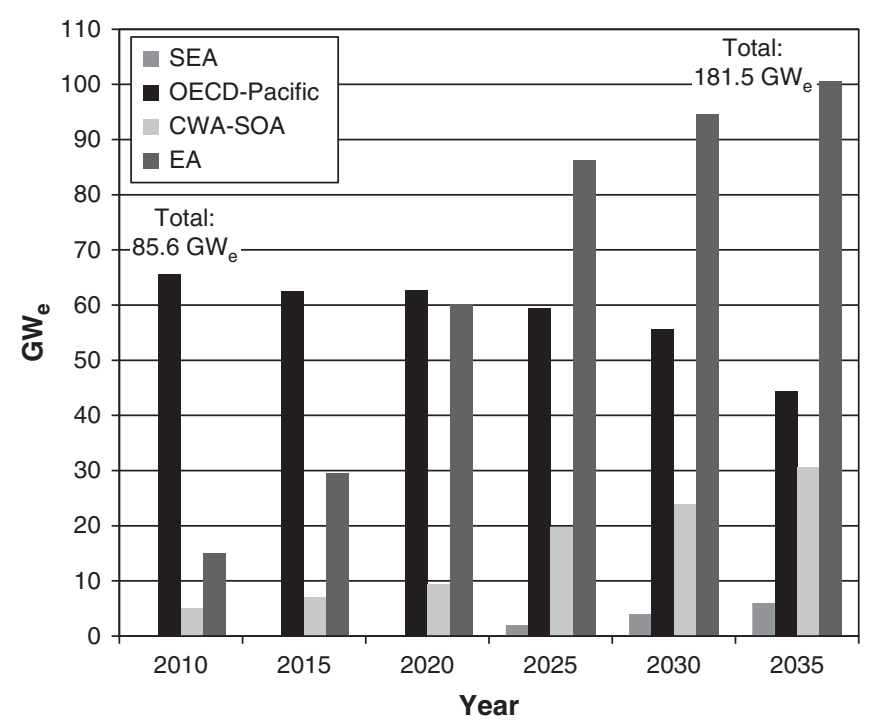

Figure 9.12 Low projections for Asian Development Bank members

Source: IAEA 2012c.

Note: SEA = South East Asia: Brunei Darussalam, Cambodia, Indonesia, Lao People's Democratic Republic, Malaysia, Myanmar, Philippines, Singapore, Thailand, Viet Nam; OECD Pacific = Australia, Japan, Republic of Korea, New Zealand; CWA = Central Western Asia: Afghanistan, Armenia, Azerbaijan, Georgia, Kazakhstan, Kyrgyz Republic, Pakistan, Tajikistan, Turkmenistan, Uzbekistan; SOA = South Asia: Bangladesh, Bhutan, India, Maldives, Nepal, Sri Lanka; EA = East Asia: PRC; Hong Kong, China; Mongolia; Taipei,China; $\mathrm{GW}_{\mathrm{e}}=$ gigawatts of electricity.

\section{Conclusions}

Is there a sustained role for nuclear power in Asia? This question can be answered only by comparisons with the alternatives. All technologies have risks and interactions with the environment, and all are subject to innovation and improvement. Currently, the advantages of nuclear power include low life-cycle GHG emissions; energy security especially during periods of price volatility; stable and predictable generation costs; the internalization of most externalities; small and managed waste volumes; productive use of a resource with no competing uses; firm base-load electricity supplies; and synergies with intermittent energy sources. Finally nuclear power is consistent with "weak sustainability" as reprocessing and advanced reactors and fuel cycles and associated knowledge make up for resource consumption.

Aspects of nuclear power that need further attention are the need (i) for permanent disposal of high-level waste; (ii) to control nuclear weapon proliferation and 
the nuclear fuel cycle; (iii) to ensure the highest level of safety in technology design and operating facilities; (iv) to reduce construction costs; and (v) for public acceptance. These aspects are continually addressed by the industry, and progress has been made.

Finally, one size does not fit all particularly since the costs of energy will vary with resource endowments. Also, different governments may place different weights on climatic objectives versus the risks from nuclear sources, on the benefits of affordable energy, or on those of energy self-sufficiency. Ultimately, local conditions determine the optimal supply and technology mix which may or may not include nuclear power. What is right for a particular Asian country also depends on internal politics and development objectives. In Asia, all options will be needed.

Nuclear power is a long-term commitment and needs solid sociopolitical support. In the short run it means committing several billion dollars for plant construction and maintaining the highest operating safety and security standards. In the longer run, it is a commitment to safekeeping nuclear waste. Societies need to understand these commitments as well as the costs, risks, and benefits associated with nuclear power. Nuclear power is readily available; if societies are serious about climate change and energy security, it cannot be ignored.

\section{References}

Burgherr P., P. Eckle, and S. Hirschberg. 2011. Final Report on Severe Accident Risk including Key Indicators. SECURE (Security of Energy Considering its Uncertainty, Risk and Economic Considerations). Energy Deliverable No. 5.7.2a. European Commission Seventh Framework Programme. Villingen, Switzerland: Paul Scherrer Institute.

Chernobyl Forum. 2006. Chernobyl's Legacy: Health, Environmental and Socio-Economic Impacts. Vienna: International Atomic Energy Agency (IAEA).

European Nuclear Energy Forum (ENEF). 2010. Strengths - Weaknesses - Opportunities Threats (SWOT) Analysis. Working Group Opportunities: Subgroup on Competitiveness of Nuclear Power. Part 1: Strengths \& Weaknesses. Luxemburg: European Commission Directorate General for Energy.

Garwin R. L. and G. Charpak. 2001. Megawatts and Megatons: A Turning Point in the Nuclear Age? New York, NY: Alfred A. Knopf.

Gerasimova N. 2008. Long Term Consequences of the Chernobyl Catastrophe and Remediation Programs in the Russian Federation. Chernobyl: Looking Back to Go Forwards. Proceedings of the International Conference on Chernobyl. Vienna. 6 September.

Goldberg, S. M. and R. Rosner. 2011. Nuclear Reactors: Generation to Generation. Cambridge, MA: American Academy of Arts and Sciences.

Government of the United Kingdom. 2012. Energy Bill 2012-2013. http://www.publications. parliament.uk/pa/bills/cbill/2012-2013/0100/130100.pdf (accessed February 2014).

Government of the United States, Environmental Protection Agency (EPA). 2012. Calculate Your Radiation Dose. http://www.epa.gov/radiation/understand/calculate.html (accessed February 2014).

International Atomic Energy Agency (IAEA). 2007. Milestones in the Development of a National Infrastructure for Nuclear Power. IAEA Nuclear Energy Series. NG-G-3.1. Vienna. 
2008. Financing of New Nuclear Power Plants. IAEA Nuclear Energy Series No.

NG-T-4.2. http://www-pub.iaea.org/MTCD/publications/PDF/Pub1345_web.pdf (accessed February 2014).

- 2011. IAEA Action Plan on Nuclear Safety. GC(55)/14. http://www.iaea.org/ NuclearPower/Downloads/Infrastructure/meetings/2012-01-TM-WS-Vienna/Day-1/3.

ActionPlan-on-NuclearSafety-GCaruso.pdf (accessed February 2014).

—. 2012a. Nuclear Technology Review 2012. http://www.iaea.org/Publications/Reports/ ntr2012.pdf (accessed February 2014).

-.2011b. Climate Change and Nuclear Power 2011.

. 2012c. Energy, Electricity and Nuclear Power Estimates for the Period up to 2050,

2012 Edition. Reference Data Series No. 1-32. http://www-pub.iaea.org/MTCD/

Publications/PDF/IAEA-RDS-1-32_web.pdf (accessed February 2014).

—. 2013 Nuclear Technology Review 2013.

International Energy Agency (IEA). 2012. World Energy Outlook 2012. Paris: IEA/

Organisation for Economic Co-operation and Development (OECD).

International Energy Agency and Nuclear Energy Agency (IEA/NEA). 2010. Projected Costs of Generating Electricity, 2010 Edition. Paris: OECD.

Intergovernmental Panel on Climate Change (IPCC). 2007. Climate Change 2007: Mitigation. Contribution of Working Group III to the Fourth Assessment Report of the Intergovernmental Panel on Climate Change. Cambridge, UK and New York, NY: Cambridge University Press.

- 2011. Special Report on Renewable Energy Systems and Climate Change. IPCC Working Group III: Climate Mitigation. Cambridge, UK and New York NY: Cambridge University Press.

Meeskens, G. 2013. The Trouble with Justification: Getting Straight on the Science and Politics of Nuclear Energy. Energy Studies Review. 1 (2013). pp. 233-242.

Nuclear Energy Agency (NEA). 2003. Nuclear Energy Today. Paris: Nuclear Energy Agency of the OECD.

- 2007. Risks and Benefits of Nuclear Energy. Paris: NEA/OECD.

Nuclear Energy Agency and International Atomic Energy Agency (NEA/IAEA). 2012. Uranium 2011: Resources, Production and Demand: A Joint Report. Paris: OECD.

Organisation for Economic Co-operation and Development. 2011. Towards Green Growth. Paris: OECD Publishing.

Rogner, H.-H. 2010. Nuclear Power and Sustainable Development. Journal of International Affairs. 64 (1). pp. 137-163.

- 2012. Green Growth and Nuclear Power. CESifo DICE Report 4/2012. Munich, Germany: Ifo-Institute, Center for Economic Studies.

Simmons, P. 2012. The 25th Anniversary of the Chernobyl Accident. Business, Economics and Public Policy Working Papers. 2012 (1). Armidale, Australia: School of Business, Economics and Public Policy, Faculty of the Professions, University of New England.

Sovacool, B. 2008. Valuing the Greenhouse Gas Emissions from Nuclear Power: A Critical Survey. Energy Policy. 36. pp. 2940-2953.

United Nations Scientific Committee on the Effects of Atomic Radiation (UNSCEAR). 2010. Sources and Effects of Ionizing Radiation. In UNSCEAR 2008 Report, Volume I. http://www.unscear.org/unscear/en/publications/2008_1.html (accessed February 2014). von Hippel, F. N. 2011. It Could Happen Here. New York Times. 23 March.

Weisser, D. 2007. A Guide to Life-Cycle Greenhouse Gas (GHG) Emissions from Electric Supply Technologies. Energy. 32 (9). pp. 1543-1559. 
World Health Organization (WHO). 2008. Air Quality and Health, Fact Sheet No. 313. Geneva: WHO.

—. 2012. Preliminary Dose Estimation from the Nuclear Accident After the 2011 Great East Japan Earthquake and Tsunami. http://www.who.int/ionizing_radiation/pub_meet/ fukushima_dose_assessment/en/index.html (accessed February 2014).

World Future Energy Summit. 2012. Abu Dhabi. 16-19 January. 


\title{
10 Asia's energy challenge Regional cooperation and integration for energy security
}

\author{
Minsoo Lee, Donghyun Park, and \\ Harry D. Saunders
}

\section{Introduction}

Aggressive action to manage demand and promote new, clean supply technologies can advance the cause of Asian energy security, but these advantages will not be fully realized unless measures are also taken to bring demand and supply together more efficiently. Achieving Asia's energy security will thus require programs that integrate energy delivery systems regionally.

Regional cooperation and integration among Asian countries is on the rise as they are responding to the multitude of common challenges they face by pursuing closer links, especially subregionally. The growing regional ties are most visible in trade. In particular, East and Southeast Asia have formed a regional production network that has transformed them into Factory Asia. For example, the share of intra-Association of Southeast Asian Nations (ASEAN) trade in ASEAN's total trade that already reached $21 \%$ in 1998 had grown to $25.4 \%$ by 2010 . The integration of financial and labor markets is more limited but is also growing. After the Asian financial crisis in 1997 and 1998, ASEAN+3 (People's Republic of China [PRC], Japan, and the Republic of Korea) governments joined forces in the Chiang Mai Initiative, a multilateral currency swap arrangement with a foreign exchange reserve pool of $\$ 240$ billion. Subregional connectivity is also increasing as is evident in transport initiatives in the Greater Mekong Subregion $(\mathrm{GMS})^{1}$ and Central Asia Regional Economic Cooperation (CAREC). ${ }^{2}$

Cross-border connectivity in Asia's energy markets and infrastructure has, however, lagged far behind the general momentum of regional cooperation and integration. This is unfortunate because the rapidly rising energy demand in Asia is making energy security a regional challenge that would benefit greatly from a collective regional response. The lack of regional cooperation and integration is all the more glaring since, in contrast to the uncertainties and high costs of

${ }^{1}$ The GMS includes Cambodia, Yunnan Province and Guangxi Zhuang Autonomous Region of the People's Republic of China, Lao People's Democratic Republic, Myanmar, Thailand, and Viet Nam.

${ }^{2}$ CAREC includes Afghanistan, Azerbaijan, Xinjiang Uygur Autonomous Region of the People's Republic of China, Kazakhstan, Kyrgyz Republic, Mongolia, Pakistan, Turkmenistan, Tajikistan, and Uzbekistan. 
developing new technology, it would be a relatively easy means for promoting energy security and saving energy as long as there is strong political will and mutual confidence. Interconnecting power and gas grids can create large regional energy markets that increase efficiency. Closer energy links among Asian economies can deliver substantial gains even in the short term. Managing demand and expanding the supply of clean, affordable energy becomes more effective with regional cooperation and integration.

Asian economies have different comparative advantages in the energy sector. Closer regional integration of energy markets through the construction of energy trade infrastructure such as pipelines offers potentially large benefits. Central Asia already benefits partially from the reliability provided by the interconnected power grid it inherited from the former Soviet Union; hydropower resources in Bhutan, Lao People's Democratic Republic, and Myanmar have been developed to provide clean energy to neighboring energy markets at low cost; a natural gas pipeline supplies energy to Singapore from Indonesia. These regional projects benefit participants and help to decrease fossil fuel use.

Harnessing the hydroelectric potential of upstream Himalayan countries, i.e., Bhutan and Nepal, for export to downstream India is another win-win scenario. Realizing these and many other cross-border synergies is both technologically feasible and commercially viable. What is missing is the political commitment of Asian governments to cooperate with each other to link their energy markets and to build the necessary infrastructure.

\section{Integrating power and gas delivery systems}

There are potentially large benefits to be gained by cross-border coordination of electricity and natural gas networks. Power system failures and gas supply disruptions can have major consequences; these can be mitigated by properly designed electricity and gas delivery systems that work collectively. When systems are designed from the outset to optimize delivery without unduly considering borders, gains in energy efficiency at minimal cost are obtainable.

\section{Interconnected power systems}

Electric power systems have traditionally grown to be more interconnected with other power systems in the region for very sound reasons of economics, reliability, and fuel conservation. Larger systems typically deliver power at lower cost per kilowatt hour than smaller ones owing to economies of scale and diversity of generation mix. Interconnected systems share backup generation and voltage support thus reducing capital costs, and larger systems generally use less energy per kilowatt hour delivered.

Similarly, interconnection advances the cause of energy efficiency. Generally speaking, larger systems can accommodate larger baseload generation units that typically have greater fuel conversion efficiency than smaller fossil fuel-based units. When power systems interconnect, fuel efficiency gains in generation can 
be greater and can be shared, and the larger and more interconnected the power systems are, the greater the energy efficiency gains are. It is possible to implement large storage hydropower projects in interconnected systems as is evident in Central Asia where without the interconnections, building the large dams for power generation in Kyrgyz Republic and Tajikistan would not have been justified.

Regional cooperation and integration are already underway although there is scope for much more. Asia is far from having a European-style single, regionwide power grid, but there is no reason why the region cannot entertain such ambitions in the long run. In the short run, however, most cooperation and integration is taking place subregionally or among geographical neighbors.

Bhutan's exports of hydroelectric power represent another example of win-win regional cooperation and integration. By virtue of its upstream Himalayan location with a landscape dotted by steep mountains, deep gorges, and fast-flowing rivers, Bhutan has a hydropower potential of 30,000 megawatts, and the large and rapidly growing neighboring Indian economy has a robust appetite for energy. There is thus plenty of scope for mutually beneficial energy cooperation and integration between these two South Asian countries. In fact, India helped Bhutan develop its hydropower potential starting in the early 1960s. Large-scale, mega power projects such as Chukha (336 megawatts), Tala (1,020 megawatts) and Kurichu (60 megawatts) were all financed by India through a mix of grants and loans. Upon completion, much of the power generated by the hydroelectric projects was exported to India, providing India with much-needed energy and Bhutan with much-needed revenues. When northern India was hit by its worst power outage in a decade in July 2012, the Indian government turned to Bhutan for assistance. Bhutan responded by releasing additional power from its hydroelectric stations. India had a deal to buy 5.480 billion kilowatt hours of power from Bhutan between 1 April 2012 and 1 April 2013, about 1\% of India's electricity needs (Government of India, Ministry of Power 2013).

The GMS illustrates the potentially large scope for cooperation and integration. The sheer diversity of the subregion's resource base gives rise to huge potential gains from pursuing energy integration. The GMS has enormous energy resource endowments. Realizing just half of its hydropower potential would generate 450 terawatt hours, almost double the subregion's 2010 total electricity generation. In addition, the subregion is endowed with abundant coal deposits and promising gas and petroleum reserves although they are unevenly distributed geographically. Hydropower potential is abundant in Yunnan Province and Guangxi Autonomous Region in the PRC, in Myanmar, in Lao People's Democratic Republic, and in Viet Nam accounting for $94 \%$ of hydro resources in the GMS (ADB and ADBI 2013). The hydro potential of Myanmar and Lao People's Democratic Republic is huge relative to their population and expected needs. Myanmar, Thailand, and Viet Nam have natural gas, Viet Nam has the most oil reserves, and Yunnan Province holds the main coal deposits.

Cambodia, PRC, and Thailand are net energy importers while Lao People's Democratic Republic, Myanmar, and Viet Nam are net exporters. In the GMS, 
the basic mechanism for regional cooperation and integration has been to expand trade in energy among members. For example, Thailand purchases hydropower from Lao People's Democratic Republic generated by the Nam Theun 2, Nam Leuk, Nam Ngnum 2, and Theun Hinboun I and II power plants with more plants under construction or in the pipeline. But growth in trade has been constrained because the transmission lines do not allow third party access. One option would be to develop a publicly owned, high voltage backbone line that various independent power producers could use to transfer power paying wheeling fees to the transmission owner. An example would be constructing a 500 kilovolt line in Lao People's Democratic Republic connected with Thailand and Viet Nam that could eventually lead to optimizing the power systems of all three. Similarly, the 275 kilovolt transmission line from Sarawak, Malaysia to West Kalimantan, Indonesia enables Malaysia to export hydropower to West Kalimantan where generation is largely oil based. This helps to improve the environment in West Kalimantan and reduces greenhouse gas (GHG) emissions. More fundamentally, investing in regional energy infrastructure and institutionalizing and systematizing regional cooperation and integration would enable the GMS to reap even bigger gains.

\section{Interconnected gas systems}

Similar economies and efficiencies are realizable when natural gas systems interconnect. Provided the endowment is large compared to domestic energy demand, interconnecting energy markets allows the use of natural resources to create a revenue stream that helps to meet development needs just like the export of any other commodity. Cross-border gas pipelines also offer the opportunity to create gas distribution networks to economically serve the needs of communities along the route, and as noted in Chapter 1, cooktops and furnaces can run on gas and save energy. Large pipeline networks operating at higher pressures also provide storage to help maintain a reliable supply during small technical interruptions.

One prominent example of regional interconnection is the Central Asia-China (PRC) gas pipeline, also known as the Turkmenistan-China (PRC) gas pipeline. The pipeline, which was completed in December 2009, carries natural gas from Turkmenistan to Xinjiang in the PRC, crossing Uzbekistan and Kazakhstan, and from Xinjiang it is connected to the PRC national west-east pipeline. This pipeline is a good example of mutually beneficial energy trade among Asian countries. For the PRC, imported Turkmen gas has increased the share of gas in total energy demand by $2 \%$, equivalent to $50 \%$ of domestic production. This has displaced the production and use of domestic coal that has higher GHG emissions and more pollutants, so there is a sizable environmental benefit. For Turkmenistan, the pipeline has diversified the export market so the country is no longer tied to the Russian Federation for all its energy exports. More broadly, the pipeline will help to quench the PRC's fast-growing thirst for energy while giving gas-rich Turkmenistan access to a large and growing energy market.

Another example is the pipeline to supply gas for power generation from South Sumatra, Indonesia to Singapore. Singapore's economy relies on services and 
high-tech industries, both of which place a very high value on a reliable power supply. Diversifying the supply base to Indonesia helps ensure energy security for Singapore and provides an assured revenue stream to Indonesia that is used for development. Prior to selling to Singapore, the only market the gas field served was for enhanced oil recovery in Aceh Province which entailed higher transportation costs and had a lower economic value. The access provided to the Singapore energy market by the pipeline has thus increased the value of the natural endowment.

\section{Smart grids and integrating renewables}

As renewable energy grows, smart grids that integrate renewables into the mainstream electricity network will play a greater role in regional cooperation and integration (see Chapter 1). The fundamental reason is that the sources of renewable energy are often distant from the main demand centers, i.e., areas with large populations and extensive economic activity. In fact, there is actually no reason why the supply and demand centers have to be in the same country. For example, wind power from sparsely populated Mongolia can provide electricity to the PRC, and hydroelectric power from Myanmar can provide electricity to the Bangkok metropolitan area of Thailand. More generally, by linking together Asian economies with potentially ample supplies of renewable energy with Asian centers of population and economic activity at an economically viable cost, smart grids can act as a catalyst for developing renewable energy in the region. In the absence of smart grids, the renewable potential of thinly populated countries will be unexploited and wasted.

As the energy system in Asia moves toward the vision of being largely based on renewables, it will need to be more intelligent. Renewables such as solar and wind are intermittent resources that cannot be relied on to deliver power at the time it is needed. Solar is available only during the day; cloud cover can reduce the power produced in unpredictable ways. Wind is highly variable and likewise unpredictable. Wind resources are only weakly correlated with system demand or load; solar is somewhat more strongly correlated with load. Integrating renewables into the power grid poses significant technical challenges, but intelligent systems can also take advantage of time-of-day demand differences across time zones and can "swing" power across large geographic regions when solar systems experience different time-of-day output capabilities.

Attendant to this problem is the need to incorporate "distributed" energy generation systems. Distributed power generation is generation not from centralized power plants but from small local sources distributed throughout the region such as solar panels on buildings, small on-site generators and cogenerators, and local biomass and waste-based power systems. Sometimes local sources are joined together in "microgrids" that operate locally with a connection to the main grid though integration with the centralized grid creates technical challenges for the central grid operator associated with voltage, phase synchronization, and stability control. 
Intelligent systems that can adjust to accommodate both decentralized generation and centralized renewable generation can optimize the system to maximize generation from renewables, to minimize costs, and to improve reliability of service. This, however, requires that smart grids in different countries can "talk" to each other and operate together seamlessly. The system cannot be optimized unless regional cooperation is extensive.

An example of regional interconnections with smart grids would be very large wind farms in Mongolia connected to transmission networks in the PRC, or even in Japan or the Republic of Korea. Mongolia has enough wind resources to install 1 terawatt of capacity. This will translate to about 200,000 wind turbines (5 megawatts each) located at different places. On such a scale and with excellent year-round resources, the price of wind energy will be lower than most onshore wind farms in other countries. Domestic demand in Mongolia does not justify the installation, but regional interconnection changes the economics completely. For such a large renewable energy system, smart grid technology will be essential for optimizing the use of the resource and for ensuring grid reliability. Another example of smart grid application is developing cascade hydropower dams in mountainous regions to supply electricity to neighboring economies.

The advent of the widespread use of electric vehicles will introduce challenges along with opportunities. Smart, interconnected power grids can tie together fleets in two countries, and a much larger overall battery capacity will then store energy. With smart grids it will be technically feasible to charge vehicles when excess renewable energy is available and, to even use some of the energy stored in the battery when vehicles are plugged in and not in use during periods of high grid demand.

\section{Resource synergies}

Asian countries enjoy different endowments of energy resources and have different energy needs. These different resource bases and corresponding mismatches to domestic needs create a natural opportunity to engage in mutually advantageous trade in energy.

\section{Conventional fossil fuels}

Asia holds a relatively small share of the world's conventional oil and natural gas resources, and their distribution across the region is far from even. Central and West Asia hold the largest share of both as Table 10.1 shows.

Kazakhstan has the largest proven oil reserves in Asia by a significant margin; Turkmenistan has the largest natural gas reserves, again by a significant margin. In fact, the whole of Central and West Asia dominates the gas reserve picture, yet compared to the rest of Asia, this subregion is home to a tiny fraction of the population.

The reserves-to-production ratio in Table 10.1 is a proxy for the remaining lifetime of the corresponding reserves (the actual lifetime will vary as new proven reserves are added and production levels change from current levels). 
Table 10.1 Proven reserves of natural gas and oil in Asia (at the end of 2012)

\begin{tabular}{|c|c|c|c|c|}
\hline \multirow[t]{2}{*}{ Subregion } & \multicolumn{2}{|l|}{ Oil } & \multicolumn{2}{|l|}{ Natural gas } \\
\hline & Billion barrels & $R / P$ & Trillion $\mathrm{m}^{3}$ & $R / P$ (in years) \\
\hline \multicolumn{5}{|l|}{ Central and West Asia } \\
\hline Azerbaijan & 7.0 & 21.9 & 0.9 & 57.1 \\
\hline Kazakhstan & 30.0 & 47.4 & 1.3 & 65.6 \\
\hline Turkmenistan $^{\mathrm{a}}$ & 0.6 & 7.4 & 17.5 & $>100$ \\
\hline Uzbekistan & 0.6 & 24.0 & 1.1 & 19.7 \\
\hline \multicolumn{5}{|l|}{ South Asia } \\
\hline Bangladesh & & & 0.2 & 8.4 \\
\hline India & 5.7 & 17.5 & 1.3 & 33.1 \\
\hline \multicolumn{5}{|l|}{ East Asia } \\
\hline People's Republic of China & 17.3 & 11.4 & 3.1 & 28.9 \\
\hline \multicolumn{5}{|l|}{ Southeast Asia } \\
\hline Brunei Darussalam & 1.1 & 19.0 & 0.3 & 22.9 \\
\hline Indonesia & 3.7 & 11.1 & 2.9 & 41.2 \\
\hline Malaysia & 3.7 & 15.6 & 1.3 & 20.3 \\
\hline Thailand & 0.4 & 2.7 & 0.3 & 6.9 \\
\hline Viet Nam & 4.4 & 34.5 & 0.6 & 65.6 \\
\hline \multicolumn{5}{|l|}{ Developed ADB countries } \\
\hline Australia & 3.9 & 23.4 & 3.8 & 76.6 \\
\hline Total $A D B$ region & 78.4 & 19.7 & 34.6 & 48.6 \\
\hline World & $1,668.9$ & 52.9 & 187.3 & $42.0 *$ \\
\hline Share of world & $4.7 \%$ & & $18.5 \%$ & \\
\hline
\end{tabular}

Source: BP 2013.

Note: $\mathrm{ADB}=$ Asian Development Bank; $\mathrm{m}^{3}=$ cubic meters; $\mathrm{R} / \mathrm{P}=$ reserves-to-production ratio; ${ }^{\mathrm{a}}$ assumes 100 years R/P for Turkmenistan.

This metric highlights the fact that Central and West Asia are producing oil and gas at far lower levels relative to other parts of Asia compared to their resource base. The implication is that mutual trade benefits could be attained by integrating energy markets.

A similar picture emerges when considering coal endowments, although India and the PRC are somewhat more favorably endowed compared to their needs (Table 10.2).

Asia has a better coal endowment compared to the rest of the world than its endowment of conventional oil and natural gas. Nonetheless, Central and West Asia boast coal resources that appear to be beyond their current needs based on their reserves-to-production ratios. Again, the implication is that there is room for exploiting trade.

\section{Unconventional fossil fuels}

The advent of the shale gas boom in North America and Europe raises the prospect of a similar windfall for Asia. In fact, from a resource perspective, Asia 
Table 10.2 Proven reserves of coal in Asia (at the end of 2102)

\begin{tabular}{|c|c|c|c|c|}
\hline \multirow[t]{2}{*}{ Subregion } & $\begin{array}{l}\text { Anthracite } \\
\text { and } \\
\text { bituminous }\end{array}$ & $\begin{array}{l}\text { Sub- } \\
\text { bituminous } \\
\text { and lignite }\end{array}$ & Total & \multirow{2}{*}{$\begin{array}{l}R / P \\
\text { Years }\end{array}$} \\
\hline & \multicolumn{3}{|l|}{ Billion tons } & \\
\hline \multicolumn{5}{|l|}{ Central and West Asia } \\
\hline Kazakhstan & 21.5 & 12.1 & 33.6 & 289 \\
\hline Pakistan $^{\mathrm{a}}$ & & 2.1 & 2.1 & $>500$ \\
\hline \multicolumn{5}{|l|}{ South Asia } \\
\hline India & 56.1 & 4.5 & 60.6 & 100 \\
\hline \multicolumn{5}{|l|}{ East Asia } \\
\hline People's Republic of China & 62.2 & 52.3 & 114.5 & 31 \\
\hline \multicolumn{5}{|l|}{ Southeast Asia } \\
\hline Indonesia & 1.5 & 4.0 & 5.5 & 14 \\
\hline Thailand & & 1.2 & 1.2 & 60 \\
\hline \multicolumn{5}{|l|}{ Developed ADB countries } \\
\hline Australia & 37.1 & 39.3 & 76.4 & 177 \\
\hline Total ADB region & 178.4 & 115.5 & 288.4 & 149.6 \\
\hline World & 404.8 & 456.2 & 860.9 & 109 \\
\hline Share of world & $44.0 \%$ & $25.3 \%$ & $34.1 \%$ & \\
\hline
\end{tabular}

Source: BP 2013.

Note: $\mathrm{ADB}=\mathrm{Asian}$ Development Bank; $\mathrm{R} / \mathrm{P}=$ reserves-to-production ratio; ${ }^{\mathrm{a}}$ assumes 500 years R/P for Pakistan.

appears to be well positioned to follow suit, although the region faces both geological and local environmental challenges not encountered elsewhere. In fact, the PRC's shale gas resource is the largest in the world. India, too, likely holds a significant resource along with Pakistan, and Indonesia's resource, while highly uncertain, may also be large (see Chapter 7, Table 7.2). As these resources become better defined and are developed, economically advantageous opportunities will arise to serve gas markets from supply centers in a way that does not necessarily honor national boundaries.

\section{Solar resources}

As renewables grow and penetrate more markets, there will be substantial opportunities to engage in mutually advantageous regional cooperation. Solar power is an excellent example. Southern regions enjoy the obvious advantage that incident solar energy is more intense and spatially denser. Figure 7.10 in Chapter 7 shows this relative advantage.

The evident regional disparity in Figure 7.10 opens the opportunity for southern Asia to exploit its solar resource advantage to supply regions further to the north. When combined with the advantages of large-scale power connections to 
better absorb time-of-day and weather-related solar power fluctuations, solar resources are yet another opportunity to take advantage of regional energy cooperation.

\section{Wind resources}

Wind power has been rapidly expanding throughout the world including in the PRC and India. The potential in Asia is enormous. According to one study (Shah 2012), the PRC and Mongolia could each install over 1 terawatt (1 million megawatts or 1,000 gigawatts) of wind capacity that together would generate more than 3,000 terawatt hours annually. This is over $60 \%$ of the PRC's total electricity consumption of 4,937 terawatt hours in 2012. Afghanistan, Kazakhstan, and Viet Nam could each install over 100 gigawatts. The only country currently exploiting more than $5 \%$ of its potential is India at $30 \%$ driven largely by an accelerated depreciation allowance.

According to the Global Wind Energy Council, a leading industry association, the installed capacity of wind power in Asia in 2011 was 82.0 gigawatts, or $36 \%$ of the total world capacity of 237.5 gigawatts and comparable to Europe's 96.5 gigawatts. By the end of 2012, global capacity had increased by $19 \%$ to 282.5 gigawatts. With 75.5 gigawatts, the PRC leads the world, and India ranks fifth with 18.5 gigawatts (Global Wind Energy Council 2013).

Wind energy is, however, distributed unevenly across Asia endowing a handful of countries with huge potential but leaving many with little as shown in Figure 7.19 in Chapter 7. In addition, wind energy is far less predictable than solar energy for a specific locale, but an interesting opportunity can be seen in Figure 7.19 when compared to the solar resource in Figure 7.10. While wind is distributed much less uniformly than solar in the sense of a north-south gradient, generally speaking northern regions claim most of the high-intensity wind resources. This suggests the possibility of a mutually beneficial interconnection between southern solar power producers and northern wind power producers. At a minimum, exploring the potential for a north-south cooperative agreement would seem to be well worth exploring.

\section{Strategic oil stockpiling}

Asia's growing dependence on oil imports creates a substantial risk of an interruption that could be highly damaging to economies especially if it were extended. This risk can be reduced by cooperative agreements to build and manage strategic oil stockpiles such as those required for International Energy Agency (IEA) members (see Chapter 2). The IEA arrangement could provide a useful model for such an undertaking. Stockpiling carries a cost, but interruptions could be much more costly. Financing arrangements will likely be necessary to allow low income countries to participate, but strategic stockpiles held there will benefit the whole region during an interruption.

Several developing Asian countries already hold strategic oil reserves including the PRC, India, the Republic of Korea, and Thailand. However, given the 
rapidly growing Asian need for oil, there is an urgent need to significantly enhance the effectiveness of reserves in protecting the region from oil shocks. In this context, a cooperative mechanism would amplify the benefits from strategic stockpiles. IEA members participate in an agreement to maintain specific levels of strategic reserves, and EU member states participate in a separate agreement to maintain minimum stocks of specific petroleum products.

The 28 IEA members realize that stockpiles held by one benefit the others since releases by any member during a supply interruption reduce pressure on global oil markets and help to restrain global oil prices for the benefit of all. This is why the IEA mandates that individual members hold reserves equivalent to 90 days of the previous year's net oil imports. In addition, there are requirements governing the release of stocks during an interruption that are somewhat complex since they must account for emergency responses that may differ from member to member such as the capability to increase production, restrain demand, and switch fuels. Synchronizing responses during an emergency can be done effectively only with substantial prior coordination and planning.

To claim the benefits of a regional strategic oil stockpiling arrangement, developing Asian governments must agree to surrender certain aspects of independent management of their existing strategic stockpiles, but the experience of the IEA suggests that the benefits may well outweigh the costs. The forum for cooperation could also provide the means to discuss other oil supply security matters such as the limited flexibility of Asia's current refining system to process heavy crudes in the event of an interruption disproportionately affecting lighter crude supplies.

\section{Key obstacles to regional cooperation and integration}

Interconnecting power and gas grids requires standardized regulations, pricing practices, and contracting. Technical standards, particularly for electricity, need to be uniform for interconnections to work. The smooth operation of regional oil markets requires standardized oil product specifications so suppliers can compete fairly. Common environmental standards eliminate distortions in production costs. Economies with established or planned nuclear energy programs stand to benefit from common nuclear licensing, operating standards, and supervision that maximize available human resources, reduce delay, and contain costs, and as radiation contamination can be cross-border, coordination will also increase public confidence. In the longer-term as compressed natural gas and electric vehicle fleets expand, harmonized standards for filling and recharging stations will have to be established for cross-border transportation systems to function smoothly.

Specific programs for regional cooperation in all these areas will need to be established to take maximum advantage of the benefits of integrating regional energy systems. Possibly the best example to learn from is the European electricity and gas markets. They started in the late 1980s with the liberalization of the power sector in the United Kingdom. The monopoly of the state-owned electricity company was broken and a competitive market was established that could 
buy excess, low-cost power from neighboring France. Similar liberalization was pursued by several other Western European countries that wanted to reduce the role of the state in delivering utility services. The 1995 Green Paper and European Directive issued by the European Parliament in 1996 for common rules for internal electricity markets (similarly for gas in 1998) form the basis of the European Union (EU) energy market. The Lisbon Strategy (2000) recognized that competiveness in energy was essential for Europe's competitiveness and knowledgebased global leadership, and it brought electricity and gas together. Later, a mandate in 2003 provided third party access to all existing infrastructure and in 2009 integrated the energy and environmental objectives of the EU.

In summary, the EU that was already interconnected recognized the value of building still stronger connections of both power and gas networks stating in 2006

An efficient energy infrastructure is essential for the internal energy market to work properly and to achieve the European Union's targets for sustainable development, competitiveness and secure energy supplies. This requires considerable investment in the existing gas and electricity networks along with rapid development of their interconnections.

(European Commission 2007)

In particular, the European Commission pointed to the value of better integrating renewable energy, stating "[interconnected networks] also prevent the risk of short supply by diversifying sources, for example for electricity, by facilitating the introduction of a 'green network' based on renewable energies." This resulted in the promulgation of the system-wide Priority Interconnection Plan. The EU already had well-established regulatory frameworks, contractual standards, and pricing practices, so this directive is a strong indication that challenges remain to making the most out of their energy infrastructure. For Asia, it is difficult to imagine how the challenges could be less demanding.

From a purely technical and commercial perspective, there is every reason for Asian economies to pursue wider and deeper regional cooperation and integration in the energy sector. In contrast to developing new technologies with uncertain, long-term payoffs, fostering closer energy ties among neighbors promises concrete payoffs even in the short run. Nevertheless, the move towards liberalization and integration is extremely slow in Asia. It is a political reality that liberalization (privatization) of existing energy infrastructure is not a priority in most developing Asian economies. Ultimately, it is the lack of political will and commitment that is preventing the forging of energy links.

For one, Asian governments and those in other parts of the world tend to view energy security as a vital component of national security and are thus reluctant to relinquish control or to share control with others. Furthermore, Asian governments intervene heavily in their energy markets as is evident in consumer subsidies and electricity tariffs, for example, reinforcing their desire to retain full control. This is because energy is a basic human need with at least some element of a public good. This explains why Asian governments subsidize the cost of 
basic fuel. Trade, let alone free trade, is challenging in the face of such extensive government involvement.

Related to national security, there is a strong element of often intense international competition precisely because energy resources are limited. Indeed there is a tendency to view the acquisition of energy resources, e.g., oil and natural gas in Central Asia, as a zero-sum game in which countries are willing to pay a premium to secure reliable, long-term, exclusive access. This makes regional cooperation all the more difficult to pursue. Cross-border oil and natural gas pipelines also have the potential to create conflicts of national interest. Disputes are possible over transit fees - the fees paid to the country that does not own the oil or gas but through whose territory the pipeline passes, i.e., Kazakhstan and Uzbekistan in the case of the Turkmenistan-China (PRC) gas pipeline. Narrow national interests thus often stand in the way of regional public good in the energy sector.

Another major obstacle to regional cooperation and integration in Asia is the presence of powerful vested interests in the energy sector. Due to economies of scale, electric utilities are frequently either state-owned monopolies or private monopolies heavily regulated by the government. In either case, the utilities and other key energy sector participants exert a great deal of political influence, and they are likely to view regional initiatives that involve other governments as potential threats to their dominant positions in their domestic markets. They may resist regionally harmonized standards, regulations, and pricing out of narrow institutional interests even when they promote the broader national interest especially since in many cases the national standards, regulations, and pricing evolved to promote their narrow institutional interests in the first place. These political considerations are probably the single biggest reason for the slow progress in energy cooperation and integration in Asia.

Asia should pursue subregional integration to eventually establish an Asian energy market; this is one of the lessons from the EU energy market that presently operates subregionally. Basically, all governments should adopt the same frequency for electricity (50 hertz) so integration will not require special designs except in the Philippines and a part of Japan that use 60 hertz. Matching grid codes (standards for design and operation of power transmission systems) may not remain a serious issue as more cross-border transmission lines are built to export power bilaterally. Where sufficient power transfer is foreseen, high-voltage, direct-current interconnections allow systems operating at different frequencies to interconnect with the added benefit of countering system instability. It is, however, difficult to predict when governments will agree to formal energy trade that can then attract the massive investments needed to build the power projects.

Integrating the subregional energy markets in Asia has not suffered from a lack of international support and expertise. All major donors that work in the region see immense benefits from regional energy trade and have readily provided grants and expertise to push the agenda forward, but recurring obstacles block progress. For one, the energy market has to be liberalized so energy is competitively priced, 
and new investments respond to market signals. In addition, governments need to better understand the EU experience and become convinced that regional energy markets will serve their strategic national interests. In any case, it will be difficult to ensure energy security for individual economies.

Clearly, moving regional integration forward requires a high level of political commitment; a ministerial level pan-Asian task force on energy cooperation and integration would provide a good point of departure. Asian leaders meet often and discuss regional trade, but these discussions have yet to include energy. Even though individual economies struggle to meet their energy demands, confidence in partnerships with neighbors remains low. Full transparency in the energy sector has not been possible because governments consider it against their national strategic interests. This needs to change because regional energy trade in Asia can strengthen energy security. Above all, what is required is the political will and commitment to more closely integrate energy sectors.

\section{References}

Asian Development Bank and Asian Development Bank Institute. 2013. Connecting South Asia and Southeast Asia, Interim Report. Asian Development Bank Institute. Tokyo, Japan. http://www.adbi.org/files/2013.05.05.book.connecting.south.asia.southeast.asia. interim.report.pdf (accessed February 2014).

British Petroleum (BP). 2013. BP Statistical Review of World Energy 2013. http://www.

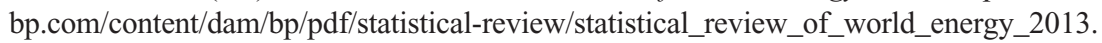
pdf (accessed February 2014).

European Commission. 2007. Priority Interconnection Plan. http://ec.europa.eu/energy/ infrastructure/infrastructure/infrastructure_en.htm (accessed 2 December 2013).

Global Wind Energy Council. 2013. Global Wind 2012 Report. Brussels, Belgium. http:// www.gwec.net/wp-content/uploads/2012/06/Annual_report_2012_LowRes.pdf?bcsi_scan_ dab5294b144736b1=+dtm1ia2FxMXU3/nsOLU018KZ8ArAAAAHMEJPw==\&bcsi_scan_ filename=Annual_report_2012_LowRes.pdf (accessed February 2014).

Government of India, Ministry of Power. 2013. Electricity generation during the month of March 2013 and during the period April 2012-March 2013. Central Electricity Authority, Operation Performance Monitoring Division, April 2013. http://cea.nic.in/ reports/monthly/elec_review/mar13.pdf (accessed February 2014).

Shah, J. 2012. Mongolian Renewable Energy. Presentation at the Asian Development Bank Conference Quantum Leap in Wind. Ulaanbaatar, Mongolia. 17-18 May. 


\title{
11 Energy in the People's Republic of China and India in 2010 and 2035
}

\author{
César Dopazo, Antonio Gómez, and \\ Norberto Fueyo
}

\section{Introduction}

The People's Republic of China (PRC) has recently surpassed the United States (US) as the leading primary energy consumer in the world in absolute terms. Its primary energy demand has more than doubled since 2002, an unparalleled trend. Its primary energy intensity (PEI) and primary energy consumption per capita are, however, commensurate with its development: the PEI is 3-8 times greater than that of developed countries; per capita consumption is 3-8 times less. Energy dependence in the PRC has increased in recent years. The country was nearly independent at the turn of the millennium, but it was importing about $10 \%$ of its primary energy in 2009 . Critically, while making an effort to resort to cleaner energy sources, the economy relies heavily on coal (both domestic and increasingly imported) as an energy source. The PRC uses more coal than Europe, Japan, and the US combined. As a consequence, it contributes about $50 \%$ of the world's carbon dioxide $\left(\mathrm{CO}_{2}\right)$ emissions from coal. From 2013 to 2016, about 273 gigawatts of new coal plants are planned, equivalent to 1.3 gigawatts per week (a new, large, coal-fired plant every week).

India experienced strong economic growth from 2000 to 2011. Its gross domestic product (GDP) increased by $120 \%$ for an average annual growth rate of $7.4 \%$; it is expected to continue to grow in the coming years. To sustain this growth, India's primary energy demand increased by $51.5 \%$ from 2000 to 2010 , and $\mathrm{CO}_{2}$ emissions increased by $66.8 \%$. India ranked fifth in energy consumption and $\mathrm{CO}_{2}$ emissions worldwide in 2000. Currently it ranks third in $\mathrm{CO}_{2}$ emissions after the PRC and the US and the fourth in energy demand after the PRC, the US, and the Russian Federation, but in all likelihood it will soon surpass the Russian Federation in primary energy consumption. The high $\mathrm{CO}_{2}$ emission rank is due to the large share of local coal (41.6\% in 2010) and oil (23.4\%) in the primary energy mix. In spite of its sizeable coal reserves, India's energy dependence increased from $20 \%$ in 2000 to $25 \%$ in 2010 due increased oil imports. Future economic development will continue to compromise the sustainability and security of its energy system. 
In this chapter, we use a bottom-up, detailed energy model for the PRC and India to research key aspects of their energy systems. We analyze the causes when performance is poor and work out the implications of various policy decisions to improve it. Specifically, we investigate the following six issues.

1 Why is primary energy intensity high?

In energy efficiency in 2010, the PRC ranked 25th and India ranked 24th out of 38 economies in the Asian Development Bank's (ADB) Asian Development Outlook (ADB 2010). Why are they so inefficient? What are the supply, demand, and economic contributions to the PEI? What will the main reasons for inefficiency be in 2035 ?

2 Why is environmental performance poor?

Again in the Asian Development Outlook, the PRC was 36th and India was 26th out of 38 economies in terms of environmental performance assessed as carbon emission intensity (CEI) of the primary energy mix (CIX). The PRC will rank 33rd in 2035, and India will rank 30th. Why are they so $\mathrm{CO}_{2}$ intense? Why will the situation in 2035 not improve significantly? What will improvements in energy efficiency and fuel substitution do for $\mathrm{CO}_{2}$ intensity in terms of supply, demand, and the structure of their economies?

3 What would the electrification of the transport sector contribute?

Several penetration profiles for electric cars and railways are possible. What will they save in oil and emissions? How much additional electricity would be needed?

4 How can the supply side help?

What levels of renewables, nuclear, and carbon capture and storage (CCS) will significantly reduce $\mathrm{CO}_{2}$ ? What investment would be required?

5 What is the role of the industry sector in saving energy?

What would the potential savings in the main energy-intensive industries in both economies be using best available technologies?

6 What is the potential contribution of the household sector?

What will the additional demand for natural gas be as it displaces traditional fuels and coal? What will the impact on $\mathrm{CO}_{2}$ emissions and urban air quality be? What is the potential impact of more efficient lighting and appliances?

The detailed model we constructed of the energy systems encompasses both the current situation and forecasts for future development and includes the following:

- an analysis of energy data for both countries;

- a benchmarking tool that relates current and future energy use to that in other countries;

- a bottom-up model of the energy sectors up to 2035 with detailed demand and supply data using long-range energy alternatives planning (LEAP) software.

We analyzed the three scenarios developed by the Asian Development Bank (ADB) for the 2013 Asian Development Outlook (ADB 2013): business as usual (BAU); Asian Century scenario-business as usual (ACS-BAU); and Asian Century scenario-alternative (ACS-ALT). 
In the BAU scenario, assumptions are considered for economic growth and for the development of the energy sector. Under ACS-BAU, projections are considered for economic growth under BAU for the energy sector. The Asian Century scenarios ". . . assume that Asian economies can maintain their momentum for another 40 years and adapt to the shifting global economic and technological environment by continually recreating their comparative advantages" (ADB 2011). ACS-ALT assumes the economic growth foreseen in ACS and an alternative development of the energy sector with a larger presence of nuclear and renewable technologies in the energy mix.

For BAU and ACS-BAU we used the exogenous variables GDP, population, and urbanization reported by ADB (ADB 2013). Then, we built cases to analyze specific characteristics of the energy systems and the implications of different energy strategies in the transport, industry, and household sectors. We analyzed ACS-ALT as a case for the supply side under ACS.

A summary of the macroeconomic and energy data used for the scenarios is presented in Tables 11.1-11.3. The BAU scenario presents slightly less primary energy consumption (by 5\%) than the Asian Century scenarios; the fuel mix is very similar to ACS-BAU. ACS-BAU and ACS-ALT differ mainly in the fuel mix with ACS-ALT featuring approximately 3\% less coal in favor of nuclear (additional 2.5\%) and renewables (additional 0.5\%).

Table 11.1 Macroeconomic variables

\begin{tabular}{|c|c|c|c|c|c|c|c|}
\hline \multirow[t]{2}{*}{ Indicator } & \multirow[t]{2}{*}{ Scenario } & \multicolumn{2}{|l|}{2010} & \multicolumn{2}{|l|}{2035} & \multicolumn{2}{|c|}{$\begin{array}{l}\text { Average } \\
\text { annual } \\
\text { increase } \\
(\%)\end{array}$} \\
\hline & & $P R C$ & India & $P R C$ & India & $P R C$ & India \\
\hline \multirow{2}{*}{$\begin{array}{l}\text { Gross domestic } \\
\text { product (GDP) } \\
\text { (\$billion) }\end{array}$} & BAU & 3,246 & 963 & 1,587 & 3,877 & 6.6 & 5.8 \\
\hline & ACS-BAU & 3,246 & 963 & 16,214 & 6,926 & 6.7 & 8.2 \\
\hline \multirow{2}{*}{$\begin{array}{l}\text { Population } \\
\text { (millions) }\end{array}$} & BAU & 1,341 & 1,225 & 1,382 & 1,580 & 0.12 & 1.0 \\
\hline & ACS-BAU & 1,341 & 1,225 & 1,382 & 1,580 & 0.12 & 1.0 \\
\hline \multirow{2}{*}{$\begin{array}{l}\text { GDP per capita } \\
\text { (\$billion) }\end{array}$} & BAU & 2,420 & 787 & 11,488 & 2,454 & 6.4 & 4.6 \\
\hline & ACS-BAU & 2,420 & 787 & 11,736 & 4,384 & 6.5 & 7.1 \\
\hline \multirow{2}{*}{$\begin{array}{l}\text { Urbanization } \\
(\%)\end{array}$} & BAU & $49.2 \%$ & $30.9 \%$ & $71.2 \%$ & $42.6 \%$ & 1.5 & 1.3 \\
\hline & ACS-BAU & $49.2 \%$ & $30.9 \%$ & $71.2 \%$ & $42.6 \%$ & 1.5 & 1.3 \\
\hline \multirow[b]{2}{*}{$\begin{array}{l}\text { Primary energy } \\
\text { demand } \\
\text { (million } \\
\text { tons of oil } \\
\text { equivalent) }\end{array}$} & BAU & 2,417 & 693 & 4,034 & 1,441 & 2.1 & 3.0 \\
\hline & ACS-BAU & 2,417 & 693 & 4,283 & 2,088 & 2.3 & 4.5 \\
\hline \multirow{2}{*}{$\begin{array}{l}\text { Electricity } \\
\text { generation } \\
\text { (terawatt } \\
\text { hours) }\end{array}$} & BAU & 4,208 & 960 & 9,542 & 3,430 & 3.34 & 5.2 \\
\hline & ACS-BAU & 4,208 & & 9,593 & & 3.35 & \\
\hline
\end{tabular}

Source: ADB 2013; World Bank 2013. 
Table 11.2 Primary energy mix

\begin{tabular}{|c|c|c|c|c|c|c|}
\hline \multirow[t]{2}{*}{$\begin{array}{l}\text { Primary } \\
\text { energy mix }\end{array}$} & \multicolumn{2}{|c|}{$2010(\%)$} & \multicolumn{2}{|c|}{$\begin{array}{l}2035 \text { Business } \\
\text { as usual (\%) }\end{array}$} & \multicolumn{2}{|c|}{$\begin{array}{l}2035 \text { Asian Century- } \\
\text { business as usual (\%) }\end{array}$} \\
\hline & $P R C$ & India & $P R C$ & India & $P R C$ & India \\
\hline Coal & 66.0 & 41.7 & 59.4 & 43.7 & 56.6 & 50.3 \\
\hline Oil & 17.8 & 23.4 & 18.6 & 24.4 & 18.8 & 23.1 \\
\hline Natural gas & 3.7 & 7.6 & 7.5 & 11.7 & 7.5 & 11.6 \\
\hline Nuclear & 2.6 & 1.0 & 3.9 & 3.9 & 4.0 & 2.7 \\
\hline Hydro & 0.8 & 1.4 & 2.8 & 1.6 & 3.6 & 1.1 \\
\hline Others & 9.1 & 24.9 & 7.8 & 14.7 & 9.5 & 11.2 \\
\hline
\end{tabular}

Source: ADB 2013.

Table 11.3 Mix of fuel for generating electricity

\begin{tabular}{|c|c|c|c|c|c|c|}
\hline & \multicolumn{2}{|c|}{ Fuel 2010 (\%) } & \multicolumn{2}{|c|}{$\begin{array}{l}2035 \text { Business } \\
\text { as usual (\%) }\end{array}$} & \multicolumn{2}{|c|}{$\begin{array}{l}2035 \text { Asian Century- } \\
\text { business as usual (\%) }\end{array}$} \\
\hline & $P R C$ & India & $P R C$ & India & $P R C$ & India \\
\hline Coal & 77.8 & 68.0 & 58.0 & 64.0 & 57.4 & 71.1 \\
\hline Oil & 0.3 & 2.8 & 0.0 & 1.7 & 0.1 & 1.5 \\
\hline Natural gas & 1.6 & 12.3 & 11.1 & 15.6 & 9.2 & 15.6 \\
\hline Nuclear & 1.8 & 2.7 & 8.6 & 6.2 & 8.1 & 3.9 \\
\hline Hydro & 17.2 & 11.9 & 14.5 & 8.1 & 15.6 & 5.0 \\
\hline Others & 1.4 & 2.3 & 7.8 & 4.4 & 9.6 & 2.9 \\
\hline
\end{tabular}

Source: ADB 2013.

\section{People's Republic of China}

\section{Why is primary energy intensity high?}

In 2010, the PEI was 6.3 times higher than that in the United Kingdom (UK), 4.6 times higher than Germany's, and 3.8 times higher than that in the US. Although energy intensity will decrease as the country develops, understanding the causes of energy inefficiency now can help identify policies that will deliver this improvement faster and more cost effectively. Are the reasons for the gap on the demand side or on the supply side of the energy system? What fraction can be attributed to the structure of the economy?

We estimated the reduction in the PEI that would result from applying energy efficiency measures currently prevailing in developed countries on both demand and supply. Once supply and demand inefficiencies are accounted for, any remaining gap can be attributed to economic structure, i.e., to the energy demand from various sectors of the economy and to the respective value added to the products and services they provide.

To investigate the contribution of the demand side to the overall PEI, we created a fictional case in which the following measures are implemented to bring efficiency in line with that in developed economies. 
- For households:

- The efficiency of boilers for heating and hot water is increased from $60 \%$ to $80 \%$ for coal, from $40 \%$ to $75 \%$ for biomass, from $75 \%$ to $90 \%$ for gas, and from $70 \%$ to $85 \%$ for oil.

- Biomass and coal cookers with current average efficiencies of $22 \%$ and $30 \%$ respectively are replaced with gas and liquefied petroleum gas (LPG) units with efficiencies of $65 \%$.

- For lighting, the share of compact fluorescent lamps (CFLs) is increased from approximately $20 \%$ to $50 \%$.

- For appliances, the average energy consumption of refrigerators is reduced from 375 to 250 kilowatt hours/year, the annual energy consumption of washing machines is reduced from 350 to 190 kilowatt hours/ year, and the average efficiency of air conditioning is improved by $15 \%$.

- In the industry sector, products and materials are manufactured at the specific energy consumption levels in best available technology standards.

- In the service sector, electricity intensity is reduced from 204 to 104 megawatt hours/\$million, and heat/fuel intensity is decreased from 30.5 to 20.1 tons of oil equivalent (Toe)/\$million. These new intensities are typical of developed countries.

- In the transport sector, the remaining steam locomotives are withdrawn from service and the electric locomotive share of passengers and freight is increased from $53 \%$ to $75 \%$.

- In the agriculture sector, electricity intensity is reduced from 301 to 130 megawatt hours/\$million, and heat/fuel intensity is decreased from 67 to 60 Toe/\$million. These new intensities are typical of developed countries.

We also assumed the following efficiency improvements in generating electricity.

- Losses in energy transport and distribution are reduced from 5.6\% to 5.0\% for electricity; from $14.2 \%$ to $6.0 \%$ for heating; and from $3.5 \%$ to $2.0 \%$ for gas. Own energy use in the power sector is reduced from $11.8 \%$ to $6.0 \%$.

- The efficiency of coal-fired heating plants is increased from $80 \%$ to $85 \%$ for heat-only plants and from $40 \%$ to $45 \%$ for heat and from $35 \%$ to $40 \%$ for electricity for combined heat and power plants.

- The efficiency of the average coal-fired unit is increased from 34\% (subcritical coal plants) to $41 \%$ (supercritical coal plants).

\section{Analysis in 2010}

Applying these measures, the PEI in 2010 would be reduced by $31.1 \%, 24.6 \%$ from improvements in demand and 6.5\% from improvements in supply (Figure 11.1). The PEI would still, however, be high at 509 Toe/\$million compared to developed countries (e.g., 192 Toe/\$million in the US). This gap can be addressed only through structural changes in the economy that could contribute an additional $42.9 \%$ reduction. 


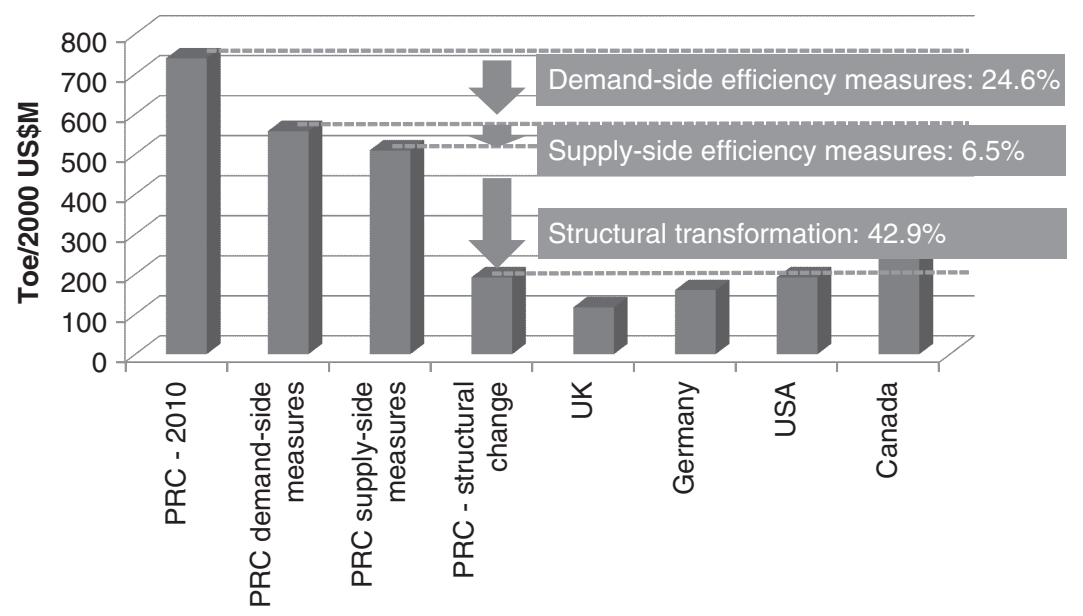

Figure 11.1 Causes of the high primary energy intensity in the People's Republic of China in 2010

Source: Authors' model.

Note: PRC $=$ People's Republic of China; Toe $=$ ton of oil equivalent; UK = United Kingdom; US $=$ United States.

Economies with larger service sectors and high value-added industries are in general less energy intensive. The service sector in the PRC currently contributes only $43 \%$ of GDP compared to around $70 \%$ in developed countries. Furthermore, energy-intensive industries (cement, steel, aluminum, and ammonia) are important in the economy: in 2010, the PRC produced $57.3 \%$ of the world's cement (European Cement Association 2010), 44.3\% of the steel (World Steel Association 2010), $43.7 \%$ of the aluminum (International Aluminum Institute 2010), and $31.4 \%$ of the ammonia (Index Mundi 2010).

The high PEI can therefore be reduced mainly through a larger role for the service sector and a reduction in energy-intensive industries. Implementing efficiency measures on the demand side can also help while efficiency measures on the supply side may have only a moderate impact.

\section{Outlook for 2035}

To estimate the PEI in 2035 we used the forecasts for the three ADB scenarios. Under the BAU scenario, the PEI will be 254 Toe/\$million, and it will be $264 \mathrm{Toe} /$ \$million under ACS-BAU. This is closer to the current (2010) one in developed countries and is even lower than that in Canada. Using a similar methodology to that for 2010, we conclude that in 2035 the PEI could be further reduced by $15.7 \%$ through demand (12.9\%) and supply (2.8\%) measures and by an additional $10.2 \%$ through structural changes (Figure 11.2) (BAU and 


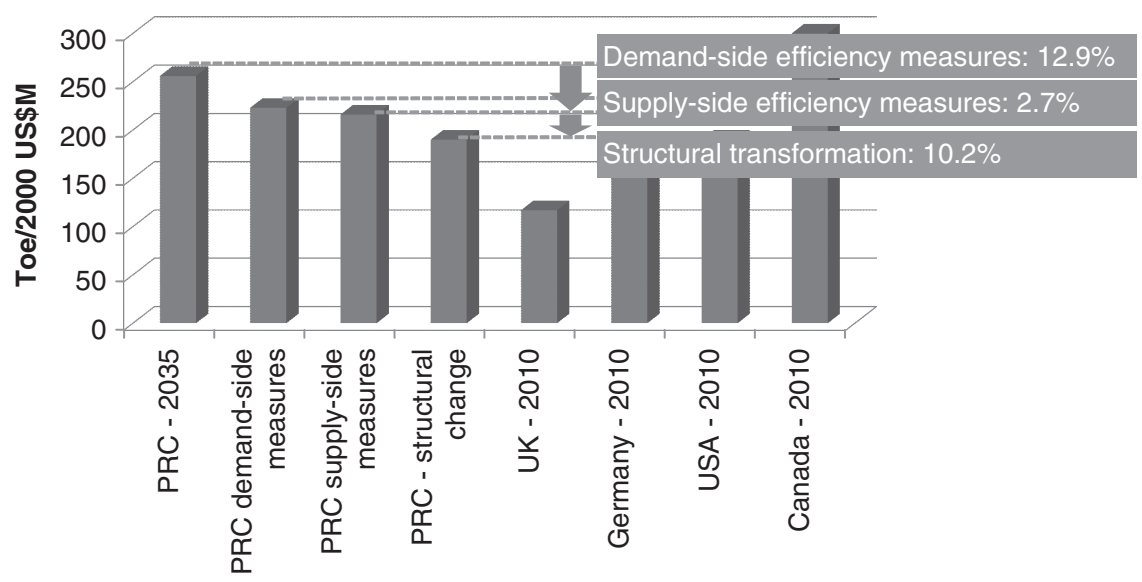

Figure 11.2 Causes of the primary energy intensity in the People's Republic of China in 2035 Source: Authors' model.

Note: PRC $=$ People's Republic of China; Toe $=$ ton of oil equivalent; UK = United Kingdom; USA $=$ United States.

ACS-BAU assume that the economic structure of the economy in 2035 will be similar to the one prevailing in developed countries in 2010).

\section{Why is environmental performance poor?}

The CEI is the amount of $\mathrm{CO}_{2}$ emissions from fossil fuels required to produce a unit of GDP and is often taken as the main indicator of the environmental performance of an economy. In 2010, the CEI in the PRC was 8.3 times higher than that in the UK, 6.3 times higher than Germany, 5.0 times more than the US, and 3.7 times higher than Canada (Figure 11.3). Understanding the causes of this high CEI can help develop more effective policies to abate greenhouse gas (GHG) emissions. What are the main reasons for the gap between the PRC and developed countries? Is it an inefficient use of energy or the type of fuels entering the primary energy mix? What is the role of the economic structure in this poor performance?

The CEI can be expressed as the product of PEI and CIX:

$\mathrm{CEI}\left(\mathrm{TCO}_{2} /\right.$ million $)=\mathrm{PEI}($ Toe $/$ million $) \times \mathrm{CIX}\left(\mathrm{TCO}_{2} / \mathrm{Toe}\right)$,

where $\mathrm{T}=$ ton.

PEI accounts for the energy efficiency of the economy while CIX takes into account the fuel mix used to generate the energy input. Energy efficiency in terms of PEI was analyzed in the previous section using the bottom-up energy 


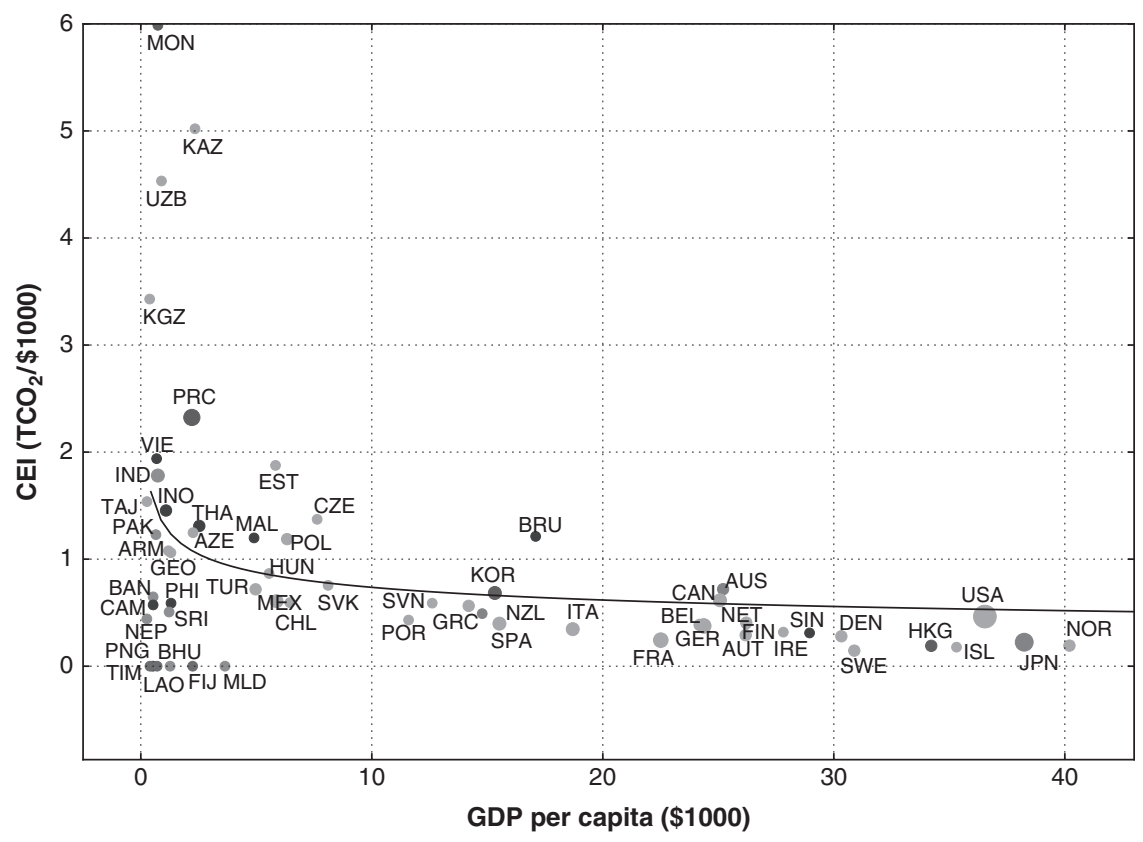

Figure 11.3 Intensity of carbon dioxide emissions in 2010 for selected economies

Source: Authors' calculations using World Bank (2013) data.

Note: $\mathrm{ARM}=$ Armenia; $\mathrm{AUS}=$ Australia $; \mathrm{AUT}=$ Austria AZE = Azerbaijan BAN = Bangladesh BEL = Belgium; $\mathrm{BRU}=$ Brunei Darussalam $\mathrm{CAM}=$ Cambodia $; \mathrm{CAN}=$ Canada $; \mathrm{CEI}=$ carbon dioxide emission intensity; $\mathrm{CHL}=$ Chile; $\mathrm{CZE}=$ Czech Republic $; \mathrm{DEN}=$ Denmark; EST $=$ Estonia; FIN = Finland; FRA $=$ France; $\mathrm{GDP}=$ gross domestic product GEO = Georgia; GER $=$ Germany; GRC $=$ Greece; HKG = Hong Kong, China; HUN = Hungary; ISL = Iceland; IND = India; INO = Indonesia; IRE = Ireland; ISR = Israel; ITA = Italy; JPN = Japan; KAZ = Kazakhstan; KOR = Republic of Korea;

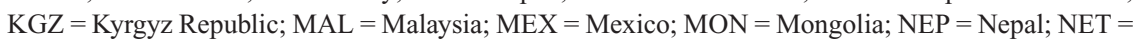
Netherlands; NZL $=$ New Zealand; NOR $=$ Norway; PAK $=$ Pakistan; PHI $=$ Philippines; $\mathrm{POL}=$ Poland; POR = Portugal; PRC = People's Rep. of China; SIN = Singapore; SVK = Slovak Republic; $\mathrm{SVN}=$ Slovenia; $\mathrm{SPA}=$ Spain; $\mathrm{SRI}=$ Sri Lanka; $\mathrm{SWE}=$ Sweden; $\mathrm{SWI}=$ Switzerland $; \mathrm{TAJ}=$ Tajikistan; $\mathrm{TCO}_{2}=$ tons of carbon dioxide; THA = Thailand; TUR = Turkey; UKG = United Kingdom; USA = United States; UZB = Uzbekistan; VIE = Viet Nam.

model. The impact of efficiency measures and structural changes on CEI is now calculated by taking into account the measures proposed to decrease PEI.

CIX is a function of the energy mix; it changes as an economy develops. Thus, initially the CIX may increase with development as convenience fuels such as biomass are replaced with fossil fuels (e.g., coal), then it may decrease as cleaner fuels (such as gas) or renewables replace more carbon-intensive ones. We analyze the influence on environmental performance of fuel substitution in the PRC by reducing the CIX to the levels currently prevailing in developed countries. Currently, the CIX is 3.3 tons of $\mathrm{CO}_{2} /$ ton of oil equivalent $\left(\mathrm{TCO}_{2} / \mathrm{Toe}\right)$ for 


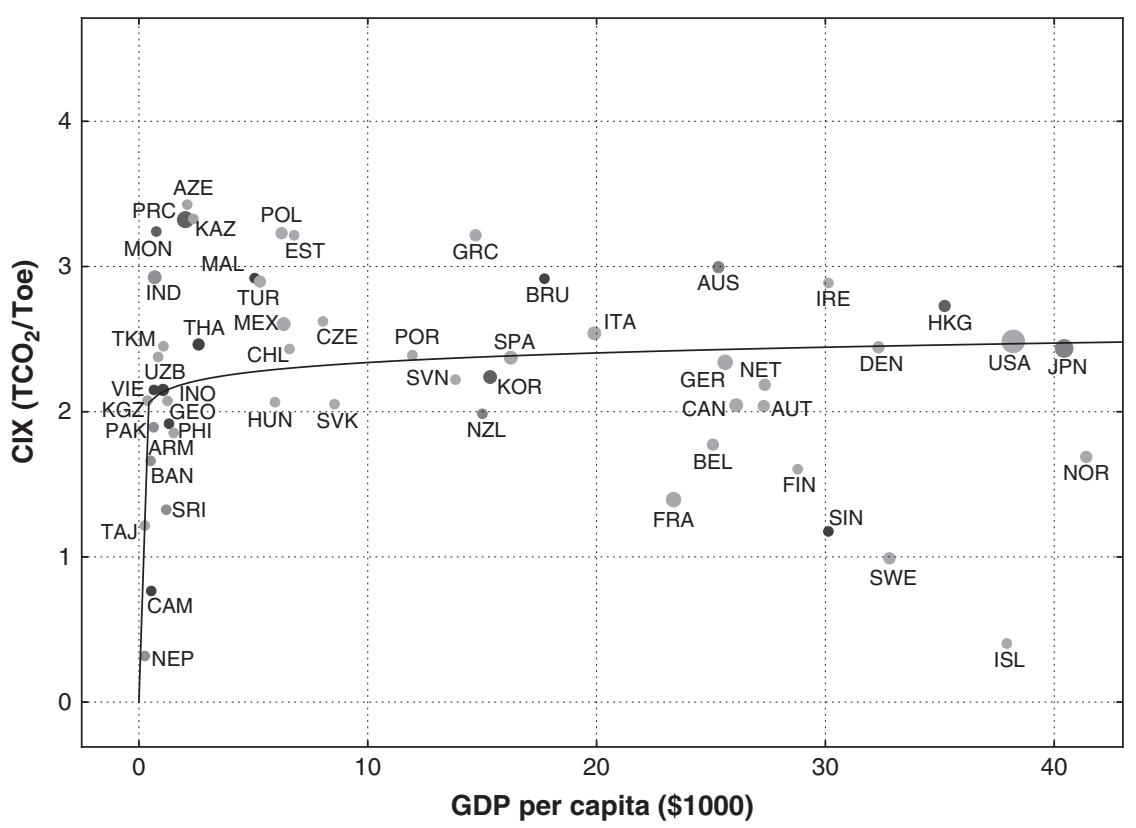

Figure 11.4 Intensity of carbon dioxide emissions of the primary energy mix in 2010 in selected economies

Source: Authors' calculations using World Bank (2013) data.

Note: $\mathrm{ARM}=$ Armenia; $\mathrm{AUS}=$ Australia; $\mathrm{AUT}=$ Austria $; \mathrm{AZE}=$ Azerbaijan BAN = Bangladesh BEL = Belgium; $\mathrm{BRU}=$ Brunei Darussalam; $\mathrm{CAN}=$ Canada $; \mathrm{CHL}=\mathrm{Chile} ; \mathrm{CIX}=$ intensity of carbon dioxide emissions in the primary energy mix $; \mathrm{CZE}=$ Czech Republic; $\mathrm{DEN}=$ Denmark; $\mathrm{EST}=$ Estonia; $\mathrm{FIN}=$ Finland; FRA $=$ France; GDP $=$ gross domestic product; GEO $=$ Georgia; GER $=$ Germany; GRC $=$ Greece; HKG = Hong Kong, China; HUN = Hungary; ISL = Iceland; IND = India; INO = Indonesia; IRE = Ireland; ISR = Israel; ITA = Italy; JPN = Japan; KAZ = Kazakhstan; KOR = Republic of Korea; KGZ = Kyrgyz Republic; MAL = Malaysia; MEX = Mexico; $\mathrm{MON}=$ Mongolia; NEP = Nepal; NET = Netherlands; NZL $=$ New Zealand; NOR $=$ Norway; PAK = Pakistan; PHI $=$ Philippines; POL $=$ Poland; POR $=$ Portugal; $\mathrm{PRC}=$ People's Republic of China; $\mathrm{SIN}=$ Singapore; $\mathrm{SVK}=$ Slovak Republic; $\mathrm{SVN}=$ Slovenia; $\mathrm{SPA}=$ Spain; $\mathrm{SRI}=$ Sri Lanka; $\mathrm{SWE}=$ Sweden; $\mathrm{TCO}_{2}=$ tons of carbon dioxide; Toe $=$ tons of oil equivalent; TAJ $=$ Tajikistan; THA $=$ Thailand; TKM $=$ Turkmenistan; TUR = Turkey; UKG = United Kingdom; USA = United States; UZB = Uzbekistan; VIE = Viet Nam.

the PRC, but is $2.25 \mathrm{TCO}_{2} /$ Toe for Germany, $2.04 \mathrm{TCO}_{2} /$ Toe for Canada, $2.35 \mathrm{TCO}_{2} /$ Toe for the UK and $2.40 \mathrm{TCO}_{2} /$ Toe for the US (Figure 11.4). We decreased the CIX for the PRC to $2.4 \mathrm{TCO}_{2} /$ Toe.

\section{Analysis in 2010}

Reducing the CIX to $2.4 \mathrm{TCO}_{2}$ /Toe would reduce the CEI in 2010 by $22.3 \%$. Coal accounted for $66.3 \%$ of primary energy consumption in 2010 (Figure 11.5); this 


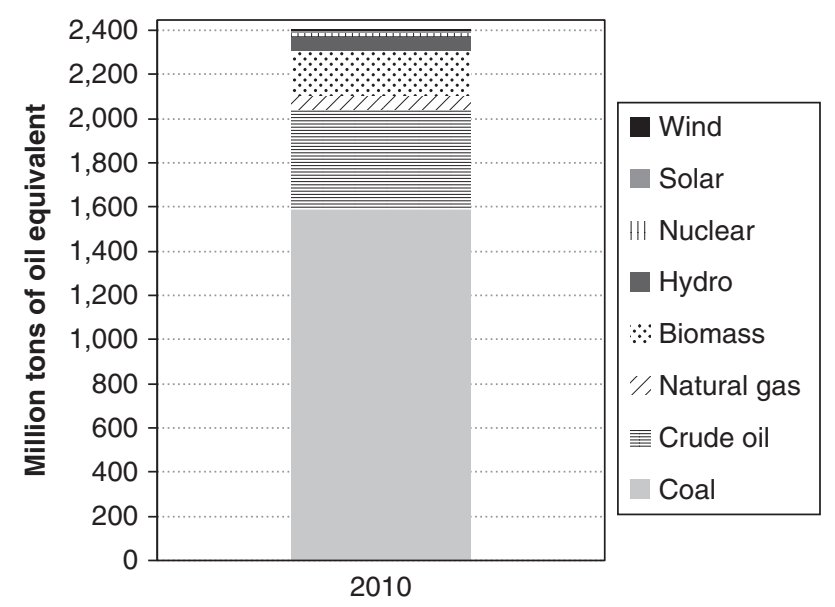

Figure 11.5 Primary energy consumption by fuel in 2010 in the People's Republic of China

Source: Authors' model.

large share results in a high CIX since coal has a greater emission factor than other fuels. Therefore, fuel substitution should play an important role in reducing the CEI.

The energy efficiency measures proposed in the previous section achieve a reduction of $25.1 \%$ in the CEI (19.1\% from demand improvements and $6 \%$ from supply); structural changes in the economy can further reduce the CEI by $32.7 \%$ by decreasing the PEI (Figure 11.6). It is worth noting that the role of structural changes in the economy is not as important for reducing emissions as it is for reducing PEI.

The combined contribution of fuel substitution and efficiency measures can reduce the CEI by $47.4 \%$. Policymakers may wish to seek measures that achieve a greater reduction in PEI and CEI simultaneously.

\section{Outlook for 2035}

The CEI in 2035 will be $728 \mathrm{TCO}_{2} /$ \$million in the BAU scenario and $743 \mathrm{TCO}_{2} /$ \$ million under ACS-BAU. This will still be 2.6 times that in the UK in 2010, 2.0 that in Germany, 1.6 that in the US, and 1.2 times that in Canada. The CIX in 2035 will be $2.87 \mathrm{TCO}_{2} /$ Toe in the BAU scenario and $2.81 \mathrm{TCO}_{2} /$ Toe under ACS-BAU compared with the 2010 value of $3.1 \mathrm{TCO}_{2} / \mathrm{Toe}$, a rather modest reduction. This is confirmed by the primary energy mix in the BAU scenario (Figure 11.7) where the contribution of coal will be 51.3\% in 2035 (66.3\% in 2010).

We estimated the influence of fuel substitution on the CEI in 2035 by decreasing the CIX to $2.0 \mathrm{TCO}_{2} /$ Toe (which we assume will be a typical value for CIX in developed countries in 2035) and used the bottom-up energy model to estimate 


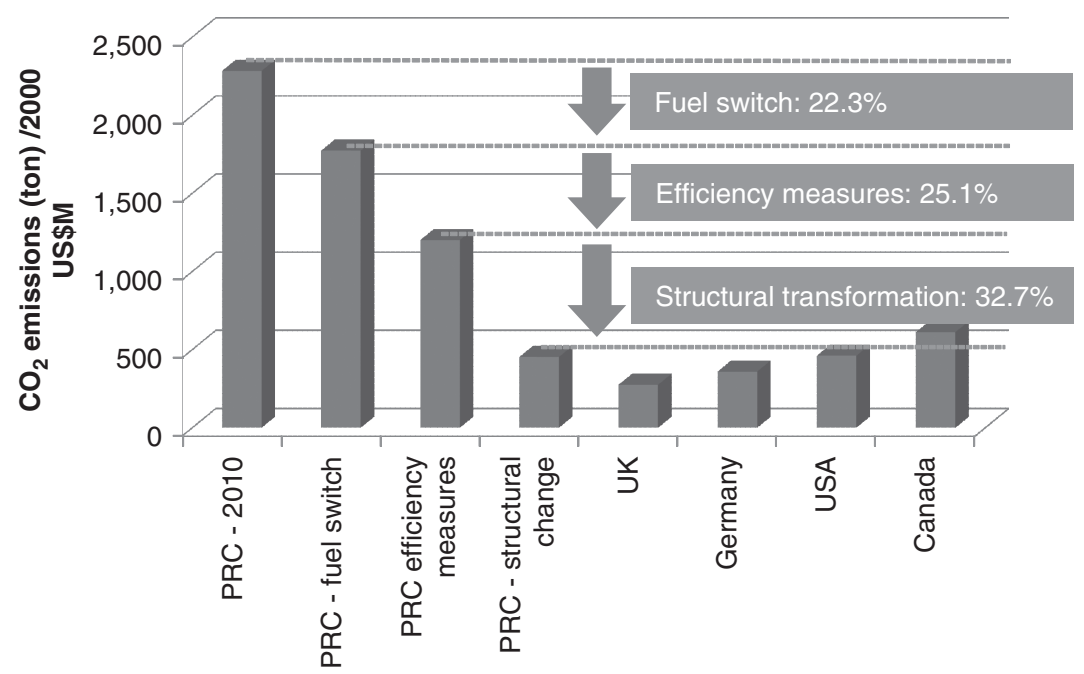

Figure 11.6 Measures to reduce carbon dioxide emission intensity in the People's Republic of China in 2010

Source: Authors' model.

Note: PRC $=$ People's Republic of China; $\mathrm{CO}_{2}=$ carbon dioxide; UK = United Kingdom; USA $=$ United States.

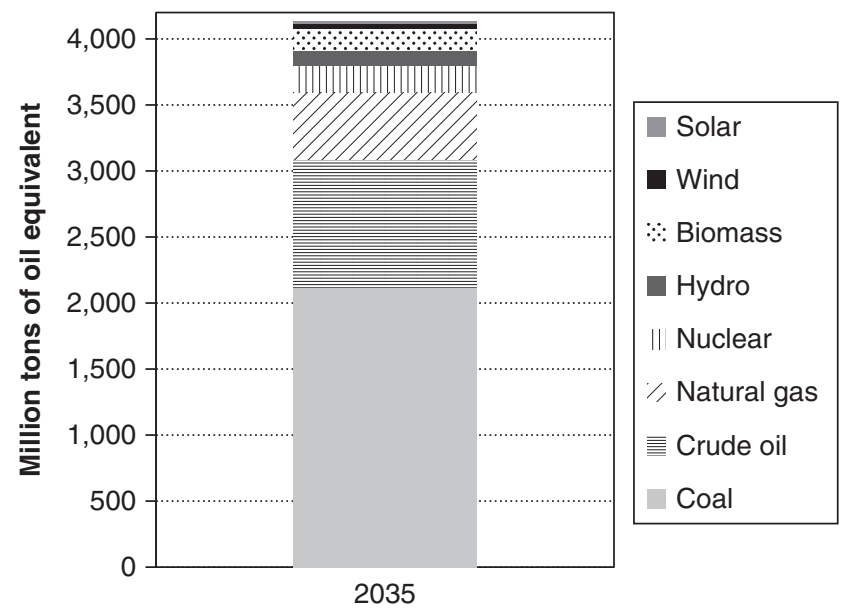

Figure 11.7 Primary energy consumption by fuel in the People's Republic of China in 2035

Source: Authors' model. 


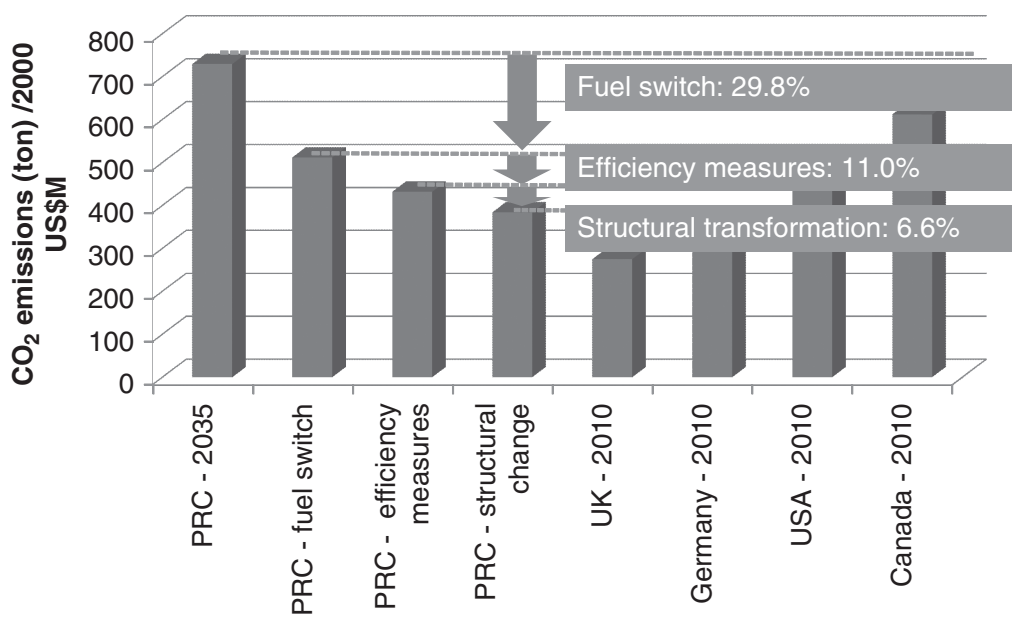

Figure 11.8 Means to reduce the intensity of carbon dioxide emissions in the People's Republic of China in 2035

Source: Authors' model.

Note: $\mathrm{PRC}=$ People's Republic of China; $\mathrm{CO}_{2}=$ carbon dioxide; UK = United Kingdom; USA $=$ United States.

the influence of energy efficiency measures and structural changes. The CEI could be further reduced in 2035 by $29.8 \%$ through fuel substitution, by $11.0 \%$ through efficiency measures, and by $6.6 \%$ from structural changes (Figure 11.8). Under BAU and ACS-BAU, the PEI will be closer to that in developed countries, so the role of structural changes and efficiency measures will be less pronounced. The primary energy mix will still be largely based on coal, however, resulting in high values for CIX and CEI.

\section{What would the electrification of the transport sector contribute?}

In 2010, the transport sector in the PRC accounted for $11.6 \%$ of total energy consumption (as estimated using our bottom-up model); however, it accounted for $48.3 \%$ of total oil consumption. In 2035, the total energy consumption in the transport sector will increase by a factor of 2.6 from 194.9 million tons of oil equivalent (MToe) to 509.0 MToe in the BAU scenario or to 518 MToe under ACS-BAU. Given the low oil reserves-to-production ratio of 9.9 years (BP 2012), reducing oil consumption in the transport sector is a desirable goal. Specifically, in the medium and long term, the electrification of the transport sector (electric cars and railways) could mitigate the demand for oil. What savings in oil and emissions would that bring? How much additional electricity would be required? 
To investigate the implications of electrifying the transport sector, we created and compared the following three scenarios.

- BAU: This is the BAU scenario from ADB to which we have added the assumptions that the penetration of electric motorcycles and electric cars will be $5 \%$ (in passengers $\times$ kilometers) by 2035 and that electric railways will have an $80 \%$ share in passengers $\times$ kilometers and tons $\times$ kilometers in rail transport.

- BAU medium electrification: The penetration of electric motorcycles and electric cars will be $25 \%$ (in passengers $\times$ kilometers) by 2035 , and electric railways will have a share of $90 \%$ in passengers $\times$ kilometers and tons $\times$ kilometers in rail transport. Additionally, $5 \%$ of road freight will be carried by light electric trucks.

- BAU accelerated electrification: The penetration of electric motorcycles and electric cars will be $50 \%$ (in passengers $\times$ kilometers) by 2035 and $100 \%$ of railway transport will be electric. Additionally, $15 \%$ of road freight will be carried by light electric trucks.

\section{Outlook for 2035}

While the electrification of the transport sector does of course reduce oil consumption, its impact is, however, moderate at reasonable penetration levels (Figure 11.9). Thus, compared to the to the BAU scenario, oil consumption in the transport sector would be reduced by $8.5 \%$ in the BAU medium scenario and by $20.5 \%$ in the BAU accelerated scenario; however, the impact on overall crude oil

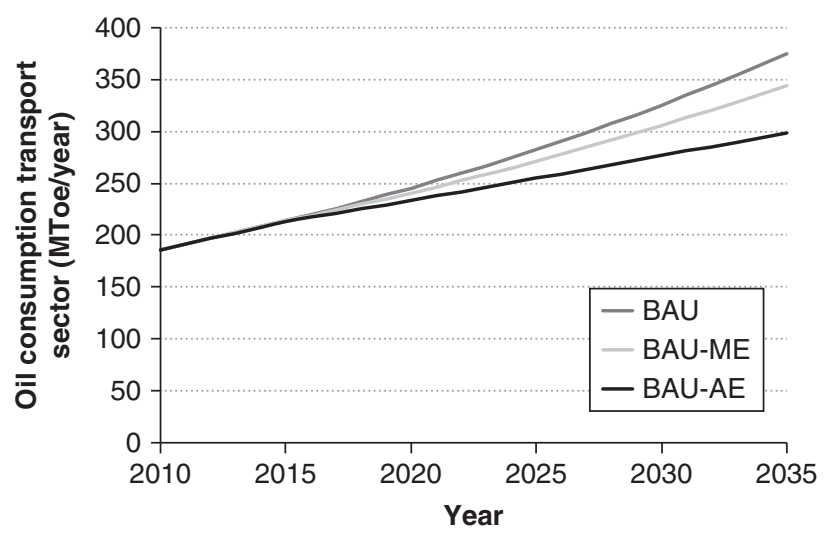

Figure 11.9 Oil consumption in the transport sector in the People's Republic of China under three scenarios, 2010-2035

Source: Authors' model.

Note: $\mathrm{BAU}=$ business as usual; $\mathrm{BAU}-\mathrm{ME}=$ medium electrification; $\mathrm{BUA}-\mathrm{AE}=$ accelerated electrification; $\mathrm{MToe}=$ million tons of oil equivalent. 


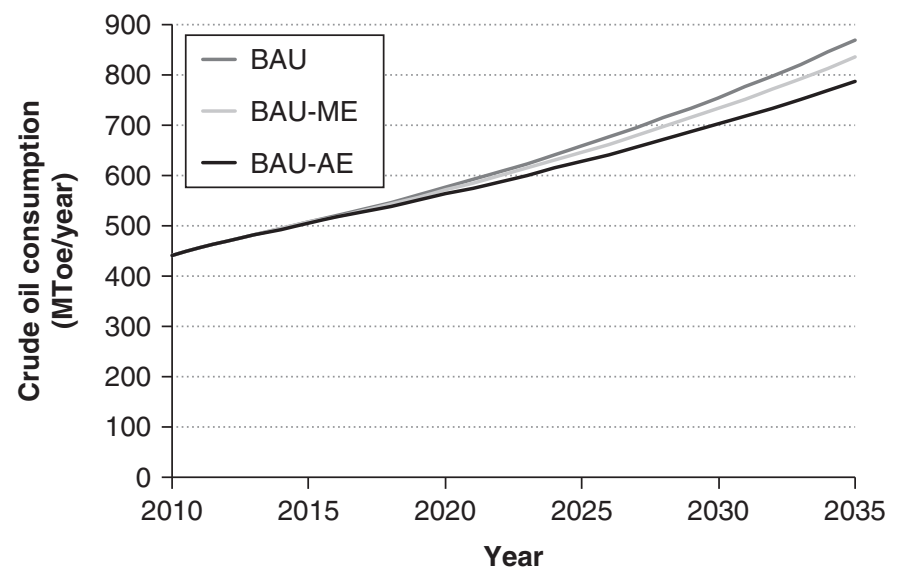

Figure 11.10 Crude oil consumption in the People's Republic of China under three scenarios, 2010-2035

Source: Authors' model.

Note: $\mathrm{BAU}=$ business as usual; $\mathrm{BAU}-\mathrm{ME}=$ medium electrification; $\mathrm{BUA}-\mathrm{AE}=$ accelerated electrification; $\mathrm{MToe}=$ million tons of oil equivalent.

demand would be low (Figure 11.10). The cumulative oil savings between 2010 and 2035 are 267 MToe in the BAU medium scenario and 662 MToe in the BAU accelerated scenario. This is equivalent to $70.0 \%$ or $173 \%$ of the annual primary oil consumption in the PRC in 2010. For the electrification of the transport sector to result in significant annual oil savings, additional measures would be required such as shifting freight transport from road to rail. The reason is that energy consumption in the sector is dominated by road freight, inland navigation, and air transport which combined account for $72 \%$ of total final energy consumption in 2010 and 2035 (BAU scenario) (Figure 11.11); the impact of electrification on these modes is either slight (road freight) or nonexistent (navigation, air).

The additional electricity required to electrify transport by 2035 will be 152 terawatt hours/year in the BAU medium scenario and 376 terawatt hours/ year in the BAU accelerated scenario. These are small fractions of the total generation in the BAU scenario of 9,500 terawatt hours/year (Figure 11.12): the electrification of the transport sector will require $1.6 \%$ more electricity in the BAU medium scenario and $4.0 \%$ more in the BAU accelerated scenario.

The impact of electrifying the transport sector on $\mathrm{CO}_{2}$ emissions is negative but only slightly so. By 2035, emissions in the medium and accelerated scenarios will be respectively 23 million tons and 57 million tons higher than in the BAU scenario (Figure 11.13). This is because power generation relies heavily on coal. Its share was $77 \%$ in 2010 and will be $58 \%$ in 2035 . Although obsolete coal plants may be retired or retrofitted, a considerable proportion of subcritical 


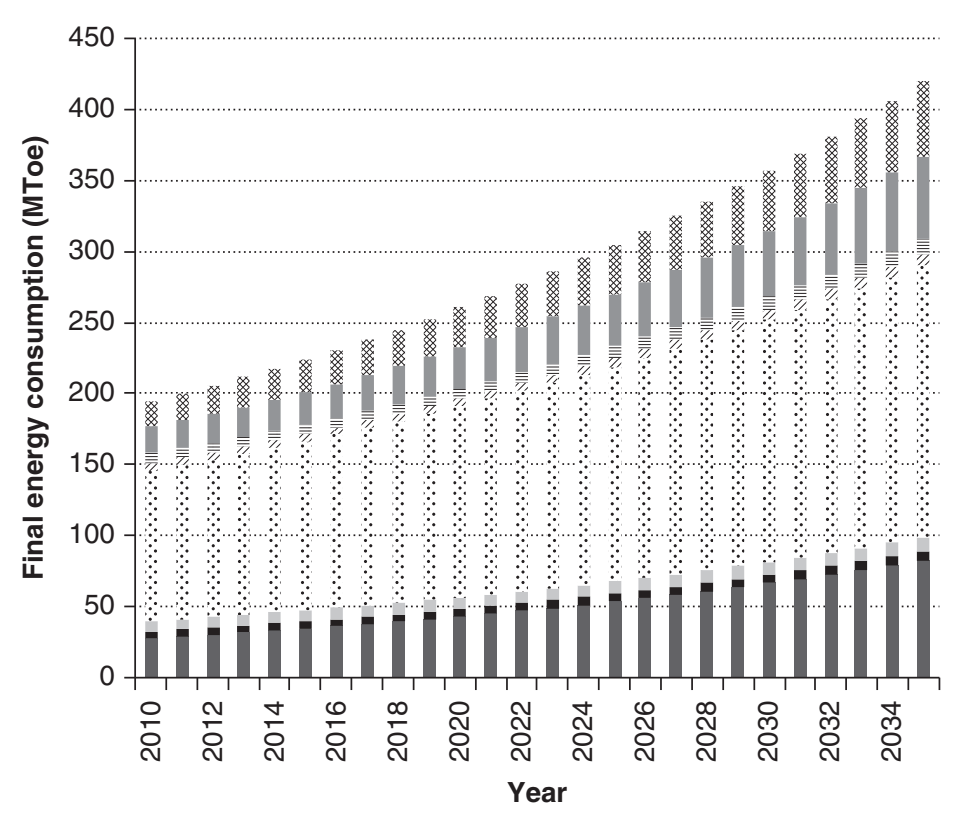

\begin{tabular}{|ll|}
\hline Air transport & $\ddots$ Freight road transport \\
Inland navigation & Motorcycle \\
$\equiv$ Railway freight transport & Coach \\
̌․, Railway passenger transport & $\square$ Private car \\
\hline
\end{tabular}

Figure 11.11 Energy consumption by mode of transport in the People's Republic of China under the business-as-usual scenario, 2010-2035

Source: Authors' model.

Note: $\mathrm{BAU}=$ business as usual; $\mathrm{BAU}-\mathrm{ME}=$ medium electrification; $\mathrm{BUA}-\mathrm{AE}=$ accelerated electrification; $\mathrm{MToe}=$ million tons of oil equivalent.

coal plants will still be operational by 2035 . Therefore, because the emission factor for power generation is high now and will remain so in the future, substituting gasoline or diesel with electricity will not eliminate $\mathrm{CO}_{2}$ emissions. Unless the emission intensity of the power sector is reduced considerably, the electrification of the transport sector will not significantly decrease overall $\mathrm{CO}_{2}$ emissions; in fact, it would increase them slightly overall.

\section{How can the supply side help?}

In 2010, the electricity mix in the PRC was based heavily on coal at $77 \%$ of total generation. In 2035 , the contribution of coal to the electricity mix will be $58 \%$ 


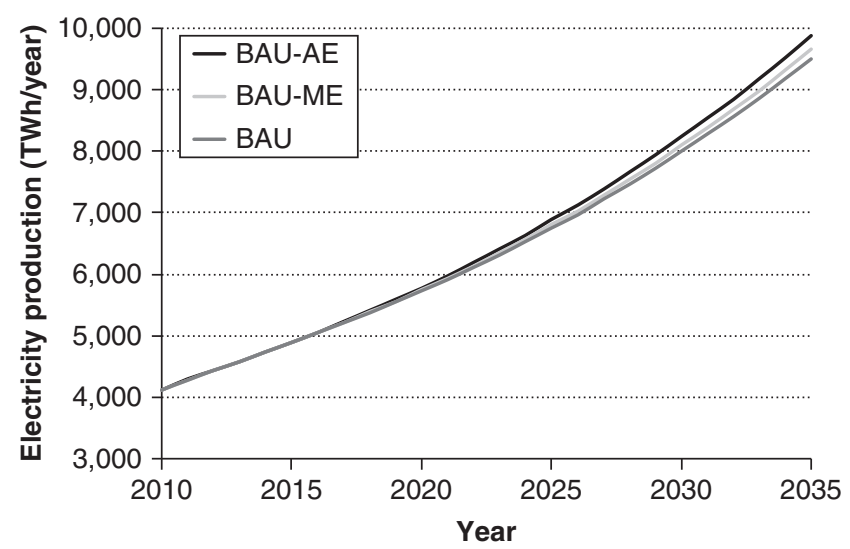

Figure 11.12 Total power required in the People's Republic of China under three scenarios, 2010-2035

Source: Authors' model.

Note: $\mathrm{BAU}=$ business as usual; $\mathrm{BAU}-\mathrm{ME}=$ medium electrification; $\mathrm{BUA}-\mathrm{AE}=$ accelerated electrification; $\mathrm{TWh}=$ terawatt hours.

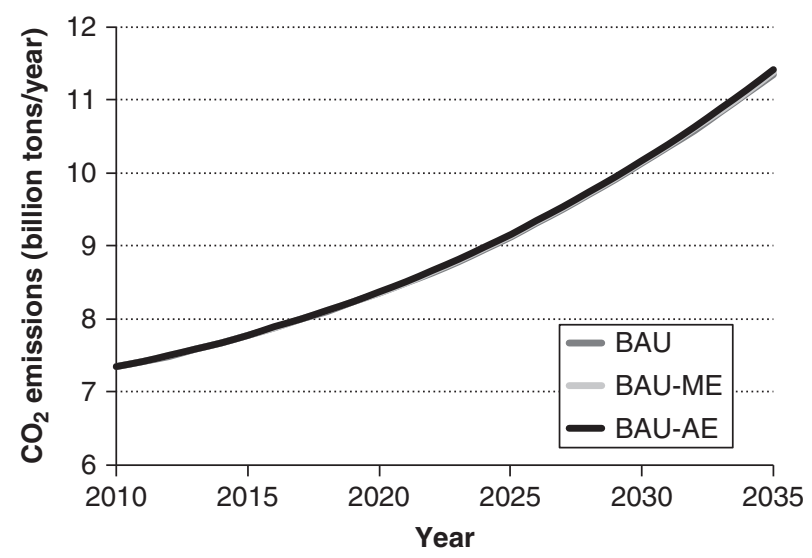

Figure 11.13 Total carbon dioxide emissions in the People's Republic of China under three scenarios, 2010-2035

Source: Authors' model.

Note: $\mathrm{BAU}=$ business as usual; $\mathrm{BAU}-\mathrm{ME}=$ medium electrification; $\mathrm{BUA}-\mathrm{AE}=$ accelerated electrification; $\mathrm{CO}_{2}=$ carbon dioxide.

which is still high. As a consequence, the $\mathrm{CO}_{2}$ intensity of the power generating sector is one of the highest in the world at 0.74 kilograms of $\mathrm{CO}_{2} /$ kilowatt hour in 2010 (Figure 11.14); there will be a modest reduction by 2035 to 0.53 kilograms in the BAU scenario. An accelerated transition to cleaner energy sources in the 


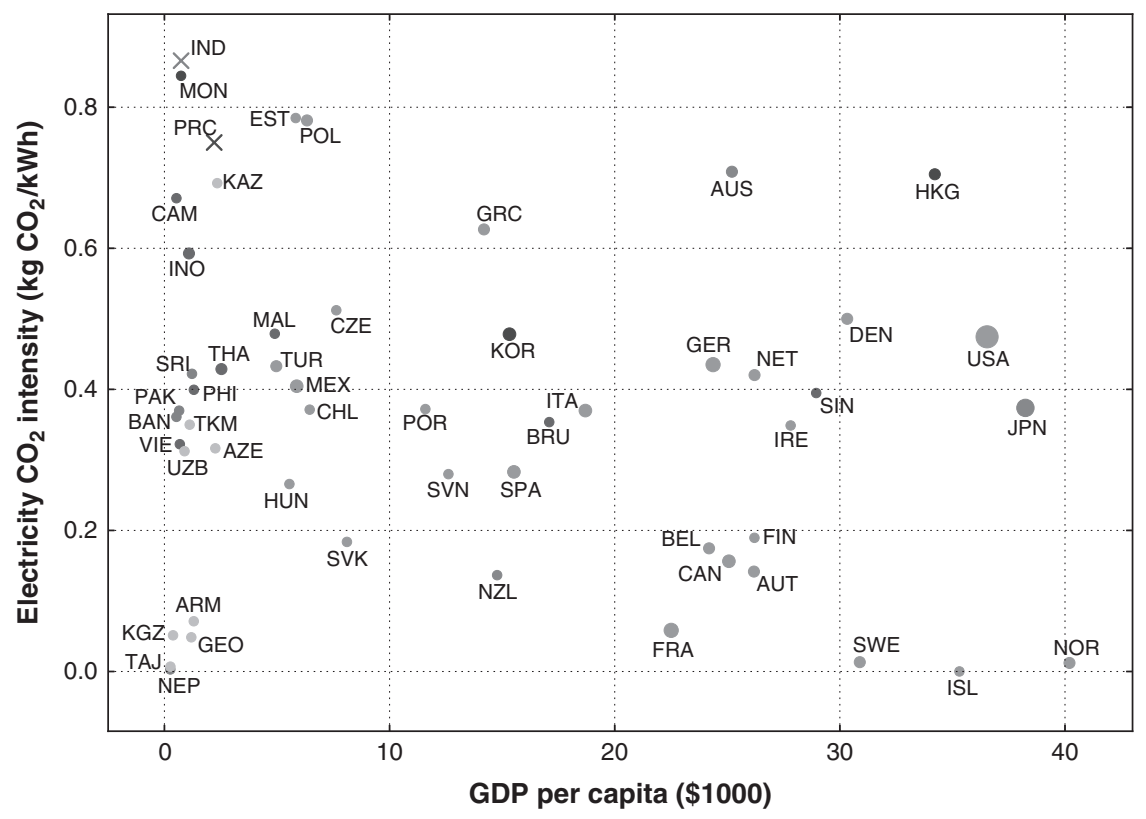

Figure 11.14 Carbon dioxide intensity of the power sector in 2010 in selected economies Source: Authors' calculations using World Bank (2013) data.

Note: $\mathrm{ARM}=$ Armenia; $\mathrm{AUS}=$ Australia; $\mathrm{AUT}=$ Austria AZE $=$ Azerbaijan BAN $=$ Bangladesh; $\mathrm{BEL}=$ Belgium $; \mathrm{BRU}=$ Brunei Darussalam $; \mathrm{CAM}=$ Cambodia; $\mathrm{CAN}=$ Canada $; \mathrm{CHL}=$ Chile; $\mathrm{CO}_{2}=$ carbon dioxide CZE $=$ Czech Republic $;$ DEN $=$ Denmark $;$ EST $=$ Estonia; FIN $=$ Finland; FRA $=$ France $;$ GDP $=$ gross domestic product $;$ GEO $=$ Georgia $;$ GER $=$ Germany $;$ GRC $=$ Greece; HKG = Hong Kong, China; HUN = Hungary; ISL = Iceland; IND = India; INO = Indonesia; IRE = Ireland; ISR = Israel; ITA = Italy; JPN = Japan; KAZ = Kazakhstan; KOR $=$ Republic of Korea; $\mathrm{kg}=$ kilogram; $\mathrm{KGZ}=$ Kyrgyz Republic; $\mathrm{kWh}=$ kilowatt hour; $\mathrm{MAL}=$ Malaysia; MEX = Mexico; $\mathrm{MON}=$ Mongolia NEP $=$ Nepal $;$ NET $=$ Netherlands $; \mathrm{NZL}=$ New Zealand $; \mathrm{NOR}=$ Norway $; \mathrm{PAK}=$ Pakistan; PHI $=$ Philippines; $\mathrm{POL}=$ Poland; POR $=$ Portugal; $\mathrm{PRC}=$ People's Republic of China; $\mathrm{SIN}=$ Singapore; $\mathrm{SVK}=$ Slovak Republic; $\mathrm{SVN}=$ Slovenia; $\mathrm{SPA}=$ Spain; $\mathrm{SRI}=$ Sri Lanka; $\mathrm{SWE}=$ Sweden; TAJ $=$ Tajikistan; THA $=$ Thailand; TKM $=$ Turkmenistan; TUR $=$ Turkey; UKG $=$ United Kingdom; USA $=$ United States; UZB $=$ Uzbekistan; VIE $=$ Viet Nam. Data for PRC and India were calculated using the authors' bottom-up models.

power generating sector is crucially needed to further reduce $\mathrm{CO}_{2}$ emissions. What should the penetration of renewables, nuclear, and coal (with CCS) be to significantly reduce the $\mathrm{CO}_{2}$ intensity of the power sector? What investment would be required?

To investigate the implications of a more accelerated transition to cleaner energy in the power sector, we analyzed three additional scenarios in which the total $\mathrm{CO}_{2}$ emissions in 2035 were at the same level as in 2010 despite increased electricity demand. To achieve this goal, the CEI of the power sector has to decrease from its 2010 value of 0.69 kilograms/kilowatt hour $(\mathrm{kg} / \mathrm{kWh})$ to 
$0.35 \mathrm{~kg} / \mathrm{kWh}$. (The latter is, coincidentally, the emissions factor of gas combined cycles, thus the goal would be hypothetically achieved by generating all power with gas combined cycles.) In our scenarios, this is achieved by replacing conventional coal generation with $\mathrm{CO}_{2}$-free technologies (renewables, coal with CCS, nuclear, and hydro). To prevent emissions from increasing between 2010 and 2035, the electricity mix must be $53 \%$ carbon free (hydro, renewables, coal with CCS, or nuclear). Since hydro is $15 \%$ in the ADB BAU scenario, $38 \%$ of the electricity must be generated with renewables, coal with CCS, or nuclear.

Together with the BAU case, the four scenarios are the following.

- BAU: This is the BAU scenario from ADB to 2035. The CEI of the power sector will decrease from 0.69 kilograms/kilowatt hour in 2010 to $0.53 \mathrm{~kg} /$ $\mathrm{kWh}$ by 2035, but because of increased generation, total emissions in 2035 will be 1.5 times those in 2010. The installed renewable power (excluding hydro) in the BAU scenario for 2035 will consist of 280 gigawatts (200 wind, 40 solar photovoltaics, and 40 of biomass), while installed nuclear power will be 104 gigawatts. No coal CCS power is assumed in this scenario.

- BAU renewables: This scenario replaces coal with 770 gigawatts of renewables (in addition to those in BAU): 430 wind and 340 solar photovoltaics (Figure 11.15). The fuel mix would therefore be $38 \%$ conventional coal, $9 \%$ gas combined cycle, $15 \%$ hydro, $9 \%$ nuclear, and $29 \%$ renewables (Figure 11.16 ).

- BAU-CCS: It should be noted that CCS technology is still in the pre-market phase, and there are uncertainties (technical and commercial challenges and

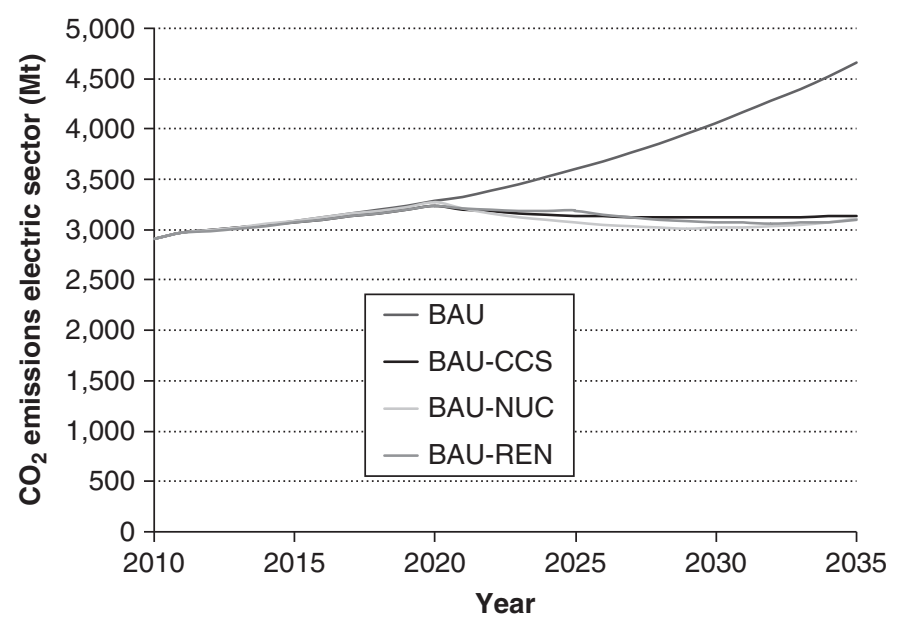

Figure 11.15 Carbon dioxide emissions in the power sector in the People's Republic of China under four alternative scenarios, 2010-2035

Source: Authors' model.

Note: $\mathrm{BAU}=$ business as usual; $\mathrm{CCS}=$ carbon capture and storage; $\mathrm{CO}_{2}=$ carbon dioxide; $\mathrm{NUC}=$ nuclear; $\mathrm{REN}=$ renewables. 
those related to $\mathrm{CO}_{2}$ storage) about its future development. For the goal to be achieved, 270 gigawatts of CCS-enabled coal generation would be needed, and the fuel mix would be $38 \%$ conventional coal, $20 \%$ coal with CCS, $9 \%$ gas combined cycle, 15\% hydro, $9 \%$ nuclear, and 9\% renewables.

- BAU nuclear: About 215 gigawatts of nuclear power would be needed (in addition to those in the BAU scenario) to maintain emissions at 2010 levels. The fuel mix would be $38 \%$ conventional coal, $9 \%$ gas combined cycle, $15 \%$ hydro, 29\% nuclear, and 9\% renewables.

ADB also developed Asian Century and Asian Century alternative BAU scenarios for the PRC. The Asian Century scenario has a fuel mix very similar to BAU: $58 \%$ conventional coal, $5 \%$ gas, $8 \%$ nuclear, $20 \%$ hydro, and $9 \%$ renewables. The alternative scenario, however, has a greater contribution of $\mathrm{CO}_{2}$-free technologies; its mix by 2035 is $51 \%$ conventional coal, $8 \%$ gas, $12 \%$ nuclear, $15 \%$ hydro, and $13 \%$ renewables. Our proposed scenarios result in a more accelerated transition to $\mathrm{CO}_{2}$-free technologies in the power sector than the Asian Century alternative does.

\section{Outlook for 2035}

With these supply-side measures, $\mathrm{CO}_{2}$ emissions from the power sector in 2035 would remain at 2010 levels (2.91 billion tons/year), but their contribution to

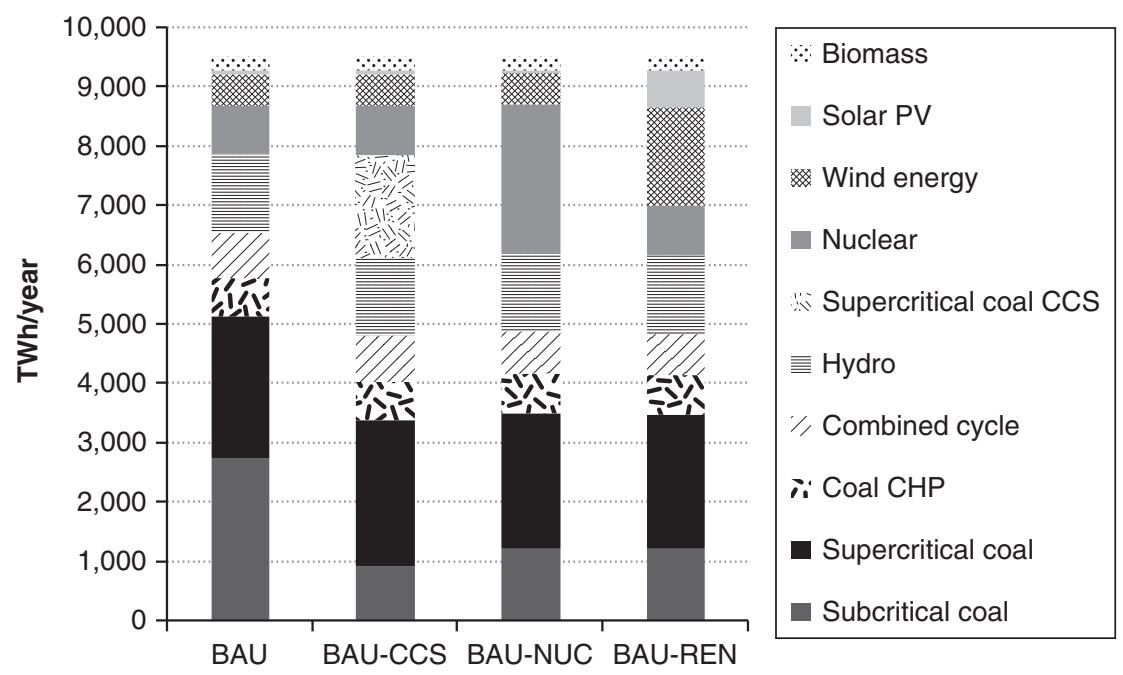

Figure 11.16 Energy mix in 2035 in the People's Republic of China under four alternative scenarios

Source: Authors' model.

Note: $\mathrm{BAU}=$ business as usual; $\mathrm{CCS}=$ carbon capture and storage; $\mathrm{CHP}=$ combined heat and power; $\mathrm{NUC}=$ nuclear; $\mathrm{PV}=$ photovoltaics; $\mathrm{REN}=$ renewables; $\mathrm{TWh}=$ terawatt hour. 
total $\mathrm{CO}_{2}$ emissions would decrease from $40 \%$ in 2010 to $30 \%$ by 2035 . The cumulative saved emissions vary slightly with each scenario since different technologies are introduced at different times, but they are all around 12 billion tons of $\mathrm{CO}_{2} /$ year.

This reduction in the CEI of the power sector will require a considerable financial effort. The amounts and percentages of cumulative GDP from 2010 to 2035 are the following:

- for BAU: $\$ 2,032$ billion- $0.58 \%$;

- for BAU renewables: $\$ 3,136$ billion $-0.91 \%$;

- for BAU-CCS: $\$ 2,937$ billion- $0.84 \%$;

- for BAU nuclear: $\$ 2,982$ billion $-0.86 \%$.

The additional cost of a unit of $\mathrm{CO}_{2}$ emissions saved can be estimated by dividing the additional investment required by the emissions saved (both with respect to BAU). This calculation has some caveats as the result depends on the lifetime of the investment and the interest rate for the capital costs. Depending on the scenario and interest rates, the additional cost varies between $\$ 9.8$ per ton of $\mathrm{CO}_{2}$ saved for BAU nuclear at a $0 \%$ interest rate and $\$ 71$ per ton for BAU renewables at a $10 \%$ interest rate (Figure 11.17). This additional specific capital cost is the lowest for the BAU nuclear scenario followed by BAU-CCS and BAU renewables. The additional cost of the nuclear option is slightly lower than that for CCS partly due to the different investment lifetimes (60 years for nuclear,

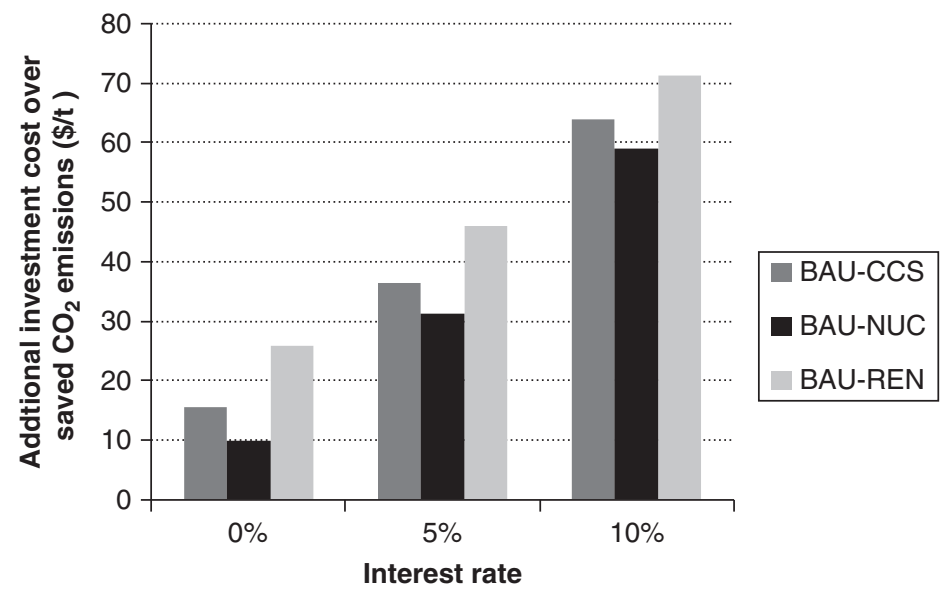

Figure 11.17 Additional cost per unit of carbon dioxide saved under three scenarios Source: Authors' model.

Note: $\mathrm{BAU}=$ business as usual; $\mathrm{CCS}=$ carbon capture and storage; $\mathrm{CO}_{2}=$ carbon dioxide; $\mathrm{NUC}=$ nuclear; $\mathrm{REN}=$ renewables. 
40 years for CCS). We must note that these additional costs comprise only investment (capital) and not operating costs (such as the cost of fuel).

\section{What is the role of the industry sector in saving energy?}

The industry sector is responsible for $46.9 \%$ of final energy consumption in the PRC (IEA 2012). Furthermore, compared with other economies, total energy consumption and the CEI of the industry sector are high as the international benchmarking presented in Figures 11.18 and 11.19 indicates, even for the country's level of development.

Just four industries accounted for $79.3 \%$ of the total energy consumed in the entire industry sector in 2010: iron and steel, nonferrous metals, chemicals and

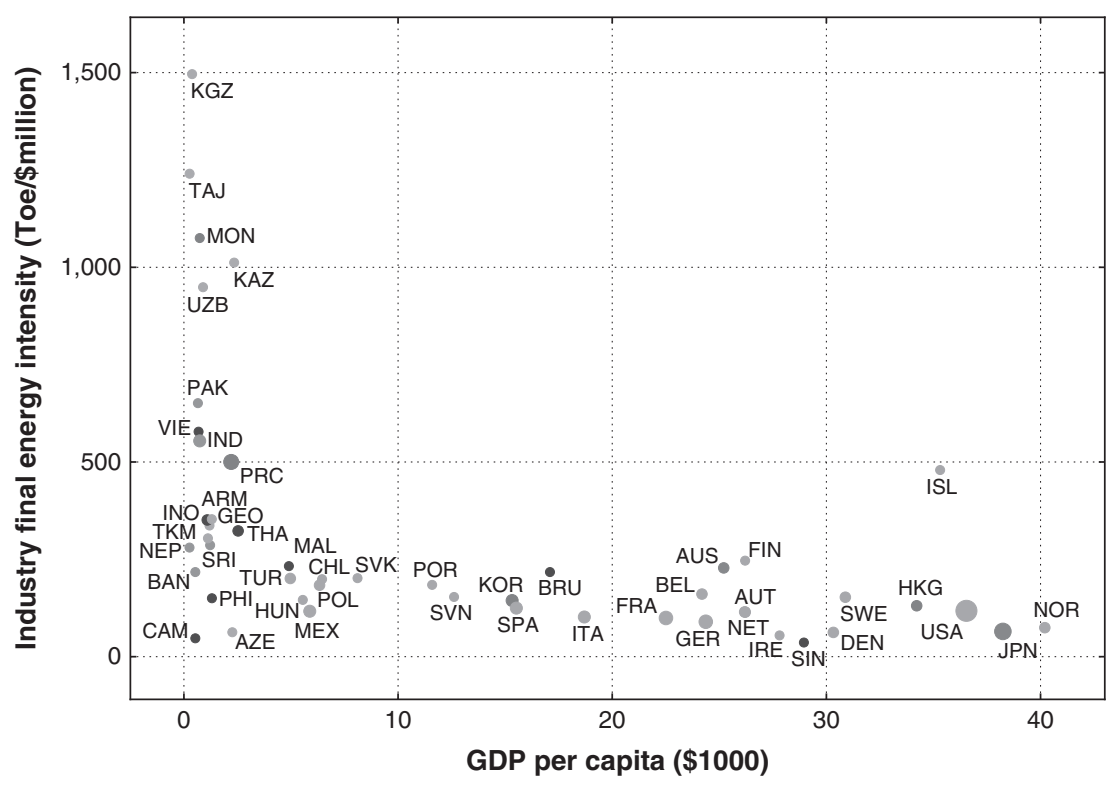

Figure 11.18 Total energy intensity of the industry sector in 2010 in selected economies Source: Authors' calculations using World Bank (2013) and IEA (2012) data.

Note: $\mathrm{ARM}=$ Armenia; AUS $=$ Australia; AUT $=$ Austria; AZE $=$ Azerbaijan; BAN = Bangladesh; $\mathrm{BEL}=$ Belgium; $\mathrm{BRU}=$ Brunei Darussalam; $\mathrm{CAM}=$ Cambodia; $\mathrm{CHL}=\mathrm{Chile} ; \mathrm{DEN}=$ Denmark; FIN = Finland; FRA = France; GDP = gross domestic product; GEO = Georgia; GER = Germany; HKG = Hong Kong, China; HUN = Hungary; ISL = Iceland; IND = India; INO = Indonesia; IRE = Ireland; ITA = Italy; JPN = Japan; KAZ = Kazakhstan; KOR = Republic of Korea; KGZ = Kyrgyz Republic; MAL $=$ Malaysia; MEX $=$ Mexico $;$ MON $=$ Mongolia; NEP $=$ Nepal; NET $=$ Netherlands; NOR $=$ Norway PAK = Pakistan; $\mathrm{PHI}=$ Philippines $; \mathrm{POL}=$ Poland POR $=$ Portugal $; \mathrm{PRC}=$ People's Republic of China; SIN = Singapore; SVK = Slovak Republic; SVN = Slovenia; SPA = Spain; SRI = Sri Lanka; SWE $=$ Sweden; TAJ $=$ Tajikistan; THA $=$ Thailand; TKM $=$ Turkmenistan; Toe $=$ tons of oil equivalent; $\mathrm{TUR}=$ Turkey; $\mathrm{UKG}=$ United Kingdom; USA = United States; UZB = Uzbekistan; VIE = Viet Nam. 


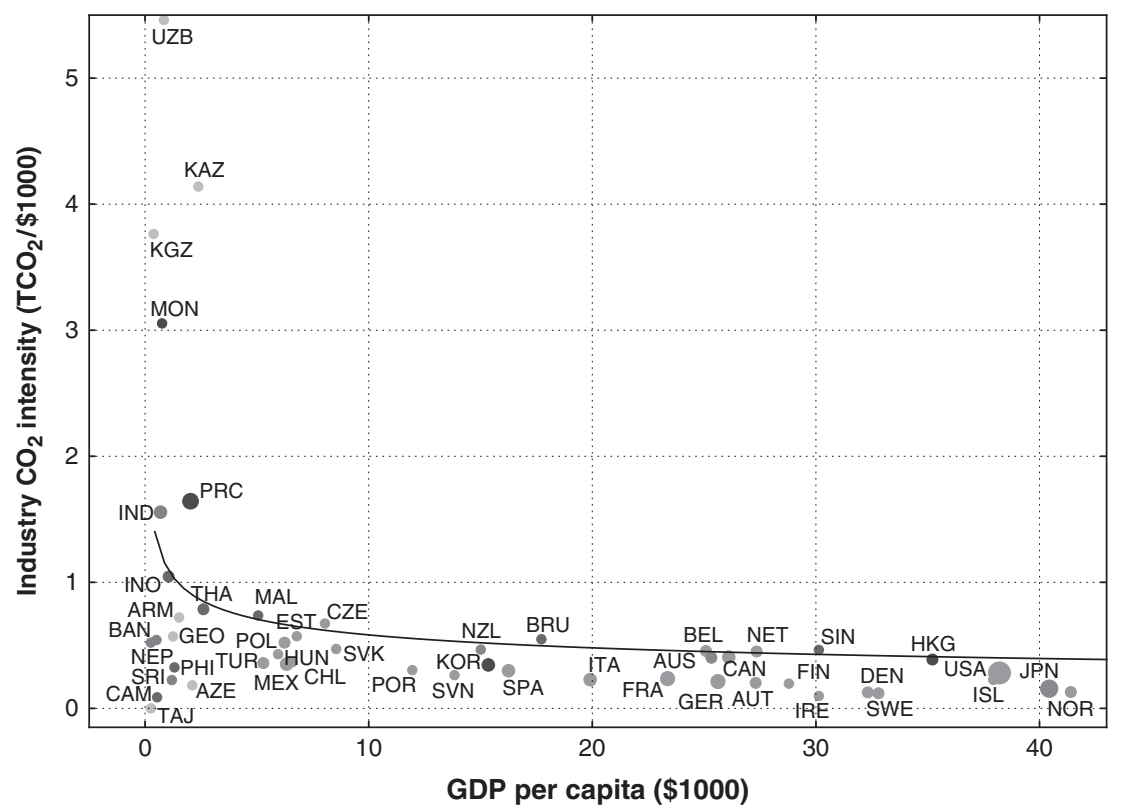

Figure 11.19 Carbon dioxide intensity of the industry sector in 2010 in selected economies Source: Authors' calculations using World Bank (2013) data.

Note: $\mathrm{ARM}=$ Armenia; $\mathrm{AUS}=$ Australia; $\mathrm{AUT}=$ Austria; $\mathrm{AZE}=$ Azerbaijan; $\mathrm{BAN}=$ Bangladesh BEL = Belgium; $\mathrm{BRU}=$ Brunei Darussalam; $\mathrm{CAM}=$ Cambodia; $\mathrm{CAN}=$ Canada $\mathrm{CHL}=$ Chile $; \mathrm{CO}_{2}=$ carbon dioxide CZE $=$ Czech Republic; $\mathrm{DEN}=$ Denmark; $\mathrm{EST}=$ Estonia; $\mathrm{FIN}=$ Finland; FRA = France; GDP = gross domestic product; $\mathrm{GEO}=$ Georgia; $\mathrm{GER}=$ Germany; HKG = Hong Kong, China; HUN = Hungary; ISL = Iceland; IND = India; INO = Indonesia; IRE = Ireland; ITA = Italy; JPN = Japan; $\mathrm{KAZ}=$ Kazakhstan KOR $=$ Republic of Korea; KGZ = Kyrgyz Republic; MAL = Malaysia; MEX = Mexico; $\mathrm{MON}=$ Mongolia; NEP $=$ Nepal; NET $=$ Netherlands; NZL = New Zealand; NOR = Norway; PAK $=$ Pakistan; PHI $=$ Philippines; POL $=$ Poland; POR $=$ Portugal; PRC $=$ People's Republic of China; SIN = Singapore; SVK = Slovak Republic; $S V N=$ Slovenia; $S P A=$ Spain; SRI = Sri Lanka; SWE $=$ Sweden; SWI $=$ Switzerland; TAJ $=$ Tajikistan; $\mathrm{TCO}_{2}=$ tons of carbon dioxide; THA = Thailand; TUR = Turkey; UKG = United Kingdom; USA = United States; UZB = Uzbekistan; VIE = Viet Nam.

petrochemicals, and nonmetallic minerals (mainly cement) (Authors' calculations). The analysis with our energy model shows that in 2035 these industries will continue to dominate in terms of energy and that their contribution is likely to decrease only slightly to $76.9 \%$ (Figure 11.20 ) in the macroeconomic parameters set out in the ADB BAU scenario.

How efficient and clean is the industry sector in the PRC compared with the best available technologies today? What is the scope for improvement? What would the savings in energy and emissions be if the best available technologies were deployed throughout the sector? 


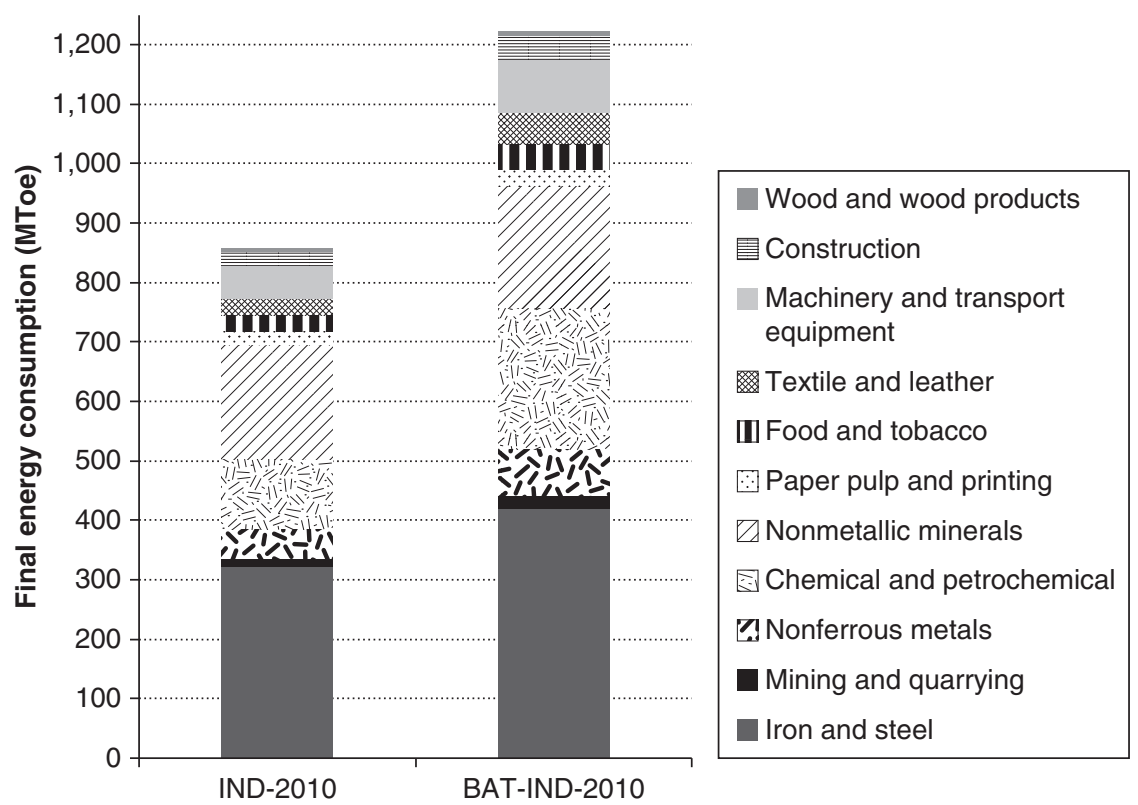

Figure 11.20 Total energy consumption by industry in the People's Republic of China in 2010 and 2035 (business-as-usual scenario)

Source: Authors' model.

To investigate potential savings in energy and emissions, we compared the consumption of the sector in 2010 with consumption using the best available technologies using the bottom-up model of the energy system and national statistics on the production of goods and the consumption of energy (Government of the People's Republic of China 2012 and 1991-2011). The total energy consumption in the industry sector would be reduced by $21 \%$ if best available technologies were deployed throughout. The reductions in the four main energy consumers would be $19.2 \%$ in iron and steel, $33.1 \%$ in nonferrous metals, $33.7 \%$ in chemicals and petrochemicals, and $20.2 \%$ in nonmetallic minerals (Figure 11.21). With these reductions, the total primary energy consumption would decrease by $12.8 \%$, and total $\mathrm{CO}_{2}$ emissions would decrease by $16 \%$.

The impact of implementing best available technologies is therefore substantial. Nevertheless, the CEI of the industry sector in the PRC is very high compared with that of developed economies (9.6 times as high as the UK, 7.8 times as high as Germany, 5.6 times the US, and 3.9 times as high as Canada) as is the final energy intensity (7.1 times the UK, 5.6 times that of Germany, 4.3 times the US, and 2.6 times Canada). Therefore, we conclude that although implementing best available technologies can help reduce this gap, their lack is not the primary reason for the high energy intensity of the industry sector in the PRC. It is instead 


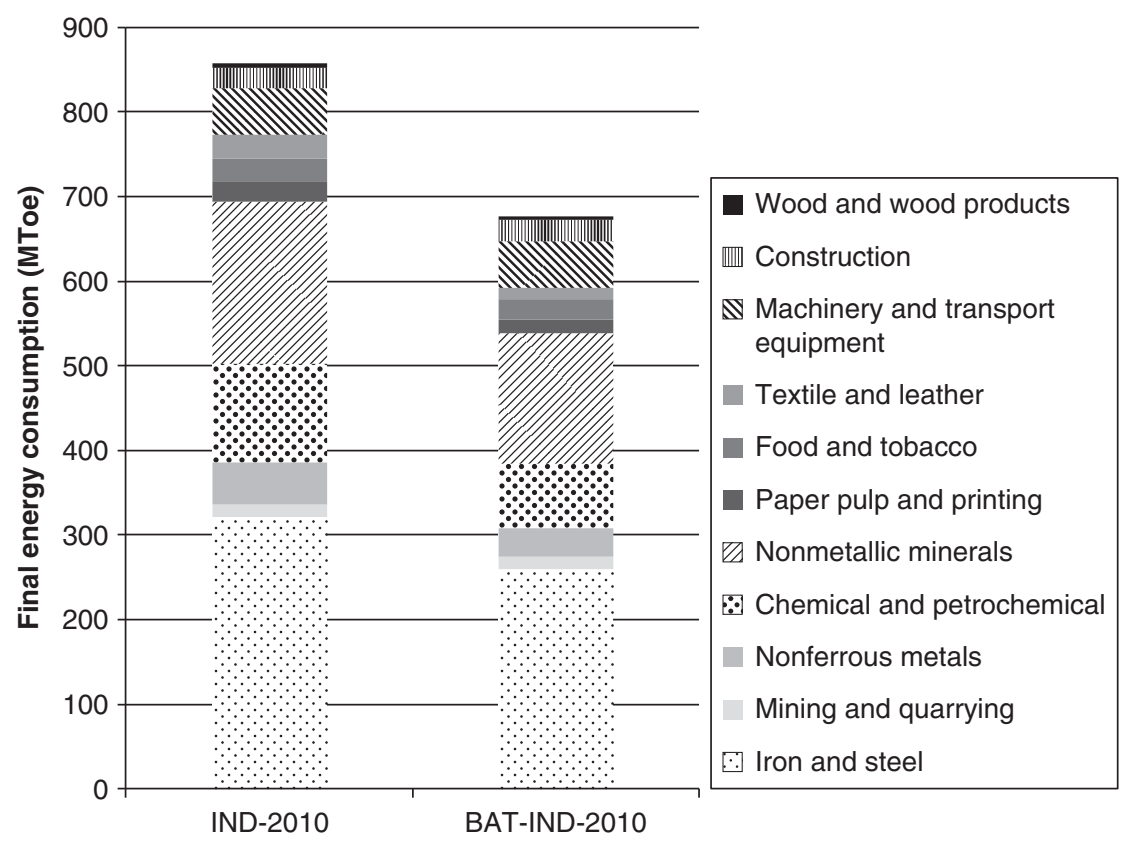

Figure 11.21 Total energy consumption in the industry sector in 2010 and with best available technologies in 2010 in the People's Republic of China

Source: Authors' model.

Note: $\mathrm{BAT}=$ best available technologies; IND = industry; MToe $=$ million tons of oil equivalent.

explained primarily by the high contribution of energy-intensive manufacturing. As noted earlier, in 2010, the PRC produced 57.3\% of the world's cement, $44.3 \%$ of the steel, $43.7 \%$ of aluminum and $31.4 \%$ of ammonia. Therefore, designing an industrial policy to reduce the sector's energy and $\mathrm{CO}_{2}$ intensities should perhaps also consider diversifying to less energy-intensive industries in addition to widely deploying energy efficiency measures.

\section{What is the potential contribution of the household sector?}

In 2010, 423 million people relied on biomass as their primary cooking fuel in the PRC (47 million in urban areas and 377 million in rural areas; IEA, UNDP, and UNIDO) that was nearly $32 \%$ of the total population. Biomass was $49.6 \%$ of all the energy consumed in households in 2010 (Figure 11.22); by 2035, it will still be $15.0 \%$ in the BAU scenario (Figure 11.22) and $14.8 \%$ under ACS-BAU.

Coal contributes $14.3 \%$ of total energy consumption in households (Figure 11.22) mainly for heating in rural and urban areas. Substituting coal with natural gas could have important environmental impacts on air pollution. In 2010, only about 


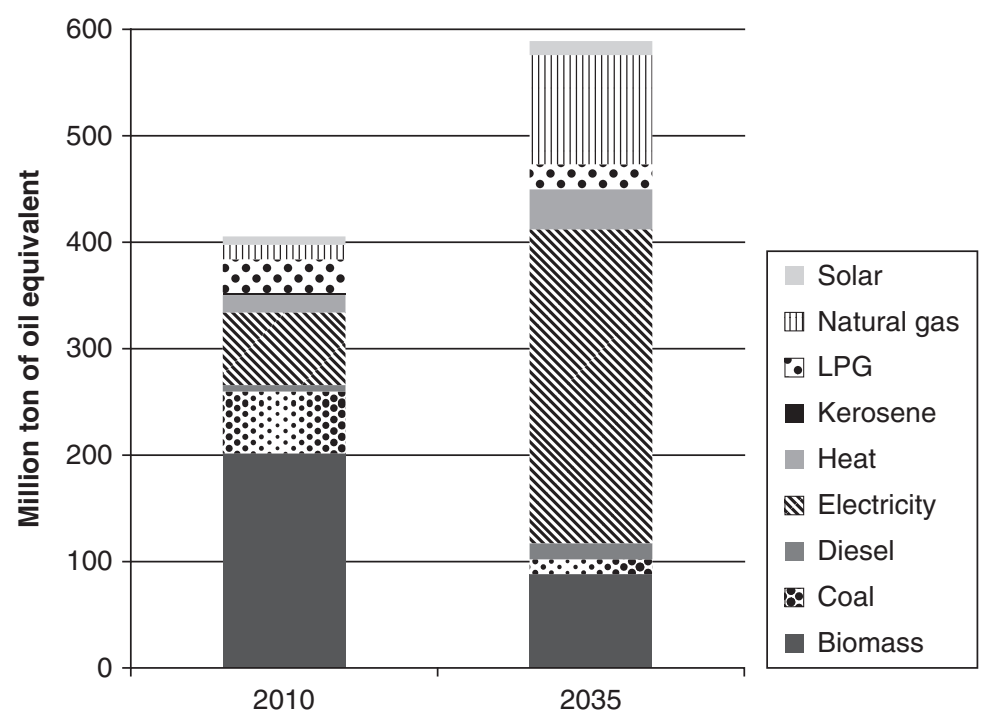

Figure 11.22 Total energy consumption of households in the People's Republic of China in 2010 and 2035 by fuel (business-as-usual scenario)

Source: Authors' model.

Note: $\mathrm{LPG}=$ liquefied petroleum gas.

8 million people $-0.5 \%$ of the population - did not have access to electricity (mostly in rural areas). It is envisaged that $100 \%$ of the population will have access to electricity by 2015 (IEA, UNDP, and UNIDO 2010).

In the last decade, economic growth in the PRC has improved living conditions and has increased ownership of electric appliances, especially in rural areas (Figure 11.23); this trend is expected to continue in the coming years. As the economy develops, more households will replace traditional fuels with natural gas or electricity. What will the additional demand for natural gas be as it displaces traditional fuels (biomass and coal) for cooking and heating? What will the impact be on $\mathrm{CO}_{2}$ emissions? What would the impact of more efficient lighting and appliances be? What would the benefits of more efficient appliances be in terms of saving energy and emissions?

To investigate the implications of the shift from traditional fuels to natural gas and electricity, we used the bottom-up model that includes the energy demanded by the following household activities (Figure 11.24): heating, heating water, cooking, lighting, and running appliances (mainly refrigerators, washing machines, and air conditioning). We analyzed scenarios in which biomass for cooking and coal for heating are replaced with natural gas, incandescent lamps are replaced by CFLs, and more efficient appliances are used. 


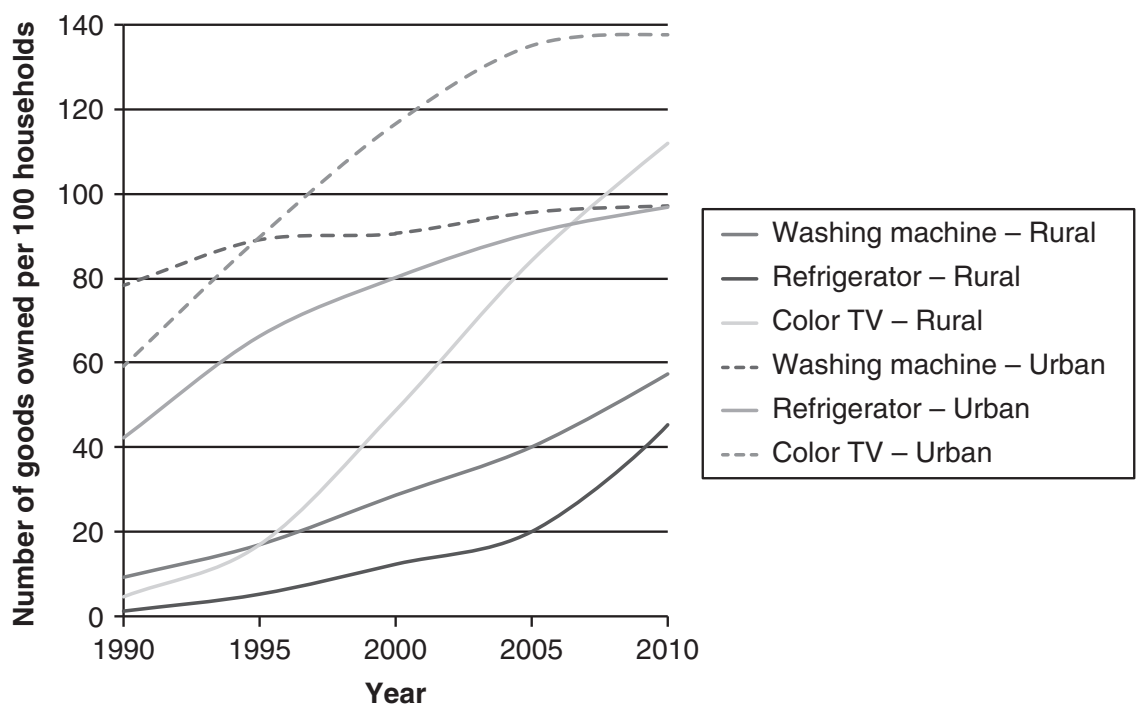

Figure 11.23 Number of appliances per 100 households in urban and rural areas in the People's Republic of China, 1990-2010

Source: Authors' calculations with data from Government of the People's Republic of China 2012.

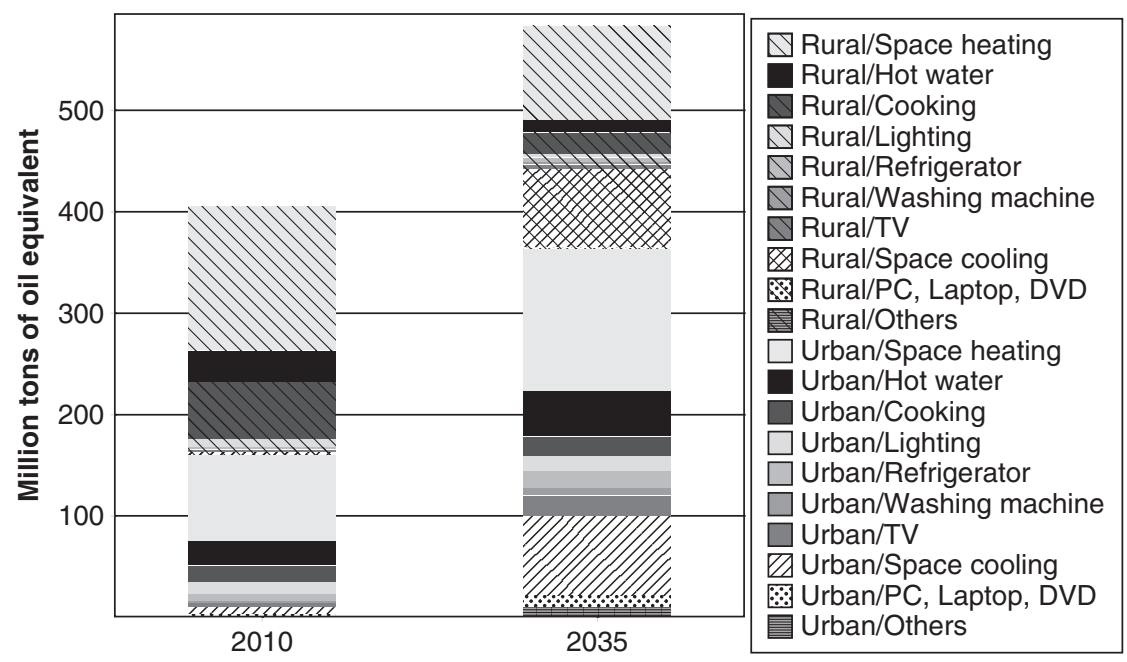

Figure 11.24 Total energy consumption by households in the People's Republic of China in 2010 and 2035 by activity (business-as-usual scenario)

Source: Authors' model. 


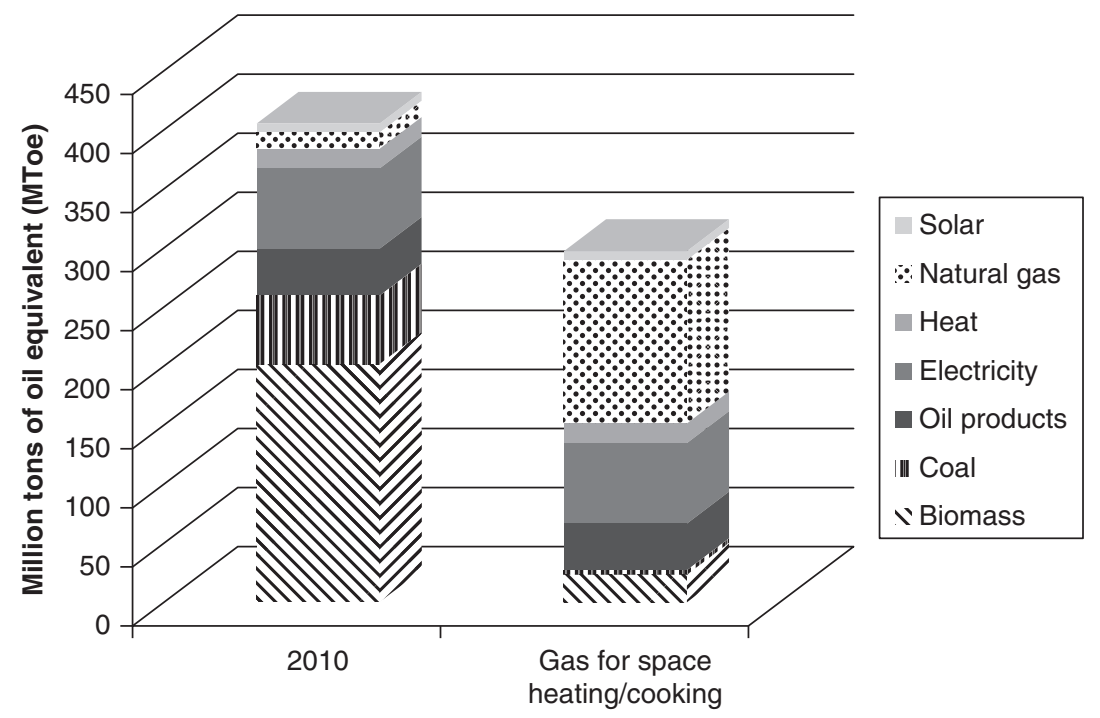

Figure 11.25 Total household energy consumption in the People's Republic of China when natural gas replaces biomass and coal for heating and cooking, 2010

Source: Authors' model.

\section{Outlook for 2035}

Substituting biomass and coal for cooking with natural gas would require 22 MToe of natural gas annually, approximately $31 \%$ of the primary natural gas consumption in 2010. The total energy consumed by households would decrease (Figure 11.25) due to the higher efficiency of gas for cooking (65\%) compared to biomass $(22 \%)$. Although a $\mathrm{CO}_{2}$-neutral fuel (biomass) is replaced with a $\mathrm{CO}_{2}-$ emitting one (natural gas), emissions would nevertheless decrease by 25 million tons since coal would not be used for cooking. Nitrous oxide emissions would be reduced by $18 \%$, and sulfur dioxide emissions would be cut by $30 \%$.

Substituting natural gas for coal and biomass for heating would require 102.7 MToe of natural gas annually (Figure 11.25), 146\% of the primary natural gas consumption in the PRC in 2010. $\mathrm{CO}_{2}$ emissions would increase by 92 million tons $(1.2 \%$ of the total) since biomass would be replaced with natural gas, but nitrous oxide emissions would be reduced by $40 \%$, and sulfur dioxide emissions would drop by $63 \%$.

Replacing incandescent bulbs with CFLs would decrease electricity consumption in households by 154 terawatt hours/year which is $19.4 \%$ of the total electricity consumption of households or $4.5 \%$ of total electricity demand. $\mathrm{CO}_{2}$ emissions would decrease by 182 million tons ( $2.5 \%$ of the total in 2010$)$. 
Replacing appliances with more efficient ones would save 65 terawatt hours/ year $(8.2 \%$ of household electricity consumption and $1.8 \%$ of total electricity demand). In addition, 76 million tons of $\mathrm{CO}_{2}$ emissions per year would be avoided. The transition from traditional fuels to modern fuels for heating and cooking would not, therefore, significantly increase energy demand, but the increase in demand for natural gas would be substantial amounting to $177 \%$ of natural gas consumption in 2010. The impact on $\mathrm{CO}_{2}$ emissions would be small, but the improvement in household air quality would be substantial with nitrous oxide emissions reduced by $58 \%$ and sulfur dioxide by $93 \%$. The reserves-to-production ratio of natural gas is 26.9 years in the PRC (BP 2012); therefore, if traditional fuels are replaced with natural gas, imports will be needed in the medium to long term.

\section{Conclusions}

A comprehensive, bottom-up model of the energy system of the PRC yields detailed insights into some of the key challenges the country faces now and will face in the next 20 years. The energy intensity, i.e., the amount of energy needed to produce a unit of GDP, in 2010 was 4-6 times as high as that in developed countries. The present analysis attributes this gap to three possible causes: inefficiencies on the supply side, inefficiencies on the demand side, and the structure of the economy. Structure explains the larger fraction of the 2010 gap as the current intensity could be reduced by $43 \%$ through structural changes. Using more efficient appliances, devices, and manufacturing processes could reduce the gap by $25 \%$ on the demand side and a more efficient energy supply could reduce it by $6 \%$. In 2035, the gap will have narrowed considerably. In the BAU scenario, energy intensity will be lower than in present-day Canada. Energy intensity in 2035 could nevertheless be further decreased by 13\% through demand-side efficiency measures, by a further $10 \%$ through structural changes, and by $3 \%$ through supply-side measures.

The CEI per unit of GDP in 2010 was 4-8 times as high as in developed economies. We attribute this to its two primary factors: the PEI (energy used per unit of GDP) and the CIX ( $\mathrm{CO}_{2}$ emissions per unit of primary energy used). Thus, with the prevailing energy sector structure in 2010, a CIX similar to that in the US would reduce the CEI by $22 \%$ while improved energy efficiency would result in a reduction of $25 \%$; structural changes can potentially reduce emissions by $33 \%$.

We examined the impact of electrifying transport on the demand for oil and on $\mathrm{CO}_{2}$ emissions. It turns out that even though electrification would reduce oil consumption, the impact is moderate for reasonable penetration levels for cars and railways. For instance, oil consumption by the transport sector is reduced by just $20 \%$ in our accelerated electrification scenario which assumes that $50 \%$ of car and motorcycle passengers $\times$ kilometers and $100 \%$ of the railway transport will be electric by 2035 ; the cumulative oil savings for the whole period are equivalent to 1.7 times the primary oil consumption in 2010. This means that for 
the electrification of the transport sector to have a sizeable impact on overall oil demand, road freight and passenger transport must shift to (electrified) railways. Additionally, it is worth noting that while the impact is positive in terms of oil savings, it is (slightly) negative for $\mathrm{CO}_{2}$ emissions which would increase with electrification. This is because power generation will rely largely on coal even in 2035 (58\% share in the BAU scenario).

We investigated how the supply side can contribute to maintaining 2010 levels of $\mathrm{CO}_{2}$ emissions in the power sector in 2035 despite increased demand. In addition to the baseline BAU scenario, we analyzed the costs of using increased contributions of renewables, coal with CCS, and nuclear. The capital cost of the generating assets to be added from 2010 to 2035 for the BAU energy mix is $\$ 2,032$ billion $(0.58 \%$ of the cumulative GDP from 2010 to 2035$)$. When the mix is alternatively counterbalanced with renewable technologies to maintain emissions at 2010 levels, the capital cost is $\$ 3,136$ billion; with coal with CCS it is $\$ 2,937$ billion; and with nuclear it is $\$ 2,982$ billion. The additional specific cost per unit of emissions saved is between $\$ 10$ and $\$ 25$ per ton of $\mathrm{CO}_{2}$ avoided at a hypothetically null interest rate or from $\$ 60$ to $\$ 70$ per ton of $\mathrm{CO}_{2}$ at a $10 \%$ interest rate. The nuclear option has the lowest specific cost followed by coal with CCS and then renewables.

In the industry sector, using best available technologies would reduce total energy consumption by $21 \%$ mainly through improvements in the four major energy consuming industries: nonferrous metals, chemicals and petrochemicals, nonmetallic minerals, and iron and steel. These improvements, however, would not be sufficient to bring energy consumption in line with that in developed economies. For this to be achieved, the industry sector must shift away from energy-intensive manufacturing.

Replacing coal and biomass for household cooking with natural gas would require about 22 MToe of natural gas annually at 2010 consumption rates or $31 \%$ of the total consumption in 2010. Replacing biomass and coal for heating would require 103 MToe of natural gas annually, nearly 1.5 times the primary natural gas consumption in 2010. The environmental effects of replacement would be mixed since biomass is carbon neutral but coal and natural gas are not. Thus, $\mathrm{CO}_{2}$ emissions would decrease by 25 million tons for cooking but would increase by 92 million tons (or 1.2\%) for heating. Indoor air quality and nitrous oxide and sulfur dioxide emissions would, however, improve substantially.

\section{India}

\section{Why is the primary energy intensity high?}

In 2010, the PEI was high compared to that in developed economies. It was 6.3 times that in the UK, 4.6 times higher than Germany, and 3.8 times higher than that in the US (Figure 11.26). Are the reasons for the gap on the demand side or on the supply side of the energy system? What fraction can be attributed to the structure of the economy? 


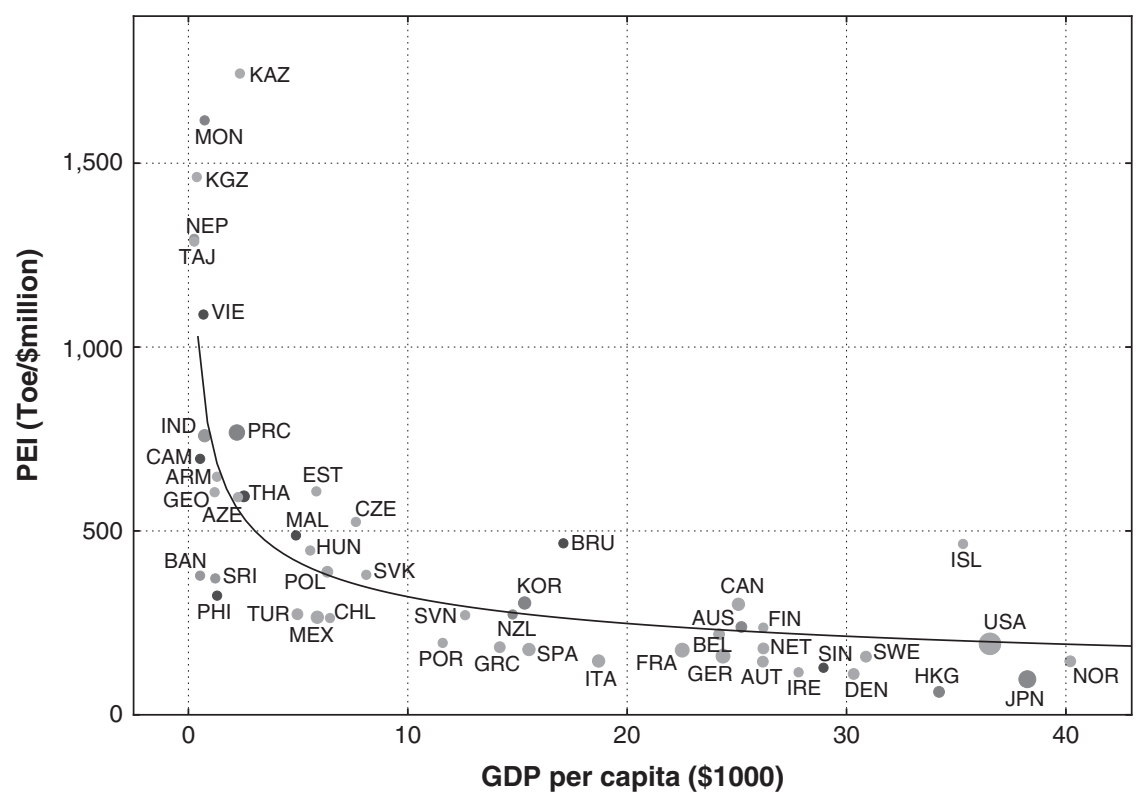

Figure 11.26 Primary energy intensity and gross domestic product per capita in selected economies

Source: Authors' calculations using World Bank (2013) data.

Note: $\mathrm{ARM}=$ Armenia; $\mathrm{AUS}=$ Australia $; \mathrm{AUT}=$ Austria AZE $=$ Azerbaijan; $\mathrm{BAN}=$ Bangladesh $; \mathrm{BEL}=$ Belgium; $\mathrm{BRU}=$ Brunei Darussalam $; \mathrm{CAM}=$ Cambodia $; \mathrm{CAN}=$ Canada $; \mathrm{CHL}=\mathrm{Chile} ; \mathrm{CZE}=\mathrm{Czech}$ Republic; DEN $=$ Denmark; EST $=$ Estonia $;$ FIN $=$ Finland; FRA $=$ France $;$ GDP $=$ gross domestic product; GEO = Georgia; GER = Germany; GRC = Greece; HKG $=$ Hong Kong, China; HUN = Hungary; ISL = Iceland; IND = India; IRE = Ireland; ISR = Israel; ITA = Italy; JPN = Japan; KAZ = Kazakhstan; KOR $=$ Republic of Korea; KGZ = Kyrgyz Republic; MAL = Malaysia; MEX = Mexico; $\mathrm{MON}=$ Mongolia $; \mathrm{NEP}=$ Nepal NET $=$ Netherlands $; \mathrm{NZL}=$ New Zealand $; \mathrm{NOR}=$ Norway; $\mathrm{PAK}=$ Pakistan; $\mathrm{PEI}=$ primary energy intensity; $\mathrm{PHI}=$ Philippines; $\mathrm{POL}=$ Poland; $\mathrm{POR}=$ Portugal $\mathrm{PRC}=$ People's Republic of China; SIN = Singapore; SVK = Slovak Republic; SVN = Slovenia; SPA = Spain; $\mathrm{SRI}=$ Sri Lanka; $\mathrm{SWE}=$ Sweden; $\mathrm{SWI}=$ Switzerland TAJ $=$ Tajikistan; THA $=$ Thailand; Toe $=$ tons of oil equivalent; TUR = Turkey; UKG = United Kingdom; USA = United States; UZB = Uzbekistan; VIE $=$ Viet Nam.

Using the same method we used for the PRC, we implemented the following hypothetical measures to bring demand efficiency in line with that in developed economies.

- For households:

- The efficiency of boilers for heating and hot water is increased from $50 \%$ to $80 \%$ for coal, from $30 \%$ to $50 \%$ for biomass, from $75 \%$ to $90 \%$ for gas, and from $70 \%$ to $85 \%$ for oil. 
- Biomass and coal cookers that now average $22 \%$ and $30 \%$ efficiency respectively are replaced with gas and $65 \%$ efficient LPG cookers.

- For lighting, the share of CFLs is increased from approximately 5\% to $30 \%$. Kerosene lamps are replaced by incandescent bulbs and CFLs.

- For appliances, the average energy consumption of refrigerators is reduced from 500 to 250 kilowatt hours/year, the annual energy consumption of washing machines is reduced from 375 to 190 kilowatt hours/year, and for air conditioning the average efficiency is improved by $15 \%$.

- In the industry sector, products are manufactured at the specific energy consumptions levels in best available technology standards.

- In the service sector, electricity intensity is reduced from 111 to 100 megawatt hours/\$million, and heat/fuel intensity is decreased from 17 to 15 Toe/\$million. The latter intensities are typical of developed countries.

- In the transport sector, the electric locomotive share in passenger and freight transport is increased from $45 \%$ to $60 \%$.

- In the agriculture sector, electricity intensity is reduced from 720 to 500 megawatt hours/\$million. The resulting total energy intensity is typical of developed countries.

For the supply side, we assumed the following improvements.

- $\quad$ Losses in electricity distribution are reduced from $24.3 \%$ to $7 \%$.

- The efficiency of the average coal-fired power plant is increased from $28.4 \%$ (subcritical plants) to $41 \%$ (supercritical plants).

- Own energy use in the power sector is reduced from $6.5 \%$ to $5.0 \%$.

- The efficiency of the average oil-fired power plant is increased from $23 \%$ to $35 \%$, and the efficiency of the average gas combined-cycle power plant is increased from $37 \%$ to $50 \%$.

\section{Analysis in 2010}

With these efficiency improvements, India's PEI in 2010 is reduced by $42.9 \%$, $30.2 \%$ by demand improvements and $12.7 \%$ by supply improvements (Figure 11.27 ); however, the resulting PEI is still high at 406 Toe/\$million compared to developed countries (e.g., 192 Toe/\$million in the US). This gap can be further reduced only through structural changes in the economy that could reduce the PEI by an additional $30.4 \%$.

Households consume the most energy in India surpassing even the industry sector; nearly $78 \%$ is from biomass (Figure 11.28) mainly used for cooking (Figure 11.29). An estimated 855 million people (nearly $75 \%$ of the population) relied on biomass as their primary cooking fuel in 2009 (IEA, UNDP, and UNIDO 2010). The efficiency of biomass for cooking is very low (15\%) compared to LPG and natural gas (65\%) or electricity (80\%). Furthermore, 404 million people-34\% of the population-lack access to electricity (IEA, UNDP, and 


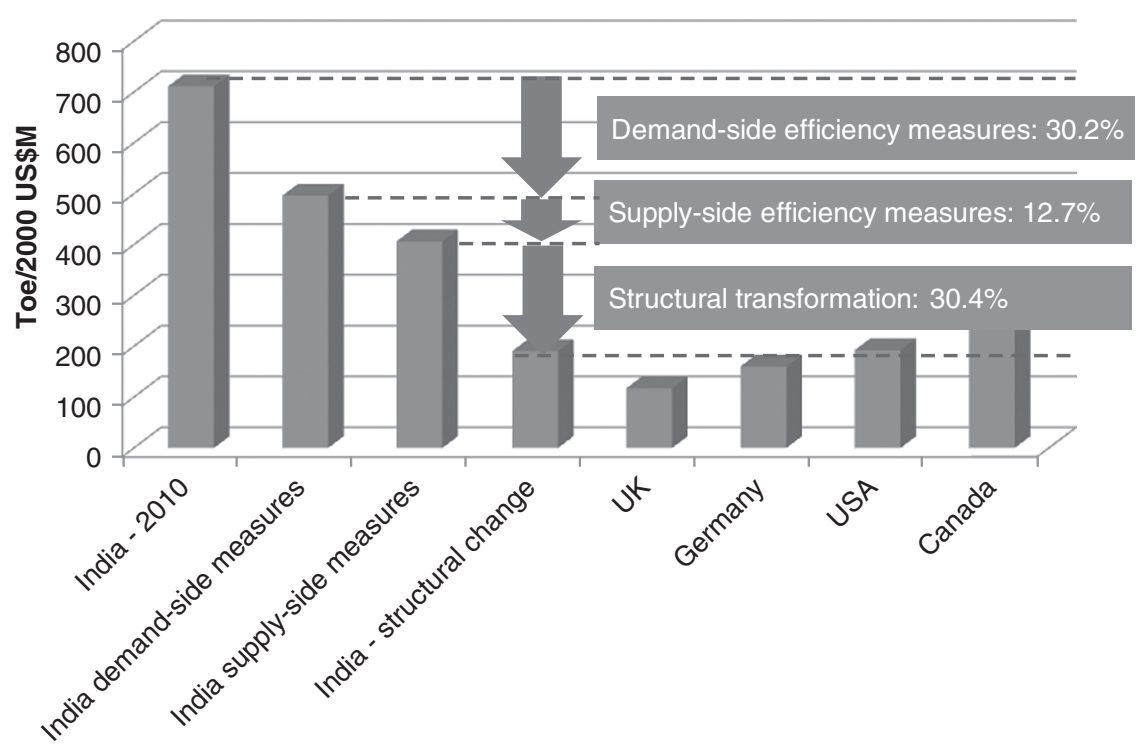

Figure 11.27 Causes of the high primary energy intensity in India in 2010 Source: Authors' model.

Note: Toe $=$ tons of oil equivalent; UK $=$ United Kingdom; USA $=$ United States.

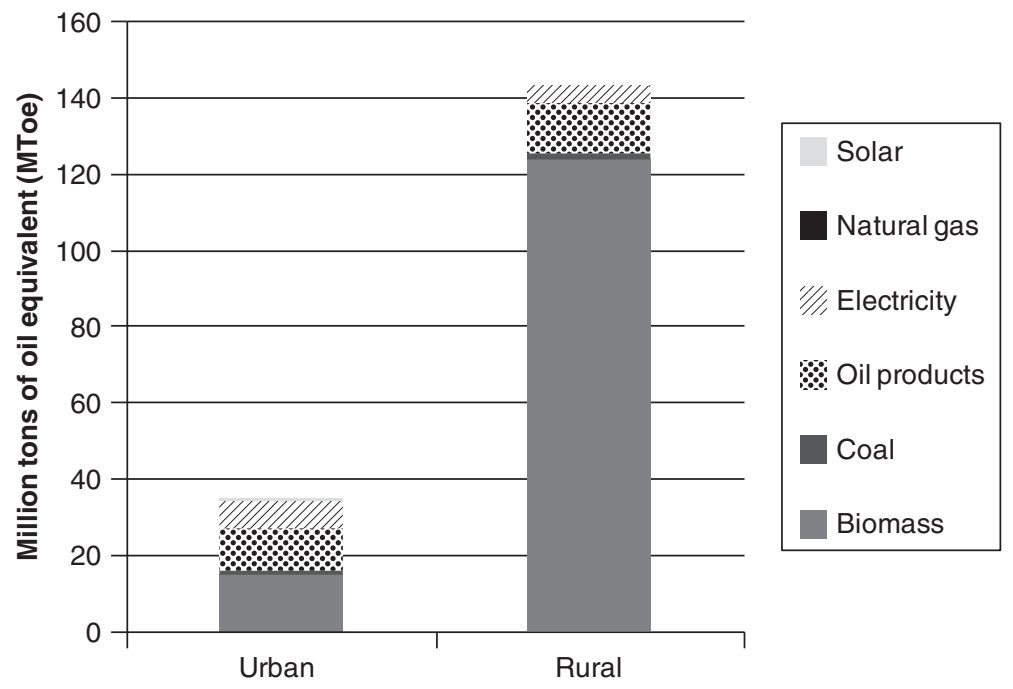

Figure 11.28 Household energy consumption by fuel in India in 2010 Source: Authors' model. 


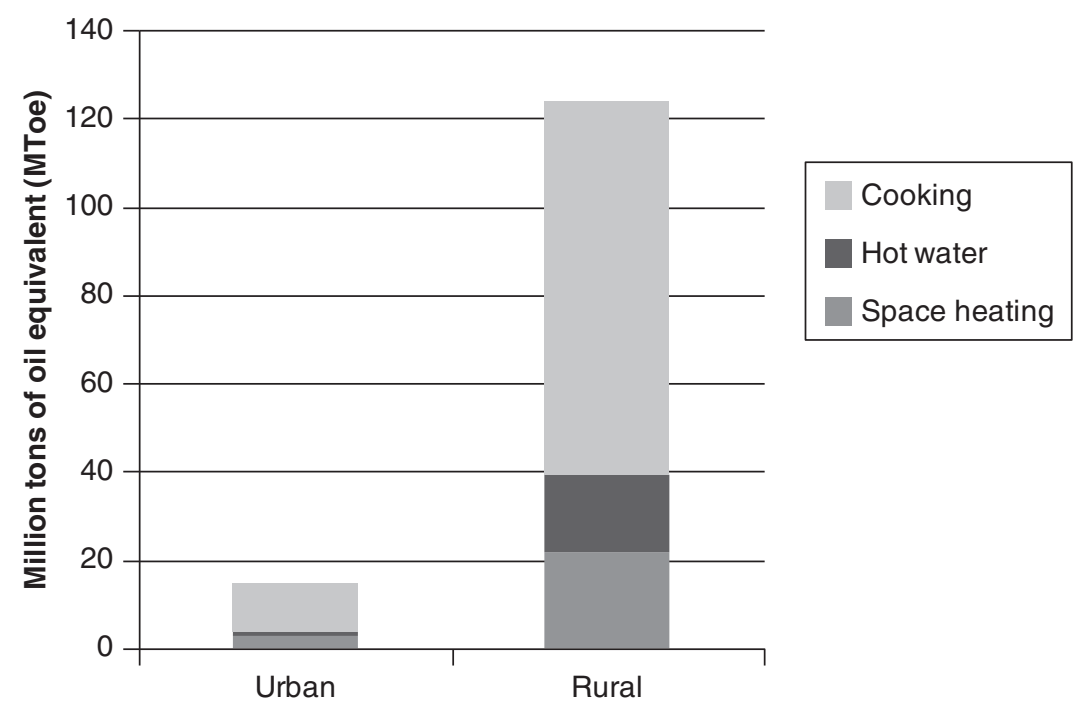

Figure 11.29 Biomass energy use in households in India in 2010

Source: Authors' model.

UNIDO 2010), hence oil (kerosene) lamps are widely used for lighting. The efficiency of incandescent bulbs is nearly 15 times that of kerosene lamps.

By implementing the efficiency measures summarized above, total energy consumption for households would be reduced by $67 \%$ primarily by substituting LPG and natural gas for biomass for cooking and replacing kerosene lamps with CFLs and incandescent bulbs. The transition from traditional fuels to modern energy sources would thus considerably reduce the PEI and would have other positive effects such as a decrease in indoor air pollution.

Industry is the second biggest consumer of energy in India. Iron and steel, nonferrous metals (mainly aluminum), chemicals and petrochemicals (ammonia), and nonmetallic minerals (cement) account for $66 \%$ of the total energy demand (Authors' calculations). The efficiency measures cited above would reduce energy consumption by $29 \%$, a more modest achievement than the result for households.

Regarding energy supply, distribution losses are high at 24\% (Figure 11.30), and generating electricity with coal is $28.4 \%$ efficient and with oil is $23 \%$. If electricity distribution losses were reduced to the level in developed countries, the electricity saved could meet the combined demand of Afghanistan, Bangladesh, Myanmar, Nepal, Pakistan, and Sri Lanka.

Structural changes in the Indian economy have an important but lesser role in energy efficiency than the supply and demand sides. The economy is already very much oriented toward the service sector $(56.3 \%$ of GDP compared to $70 \%$ 


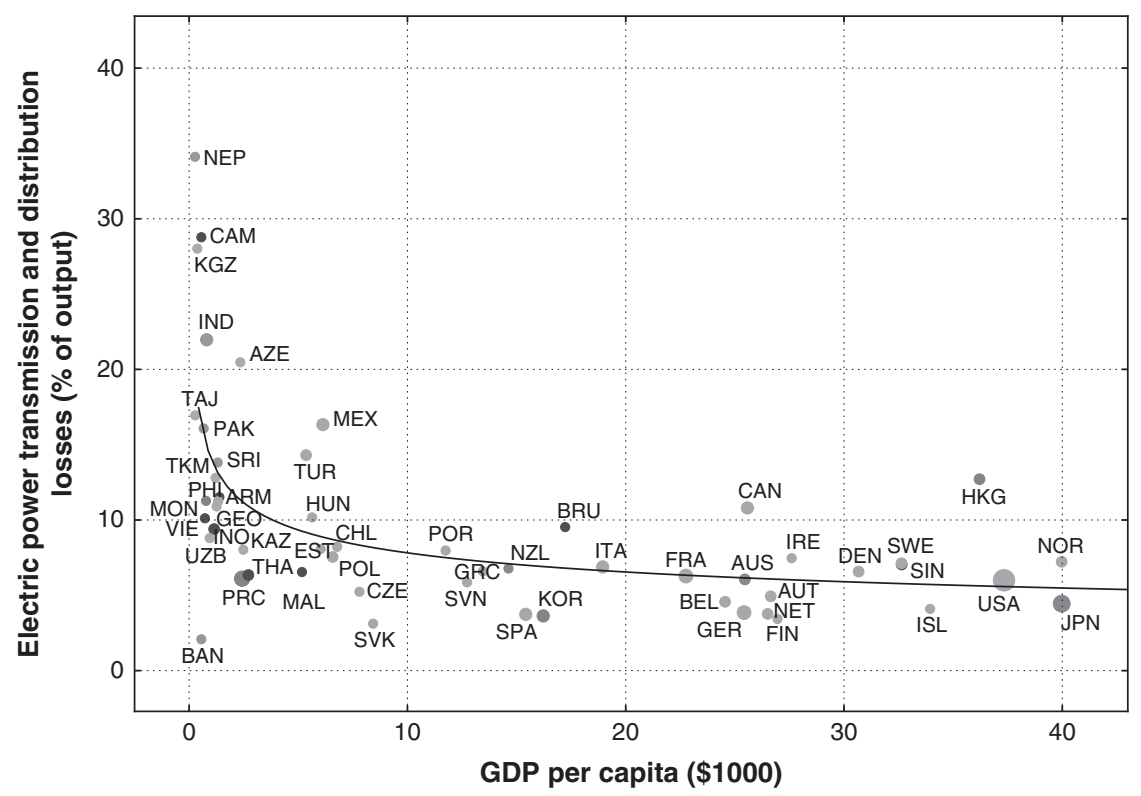

Figure 11.30 Electricity distribution losses and gross domestic product per capita

Source: Authors' calculations using World Bank (2013) data.

Note: $\mathrm{ARM}=$ Armenia; $\mathrm{AUS}=$ Australia $; \mathrm{AUT}=$ Austria; $\mathrm{AZE}=$ Azerbaijan BAN $=$ Bangladesh BEL = Belgium; $\mathrm{BRU}=$ Brunei Darussalam $; \mathrm{CAM}=$ Cambodia $\mathrm{CAN}=\mathrm{Canada} ; \mathrm{CHL}=\mathrm{Chile} ; \mathrm{CZE}=\mathrm{Czech}$ Republic; DEN $=$ Denmark; EST $=$ Estonia; FIN $=$ Finland; FRA $=$ France $;$ GEO $=$ Georgia $;$ GER $=$ Germany; GRC = Greece; HKG = Hong Kong, China; HUN = Hungary; ISL = Iceland; IND = India; $\mathrm{INO}=$ Indonesia; IRE = Ireland; ISR = Israel; ITA = Italy; JPN = Japan; KAZ = Kazakhstan; KOR = Republic of Korea; KGZ = Kyrgyz Republic; MAL = Malaysia; MEX = Mexico; MON = Mongolia; $\mathrm{NEP}=$ Nepal; NET $=$ Netherlands; $\mathrm{NZL}=$ New Zealand $; \mathrm{NOR}=$ Norway; PAK $=$ Pakistan $; \mathrm{PHI}=$ Philippines; $\mathrm{POL}=$ Poland; $\mathrm{POR}=$ Portugal; $\mathrm{PRC}=$ People's Republic of China; $\mathrm{SIN}=$ Singapore; SVK = Slovak Republic; SVN = Slovenia; SPA = Spain; SRI = Sri Lanka; SWE = Sweden; SWI = Switzerland; TAJ $=$ Tajikistan; THA $=$ Thailand; TKM $=$ Turkmenistan; TUR $=$ Turkey; $\mathrm{UKG}=$ United Kingdom; USA = United States; UZB = Uzbekistan; VIE = Viet Nam.

in developed countries), and the weight of the industry sector (26.5\% of GDP) is comparable to that in developed countries. A reduction in the importance of the agriculture sector (17.2\% of GDP compared to around 3\% in developed countries) in favor of higher value-added activities should be the main change to introduce.

\section{Outlook for 2035}

To estimate the PEI for India in 2035 we used the forecasts in BAU and ACSBAU. In 2035, the PEI in the BAU scenario will be 372 Toe/\$million, and it will 


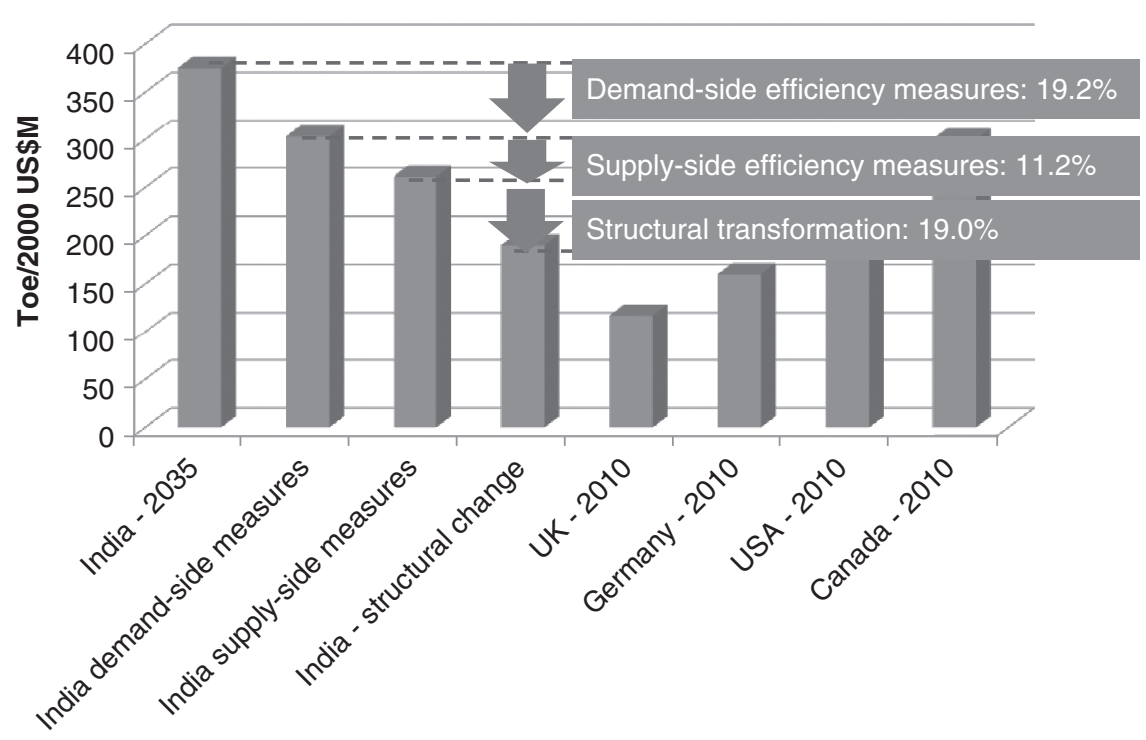

Figure 11.31 Causes of high primary energy intensity in India in 2035

Source: Authors' model.

Note: Toe $=$ tons of oil equivalent; UK = United Kingdom; USA = United States.

be 302 Toe/\$million in ACS-BAU. This intensity will be closer to that for 2010 in developed countries or even lower than in present-day Canada. Using a similar methodology to that presented above for 2010, we conclude that in 2035 in the BAU scenario, the PEI could be reduced by $30.4 \%$ through demand (19.2\%) and supply (11.2\%) measures and a further $19.0 \%$ through additional structural changes (Figure 11.31).

Economic growth under ACS-BAU is substantially higher than in the BAU scenario with the GDP in the former nearly twice the latter by 2035. In ACS-BAU, the PEI in 2035 could be reduced by $30.4 \%$ through demand (18.7\%) and supply $(11.0 \%)$ measures and a further $7.0 \%$ through additional structural changes (Figure 11.32). Economic growth is in general linked to structural change in an economy. For this reason, under ACS-BAU when economic growth is faster, the influence of structural changes on the PEI is lower than in the BAU scenario.

The causes of energy inefficiency in 2035 are similar to those in 2010. Traditional fuels for cooking will still be commonplace in households as $54 \%$ of the population (780 million people) will still rely on biomass as their primary fuel for cooking, and 404 million people ( $20 \%$ of the population) will still have no access to electricity (IEA, UNDP, and UNIDO 2010). Although electrification rates are higher under ACS-BAU than in the BAU scenario, the use of biomass for cooking fuel is similar in both. 


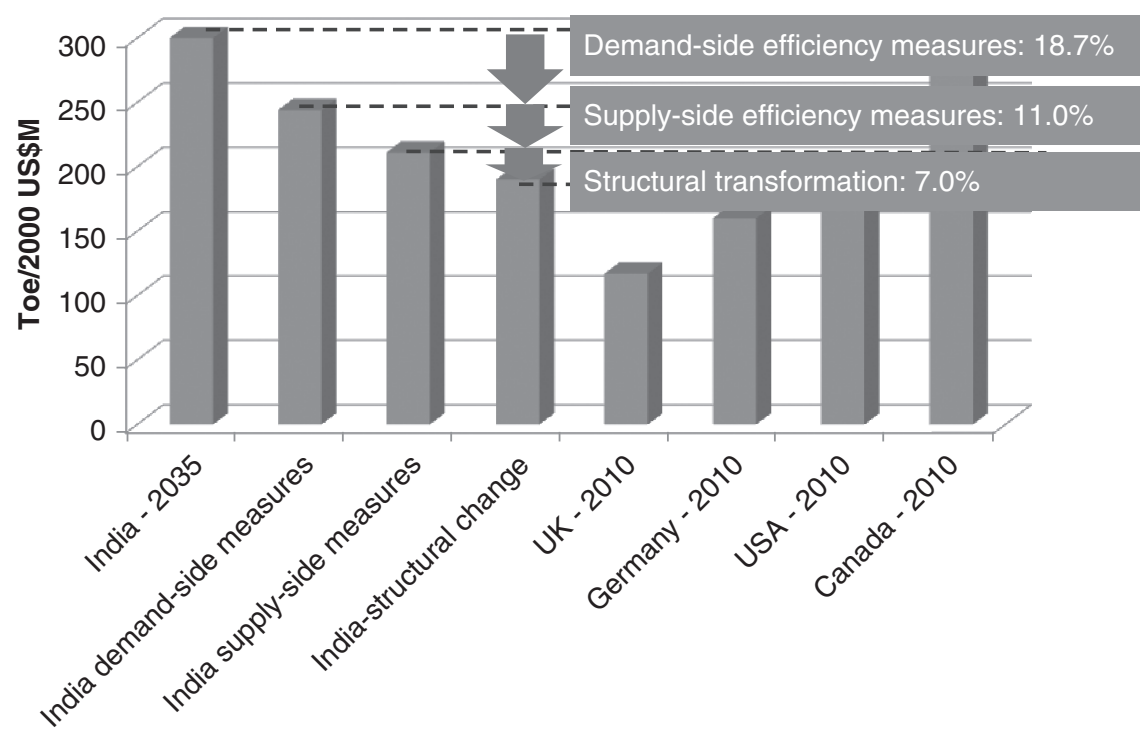

Figure 11.32 Causes of high primary energy intensity in India in 2035 (Asian Centurybusiness-as-usual scenario)

Source: Authors' model.

Note: Toe $=$ tons of oil equivalent; $\mathrm{UK}=$ United Kingdom; USA $=$ United States.

The addition of supercritical coal power plants will increase the average efficiency of coal-generated electricity from $28.4 \%$ to nearly $38 \%$ by 2035 . Thus, the PEI in 2035 will not be adversely affected by inefficiencies in power generation; however, the high losses in electricity distribution will remain one of the main causes of inefficiency on the supply side.

\section{Why is environmental performance poor?}

International benchmarking shows that the CEI of India in 2010 was 6.6 times that of the UK, 4.6 times that of Germany, 3.9 that of the US, and 2.9 times greater than that of Canada and was slightly high for the country's level of development (Figure 11.3). What are the main causes of the gap between India and developed countries?

As stated previously, CEI is the product of the PEI and CIX:

$\mathrm{CEI}\left(\mathrm{TCO}_{2} /\right.$ million $)=\mathrm{PEI}(\mathrm{Toe} / \$$ million $) \times \mathrm{CIX}\left(\mathrm{TCO}_{2} / \mathrm{Toe}\right)$.

In this section, the impacts of efficiency measures and structural changes on the CEI are calculated. Cleaner fuels (such as gas) or renewables replace more polluting ones. 


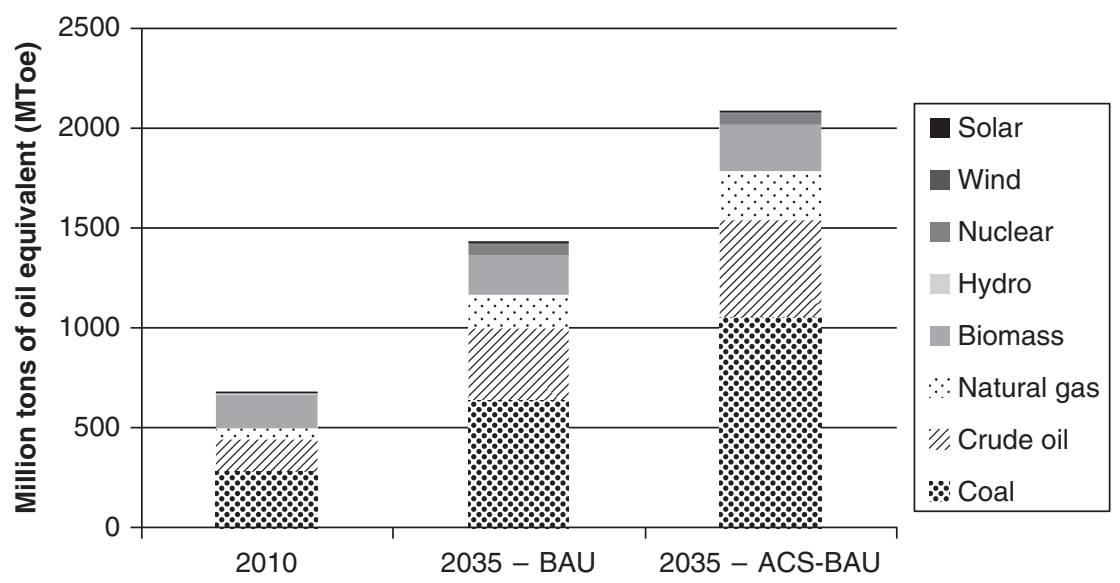

Figure 11.33 Primary energy consumption by fuel in India in 2010 and 2035 (businessas-usual and Asian Century-business-as-usual scenarios)

Source: Authors' model.

Note: $\mathrm{ACS}=$ Asian Century scenario; $\mathrm{BAU}=$ business as usual.

\section{Analysis in 2010}

India's high PEI and economic structure are the main causes of the high CEI; CIX plays a much less significant role. Currently the CIX is $2.4 \mathrm{TCO}_{2} / \mathrm{Toe}$ which is not too far from that in developed economies, e.g., $2.40 \mathrm{TCO}_{2} / \mathrm{Toe}$ for the US, $2.35 \mathrm{TCO}_{2} /$ Toe for the UK, $2.25 \mathrm{TCO}_{2} /$ Toe for Germany, and $2.04 \mathrm{TCO}_{2} /$ Toe for Canada (Figure 11.4).

The reason for this relatively low CIX is that the high share of $\mathrm{CO}_{2}$-free energy sources $(27.5 \%)$ compensates for the $41.2 \%$ of coal in primary energy consumption in 2010 (Figure 11.33). We have nevertheless analyzed the influence of fuel substitution on environmental performance by reducing the CIX from 2.4 to $2.3 \mathrm{TCO}_{2} /$ Toe. With this improvement, India's CEI in 2010 would be reduced by $4.2 \%$. The conclusion is therefore that fuel substitution (to the reasonable levels now prevailing in developed economies) would at this time have a small effect in reducing India's CEI.

The energy efficiency measures listed in the previous section achieve a reduction of $38.7 \%$ in the CEI, $26.1 \%$ from demand improvements and $12.6 \%$ from supply improvements. It is important to note that some of the efficiency measures on the demand side imply substituting convenience fuels with fossil fuels which will increase the CIX, e.g., replacing biomass with natural gas or LPG for cooking and kerosene with electricity for lighting. These measures improve the PEI but would result in an increase in the CIX of about $0.1 \mathrm{TCO}_{2} / \mathrm{Toe}$ (about 4\%). Their net combined effect on CEI would be positive, but the slight 
increase in CIX is the reason the $42.8 \%$ in PEI translates to a reduction of only $38.7 \%$ in CEI.

To minimize the impact on emissions of fuel substitution, it is important to simultaneously implement efficiency measures when designing policies. For instance, substituting kerosene with electricity improves the CEI provided that specific measures are taken in power generation and distribution to improve the average efficiency of coal generation and to reduce electricity distribution losses.

We estimated that additional structural changes in the economy would contribute a reduction of $30.1 \%$ in the CEI through a decrease in the PEI (Figure 11.34).

\section{Outlook for 2035}

The CEI for India in 2035 will be $966 \mathrm{TCO}_{2} / \$$ million in the BAU scenario and $848 \mathrm{TCO}_{2} / \$$ million under ACS-BAU. For the BAU scenario, the CEI will be 3.5, 2.5, 2.1 and 1.5 times as high as the 2010 values in (respectively) the UK, Germany, the US, and Canada, and for ACS-BAU they will 3.1, 2.2, 1.8 and 1.3 times higher. The CIX in 2035 will be $2.6 \mathrm{TCO}_{2} /$ Toe in the BAU scenario and $2.8 \mathrm{TCO}_{2}$ /Toe under ACS-BAU both of which are greater than the 2010 value of $2.4 \mathrm{TCO}_{2} /$ Toe. This increase in CIX is due to substituting traditional fuels with modern ones (mainly natural gas and electricity) and to the fact that the power sector is largely based on coal generation. In 2035, the BAU scenario maintains

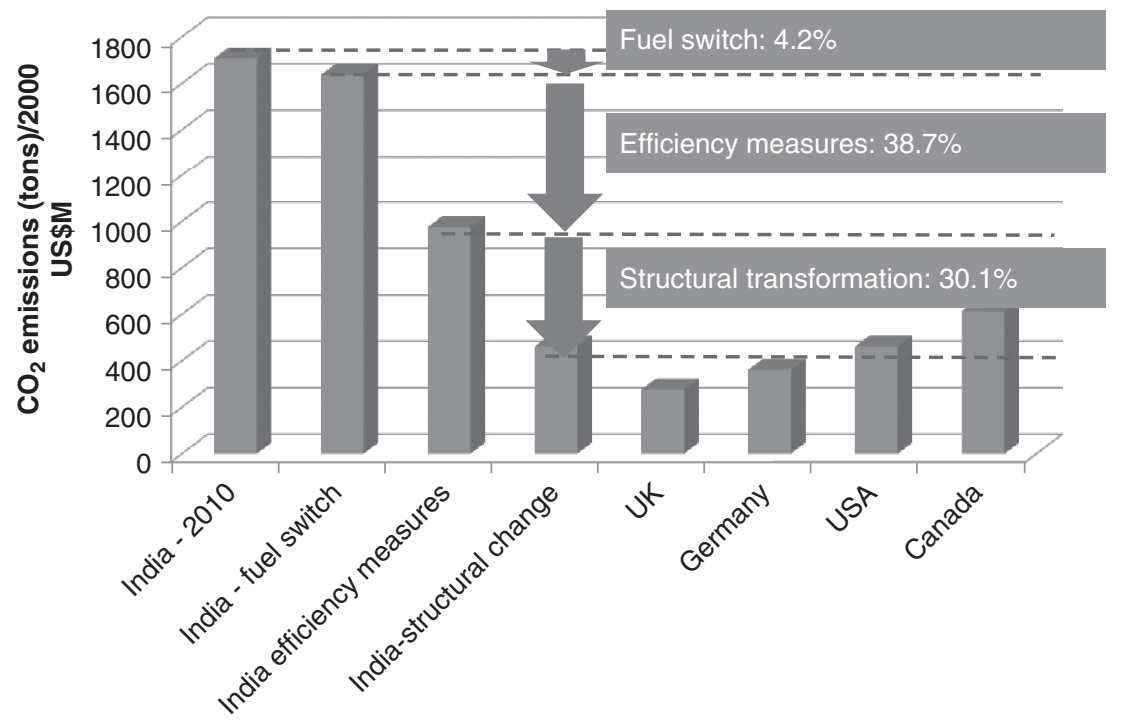

Figure 11.34 Measures to reduce carbon dioxide emission intensity in India in 2010 Source: Authors' model.

Note: $\mathrm{CO}_{2}=$ carbon dioxide; $\mathrm{UK}=$ United Kingdom; USA = United States. 
the $43 \%$ share of coal in the primary energy mix in 2010, but this will increase to $50 \%$ under ACS-BAU (Figure 11.33).

We estimated the influence of fuel substitution on the CEI in 2035 by decreasing the CIX value to $2.0 \mathrm{TCO}_{2}$ /Toe which we assume will be a typical value for CIX in developed countries at that point. To estimate the influence of energy efficiency measures and structural changes on the economy, we used the bottom-up model and found that the CEI in 2035 could be reduced in the BAU scenario by $23.1 \%$ through fuel substitution, by $23.4 \%$ through efficiency measures, and by $14.2 \%$ through additional structural changes (Figure 11.35). Under ACS-BAU (Figure 11.36), the CEI could be reduced by $28.5 \%$ through fuel substitution, by $21.5 \%$ through efficiency measures, and by $5.0 \%$ through additional structural changes.

Economic growth will increase primary energy consumption by 2035 that will be met primarily with fossil fuels (coal, oil, and natural gas) while the share of renewables will grow only moderately (Figure 11.33). As a consequence, the CIX will increase from 2010 to 2035 while the trend for developed countries will be the opposite. For the same reason, the potential for substituting fossil fuels to reduce the CEI in 2035 will be larger, especially under ACS-BAU. The role of efficiency measures will be important as well while the influence of structural changes will be small.

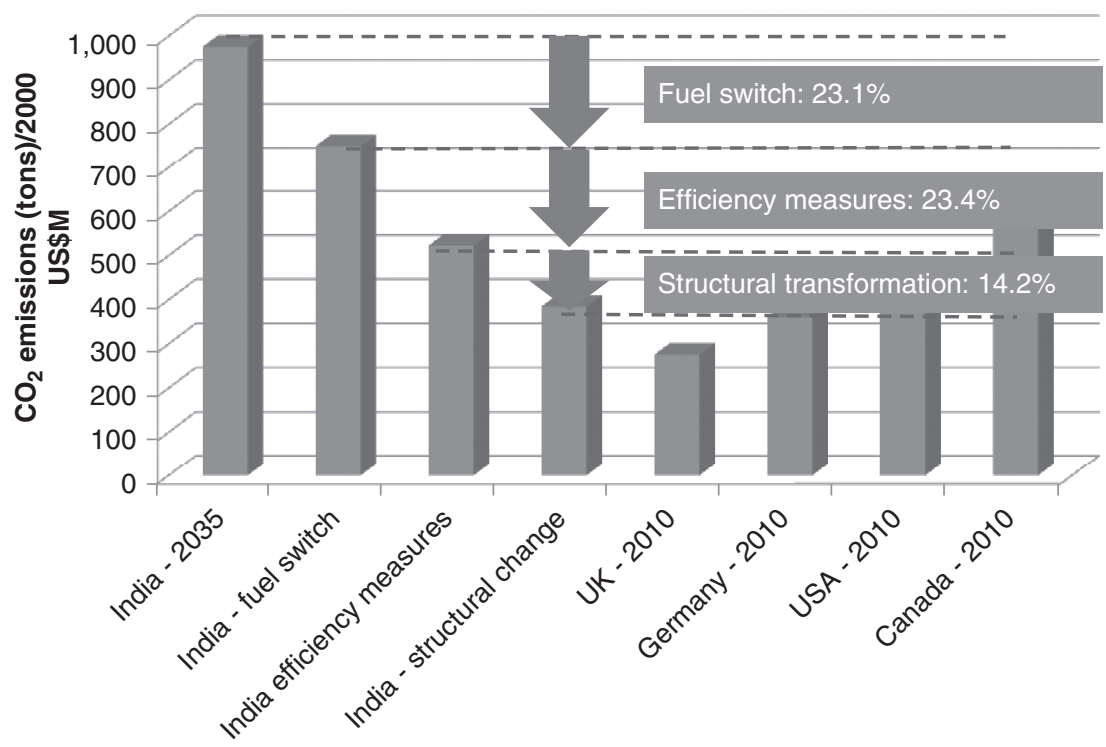

Figure 11.35 Measures to reduce carbon dioxide emission intensity in India in 2035 (business-as-usual scenario)

Source: Authors' model.

Note: $\mathrm{CO}_{2}=$ carbon dioxide; $\mathrm{UK}=$ United Kingdom; USA = United States. 


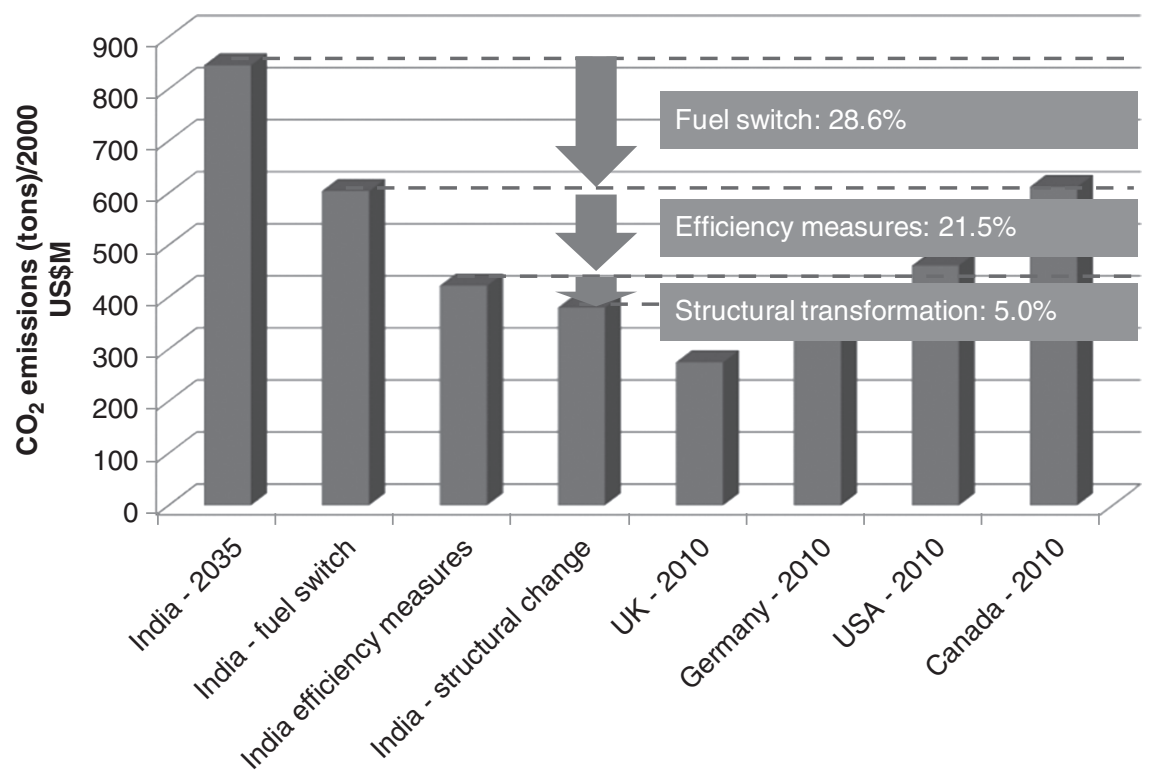

Figure 11.36 Measures to reduce carbon dioxide emission intensity in India in 2035 (Asian Century-business-as-usual scenario)

Source: Authors' model.

Note: $\mathrm{CO}_{2}=$ carbon dioxide; $\mathrm{UK}=$ United Kingdom; USA = United States; $\mathrm{PRC}=$ People's Republic of China.

The increase in the CIX from 2010 to 2035 will be the main cause of the high CEI in India in 2035, particularly under ACS-BAU. Maintaining the value of CIX at 2010 levels will be the challenge for policymakers.

\section{What would the electrification of the transport sector contribute?}

In 2010, the energy consumption of the transport sector in India was $12.1 \%$ of the total (calculated using our bottom-up model); however, it accounted for $36.5 \%$ of total oil consumption. In 2035, total energy consumption in the transport sector will increase in the BAU scenario with respect to 2010 by a factor of 3.1 from 55.5 MToe to 175.9 MToe and by a factor of 4.9 under ACS-BAU to 275 MToe. India has a low reserves-to-production ratio for oil of 18.2 years (BP 2012); thus reducing oil consumption in the transport sector is a desirable goal. Specifically, in the medium and long term, the electrification of the transport sector (cars and railways) could alleviate the demand for oil. What savings in oil and emissions would electrification bring and how much additional electricity would be required? 
To investigate the implications of electrifying the transport sector, we produced and compared the following scenarios.

- BAU/ACS-BAU: This is the BAU scenario from ADB to which we added the assumptions that the penetration of electric motorcycles and cars will be 5\% of total passengers $\times$ kilometers by 2035 and that electric railways will have a $90 \%$ share in overall railway transport.

- BAU medium/ACS-BAU medium electrification: The penetration of electric motorcycles and cars will be $25 \%$ by 2035 , and railway transport of passengers and freight will be $100 \%$ electric. Additionally, $5 \%$ of road freight will be carried by light electric trucks.

- BAU accelerated/ACS-BAU accelerated electrification: The penetration of electric motorcycles and cars will be $50 \%$ by 2035 , and $100 \%$ of the railway transport will be electric. Additionally, $15 \%$ of road freight will be carried by light electric trucks.

\section{Outlook for 2035}

The impact of transport electrification on reducing oil consumption is moderate in the medium scenario, but it is substantial in the accelerated scenario (Figure 11.37).

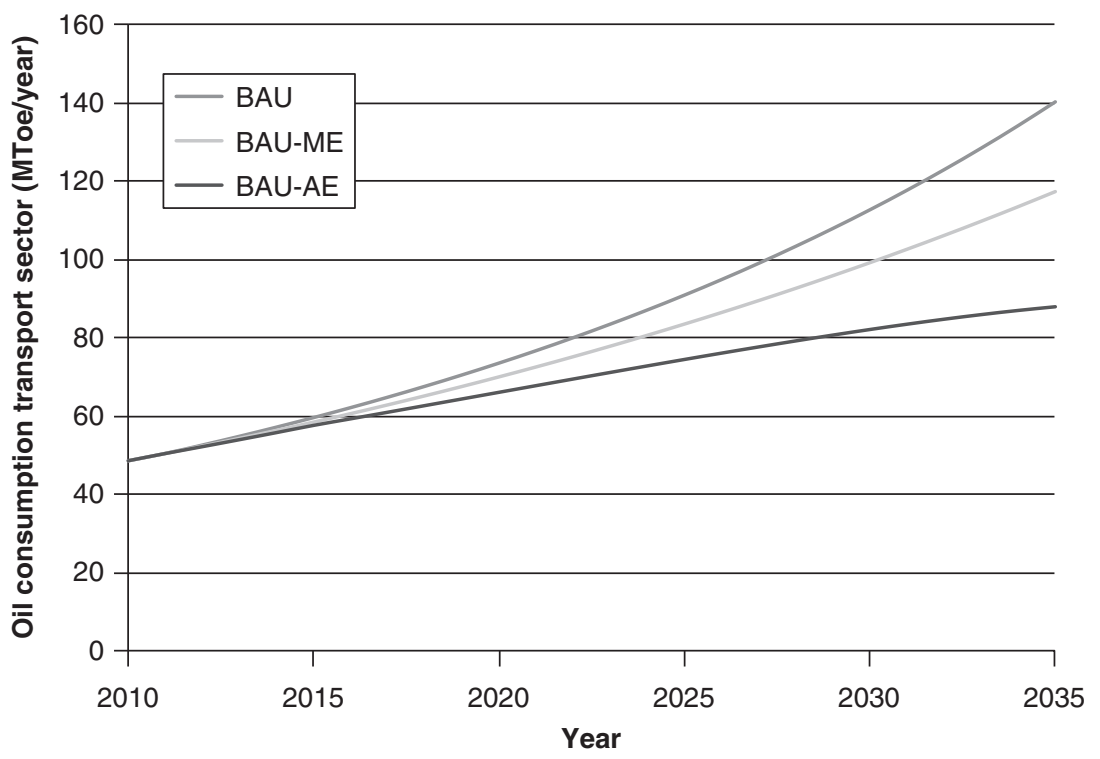

Figure 11.37 Oil consumption in the transport sector in India under three business-as-usual scenarios, 2010-2035

Source: Authors' model.

Note: $\mathrm{AE}=$ accelerated; $\mathrm{BAU}=$ business as usual; $\mathrm{ME}=$ medium; $\mathrm{MToe}=$ million tons of oil equivalent. 


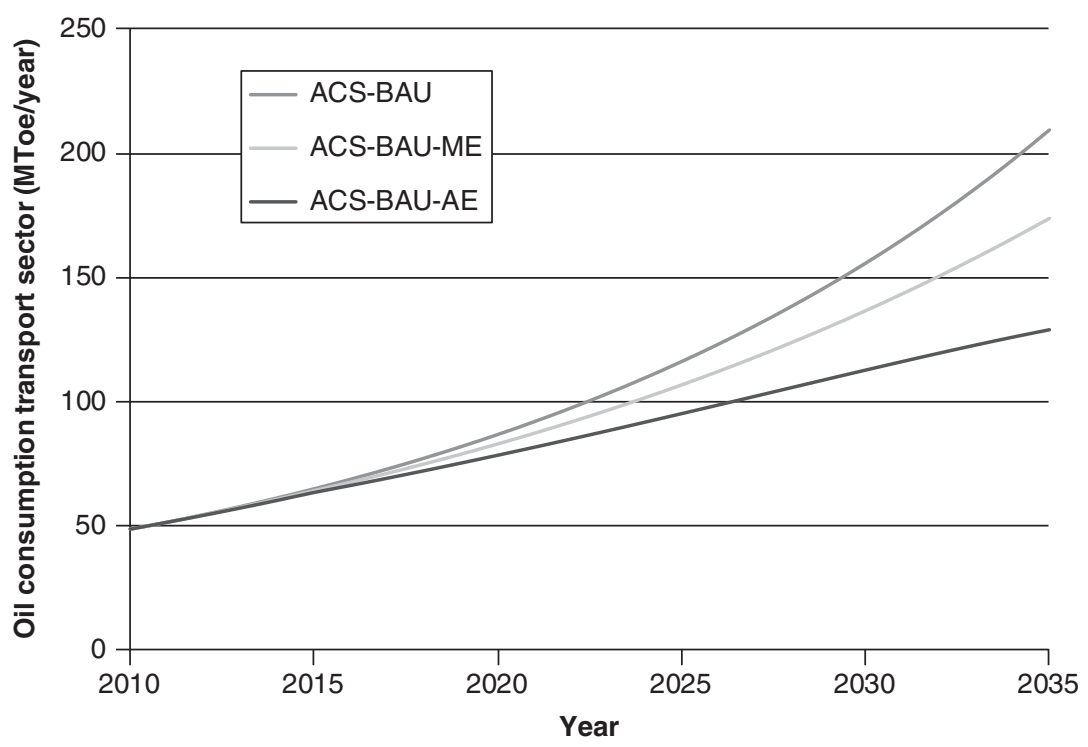

Figure 11.38 Oil consumption in the transport sector in India under three Asian Century scenarios, 2010-2035

Source: Authors' model.

Note: $\mathrm{ACS}=$ Asian Century scenario; $\mathrm{AE}=$ accelerated; $\mathrm{BAU}=$ business as usual; $\mathrm{ME}=$ medium; MToe $=$ million tons of oil equivalent.

Thus, oil consumption in the transport sector would be reduced by $16.4 \%$ in the medium scenario and by $37.1 \%$ in the accelerated scenario. The results are similar under ACS-BAU (Figure 11.38) with a $17.2 \%$ reduction in the medium scenario and a $38.7 \%$ reduction in the accelerated scenario.

The impact on overall crude oil demand would also be significant, especially in the accelerated scenarios. The cumulative oil savings between 2010 and 2035 are 201 MToe in the BAU medium scenario and 450 MToin the accelerated scenario. This is equivalent to $123.0 \%$ and $277 \%$ of the annual primary oil consumption in India in 2010. Under ACS-BAU, the cumulative oil savings are 273 MToe in the medium scenario and 627 MToe in the accelerated scenario (equivalent to $168 \%$ and $387 \%$ of annual primary oil consumption in 2010 ).

Energy consumption in the transport sector is dominated by road transport which accounted for $85 \%$ of the total in 2010 and will increase to $90 \%$ by 2035 in the BAU scenario (Figure 11.39). The share of road passenger transport in total consumption is high (44\% in 2010 and 59\% in 2035); this is the reason electrifying car and motorcycle passenger transport and railways would have a significant impact on oil consumption overall. Further reductions in oil consumption would require a shift from road transport to (electrified) railways. 


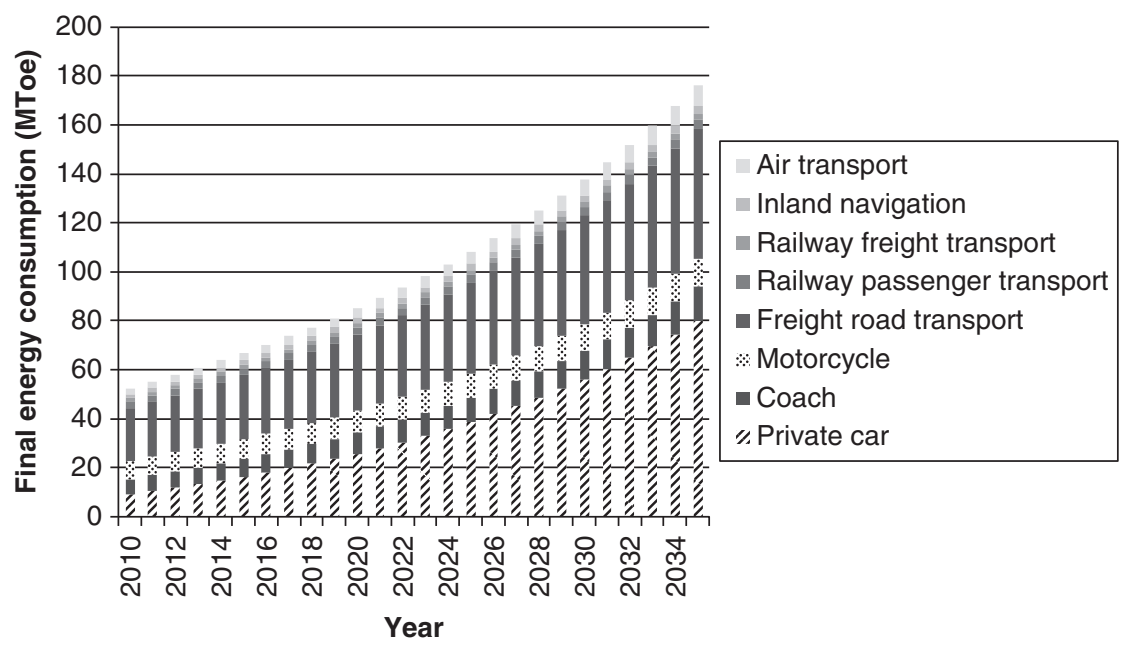

Figure 11.39 Total energy consumption by mode of transport in India, 2010-2035 (businessas-usual scenario)

Source: Authors' model.

Note: $\mathrm{MToe}=$ million tons of oil equivalent.

The additional generation required to electrify the transport sector would be 136 terawatt hours/year in the BAU medium scenario by 2035 and 307 terawatt hours/year in the BAU accelerated scenario. These are small fractions of the total generation in the BAU scenario of 3,430 terawatt hours/year (Figure 11.40). Electrifying the transport sector will require $3.9 \%$ more power in the BAU medium scenario and $8.2 \%$ more in the BAU accelerated scenario. Under ACS-BAU, the additional electricity generation requirement is 205 terawatt hours/year in the medium scenario and 466 terawatt hours/year in the accelerated scenario, or 3.7\% and $7.8 \%$ of the electricity generated in the ACS-BAU scenario (Figure 11.41).

Electrifying the transport sector may well, however, result in higher $\mathrm{CO}_{2}$ emissions. In 2035, emissions in the medium and accelerated scenarios would be 10 million tons and 37 million tons higher than in the BAU scenario (Figure 11.42). Under ACS-BAU, emissions would be 20 million tons or 38 million tons higher in the medium and accelerated scenarios, respectively, than in BAU (Figure 11.43). This is because power generation in India relies heavily on coal. It was $68 \%$ in 2010 and will be $64 \%$ by 2035 in the BAU-scenario and $71 \%$ under ACS-BAU. Furthermore, electricity distribution losses are very high (24.3\% in 2010) and are likely to remain so in 2035 (around 20\%). Therefore, although the average efficiency of coal generation will improve from $28.4 \%$ to $38 \%$, the emission factor will remain high, and substituting gasoline or diesel with electricity will not reduce $\mathrm{CO}_{2}$ emissions. Unless the CEI of the power sector is 


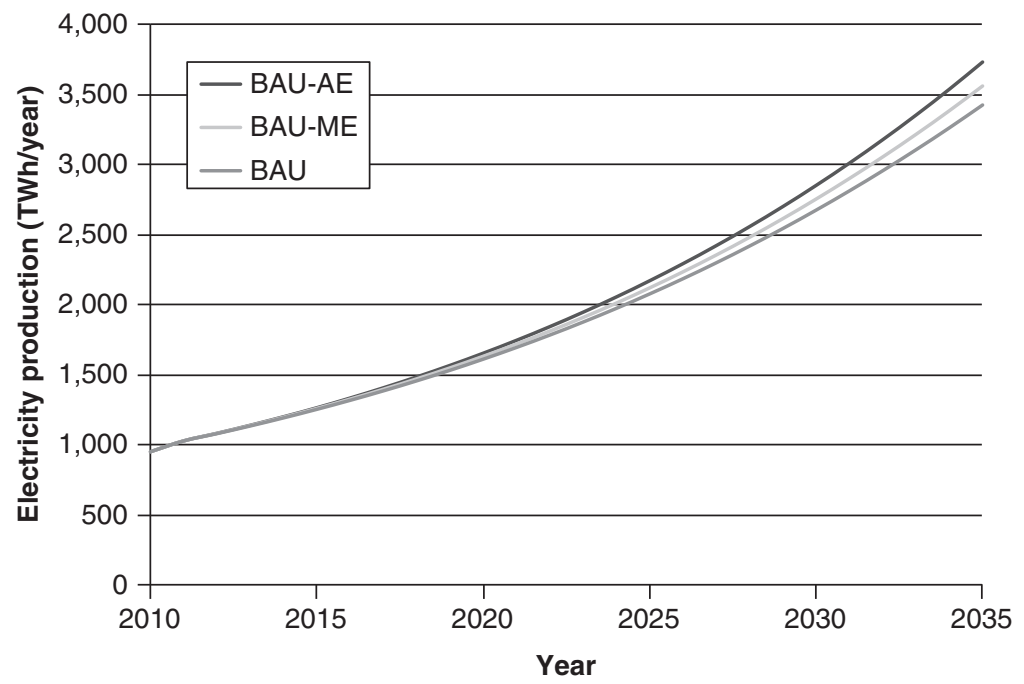

Figure 11.40 Total power generation required in the business-as-usual and the businessas-usual medium and accelerated scenarios in India, 2010-2035

Source: Authors' model.

Note: $\mathrm{AE}=$ accelerated $; \mathrm{BAU}=$ business as usual $\mathrm{ME}=$ medium $; \mathrm{TWh}=$ terawatt hours.

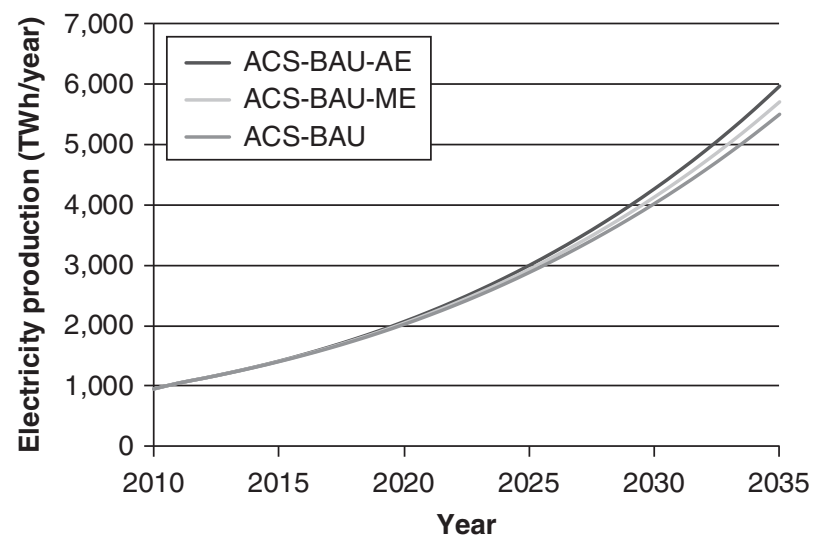

Figure 11.41 Total power generation required in the Asian Century Business-asUsual and the Asian Century-business-as-usual medium and accelerated scenarios in India, 2010-2035

Source: Authors' model.

Note: $\mathrm{ACS}=$ Asian Century scenario; $\mathrm{AE}=$ accelerated; $\mathrm{BAU}=$ business as usual, $\mathrm{ME}=$ medium; $\mathrm{TWh}=$ terawatt hours. 


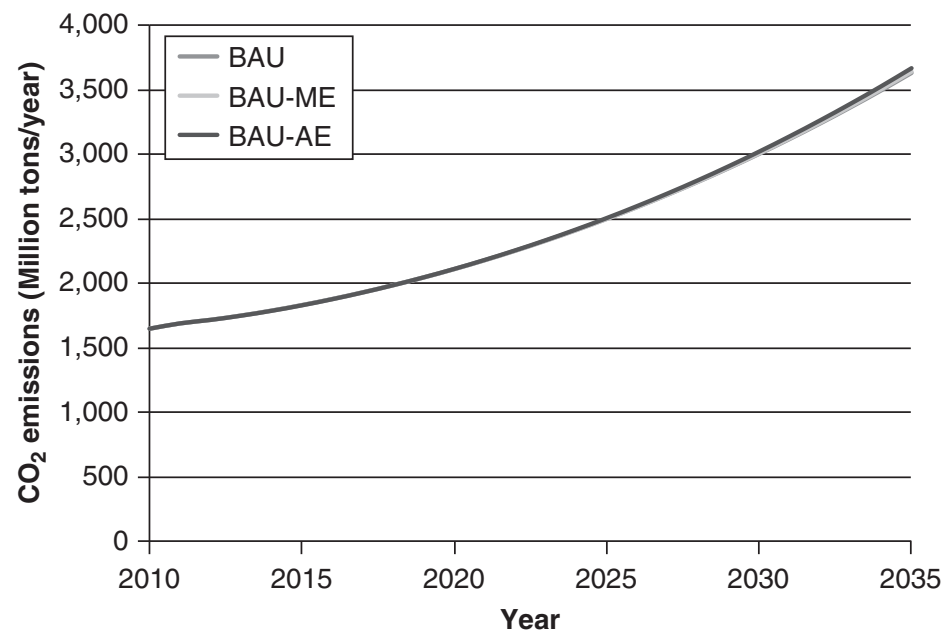

Figure 11.42 Total carbon dioxide emissions in the business-as-usual and the business-as-usual medium and accelerated scenarios in India, 2010-2035

Source: Authors' model.

Note: $\mathrm{AE}=$ accelerated; $\mathrm{BAU}=$ business as usual $; \mathrm{CO}_{2}=$ carbon dioxide; $\mathrm{ME}=$ medium .

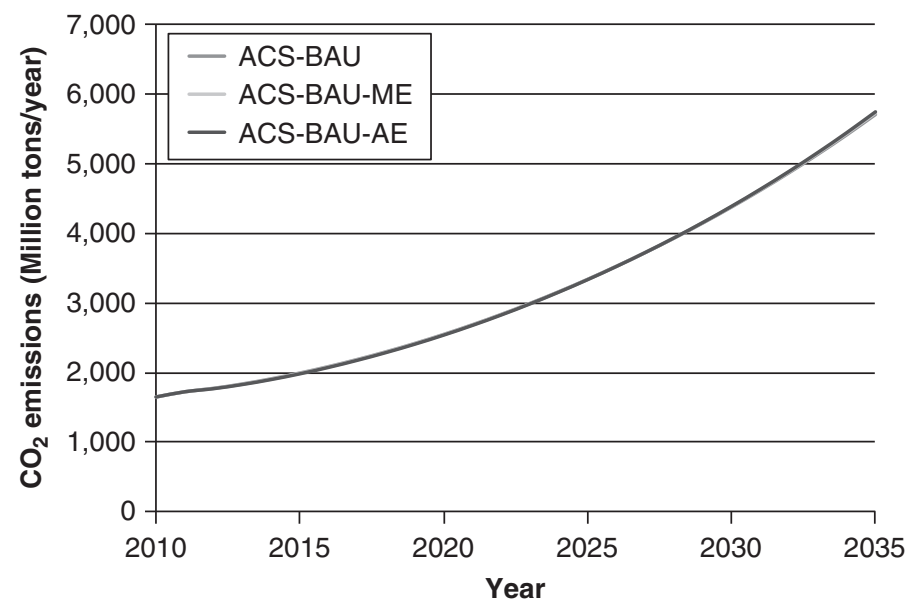

Figure 11.43 Total carbon dioxide emissions in the Asian Century-business-as-usual and the Asian Century-business-as-usual medium and accelerated scenarios in India, 2010-2035

Source: Authors' model.

Note: $\mathrm{ACS}=\mathrm{Asian}$ Century Scenario $\mathrm{AE}=$ accelerated; $\mathrm{BAU}=$ business as usual $; \mathrm{CO}_{2}=$ carbon dioxide; $\mathrm{ME}=$ medium. 
reduced considerably, the electrification of the transport sector will not significantly decrease overall $\mathrm{CO}_{2}$ emissions.

\section{How can the supply side help?}

In 2010, the fuel mix for generating electricity in India was based heavily on coal at $68 \%$ of total generation. In 2035 , the contribution of coal will be only slightly smaller at $64 \%$ in the BAU scenario or will be even greater at $71 \%$ under ACS-BAU. As a consequence, the CEI of the power-generating sector is one of the highest in the world at 0.86 kilograms of $\mathrm{CO}_{2} /$ kilowatt hour in 2010 (Figure 11.14). The reduction in the CEI will be modest by 2035 at 0.60 kilograms of $\mathrm{CO}_{2} /$ kilowatt hour in the BAU scenario or 0.63 kilograms of $\mathrm{CO}_{2} /$ kilowatt hour under ACS-BAU. An accelerated transition to cleaner energy sources in the power sector is crucially needed to further reduce $\mathrm{CO}_{2}$ emissions. What should the penetration of renewables, nuclear, and coal (with CCS) be to significantly reduce the CEI of the power sector, and what investment would be required?

To investigate the implications of a more accelerated transition to cleaner fuel sources in the power sector, we set up and analyzed additional scenarios that maintained total $\mathrm{CO}_{2}$ emissions in 2035 at the same level as 2010 (despite increased electricity demand). To achieve this goal, the CEI of the power sector has to decrease from its 2010 value of 0.86 to 0.25 kilograms/kilowatt hour in the BAU scenario and to 0.16 kilograms/kilowatt hour under ACS-BAU. In our scenarios this is achieved by replacing conventional coal with $\mathrm{CO}_{2}$-free technologies (renewables, coal with $\mathrm{CCS}$, nuclear, and hydro). For $\mathrm{CO}_{2}$ emissions to be contained, the fuel mix in 2035 must be $60 \%$ carbon free (hydro, renewables, coal with $\mathrm{CCS}$, or nuclear) in the BAU scenario and $71 \%$ under ACS-BAU.

Together with the BAU and ACS-BAU cases, the scenarios are the following.

- BAU: This is the BAU scenario from ADB to 2035. The $\mathrm{CO}_{2}$ emission intensity of the power sector decreases from 0.86 kilograms/kilowatt hour in 2010 to 0.60 kilograms/kilowatt hour by 2035 , but total $\mathrm{CO}_{2}$ emissions in 2035 are 2.5 times those in 2010 because total power generation increases by a factor of 3.5. The installed renewable power in the BAU scenario for 2035 is 143 gigawatts (GW) (80 GW of hydro, $48 \mathrm{GW}$ of wind, $10 \mathrm{GW}$ of solar photovoltaics, and $5 \mathrm{GW}$ of biomass) while the installed nuclear power is 28 gigawatts. No coal with CCS is assumed in the BAU scenario. This fuel mix is consistent with the ADB BAU scenario.

- ACS-BAU: This is the ACS-BAU scenario from ADB to 2035. The $\mathrm{CO}_{2}$ emission intensity of the power sector decreases from 0.86 kilograms/ kilowatt hour in 2010 to 0.63 kilograms/kilowatt hour by 2035 , but because generation increases by a factor of 5.7, the total $\mathrm{CO}_{2}$ emissions of the power sector in 2035 are 4.2 times those in 2010 . The installed renewable power in the ACS-BAU scenario for 2035 is 146 gigawatts, $80 \mathrm{GW}$ of hydro, $50 \mathrm{GW}$ of wind, $11 \mathrm{GW}$ of solar photovoltaics and $5 \mathrm{GW}$ of biomass, and the installed 
nuclear power is 28 gigawatts. No coal with CCS power is assumed in this scenario. This mix is compatible with the ADB ACS-BAU scenario.

- BAU Renewable and ACS-BAU Renewable: These two scenarios replace coal with renewables.

- BAU-CCS and ACS-BAU-CCS: Emission levels are maintained by introducing coal-fired plants with CCS. Again, CCS is still in the pre-market phase; there are uncertainties about its future development on a large scale (technical and commercial challenges and those related to storage).

- BAU Nuclear and ACS-BAU Nuclear: The emission levels are maintained by introducing nuclear power.

\section{Analysis of the business-as-usual scenarios}

In 2035, electricity generation will increase 3.5 times; maintaining $\mathrm{CO}_{2}$ emissions at 2010 levels would require a considerable effort (Figure 11.44). In each of the three scenarios, the additional power and the fuel mix are the following (Figure 11.45).

- For the BAU renewable scenario, 537 gigawatts of renewables are needed in addition to those in the BAU scenario which are $50 \mathrm{GW}$ of hydro, $252 \mathrm{GW}$ of wind, $190 \mathrm{GW}$ of solar photovoltaics, and $45 \mathrm{GW}$ of biomass. The fuel mix for generating electricity would therefore be $28 \%$ conventional coal, $10 \%$ gas combined cycle, $1 \%$ oil, $13 \%$ hydro, $7 \%$ nuclear, and $41 \%$ renewables.

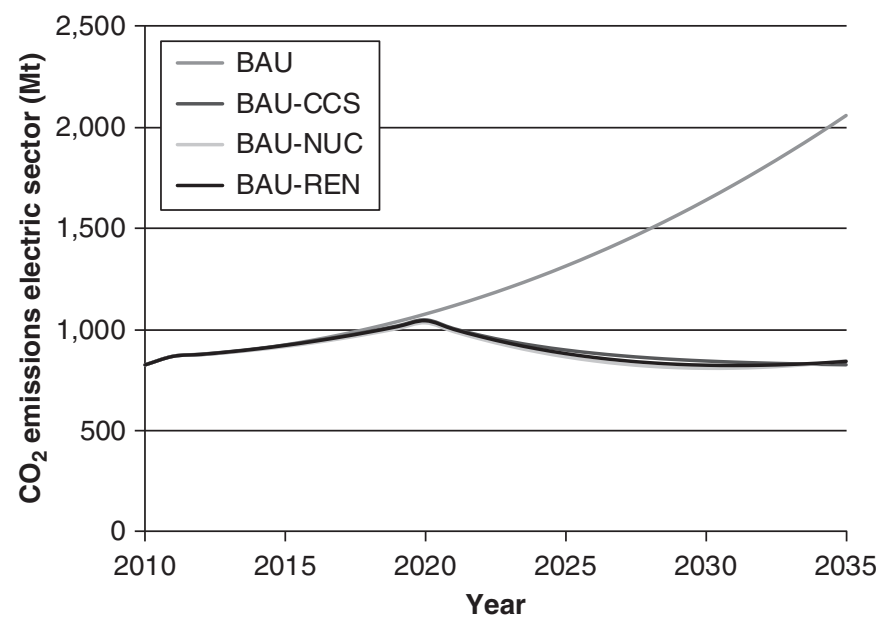

Figure 11.44 Carbon dioxide emissions in the power sector for four businessas-usual scenarios in India

Source: Authors' model.

Note: $\mathrm{BAU}=$ business as usual; $\mathrm{CCS}=$ carbon capture and storage; $\mathrm{CO}_{2}=$ carbon dioxide; $\mathrm{Nuc}=$ nuclear; $\mathrm{REN}=$ renewable. 


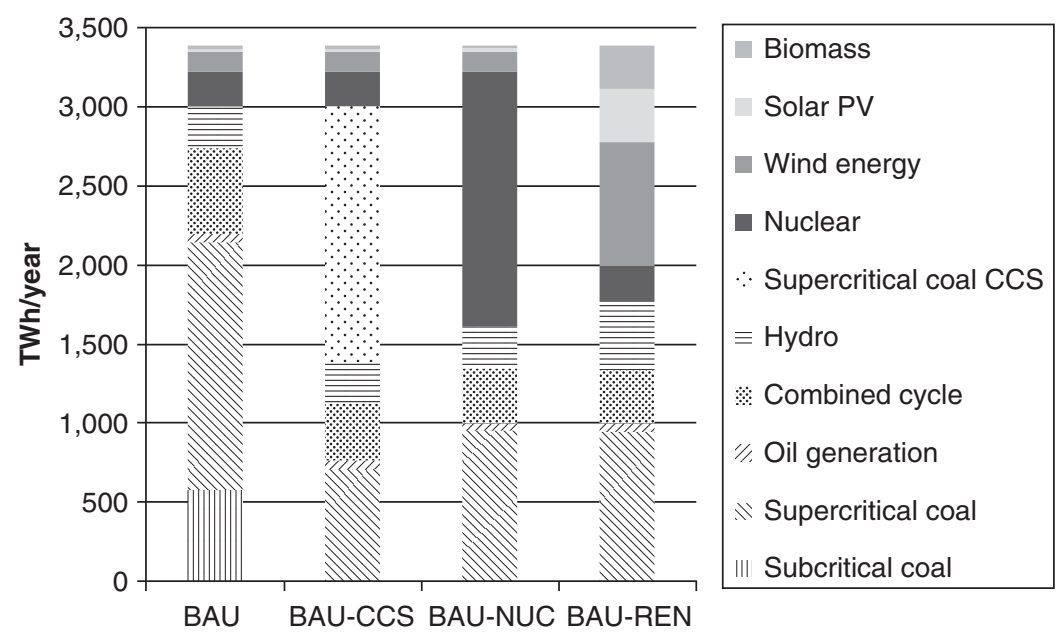

Figure 11.45 Fuel mix for generating electricity in 2035 for four business-as-usual scenarios in India

Source: Authors' model.

Note: $\mathrm{BAU}=$ business as usual; $\mathrm{CCS}=$ carbon capture and storage; $\mathrm{NUC}=$ nuclear; $\mathrm{PV}=$ photovoltaics; $\mathrm{REN}=$ renewable; $\mathrm{TWh}=$ terawatt hour.

- In BAU-CCS, 250 gigawatts of CCS-enabled coal generation are needed, and the fuel mix for generating electricity would be $21 \%$ conventional coal, $47 \%$ coal with CCS, $11 \%$ gas combined cycle, $1 \%$ oil, $8 \%$ hydro, $7 \%$ nuclear, and $5 \%$ renewables.

- In BAU nuclear, 177 gigawatts of nuclear power are needed in addition to the 28 gigawatts included in the BAU scenario; the resulting fuel mix would be $28 \%$ conventional coal, $10 \%$ gas combined cycle, $1 \%$ oil, $8 \%$ hydro, $48 \%$ nuclear, and $5 \%$ renewables.

With these supply measures, the $\mathrm{CO}_{2}$ emissions from the power sector in 2035 would remain at 2010 levels (825 million tons/year), but their share in the total $\mathrm{CO}_{2}$ emissions of the country would decrease from $53 \%$ in 2010 to $23.2 \%$ by 2035. The cumulative saved emissions vary slightly by scenario since different technologies are introduced at different times, but they are all around 10 billion tons of $\mathrm{CO}_{2} /$ year.

The required investments and percentages of cumulative GDP from 2010 to 2035 are the following:

- for BAU: $\$ 779$ billion-0.85\%;

- for BAU renewable: $\$ 1,598$ billion-1.75\%; 


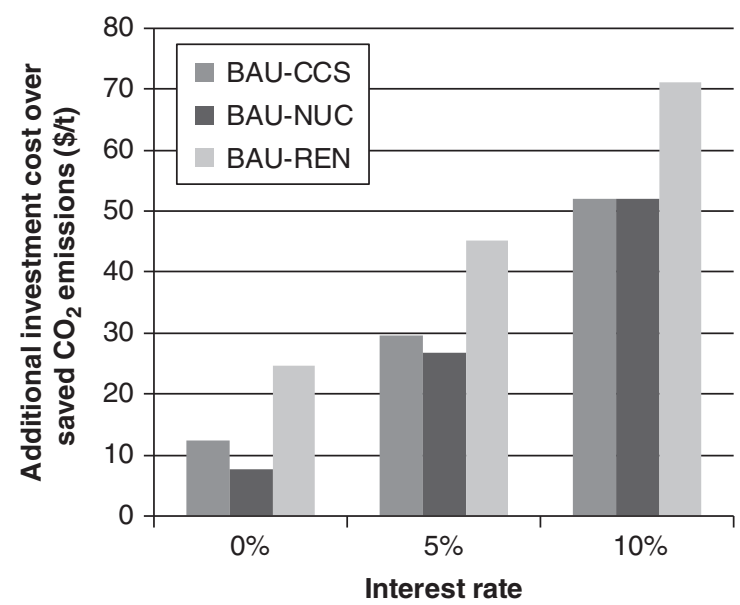

Figure 11.46 Additional Investment Cost per Unit of Carbon Dioxide Emissions for Three Business-as-Usual Scenarios in India

Source: Authors' model.

Note: $\mathrm{BAU}=$ business as usual; $\mathrm{CCS}=$ carbon capture and storage; $\mathrm{CO}_{2}=$ carbon dioxide, Nuc $=$ nuclear; $\mathrm{REN}=$ renewable.

- for BAU-CSS: $\$ 1,417$ billion-1.55\%;

- for BAU nuclear: $\$ 1,455$ billion- $1.60 \%$.

Depending on the scenario and interest rates, the additional cost per unit of $\mathrm{CO}_{2}$ saved varies between $\$ 7.6$ per ton in BAU nuclear at a $0 \%$ interest rate and $\$ 71$ per ton in BAU renewable at a $10 \%$ interest rate (Figure 11.46). The additional cost is the lowest in BAU nuclear followed by BAU-CCS and BAU renewable. The additional cost of the nuclear option is slightly lower than that for BAU-CCS partly due to the different investment lifetimes (60 years for nuclear, 40 years for CCS). These additional costs comprise only investments and not operating costs.

\section{Analysis of Asian Century business-as-usual scenarios}

By 2035, electricity generation will be 5.7 times the level in 2010 under ACSBAU; maintaining $\mathrm{CO}_{2}$ emissions at 2010 levels (Figure 11.47) will require a significant effort. The additional power and the resulting fuel mixes are as follow (Figure 11.48).

- In ACS-BAU renewable, 1,332 gigawatts of renewables are needed in addition to those in the BAU scenario which are $100 \mathrm{GW}$ of hydro, $702 \mathrm{GW}$ of 


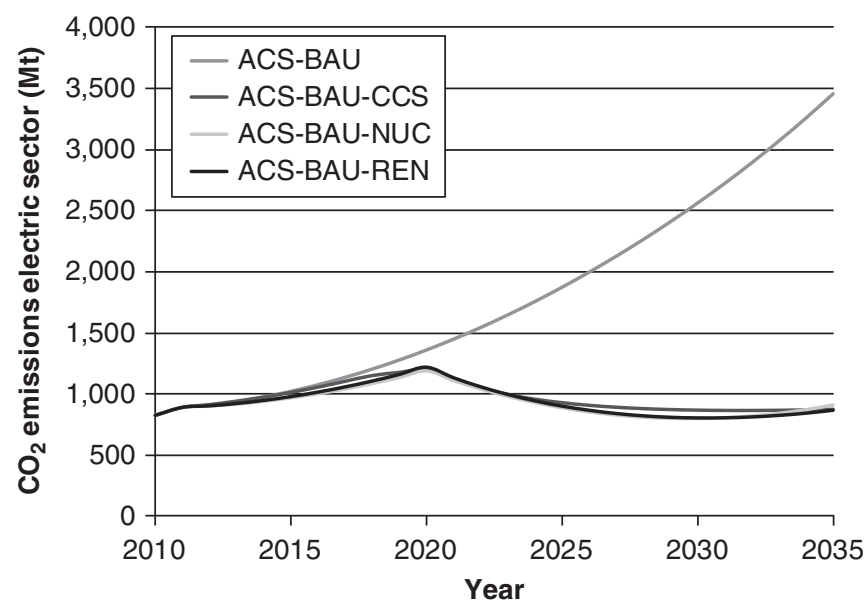

Figure 11.47 Carbon dioxide emissions in the power sector in India for four Asian Century business-as-usual scenarios, 2010-2035

Source: Authors' model.

Note: $\mathrm{ACS}=$ Asian Century scenario; $\mathrm{BAU}=$ business as usual; $\mathrm{CCS}=$ carbon capture and storage; $\mathrm{CO}_{2}=$ carbon dioxide; $\mathrm{NUC}=$ nuclear $; \mathrm{REN}=$ renewable.

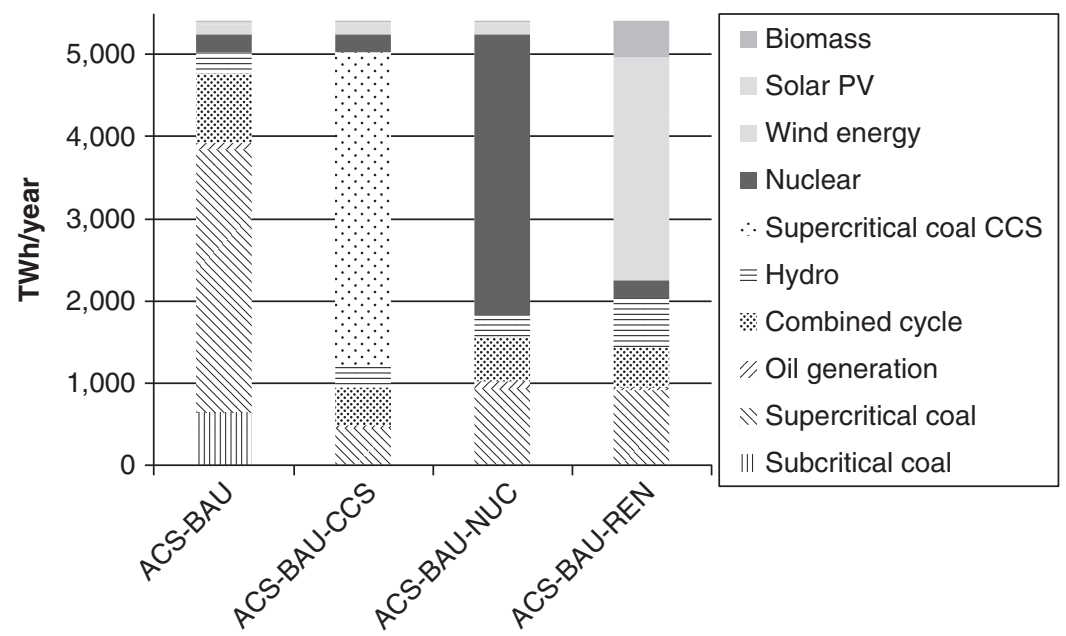

Figure 11.48 Mix of fuels for generating electricity in India in 2035 in four Asian Century business-as-usual scenarios

Source: Authors' model.

Note: $\mathrm{ACS}=$ Asian Century scenario; $\mathrm{BAU}=$ business as usual; $\mathrm{CCS}=$ carbon capture and storage; $\mathrm{NUC}=$ nuclear $; \mathrm{PV}=$ photovoltaics $; \mathrm{REN}=$ renewable; $\mathrm{TWh}=$ terawatt hour. 
wind, $440 \mathrm{GW}$ of solar photovoltaics, and $90 \mathrm{GW}$ of biomass. The fuel mix for generating electricity would be $17 \%$ conventional coal, $9 \%$ gas combined cycle, $1 \%$ oil, $11 \%$ hydro, $4 \%$ nuclear, and $58.3 \%$ renewables.

- In ACS-BAU-CCS, 650 gigawatts of CCS-enabled coal generation are needed. The fuel mix would be $8 \%$ conventional coal, $71 \%$ coal with CCS, $8 \%$ gas combined cycle, $1 \%$ oil, $5 \%$ hydro, $4 \%$ nuclear, and $3 \%$ renewables.

- For ACS-BAU nuclear, 417 gigawatts of nuclear power are needed in addition to the 28 gigawatts included in the BAU scenario. The resulting fuel mix would be $17 \%$ conventional coal, $10 \%$ gas combined cycle, $1 \%$ oil, $5 \%$ hydro, $64 \%$ nuclear, and $3 \%$ renewables.

With these measures, $\mathrm{CO}_{2}$ emissions would remain at 2010 levels (825 million tons/year) in 2035, and their share in total $\mathrm{CO}_{2}$ emissions would decrease from $53 \%$ in 2010 to $14.6 \%$. Cumulative saved emissions vary slightly by scenario since different technologies are introduced at different times, but they are all around 22 billion tons of $\mathrm{CO}_{2} /$ year.

The required investments and percentage of India's cumulative GDP from 2010 to 2035 are the following:

- for ACS-BAU: $\$ 1,231$ billion-0.92\%;

- for ACS-BAU renewable: $\$ 2,940$ billion-2.21\%;

- for ACS-BAU-CSS: $\$ 2,728$ billion-2.05\%;

- for ACS-BAU nuclear: $\$ 2,549$ billion-1.92\%.

The additional cost per unit of $\mathrm{CO}_{2}$ emissions saved ranges from $\$ 4.80$ per ton in BAU nuclear at a $0 \%$ interest rate and $\$ 67.00$ per ton in BAU renewable at a $10 \%$ interest rate (Figure 11.49). Generally the additional cost is the lowest for BAU nuclear followed by BAU-CCS and BAU renewable. The additional cost of the nuclear option is slightly lower than that for CCS partly due to the different investment lifetimes (60 years for nuclear, 40 years for CCS). Again, the additional costs comprise only investment and not operating costs.

\section{What is the role of the industry sector in saving energy?}

The Indian industry sector is responsible for $33.2 \%$ of total national energy consumption (IEA 2013). Compared with other economies, both the total energy use and the CEI of the industry sector are high for the country's level of development (Figures 11.18 and 11.19). Four industries account for $65.7 \%$ of the energy consumed by the entire sector: iron and steel, nonferrous metals, chemicals and petrochemicals, and nonmetallic minerals (mainly cement) (Authors' calculations). Our energy model shows that in 2035 these industries will continue to dominate in terms of energy consumption, and their contribution is likely to increase to $73.3 \%$ for the macroeconomic parameters set out in the ADB BAU scenario (Figure 11.50 ) or to $76.7 \%$ in the ACS-BAU scenario. What would the savings in energy and emissions be if today's best available technologies were 


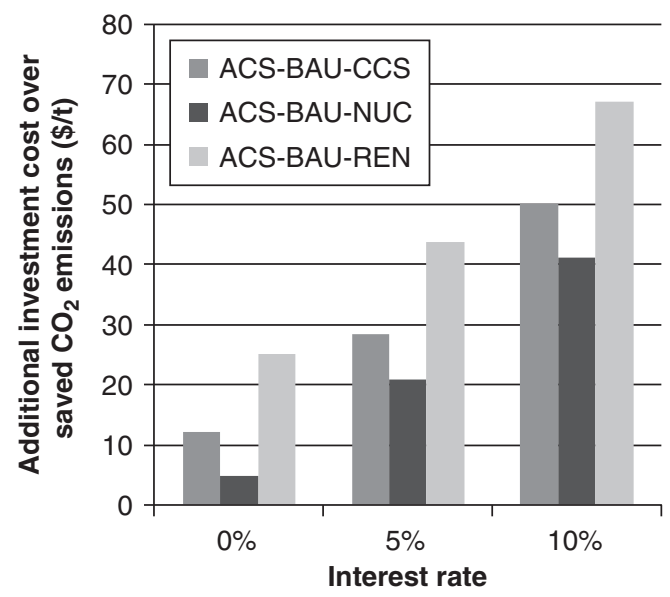

Figure 11.49 Additional cost per unit of carbon dioxide emissions saved in India for four Asian Century business-as-usual scenarios

Source: Authors' model.

Note: $\mathrm{ACS}=$ Asian Century scenario; $\mathrm{BAU}=$ business as usual; $\mathrm{CCS}=$ carbon capture and storage; $\mathrm{CO}_{2}=$ carbon dioxide $; \mathrm{NUC}=$ nuclear; $\mathrm{REN}=$ renewable.

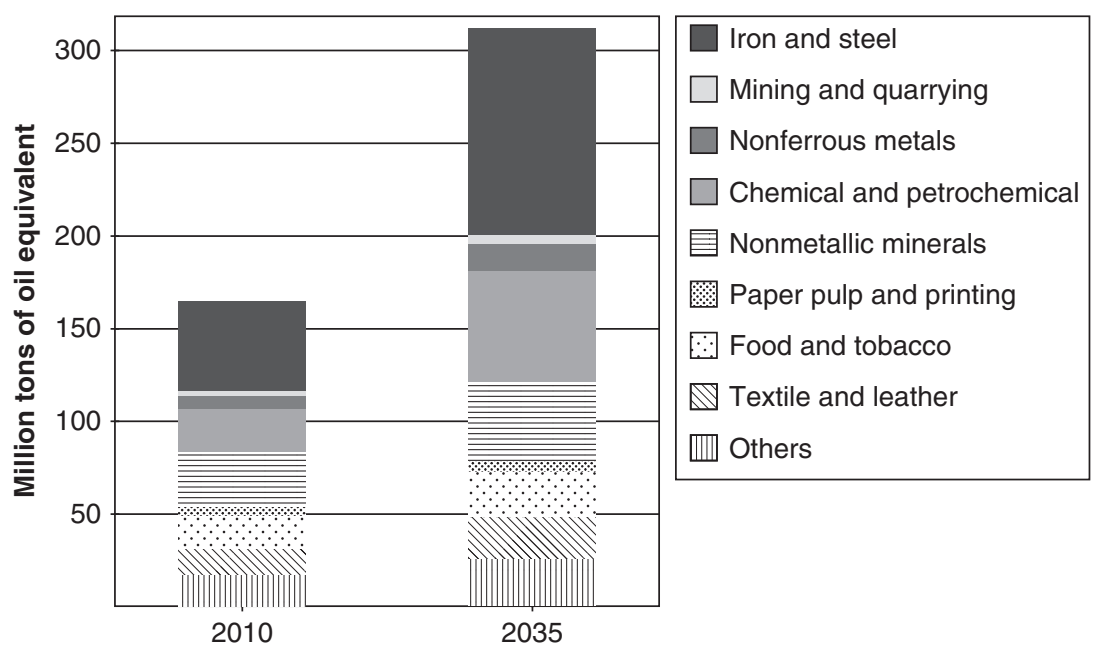

Figure 11.50 Energy consumption of the industry sector in India in 2010 and 2035 by industry (business-as-usual scenario)

Source: Authors' model. 
implemented? To investigate, we compared the consumption of the sector in 2010 with consumption with the best available technologies using the bottom-up model of the energy system and national statistics on the production of goods and the consumption of energy (Government of India 2012).

\section{Analysis}

The energy consumption of the industry sector would be reduced by $29 \%$ if best available technologies were implemented. The savings in the four main energy consuming industries would be $38.6 \%$ in iron and steel, $26.8 \%$ in nonferrous metals, $21.5 \%$ in chemicals and petrochemicals, and $31.2 \%$ in nonmetallic minerals (Figure 11.51). As a result, overall primary energy consumption would be reduced by $12.1 \%$ and total $\mathrm{CO}_{2}$ emissions by $18.8 \%$. The impact of implementing best available technologies is therefore substantial.

Indian industry is currently 7.8 times as energy intensive as the UK's, 6.2 times as intensive as Germany's, and 4.7 times as intensive as that in the US, and the $\mathrm{CO}_{2}$ intensity is 9.7 times that of the UK, 7.4 times that of Germany, and 5.5 times that of the US. Although best available technologies can help reduce these gaps, technology is not the primary reason for the high intensity of Indian industry; rather, it is caused primarily by the large contribution of energy-intensive manufacturing. Although the contribution of the industry sector to GDP in 2010 was relatively low (26\%) compared with other economies (such as the PRC at 47\%),

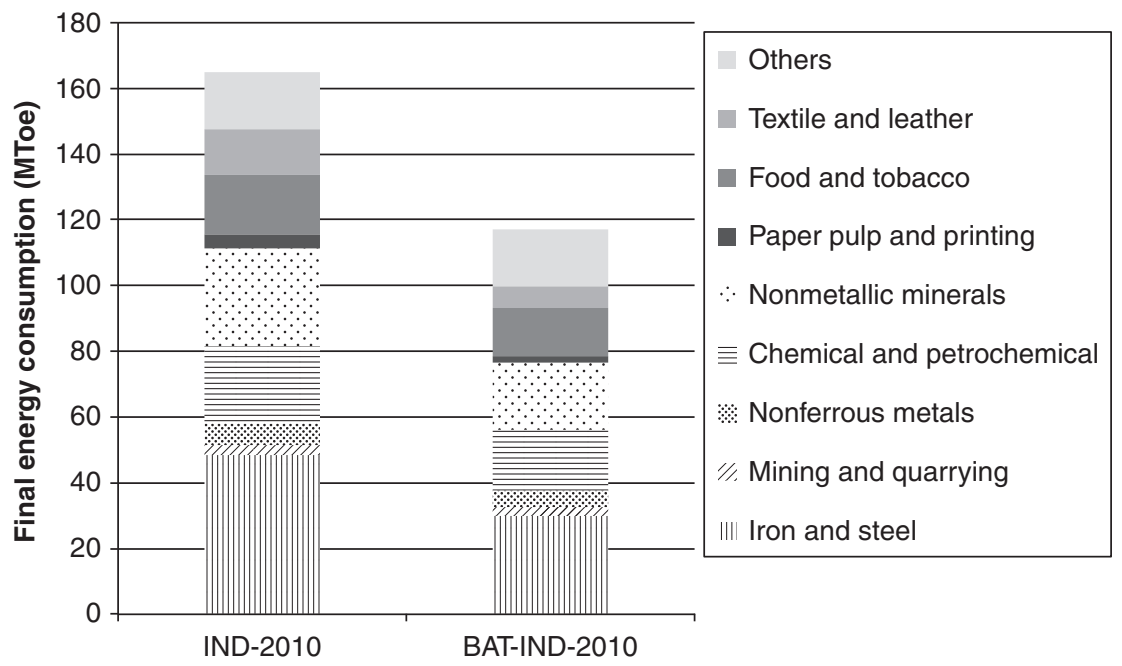

Figure 11.51 Energy consumption in India's industry sector in 2010 and with best available technologies in 2010

Source: Authors' model.

Note: $\mathrm{BAT}=$ best available technology; IND = industry sector. 


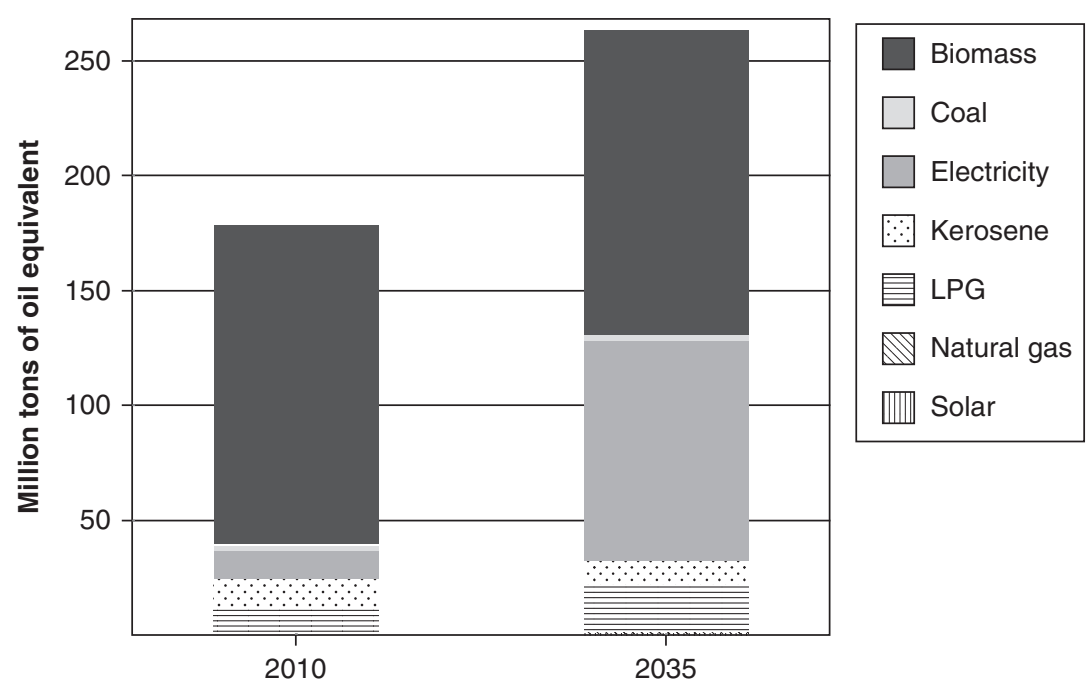

Figure 11.52 Energy consumption of households in India in 2010 and 2035 by fuel (business-as-usual scenario)

Source: Authors' model.

in 2010 India produced $6.1 \%$ of the world's cement ranking it 2nd (European Cement Association[MM86] 2010), 4.8\% of the steel (4th; World Steel Association 2010), 3.8\% of the aluminum (7th; Government of the United States 2010), and $8.7 \%$ of the ammonia (2nd; Index Mundi). Therefore in addition to efficiency measures, an industrial policy to reduce energy consumption and $\mathrm{CO}_{2}$ intensities should perhaps also consider diversifying to less energy-intensive industries.

\section{What is the potential contribution of the household sector?}

In 2010, 855 million citizens relied on biomass as their primary cooking fuel in India (90 million in urban areas and 765 million in rural areas; IEA, UNDP, and UNIDO 2010); that was nearly $75 \%$ of the total population. Furthermore, 404 million people - nearly $33 \%$ of the total population — did not have access to electricity (23 million urban and 380 million rural). In 2010, biomass accounted for $77.1 \%$ of the total energy consumption of households, and by 2035, the biomass share will still be $50.3 \%$ in the BAU scenario (Figure 11.52) and $43.1 \%$ under ACS-BAU, and nearly $20 \%$ of the population will lack access to electricity (IEA, UNDP, and UNIDO 2010).

As the country develops, more people will replace traditional fuels with natural gas or electricity. What will the additional demand for natural gas be as it displaces traditional fuels? What will the additional demand for electricity 


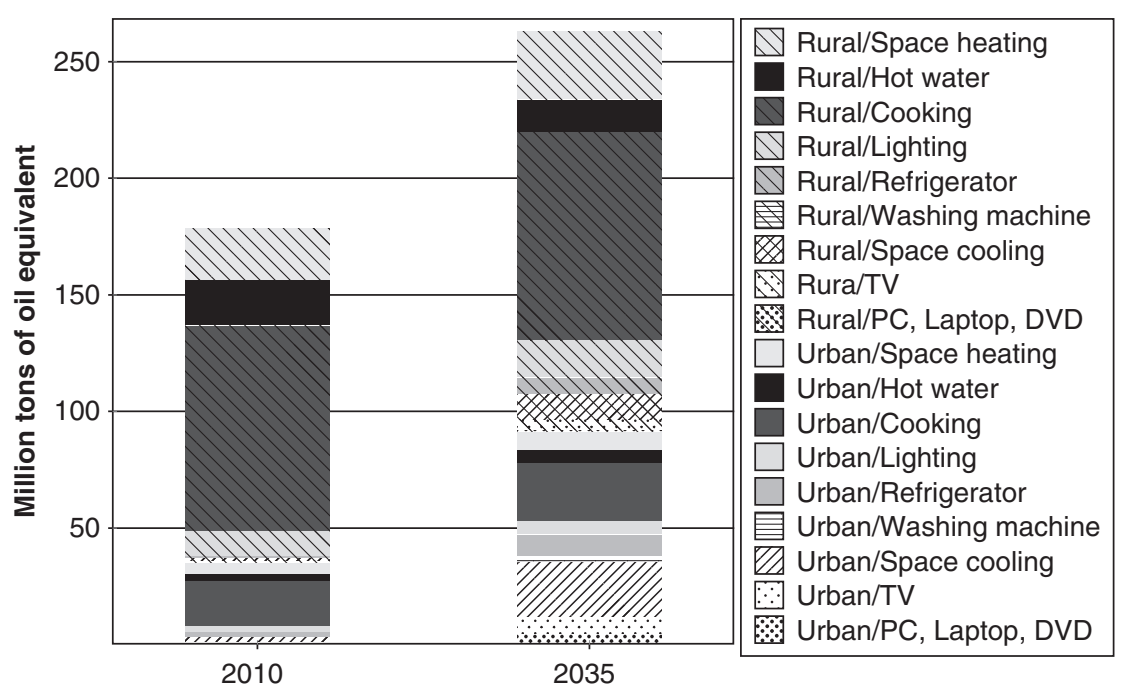

Figure 11.53 Energy consumption of households in India in 2010 and 2035 by activity (business-as-usual scenario)

Source: Authors' model.

(for lighting mainly) be as access increases? What will the impact on $\mathrm{CO}_{2}$ emissions be, and what potential impacts will more efficient lighting and appliances have?

To investigate the implications of shifting from traditional fuels to natural gas and electricity, we again used the bottom-up model of the energy system which includes the energy consumed for heating, heating water, cooking, lighting, and running appliances in households (Figure 11.53). We analyzed scenarios in which biomass is replaced by natural gas for cooking, oil lamps are replaced by electric bulbs (incandescent or CFLs), and appliances are more efficient.

\section{Analysis}

Substituting biomass, coal, and kerosene for cooking with natural gas would require $23.5 \mathrm{MToe}$ of natural gas per year, approximately $50 \%$ of the total natural gas demand in India in 2010. As a result, the energy consumed by households would decrease (Figure 11.54) as cooking with gas is more efficient (65\%) than with biomass (22\%). $\mathrm{CO}_{2}$ emissions would increase by 15 million tons which is less than $1 \%$ of the total emissions in India in 2010 (1.656 billion tons). In addition, nitrous oxide emissions would be reduced by $55 \%$, and sulfur dioxide emissions would drop by $56 \%$. 


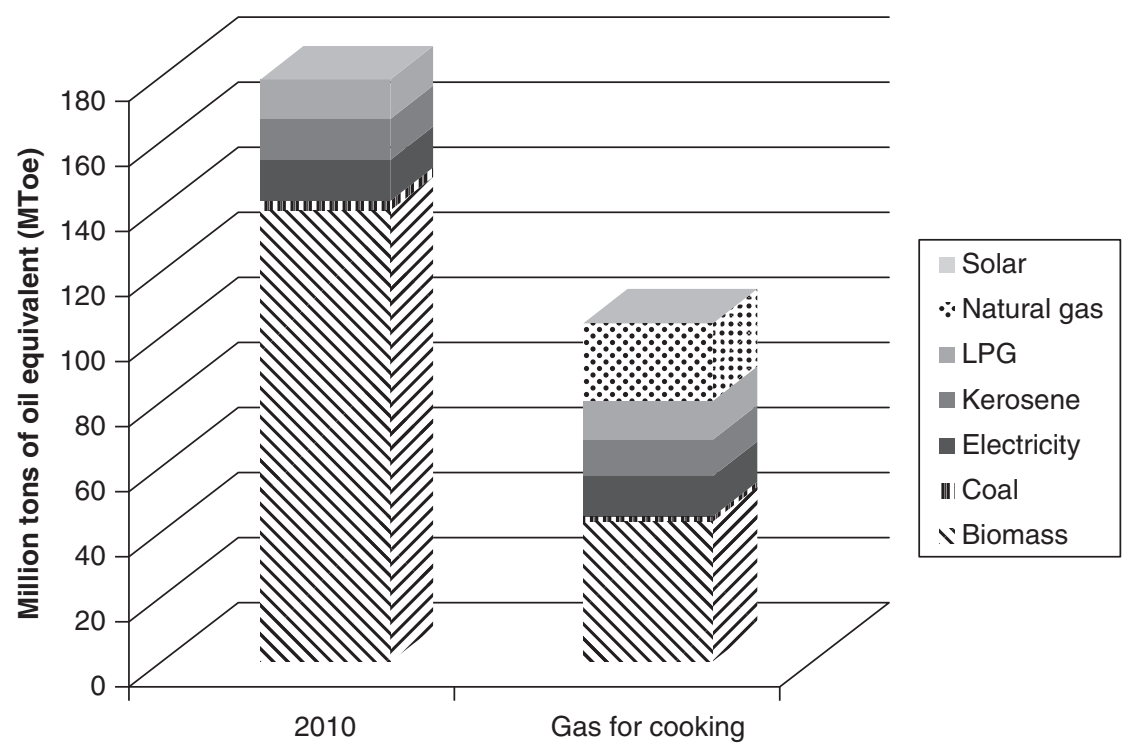

Figure 11.54 Energy consumption in Indian households in 2010 and substituting biomass for cooking with natural gas

Source: Authors' model.

Note: $\mathrm{LPG}=$ liquefied petroleum gas.

Replacing oil lamps with incandescent bulbs would increase electricity consumption by 19.2 terawatt hours/year (about $2.8 \%$ of total electricity consumption in India), but $\mathrm{CO}_{2}$ emissions would decrease by only 3 million tons since power generation is largely based on coal and distribution losses are high. Nitrous oxide emissions would be reduced by $6 \%$ and sulfur dioxide emissions would fall by $2.9 \%$. If oil lamps were replaced with CFLs, electricity consumption would be reduced from 146.7 to 122.1 terawatt hours/year $(3.6 \%$ of the total annual electricity demand in India), and $\mathrm{CO}_{2}$ emissions would decrease by 69 million tons.

More efficient appliances would save 22.7 terawatt hours/year (15.5\% of consumption by households and 3.3\% of total electricity demand). Furthermore, 35 million tons of $\mathrm{CO}_{2}$ emissions would be avoided annually.

The transition from traditional fuels to modern fuels would not, therefore, significantly increase energy demand or $\mathrm{CO}_{2}$ emissions, and the improvement in indoor air quality in rural and urban areas would be considerable. The main drawback for using natural gas for cooking is the limited indigenous gas reserves (the reserves-to-production ratio is 26.9 years; BP 2012) so additional imports would be needed in the long term. Using more efficient lighting could offset the increase in electricity demand. 


\section{Conclusions}

We developed a bottom-up model of India's energy system that embodies a comprehensive representation of the energy performance of the main sectors of the economy. The model was calibrated with historical statistical data to provide a detailed picture of the current state of the system. We then used it to project future demand in a manner consistent with the macroeconomic and energy data provided by the ADB energy outlook up to 2035 .

India's high primary energy intensity is mainly due to demand inefficiencies and to its economic structure and less to supply inefficiencies. The PEI can be reduced by about $30 \%$ through demand-side measures and by $13 \%$ through more efficient supply. Changes in the economic structure to make it closer to that in developed economies would yield a $30 \%$ improvement. Households consume the most energy in India, and the biomass share of that consumption is very high at nearly $78 \%$. Oil (kerosene) is widely used for lighting. Both biomass cookers and oil lamps are very inefficient (albeit biomass is carbon neutral); replacing the inefficient equipment can achieve a $67 \%$ reduction in the energy consumption of households and dramatically improve indoor air quality.

India has a high CEI. Our analysis shows that the main causes are energy inefficiency (high PEI) and the structure of the economy. The CIX plays a lesser role. It is interesting to note that India's CIX of $2.40 \mathrm{TCO}_{2} /$ Toe is not too far from that in developed economies: $2.40 \mathrm{TCO}_{2} /$ Toe in the US, $2.35 \mathrm{TCO}_{2} /$ Toe in the UK, $2.25 \mathrm{TCO}_{2} /$ Toe in Germany, and $2.04 \mathrm{TCO}_{2} /$ Toe in Canada. The reason is that the large share of $\mathrm{CO}_{2}$-free energy sources $(27.5 \%)$ compensates for the $41.2 \%$ contribution from coal. An increase in the CIX from 2010 to 2035 will be the main cause of the high CEI in 2035, particularly in the high-growth scenarios. Containing the CIX will be a challenge for policymakers.

To achieve significant savings in oil consumption by 2035 , the electrification of the transport sector must be accelerated. Energy consumption is currently dominated by road transport at $85 \%$; this will increase to $90 \%$ by 2035 . Since the share of road passenger transport is high (44\% in 2010, 59\% in 2035), there are opportunities for savings through electrification. Oil savings of $37 \%$ to $39 \%$ would be achieved (depending on the scenario) with high penetrations of electric cars and motorcycles (50\%), 100\% railway electrification, and the use of light electric trucks for $15 \%$ of road freight. The additional electricity required is modest and manageable (about $8.2 \%$ additional power for these scenarios). Electrifying the transport sector will not, however, significantly decrease overall $\mathrm{CO}_{2}$ emissions because power generation relies heavily on low-efficiency coal, and distribution losses are very high.

The largely coal-based supply is the main reason for the $\mathrm{CO}_{2}$ intensity of the Indian power sector; it is one of the highest in the world. Coal supplied $68 \%$ of fuel to generate electricity in 2010 and will supply between $64 \%$ and $71 \%$ in 2035. An accelerated transition to $\mathrm{CO}_{2}$-free technologies would improve the $\mathrm{CO}_{2}$ intensity but at a cost. To cope with growing demand, the investment in (mainly conventional) power assets up to 2035 is estimated at $\$ 779$ billion in the BAU 
scenario (this is about $0.8 \%$ of the cumulative GDP from 2010 to 2035). If new power assets are carbon free to maintain $\mathrm{CO}_{2}$ emissions at 2010 levels, this investment would be $\$ 1,417$ billion (1.5\% of the cumulative GDP) for coal with CCS, $\$ 1,455$ billion for nuclear, and $\$ 1,598$ billion for a portfolio of renewables. The cost of the saved emissions is between $\$ 50$ and $\$ 70$ per ton of $\mathrm{CO}_{2}$ at a $10 \%$ interest rate or $\$ 28$ to $\$ 45$ at a $5 \%$ interest rate.

The Indian industry sector is very energy intensive for the country's level of development and accounted in 2010 for $33 \%$ of total energy consumption. Iron and steel, nonferrous metals, chemicals and petrochemicals, and nonmetallic minerals accounted for $66 \%$ of the demand; that will increase by 2035 . Our analysis shows that using best available technologies throughout the industry sector would reduce energy consumption by $29 \%$, but the difference in energy intensity compared with developed economies would remain. For this to be further reduced, the sector needs to diversify to less energy-intensive manufacturing.

Replacing biomass, coal, and kerosene as cooking fuels in households and oil for lighting would both increase energy efficiency and provide better indoor air environments. The widespread use of gas for cooking would require an additional 23.5 MToe of natural gas per year and would decrease total energy consumption in houseolds by about $42 \%$. Because biomass is carbon neutral but natural gas is not, total $\mathrm{CO}_{2}$ emisions in India would increase by about $1 \%$, but nitrous oxide and sulfur dioxide emissions would be reduced by $55 \%$. For lighting, 19 terawatt hours/year would additionally be required if incandescent bulbs are used, but about 24 terawatt hours/year would be saved by using CFLs. This is about $3 \%$ of the total electricity demand. A similar saving could be achieved by replacing current appliances with more efficient ones.

\section{References}

Asian Development Bank (ADB). 2010. Asian Development Outlook. Manila: ADB.

- 2011. Asia 2050. Realizing the Asian Century. Manila: ADB.

—. 2013. Asian Development Outlook: Asia's Energy Challenge. Manila: ADB.

BP. 2012. Statistical Review of World Energy. www.bp.com/statisticalreview (accessed February 2014).

European Cement Association. 2010. Key facts \& figures. http://www.cembureau.eu/ about-cement/key-facts-figures (accessed February 2014).

Government of the People's Republic of China. National Bureau of Statistics. 2012. Statistical Yearbook 2012. Beijing: China Statistical Press.

—. National Bureau of Statistics. 1991-2011. [People's Republic of] China Energy Statistical Yearbook. Beijing: China Statistical Press.

Government of India, Ministry of Statistics and Programme Implementation. 2012. Statistical Yearbook. New Delhi.

Government of the United States. Department of the Interior, United States Geological Survey. 2010. Aluminum Statistics and Information. http://minerals.usgs.gov/minerals/ pubs/commodity/aluminum/(accessed February 2014).

Index Mundi. 2010. Ammonia: Estimated World Production By Country. http:// www.indexmundi.com/en/commodities/minerals/nitrogen/nitrogen_t12.html (accessed February 2014). 
International Aluminium Institute. 2010. Primary Aluminium Production. http://www. world-aluminium.org/statistics/ (accessed February 2014).

International Energy Agency (IEA). 2012. Energy Balances of Non-OECD countries. Paris: Organisation for Economic Co-operation and Development.

—. 2013. Statistics. http://www.iea.org/stats/index.asp (accessed February 2014).

International Energy Agency (IEA), United Nations Development Programme (UNDP), and United Nations Industrial Development Organization (UNIDO). 2010. Energy Poverty: How to Make Modern Energy Access Universal? Special early excerpt from the World Energy Outlook 2010 for the UN General Assembly on the Millennium Development Goals. New York: United Nations.

World Bank. Data. http://data.worldbank.org/ (accessed January 2013).

World Steel Association. 2010. Annual crude steel production. http://www.worldsteel.org/ statistics/statistics-archive/annual-steel-archive.html (accessed February 2014). 



\section{Part V}

\section{Key findings and policy recommendations}





\title{
12 Findings and recommendations
}

\author{
Minsoo Lee, Donghyun Park, and \\ Harry D. Saunders
}

\section{Current state of energy security in developing Asia}

Rapid economic growth during the past few decades has transformed developing Asia into one of the major centers of the world economy and has lifted hundreds of millions of Asians out of poverty. Going forward, sustaining growth will require a huge increase in energy, so the foremost challenge is to secure an adequate and reliable physical supply or growth will be curtailed. Even if Asia were to successfully meet this challenge, it must further ensure that the expanded supply is environmentally sustainable and affordable to the poor. Overall, the current energy situation is grim and raises serious concerns about the capacity to secure a clean, affordable, adequate supply.

Energy requirements in Asia are growing rapidly largely as a result of rapid economic growth In 2010, Asia contributed 28\% of global GDP. If it follows the expected growth trajectory, by 2050 its per capita gross domestic product (GDP) will reach the current level in Europe, and its share of global GDP will nearly double to 52.3\%, making about 3 billion more Asians affluent (ADB 2011). Asia will already account for $44.3 \%$ of global GDP by 2035 . Such economic expansion requires huge amounts of energy. Already in 2010, Asia accounted for $34 \%$ of world energy consumption. Assumptions about the evolution of energy intensity - changes in the physical energy used to generate each unit of GDPhave significant effects on forecast demand. For example, if Asia's energy intensity declines by $3.2 \%$ per year on average, energy intensity will fall in 2035 to $45 \%$ of its 2010 value - an improvement by better than half - and the regional share of global energy use is projected to increase to $51 \%$ by 2035 . On the other hand, if energy intensity follows its historical trend from 1990 to 2000 and declines by $2.47 \%$ per year, Asia's share of global energy consumption in 2035 will be even higher at $56 \%$.

Fossil fuels will account for most of the increase in energy consumption between 2010 and 2035 The current composition of energy demand in Asia holds some important clues about the mix of primary sources that will satisfy the growing appetite for energy. According to our baseline scenario (see Chapter 1), most of 
the two fold (202\%) increase in energy consumption from 2010 to 2035 will come from fossil fuels. Coal use is expected to increase by $81 \%$ as oil consumption approximately doubles and natural gas use more than triples. The use of renewables is set to increase but will make a relatively small contribution to 2035 energy requirements. The same goes for nuclear power.

East and South Asia account for the lion's share of regional energy consumption, but there are significant differences and similarities across subregions in terms of the energy mix. For example, coal plays a much larger role in East and South Asia than in Central and West Asia, Southeast Asia, or the Pacific. On the other hand, coal, oil, and natural gas dominate in all while renewables and nuclear occupy only a limited share.

Oil poses the biggest risk to an adequate and reliable supply of energy in Asia Coal is abundant in Asia at $35 \%$ of world endowment. Less abundant than coal is conventional natural gas of which Asia has $16 \%$ of proven global reserves. Asians can, however, expect to have relatively unfettered access to both coal and gas through international trade. In contrast, oil poses the greatest threat to the adequacy of the physical energy supply as proven reserves of crude oil amount to a mere $9 \%$ of the world total. When combined with natural gas liquids, the Asian share is $15 \%$ of world reserves. Taking into account Asian production, oil imports are expected to almost triple from 11 million barrels per day to over 31 million by 2035 , growing annually by $4.2 \%$. In $1990,33 \%$ of oil imports came from the Middle East; by 2010, this figure had increased by half to $48 \%$. As this accelerating trend will likely continue, the high and growing dependence on a single region poses a risk to an adequate and reliable energy supply. Asia uses oil largely for transportation (48\% in 2010) which is difficult to substitute in the short run. Much of the projected surge in oil imports reflects the expected rapid expansion of motor traffic.

Expanding the primary energy mix as currently projected will have serious consequences for the environment This is true both in Asia and globally. Local air and water quality, water availability, land use, and the global climate all stand to suffer greatly if projected energy demand is met mostly by fossil fuels. Air pollution is caused largely by energy production and use. The energy and transport sectors generate $70 \%$ of nitrogen oxide emissions and $80 \%$ of emissions of sulfur dioxide and particulate matter. Air pollution is projected to cause more than 3.6 million deaths per year by 2030 throughout the region, mostly in the People's Republic of China (PRC) and India. If developing Asia continues to rely on fossil fuels, its energy-related carbon emissions (ignoring other greenhouse gas (GHG) emissions) will more than double. By 2035, Asia will contribute nearly half of global carbon dioxide $\left(\mathrm{CO}_{2}\right)$ emissions (IEA 2012).

Asia currently has the unfortunate distinction of harboring most of the world's energy poor Assuming Asia can secure an adequate physical energy supply to power growth and safeguard the environment, the challenge of ensuring that 
energy is accessible and affordable remains. Affordable energy is a prerequisite for inclusive growth and for the political support that makes policies effective. Energy poverty perpetuates hunger by forcing women and children to gather fuel instead of earning incomes or studying. Nearly half of the world's people without electricity live in Asia as do the majority of people who rely on traditional fuels such as wood, charcoal, and dung. In 2010, 2.8 billion Asians relied on such traditional fuels which provide low-quality energy while often destroying natural ecosystems. Affordable access to modern energy is shockingly deficient in Asia. In 2010, 18\% of Asians - 628 million people-had no electricity. In that year, the percentage of the population without electricity and reliant on biomass for cooking was higher in Africa than in Asia, but some Asian countries such as Bangladesh approached the African average.

Based on current trends, the energy future of Asia is stark. It suggests that Asia will be hard pressed to secure enough energy to achieve the rapid growth required for widespread poverty reduction. Further, high growth in energy supply must be accompanied by significant changes in quality to protect the environment and to ensure affordable access. This threefold challenge requires a multipronged approach. The region needs to aggressively explore all options by which to (i) curb its burgeoning energy demand; (ii) tap new energy supplies; and (iii) foster regional market synergies that maximize the gains achieved on both sides of the demand-supply equation.

\section{Curbing burgeoning energy demand}

Several strategies offer promise for more efficiently managing demand even in the short term. Broadly speaking, these strategies fall into three groups. First, eliminating consumer subsidies and taxing GHG emissions will move the price of energy toward its true cost. Second, green innovations such as smart cities and clean transportation will improve energy efficiency and environmental sustainability. Third, changing behavior can curtail wasteful energy consumption. Demand management strategies are promising but present various challenges. Tackling outmoded subsidies requires political will, green innovation takes investment in technology, and changing behavior entails instilling fundamentally new attitudes.

Reforming consumer subsidies can reduce overconsumption Consumer subsidies designed to guarantee affordability and protect households from the potentially large shocks of fuel price increases artificially reduce the price of energy and thus encourage overconsumption. Worse, the main beneficiaries of energy subsidies are not the poor. If the intent is to make energy more affordable to the poor, only the poorest $20 \%$ should benefit from the subsidy. In fact, the poor in Asia benefit little from subsidized fuel prices because many lack electricity and gas connections, few own vehicles, and most use transport sparingly. The International Energy Agency (IEA 2011) surveyed nine Asian countries with the highest fossil fuel subsidies along with two countries in Africa and found that 
only $15 \%$ of the benefit of kerosene subsidies - and a paltry $5 \%$ of subsides for liquefied petroleum gas-went to the poorest $20 \%$. Replacing general energy subsidies with subsidies targeting the energy poor can immediately restrain energy demand without denying those in need.

Technological innovation can promote energy efficiency as well as environmental sustainability Good city planning and design can lower individual and aggregate energy requirements by, for example, using waste heat from power generation to serve the heating and cooling needs of commercial buildings and households if the geographic configuration is compact enough. Ulaanbaatar, Mongolia is procuring a combined heat and power plant to replace aging counterparts. Gaseous transportation fuels such as compressed natural gas $(\mathrm{CNG})$ can mitigate the environmental impact of urban transportation. In Seoul, the city government restricted buses operating in the city to CNG starting in 2010. Substituting gas for electricity in end-use applications saves gas and displaces coal and other dirtier types of energy. Green innovation requires large investments in new technology and infrastructure, but the benefits are potentially huge.

Fundamental changes in behavior are required to more efficiently use energy Prices that reflect the true cost of energy will induce Asian households and firms to use energy more efficiently, but much more can and should be done to promote more efficient energy use. Above all, the general public must recognize that energy is a scarce, valuable resource and must use it accordingly. The impact of new energy efficiency technologies will depend on the scale and speed of their uptake. Conservation programs can induce individuals to refrain from purely wasteful energy consumption. Changing behavior ultimately requires a fundamental shift in attitudes. The government should act as a catalyst in this endeavor as the Japanese experience shows. Japan has steadily improved its energy efficiency over time. In fact, energy efficiency improved by 25\% between 1980 and 2010, and today Japan enjoys the lowest energy intensity in the world. Asia thus stands to reap large gains from emulating Japan's efforts to change energy behavior.

In summary, better demand management can bring Asia significantly closer to the goal of energy security. It can do so by reducing the risk of inadequate supply and promoting environmental sustainability. While better demand management is absolutely necessary for energy security, it cannot cover the whole distance. The journey requires solving the supply side of the equation by augmenting the supply of clean, affordable energy. Fortunately, like the demand side, the supply side is as full of promising options.

\section{Tapping a cleaner energy supply}

The current energy picture in Asia contemplates some degree of enhancing energy supply: introducing unconventional gas, deploying renewables, and modestly expanding nuclear power. As noted, however, meeting the needs of sustained rapid growth would mean a tremendous increase in energy imports based 
on current plans to enhance indigenous supplies. Expanding its energy supply in a way that is environmentally sustainable will require a combination of renewable energy, cleaner nonrenewable sources, and technologies to make carbonbased fuels cleaner to use.

Renewable energy is growing rapidly in Asia, but substantially greater investments are needed Wind, solar, and other renewable energy technologies directly harness naturally available energy sources. They thus help to insulate prices from the ups and downs of fossil fuel production thereby strengthening future energy security. The use of renewables is projected to increase by half in Asia until 2035. For example, the installed capacity of wind power in Asia in 2011 was 82.0 gigawatts - $36 \%$ of the total world capacity of 237.5 gigawatts - and comparable to the 96.5 gigawatts in Europe. By the end of 2012, global capacity had increased by $19 \%$ to 282.5 gigawatts. At 75.5 gigawatts, the PRC leads the world, and India ranks fifth with 18.5 gigawatts. Despite their rapid expansion, due to their high costs relative to nonrenewable energy, renewables will not make a major difference in Asia's energy future any time soon. Renewables together will still account for only $13 \%$ of the power generation mix in 2035 . However, investing in capacity and technology can accelerate development and bring down costs. The massive energy market in Asia provides opportunity and room to introduce and develop new technologies. Asia is already a world leader in the manufacture of state-of-the-art equipment for renewable technologies.

Asia is home to large shale gas reserves; effectively developing them can contribute to energy security The shale gas revolution is perhaps the single biggest supply-side development in global energy markets in recent years. Since natural gas is a relatively clean source of energy, shale gas can promote both an adequate supply and environmental sustainability. The recent revolution in shale gas production arose as two technologies came together: horizontal drilling and hydraulic fracturing. In the United States, the shale gas share of all gas production exploded from $8 \%$ in 2007 to $30 \%$ in 2011 . Asia almost certainly has significant reserves of unconventional gas. What is uncertain is where it is and how much of it is technically recoverable. The PRC has the largest shale gas resources in the world at nearly $20 \%$ of the global total. India and Pakistan also have substantial reserves. A number of challenges stand in the way of an Asian shale gas revolution, however, including difficult geological conditions, lack of geological data, and the fact that reserves are on densely populated land. Addressing the geological, technological, and environmental obstacles will improve developing Asia's energy security.

Cleaner coal technology can deliver sizable environmental benefits for Asia, while phasing out nuclear power would impose sizable environmental costs The energy future of Asia would have far different GHG consequences if the coal used for generation were more benign. GHG-benign coal requires carbon capture and storage (CCS) technology which is at an early stage of development and thus 
very expensive. Some Asian economies have shown interest and are studying the status of the technology, how CCS could be used to reduce industrial $\mathrm{CO}_{2}$ emissions, and what types of geological options exist for sequestering $\mathrm{CO}_{2}$. In 2012, the Republic of Korea opened the Carbon Capture and Sequestration Research Center to develop new CCS technologies. Asia can become a hub of technological leadership in developing CCS as it is the world's biggest user of coal. While the Fukushima nuclear accident highlighted the potentially large safety risks of nuclear power, a dispassionate country-by-country assessment is required. In contrast to renewable energy, nuclear power is already cost competitive with fossil fuels. Furthermore, phasing out nuclear power from 2010 to 2035 would increase carbon emissions by $220 \%$ to $375 \%$ more than the combined emissions of the PRC and India in 2010.

Each new energy source has its merits and shortcomings. Individually, their contributions to improving energy security in Asia will be limited, but collectively the various sources can make a big difference, especially when combined with better demand management. Asia must therefore strive on all fronts to secure ample, affordable, and clean energy supplies. More specifically, Asian economies must aggressively explore and invest in a good mix of sources and technologies in line with their specific needs and comparative advantages. Developing these future technologies will often require government support in the early stages when they are a long way from commercial viability. Different energy supply endowments - different comparative advantages-across the region suggest scope for gains from trade if arrangements can be devised. Regional coordination can make the most of individual efforts to boost energy security.

\section{Fostering regional market synergies}

Cross-border energy markets and infrastructure connectivity have so far been largely ignored in regional cooperation and integration. This is unfortunate in light of the rapidly rising energy demand that makes energy security a regional challenge that would benefit greatly from a collective response. The lack of regional cooperation and integration is all the more glaring as jointly promoting energy savings and energy security would not require new technology or pose the high cost and financial risk developing it might entail. It does, however, require the political will to cooperate and the mutual confidence that makes cooperation possible.

Cross-border integration of electricity and natural gas networks in Asia is currently limited but has enormous potential benefits The incentives to interconnect electric power systems are strong in terms of improved reliability, more effective fuel conservation, and broader economic benefits. Larger systems typically deliver power at a lower cost per kilowatt hour than do smaller ones owing to economies of scale and to diversified generation mix, and they advance the cause of energy efficiency. For example, the uneven distribution of the Greater Mekong Subregion's substantial energy resource base multiplies the huge 
potential gains achievable from regional energy integration. Integrating power transmission in the subregion would save an estimated $\$ 14$ billion over 20 years by substituting hydropower for fossil fuels. Further, it would reduce $\mathrm{CO}_{2}$ emissions by 14 million tons per year by 2020. Similar economies and efficiencies are realizable by connecting natural gas systems. One prominent example of mutual benefit through regional interconnection is the gas pipeline running from Turkmenistan to the PRC that was completed in December 2009. The pipeline will help to quench the PRC's fast-growing thirst for energy while giving gasrich Turkmenistan access to a large and growing energy market.

Smart grids can advance the cause of regional energy integration by linking supply and demand across borders As renewable energy sources grow, so-called smart grids that integrate renewables into the electricity network will play a bigger role in regional cooperation and integration. The fundamental reason is that renewable energy endowments are often remote from demand centers, but there is no reason to expect readily paired supply and demand centers to even be in the same country. Wind power from thinly populated Mongolia can provide electricity to the PRC or even to the Republic of Korea. Mongolia has enough wind resources for 1 terawatt of installed capacity collected by about 200,000 wind turbines, each with a 5 megawatt capacity. Similarly, hydropower from Myanmar can provide electricity to the Bangkok metropolitan area in Thailand. Cost effectively linking thinly populated areas that offer ample renewable supply potential with populous, economically active markets through smart grids can catalyze the development of renewable energy in Asia.

Asia must overcome technical and policy challenges to realize the fruit of regional cooperation and integration Interconnecting energy systems across international frontiers requires participating governments to adopt compatible technical standards and regulatory regimes. Interconnecting electricity and gas grids requires standardized regulations, pricing practices, and contracts. As the European experience illustrates, the technical barriers to integration are readily surmountable. The larger challenge inhibiting energy integration in Asia is summoning the political will to coordinate policy. Asian leaders, like others around the world, tend to view energy security as a vital component of national security which makes them reluctant to relinquish control. In addition to national security, there is a strong element of international competition for energy that is often intense because energy resources are limited. Within individual countries, powerful vested interests that may see their dominant positions in domestic energy markets eroded also stand in the way of regional cooperation and integration.

While regional cooperation and integration are on the rise in Asia, especially subregionally, they remain limited in the energy sector. This is unfortunate since cross-border energy markets and infrastructure connectivity can contribute significantly to energy security. Technological progress, e.g., smart grids that link renewable energy in sparsely populated areas to heavily populated centers of economic activity, can help promote regional cooperation and integration, as can 
harmonization of technical standards and regulatory regimes. Above all, what is required is the political will and commitment to more closely integrate energy sectors.

\section{Policy options for a brighter Asian energy future: every watt counts}

The analysis in this book makes it abundantly clear that developing Asia must urgently take aggressive policy actions to abandon the path to a decidedly stark energy future and instead pursue a future in which Asians enjoy secure access to adequate supplies of clean energy that is affordable to all. To realize the vision of a Clean Asian Century with its promise of robust economic growth and substantially rising incomes, Asia must adopt a broad program of policy prescriptions on several fronts.

Asia must aspire to create a pan-Asian energy market by 2030 When it comes to regionally integrated electricity and gas markets, thinking big maximizes benefits. Asia must aspire to the degree of regional cooperation and integration in energy that currently prevails in Europe. The first step is to set up a ministerial task force to study the European experience and to promote the political will to share information on national power sectors more openly and to better harmonize regulations, standards, and pricing policies. To achieve a pan-Asian energy market, Asian economies need to muster the political will to look beyond narrow self-interests and clear the political hurdles that stand in the way of energy integration that is technically feasible and commercially viable. Overcoming technical obstacles - differences in standards, regulations, and energy pricingrequires fostering goodwill in political relations to build the confidence to be open and equitable about sharing benefits.

Asia must immediately take concrete steps to curb demand Replacing inefficient general fuel subsidies with targeted subsidies can be a politically acceptable approach to eliminating broad inefficiencies without leaving the out the poor. Second-generation GHG-emission taxes recycle tax proceeds to help reduce the cost of cleaner inputs thereby limiting their adverse impact on economic activity while mitigating global warming. Planning for "green cities" is crucial for an increasingly urban Asia. Reducing demand not only reduces the risk of supply bottlenecks but also promotes a cleaner environment. A good place to start with energy is getting the price right. Developing Asia must eliminate or rationalize distortionary subsidies as rapidly as practical to reduce energy overuse and waste. Subsidies impose a tremendous burden on public budgets exceeding $2 \%$ of GDP in India, Indonesia, and Viet Nam and 4\% in Bangladesh and Pakistan. Asian governments must take the lead in changing the public's attitude toward energy use.

Asia should strive to diversify and optimize its energy mix in the medium and long term In particular, it should rein in its disturbingly heavy dependence on 
imported oil. The share of imports supplied from the Middle East rose from $33 \%$ in 1990 to $48 \%$ in 2010 . Such deepening dependence on a single region combined with the lack of substitutes for oil in transportation and industrial uses, undermines the reliability and adequacy of the energy supply. Securing adequate and reliable supplies of clean, affordable energy is challenging but achievable. As energy sources vary across the region, the options of economies to augment energy supplies will depend on endowments and needs. Potential energy sources have their own merits and shortcomings, but every drop-every watt-counts! Developing future technologies requires government support in the beginning. Effort is required on all fronts according to the comparative advantages of each economy. Asia should take full advantage of its rich renewable energy potential as well as its sizable nonrenewable energy sources including shale gas reserves.

\section{Asia should address the needs of the poor and residents of low-income countries} in order to achieve true energy security Low-income economies need international aid to help them build equitable energy infrastructure that protects the poor. Extending affordable access to the entire population and narrowing the wide gaps between Asian economies will promote inclusive growth across the continent. A high priority should be expanding the delivery of affordable energy to the poor. Despite rising affluence, in 2012 almost 700 million Asians - 18\% - still lacked access to basic energy services such as electricity or to modern fuels. Developing Asia must thus strive to achieve universal access to affordable energy as soon as possible. This necessarily entails special programs that support the energy consumption of the poor. Unlike general energy subsidies that disproportionately benefit the non-poor, means-tested assistance that targets the poor extends energy access without jeopardizing fiscal sustainability. Also important is exploring how to adapt new technologies to the energy needs of the poor.

Asia must broaden and deepen its intellectual capital to better support its physical investments in energy A modern energy sector will come about only if the knowledge base is there to support it. As the biggest energy user, Asia must acknowledge its role as the lynchpin of climate change mitigation and strive to marshal research and development capacity equal to the task. Transfer from developed countries can accelerate the deployment of new technologies, but the region must aggressively invest more on researching and developing new energy technologies. At the same time, Asia needs to engender an institutional and policy environment conducive to creating and adopting new technologies. A policy priority for the whole region is to invest more in educating and training energy specialists, scientists, and engineers and to allocate more funds to education, especially at the tertiary level, to develop the human capital required to meet the energy challenge. Individually, each new energy technology makes only a limited contribution to energy security; collectively they can make a big positive difference. 


\section{Minsoo Lee, Donghyun Park, Harry D. Saunders}

Achieving energy security in Asia requires a multipronged strategy that includes the following five policy elements.

- Create a pan-Asian energy market by 2030.

- Immediately take concrete steps to curb demand.

- Diversify and optimize the energy mix in the medium and long term.

- Address the needs of the poor and residents of low-income countries to achieve true energy security.

- Broaden and deepen intellectual capital to better support physical investments in energy.

\section{References}

Asian Development Bank (ADB). 2011. Asia 2050: Realizing the Asian Century. Manila: ADB.

International Energy Agency (IEA). 2011. Energy for All: Financing Access for the Poor. Paris: Organisation for Economic Co-operation and Development (OECD)/IEA. http://www.worldenergyoutlook.org/media/weowebsite/2011/weo2011_energy_for_all. pdf (accessed February 2014).

- 2012. Golden Rules for a Golden Age of Gas: World Energy Outlook Special Report on Unconventional Gas. Paris. http://www.worldenergyoutlook.org/goldenrules/ (accessed February 2014). 


\section{Index}

Act on Granting Priority to Renewable

Sources, Germany 318

Action Plan on Nuclear Safety

(IAEA) 346

Advisory Group on Energy and Climate Change 133

affordability of electricity (EOL) 82,85 , 99, 108-9, 112, 121-2, 126-7

air pollution: energy security $162,166-7$; fossil fuels 266; GDP 166; premature deaths 340; regional acidification 340; "threat multipliers" 161

Alternative Energy Promotion Center, Nepal 148

Arab oil embargo 66

Armenia: nuclear power 330-1

ASEAN Petroleum Security Agreement, 198666

ASEAN trade statistics 362

ASEAN+3: Chiang Mai initiative 362

Asia 2050: Realizing the Asian Century 187

Asia: GDP 336

Asia Pacific Energy Research Centre (APERC) 190-3

Asian Century Scenario (ACS) 52, 55-6, 122-6, 179, 190, 193-7, 200-25, 297, 393

Asian Century Scenario-alternative (ACS-ALT) see energy in PRC/India...

Asian Century Scenario-business as usual (ACS-BAU) see energy in $\mathrm{PRC} /$ India...

Asian Development Outlook: 2010 376; 2013376

Asian energy security (challenge): adequacy/reliability of physical energy supply 4; affordability/access 5-6; cleaner energy supply $16-25$; conclusions 27 ; energy demand 6-16; environmental sustainability 4 ; regional market collaboration 25-7; summary 6 ; three pillars 3, 10, 15

Association of Southeast Asian Nations see ASEAN

"Atoms for Peace" 348

Australia: coal 53; electricity 137; transport share of total oil demand 44

Bangladesh: electricity 150; GDP 444; nuclear power 329; rural electrification 150; solar home systems 152

Bernstein Research 38-9

best practice (BP) scenario 190, 193, 195-6, 200-25

biofuels 10, 21-2, 178

biomass fuels 133, 144, 178; cooking 401, 432

Boeing 36

Brazil: deforestation 170

business-as-usual (BAU) scenario 82, 86, 117, 122-9, 190, 193-4, 196, 200-25; see also energy in PRC/India...

Canada: bitumen 68; oil demand 35 carbon capture and storage (CCS): People's Republic of China 391-4, 403; clean coal 175, 391-4, 441-2; India 420-3, 425, 430; nuclear power comparison 336, 339

Carbon Capture and Sequestration Research Center, Republic of Korea 442

carbon dioxide $\left(\mathrm{CO}_{2}\right)$ : biofuels 21, 178; biomass energy 178; People's Republic of China 375, 388-94, 397, 399, 401-2; CIX (intensity of primary energy mix) 82-3; cleaner coal 24; climate change 
161; cross-border integration of electricity/gas 443; emissions 4, 17, 293; environment 270; geothermal energy 178; greenhouse gas intensity 210; hydroelectricity 177 ; India 375 , 420, 422, 425, 427, 429-30, 431-2; land-use change 169; natural gas 176; nuclear power 338-9; nuclear power 172, 314; Tapei,China 162

carbon dioxide emission intensity (CEI) $117-20,125,128$

catalytic converters (automobiles) 69

CEI: definition 381, 410; India 411-14, 420, 425, 431; People's Republic of

China 381-6, 391-2, 394-5, 397, 402

"cellulosics" (food production) 21

Central Asia Region Economic Cooperation (CAREC) 362

CFLs (compact fluorescent lamps) 399, 401, 407, 429-30, 432

Chernobyl nuclear accident, 1986 324, 326, 329, 344-6

China see People's Republic of China

Churchill, Winston 61

CIA (Central Intelligence Agency), US 168

Cinta Mekat microhydro project, Indonesia 147-8

CIX see primary energy mix

Clean Asian Century vision 444

clean coal 24, 174-5, 441-2

cleaner energy supply: Asia 16-17; coal technology 441-2; renewable energy and investment 441 ; shale gas reserves 441

cleaner energy supply (nonrenewables): cleaner coal 24; nuclear power 23-4; summary 24-5; unconventional gas 22-3

cleaner energy supply (renewables): biofuels 21-2; description 17-18; hydropower 20-1; solar power

19-20; summary 21-2; wind power $18-19$

climate change: energy security $161-6$; forestry 169; hydropower 20; nuclear power 340

"climate change levy", UK 10

"co-evolution" strategy (electric vehicles) 12,27

coal: Australia 53; People's Republic of China 24, 53, 167; cleaner energy supply $24,174-5,441-2$; conventional 174; cooking 144, 401, 429, 432; greenhouse gases 441-2; India 53; nuclear power 336

coal bed methane (CBM): environmental challenges 248; natural gas 285-6; unconventional gas 22-3; world energy requirement 252

coal bed methane (CBM)/coal mine methane (CMM): People's Republic of China 238-40, 242-3, 247; India 240; Indonesia 240, 244; Kazakhstan 240; summary 238-9

coal mine methane (CMM) formation 285

"coaling stations" (Great Britain) 62

Commodity Futures Trading Commission 74

compressed natural gas (CNG) 10, 12, 36, 440

conventional coal 174

Copenhagen Accord 169

Cost Verification Committee, Japan 318

country policy (CP) scenario 190, 193-7, 200-25

"cracked fuel oil" 59

"crackers" (oil refining) 59

cracking-to-distillation ratios 60-1

deforestation: Brazil 170; climate change 143-4; energy sources 170

diesel (gasoline) 49, 59

dilbits (Canadian bitumen) 68

DIV see primary energy diversification

diversification of energy supply: appendix - formation/exploitation of natural gas 284-6; introduction 229; photovoltaics 257-70; unconventional gas 229-57; wind energy 271-84

Dubai Mercantile Exchange (DME) 72, 75-6, 77

Eastern Siberian-Pacific Ocean (ESPO) pipeline crude 75,77

EIA energy and financial market initiative: expanded collection and publication of data 73 ; interdepartmental coordination 74 ; new analytical reports $73-4$; outreach efforts 74

Eisenhower, President 348

electric-powered transport 27

electricity: Australia 137; Bangladesh 150; People's Republic of China 136; GDP 85, 99; Japan 294; Republic of Korea 294; Lao 149; Philippines 148; 
Sri Lanka 150, see also rural electrification

electricity based on tariffs (EOT) 85, 99

electricity supply/demand: People's

Republic of China 297-8;

energy/electricity demand in Asia 294;

greenhouse gases 294; India 298-300;

Japan 300-2; Republic of Korea 302-3

electricity/gas delivery systems

(interconnected): electricity 25-6; gas 26

energy access/security in Asia/Pacific: energy poverty and access $132-45$; introduction 132; sustainable energy for all $145-54$

energy access/security in Asia/Pacific (energy poverty and access): energy development index 144-5; energy ladder 132-5; measurement 136-8; security concerns $138-44$

energy access/security in Asia/Pacific (security concerns): deforestation and climate change 143-4; gender and education 142-3; household health 139-42; poverty/economic security 139 energy access/security in Asia/Pacific (sustainable energy for all): household needs for off-grid programs 148-9; policy recommendations 150; pro-poor public-private partnership model 146-8; rural electrification 149-50; technology 150-4; universal energy access $145-6$

energy access/security in Asia/Pacific (sustainable energy for all, technology): community participation $150-1$; description 150-1; energy services with incomes coupling 153 ; local capacity 154; maintenance and after-sales service $152-3$

energy challenge (Asia, regional cooperation/integration for energy security): introduction 362-3; obstacles 371-2; power/gas delivery systems integration 363-7; resource synergies 367-70; strategic oil stockpiling $370-1$

energy challenge (Asia, regional cooperation/integration for energy security) power/gas delivery systems: interconnected gas systems 305-6; interconnected power systems 363-5; smart grids and renewables 366-7 energy challenge (Asia, regional cooperation/integration for energy security) resource synergies: conventional fossil fuels 367-8; solar resources 369-70; unconventional fossil fuels 368-9; wind resources 370 energy demand: economic growth 6-8; prices and true costs $8-16$

energy demand (curbing): behavior changes and energy efficiency 440 ; consumer subsidies 439-40; technological innovation 440

energy development index 144-5

Energy Information Administration (EIA), US 20, 36, 37-8, 73-4, 84, 167, 232-8, 244, 245, 265

energy ladder $132-5$

"energy poor" term 3

"energy poverty" $132,144-5$

energy in People's Republic of

China/India in 2010/2035: People's

Republic of China 378-403; India

403-32; introduction 375-8

energy in People's Republic of

China/India in 2010/2035 (India): conclusions 431-2; electrification of transport 414-20; environmental performance 410-14; households 428-9; industry and saving energy 425-8; primary energy intensity 403-10; supply 420-5

energy in People's Republic of China/India in 2010/2035 (People's Republic of China): conclusions 402-3; electrification of transport 386-9; environmental performance 381-6; households 398-402; industry and saving energy $395-8$; primary energy intensity $378-81$; supply $389-95$

energy prices and true costs: awareness/ conservation programs 16; clean, green transportation 12-13; consumer subsidies 8-9; green innovation 10-11; greenhouse gas emissions 10-11; rebound effects 15-16; switching electricity for gas 13-15

energy security in developing Asia (current state): economic growth 436; energy poor 438-9; fossil fuels 436-7; oil risks 438 ; primary energy mix 438

energy security in developing Asia (demand): consumer subsidies and overconsumption 439-40 
energy security, sustainability and affordability: alternative scenarios 121-7; conclusions and policy recommendations $127-31$; indicators 82-109; integration benefits 109-16; international benchmarking 117-21; introduction 81-2

energy security, sustainability and affordability (alternative scenarios): affordability 127 ; security $125-6$; sustainability 123-4

energy security, sustainability and affordability (conclusions/policy recommendations): affordability 130 ; regional cooperation 131; security 128-30; sustainability $127-8$ energy security, sustainability and affordability (indicators): affordability 99-109; affordability of electricity 84-6; carbon dioxide intensity of primary energy mix $82-3$; primary energy diversification 84 ; primary energy intensity 82 ; security $86-99$; self-sufficiency $83-4$; sustainability 86 energy security, sustainability and affordability (integration benefits): affordability 116-17; description 113-16; security 110-13; sustainability 109-10

energy security, sustainability and affordability (international benchmarking): affordability 121 ; security $120-1$; sustainability $117-20$ "energy security" term 33 energy of self-sufficiency (ESS) 82, 83-4, 86, 94, 99, 110, 113, 121, 125, 129

Energy Service Delivery Project, Sri Lanka 152-3

environment and energy security: air pollution 166-7; climate change 161-6; conclusions 179-80; energy technology 171-9; introduction 161; land-use change 162, 169-71; water quality and availability $167-9$

environment and energy security (energy technology): biofuels 178-9; biomass 178; clean coal 174; conventional coal 174; energy efficiency 171-2; geothermal 178; hydroelectricity 176-7; nuclear power 172-3; oil and natural gas 175-6; shale gas 173-4; solar photovoltaics 177; solar thermal 177-8; wind energy 177

Europe: oil demand 35, 56; oil price policies 64; urban centers 11

European Commission 10, 372

European Union (EU): energy market 372-4; feed-in tariffs 318; greenhouse gas emissions 10; IMO banker regulations 67; strategic oil reserves 371

FACTS Global Energy (FGE) 37, 46, 47, $48,52,57,60$

Federal Energy Regulatory Commission 74

findings/recommendations: cleaner energy supply 440-2; energy demand (curbing) 439-40; energy security in developing Asia (current state) 446-29; policy options for brighter future 444-6; regional market synergies $442-4$

forestry and climate change 169

"fracking" (hydraulic fracturing) see shale gas

Frankel, Paul 36

fuel consumption (Asian energy) 16

fuel oil 50-2

Fukushima Daiichi, Japan nuclear accident 16, 23-4, 44, 310-11, 315-18, 326-8, 329-31, 344-6, 351-2, 355-6

futures market (oil) 72-3

\section{gasoline 47, 59}

GDP (gross domestic product): air pollution 166; Asia 6-7, 336; Bangladesh 444; Brunei Darussalam 108; People's Republic of China 164, 167, 193-4, 215, 225, 375, 380, 402; electricity $85,99,315$; energy efficient policies 193-4; global 3; India 164, 215-16, 225, 375, 427, 432, 444; Indonesia 194, 217, 225, 444; Japan 219, 225; Republic of Korea 220; Malaysia 195, 225; Pakistan 444; Philippines 166; Singapore 108; Thailand 225; Viet Nam 444

geothermal energy 178

Germany: feed-in tariffs 310

Global Energy Assessment 145

Global Trade Analysis Project 187

Global Wind Energy Council 370

Golden Rules Report, IEA 251-2

Grameen Shakti, Bangladesh 152

Greater Mekong Subregion (GMS), People's Republic of China 362 
greenhouse gases (GHG): Asian countries 187; biofuels 21, 178; biomass fuels/ coal 144; People's Republic of China 212, 214-15; cleaner coal 24, 441; climate change 161-4; coal 441-2; electricity consumption 293, 315; emissions 163; energy efficiency improvements 186-7; energy poverty 143; environment 179, 210-12, 270, 381 ; forestry 169-71; fossil fuels 266; fugitive methane 249; hydroelectricity 176; hydropower 20; Indonesia 217-18; Republic of Korea 220-1, 313;

Malaysia 212; nuclear power 23-4, 172; nuclear power development (Asia) 332, 337, 338-9, 350, 358; photovoltaics 265; power generation 294; taxation 8 , 10-11, 444; unconventional gas 255; wind energy 19, 282-3

Henry Hub gas prices, US 232-3

historic trend (HT) scenario 190, 193-4, 196-7, 200-25

hydroelectricity $176-7$

hydropower: clean energy 363; climate change 20-1; nuclear power 336 ; renewables 17

India: best practice technology 195; carbon dioxide 375; coal 53; coal bed methane 23, 240; electricity supply/ demand 298-300; GDP 164, 215-16, 225, 375, 427, 432, 444; liquefied natural gas 47; nuclear power 309-10, $328,331,338$; policy trade-offs $215-16$, 215-17; shale gas 235-7; strategic oil reserves 370 ; subways 11 ; unconventional gas 244, 252; wind energy 278, 280; see also energy in PRC/India in 2010/2035; policy issues in Asia's power sector

Indonesia: CBM, CMM 240, 244; deforestation 170-1; GDP 194, 217, 225, 444; greenhouse gases 217-18; policy trade-offs 217-19; shale gas 236-8; unconventional gas 244-5

indoor air pollution (IAP) 140-2

Innovative Nuclear Reactors and Fuel Cycles (INPRO) 352

Institute of Energy Economics, (IEEJ) Japan 310

InterContinental Exchange (ICE) Brent $72,74-5$
Intergovernmental Panel on Climate Change 164

International Convention for the Suppression of Acts of Nuclear Terrorism 349

International Energy Agency 356

International Energy Agency (IEA) 9, 12, $13,20-2,44-5,47,50,64-5,133,136$, 144-5, 166, 172, 186-7, 193, 233, 248-51, 251-3, 260, 293, 294, 370-1, $395,398-9,428,439$

International Fuel Bank 349

International Maritime Organization (IMO) 51, 61, 67-8

Japan: cleaner coal 24; crude oil 50; electricity 294,315 ; electricity supply/ demand 300-2; GDP 219, 225; greenhouse gas intensity 212 ; nuclear power 328; oil for power generation 44-5; oil-sharing agreements 66 ; policy trade-offs 219-20; Republic of Korea 66; Setsuden conservation programs 16; transport share of oil demand 45, see also Fukushima Daiichi nuclear accident

Japan (power policy): feed-in tariffs to promote renewables 311-13; nuclear power after Fukushima accident 310-11 jet fuel $45-8$

Kazakhstan: CBM, CMM 240; clean coal 131; renewables 130; shale gas 230; unconventional gas 245 ; wind energy 370

kerosene 48-9, 59, 133, 407, 429, 431

Korea see Republic of Korea

Kyoto Protocol 2005325

land-use change: carbon dioxide 169; environment and energy security $162,169-71$

Lao PDC: National Growth and Poverty Eradication Strategy 149; Power to the Poor Program 149; Productive Use of Electricity Program 149; Rural Electrification Project 150, 152

lead-acid batteries 266-7

levelized cost of energy (LCOE) 261-5, 267-8, 278-9, 280, 282

levelized electricity cost (LEC) 85 , 99-100, 108-9, 116, 127, 334-5

liquefied natural gas (LNG) 34, 36, 41, 45, $53,66,68,75,233-4,253,256$ 
Liquefied Petroleum Gas (LPG) 41, 44, 46-49, 54, 57, 67, 148, 379, 405, 407, 411

Long-range energy alternatives (LEAP) software 376

Lovins, Amory 151

low-sulfur fuel oil 67-8

Macquarie Bank 343

macroeconomic impacts of energy efficiency improvements: economic and social 193-202; energy 202-10; environmental 210-12; introduction 186-7; methods 187-93; policy trade-offs 212-25

macroeconomic impacts of energy efficiency improvements (economic and social): economic growth 193-6; employment 200-2; total industry output 196-7; trade balance 200 macroeconomic impacts of energy efficiency improvements (energy): diversity 207-8; import dependency 208-10; intensity 204-6; rebound effect 206-7; total final energy demand 202-4

macroeconomic impacts of energy efficiency improvements (environmental): greenhouse gas emissions 210-12; greenhouse gas intensity 212

macroeconomic impacts of energy efficiency improvements (methods): assumptions 190-3; modeling 187-9; scenario descriptions 190 macroeconomic impacts of energy efficiency improvements (policy trade-offs): People's Republic of China 213-15; India 215-17; Indonesia 217-19; Japan 219-20; Republic of Korea 220-2; Malaysia 22-3; summary 225; Thailand 223-5

Madras Atomic Power Station, India 173

Malaysia: GDP 195, 225; greenhouse gases 212; nuclear power 329; policy trade-offs 222-3

Mankala model, Finland (nuclear financing) 341

methane: coal deposits 229; leakage from shale gas 174; natural gas 284-5; see also coal bed methane; coal mine methane

"middle distillate bulge" 47
Ministry of Knowledge Economy, Republic of Korea 313

Mongolia: cellular telephony 153; Rural Energy for Access Project 153; wind energy 18, 273-4, 283, 370,443

naphtha 46, 47

National Electrification Act, 1969, Philippines 149

National Growth and Poverty Eradication Strategy, Lao 149

natural gas 176, 284-6, 363, 401, 429

Nature 173

Nelson Complexity Index (oil refining) 60

Nepal: Alternative Energy Promotion Center 148; microhydro energy systems 148-9; Renewable Energy Development Project 152; Rural Energy Promotion Program 148

New York Mercantile Exchange (NYMEX) 72-3, 74-5

New Zealand 44-5, 66

Noda, Prime Minister 327

Non-Proliferation Treaty (NPT, nuclear power) 331-2, 348-9

North American unconventional gas: bargaining power for importers 255-6; coal prices 256 ; investment/business 256 ; liquid natural gas 256 ; other fossil fuels 256

Nuclear Energy Index (Standard \& Poor) 344

nuclear power: Armenia 330-1; Asia 319-20; Bangladesh 329; People's Republic of China 318, 328, 331; climate change 340 ; coal 336 ; economics 314 ; environment 172-3; hydro 336; India 328, 331; Japan 328; Republic of Korea 314, 330; Malaysia 329; nonrenewables 23-4; Pakistan 332; Philippines 330; reduction 315-18; Thailand 329; Viet Nam 328-9; wind 336

nuclear power development: conclusions 358-9; critical issues 340-51; global situation 324-32; green growth 332-40; greenhouse gases 332 , 337, 338-9, 358; introduction 324

non-proliferation 348-9; nuclear infrastructure 350-1; outlook 354-7; public acceptance 350 ; technological changes 351-4 
nuclear power development (financing): description 340-4; institutions 342 ; options 341 ; private sector $342-4$

nuclear power development (global situation): Asia/Pacific - ADB 328-32; description 324-6; Fukushima Daiichi nuclear accident $326-8$

nuclear power development (green growth): criteria 332; economics of nuclear power 332-4; energy security 337-8; environmental characteristics 338-40; nuclear power investment/ electricity generating costs comparison 334-7

nuclear power development (outlook): Asia and the Pacific 356-8; global 354-6

nuclear power development (safety): description 344-6; nuclear waste management 346-8

nuclear power development (technological changes): innovations 351-3; small/medium-sized reactors 353-4

Obama, President 68

oil and natural gas 175-6

oil security in Asia/Pacific: context 33-7; critical issues 61-72; demand 42-53; energy and financial markets in Asia 72-6; introduction 33; policy recommendations $76-8$; prices $37-42$; supply 53-61

oil security (critical issues): destructive competition? 71-2; gas/unconventional gas sources 66-7; IMO banker regulations 67-8; oil stocks and oil-sharing agreements 64-6; overseas investment and international trading $70-1$; pricing policies $63-4$; product specifications 69-70; refinery configuration 68-9; traditional/ contemporary views 61-3

oil security (demand): composition by product and end use 42-5; diesel (gas oil) 49; fuel oil 50-2; gasoline 47; jet fuel 47-8, 52; kerosene 48-9, 52; liquefied natural gas 46-7; naphtha 47; other products 52 ; outlook $52-3$

oil security (energy and financial markets in Asia): EIA energy and financial market initiative 73-4; futures market 72-3; futures markets in Asia and security $74-6$

oil security (prices): crude oil price outlook 37-40; policies in Asia and the Pacific 40-2

oil security (summary): consumer-product dialogue 77; futures market east of Suez 77-8; harmonization of product specifications 77 ; overseas investment and trading 77; product subsidies 76; refining configuration 76-7; stockpiles and oil-sharing arrangements 76 ; unconventional gas 76

oil security (supply): crude quality and refining capabilities 58-61; growing importance of product trade 56-7; import requirements 55-6; production outlook for developing Asia 53-5; reliance on Middle East oil exports $57-8$

OPEC (Organization of Petroleum Exporting Countries) 62, 66, 71, 72

Organisation for Economic Co-operation and Development (OECD) 332, 334

Pakistan: GDP 444; nuclear power 332; shale gas $235-7$

palm oil 170

particulate matter pollution in People's Republic of China 166-7

PED see primary energy demand

PEDCO, Republic of Korea 65

PEI see primary energy intensity

People's Republic of China (PRC): bioenergy 34; carbon dioxide 375, 388-94, 397, 399; CBM, CMM 23, 238-40, 242-3, 247; CEI 381; coal 24, 53,167 ; coking capacity 69 ; economy 293-4; electricity 20, 136, 315; electricity supply/demand 297-8; forests and fuel 144; fuel consumption 60; GDP 164, 167, 193-4, 215, 225, 375, 380,402 ; greenhouse gases $214-15$; liquefied natural gas 47 ; mass transit systems 11; naphtha 47; natural gas prices 252-3; nuclear power 318, 328, 331, 338; particulate matter pollution 166-7; photovoltaic capacity 269 ; policy trade-offs 213-15; Renewable Energy Development Project 153; shale gas 23, 234-5; tight gas 247; transmission/distribution (photovoltaics) 267-8; unconventional gas 241-4, 253; water tables 168; wind energy $18,273-4,278,280-1,283$, 
370; see also energy in PRC/India in 2010/2035; policy issues in Asia's power sector People's Republic of China - oil: cracking-to-distillation ratio 60 ; demand by sector 45 ; fuel in utilities 44; imports 58-9; price reforms 40 ; production 53, 55; strategic reserves 370

Philippines: electric lighting and literacy 142; GDP 166; National Electrification Act, 1969 149; nuclear power 330; rural electrification 149

photovoltaics: Asia in world market 269-70; cost effectiveness off-grid 266-7; cost effectiveness on-grid 261-6; costs and market 258-61; environment 270; limits to grid penetration 267-9; solar resource 257-8; winners and losers 270

plutonium breeding 353

policy options for brighter future (energy in Asia): demand curb 444; diversify/ optimize energy mix 444-5; intellectual capital to support physical energy investments 445; pan-Asian energy market by 2030 444; poor/low income residents 445 ; summary 446

power (policy issues in Asia): comparisons and recommendations 315-19; conclusions 319-20; current status/future for electricity 294-7; India 298-300, 306-10; introduction 293-4; Japan 200-302, 300-2, 310-13; People's Republic of China 297-8, 304-6; Republic of Korea 302-3, $313-15$

power (policy issues in Asia) comparisons and policy recommendations: electricity consumption per GDP 315; nuclear power 315-16; renewable portfolio standards or feed-in tariffs 318-19

power (policy issues in Asia) - current status/future for electricity: electric power consumption 296-7; energy/ electricity demand 294; greenhouse gases 294

Power to the Poor Program, Lao 149 primary energy demand (PED) 82-3, 99 primary energy diversification (DIV) 82 , 84-5, 93, 99, 111, 129

primary energy intensity (PEI) 82-3, 86, 109, 117-18, 123, 127; People's
Republic of China 375, 378-82; India 403-10

primary energy mix (CIX) definition 82-3; People's Republic of China 382-4, 386, 402; India 410-14, 431; sustainability $86,109-10,117-20$, 123-4, 127, 128

pro-poor public-private partnership model (5P) 146-8

"produced water" 176

Productive Use of Electricity Program, Lao 149

pump prices 42

Rajapaksa, Mahinda 150

"rebound effect" 15

regional market collaboration: electricity/ gas delivery systems 25-6; "smart grids" to integrate renewables 12 , 26-7

regional market synergies: cross-border integration of electricity/natural gas networks 442-3; smart grids 443; technical/policy challenges 443-4

Renewable Energy Development Project: People's Republic of China 152-3; Lao 153; Nepal 152, 153

Republic of Korea: borrow-and-repay option 76; cleaner coal 24, 76; electricity 294; electricity supply/ demand 302-3; GDP 220; greenhouse gases 220-1; Japan 66; liquefied natural gas 253; nuclear power 330; oil for power generation 45; oil stocks 65 ; PEDCO 65; policy trade-offs 220-2; renewable energy policy $314-15$; strategic oil reserves 370 ; wind energy 273, 443

Republic of Korea (power policy): electricity consumption per GDP 297, 315; nuclear power 314 ; renewable energy 314-15, 319

"ResCom" (oil uses) 44

"resid" crackers 59

rural electrification: Bangladesh 150; energy access/security 149-50, 152; Lao 150, 152; Philippines 149; Sri Lanka 150

Rural Electrification Project, Lao 150, 152

Rural Energy for Access Project, Mongolia 153

Rural Energy Development Program, Nepal 148 
Saudi Aramco 57

Setsuden ("saving electricity"), Japan 16 shale gas: environmental challenges

173-4, 248-51; flow/permeability properties 285; "fracking" 22-3, 39, 67, 285; geology 285; reserves in Asia 441; revolution 229-33, 245-7; sustainability 128 ; unconventional gas 229; United States 22, 67, 229-32, 319, 441; world energy requirement 252; see also fracking

shale gas (country assessments): People's Republic of China 234-5; India/ Pakistan 235-6; Indonesia 236-7; others 238

shale gas (environmental challenges): earthquakes 250; fugitive methane 249-50; lifecycle 173; local pollution and land impacts 250; methane leakage 174; surface water contamination 249; water contamination 248; water requirements 248

"shale gas revolution" 67,229

shale gas revolution in Asia: CBM, tight gas and imports 257-8; competitive industry 246; dense populations 246 ; gas-service industry 246; geological conditions 245; geological data 245; industry development 247 ; pipelines 247; regulatory framework 247 ; subsurface rights 246-7; technology and knowledge 246

"shale liquid revolution" 67

Singapore: GDP 108

"smart grids" to integrate renewables 12 , $26-7$

solar energy: Asia 369-70; environment 177; "smart grids" 26; summary 19-20; thermal 177-8; see also photovoltaics

"spinning reserves" (power systems) 12

Sri Lanka: electricity 150; Energy Service Delivery Project 152-3; rural electrification 150

subcontinent see India; Pakistan sulfur scrubbers 68 sustainable energy for all (SE4ALL) 145

Swedish Nuclear Fuel and Waste Management Company (SKB) 347 switching electricity for gas 13-14

Ten Cities, Ten Thousand Vehicles Program, People's Republic of China 12
Thailand: GDP 225; nuclear power 329; policy trade-offs 223-5; strategic oil reserves 370

"the oil weapon" concept 62

Three Mile Island accident, US 344

tight gas 229, 240-1, 247, 285

Turkmenistan to People's Republic of China pipeline 443

unconventional gas: People's Republic of China 241-3; coal mines 285; country assessments for CBM/CMM 238-41; country assessments for shale gas 234-8; current status in Asia 241-5; energy supply and power generation 251-3; India 244, 252; Indonesia 244-5; investment and infrastructure 253-4; Kazakhstan 245; nonrenewables 22-3; North America 255-6; resources in Asia 233-41; risks 254-5; shale gas environmental challenges 248-51; shale gas revolution 229-33, 245-7; subregional assessments 234; winners and losers 256-7

unconventional gas (risks): energy efficiency and renewables 255 ; greenhouse gases 255; local disruptions and environmental degradation 255; production shortfalls $254-5$

United Kingdom (UK): "climate change levy" 10; energy bill 343; fuel prices 41; power sector liberalization 371

United Nations Development Program (UNDP) 132-3, 136, 147, 148, 149, 150, 398-9, 405, 428

United Nations Environment Program (UNEP) 167, 174

United Nations Framework Convention on Climate Change 169

United Nations Scientific Committee on the Effects of Atomic Radiation (UNSCEAR) 344

United Nations (UN): agriculture and freshwater 167; Global Trade Analysis Project 187

United States (US): annual radiation dose 344; compressed natural gas 36 ; cracking-to-distillation ratio 60 ; crude oil exports 69; economy 294; futures market 72-3; liquefied natural gas 36 ; oil demand 56; oil supplies protection 72; Persian Gulf 58; refining configurations 69; renewable portfolio 


\section{Index}

standards 318; shale deposits 54; shale gas 22, 67, 229-32, 319, 441; "shale gas revolution" 229

uranium reserves 338

US Agency for International Development 164

US Environmental Protection Agency 173

Van Eck Global Fund 343-4

Viet Nam: GDP 444; nuclear power 328-9; wind energy 370

virgin fuel oil 59

water: People's Republic of China 168; pollution ("threat multipliers") 161; quality/availability $162,167-9$

West Texas Intermediate (WTI) 72, 74-5 wind energy: Asia 370; Asian wind industry 283; cost effectiveness 275-80; costs 275; cross-border integration 443; environment 177, 282-3; global market 273-5; limits to grid penetration 280-1; nuclear power 336; offshore wind 281-2; resource/capacity 271-3; "smart grids" 26; summary 18-19; winners and losers 283-4

World Bank 150, 174, 187

World Energy Outlook: 2010 117, 144; 2012 37, 294, 297, 298, 356

World Health Organization (WHO) 136, 140-1, 166-7, 340, 345

Younggwang Nuclear Power Plant, Republic of Korea 173 
This book examines key issues and policy options in the development of Asia's energy security. Rapid growth has transformed Asia's presence in the world economy: Past growth has dramatically improved Asia's living standards, lifting millions out of poverty. Future growth will do the same. But, crucially, can Asia secure the energy it needs to fuel this dramatic economic expansion? This book stresses that the threefold challenge of energy supply security, environmental sustainability, and affordable access requires a multipronged approach. The book also explains that the region must actively contain its rising demand, aggressively explore new energy supply sources and technology, and progressively promote the regional integration of energy markets and infrastructure.

The book also highlights that, unless there is a paradigm shift in the current energy use, Asia will struggle to deliver the inclusive growth needed to lift millions of its citizens out of poverty. The book also considers the range of policy reforms and technological developments that can ensure a future of ample, affordable, clean energy for Asia.

Minsoo Lee is a Senior Economist in the Macroeconomics and Finance Research Division of the Economics and Research Department at the Asian Development Bank (ADB). Prior to joining ADB, he was an Associate Dean and a tenured Full Professor at Peking University, HSBC Business School. His main research fields are international finance, international trade, applied econometrics, and energy economics.

Donghyun Park is currently Principal Economist at the Economics and Research Department (ERD) of the Asian Development Bank (ADB), which he joined in April 2007. Prior to joining ADB, he was a tenured Associate Professor of Economics at Nanyang Technological University in Singapore. Dr. Park has a PhD in economics from UCLA and his main research fields are international finance and trade.

Harry D. Saunders conducts research in energy economics, evolutionary biology, and the law of evidence theory as his "hobby." He earns his living by consulting to executive teams who face major, risky decisions. Research is driven by curiosity and is entirely selffunded. Harry enjoys the fact that he has numerous academic colleagues worldwide in each of these three disciplines. He has a PhD in engineering-economic systems from Stanford.

\section{ECONOMICS}

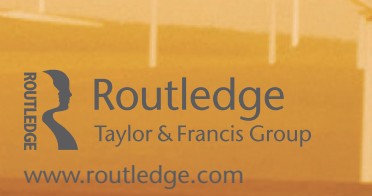

Routledge titles are available as eBook

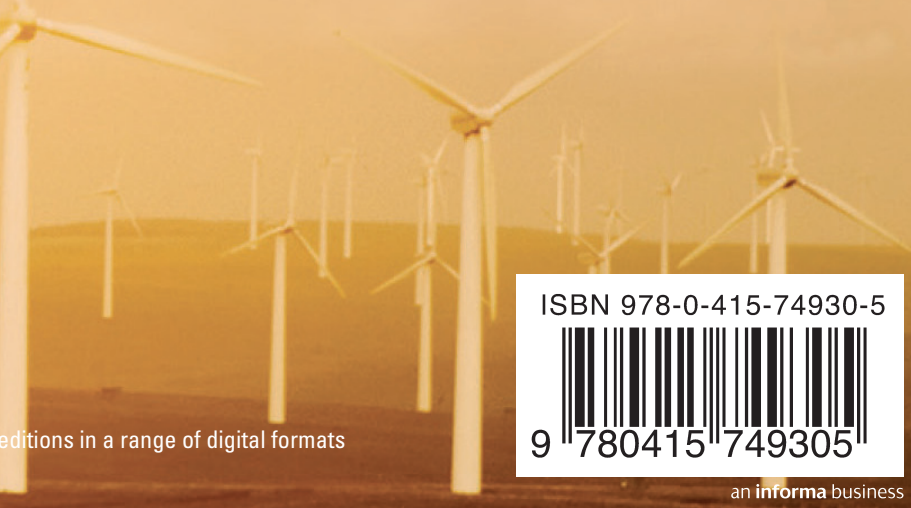

